\title{
Absorbent products for urinary/faecal incontinence: a comparative evaluation of key product designs
}

M Fader, A Cottenden, K Getliffe, H Gage, $S$ Clarke-O'Neill, K Jamieson, N Green, P Williams, R Brooks and J Malone-Lee

July 2008

Health Technology Assessment NHS R\&D HTA Programme www.hta.ac.uk

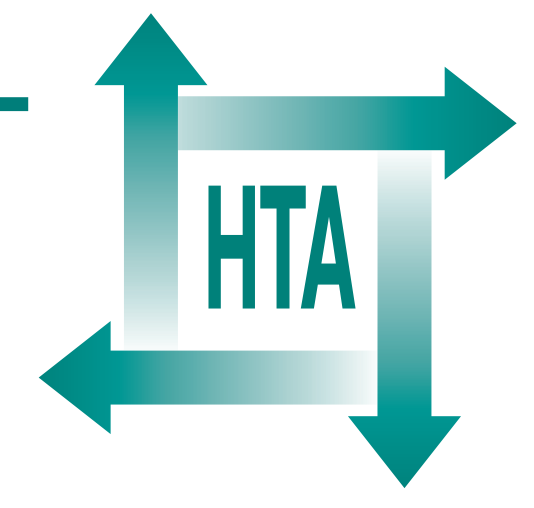



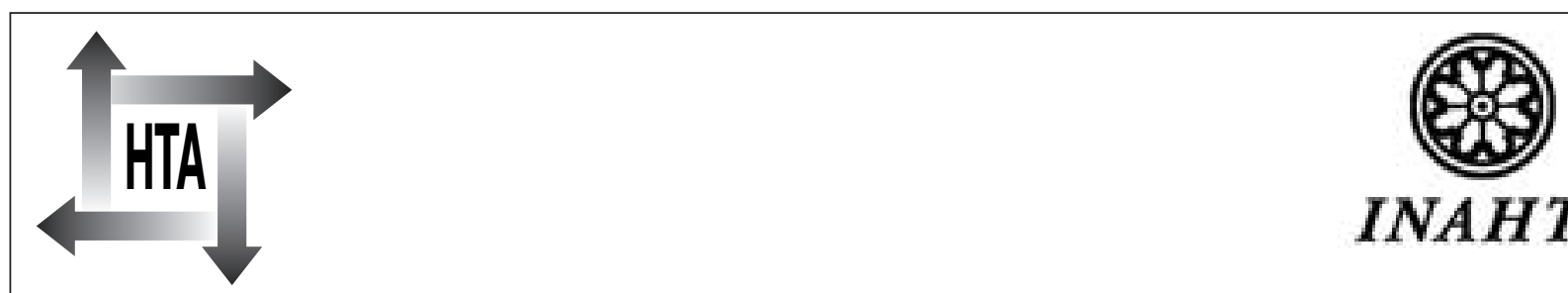

INAHTA

How to obtain copies of this and other HTA Programme reports.

An electronic version of this publication, in Adobe Acrobat format, is available for downloading free of charge for personal use from the HTA website (http://www.hta.ac.uk). A fully searchable CD-ROM is also available (see below).

Printed copies of HTA monographs cost $£ 20$ each (post and packing free in the UK) to both public and private sector purchasers from our Despatch Agents.

Non-UK purchasers will have to pay a small fee for post and packing. For European countries the cost is $£ 2$ per monograph and for the rest of the world $£ 3$ per monograph.

You can order HTA monographs from our Despatch Agents:

- fax (with credit card or official purchase order)

- post (with credit card or official purchase order or cheque)

- phone during office hours (credit card only).

Additionally the HTA website allows you either to pay securely by credit card or to print out your order and then post or fax it.

Contact details are as follows:

HTA Despatch

c/o Direct Mail Works Ltd

Email: orders@hta.ac.uk

4 Oakwood Business Centre

Tel: 02392492000

Downley, HAVANT PO9 2NP, UK

Fax: 02392478555

Fax from outside the UK: +442392478555

$\mathrm{NHS}$ libraries can subscribe free of charge. Public libraries can subscribe at a very reduced cost of $£ 100$ for each volume (normally comprising $30-40$ titles). The commercial subscription rate is $£ 300$ per volume. Please see our website for details. Subscriptions can only be purchased for the current or forthcoming volume.

\section{Payment methods}

Paying by cheque

If you pay by cheque, the cheque must be in pounds sterling, made payable to Direct Mail Works Ltd and drawn on a bank with a UK address.

Paying by credit card

The following cards are accepted by phone, fax, post or via the website ordering pages: Delta, Eurocard, Mastercard, Solo, Switch and Visa. We advise against sending credit card details in a plain email.

Paying by official purchase order

You can post or fax these, but they must be from public bodies (i.e. NHS or universities) within the UK. We cannot at present accept purchase orders from commercial companies or from outside the UK.

\section{How do I get a copy of HTA on CD?}

Please use the form on the HTA website (www.hta.ac.uk/htacd.htm). Or contact Direct Mail Works (see contact details above) by email, post, fax or phone. HTA on CD is currently free of charge worldwide.

The website also provides information about the HTA Programme and lists the membership of the various committees. 


\title{
Absorbent products for urinary/faecal incontinence: a comparative evaluation of key product designs
}

\author{
M Fader, ${ }^{1,2 *}$ A Cottenden, ${ }^{1} \mathrm{~K}$ Getliffe, ${ }^{2} \mathrm{H}$ Gage, ${ }^{3}$ \\ S Clarke-O'Neill,' K Jamieson, ${ }^{2} \mathrm{~N}$ Green,' \\ P Williams, ${ }^{4}$ R Brooks $^{5}$ and J Malone-Lee'
}

I Continence and Skin Technology Group, Department of Medical Physics and Bioengineering/Department of Medicine, University College London, UK

${ }^{2}$ Department of Nursing and Midwifery, University of Southampton, UK

${ }^{3}$ Department of Economics, Faculty of Arts and Human Sciences, University of Surrey, Guildford, UK

${ }^{4}$ Department of Mathematics, Faculty of Engineering and Physical Sciences, University of Surrey, Guildford, UK

${ }^{5}$ Department of Statistical Science, University College London, UK

* Corresponding author. Present address: Department of Nursing and Midwifery, University of Southampton, UK

Declared competing interests of authors: M Fader, A Cottenden and S Clarke-O'Neill have received research grant money and travel grant money from SCA AB, which is a multinational absorbent pad manufacturing company

Published July 2008

This report should be referenced as follows:

Fader M, Cottenden A, Getliffe K, Gage H, Clarke-O'Neill S, Jamieson K, et al. Absorbent products for urinary/faecal incontinence: a comparative evaluation of key product designs. Health Technol Assess 2008; 12(29).

Health Technology Assessment is indexed and abstracted in Index Medicus/MEDLINE, Excerpta Medica/EMBASE and Science Citation Index Expanded (SciSearch ${ }^{\circledR}$ ) and Current Contents ${ }^{\circledR} /$ Clinical Medicine. 


\section{NIHR Health Technology Assessment Programme}

$\mathrm{T}$ he Health Technology Assessment (HTA) Programme, part of the National Institute for Health Research (NIHR), was set up in 1993. It produces high-quality research information on the effectiveness, costs and broader impact of health technologies for those who use, manage and provide care in the NHS. 'Health technologies' are broadly defined as all interventions used to promote health, prevent and treat disease, and improve rehabilitation and long-term care.

The research findings from the HTA Programme directly influence decision-making bodies such as the National Institute for Health and Clinical Excellence (NICE) and the National Screening Committee (NSC). HTA findings also help to improve the quality of clinical practice in the NHS indirectly in that they form a key component of the 'National Knowledge Service'.

The HTA Programme is needs-led in that it fills gaps in the evidence needed by the NHS. There are three routes to the start of projects.

First is the commissioned route. Suggestions for research are actively sought from people working in the NHS, the public and consumer groups and professional bodies such as royal colleges and NHS trusts. These suggestions are carefully prioritised by panels of independent experts (including NHS service users). The HTA Programme then commissions the research by competitive tender.

Secondly, the HTA Programme provides grants for clinical trials for researchers who identify research questions. These are assessed for importance to patients and the NHS, and scientific rigour.

Thirdly, through its Technology Assessment Report (TAR) call-off contract, the HTA Programme commissions bespoke reports, principally for NICE, but also for other policy-makers. TARs bring together evidence on the value of specific technologies.

Some HTA research projects, including TARs, may take only months, others need several years. They can cost from as little as $£ 40,000$ to over $£ 1$ million, and may involve synthesising existing evidence, undertaking a trial, or other research collecting new data to answer a research problem.

The final reports from HTA projects are peer-reviewed by a number of independent expert referees before publication in the widely read journal series Health Technology Assessment.

\section{Criteria for inclusion in the HTA journal series}

Reports are published in the HTA journal series if (1) they have resulted from work for the HTA Programme, and (2) they are of a sufficiently high scientific quality as assessed by the referees and editors.

Reviews in Health Technology Assessment are termed 'systematic' when the account of the search, appraisal and synthesis methods (to minimise biases and random errors) would, in theory, permit the replication of the review by others.

The research reported in this issue of the journal was commissioned by the HTA Programme as project number 01/11/02. The contractual start date was in April 2003. The draft report began editorial review in February 2007 and was accepted for publication in December 2007. As the funder, by devising a commissioning brief, the HTA Programme specified the research question and study design. The authors have been wholly responsible for all data collection, analysis and interpretation, and for writing up their work. The HTA editors and publisher have tried to ensure the accuracy of the authors' report and would like to thank the referees for their constructive comments on the draft document. However, they do not accept liability for damages or losses arising from material published in this report.

The views expressed in this publication are those of the authors and not necessarily those of the HTA Programme or the Department of Health.

Editor-in-Chief:

Series Editors:

Programme Managers:
Professor Tom Walley

Dr Aileen Clarke, Dr Peter Davidson, Dr Chris Hyde, Dr John Powell, Dr Rob Riemsma and Professor Ken Stein

Sarah Llewellyn Lloyd, Stephen Lemon, Kate Rodger,

Stephanie Russell and Pauline Swinburne

ISSN $1366-5278$

\section{(C) Queen's Printer and Controller of HMSO 2008}

This monograph may be freely reproduced for the purposes of private research and study and may be included in professional journals provided that suitable acknowledgement is made and the reproduction is not associated with any form of advertising.

Applications for commercial reproduction should be addressed to: NCCHTA, Alpha House, Enterprise Road, Southampton Science Park, Chilworth, Southampton SOI6 7NS, UK. 


\title{
Abstract
}

\section{Absorbent products for urinary/faecal incontinence: a comparative evaluation of key product designs}

\author{
M Fader, ${ }^{1,2 *}$ A Cottenden, ' K Getliffe, ${ }^{2} \mathrm{H}$ Gage, ${ }^{3}$ S Clarke-O'Neill,' K Jamieson, ${ }^{2}$ \\ N Green, ${ }^{\prime}$ P Williams, ${ }^{4}$ R Brooks ${ }^{5}$ and J Malone-Lee'
}

\author{
' Continence and Skin Technology Group, Department of Medical Physics and Bioengineering/Department of \\ Medicine, University College London, UK \\ 2 Department of Nursing and Midwifery, University of Southampton, UK \\ ${ }^{3}$ Department of Economics, Faculty of Arts and Human Sciences, University of Surrey, Guildford, UK \\ ${ }^{4}$ Department of Mathematics, Faculty of Engineering and Physical Sciences, University of Surrey, Guildford, UK \\ ${ }^{5}$ Department of Statistical Science, University College London, UK \\ * Corresponding author. Present address: Department of Nursing and Midwifery, University of Southampton, UK
}

Objectives: To compare the performance and costeffectiveness of the key absorbent product designs to provide a more solid basis for guiding selection and purchase. Also to carry out the first stage in the development of a quality of life (QoL) instrument for measuring the impact of absorbent product use on users' lives.

Design: Three clinical trials focused on the three biggest market sectors. Each trial had a similar crossover design in which each participant tested all products within their group in random order.

Setting, participants and interventions: In Trial I, 85 women with light urinary incontinence living in the community tested three products from each of the four design categories available (total of 12 test products): disposable inserts (pads); menstrual pads; washable pants with integral pad; and washable inserts. In Trial 2a, 85 moderate/heavily incontinent adults (urinary or urinary/faecal) living in the community (49 men and 36 women) tested three (or two) products from each of the five design categories available (total of 14 test products): disposable inserts (with mesh pants); disposable diapers (nappies); disposable pull-ups (similar to toddlers' trainer pants); disposable T-shaped diapers (nappies with waist-band); and washable diapers. All products were provided in a daytime and a (mostly more absorbent) night-time variant. In these first two trials, the test products were selected on the basis of data from pilot studies. In Trial 2b, 100 moderate/heavily incontinent adults (urinary or urinary/faecal) living in 10 nursing homes (27 men and 73 women) evaluated one product from each of the four disposable design categories from Trial $2 a$.
Products were selected on the basis of product performance in Trial 2a and, again, day time and night-time variants were provided. The first phase of developing a QoL tool for measuring the impact of using different pad designs was carried out by interviewing participants from Trials I and $2 \mathrm{a}$.

Main outcome measures: Product performance (e.g. comfort, discreetness) was characterised using a weekly validated questionnaire. A daily pad change and leakage diary was used to record severity of leakage, numbers of laundry items and pads. Skin health changes were recorded weekly. At a final interview preferences were ranked, acceptability of each design recorded, and overall opinion marked on a visual analogue scale (VAS) of 0-100 points. This VAS score was used to estimate cost-effectiveness. In addition, a timed pad changing exercise was conducted with 10 women from Trial $2 b$ to determine any differences between product designs.

Results: Disposable inserts are currently the mainstay of management for lightly incontinent women (Trial I) and they were better for leakage and other variables (but not discreetness) and better overall than the other three designs. However, some women preferred menstrual pads $(6 / 85)$ or washable pants (I3/85), both of which are cheaper to use. Washable inserts were worse both overall and for leakage than the other three designs (72/85 found them unacceptable). For disposable inserts and disposable diapers, findings from the community (Trial $2 \mathrm{a}$ ) and nursing home trials (Trial $2 b$ ) were broadly similar. Leakage performance of disposable inserts was worse than that of the other designs for day and night. Pull-ups were preferred over 
inserts for the daytime. The new T-shaped diaper was not better overall than the traditional disposable one. However, there were important differences in performance and preference findings for men and women from both trials. Pull-ups (the most expensive) were better overall than the other designs for women during the day and for community-dwelling women during the night. Although disposable diapers were better for leakage than disposable inserts (the cheapest), women did not prefer them (except in nursing homes at night), but for men the diapers were better both overall and for leakage and were the most cost-effective design. No firm conclusions could be drawn about the performance of designs for faecal incontinence. Nursing home carers found pull-ups and inserts easier to apply (in the standing position) and quicker (in the pad change experiment) than the diaper designs; the ability to stand was associated with preference for pull-ups or inserts. The T-shaped diaper was not easier or quicker to change than the diaper. The washable products (Trial 2a) gave diverse results: they were better for leakage at night, but were worse overall for daytime than the other designs. Threequarters of the women (27/36) found them unacceptable, but nearly two-thirds of men (31/49) found them highly acceptable at night. Findings from the two community trials (Trials I and 2a) showed that there were many practical problems in dealing with washable products but, together with the less effective and less expensive products, such as menstrual pads, they were more acceptable at home (and, in the case of washables, at night). This suggests that cost-effective management may involve combining products by using more effective (for a given user) but more expensive designs (e.g. pull-ups) when out and less effective but less expensive designs when at home. The interviews examining the impact of pad use on QoL provided themes and domains that can be further developed into a tool for further evaluation of absorbent products. Conclusions: This study showed that there were significant and substantial differences between the designs of absorbent products and for moderate/heavy incontinence some designs are better for men/women than others. There was considerable individual variability in preferences and cost-effective management may best be achieved by allowing users to choose combinations of designs for different circumstances within a budget. Further research is needed into the feasibility of providing choice and combinations of designs to users, as well as into the development of more effective washables and of specifically male disposable products. QoL measurement tools are needed for users of absorbent products, as are clinical trials of designs for communitydwelling carer-dependent men and women with moderate/heavy incontinence. 


\section{Contents}

List of abbreviations

Executive summary

I Introduction

Background

Literature review

Methodological issues affecting absorbent product research

Which designs should be evaluated? .........

Aims

Overall project plan

2 Research design and methods

Introduction

Design

Absorbent product selection and

representation

participant interviews .................... 14

Sample size and methods of analysis ........ 16

Economic analysis ............................... 17

Ethical arrangements ............................ 18

3 Randomised crossover trial of disposable and washable absorbent products for women with light urinary incontinence

(Trial I)

Background summary

Aim

Design and methods

Recruitment of participants

Outcome measures

Selection of absorbent products to

represent design groups

Study preparation and procedures: participant

preparation and interviews ...................... 21

Product preparation, randomisation and

blinding

Analysis

Results

Final interview: overall opinion and

preferences

Discussion

Conclusions

4 Randomised clinical crossover trial of disposable and washable absorbent products for women and men with moderate/heavy urinary and faecal incontinence living in community settings (Trial $\mathbf{2 a}$ )
Aims ..................................................... 45

Design and methods ............................. 45

Recruitment of participants .................... 45

Outcome measures ............................... 47

Selection of absorbent products to

represent design groups ......................... 48

Study preparation and procedures .......... 48

Analysis ............................................ 50

Results ................................................ 50

Final interview: overall opinion and

preferences ............................................ 60

Discussion ................................................ 75

Conclusions …........................................ 79

5 Randomised clinical crossover trial of disposable absorbent products for women and men with moderate/heavy urinary and faecal incontinence living in nursing homes (Trial 2b)

Background summary ........................... 81

Aims ….......................................... 81

Design and methods ............................ 81

Recruitment of participants ................... 81

Outcome measures ................................... 83

Selection of absorbent products to

represent design groups .......................... 83

Study preparation and procedures ............ 84

Analysis ............................................... 85

Results .................................................. 86

Final interview: overall opinion and

preferences ............................................ 93

Discussion ............................................ 107

Conclusions ...................................... 110

6 Absorbent products for incontinence: first stage in the development of a

quality of life instrument ...................... 113

Introduction ............................................ 113

Background summary ........................... 113

Results ................................................ 114

Discussion .............................................. 118

Conclusions …..................................... 119

7 Discussion, conclusions, implications for healthcare and recommendations for future research .................................... 121

Study limitations ................................... 121

Discussion ............................................ 122

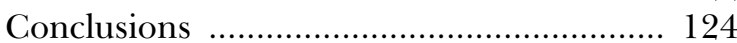

Implications for healthcare .................... 124

Recommendations for research .............. 124

Acknowledgements ............................. 125 
References

Appendix I Trial 1: method of product selection

Appendix 2 Trial 1: product performance questionnaires (results for each product in a design)

Appendix 3 Trial 1: calculation of the extra laundry costs associated with reusable products

Appendix 4 Trial 2a: pilot study and product selection

Appendix 5 Trial 2a: median urine mass in each design, combined and by gender .. 141

Appendix 6 Trial 2a: estimated probabilities of no leakage at different urine masses, by gender

Appendix 7 Trial 2a: leakage performance of designs, by gender

Appendix 8 Trial 2a: consumption by gender - weighted mean number of products used per day/night (SD)

Appendix 9 Trial 2a: product performance questionnaires (results for each product in a design)

Appendix 10 Trial 2a: design performance by gender $(\%)$

Appendix I I Trial 2a: preference for designs, by gender
Appendix 12 Trial 2a: acceptability of designs for day and night, by gender

Appendix 13 Trial 2a: mean VAS scores (SD), by gender

Appendix I4 Trial 2a: comments by gender

Appendix I5 Trial 2b: consenting procedure for nursing home residents

Appendix 16 Trial 2b: resident first-choice preference

Appendix 17 Trial 2b: mean VAS scores (SD), by gender

Appendix 18 Trial 2b: paired comparisons of preferences between the different designs, by gender

Appendix 19 Trial 2b: comments from carers by resident gender

Appendix 20 Trial 2b: care staff views about the number of staff needed to change residents in different positions

Appendix 2 I Trial 2b: care staff views about the relative value for money of different designs

Health Technology Assessment reports published to date

Health Technology Assessment

Programme 


\section{List of abbreviations}

\begin{tabular}{|c|c|c|c|}
\hline ACER & average cost-effectiveness ratio & OR & odds ratio \\
\hline AGM & absorbent gelling material & PASA & Purchasing and Supplies Agency \\
\hline CI & confidence interval & QoL & quality of life \\
\hline DI & disposable insert & RCT & randomised controlled trial \\
\hline \multirow[t]{2}{*}{ HADS } & $\begin{array}{l}\text { Hospital Anxiety and Depression } \\
\text { Scale }\end{array}$ & SAP & superabsorbent polymer \\
\hline & incremental cost-effectiveness ratio & SD & standard deviation \\
\hline \multirow[t]{3}{*}{ ICIQ-UI } & International Consultation on & SF-12 & Short Form with 12 Items \\
\hline & $\begin{array}{l}\text { Incontinence Questionnaire - } \\
\text { Urinary Incontinence }\end{array}$ & VAS & visual analogue scale \\
\hline & & WI & washable insert \\
\hline MP & menstrual pad & & washable pant \\
\hline NS & not significant & & \\
\hline $\begin{array}{l}\text { All abbrevia } \\
\text { it has been } \\
\text { the abbrevi: }\end{array}$ & $\begin{array}{l}\text { ons that have been used in this report are lis } \\
\text { ed only once, or it is a non-standard abbrev } \\
\text { on is defined in the figure legend or at the }\end{array}$ & $\begin{array}{l}\text { unles } \\
\text { eed on } \\
\text { he tabl }\end{array}$ & $\begin{array}{l}\text { abbreviation is well known (e.g. NHS), or } \\
\text { igures/tables/appendices in which case }\end{array}$ \\
\hline
\end{tabular}





\section{. \\ Executive summary}

\section{Background}

The UK health service, nursing homes and public spend around £94 million per year on incontinence pads (absorbent products) to contain urine and/or faeces, but the research base for making informed choices between different product designs is very weak.

\section{Objectives}

The aim of this trial was to compare the performance and cost-effectiveness of the key absorbent product designs to provide a more solid basis for guiding selection and purchase.

A further aim was to carry out the first stage in the development of a quality of life instrument for measuring the impact of absorbent product use on users' lives.

\section{Design}

The work involved three clinical trials focusing on the three biggest market sectors. Each trial had a similar crossover design in which each participant tested all products within their group in random order.

\section{Settings, participants and methods}

In Trial 1, 85 women with light urinary incontinence living in the community tested three products from each of the four design categories available (total of 12 test products): disposable inserts (pads); menstrual pads; washable pants with integral pad; and washable inserts. In Trial 2a, 85 moderate/heavily incontinent adults (urinary or urinary/faecal) living in the community (49 men and 36 women) tested three (or two) products from each of the five design categories available (total of 14 test products): disposable inserts (with mesh pants); disposable diapers (nappies); disposable pull-ups (similar to toddlers' trainer pants); disposable T-shaped diapers (nappies with waist-band); and washable diapers. All products were provided in a daytime and a (mostly more absorbent) night-time variant. In these first two trials, the test products were selected on the basis of data from pilot studies. In Trial 2b, 100 moderate/heavily incontinent adults (urinary or urinary/faecal) living in 10 nursing homes (27 men and 73 women) evaluated one product from each of the four disposable design categories from Trial 2a. Products were selected on the basis of product performance in Trial 2a and, again, daytime and night-time variants were provided. The first phase of work to develop a quality of life tool for measuring the impact of using different pad designs was carried out by interviewing participants from Trials 1 and $2 \mathrm{a}$.

\section{Outcome measures}

Product performance was characterised using validated questionnaires, which asked the participants (in Trials 1 and 2a) or carers (all participants in Trial 2b, except for the few who could report for themselves) to evaluate various aspects of pad performance (leakage, ease of putting on, discreetness, etc.) using a five-point scale (very good-very poor) at the end of the week (or 2 weeks for Trial $2 b$ ) of product testing. In addition, participants/carers were asked to save individual used pads in bags for weighing and to indicate the severity of any leakage from them on a three-point scale (none, a little, a lot). These data were used to determine differences in leakage performance. Numbers of laundry items and pads used were recorded to estimate costs, and skin health changes were recorded by the participant or by the researchers (Trial 2b). At the end of testing, participants were interviewed and ranked their preferences (with and without costs), stated the acceptability of each design (highly acceptable-totally unacceptable) and recorded their overall opinion on a visual analogue scale (VAS) of 0-100 points (worst design-best design). This VAS score was used with product costs to estimate cost-effectiveness. In addition, a timed pad changing exercise was conducted with 10 women from Trial $2 b$ to determine any differences between product designs. 


\section{Results}

Results presented are for statistically and clinically significant findings.

\section{Trial I}

Disposable inserts are currently the mainstay of management for lightly incontinent women and they were better for leakage and other variables (but not discreetness) and better overall than the other three designs. However, some women preferred menstrual pads $(6 / 85)$ or washable pants $(13 / 85)$, both of which are cheaper to use.

Washable inserts were worse both overall and for leakage than the other three designs (72/85 found them unacceptable).

\section{Trials $\mathbf{2 a}$ and $\mathbf{2 b}$}

Disposable inserts and disposable diapers are the designs currently most commonly used by moderate/heavily incontinent adults. Findings from the community (Trial 2a) and nursing home trials (Trial 2b) were broadly similar. The leakage performance for the disposable inserts was worse than that of the other designs for day and night and pull-ups were preferred over inserts for the daytime. The new T-shaped diaper was not better overall than the traditional disposable diaper. However, there were important differences in performance and preference findings for men and women from both trials and the communitydwelling men had more severe urinary incontinence than the women - mean daytime urine mass $375 \mathrm{~g}$ for men and $215 \mathrm{~g}$ for women [difference $148 \mathrm{~g}$, 95\% confidence interval (CI) 79.8 to 217.7]. Pull-ups (the most expensive) were better overall than the other designs for women during the day and for community-dwelling women during the night also. Although disposable diapers were better for leakage than disposable inserts (the cheapest), women did not prefer them (except in nursing homes at night) but for men the diapers were better both overall and for leakage and were the most cost-effective design. No firm conclusions could be drawn about the performance of designs for faecal incontinence and there was no firm evidence that there were differences in skin health problems between designs.

In the nursing home trial, the carers found pullups and inserts easier to apply (in the standing position) and quicker (in the pad change experiment) than the diaper designs, and ability to stand was associated with preference for pull-ups or inserts. Despite being designed for ease of changing, the T-shaped diaper was not easier or quicker to change than the diaper.

The washable products (Trial 2a) gave diverse results. The washables were better for leakage at night than the other designs, but were worse overall for daytime than the other designs. Threequarters of the women $(27 / 36)$ found them unacceptable, but nearly two-thirds of men (31/49) found them highly acceptable at night.

Findings from the two community trials (Trials 1 and 2a) showed that there were many practical problems in dealing with washable products but, together with the less effective and less expensive products, such as menstrual pads, they were more acceptable at home (and, in the case of washables, at night). This suggests that cost-effective management may involve combining products by using more effective (for a given user) but more expensive designs (e.g. pull-ups) when out and less effective but less expensive designs when at home.

The interviews examining the impact of pad use on quality of life provided themes and domains (such as hiding the problem, perceptions of normality, coping with incontinence) that can be further developed into a tool for further evaluation of absorbent products.

\section{Conclusions}

This study showed that there were significant and substantial differences between the designs of absorbent products and for moderate/heavy incontinence some designs are better for men/women than others. There was considerable individual variability in preferences, and costeffective management may best be achieved by allowing users to choose combinations of designs for different circumstances within a budget.

\section{Implications for healthcare}

There is evidence that:

- A range of disposable and washable designs need to be provided to cost-effectively meet the needs of men and women with incontinence.

- Men may require more, or more absorbent, products than women.

- Although some users prefer washables, current products have important limitations and a blanket policy of providing only washables is not recommended. 
- Allowing men and women to choose combinations of designs for day and night and for different circumstances, within a limited budget, is likely to be economical for the NHS.

\section{Recommendations for research}

The following areas need to be addressed.

- Translational research: to pilot the feasibility of providing choice and combinations of designs to users
- Development of more effective washables for women with light incontinence and more effective and appealing (particularly to women) washables for moderate/heavy incontinence.

- Development of specifically male disposable products for moderate/heavy incontinence.

- Further development of a tool to measure quality of life for users of absorbent products.

- Clinical trial of designs for community-dwelling carer-dependent men and women with moderate/heavy incontinence. 



\section{Chapter I Introduction}

\section{Background}

Despite advances in treatments and therapies for incontinence, completely reliable bladder or bowel control is not an attainable goal for everyone. Many people need support from products to achieve "contained incontinence ${ }^{1}$ to enable them to carry out their everyday lives confidently and to maintain their quality of life (QoL). Successful management with continence products can help people avoid the stigmatising consequences of incontinence, which can otherwise threaten social and working lives, and also personal relationships. ${ }^{2,3}$

Absorbent products for incontinence are the most common type of continence product in use and account for the majority of NHS expenditure on continence aids and appliances (estimated to be around $£ 94$ million per annum ${ }^{4}$ ). They are available in a wide range of designs, sizes and absorbencies encompassing light through to heavy incontinence. Users of products also vary widely, from children with special needs through to independent adults and to older people with multiple disabilities living in nursing homes.

In the UK, these products are available to people living at home and in residential settings through the NHS, although local provision may be restricted and varies widely between primary care trusts. Product selection is usually carried out by nurses in consultation with patients, but there is little evidence to support the efficacy of the different designs of products for different patient groups and to provide a firm basis for making choices for individual patients.

\section{Designs}

Absorbent products may be classified into two broad categories based on the incontinence severity of the user: light, and moderate/heavy incontinence. Within these categories are disposable (single-use) and reusable (washable) products, which are subdivided into different body-worn designs and different underpad designs, the latter being used mainly for moderate/heavy incontinence. There are only two absorbent products on the market designed specifically for faecal incontinence (both inserts without superabsorber; see below) and pads designed for urinary incontinence are frequently used for this purpose. ${ }^{5,6}$ Table 1 shows a classification of absorbent products.

Body-worn absorbent products can be divided into several main design groups. Inserts (sometimes called two-piece system, liners or, in the case of small pads, shields) are made in a wide range of sizes suitable for light through to very heavy incontinence. They are held in place by closefitting underwear or stretch mesh briefs (Figure 1) and sometimes have an indicator that changes colour when wet to signal the need for a pad change. They may have longitudinal, elasticated standing gathers of hydrophobic material intended to impede lateral leakage of urine and

TABLE I Classification of absorbent continence products ${ }^{a}$

\begin{tabular}{|c|c|c|}
\hline Method of use & Body-worns & Underpads \\
\hline \multirow[t]{4}{*}{ Designs for moderate/heavy incontinence } & Inserts & Bedpads \\
\hline & Diapers & Chairpads \\
\hline & T-shaped diapers & \\
\hline & Pull-ups & \\
\hline \multirow[t]{5}{*}{ Design for light incontinence } & Inserts & \\
\hline & Menstrual pads (W) (disposable only) & \\
\hline & Pouches (M) & \\
\hline & Leafs $(M)$ & \\
\hline & Pants with integral pad & \\
\hline
\end{tabular}



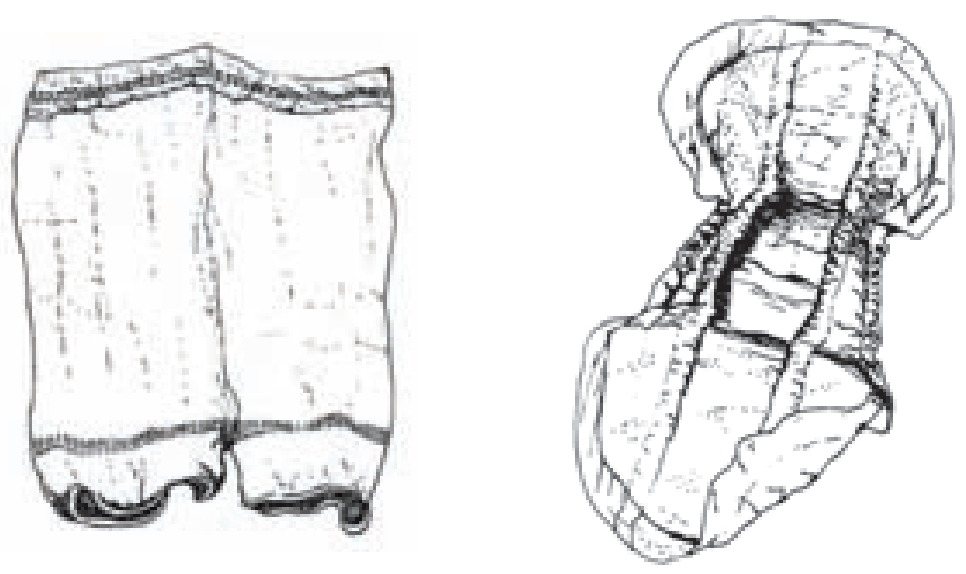

FIGURE I Stretch mesh briefs and disposable insert pad

faeces. Generally, they are shaped to fit the body more snugly and elastication at the legs may also be used to enhance fit.

Disposable inserts for light incontinence (Figure 2) usually have an adhesive strip on the back to help secure them. Washable inserts (Figure 3) are usually more simply designed than disposable inserts, with no elastication, and are either shaped or a simple rectangle.

Diapers (or one-piece system/all-in-ones) are adult-sized versions of babies' diapers (nappies). Disposable diapers (Figure 4) usually have elasticated waist and legs and self-adhesive tabs (usually resealable), and often a wetness indicator and standing gathers. Washable diapers are usually elasticated at the waist and legs and are fixed with Velcro or press-studs (Figure 5). Diapers are intended for moderate to very heavy incontinence.

T-shaped diapers have recently been introduced that fasten round the waist before the front is pulled into position and secured, to enable users to apply the diaper while standing (Figure 6).

Pull-ups are similar in construction to trainer pants for toddlers. The absorbent material is built into a pull-up pant and is either limited to the crotch area or distributed throughout the pants. Disposable pull-ups (Figure 7) are usually elasticated throughout the pants to give a close fit. Washable pull-ups are usually made in terry towelling with an outer waterproof layer (Figure 8). Both disposable and washable pull-ups have versions for different levels of incontinence. Washable pull-ups for light incontinence are often

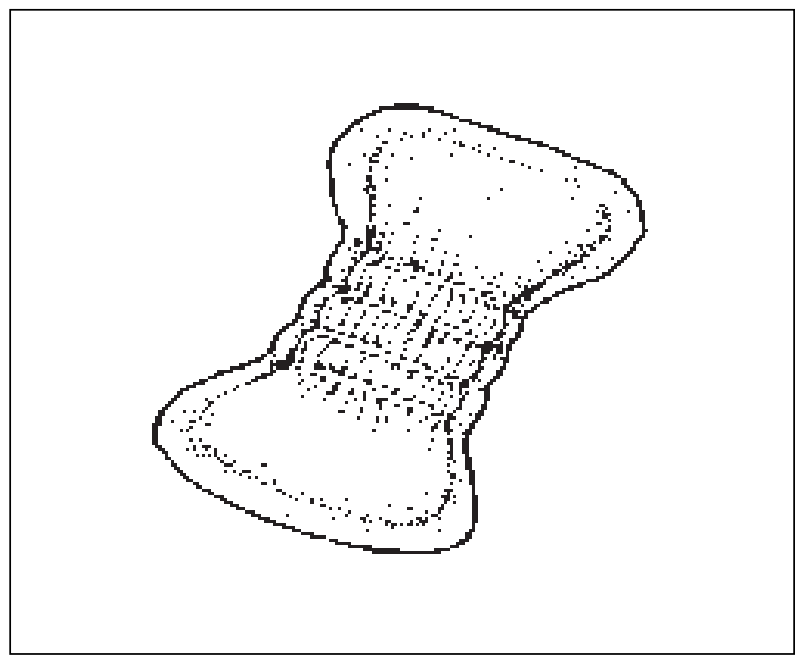

FIGURE 2 Disposable insert pads (light)

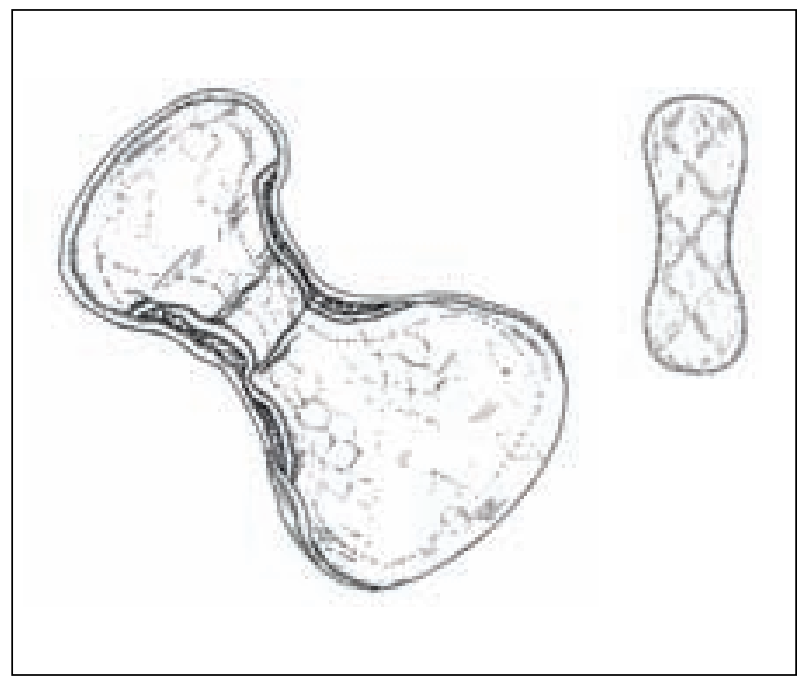

FIGURE 3 Washable insert pads (heavy and light) 

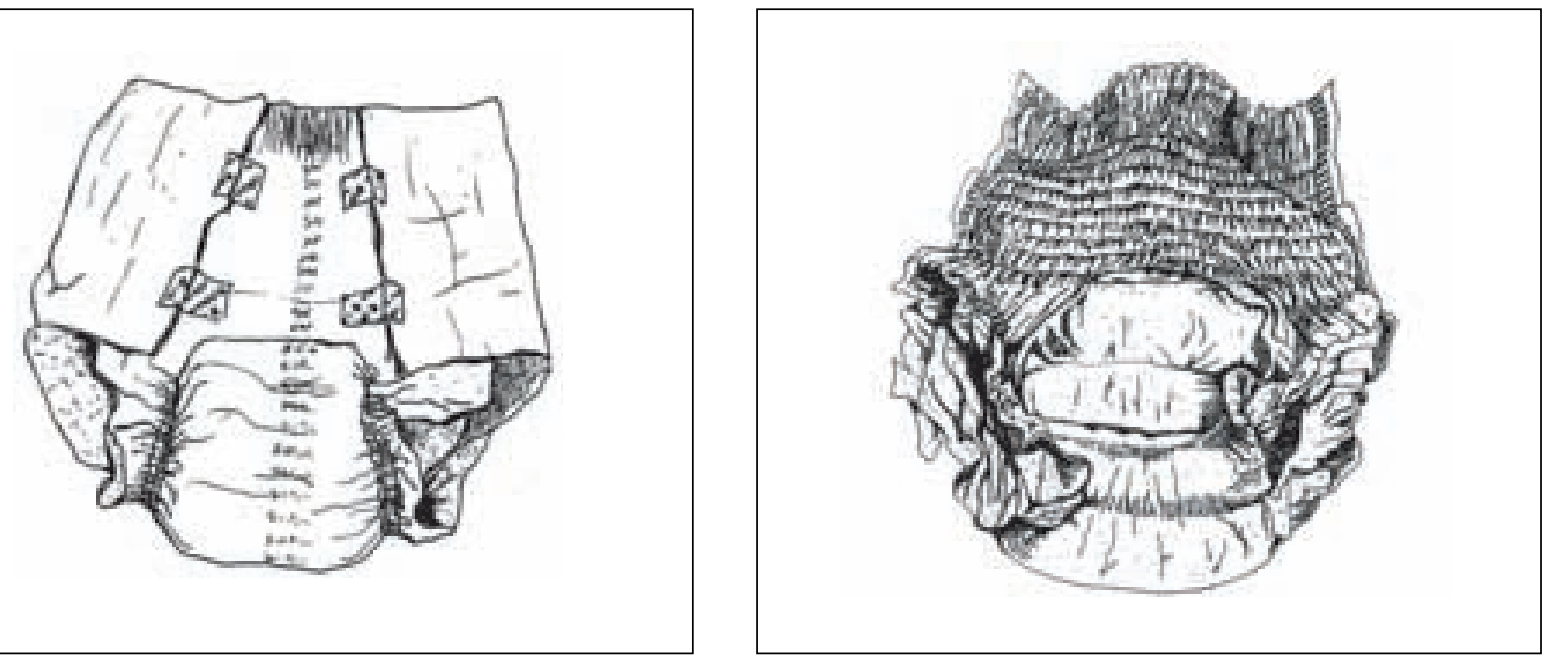

FIGURE 7 Disposable pull-up

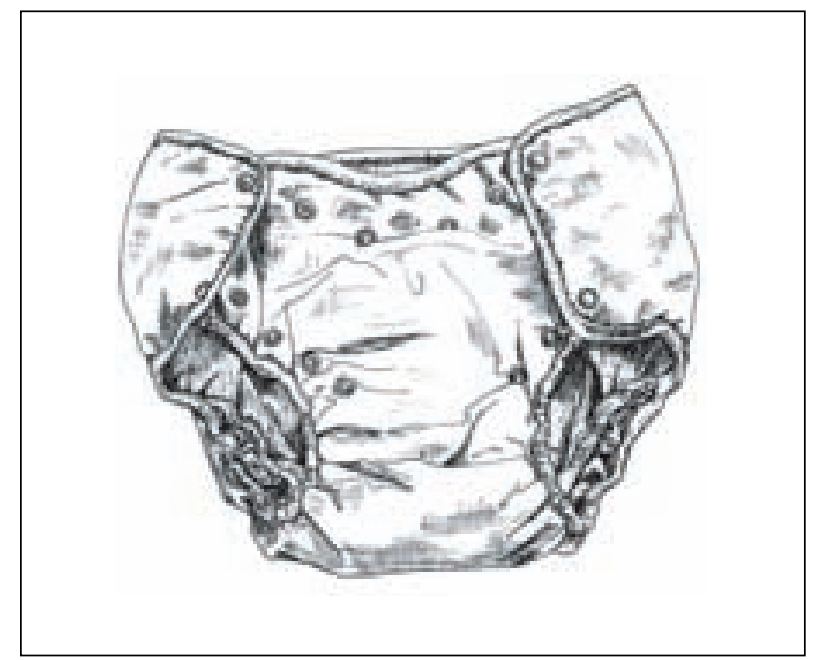

FIGURE 5 Washable diaper

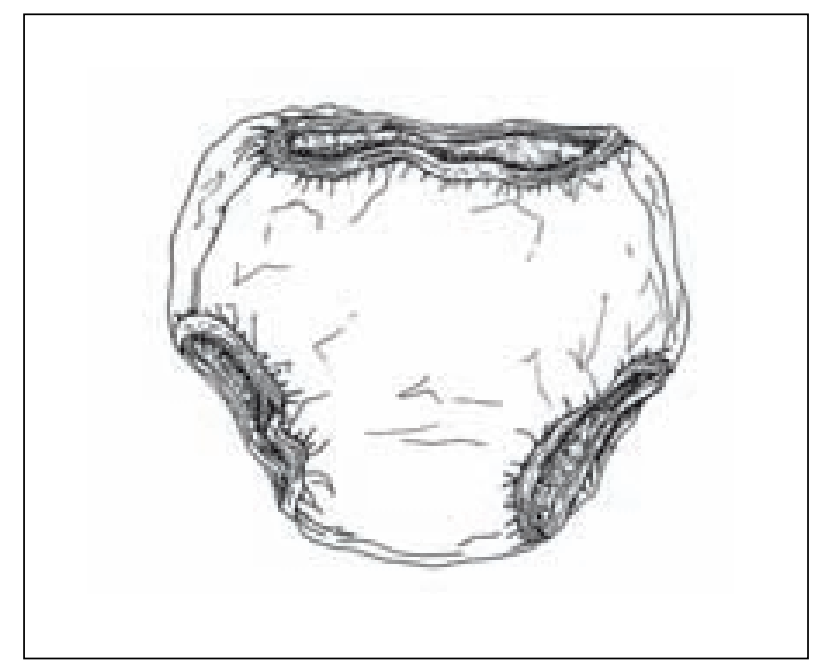

FIGURE 8 Washable pull-up
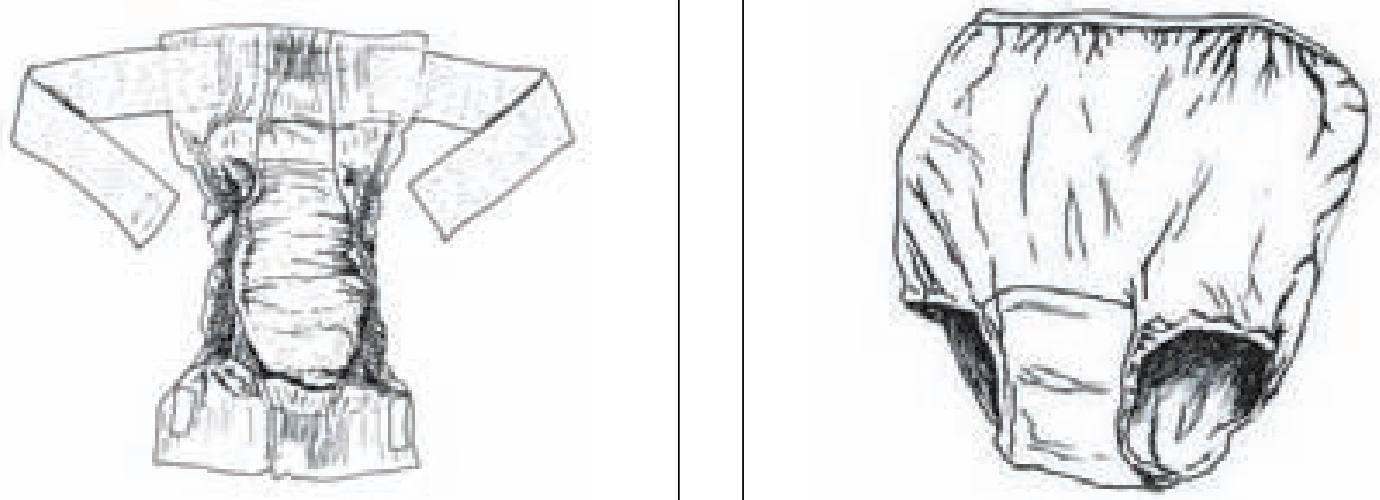

FIGURE 6 Disposable T-shaped diaper

FIGURE 9 Washable pant with integral pad (light)

(C) Queen's Printer and Controller of HMSO 2008. All rights reserved. 
Male pouches are for lightly incontinent men and are designed to fit over the penis (Figure 10). Larger pouches (often called leafs) are designed to fit around the scrotum also. All are worn with close-fitting underwear or stretch mesh briefs. An adhesive strip is often provided on the disposable versions to help hold them in place.

Underpads are usually simple rectangles of different sizes to be used on the bed or chair (Figure 11). Washable underpads may have a high friction backing or have 'wings' for tucking beneath the mattress of single beds to help keep them in place. Underpads vary widely in absorbency, with less absorbent products being used as 'back-up', with body-worn absorbents and more absorbent products being used as sole protection on the bed at night.

\section{Materials}

Absorbent products - disposable or washable usually comprise three main layers: an absorbent core sandwiched between a waterproof backing

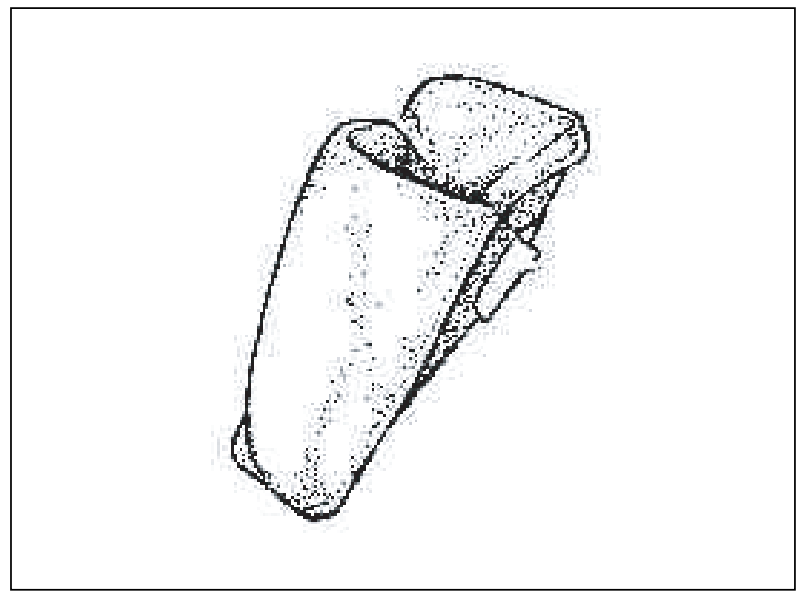

FIGURE 10 Disposable pouch beneath and a water-permeable coverstock (or topsheet) above, next to the wearer's skin.

The main component in disposable absorbent cores is invariably some kind of fluffed wood pulp fibres, but most also now contain some powdered superabsorber [sometimes referred to as superabsorbent polymer (SAP) or absorbent gelling material (AGM)], which is often concentrated in the crotch region. Superabsorbers hold much more urine - weight for weight - than fluff pulp and retain it far more tenaciously under pressure. They are usually based on cross-linked salts of polyacrylic acid, whose chemistry can be varied according to the balance of properties such as absorption capacity and absorption speed desired. Some thermoplastic fibres are also sometimes included in absorbent cores to reduce core break-up and the collapse of the structure when wet. It is increasingly common for absorbent cores to comprise two or more layers, each designed to perform a different function. For example, an upper layer might comprise lowabsorbency fibres selected to receive and distribute urine efficiently and maintain a dry layer next to the skin, whereas lower layers provide absorption capacity. Some disposable products have 'breathable' plastic backings designed to reduce skin occlusion.

Washable absorbent cores are usually made either from a needlefelt or knitted fabric comprising rayon and/or polyester fibres or from terry towelling. A variety of polymers are used for the water proofing. In general, the thicker, stiffer materials are more durable (the durability of the plastic backing often determines the lifetime of the product) but less comfortable. Topsheets are usually made from either cotton, which is

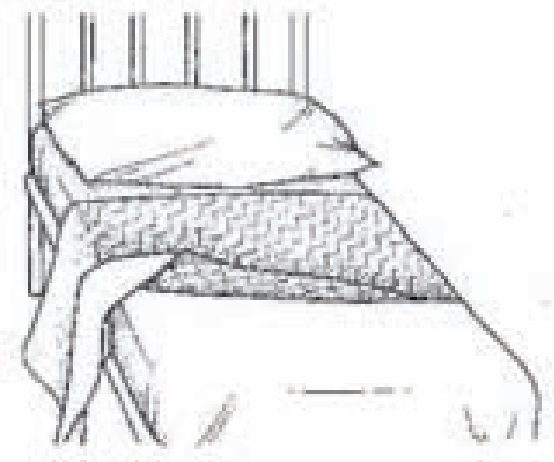


hydrophilic and said to have good dry comfort, or polyester, which is hydrophobic and said to have good wet comfort.

\section{Users of absorbent products}

Continence pad users are a heterogeneous group, ranging from young, mobile individuals (usually with light incontinence) living independently in the community to very disabled older people (often with heavy incontinence) living in residential settings. People in different user groups may vary in their responses to the same designs; a user of designs for moderate/heavy incontinence may be an employed young adult and live independently in the community or may be an older person with multiple physical and cognitive disabilities living in a nursing home and highly dependent on care staff to meet their needs. It is possible that their requirements are best met by different designs. People with similar characteristics may also vary in how acceptable they find different designs and which they prefer. The broad categories of user groups are shown in Table 2.

\section{Costs and provision of absorbent products in the UK}

The NHS usually provides free absorbent products to people with incontinence in the UK. Products are selected at different levels in the supply chain. Until recently, the purchasing and distribution of incontinence products were handled by separate agencies. The NHS Purchasing and Supplies Agency (PASA) purchased products from manufacturers which it then advertised to NHS Trusts in the NHS Logistics catalogue and distributed to them using the NHS Logistics delivery network. PASA could negotiate very large contracts with manufacturers at favourable prices, but purchased a limited range of products. Some Trusts (up to two-thirds) chose to buy supplies direct from manufacturers (usually by tender) because they could access a wider range of products and arrange for them to be delivered direct to the homes of users.

In October 2006, PASA and NHS Logistics were merged into NHS Supply Chain, which, using outsourcing to DHL, combines the procurement, storage and distribution of products within the NHS. Supply Chain incorporates a home delivery service, and it is expected that Trusts will increasingly use this service rather than deal direct with manufacturers. In this way, Trusts will benefit from Supply Chain's considerable bulk purchasing economies, although they will face reduced choice in terms of the products they can offer to their clients. PASA agrees prices and contracts with manufacturers by auction that begins with paper tenders and culminates with electronic bidding. This method ensures that the NHS secures the best possible procurement price.

The products that PASA will consider buying are selected on the basis of recommendations by a panel of expert clinicians and continence advisers. The products within each design are available in different absorbencies and PASA categorises them into bands according to the Rothwell method ${ }^{7}$ to aid selection. At the local level, NHS Trusts (usually in collaboration with local continence services or district nurses) decide which products to include in their formulary. Individual patients are assessed and, if they are eligible for free NHS supplies, they will be offered products from the limited range provided by their Trust. Eligibility criteria vary and the choice of designs for the patient at this level is restricted. Many Trusts limit

TABLE 2 Broad user-group categories

\begin{tabular}{|c|c|c|}
\hline \multirow[t]{2}{*}{ User group } & \multicolumn{2}{|c|}{ Main setting } \\
\hline & Own homes & Residential settings \\
\hline Children with enuresis & $\times$ & \\
\hline Children with special needs & $\times$ & $x$ \\
\hline Men with light incontinence (commonly prostate related) & $\times$ & \\
\hline Women with light incontinence (commonly stress or urge related) & $\times$ & \\
\hline $\begin{array}{l}\text { Men with moderate/heavy incontinence (multiple causes including } \\
\text { neuro-disability related) }\end{array}$ & $x$ & \\
\hline $\begin{array}{l}\text { Women with moderate/heavy incontinence (multiple causes including } \\
\text { neuro-disability related) }\end{array}$ & $\times$ & \\
\hline $\begin{array}{l}\text { Older men with moderate/heavy incontinence (commonly with complex } \\
\text { disabilities) }\end{array}$ & $x$ & $x$ \\
\hline $\begin{array}{l}\text { Older women with moderate/heavy incontinence (commonly with complex } \\
\text { disabilities) }\end{array}$ & $x$ & $\times$ \\
\hline
\end{tabular}


the number of pads supplied per day in order to contain costs. There is little evidence to determine which designs should be purchased at the bulk-buy level and which designs would be most costeffective at the individual level.

\section{Literature review}

Broadly, the literature reporting clinical trials on absorbent products can be divided into two groups: trials of small body-worn products for light incontinence when used by communitydwelling individuals (mainly women) and trials of large body-worn products and underpads when used by more dependent people in residential settings such as wards for older people or nursing homes. Both have included washable and disposable products.

Typically, studies have either examined a range of products within a single product group (e.g. 12 disposable inserts for women with light incontinence) or have made comparisons between different product designs (e.g. body-worns versus underpads), often using a new product against an existing product, of undefined quality and performance. The problem with the latter type of study is that usually the extent to which either the existing or the new product represents the group of products it purports to is unknown. Results from the former, single-group clinical trials, show that where multiple products of nominally similar products have been tested there have usually been significant and substantial differences in product performance. ${ }^{8,9}$ Generalising the results of comparisons of one product within a design group with a single product from another design group is therefore meaningless and misleading. It is perfectly possible to select (either by accident or purposefully) a particularly 'good' product from one category and a particularly 'poor' product from another. A well-designed study will therefore be seriously flawed if there is no clear process to determine and justify the inclusion of the products selected for testing.

\section{Designs for children}

Most designs for light and moderate/heavy incontinence (Table 1) are available for children, (except for pouches and leafs which are designed for adult men). There has been only one study of absorbent products for children ${ }^{10}$ and this compared diapers (six products) with (the more expensive) pull-ups (six products) when used by children with disabilities. Findings showed that the different designs were similar in performance but design preferences were influenced by specific factors or needs, such as the use of calipers or faecal incontinence.

\section{Designs for men and women with light incontinence}

The main designs of products for light incontinence are shown in Table 1 and are mainly gender specific, that is, the designs are specifically for men or for women.

\section{Comparisons of products for light incontinence Designs for men}

There are eight product designs that are potentially suitable for men with light incontinence (disposable and washable pouches for penis only; disposable and washable leafs large pouches for penis and scrotum; disposable and washable insert pads; and disposable and washable pants with integral pad). Designs for men have been the subject of only one study. Fader and colleagues ${ }^{11}$ used a crossover design and compared all six pouches with all six leafs available in the UK with a single disposable insert pad and washable pants with integral pad; a total of four designs. Seventy-four men tested these four product designs in a randomised order and rated products using weekly product performance questionnaires and pad leakage diaries. Findings showed that the performance of the pouch products (as judged by participants' 'overall opinion' scores) was significantly poorer than those of the leaf and insert products. However, scores for individual products within the pouch and leaf design groups varied widely and one particular leaf product was significantly better than all the other products in the trial. The washable pants with integral pad scored poorly for leakage but overall were 'loved or hated' by participants; men with very light incontinence were the most likely to favour the pants.

\section{Designs for women}

There are five product designs suitable for women with light incontinence. Disposable insert pads are the most commonly used products, but it is known that menstrual pads are also frequently purchased for this purpose. Washable pants with integral pads and washable insert pads comprise a small share of the market. Disposable pants with integral pad (pull-ups) are available but are expensive and seldom used for light incontinence.

Baker and Norton ${ }^{12}$ evaluated six small disposable inserts and two menstrual pads (available in the USA in 1991) with 65 community-dwelling women. The products were rated using an evaluation 
questionnaire and daily diary of pad use. The two menstrual pads (which were the least expensive pads in the study) scored significantly higher than many of the incontinence products, although neither was the most popular pad. The authors concluded that for economic reasons women should try a 'maxi' menstrual pad first and then move on to a higher capacity (incontinence) pad if this is inadequate. However, products have changed considerably since this study was carried out and the current relative performance of menstrual pads compared with disposable inserts for incontinence is not known.

There have been two trials of products for women which have compared products of a single design. Clarke-O'Neill and colleagues ${ }^{9}$ compared the complete range (12 products) of disposable inserts for lightly incontinent women available in the UK in 2000 when tested by 60 community-based women aged 50 years or older. Products were evaluated using a pad performance questionnaire and a pad leakage diary. As a group, the products performed well in terms of their ability to hold urine without leakage, but there were significant and substantial differences between products on 'overall opinion' (primary outcome variable) scores.

A similar study by the same research group ${ }^{8}$ compared the 10 washable pants with integral pads available in the UK. Seventy-two communitybased women who usually used absorbent products for light incontinence tested each product for 1 week each. Again, overall opinion scores showed wide differences in product performance, although leakage performance in general was found to be poor.

\section{Summary of evidence for efficacy of absorbent designs for light incontinence}

- The main designs of absorbent products for men with light incontinence have recently been tested in a randomised cross-over trial and there is evidence that one particular disposable leaf design is significantly better than all disposable pouch designs, disposable inserts and washable pants with integral pad. However, there has been no economic evaluation of these designs.

- There have been no recent clinical trials comparing the different designs of products for women with light incontinence.

- There are indications that menstrual pads may perform similarly to disposable inserts and that washable pants with integral pad may not be as effective for leakage.
- There are no data on the performance of washable inserts and no data on comparative costs of each design.

\section{Designs for men and women with moderate/heavy incontinence}

These designs are suitable for both men and women (see Table 1). A large number of comparative studies of absorbent products for moderate/heavy incontinence have been made but most include products that are no longer available. Furthermore, changes in materials and design features mean that it is impossible to generalise any particular findings to products of today. Brink $^{13}$ identified 30 studies of absorbent products published between 1965 and 1990 .

\section{Comparisons between disposable body-worn products for men and women with moderate/heavy incontinence}

Since 1990, there have been few studies comparing different body-worn products for moderate/heavy incontinence. In a double-blind crossover study involving 45 heavily incontinent older adults (38 women, seven men) Clancy and Malone-Lee ${ }^{14}$ compared the leakage performance of four different variants (each available in three absorbencies) of a large, shaped, body-worn pad. Each variant had been manufactured specifically for the study, that is, none of the products was available commercially. The results were complex but, in general, the variant with two layers of fluff pulp leaked significantly less than that with one layer. Although adding some superabsorber to the lower pulp layer produced a further significant improvement, simply increasing the quantity of superabsorber overall yielded no clear advantage. It was also found that pads were more likely to leak if they were not held in place by pants $(p<0.0001)$ and that, if there was any leakage from a pad, this tended to be less severe if the supplied mesh pants were worn than if normal pants were worn $(p<0.05)$. The mesh pants probably held pads more firmly to the body.

There have been two single design group studies of body-worn products for moderate/heavy incontinence, both carried out in nursing homes. ${ }^{15,16}$ A study of shaped insert pads included 228 subjects from 33 nursing/residential homes who tested 20 ranges of insert pads (74 products in total). A similar study of diapers involved 192 subjects from 37 nursing/residential homes who tested 36 products. These studies showed the wide range of product performance within single design groups. For example, the least successful diaper (based on 'overall opinion') was found to be 
unacceptable to $100 \%$ of the test subjects whereas the most successful was unacceptable to only $6 \%$. Overall the diapers performed better for leakage than the inserts.

Because clinical evaluations are expensive and time consuming, laboratory evaluation procedures are in widespread use. Few have been clinically validated but there is a clinically validated International Standard relating to the leakage performance of disposable body-worn pads for moderate/heavy incontinence (ISO 11948-1, 1996). It describes a simple method for measuring the absorption capacity of pads in the laboratory that was shown to correlate well with the leakage performance of 18 different products evaluated in an international multi-centre clinical study involving 112 heavily incontinent adults. ${ }^{17}$ PASA uses this standard (known as the Rothwell Method $^{7}$ ) as a basis for classifying pads by absorbency to assist them in dealing with tenders for national contracts.

\section{Comparisons of washable body-worn products for men and women with moderate/heavy incontinence}

There have been no robust clinical evaluations comparing washable absorbent body-worn products for moderate/heavy adult incontinence. However, Macaulay and colleagues ${ }^{18}$ recently carried out a pilot study of 19 products with 14 community-dwelling subjects. The products included a mixture of washable insert, diaper and pull-up designs and two disposable body-worn products. Product performances varied widely: the most popular was rated as good (for overall opinion) by $78 \%$ of testers, whereas the least popular scored 22\%. Although most of the washable products performed poorly for leakage, one washable product made of cotton terry towelling scored better than all the other washable and disposable products.

\section{Comparison between disposable and washable body-worn products}

Seven trials have compared disposable with washable body-worn products for moderate/heavy incontinence. ${ }^{19-24}$ The trials varied in size and design from a large controlled trial with 276 subjects ${ }^{19}$ to a small trial of 11 subjects. ${ }^{22}$ In addition, some trials have compared disposable and washable bedpads and body-worns. ${ }^{25,26}$ No systematic methods of product selection were used for these studies, which limits the utility of the results since particularly good or poor products may have been selected to represent the
Skin condition was used as an outcome measure in five of the above trials. However, only three used an experimental design and statistical methods of analysis. ${ }^{19,20,27}$ Two studies reported that they did not find statistically significant differences between the washable and disposable products in terms of an adverse change in skin condition, but one $\mathrm{e}^{27}$ reported a statistically significant improvement in the skin condition of the disposable users as compared with the washable users.

Other parameters frequently investigated in these studies were staff preference, leakage and laundry. Overall, the disposables in the studies were considered to have performed better than the washable products in terms of preventing leakage (often measured by quantity of laundry) and staff preference.

Four studies attempted to measure costs. ${ }^{20,21,26,28}$ Of these, three used statistical methods of analysis. ${ }^{20,26,28}$ Two studies reported no statistically significant differences ${ }^{26,28}$ in terms of per day product costs between disposable and washable products. However, Brown and colleagues ${ }^{26}$ reported that the laundry costs associated with the disposable product (i.e. for laundering soiled bed linen and clothes) were significantly lower than those associated with the washable product (i.e. for laundering the products in addition to soiled bed linen and clothes). There were no significant differences between daily costs of the washable or disposable products. However, statistically significant differences were found between the groups in terms of incontinence-related laundry, with the disposable group producing less laundry than the washable group. Grant ${ }^{20}$ reported that the cost of washable products was significantly cheaper than that of disposables, but laundry costs were not taken into account.

In a small trial comparing two new disposable products with a washable product that was in established use, ${ }^{29}$ the results favoured the disposable products. However, the washable product was not adequately described and it is not clear whether this product was a body-worn product or a bedpad. Staff morale improved with the disposable product and they reported a decrease in unpleasantness associated with changing pads.

\section{Summary of evidence for efficacy of absorbent designs for moderate/heavy incontinence}

- Research evidence indicates that disposable insert pads leak significantly less if they are held 
in place by mesh pants than by ordinary pants, and using no pants at all is associated with significantly more leakage than if either kind of pant is worn.

- There is evidence that disposable pads containing superabsorber leak less than those without.

- The leakage performance of disposable inserts and diapers for heavy incontinence can be predicted with reasonable precision using international standard laboratory tests.

- The leakage performance of disposable diapers may be better than that of disposable inserts of similar absorption capacity, although this has not been demonstrated in a clinical trial.

- The literature indicates that disposable bodyworn products generally perform better than washables in terms of skin condition and leakage. However, it is clear that there are more and less effective products in each category.

\section{Systematic reviews of literature comparing designs for moderate/heavy incontinence}

The majority of the clinical trials comparing different designs of absorbent products for moderate/heavy incontinence are more than 10 years old and include products that are not available today. Reviewers of the absorbent product literature ${ }^{30-32}$ have also commented on problems of weak study design, small study size and lack of statistical power.

Shirran and Brazzelli ${ }^{33}$ carried out a Cochrane review of four different comparisons:

(1) disposable body-worns versus washable bodyworns; (2) disposable underpads versus nondisposable underpads; (3) one type of material versus another; and (4) body-worns versus underpads. The authors concluded that data from examined studies were too few and of insufficient quality to provide a firm basis for practice and that there was a need for larger, well-designed trials of products. Tentative practice recommendations were that disposable products may be preferable to washable products for those with skin problems, that underpads may be cheaper than body-worns and that disposable pads with superabsorber appear to perform better than those without.

The reasons for selecting the four comparisons made in the Cochrane review are unclear. It seems likely that the rationale for the comparisons chosen was that they were those most commonly made over the last 20 years, but changes in product use and practice mean that comparisons of body-worn products are more clinically relevant today (see the section 'Which designs should be evaluated?', p. 10).

\section{Methodological issues affecting absorbent product research}

Method problems affecting product evaluation have been analysed by Fader and colleagues. ${ }^{34}$ The authors (ourselves) suggest that a simple randomised control trial (RCT) is inappropriate because of the difficulty in determining a 'control' pad. A crossover trial is therefore the most appropriate design, particularly as incontinence is frequently a chronic condition and use of products does not affect the underlying symptoms. ${ }^{34}$

The problem of selecting a single product to represent a design group (when it is known that individual products vary considerably) may be addressed by including several products from the same design group rather than by simply relying on one representative product. The need for many secondary outcome variables to reflect the diversity of product characteristics that influence user preference is also discussed. For example, invisibility under clothing may be of vital importance to some people, whereas others are less concerned about bulk and more concerned about preventing leakage. We conclude that patient 'overall opinion' is likely to provide the most appropriate primary outcome variable because it synthesises the various strengths and limitations of the product from the patient perspective.

A number of product characteristics which contribute to patient 'overall opinion' are also expected to be relevant to the development of a health-related QoL measure for people who use absorbent products. QoL measures are of particular importance in clinical trials for the comparison of treatments/products with little apparent difference in objective clinical outcomes in the patient's condition but where patient morbidity and everyday life are affected. This is relevant for patients whose urinary or faecal incontinence is managed by the use of absorbent products and which are used to contain the problem rather than improve it. Currently, there is no validated measure for QoL for people using absorbent products; most existing QoL instruments measure severity of urinary symptoms. ${ }^{35}$ Such symptoms are not expected to change when wearing different continence products, although patients with similar symptoms often have different views of the 'bothersomeness' 
of their continence problem. This may be associated with the effectiveness of the absorbent products that they use. The development of a specific QoL instrument to reflect the QoL impact of different absorbent products would be a valuable addition to product evaluation methodology and would contribute to more meaningful comparisons between studies.

\section{Which designs should be evaluated?}

There are many designs of absorbent products and therefore many different comparisons could be made within the broad categories of light and moderate/heavy incontinence. The Cochrane review mentioned in the last section ${ }^{33}$ focused on comparisons between bedpads and body-worns, and washable and disposable bedpads. About 10-20 years ago it was common for incontinent people to use bedpads alone, sometimes for both day and night, and studies involving bedpads were therefore of importance. Times have changed and the use of bedpads as the primary method of containing incontinence is not considered optimum practice these days. Body-worn pads are now the mainstay of management, with bedpads being used primarily as 'back-up' to contain leakage from body-worn pads. There are dignity issues with the use of bedpads; when used on their own bedpads require the individual to stay in one place and be naked from the waist down, which many regard as unacceptable. Although tentative review findings suggest that bedpad use may be cheaper than body-worn use, it is likely that patient and staff acceptability will be low and it is questionable whether there is value in attempting to demonstrate this further.

Product designs have also already changed to incorporate favourable features. It is hard now to find a body-worn disposable pad without superabsorber and virtually all products are shaped. It is difficult to justify a study seeking to measure the value of such features.

Of greater importance is the need to determine which of the main body-worn designs are most effective and most preferred by patients and carers. The current NHS purchasing of absorbent products is dominated by disposable insert pads for both light and heavy incontinence; data supplied by PASA indicate that insert pads comprise about two-thirds of the total body-worn market and diapers about one-quarter. Washable absorbent products constitute less than $1 \%$ of the market. In this way, the UK differs from other European countries and the USA, where diaper designs are much more popular than insert pads for moderate/heavy incontinence.

New designs have been introduced in the last few years which may have benefits for patients but have yet to be tested. Both the 'pull-up' design and the modified T-shaped diaper have been designed to make application easier. Companies are investing substantially in these designs but it is unknown whether patients and staff prefer them and whether they are worth their higher cost. Although more expensive on a 'per pad' basis than diaper or insert products, these products may enable some patients to manage their toileting and pads themselves and may save nursing time.

The UK remains largely a 'disposable' rather than a 'washable' nation, but it is possible that a shift to washable products would be more cost-effective. Washable products have the potential to be less expensive to use than disposable products in the long term, ${ }^{36}$ but their leakage performance (for heavy incontinence particularly) has been found to be poor. However most studies of these products are old and technological developments have been made which may mean that the products of today have better performance.

\section{Summary}

- Absorbent products are the common method of managing urinary and faecal incontinence and their cost to the NHS is estimated to be about $£ 94$ million per annum.

- Absorbent products comprise many different designs, which may be broadly classified into two groups: products suitable for light incontinence or those suitable for moderate/heavy incontinence.

- Absorbent product users are a heterogeneous group and vary widely in terms of their ages, abilities and needs and live both in the community and in residential settings.

- Absorbent products for men with light incontinence and products for children with disabilities have been studied recently and there is evidence to guide product selection.

- Systematic literature reviews indicate that there is no firm basis for making choices between designs of absorbent products for women with light incontinence and for individuals with moderate/heavy urinary and/or faecal incontinence. Furthermore, there is no current evidence on the cost-effectiveness of current designs. 
- Product technology and clinical practice have changed over the last few years and new bodyworn designs have been introduced.

- Comparisons of different body-worn designs (both disposable and washable) for both light and moderate/heavy incontinence are the most clinically relevant.

- Absorbent product evaluation is methodologically challenging and requires careful planning and special measures (particularly with regard to product selection and representation) to produce valid, reliable and generalisable results.

- The development of a QoL instrument would be a valuable addition to product evaluation methodology.

- Given the substantial cost of absorbent products to the NHS, clinical trials should incorporate an economic component.

A project was therefore planned with the following aims.

\section{Aims}

The aims were to compare the performance and cost-effectiveness of the key absorbent product designs for the containment of urinary or urinary and faecal incontinence for women with light incontinence and men and women with moderate/heavy incontinence living in the community and in nursing homes, and to identify aspects of absorbent product use that impact on QoL for users and carers to form the basis for the development of a QoL instrument.

\section{Overall project plan}

The plan for this research project comprises three clinical trials comparing the performance of key absorbent designs:

- Clinical trial 1. A comparison of the performance and cost-effectiveness of disposable and washable designs for light incontinence (disposable inserts, menstrual pads, washable pants with integral pad, washable inserts - four designs) when used by women living in the community.

- Clinical trial 2a. A comparison of the performance and cost-effectiveness of disposable and washable designs for moderate/heavy incontinence (disposable inserts, diapers, T-shaped diapers, pull-ups and washable diapers - five designs) when used by men and women living in the community.

- Clinical trial 2b. A comparison of the performance and cost-effectiveness of disposable designs for moderate/heavy incontinence (disposable inserts, diapers, T-shaped diapers, pull-ups - four designs) when used by men and women living in nursing homes.

Data collected during the clinical trials will be used for the first stage in the development of a QoL instrument for people using absorbent products. 



\section{Chapter 2 \\ Research design and methods}

\section{Introduction}

This project comprised three clinical trials of absorbent product designs. This section gives an overview of the research design, methods and outcomes used in the trials. Details specific to each clinical trial are given in the separate chapters relating to each trial. The three clinical trials were as follows.

1. Designs for women with light incontinence

(a) Clinical trial 1. A comparison of the performance and cost-effectiveness of disposable and washable designs for light incontinence (disposable inserts, menstrual pads, washable pants with integral pad, washable inserts - four designs) when used by women living in the community.

2. Designs for men and women with moderate/heavy incontinence

(a) Clinical trial 2a. A comparison of the performance and cost-effectiveness of disposable and washable designs for moderate/heavy incontinence (disposable inserts, diapers, T-shaped diapers, pull-ups and washable diapers - five designs) when used by men and women living in the community.

(b) Clinical trial 2b. A comparison of the performance and cost-effectiveness of disposable designs for moderate/heavy incontinence (disposable inserts, diapers, T-shaped diapers, pull-ups - four designs) when used by men and women living in nursing homes.

3. Centres

The trials were conducted from two centres (University College London and the University of Southampton) who work in partnership as the Continence and Skin Technology Group.

\section{Design}

The three clinical trials were carried out using randomised crossover designs. A crossover design is appropriate for testing interventions with participants who have chronic conditions (such as incontinence) which will not be changed by the intervention (such as an absorbent product). A crossover design has advantages over RCTs in that all participants receive each of the interventions allowing for comparison at the individual rather than the group level. Also, as patients receive multiple interventions, preferences may be expressed. ${ }^{37}$ This is particularly appropriate when there is no 'control' intervention, such as in these trials, when all tested products are potential interventions.

For crossover designs, smaller sample sizes are needed to produce the same precision as a parallel group design. Responses between subjects (which may be large) in parallel group designs are replaced by repeated responses from the same patients (which are usually smaller) in crossover designs and more precise results are therefore achievable.

\section{Absorbent product selection and representation}

Absorbent products within a design group have been found to vary substantially in performance (see the section 'Literature review' p. 6). To overcome the potential threat to validity of including a single product, which may not be representative of each design under study, three products were selected (where possible) to represent each design group for clinical trials 1 (light, community) and 2a (moderate/heavy community). Selection was based on data from recent studies (where available) or from pilot data collected before the trial began. The aim was to include the 'best' of the most commonly used products within a design group. Some design groups, particularly newer designs, had only three or, in one case, only two products available, in which case all were used in the trial. The methods used to select the products for for clinical trials 1 (light, community) and 2a (moderate/heavy, community) are shown in Appendices 1 and 4.

For clinical trial 2b (moderate/heavy, nursing homes), a simpler approach was used to make the study easier for homes to administer. A single product was selected from the three products chosen for clinical trial 2a to represent each design. Product selection was based on data from 
participants from clinical trial 2a (moderate/heavy, community) who had completed the trial and on product availability through PASA.

\section{Randomisation}

Crossover designs require participants to receive all interventions and it is therefore the order of testing that requires randomisation. For clinical trials 1 and $2 \mathrm{a}$, the three products selected to represent each design were tested in random order for 1 week each, as a 3-week block of testing. The order of each block was also randomised. For clinical trial $2 b$ (moderate/heavy, nursing homes), which had only one product to represent each design, the order of testing each design was randomised and each design was tested for a 2-week period (to allow sufficient time for staff and residents to experience each design). Latin squares ${ }^{38}$ were used to prepare all order sequences.

\section{Blinding}

It was not possible to blind the products. Each design is different and most products within each design have some identifiable company or product names printed on the product backing.

\section{Initial participant interviews}

\section{Background information}

Each participant (or carer/participant in the case of clinical trial $2 b-$ moderate/heavy incontinence, nursing homes) was interviewed following recruitment and the background descriptive data shown in Table 3 were obtained.
Participant background data were collected to assemble individual characteristics and incontinence-related details (e.g. age, type of incontinence, type of absorbent products currently used) and economic information (e.g. self or NHS purchase of supplies, household income). It is known that physical impairment is associated with incontinence and the Barthel score ${ }^{39}$ (to assess independence in activities of daily living) was used to assess this. To measure the effect that incontinence has on QoL, the two most commonly used scores were used: the International Consultation on Incontinence Questionnaire Urinary Incontinence (short form) (ICIQ-UI) ${ }^{40}$ and the Kings QoL score ${ }^{41}$; a generic score (SF$12)^{42}$ was also used to enable comparisons of the samples across other groups. Incontinence is known to be associated with anxiety and depression $^{43}$ and the Hospital Anxiety and Depression Scale (HADS) was therefore used. ${ }^{44} \mathrm{~A}$ brief laundry questionnaire was used to determine laundry habits to allow relevant calculation of laundry burden. For the nursing home residents (Trial 2b), who were more likely to be most at risk of skin health problems, two scores were used to assess pressure ulcer risk: the Braden scale, ${ }^{45}$ commonly used in the USA, and the Norton score ${ }^{46}$ commonly used in the UK. The Hodkinson mental test ${ }^{47}$ score was used to assess the extent of cognitive impairment in the nursing home residents.

\section{Product performance priorities and effects of pad wearing on quality of life} Participants (and carers in trial 2b) were asked to identify what aspects of absorbent product

TABLE 3 Background descriptive data

\begin{tabular}{lll}
\hline Questionnaire/score & Purpose: to provide & Clinical trial \\
\hline $\begin{array}{l}\text { Background demographic } \\
\text { socio-economic information }\end{array}$ & $\begin{array}{l}\text { Descriptive data on age, gender, product use, } \\
\text { socio-economic data } \\
\text { Laundry questionnaire }\end{array}$ & $\begin{array}{l}\text { I, 2a and 2b (socio-economic } \\
\text { Information oxcluded from 2b) }\end{array}$ \\
$\begin{array}{l}\text { Barthel score } \\
\text { SF-I2 }\end{array}$ & A measure of independence in activities of daily living score & All and 2a \\
Kings QoL score & A measure of general QoL & I and 2a \\
ICIQ-UI (short form) & A measure of incontinence-specific QoL & I and 2a \\
$\begin{array}{l}\text { Hospital Anxiety and } \\
\text { Depression Scale (HADS) }\end{array}$ & A brief measure of incontinence-specific QoL & I and 2a \\
Hodkinson mental test score & A (brief) assessment of cognitive function & I and 2a \\
Norton score & An assessment of pressure ulcer risk (UK orientated) & $2 \mathrm{~b}$ only \\
Braden score & An assessment of pressure ulcer risk (US orientated) & $2 \mathrm{~b}$ only
\end{tabular}


performance were most important to them. They were also asked to describe how problems with these aspects affected their QoL. For example, if discreetness under clothes was considered important, the effect on the participant's QoL may be to alter the types of clothing they might wear or to avoid social situations where they may feel conscious of the pad showing. These interviews identified the most important secondary outcome variables to utilise in the analysis of the product performance questionnaires and also provided data for the development of the QoL tool.

\section{Outcome variables}

\section{Primary outcome variable}

The primary function of an absorbent product is to absorb and contain urine (and/or faeces) without leakage. However, a design with very good leakage performance may also be bulky, uncomfortable or unacceptable to the individual in some other way, and measurement of leakage performance is not therefore the most appropriate primary outcome variable.

This study used the participant 'overall opinion' of each absorbent design, taken at a final interview at the end of the study after all product designs had been tested, as the primary outcome variable because this gives a synthesis of the individual's perceptions of the design. Individuals rate products for various aspects of performance (such as leakage, comfort or staying in place), but they have different priorities and may weight characteristics differently, so an aggregate score may not give an accurate reflection of the individual's overall opinion of the design.

The aim was to carry out the final interview within 4 weeks of completion of the testing period. To minimise dependence on recall, the data collection booklets containing the participants' product performance scores (including 'overall opinion') and written comments about the products were reviewed with the participants at their final interviews. The products were displayed to aid memory and participants were asked to consider their scores and comments before comparing the designs and giving their final 'overall opinion' scores.

Overall opinion was measured on a simple rating scale of acceptability to the individual: highly acceptable, acceptable, unacceptable, totally unacceptable. For analysis purposes, this scale can be binarised to establish which designs are unacceptable (highly acceptable + acceptable) versus (unacceptable + totally unacceptable).

Overall opinion was also measured using a 100-mm visual analogue scale (VAS) from 'worst possible design' to 'best possible design' to measure strength of preference. Participants were asked to mark the relative positions of each design along this scale. This method provided a single score (out of 100) of the individual's overall opinion of the design. For the nursing home staff (clinical trial 2b), a simplified 10-point measure was used because this was found to be easier for staff to use.

Respondents were also asked to rank the designs to determine preferences. They were then told the relative cost of the different designs and asked to re-rank them.

\section{Secondary outcome variables Pad change/leakage diary}

During the product testing period, participants were asked to keep a diary to record individual pad changes. An example of how this was recorded is shown in Table 4.

This provided the following data.

TABLE 4 Example of pad weight and leakage diary

\begin{tabular}{|c|c|c|c|c|c|}
\hline \multirow[t]{2}{*}{ Date } & \multirow[t]{2}{*}{$\begin{array}{l}\text { Unable } \\
\text { to weigh }\end{array}$} & \multirow[t]{2}{*}{$\begin{array}{l}\text { Weight } \\
\text { (g) }\end{array}$} & $\frac{\text { NO }}{\text { LEAKAGE }}$ & $\frac{\text { A LITTLE }}{\text { LEAKAGE }}$ & $\frac{\text { A LOT OF }}{\text { LEAKAGE }}$ \\
\hline & & & $\begin{array}{l}\text { No urine leaked } \\
\text { out of the pad } \\
\text { area }\end{array}$ & $\begin{array}{l}\text { Urine leaked on to } \\
\text { underwear only }\end{array}$ & $\begin{array}{l}\text { Urine leaked } \\
\text { onto clothing or } \\
\text { other items (e.g. } \\
\text { cushion) }\end{array}$ \\
\hline 0I.05.04 & & 100 & & $\checkmark$ & \\
\hline & & & & & \\
\hline & & & & & \\
\hline
\end{tabular}




\section{Leakage performance}

Leakage has been shown by pad users to be the most important performance outcome variable. ${ }^{48}$ Leakage is dependent on urine volume (a pad with $10 \mathrm{ml}$ of urine is much less likely to leak than a pad with $100 \mathrm{ml}$ of urine), and this may vary for different designs. An individual may change their pads more frequently or undertake efforts to minimise their incontinence if they are concerned that a product will leak. Differences in product weights may also reflect differences in leakage performance, with less urine being contained by leaky products. Leakage performance was calculated in two ways, using methods that have been used successfully in previous studies ${ }^{8,11}$ - each used pad was collected and weighed using digital scales, and the participants (or carers in trial $2 \mathrm{~b}$ ) then rated any leakage that occurred on a three-point scale, as 'none', 'a little' or 'a lot'. For clinical trial 1 'a little' was defined as leakage on to underwear only and 'a lot' as on to underwear plus other clothing. However, for clinical trials $2 \mathrm{a}$ and $2 \mathrm{~b}$ definitions were not given because most of the designs replaced underwear and participants were left to make these judgements. These diary data permit the analysis of leakage performance in two ways: (none) versus (a little + a lot) and (none + a little) versus (a lot). Modelling of leakage performance as a function of urine weight and a calculation of leakage event frequency were also performed.

For clinical trial 2b (moderate/heavy, nursing homes), rather than use pad change/leakage diaries, which can be very difficult for staff to maintain, labelled plastic bags were used to store each used pad, which had simple tick boxes to indicate leakage and laundry generated (if any) and to identify any staff-observed skin problems. These pads were weighed (as above) mainly by research staff or by nursing home staff with training (if volunteers were available) and the labels placed in a data book.

\section{Pad and laundry consumption}

The number of products used per day and the number of laundry items (small and large) produced from leakage were calculated using pad change/leakage diary data. For clinical trial $2 b$ (moderate/heavy, nursing homes), product consumption was calculated by regular checking of each individual's labelled packs and counting the number of pads used.

\section{Weekly product performance questionnaire}

Based on outcomes and validated questionnaires used in previous studies ${ }^{8,11}$ of absorbent products such as comfort when wet, comfort when dry, ease of application and invisibility under clothes, a questionnaire was devised for participants to complete at the end of each week of product testing. To add to the validity of these items, the data obtained from the preliminary participant interviews were used to determine and prioritise questionnaire items. The self-report questionnaire utilised a five-point rating scale (very good, good, okay, poor, very poor) with the intention that questions would be analysed by binarising in two ways: to establish good performance (very good + good) versus (otherwise) and poor performance (very good + good + okay) versus (otherwise). For trials 2a and 2b (moderate/heavy), separate product performance questionnaires were used for day and for night.

\section{Skin health}

Participants in clinical trials 1 and 2a rated their own skin health using a rating scale 'no skin problems', 'a little or mild' or 'a lot or moderate/ severe'). Participants in clinical trial 2a (moderate/ heavy, community), who used much larger products covering extensive skin areas, were also asked to identify the location of their skin problems (groins, buttocks, sacrum, other). If skin problems were experienced, the participants were asked to record what action (if any) they took to treat the problem.

For clinical trial $2 \mathrm{~b}$, skin problems were identified by research staff inspecting and rating each participant's skin during the second week of product testing.

\section{Sample size and methods of analysis}

The sample size for each module was calculated to allow the detection, with about $90 \%$ power, of a difference of $30 \%$ in 'overall opinion' scores in any pairwise comparison of design groups, with an overall significance level at most $5 \%$ for all such pairwise comparisons. Using these criteria, target participant numbers for each clinical trial were as follows:

- clinical trial 1 (light, community): four design comparisons, 80 participants

- clinical trial 2a (moderate/heavy, community): five design comparisons, 85 participants

- clinical trial 2b (moderate/heavy, nursing homes): four designs, 80 participants.

Most design groups were expected to perform very similarly. To check this, comparisons would be made on products within each design group for leakage and overall opinion. With 80 participants 
a $25 \%$ difference is detected with about $80 \%$ power with an overall significance level of at most $5 \%$ for all pairwise comparisons.

Data were entered into Microsoft Excel (Version 2003), cleaned, and 10\% of the data set and $100 \%$ of the primary outcome variable data were checked for accurate entry. Ordinal outcome variables were analysed using cumulative logit modelling and quantitative outcome variables were analysed by linear modelling, allowing for repeated observations by each subject. Bonferroni adjustments were made in significance tests and to confidence intervals (CIs) for multiple comparisons between designs. $\mathrm{R}$ software was used (www.r-project.org).

\section{Economic analysis}

The economic analysis adopted the perspectives of individual participants and the health service. A cost-effectiveness analysis was conducted based on mean VAS scores (as a measure of product performance) and the cost of products/designs. VAS scores were used as the primary measure of effectiveness because they were assigned by participants after testing all designs, and were therefore assumed to reflect their evaluation of overall performance based on experience. If there is no statistically significant difference in mean VAS scores between designs, then a cost minimisation approach is adopted with the less expensive design recommended. If one design dominates [i.e. is more effective (higher mean VAS) and cheaper than others], it is recommended. Where one design is more effective and more costly than others, incremental costeffectiveness ratios (ICERs) are calculated to show the cost of generating one more unit of effectiveness (one more VAS point).

For disposable designs, costs are based on purchase prices and mean product consumption data reported by participants at baseline. For washable designs, costs were calculated from purchase prices and estimated replacement rates. Data from manufacturers on the life of products (number of washes) and assumptions about the stocks of products held by users were made to estimate replacement rates. Laundry costs of washable designs were considered. If differential leakage performance resulted in significant variation in the amount of laundry generated amongst designs, this was also included in the analysis. Laundry costs are borne by the user, although the NHS provides the products to most people with moderate/heavy incontinence and some of the women with light incontinence. In the nursing home trial (2b), differences between designs in the amount of time it takes to change residents and the number of staff involved were investigated.

Prices of products used in trials were collected from various sources. The prices faced by women with light incontinence in the community, many of whom purchase their own products, were obtained from national chain retail outlets and mail order catalogues. The prices paid by NHS providers were derived from the current NHS Logistics catalogue at the time of the trial.

\section{Environmental considerations}

An important consideration in the comparison of washable and disposable designs is the relative environmental cost. A recent report on baby nappies concluded that there was no significant difference in environmental impact between three main nappy systems (disposables, home and commercial laundered), although the types of impacts did vary. ${ }^{49}$ It was assumed that these findings are generalisable to adult incontinence products, and accordingly no allowance was made in the cost-effectiveness calculations for environmental factors.

\section{Effect of costs on participant preferences}

During the final interview, after all product testing was completed, participants were shown the relative costs of products in different designs and asked which they would select first, second, third and fourth, and why. They were also asked about their willingness-to-buy different designs from their own perspectives (at retail/mail order prices) and from the NHS perspective (at lower NHS bulk buying prices, but after being reminded that the finance is from taxpayers' money). Changes in respondents' rankings of designs after costs were disclosed were analysed. Of particular interest were participants' stated preferences between disposable and washable products when potential savings associated with washables became apparent. The value-for-money question was simplified in the care home trial because piloting with care staff showed they found this line of enquiry difficult. They were asked to focus on differences between designs in the average daily (or nightly) cost of providing products to residents.

To try to establish the extent to which participants valued their most preferred product over their 
second best, they were asked at what cost of their second choice product they would buy that instead of their first choice. In piloting, however, respondents found this line of questioning difficult, so it was dropped in order to limit the length of the interview.

\section{Ethical arrangements}

The study was reviewed by the London multicentre research ethics committee and complied fully with ethical, governance and data protection requirements and approval was obtained through appropriate NHS research ethics committees.

Written informed consent was obtained from each participant. In clinical trial $2 \mathrm{~b}$, most participants were unable to give informed consent due to mental impairment and a specialised consenting procedure was devised and approved by the ethics committee and is described in more detail in Chapter 5.

\section{Withdrawal}

Participants were able to withdraw from using any particular product at any time. If withdrawal occurred, we requested that a product performance questionnaire was completed and a 'reason for withdrawal from product' form completed. Participants were able to move on to their next product should they wish to continue in the study. Participants who wished to discontinue taking part in the study could do so at any time without giving a reason.

\section{Confidentiality}

Participants received a code number which was used on all study documentation. The recruitment forms containing personal details are kept in a locked filing cabinet in a separate room from the data. The data will be kept in a locked cabinet in a data storage room for 15 years following study completion.

\section{Project supervision}

The project was guided and monitored by a steering group which comprised an independent chairman with expertise in the urinary and faecal incontinence field, two representatives from Incontact (the consumer organisation for people with bladder and bowel problems), a representative from PASA, a representative from the Registered Nursing Home Association, a clinical continence service manager and other members of the project team. 


\section{Chapter 3}

\section{Randomised crossover trial of disposable and washable absorbent products for women with light urinary incontinence (Trial I)}

\section{Background summary}

There are four designs of absorbent products suitable for women with light incontinence (Table 5). Disposable insert pads are the most commonly used products, but it is known that menstrual pads are also frequently purchased for this purpose. Washable pants with integral pad and washable insert pads comprise a small share of the market. There have been no recent clinical trials comparing the different designs of products for women with light incontinence. There are indications that menstrual pads may perform similarly to disposable inserts ${ }^{12}$ and that washable pants may not be as effective for preventing leakage, although washable designs may be cheaper on a per use basis. There are no published data on the performance of washable inserts and no data on comparative costs of each design. There is therefore very little evidence on which to base product selection decisions for NHS purchasing and for individuals.

\section{Aim \\ The aim of the study was to compare the performance and cost-effectiveness of absorbent product designs for women with light urinary incontinence living in the community.}

\section{Design and methods}

The trial was a randomised crossover clinical trial comparing four absorbent product designs: disposable insert (DI), menstrual pad (MP), washable pant with integral pad (WP) and washable insert (WI) (Figure 12).

\section{Recruitment of participants}

The inclusion and exclusion criteria for participants are shown in Box 1. The aim was to recruit participants who were already using an absorbent product suitable for light incontinence (including MPs) and whose incontinence was consistent and stable and occurred at least five times per week. This was to ensure that the participants' incontinence was not likely to change during the period of the trial and that their frequency of incontinence was sufficient to justify the provision of an absorbent product from the NHS and to test the efficacy of the products included in the trial.

Participants were recruited to the study in the following ways:

- A press release was prepared to announce the study and this was distributed to local and national newspapers and magazines.

- An invitation letter was sent to purchasers of absorbent products through Promocon (the national information centre for continence products) and to receivers of absorbent products through local NHS Trust delivery services.

\section{Study process}

During the study, participants tested the four designs (comprising 12 products, three for each

TABLE 5 Classification of absorbent products for women with light incontinence

\begin{tabular}{|lll|}
\hline & \multicolumn{2}{c|}{ Materials } \\
\cline { 2 - 3 } & Disposable $^{a}$ & Washable \\
\hline Design for light incontinence & $\begin{array}{l}\text { Disposable inserts (Dls) } \\
\text { Menstrual pads (MPs) }\end{array}$ & $\begin{array}{l}\text { Washable inserts (Wls) } \\
\text { Washable pants with integral pad (WPs) }\end{array}$ \\
\hline${ }^{a}$ Disposable pants with integral pad (pull-ups) are available but are expensive and seldom used for light incontinence.
\end{tabular}


(a)

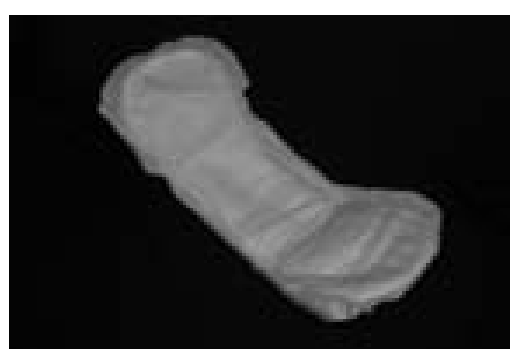

(b)

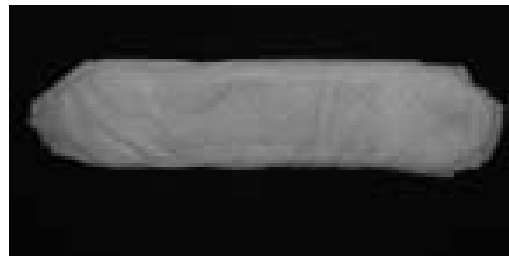

(c)

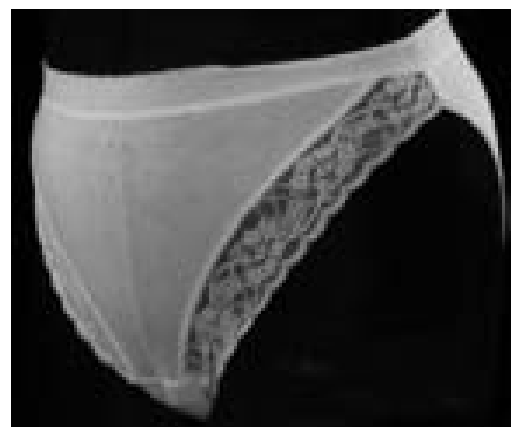

(d)

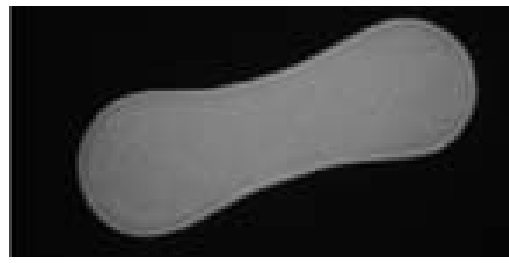

BOX I Participant inclusion and exclusion criteria

\section{Inclusion criteria:}

Adult women, over 18 years of age

Resident in community

Stable and consistent incontinence at least 5 times per week

Currently using absorbent products suitable for light incontinence, e.g. small insert or MP

Able to complete self-report questionnaires

\section{Exclusion criteria:}

Acute illness

Terminal phase of illness

design,) over a 12-week period (1 week for each product). During testing, they weighed used products and kept a pad change/leakage diary, and completed a product performance questionnaire at the end of each week of testing. At the end of the testing period, a final interview was completed to determine preferences and opinions. The study process is shown in Figure 13.

\section{Outcome measures}

The outcome measures (see Chapter 2 for more details) are listed below. These documents were individualised according to the participant's randomisation plan, colour coded by design to facilitate completion and assembled into a bound booklet (case record form).

FIGURE I2 (a) Disposable insert (DI); (b) menstrual pad (MI);

(c) washable pant (WP) and (d) washable insert (WI)

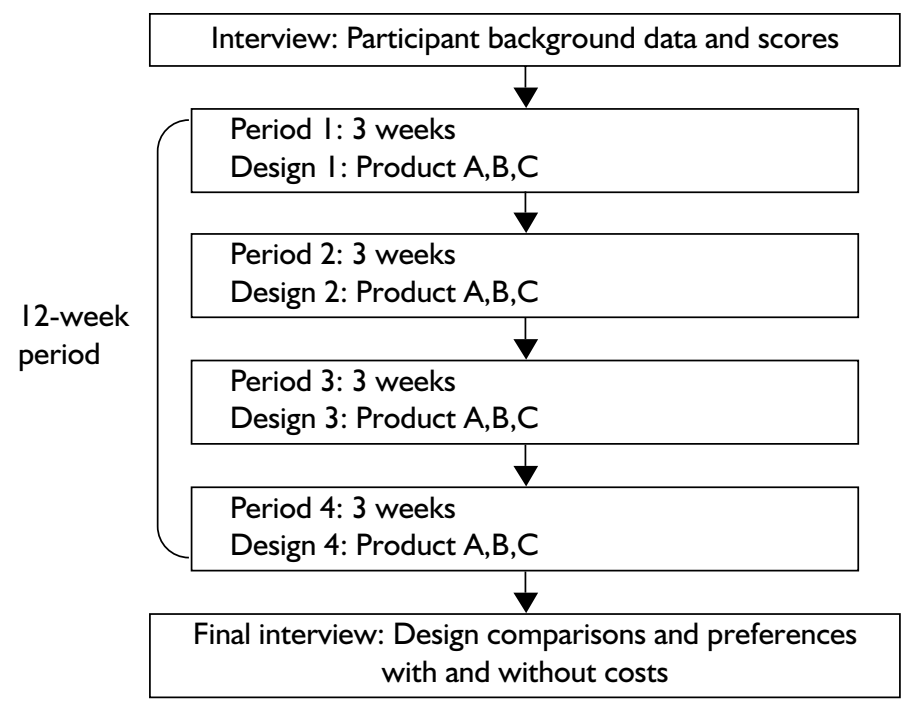

Outcomes during testing period

Product consumption, laundry and leakage diary

Weekly product performance

questionnaire

Weekly skin health diary 
During the period of product testing, a pad change/leakage diary (completed at each pad change) was maintained to record:

- number of products used per day and night (consumption)

- laundry resulting from incontinence (small and large items)

- leakage from product (none, a little, a lot)

- weight of used pad (g).

At the end of each week of product testing, a product performance questionnaire was completed to record:

- product performance variables (e.g. discreetness) rated as very good, good, okay, poor, very poor

- changes in skin health problems in pad area (none, a little or mild, a lot or moderate/severe).

At the end of the trial, a final interview was completed to record:

- design preferences and rankings with and without costs

- overall acceptability of design (highly acceptable, acceptable, unacceptable, totally unacceptable)

- VAS (worst possible design-best possible design)

- comments about good and poor aspects of designs

- views about washables versus disposable designs

- views about costs and NHS provision

- willingness to buy (after prices disclosed).

\section{Selection of absorbent products to represent design groups}

It is known that individual products within absorbent product design groups vary widely ${ }^{48}$ and selection of a single product to represent a given design is unsafe. Three products were therefore selected to represent each design with the aim of including the 'best' of the most commonly used products within a design group. Products were selected to include (in order of priority) the highest scoring products from previous clinical trials, those in common use (available through PASA and/or from major manufacturer) and from a range of manufacturers. The method of selection is shown in detail in Appendix 1. The full range of DIs and WPs available in the UK have recently been compared in separate studies and data were used from these studies to select the three products within the design group. Three night- time MPs were selected from those commonly available in chemists and supermarkets and all the three WIs for light incontinence available on the market were included. The size of the absorbent area of all products was similar except for the MPs, which were slightly smaller than the products in the other three groups.

\section{Securing the product in place}

The two disposable designs (DIs and MPs) incorporated an adhesive backing to fix the product in the pants. The WI designs were worn with close-fitting pants and one of the products had a Velcro patch to aid fixation in pants. The WP designs incorporated underpants and therefore required no additional fixings.

\section{Study preparation and procedures: participant preparation and interviews}

\section{Eligibility interview}

Potential participants who contacted us by telephone, reply-paid slip, letter or email were interviewed on the telephone. The study was described according to the participant information sheet and eligibility to join the study was established. If the person was eligible and expressed willingness to join the study, the participant information sheet and consent form were posted with a reply-paid envelope.

\section{Participant information interview}

Potential participants who returned the signed consent form were contacted and an interview was arranged either at the research centre or in their own home, or exceptionally, when neither was practical, on the telephone. During this interview, the participant background information and scores were completed (Table 6). Participants were also asked about the effects that incontinence pad usage had on their QoL (see Chapter 6) and were asked to name and rank product performance characteristics that they considered to be of greatest importance.

At this interview, the self-report study documentation and instruction booklet were explained to the participant and the digital scales for product weighing were demonstrated to ensure competence.

\section{Product testing period}

Together with their box of test products, participants were provided with an instruction booklet, which had been piloted on volunteer 
TABLE 6 Participant background information and scores

\begin{tabular}{|ll|}
\hline Questionnaire/score & Purpose: to provide \\
\hline $\begin{array}{l}\text { Background demographic socio-economic } \\
\text { information }\end{array}$ & Descriptive data on age, gender, product use, socio-economic data \\
Barthel score & A measure of independence in activities of daily living score \\
SF-12 & A measure of general QoL \\
Kings QoL score & A measure of incontinence-specific QoL \\
ICIQ-UI (short form) & A (brief) measure of incontinence-specific QoL \\
HADS & An assessment of anxiety and depressive symptoms
\end{tabular}

participants for clarity and comprehension. Electronic digital scales and plastic bags were provided for pad weighing. Participants were asked to telephone the research centre when they received the box to inform us when they were starting testing and to enable us to answer any queries.

Participants tested their 12 products (four designs) for 1 week each and completed the pad change/leakage diary and weekly product performance questionnaire during this 12-week period. Participants could withdraw from testing a product at any time, but were asked to complete the product performance questionnaire and early stopping form to record the reasons for stopping using the product. The participant would then move on to the next product. Participants were free to withdraw from the study at any time and without giving any reason.

\section{Participant monitoring}

Participants were given contact numbers of their designated research nurse and invited to telephone the research centre if they had any queries. In addition, the research nurses contacted the participants regularly by fortnightly phone calls to monitor trial progress.

\section{Final interview}

On completion of testing, a final interview was arranged either at the research centre or in the participant's home to complete the design comparison and preferences questionnaire and to return all questionnaires and diaries.

At the final interview, participants were asked to rank the individual products tested (with and without costs) within each design group and then rank the different designs. The different designs were scored on a VAS and participants rated the designs using the overall acceptability score.
To assess views on value for money of different designs, participants were shown the monthly cost of using the product they had previously identified as the best value for money in each design.

Monthly costs were based on the assumption that people used four products per 24 hours (the most common rate of consumption reported by participants at recruitment). For washables, it was assumed that women need to hold a stock of 12 products and each product could be washed 120 times before it needed to be replaced (manufacturers' data and researchers' experience). Laundry costs of washable items were not included, although respondents were reminded of this when making their choice among designs.

Participants were then asked about the acceptability of using the designs in different situations and the practicalities of using disposable and washable designs. They were also asked to comment on the relative strengths and limitations of the designs and their views on provision of products by the NHS.

\section{Ethics}

The study was reviewed by the London multicentre research ethics committee and complied fully with ethical, governance and data protection requirements and approval was obtained through appropriate NHS research ethics committees.

\section{Product preparation, randomisation and blinding}

Waist and hip measurements (for the WP design) were used to prepare individualised boxes of products for sending to participants. Blinding was not practical because most products were labelled in some way (disposable products had the name of the product printed on their adhesive strips). Products were therefore provided in their original packaging complete with any instructions but, 
because washing instructions varied slightly between manufacturers, participants were provided with generic ones used in a previous trial. ${ }^{8}$ The washable products were washed twice to remove any dressing and repackaged. Product packages were marked with study labels indicating the week number in which the product should be tested.

The order of testing products was randomised using Latin squares ${ }^{38}$ both for the order between design group and within design group (i.e. the order of the three products of the same design). Each product was tested for 1 week and the testing of a complete design therefore took 3 weeks.

\section{Analysis}

Data were entered into Microsoft Excel Version 2003, cleaned and $10 \%$ of the data set and $100 \%$ of the primary outcome variable data were checked for accurate entry. The data were transferred to SPSS Version 14, for further analysis.

Ordinal outcome variables were analysed using cumulative logit modelling and quantitative outcome variables were analysed by linear modelling, allowing for repeated observations by each subject. Bonferroni adjustments were made in significance tests and to CIs for multiple comparisons between designs. R software was used (www.r-project.org).

\section{Results}

\section{Participant characteristics}

A total of 272 potential participants contacted the research centre, of whom 115 were both eligible and consented to take part in the trial. Ninetynine participants began testing products and 85 completed testing of all products and gave a final interview. Four women were unable to use the WP designs because the pants were not available in sufficiently large sizes. Progress of participants through the trial is shown in Figure 14. Participant characteristics are shown in Table 7.

Generally, participants were older women (mean age 60 years), living in their own homes with good mobility and independence in activities of daily living. Twenty (23.5\%) were in full- or parttime employment or seeking work, 50 (58.8\%) were married or had a partner, about $90 \%$ had annual household income below the national average and the income of $40 \%$ of participants was reported to be in the lowest quintile. Around twothirds of the participants bought their own absorbent pads and the remaining one-third obtained them from the NHS. Sixty-one (71.8\%) of the participants used products during the night in addition to during the day. Twelve women stated that they had experienced faecal incontinence and seven women were carrying out intermittent catheterisation in addition to using absorbent products.

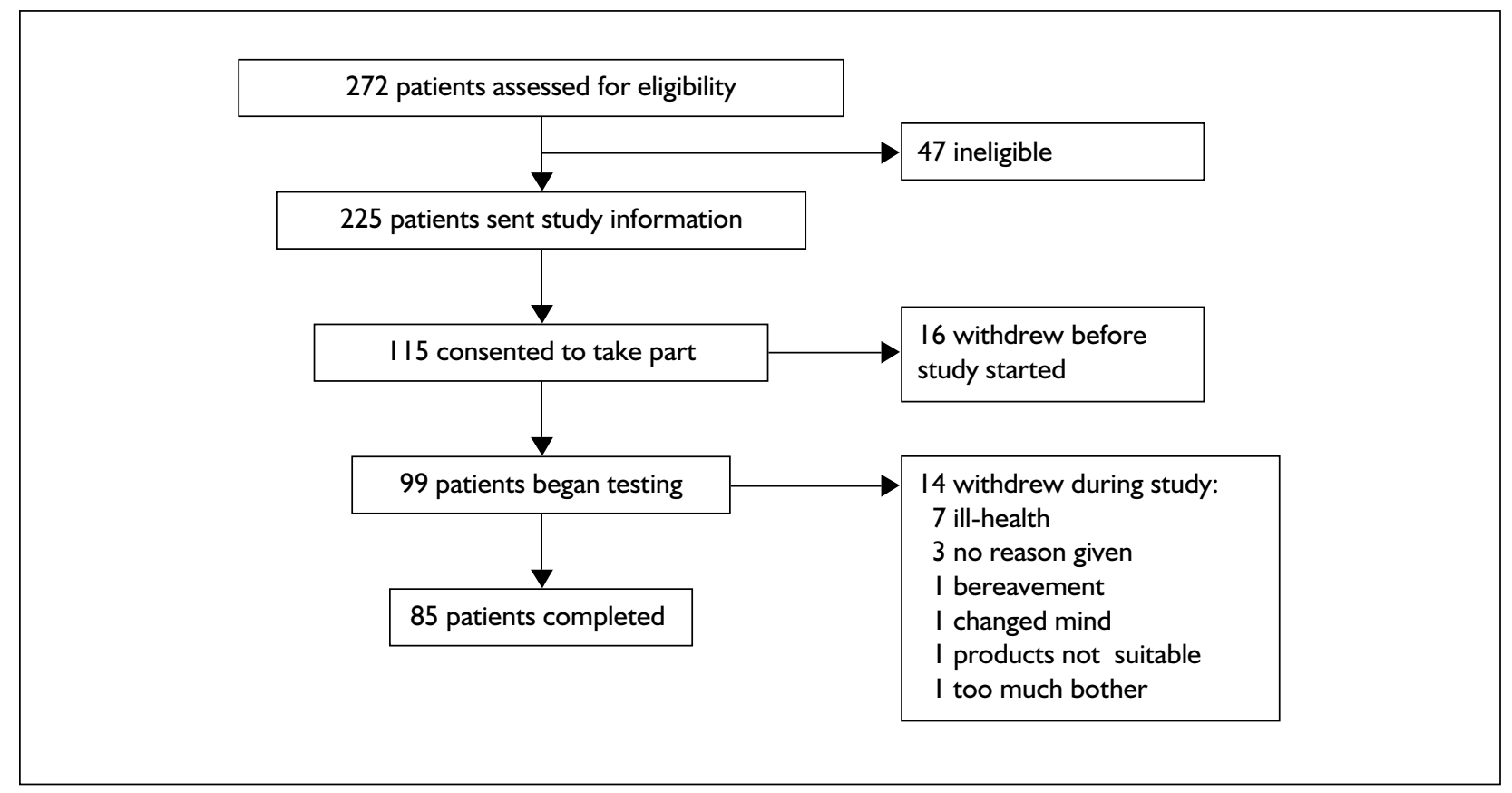

FIGURE I4 Progress of participants through the trial 
TABLE 7 Participant characteristics ( $\mathrm{N}=85$, except where missing data stated)

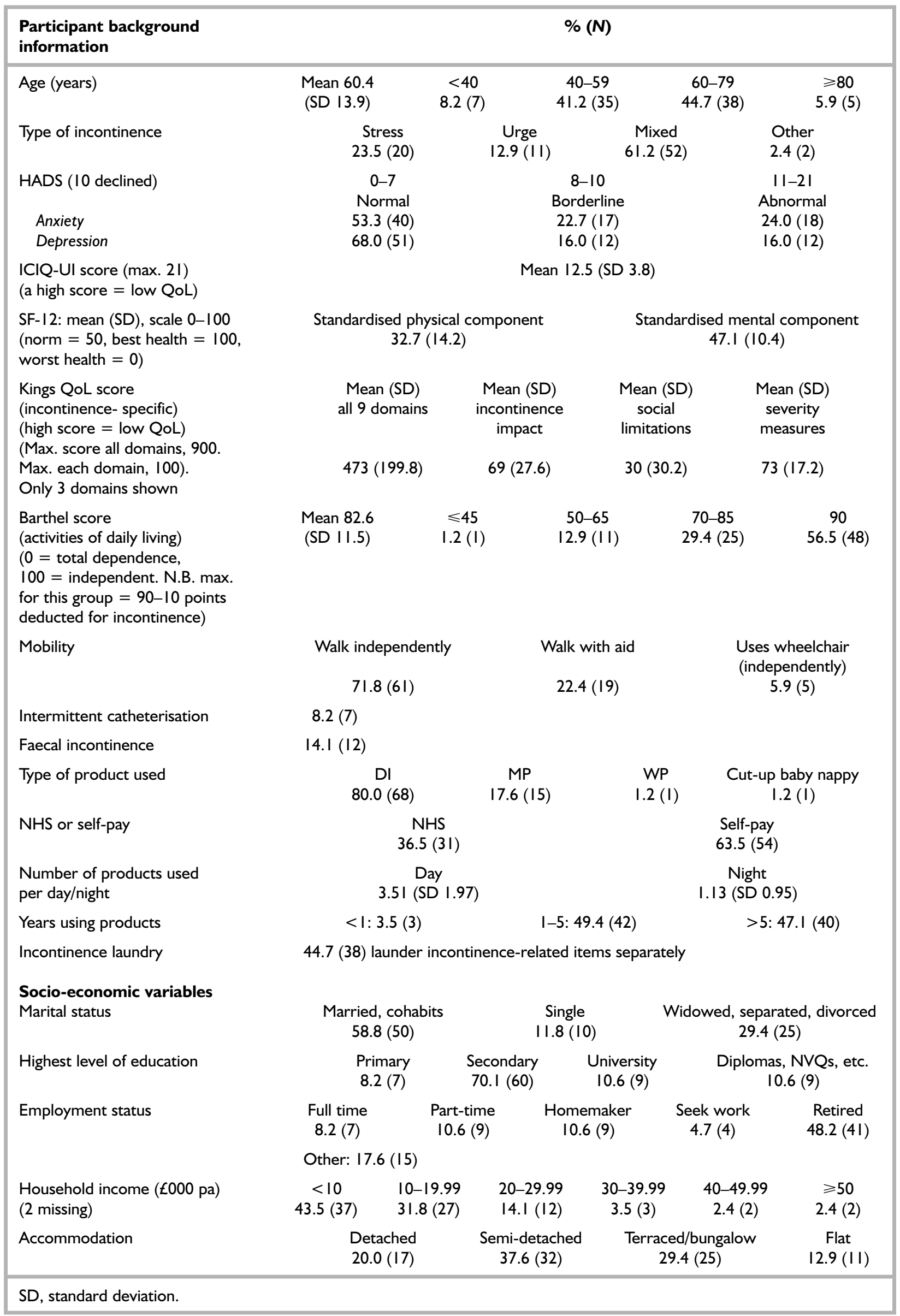




\section{Product results within design groups}

The product performance questionnaires were analysed and comparisons made between the three different products comprising each design group. This showed that there were no products that were significantly worse than the two other products in its group for leakage. The data from the product performance questionnaires and leakage diaries were therefore combined for all the products within each design group.

\section{Frequency and severity of leakage}

A total of 8691 used products were saved and weighed by participants and leakage severity scores (none, a little, a lot) were recorded for 8402 products. Pad leakage diary data were used to estimate the probability of the different designs leaking for different urine masses. Table 8 shows the median urine weights in the different designs.
Leakage performance was modelled for each design, based on the binarised leakage data (none) versus (a little + a lot) and urine weights; Figure 15 shows the plots of the probabilities of no leakage at all for increasing urine masses and Table 9 shows the proportions of the saved and weighed pads that leaked. Urine mass was found to be a significant variable and analysis was therefore adjusted for this. There were significant differences between all the designs in their ability to prevent leakage, in the order DI better than MP, MP better than WP and WP better than WI, for all urine masses.

\section{Explanation of leakage curves}

Pads do not have a simple capacity below which they are guaranteed not to leak and above which they will definitely leak. Rather, as the volume (i.e. mass) of urine increases, the probability of the pad leaking increases. The leakage performance curves

TABLE 8 Median urine mass in each design (weighed from collected pads) for 8691 total products

\begin{tabular}{|lcccc|}
\hline & MP & DI & WP & WI \\
\hline Daytime & 10.7 & 17.0 & 8.3 & 6.0 \\
Median urine mass (g) (IQ range) & $(4.3-28.0)$ & $(5.0-48.8)$ & $(3.9-23.0)$ & $(2.15-18.0)$ \\
No. of products & 1835 & 1876 & 1455 & 1210 \\
Night-time & 12.0 & 17 & 9.0 & 6 \\
Median urine mass (g) (IQ range) & $(4.3-28.3)$ & $(5.0-44.0)$ & $(4.0-24.2)$ & $(2.0-13.6)$ \\
No. of products & 699 & 747 & $45 I$ & 418 \\
\hline IQ, inter-quartile. & & & & \\
\hline
\end{tabular}

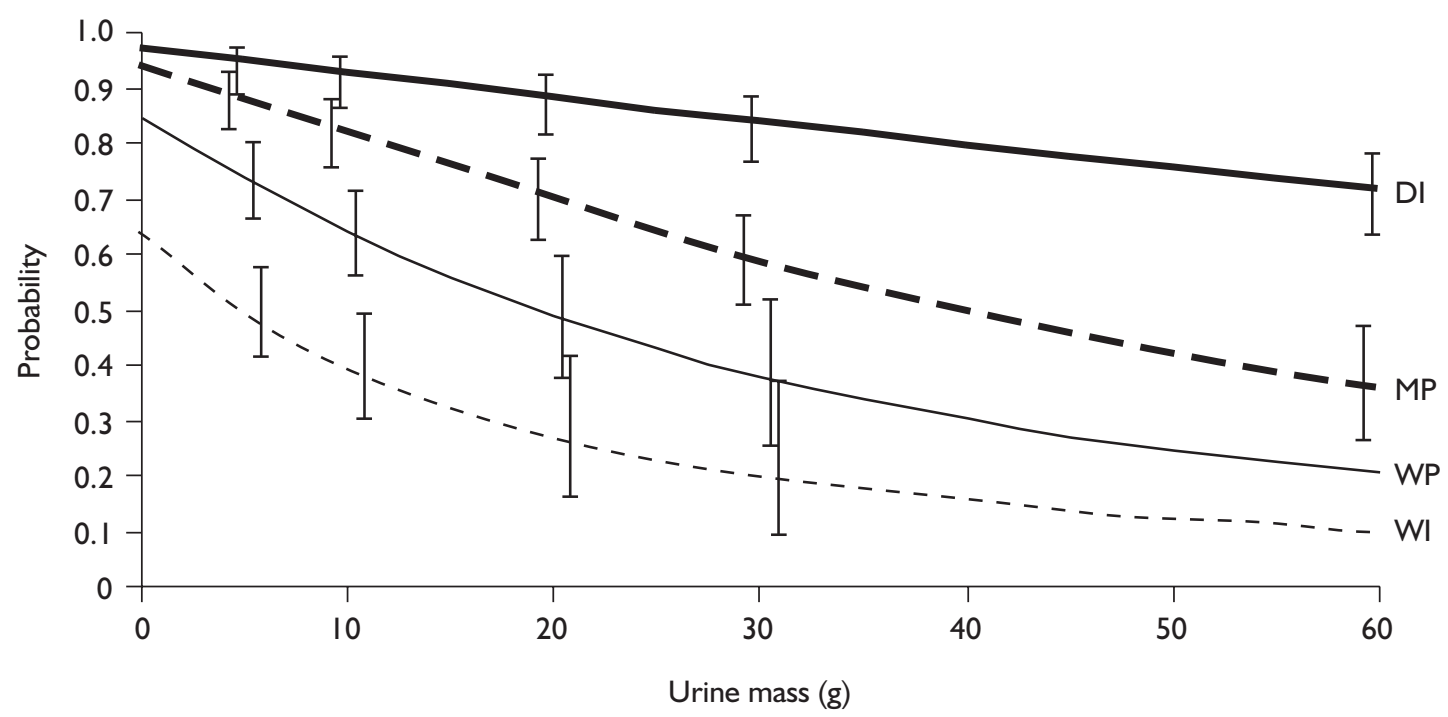

FIGURE I5 Estimated probabilities of no leakage at different urine masses by design (with $95 \% \mathrm{Cl}$ ) 
TABLE 9 Proportions of saved and weighed pads that leaked, for 8402 total products weighed (with leakage amount recorded) ${ }^{\mathrm{a}}$

\begin{tabular}{|c|c|c|c|c|}
\hline & \multicolumn{4}{|c|}{$\%(N)$} \\
\hline & $\begin{array}{c}\text { MP } \\
(2459)^{b}\end{array}$ & $\begin{array}{c}\text { DI } \\
(2578)^{b}\end{array}$ & $\begin{array}{c}\text { WP } \\
(1819)^{b}\end{array}$ & $\begin{array}{c}\text { WI } \\
(1546)^{b}\end{array}$ \\
\hline No leakage & $\begin{array}{c}74.0 \\
(1820)\end{array}$ & $\begin{array}{c}84.3 \\
(2172)\end{array}$ & $\begin{array}{c}62.6 \\
(1139)\end{array}$ & $\begin{array}{l}46.3 \\
(715)\end{array}$ \\
\hline A little leakage & $\begin{array}{l}18.3 \\
(451)\end{array}$ & $\begin{array}{l}13.2 \\
(340)\end{array}$ & $\begin{array}{l}21.2 \\
(386)\end{array}$ & $\begin{array}{l}33.3 \\
(514)\end{array}$ \\
\hline A lot of leakage & $\begin{array}{c}7.7 \\
(188)\end{array}$ & $\begin{array}{l}2.6 \\
(66)\end{array}$ & $\begin{array}{l}16.2 \\
(294)\end{array}$ & $\begin{array}{l}20.5 \\
(317)\end{array}$ \\
\hline \multicolumn{5}{|c|}{$\begin{array}{l}{ }^{a} \text { Comparisons between designs and Cls shown in forest } \\
\text { plots in Figures I }-22 \text {. } \\
b \text { No. of products. }\end{array}$} \\
\hline
\end{tabular}

were constructed for each design (by combining data from the various products of the same design) and show how the probability of the design not leaking changed with increasing urine mass. In general, the more successful a design, the higher was the performance curve on the graph: a perfect design would have a probability of not leaking at all of 1 (= certainty) for all urine masses.

Intuitively, these probability curves should have a value of 1.0 for zero urine mass - how can a pad leak if there is no urine in it? Weighing used pads provides an estimate only of the mass of urine in the pad and excludes any leakage from the pad: accordingly, the urine masses used in constructing the curves will often have been (slight) underestimates of the actual masses voided by the wearer. For example, a pad may leak (and the urine mass in the pad be recorded as zero) if the absorbent area is out of position. One of the effects of this is that the leakage performance curves of products will meet the $y$-axis at values $<1.0$, the value which would be expected naturally. In the extreme, a pad capable of holding no urine at all would be certain to leak whatever quantity of urine its user voided and yet all used pads would contain zero urine mass. It is therefore not surprising that the leakage curves of very poorly performing products, such as WIs, meet the $y$-axis at values substantially less than 1.0 .

In addition, dry masses vary (coefficient of variation of the order of $10 \%$ ) and so there will be small errors in estimated urine masses. These errors will be negligible for high urine masses but more substantial for (nearly) dry pads.
TABLE 10 Mean number of participants who stopped testing a design early $(\mathrm{N}=85)$

\begin{tabular}{|cccc|}
\hline MP & DI & WP & WI \\
\hline II & 5 & 25 & 34 \\
\hline
\end{tabular}

TABLE II Mean number of products used day and night by design $(\mathrm{N}=85)$

\begin{tabular}{|lcccc|}
\hline & MP & DI & WP & WI \\
\hline $\begin{array}{l}\text { Weighted mean number } \\
\text { of products used per } \\
\text { day (SD) }\end{array}$ & 1.77 & 1.71 & 1.64 & 1.79 \\
$\begin{array}{l}\text { Weighted mean number } \\
\text { of products used per }\end{array}$ & 1.15 & $(0.81)$ & $(0.86)$ & $(0.90)$ \\
night (SD) & $(0.34)$ & $(0.29)$ & 1.10 & 1.13 \\
& & & & \\
\hline
\end{tabular}

Less washable products were saved and weighed, which reflects the higher number of participants that discontinued use of washable products. This can be seen in the early stopping data shown in Table 10.

\section{Consumption of products}

Pad change diary data were used to calculate the mean number of products used per day and night. Table 11 shows the results [with standard deviation (SD)] for the different design groups. Weighted means are used because participants recorded numbers of products used per day over variable periods (up to 7 days).

There were no significant differences in consumption for day or night, except that WPs were used slightly less than WIs during the day; this result just reached significance (estimated difference of means $0.91,95 \%$ CI for ratio of means 0.82 to 0.99 ).

\section{Laundry resulting from leakage}

Pad change/leakage diary data were used to calculate the mean number of items (small and large) sent for laundering as a result of leakage from the product. Table 12 shows the mean number of laundry items per 24 hours by design, including laundering the washable products themselves.

There were significant differences in laundry amounts between all designs with the DI design generating the least amount of laundry (around half as much as MPs). The washable designs (obviously) created more washing (around 9-10 times more than the DI). The WI design was worse 
TABLE I2 Weighted mean number of laundry items per 24 hours by design $(\mathrm{N}=84)$

\begin{tabular}{|c|c|c|c|c|c|c|}
\hline & & & MP & DI & WP & WI \\
\hline \multicolumn{3}{|c|}{$\begin{array}{l}\text { Weighted mean number of laundry items per } \\
24 \text { hours (SD) }\end{array}$} & $0.64(0.99)$ & $0.37(0.96)$ & $3.23(2.39)$ & $3.75(2.19)$ \\
\hline \multicolumn{7}{|c|}{ Laundry: comparisons between designs } \\
\hline & & & \multicolumn{3}{|c|}{ Estimated ratio of means } & $95 \% \mathrm{Cl}^{a}$ \\
\hline MP & More laundry than: & DI & & 1.93 & & 1.02 to 3.66 \\
\hline MP & Less laundry than: & WP & & 0.20 & & 0.14 to 0.29 \\
\hline MP & Less laundry than: & WI & & 0.17 & & 0.11 to 0.26 \\
\hline DI & Less laundry than: & WP & & 0.10 & & 0.05 to 0.24 \\
\hline DI & Less laundry than: & WI & & 0.09 & & 0.04 to 0.21 \\
\hline WP & Less laundry than: & $\mathrm{WI}$ & & 0.85 & & 0.75 to 0.98 \\
\hline
\end{tabular}

than the WP design, but this difference was small and only just significant.

\section{Skin health}

Participants were asked to keep a weekly diary of skin health. Table 13 shows the proportions reporting skin health problems associated with product use.

The DI design was significantly better than the two washable designs, and the MP design was significantly better than the WP design. The two washable designs were not significantly different from each other.

\section{Product performance questionnaires}

Participants completed a weekly product performance questionnaire to score the performance of each product. Scores for the

TABLE I3 Skin health: proportions of participants reporting skin health problems $[\mathrm{N}=3$ observations for each design (maximum of 255 observations)] $]^{\mathrm{a}}$

\begin{tabular}{|c|c|c|c|c|}
\hline & \multicolumn{4}{|c|}{$\%(N)$} \\
\hline & $\begin{array}{c}\text { MP } \\
(247)^{b}\end{array}$ & $\begin{array}{c}\text { DI } \\
(248)^{b}\end{array}$ & $\begin{array}{l}\text { WP } \\
(229)^{b}\end{array}$ & $\begin{array}{c}\text { WI } \\
(222)^{b}\end{array}$ \\
\hline No skin problem & $\begin{array}{l}84.2 \\
(208)\end{array}$ & $\begin{array}{l}88.3 \\
(219)\end{array}$ & $\begin{array}{l}78.6 \\
(180)\end{array}$ & $\begin{array}{l}73.9 \\
(164)\end{array}$ \\
\hline A little (mild) & $\begin{array}{l}13.0 \\
(32)\end{array}$ & $\begin{array}{l}9.7 \\
(24)\end{array}$ & $\begin{array}{l}14.9 \\
(34)\end{array}$ & $\begin{array}{l}20.7 \\
(46)\end{array}$ \\
\hline $\begin{array}{l}\text { A lot (moderate/ } \\
\text { severe) }\end{array}$ & $\begin{array}{l}2.8 \\
(7)\end{array}$ & $\begin{array}{l}2.0 \\
(5)\end{array}$ & $\begin{array}{l}6.6 \\
(15)\end{array}$ & $\begin{array}{l}5.4 \\
(12)\end{array}$ \\
\hline \multicolumn{5}{|c|}{$\begin{array}{l}{ }^{a} \text { Cls for comparisons between designs are shown in } \\
\text { Figures } 17-22 \text {. } \\
{ }^{b} \text { No. of products. }\end{array}$} \\
\hline
\end{tabular}

highest priority variables (leakage, discreetness, smell, comfort when dry, comfort when wet and staying in place; see Chapter 6) were analysed and those for individual products within designs are shown in Appendix 2. There were some significant differences between products within designs but no product was significantly worse than the other two products in the same group for leakage and overall opinion. The scores for each of the three products within a design were therefore combined to give an average response result for each variable and these are shown in Table 14. CIs and comparisons between pairs of designs are shown in the summary forest plots in Figures 17-22).

Participants' rating of the ability of the product to hold urine without leaking reflected the leakage performance from the pad leakage diary data (DI better than MP, MP better than WP, WP better than WI). For comfort when wet and smell there were significant differences between all designs in the same order as above, but no significant differences between the two washable designs. For comfort when dry there were no significant differences between designs, except that the DI and WP designs were significantly more comfortable than the WI pads. The DI design was significantly worse than the MP design for discreetness but there were no significant differences between the other designs. For staying in place, the WI pad was significantly worse than all the other designs.

\section{Final interview: overall opinion and preferences}

Participants were asked to rank the designs in order of their preference (Table 15) and state 
TABLE I4 Product performance questionnaire: product responses combined to give an average response for each design (\%) $)^{\mathrm{a}, \mathrm{b}}$

\begin{tabular}{|c|c|c|c|c|c|}
\hline & & MP & DI & WP & WI \\
\hline Leakage (day) & $\begin{array}{l}\text { Very good } \\
\text { Good } \\
\text { OK } \\
\text { Poor } \\
\text { Very poor }\end{array}$ & $\begin{array}{r}16 \\
25 \\
30 \\
20 \\
9\end{array}$ & $\begin{array}{r}33 \\
32 \\
26 \\
7 \\
3\end{array}$ & $\begin{array}{r}9 \\
23 \\
20 \\
25 \\
22\end{array}$ & $\begin{array}{r}3 \\
10 \\
20 \\
28 \\
40\end{array}$ \\
\hline Leakage (night) & $\begin{array}{l}\text { Very good } \\
\text { Good } \\
\text { OK } \\
\text { Poor } \\
\text { Very poor }\end{array}$ & $\begin{array}{r}16 \\
23 \\
33 \\
20 \\
8\end{array}$ & $\begin{array}{r}36 \\
30 \\
25 \\
6 \\
3\end{array}$ & $\begin{array}{l}10 \\
22 \\
28 \\
16 \\
24\end{array}$ & $\begin{array}{r}3 \\
12 \\
24 \\
31 \\
31\end{array}$ \\
\hline Stay in place (day) & $\begin{array}{l}\text { Very good } \\
\text { Good } \\
\text { OK } \\
\text { Poor } \\
\text { Very poor }\end{array}$ & $\begin{array}{r}18 \\
37 \\
36 \\
8 \\
1\end{array}$ & $\begin{array}{r}28 \\
36 \\
31 \\
5 \\
1\end{array}$ & $\begin{array}{r}26 \\
37 \\
29 \\
6 \\
2\end{array}$ & $\begin{array}{r}4 \\
13 \\
22 \\
34 \\
26\end{array}$ \\
\hline Smell & $\begin{array}{l}\text { Very good } \\
\text { Good } \\
\text { OK } \\
\text { Poor } \\
\text { Very poor }\end{array}$ & $\begin{array}{r}6 \\
24 \\
46 \\
17 \\
6\end{array}$ & $\begin{array}{r}20 \\
33 \\
35 \\
10 \\
2\end{array}$ & $\begin{array}{r}8 \\
17 \\
34 \\
29 \\
12\end{array}$ & $\begin{array}{l}2 \\
11 \\
43 \\
29 \\
17\end{array}$ \\
\hline Discreet & $\begin{array}{l}\text { Very good } \\
\text { Good } \\
\text { OK } \\
\text { Poor } \\
\text { Very poor }\end{array}$ & $\begin{array}{r}15 \\
32 \\
37 \\
13 \\
2\end{array}$ & $\begin{array}{r}16 \\
24 \\
36 \\
22 \\
2\end{array}$ & $\begin{array}{r}18 \\
34 \\
27 \\
16 \\
4\end{array}$ & $\begin{array}{r}8 \\
25 \\
48 \\
14 \\
4\end{array}$ \\
\hline Dry comfort & $\begin{array}{l}\text { Very good } \\
\text { Good } \\
\text { OK } \\
\text { Poor } \\
\text { Very poor }\end{array}$ & $\begin{array}{r}20 \\
38 \\
33 \\
8 \\
2\end{array}$ & $\begin{array}{r}27 \\
41 \\
27 \\
5 \\
1\end{array}$ & $\begin{array}{r}29 \\
32 \\
29 \\
7 \\
3\end{array}$ & $\begin{array}{r}9 \\
24 \\
47 \\
16 \\
5\end{array}$ \\
\hline Wet comfort & $\begin{array}{l}\text { Very good } \\
\text { Good } \\
\text { OK } \\
\text { Poor } \\
\text { Very poor }\end{array}$ & $\begin{array}{r}5 \\
25 \\
35 \\
25 \\
10\end{array}$ & $\begin{array}{r}16 \\
26 \\
41 \\
13 \\
5\end{array}$ & $\begin{array}{r}7 \\
14 \\
25 \\
34 \\
21\end{array}$ & $\begin{array}{r}0 \\
9 \\
28 \\
30 \\
32\end{array}$ \\
\hline Keep skin dry & $\begin{array}{l}\text { Very good } \\
\text { Good } \\
\text { OK } \\
\text { Poor } \\
\text { Very poor }\end{array}$ & $\begin{array}{r}7 \\
27 \\
41 \\
19 \\
5\end{array}$ & $\begin{array}{r}21 \\
34 \\
35 \\
7 \\
3\end{array}$ & $\begin{array}{r}7 \\
17 \\
28 \\
30 \\
19\end{array}$ & $\begin{array}{r}3 \\
7 \\
30 \\
34 \\
26\end{array}$ \\
\hline
\end{tabular}

their overall acceptability of the different designs (highly acceptable, acceptable, unacceptable, totally unacceptable) (Table 16) and score each design out of 100 on a VAS (Table 17). No night VAS scores were requested but participants were asked if they would alter their design ratings at night. Three people replied that they would rate a different design as best (DI to MP, DI to WP, MP to DI). Participants were also asked whether they would recommend a
There were significant differences between all designs in the order DI better than MP, MP better than WP and WP better than WI for paired comparisons of preferences (see Figures 17-22). Disposable designs were the most preferred and women mainly chose the DIs first $(N=63)$ and the MPs second $(N=51)$. Over $90 \%$ of subjects found DIs acceptable on a binarised acceptability scale: (highly acceptable + acceptable) versus (unacceptable + totally unacceptable) and said they would recommend them. 


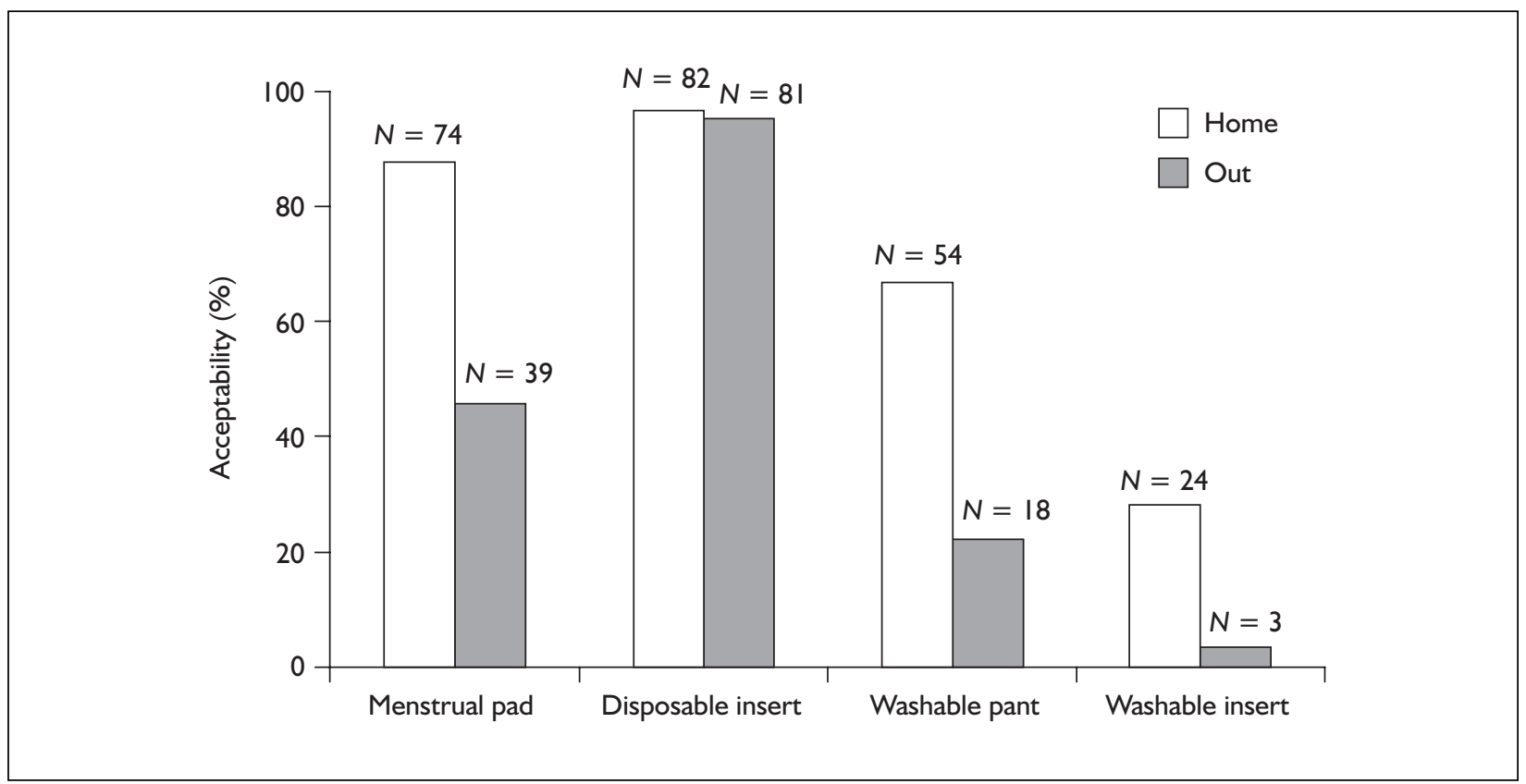

FIGURE I6 Acceptability of designs in different situations, for use 'at home' compared with 'when out'

calculated. If there is no difference between the two results, this will give an OR of 1 . Where there are differences (as in the example of discreetness above), the OR will be greater or less than one. The CI is a number that spans the OR (giving a higher and a lower limit) and shows how much uncertainty there is about the OR.

The ORs and CIs have been calculated for comparisons between each pair of designs and for each variable where the results are shown as proportions. The ORs and CIs have been stacked one on top of each other on a forest plot showing comparisons between each pair of designs.

The ORs and CIs are shown in relation to a vertical line which is the centre of the forest plot. This line gives the OR of 1 (i.e. no difference). Each variable is named on the far left of the forest plot and the OR and CI are written on the far right. The scale is shown on the bottom with numbers below 1 on the left and above 1 on the right.

Each OR is shown as a black box with a horizontal line (the $95 \%$ CI) running through it. Where the line touches or crosses the vertical line (at OR $=1$ ) there is no significant difference between the proportions for the two designs. Where the box and horizontal line lie completely to one or other side of the vertical line, one can be confident that the proportions for each design are significantly different.
To show readily how each pair of designs compare with each other, the ORs are plotted so that where a design scores better than the other design for any variable, the OR (i.e. the black box) is on the side of the vertical line that favours that design. Hence the ORs shown are for the second named design versus the first named design in the heading. The primary outcome variables from the final interview (overall acceptability and preference) are shown at the bottom of each forest plot and these reflect the overall performance of the different designs. The other secondary outcome variables measure different aspects of performance and some designs may be particularly good or bad at different variables. For example, in the forest plot comparing the DI with the MP, the plot shows that the DI is better than the MP on almost all variables (including overall acceptability and preference), but is worse for discreetness (the OR black box is on the 'favours' MP side and does not (quite) touch the vertical line of no difference. The last line of the forest plot shows the odds on the second named design being preferred to the first.

There are four designs and six comparisons; each forest plot in Figures 17-22 shows the data obtained from:

- Leakage - pad diary: (from the pad change/leakage diary) binarised as (none) versus (a little + a lot).

- Leakage - participant rating: (from the final 


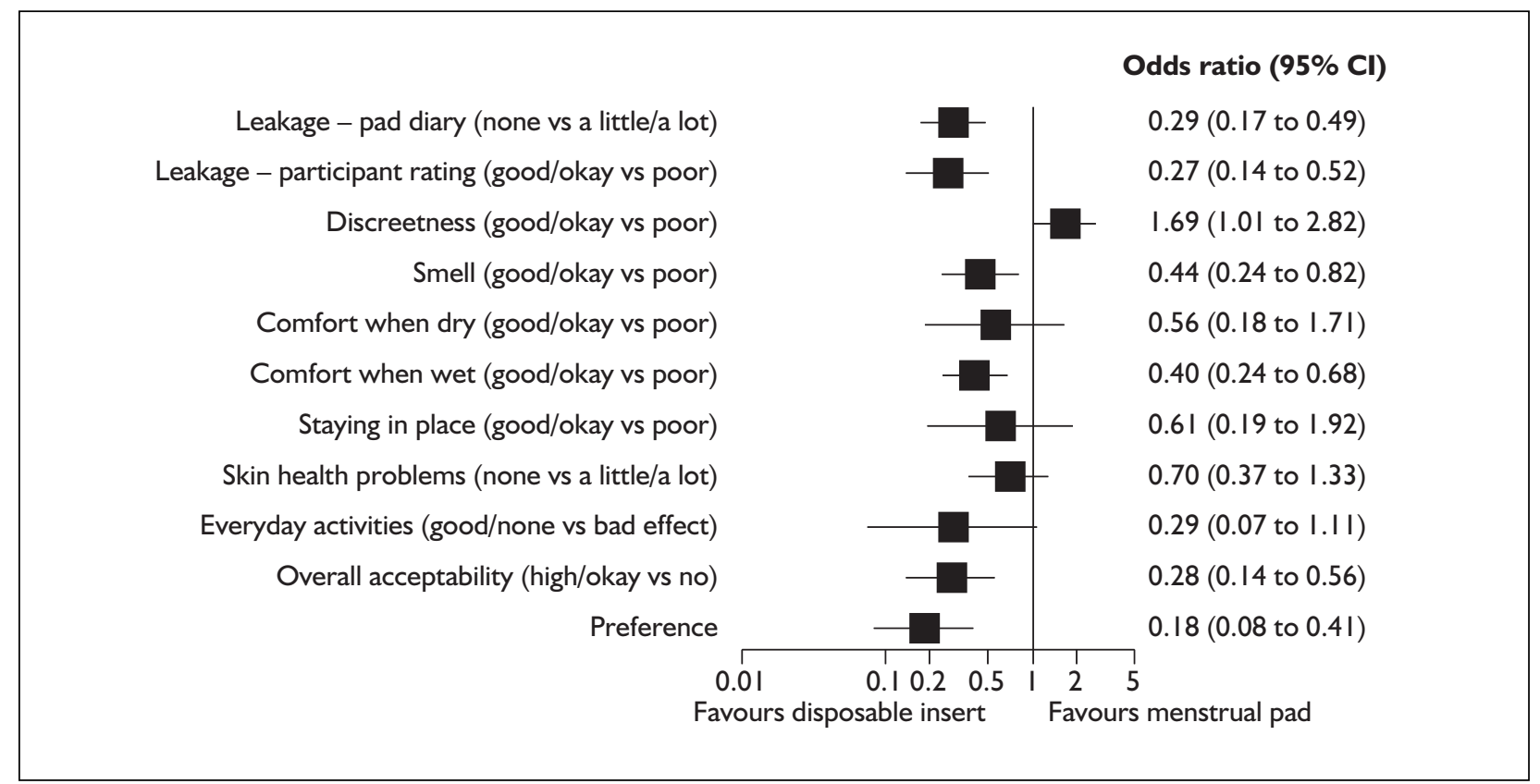

FIGURE I7 Forest plot: DI versus MP

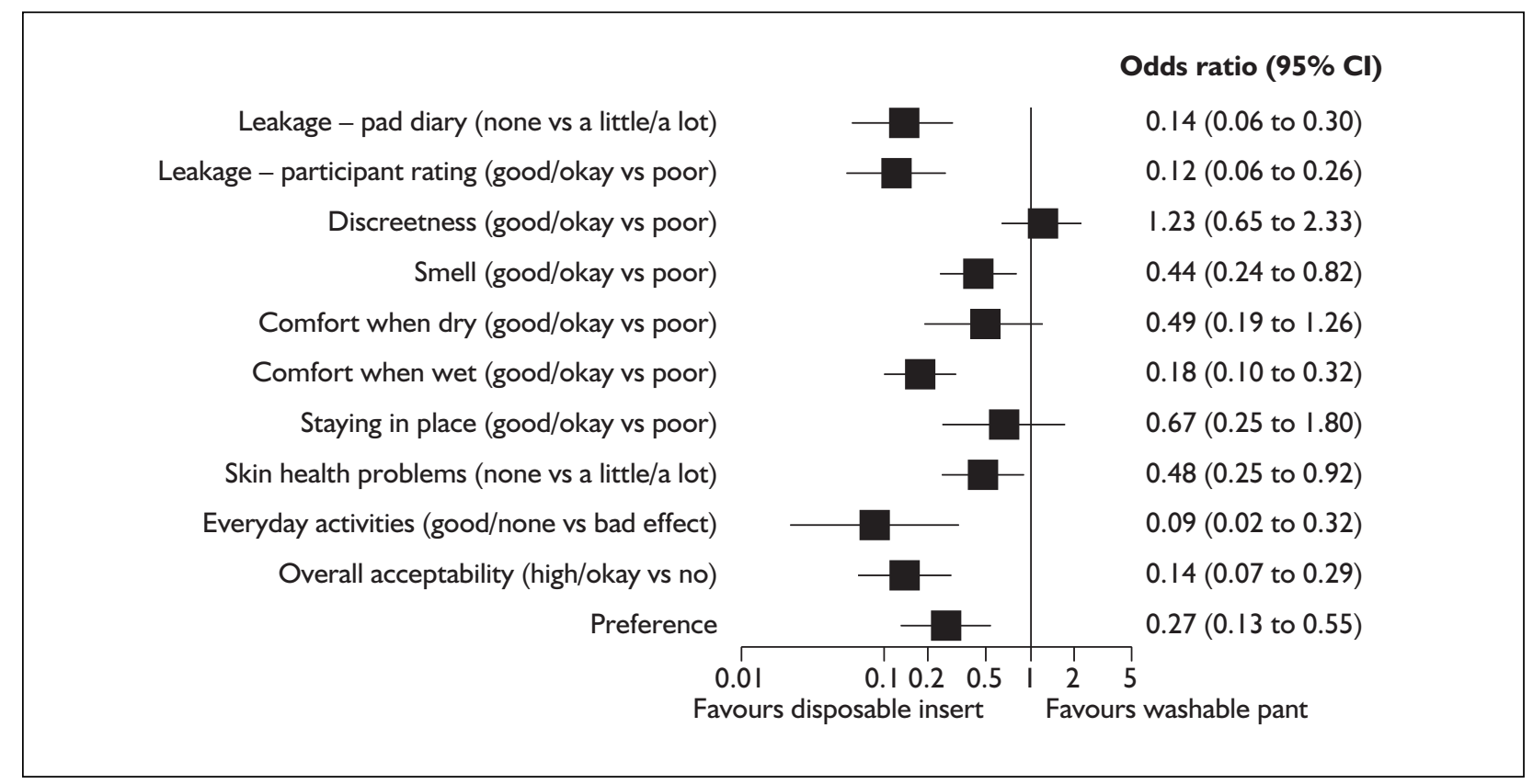

FIGURE I8 Forest plot: DI versus WP

interview) binarised as (very good + good + OK) versus (poor + very poor)

- Five key variables from the product performance questionnaire: all binarised as (very good + good + OK) versus (poor + very poor)

- Skin health problems: (data from the participants' skin health diary) binarised as (none) versus (a little + a lot).

- Every day activities: (taken from the final interview and indicating the effect that the design had on the users' everyday life), binarised as (good + none) versus (bad effect).

- Overall acceptability: (from the final interview) and binarised as (highly acceptable + acceptable) versus (unacceptable + totally unacceptable), abbreviated on the forest plots as (high/okay) versus (no).

- Preference: (from the final interview) this indicates the odds on the second named design being preferred to the first. 


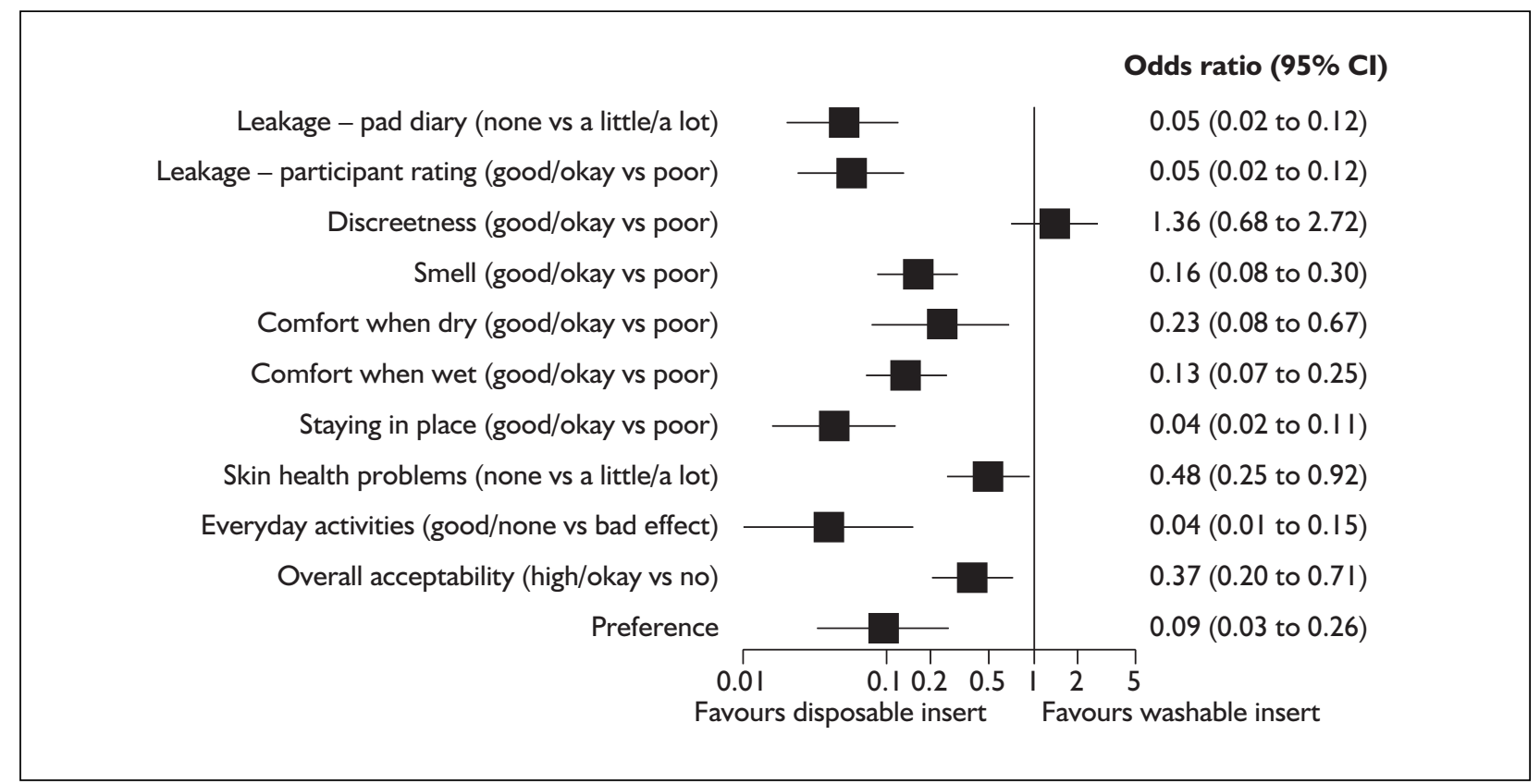

FIGURE I9 Forest plot: DI versus WI

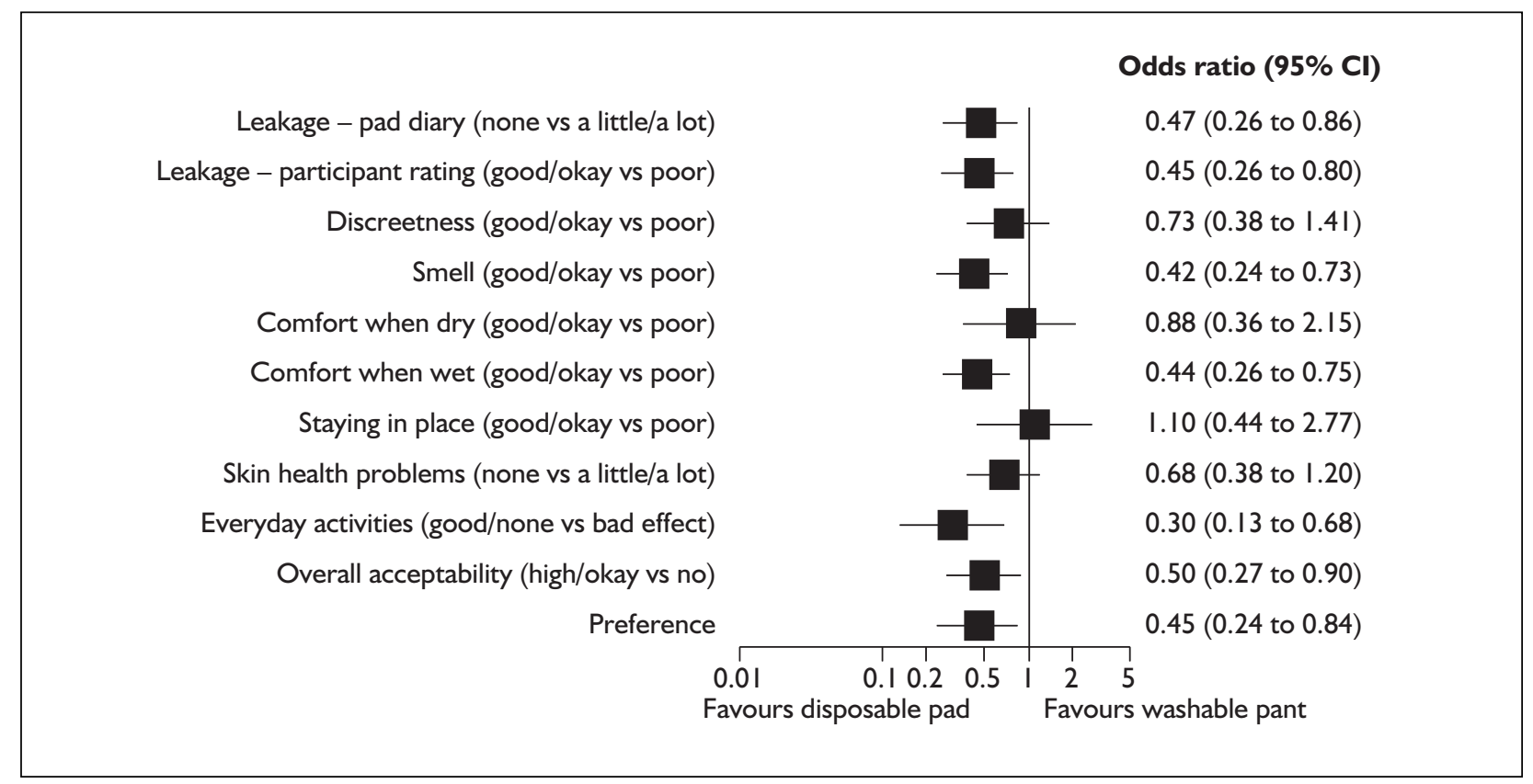

FIGURE 20 Forest plot: MP versus WP

\section{Comments about designs}

When ranking designs, participants were asked about the good and poor aspects of each and about why they thought their top and lowest ranked products were best/worst, respectively. An analysis of the responses given is shown in Table 18. Key themes were identified and the number of times each was mentioned is
Absorbency/good leakage performance/confidence are strong points for disposable products, especially DIs, although negative comments relating to bulkiness were also made against DIs.

\section{Economic analysis \\ Value for money}

To establish respondents' views about the relative value for money of each design, researchers asked 


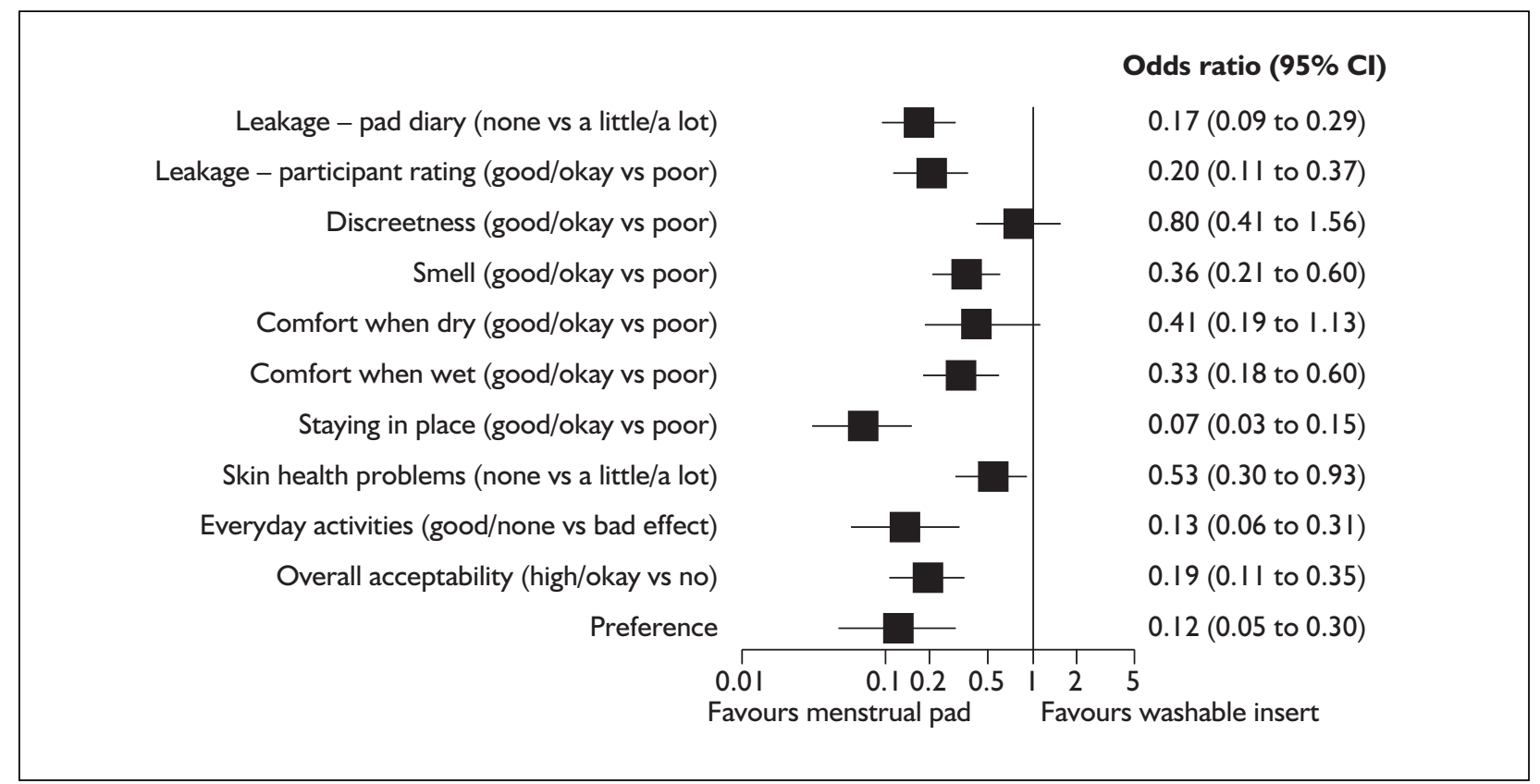

FIGURE 2 I Forest plot: MP versus WI

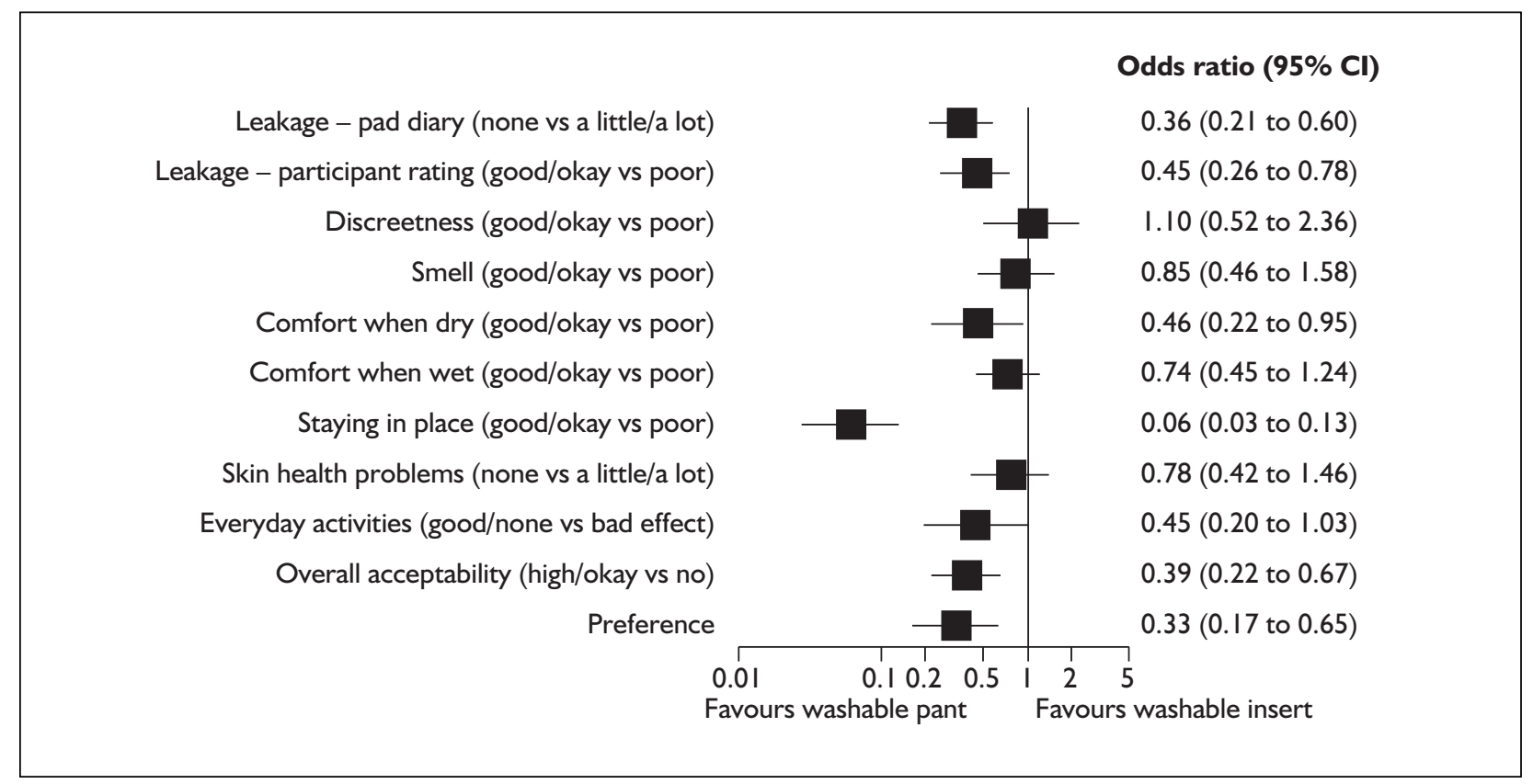

FIGURE 22 Forest plot: WP versus WI

them to consider the monthly cost of supplying the products that they had previously identified as the best value for money in each design. As most women in the trial purchased their own products, the retail and mail order prices prevailing at the time (September 2004) were used. Monthly costs were based on median reported product utilisation at baseline (three/day, one/night). For washable products, replacement rates were calculated from manufacturers' data about product life and researchers' experience (suggesting120 washes), and an assumption that women would hold a stock of 12 products.

There was considerable variation in the costs of products within designs, but no overlap between designs (Table 19). The expense of laundering washable products (which is borne by individuals) is not included in the monthly costs and respondents were reminded of this when asked to 
TABLE I8 Summary of comments (count of key themes) on design preferences

\begin{tabular}{|c|c|c|c|c|c|c|c|c|}
\hline & \multicolumn{2}{|l|}{ MP } & \multicolumn{2}{|l|}{ DI } & \multicolumn{2}{|l|}{ WP } & \multicolumn{2}{|l|}{ WI } \\
\hline & Aspect & $N$ & Aspect & $\mathbf{N}$ & Aspect & $\mathbf{N}$ & Aspect & $\mathbf{N}$ \\
\hline $\begin{array}{l}\text { Good } \\
\text { aspects }\end{array}$ & $\begin{array}{l}\text { Absorbency (good) } \\
\text { Comfort } \\
\text { Not bulky/discreet } \\
\text { Stay in place } \\
\text { Disposable aspects } \\
\text { Fit } \\
\text { No odour/smell }\end{array}$ & $\begin{array}{l}8 \\
5 \\
3 \\
2 \\
4 \\
2 \\
2\end{array}$ & $\begin{array}{l}\text { Absorbency (good) } \\
\text { Comfort } \\
\text { Disposable aspects } \\
\text { No smell } \\
\text { Stay in place } \\
\text { Fit } \\
\text { Not bulky }\end{array}$ & $\begin{array}{r}34 \\
24 \\
17 \\
8 \\
7 \\
3 \\
1\end{array}$ & $\begin{array}{l}\text { Comfort } \\
\text { Cost } \\
\text { Environment } \\
\text { Washable } \\
\text { Stay in place } \\
\text { Fit } \\
\text { Not bulky }\end{array}$ & $\begin{array}{l}6 \\
2 \\
2 \\
3 \\
3 \\
2 \\
2\end{array}$ & $\begin{array}{l}\text { Washable } \\
\text { Not bulky/discreet } \\
\text { Comfort } \\
\text { Cost } \\
\text { Environment } \\
\text { Stay in place } \\
\text { Absorbency (good) }\end{array}$ & $\begin{array}{l}4 \\
3 \\
4 \\
2 \\
1 \\
1 \\
1\end{array}$ \\
\hline $\begin{array}{l}\text { Poor } \\
\text { aspects }\end{array}$ & $\begin{array}{l}\text { Absorbency (poor) } \\
\text { Bulky } \\
\text { Uncomfortable } \\
\text { Too long }\end{array}$ & $\begin{array}{l}2 \\
2 \\
1 \\
1\end{array}$ & $\begin{array}{l}\text { Bulky } \\
\text { Heavy when wet } \\
\text { Irritate skin } \\
\text { Stay in place } \\
\text { Fit (poor) } \\
\text { Cost } \\
\text { Environment } \\
\text { Stay in place } \\
\text { Absorbency (poor) } \\
\text { Comfort }\end{array}$ & $\begin{array}{r}15 \\
2 \\
5 \\
1 \\
2 \\
3 \\
1 \\
1 \\
1 \\
1\end{array}$ & $\begin{array}{l}\text { Washing drying } \\
\text { Comfort } \\
\text { Washable } \\
\text { Heavy when wet } \\
\text { Absorbency }\end{array}$ & $\begin{array}{l}4 \\
4 \\
1 \\
1 \\
1\end{array}$ & $\begin{array}{l}\text { Absorbency (poor) } \\
\text { Not stay in place } \\
\text { Irritate skin } \\
\text { Odour/smell } \\
\text { Noisy } \\
\text { Uncomfortable }\end{array}$ & $\begin{array}{l}4 \\
7 \\
2 \\
1 \\
1 \\
1\end{array}$ \\
\hline
\end{tabular}

state their preferences. Participants were asked, if they were buying their own products, which designs they would select first, second, third and fourth, and why, and which designs they would be willing to buy (Table 19). Of particular interest were participants' stated preferences between disposable and washable products when potential savings associated with washables became apparent.

When relative monthly costs were disclosed, the main trend was for switching between disposable designs from more expensive DIs (11 women demoted them from top place) to less expensive
MPs (promoted to first place by six respondents). By contrast, the switch to washable products was small (MPs gained two top places and DIs gained one). Willingness to buy for the two disposable designs are similar at $80 \%$ and the clear superiority of DIs before prices were disclosed has been reduced (see Table 19). Less than $10 \%$ of participants expressed a willingness to buy WIs even though they are the cheapest design by a large margin.

In addition, we compared the first choice preferences (from the ranking data) of self-payers with NHS-funded participants (Table 20).

TABLE 19 Ranking with and without price (day)

\begin{tabular}{|c|c|c|c|c|c|c|c|c|c|}
\hline & \multirow[t]{2}{*}{$\mathbf{N}$} & \multicolumn{4}{|c|}{ Rank } & \multicolumn{3}{|c|}{$\begin{array}{l}\text { Willing to buy } \\
\text { (with price only) }\end{array}$} & \multirow[t]{2}{*}{$\begin{array}{l}\text { Cost } / \text { month } \\
\text { (range) }(t)\end{array}$} \\
\hline & & I st & 2nd & 3rd & 4th & $\mathbf{N}$ & Yes & $\%$ & \\
\hline $\begin{array}{l}\text { MP no price } \\
\text { With price }\end{array}$ & $\begin{array}{l}85 \\
83^{a}\end{array}$ & $\begin{array}{c}9.4(8) \\
16.9(14)\end{array}$ & $\begin{array}{l}60.0(51) \\
60.2(50)\end{array}$ & $\begin{array}{l}23.5(20) \\
18.1(15)\end{array}$ & $\begin{array}{l}7.1(6) \\
4.8(4)\end{array}$ & 83 & 66 & 79.5 & $9.90-16.80$ \\
\hline $\begin{array}{l}\text { DI no price } \\
\text { With price }\end{array}$ & $\begin{array}{l}85 \\
83^{a}\end{array}$ & $\begin{array}{l}74.1(63) \\
62.7(52)\end{array}$ & $\begin{array}{l}16.5(14) \\
19.3(16)\end{array}$ & $\begin{array}{c}8.2(7) \\
14.5(12)\end{array}$ & $\begin{array}{l}1.2(1) \\
3.6(3)\end{array}$ & 83 & 66 & 79.5 & $21.00-27.60$ \\
\hline $\begin{array}{l}\text { WP no price } \\
\text { With price }\end{array}$ & $\begin{array}{l}81^{b} \\
79^{a b}\end{array}$ & $\begin{array}{l}16.0(13) \\
19.0(15)\end{array}$ & $\begin{array}{l}14.8(12) \\
13.9(11)\end{array}$ & $\begin{array}{l}50.6(4 I) \\
48.1(38)\end{array}$ & $\begin{array}{l}18.5(15) \\
19.0(15)\end{array}$ & 79 & 33 & 41.8 & $6.00-10.25$ \\
\hline $\begin{array}{l}\text { WI no price } \\
\text { With price }\end{array}$ & $\begin{array}{l}85 \\
83^{a}\end{array}$ & $\begin{array}{l}1.2(1) \\
2.5(2)\end{array}$ & $\begin{array}{l}9.4(8) \\
7.4(6)\end{array}$ & $\begin{array}{l}14.1(13) \\
22.2(18)\end{array}$ & $\begin{array}{l}74.1(63) \\
70.4(57)\end{array}$ & 83 & 8 & 9.6 & $1.40-3.50$ \\
\hline
\end{tabular}


TABLE 20 Design preferences comparing self-payers with NHS funded women

\begin{tabular}{|c|c|c|c|c|c|c|c|c|c|c|}
\hline & \multicolumn{5}{|c|}{ Without price } & \multicolumn{5}{|c|}{ After price disclosed } \\
\hline & $\mathbf{N}$ & DI & WP & MP & WI & $\mathbf{N}$ & DI & WP & MP & WI \\
\hline NHS pay & 30 & $\begin{array}{c}25 \\
(83 \%)\end{array}$ & $\begin{array}{c}5 \\
(17 \%)\end{array}$ & 0 & 0 & 30 & $\begin{array}{c}21 \\
(70 \%)\end{array}$ & $\begin{array}{c}5 \\
(17 \%)\end{array}$ & $\begin{array}{c}3 \\
10 \%\end{array}$ & $\begin{array}{c}1 \\
(3 \%)\end{array}$ \\
\hline Self-pay & 55 & $\begin{array}{c}38 \\
(69 \%)\end{array}$ & $\begin{array}{c}8 \\
(14.5 \%)\end{array}$ & $\begin{array}{c}8 \\
(14.5 \%)\end{array}$ & $\begin{array}{c}1 \\
(2 \%)\end{array}$ & 53 & $\begin{array}{c}31 \\
(59 \%)\end{array}$ & $\begin{array}{c}10 \\
(19 \%)\end{array}$ & $\begin{array}{c}11 \\
(21 \%)\end{array}$ & $\begin{array}{c}\text { I } \\
(2 \%)\end{array}$ \\
\hline
\end{tabular}

Lower proportions of self-payers chose DIs and higher proportions chose MPs as their first-choice design, compared with NHS-funded women. This could be because the self-payers were more price aware and did not buy DIs before the study because they are more expensive. Disclosing the price causes a $13 \%$ swing away from DIs in both groups, four (of 30) NHS-funded women alter their first choices to MPs and WIs. Seven (of 55) self-payers altered their first choices to MPs and WPs.

\section{Cost-effectiveness}

A cost-effectiveness analysis was performed as the mean VAS scores were significantly different between designs in multivariate and paired comparisons. To calculate the ICER the mean monthly cost of the products in each design and the mean of the mean product VAS scores in each design were used. Average and incremental ratios for the designs are shown in Table 21. The expense of laundering washable products (which is borne by individuals) is not included in the monthly costs.

The cheapest and least preferred product (WI) has the lowest average cost $(£ 0.14)$ per unit of effectiveness [highest average effectiveness (7.1
VAS points) per $£ 1$ spent]. DIs [the most expensive and most effective design (according to mean VAS scores)] have the highest average cost (£0.32) per unit of effectiveness [lowest average effectiveness (3.1 VAS points) per $£ 1$ spent]. Mean VAS and monthly costs of products were inversely related. There is no strictly dominant design. The cost for VAS points is shown in Figure 23.

There is more benefit for given expenditure [lower average cost-effectiveness ratio (ACER)] with cheaper designs. As costs go up, effectiveness goes up also, but less than proportionately. Hence cheaper washable products are on average better value for money. However, more than $50 \%$ of participants stated that WPs were unacceptable. The proportion for WIs was above $80 \%$. Of the more highly rated disposable products, MPs appear better value for money than DIs, but have a lower acceptability rating (80 versus $95 \%$ ). The 'highly acceptable' ratings are 12 and 69\%, respectively, and less than half of participants would be willing to use MPs when outside their homes.

Incremental ratios show that it costs $£ 0.56$ to gain an extra unit of effectiveness from DIs compared

TABLE 2 I Between-design average and incremental cost-effectiveness ratios

\begin{tabular}{|c|c|c|c|c|c|}
\hline $\begin{array}{l}\text { Design in order } \\
\text { of effectiveness }\end{array}$ & $\begin{array}{c}\text { Mean } \\
\text { monthly } \\
\text { cost }(t)\end{array}$ & $\begin{array}{l}\text { Mean } \\
\text { VAS } \\
\text { score }\end{array}$ & $\begin{array}{c}\text { Average } \\
\text { cost-effectiveness } \\
\text { ratio (ACER) } \\
\text { (t) }\end{array}$ & $\begin{array}{c}\text { Average } \\
\text { effectiveness-cost } \\
\text { ratio (AECR) } \\
\text { (VAS points) }\end{array}$ & $\begin{array}{l}\text { Product pair comparisons: } \\
\text { ICER }^{a}\end{array}$ \\
\hline DI & 25.40 & 79.3 & 0.32 & 3.12 & No design dominates. \\
\hline MP & 13.70 & 58.3 & 0.24 & 4.26 & $\begin{array}{l}\text { WI-WP: ICER }(£) 0.246 \\
\text { IECR (VAS points) } 4.07\end{array}$ \\
\hline WP & 8.40 & 42.7 & 0.20 & 5.08 & $\begin{array}{l}\text { WP-MP: ICER }(E) 0.340 \\
\text { IECR (VAS points) } 2.94\end{array}$ \\
\hline WI & 2.80 & 19.9 & 0.14 & 7.10 & $\begin{array}{l}\text { MP-DI: ICER( }(£) \text { 0.557, } \\
\text { IECR (VAS points) I.80 }\end{array}$ \\
\hline
\end{tabular}




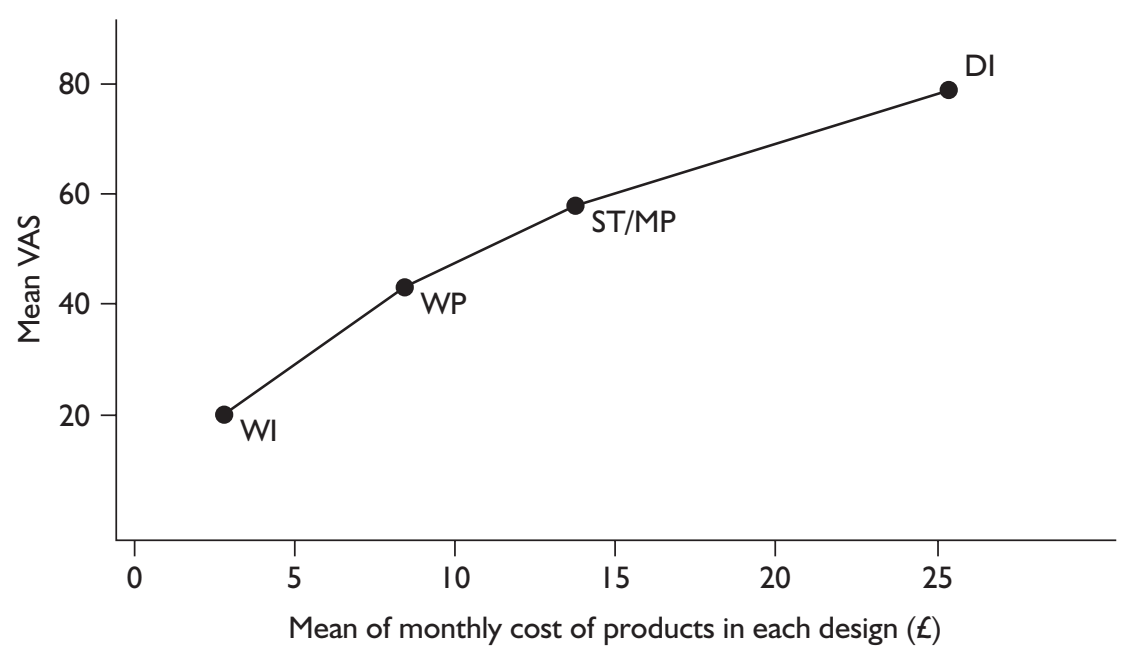

FIGURE 23 Cost for VAS points

with MPs (or that an extra $£ 1$ spent on DIs rather than MPs gains 1.8 extra VAS points). The equivalent incremental ratios between WPs and MPs are more favourable (£0.34 for an extra unit of effectiveness and 2.9 extra VAS points for each extra $£ 1$ spent). The best incremental ratios are between WIs and WPs: extra VAS points cost $£ 0.25$; an extra £1 generates 4.1 VAS points.

Comparing designs, the data show that if a woman were to use DIs rather than MPs, she would gain (on average) some 21 VAS points of benefit at an extra cost of $£ 11.70$ per month. Similarly, use of MPs instead of WPs, or WPs instead of WIs, would give 15.6 and 22.8 extra units of effectiveness, at extra costs of $£ 5.30$ and $£ 5.60$ per month, respectively.

MPs seem to be a relatively inexpensive product for the benefit gained and were deemed acceptable by around $87 \%$ of participants for home use and $46 \%$ for outside the home. DIs provide improved benefit but cost almost twice as much. They are acceptable to over $95 \%$ of women in all situations. Spearman's rank correlation between four-point acceptability scale for MPs and ICIQ summary measure of incontinence was significant $(\rho=-0.260, p=0.017)$, showing that women with lighter incontinence tend to be the ones who find MPs more acceptable. Although women who found MPs acceptable in situations outside the home had slightly lower ICIQ summary scores (lower incontinence) than those who did not (11.47 versus 12.83), the difference was not significant.
The most cost-effective option might be to allow women to mix and match products. Women with lighter incontinence can use the cheaper MPs or WPs in their homes and be provided with more expensive DIs for going out and special occasions.

\section{Sensitivity analysis and sources of uncertainty}

The cost-effectiveness ratios are based on point estimates of costs and effectiveness (the mean values of products in designs). The $95 \%$ CIs surrounding the mean design VAS and the cost ranges do not overlap (except at the cost margins between WP and MP). Using the extreme values of the CIs or the cost ranges would not alter the design ranks, although the values of the ACERs and the ICERs would change.

There are several sources of uncertainty in the costs that were used. First, the costs reflect the prices of the products selected for the trial. There was considerable variability in the prices of selected products within designs, and the mean price was used. There are many different products available, so a different choice of products could result in different mean design costs.

Second, the product prices were those of retail/mail order outlets because many women with light incontinence purchase their own supplies and the NHS did not provide two of the designs tested (MPs and WIs) at the time of the study. The prices charged by PASA were about $50 \%$ lower than those on the open market (52 and $45 \%$ lower for the WP and DI products, respectively, included in the trial). PASA offers a restricted product range, and 
variability of prices within design tends to be lower. Use of NHS prices would affect the costeffectiveness ratios, but would only affect relative values to the extent to which the NHS bulk purchase discount varies across designs.

Third, all monthly cost estimates were based on a consumption rate of four products per 24 hours, which was the mean utilisation reported by participants at baseline. This overstated the actual consumption of products in the trial by about $25 \%$ (see Table 11), so costs used in the costeffectiveness analysis were high-end estimates for each design. This will have affected all designs equally and will not affect relative cost-effectiveness.

Fourth, calculation of the costs of the washables was based on assumptions about the life (number of washes) of products and the stocks that women would hold. Manufacturers' data were used on product life (120 washes assumed) and stock levels (minimum of 12 products) were based on daily product use and the experience of the research team. Varying these assumptions affects the costeffectiveness of washables relative to disposables. Holding more stocks and increasing the replacement rate increase the cost of washables, but they still remain markedly cheaper than disposable alternatives. When participants were asked in the final interview how many stocks of washables they would need to hold, the median response was 12 .

Fifth, the cost-effectiveness calculations are based on the purchase price of products and exclude other costs borne by consumers, the most important of which is the cost of laundering in the case of washable designs. Use of disposables involves 'shoe leather' costs of purchase (unless delivered by the NHS) and also issues around storage and disposal, but none of these are generally considered to have a significant financial impact for users.

\section{Laundry costs and environmental issues}

Laundry costs are of two types: those associated with washing reusable products and laundry generated by leakages. Women were reminded when making their selections between designs that the costs they were given did not include the cost of laundering the washable products. Including the laundry costs associated with washable products would reduce their cost-effectiveness relative to disposables.

There were significant differences in laundry generated between all designs $(\mathrm{DI}<\mathrm{MP}<\mathrm{WP}<$
WI). These costs would be borne by the product users. They were not estimated because they were judged to be relatively small. Moreover, the costs would vary, depending on the laundry arrangements of individual women. Data collected at baseline showed different practices regarding whether incontinence-related items were washed separately and regarding the use of more expensive equipment such as tumble driers.

An important consideration in the comparison of washable and disposable designs is the relative environmental cost, particularly disposal (landfill) costs of disposable designs and energy costs associated with laundering the washables. A recent report on baby nappies concluded that there was no significant difference in environmental impact between three nappy systems (disposables, home and commercial laundered), although the types of impacts did vary. ${ }^{49}$ It is assumed that these findings are generalisable to adult incontinence products and, accordingly, no allowance was made in the cost-effectiveness calculations for environmental factors.

\section{Views about designs that should be provided through the NHS}

At the time of the study, only two of the designs tested were purchased by the NHS: DIs and WPs. PASA buys large quantities of products and uses its market power to secure favourable contracts with producers, which it then passes on to the Trusts that choose to buy supplies from it. Some Trusts buy direct from manufacturers and will also negotiate more favourable terms than retail or mail order rates, but these are unlikely to match those of PASA.

Respondents were asked to compare DIs and WPs at the NHS prices (including delivery), converted to an annual cost of supplying one woman with light incontinence, and to identify the best and worst value-for-money design. They were also asked whether they thought the NHS should purchase each, giving reasons. The annual cost of DIs is 3-4 times higher than that of WPs.

Respondents were reminded that NHS expenditure comes from taxpayers. The responses are shown in Table 22. Significantly more people thought that the NHS should buy DIs than WPs $\left(x^{2}, p=0.02\right)$.

Compared with rankings that participants made for personal purchases, DIs were ranked first by similar numbers of women when they were asked to compare them with WPs in the context of NHS provision (52 versus 49) (Tables 19 and 22). In the 
TABLE 22 Ranking of designs provided by NHS only

\begin{tabular}{|c|c|c|c|c|c|c|}
\hline \multirow[t]{2}{*}{ Design } & \multirow[t]{2}{*}{ Annual cost (E) } & \multicolumn{2}{|c|}{ Day rank } & \multicolumn{3}{|c|}{ NHS should buy } \\
\hline & & Ist & 2nd & Total & $n$ & Yes vs no \\
\hline DI & $145-166$ & $\begin{array}{c}49 \\
(57.6 \%)\end{array}$ & $\begin{array}{c}33 \\
(38.8 \%)\end{array}$ & 82 & 79 & $\begin{array}{c}64 \\
(81.0 \%)\end{array}$ \\
\hline WP & $40-60$ & $\begin{array}{c}34 \\
(40.0 \%)\end{array}$ & $\begin{array}{c}50 \\
(58.8 \%)\end{array}$ & 84 & 79 & $\begin{array}{c}51 \\
(64.6 \%)\end{array}$ \\
\hline Total & & $\begin{array}{c}83 \\
(97.6 \%)\end{array}$ & $\begin{array}{c}83 \\
(97.6 \%)\end{array}$ & & & \\
\hline Missing & & $\begin{array}{c}2 \\
(2.4 \%)\end{array}$ & $\begin{array}{c}2 \\
(2.4 \%)\end{array}$ & & & \\
\hline
\end{tabular}

absence of competition from MPs and WIs, WPs were ranked best for NHS purchasing by a larger number of women (15 versus 34 ). There was higher support for the NHS purchasing WPs than willingness-to-pay at the personal level $(65 \%$ versus $42 \%$ ). Stated reasons showed that lower cost was an important factor for ranking WPs highest, although some people felt that the relatively poor performance of this design rendered the products to be poor value.

Participants were asked whether they thought DIs, compared with WPs, were worth the extra cost to the taxpayer. Of 72 responses made, 50 (69.4\%) said they were, citing superior reliability, convenience, comfort and hygiene (in that order).

\section{Attitudes towards washable and disposable products}

At the final interview, participants were asked an open question as to whether they favoured washable or disposable products, and why. The results are shown in Table 23. The majority favoured disposables $(N=53,62.4 \%)$, which were overwhelmingly preferred for convenience aspects.
A substantial minority $(N=23,27.1 \%)$ favoured washables, largely for cost and environmental reasons, and eight participants $(9.4 \%)$ did not feel strongly either way.

\section{Practical aspects of washables and disposables}

Respondents were asked for their views about the practical aspects of using each type of product and the extent to which these constituted a problem (four-point scale). The results are presented in Table 24. Practical issues associated with use of washables constitute greater problems in the opinions of participants, in particular dealing with wet washable products when out. When asked how they would feel if WPs were the only incontinence products supplied by the NHS, 13 (15.5\% of respondents) said it would not worry them, six $(7.1 \%)$ said they would be pleased and $54(64.3 \%)$ said they would be concerned.

\section{Provision of products}

The final section of the questionnaire asked respondents about provision of their products. People who received NHS products and those who did not were treated separately. The NHS

TABLE 23 Views on washable and disposable products, daytime

$\begin{array}{lr}\text { Favour disposables } & 62.3 \%(53) \\ \text { Favour washables } & 27.0 \%(23) \\ \text { No strong feeling either way } & 9.4 \%(8) \text { ( I missing) }\end{array}$


TABLE 24 Practical aspects

\begin{tabular}{|c|c|c|c|c|}
\hline \multirow[t]{2}{*}{ Feature $(N=85)$} & \multicolumn{4}{|c|}{$\%(N)$} \\
\hline & No problem & Small problem & Big problem & $\begin{array}{l}\text { Insurmountable } \\
\text { problem }\end{array}$ \\
\hline $\begin{array}{l}\text { Dealing with washable products before washing } \\
\text { (e.g. rinsing out, nappy bucket) }\end{array}$ & $41.2(35)$ & $31.8(27)$ & $24.7(2 \mathrm{I})$ & $2.4(2)$ \\
\hline Washing washables & $45.9(39)$ & $30.6(26)$ & $22.4(19)$ & $1.2(1)$ \\
\hline Drying washables (I missing) & $42.4(36)$ & $21.2(18)$ & $30.6(26)$ & $4.7(4)$ \\
\hline Dealing with wet washable products when out & $15.3(13)$ & $24.7(21)$ & $42.4(36)$ & $17.6(15)$ \\
\hline Disposal of used disposable products & $80.0(68)$ & $16.5(14)$ & $3.5(3)$ & 0 \\
\hline Storage of disposable products & $78.8(67)$ & $18.8(16)$ & $2.4(2)$ & 0 \\
\hline Obtaining supplies of disposable products & $89.4(76)$ & $8.2(7)$ & $2.4(2)$ & 0 \\
\hline
\end{tabular}

provided products to 31 women, of whom six also self-paid for additional products. There were 54 women who bought all their own products.

\section{Self-payers}

Women without NHS provision $(N=54)$ were asked about their purchasing behaviour, whether they had requested NHS supplies and whether they would like to purchase supplies direct from NHS. Responses are shown in Table 25. Most women buy their products locally and regularly use the same brand. A few may shop for bargains or be influenced by availability. Most would like to cut the cost of supplies by buying through the NHS.

Approximately one-third of women had been refused NHS supplies although many of these had been offered other treatments. About one-quarter did not feel that their problem was severe enough to warrant NHS supplies. A further $20 \%$ did not realise that the NHS provided supplies for women with light incontinence.

Several of the 60 women who fully or partly provided their own products reported that the

TABLE 25 Self-payers' purchasing behaviours: questions to self-payers about buying behaviours $(\mathrm{N}=54)$ (plus 2 NHS/self-pay mix who additionally answered these questions): \% (N)

\begin{tabular}{|c|c|c|c|c|c|c|}
\hline $\begin{array}{l}\text { Where do you usually buy } \\
\text { your supplies? }\end{array}$ & \multicolumn{2}{|c|}{$\begin{array}{l}\text { Mail order } \\
7.1(4)\end{array}$} & $\begin{array}{l}\text { Local store } \\
78.6(44)\end{array}$ & \multicolumn{2}{|c|}{$\begin{array}{l}\text { Varies according to special offers } \\
\qquad 7.1 \text { (4) }\end{array}$} & $\begin{array}{l}\text { Other } \\
7.1(4)\end{array}$ \\
\hline $\begin{array}{l}\text { Did you realise that the NHS } \\
\text { can buy products at about half } \\
\text { the price that individuals pay } \\
\text { as they buy in bulk? } \\
\text { (I missing) }\end{array}$ & \multicolumn{3}{|c|}{$\begin{array}{c}\text { Yes } \\
32.7(18)\end{array}$} & \multicolumn{3}{|c|}{$\begin{array}{c}\text { No } \\
67.2(37)\end{array}$} \\
\hline $\begin{array}{l}\text { If you could buy your supplies } \\
\text { through the NHS at a lower } \\
\text { price, would you? } \\
\text { (I missing) }\end{array}$ & \multicolumn{3}{|c|}{ Yes, would buy from NHS } & \multicolumn{3}{|c|}{$\begin{array}{l}\text { No, would continue to buy from local shop } \\
\text { or mail order } \\
5.5(3)\end{array}$} \\
\hline \multirow{2}{*}{$\begin{array}{l}\text { Have you ever asked your } \\
\text { GP or continence adviser if } \\
\text { the NHS could provide } \\
\text { pads to you? }\end{array}$} & \multicolumn{2}{|c|}{$\begin{array}{l}\text { Yes } \\
33.9 \text { (19), of whom: }\end{array}$} & $\begin{array}{l}\text { Refused } \\
\text { products } \\
15.8(3)\end{array}$ & \multicolumn{2}{|c|}{$\begin{array}{l}\text { No } \\
66.1 \text { (37), of whom: }\end{array}$} & $\begin{array}{l}\text { Did not realise } \\
\text { could get } \\
32.4(12)\end{array}$ \\
\hline & $\begin{array}{l}\text { Refused } \\
\text { products but } \\
\text { offered } \\
\text { treatment } \\
\text { instead } \\
57.9(1 \mathrm{I})\end{array}$ & $\begin{array}{l}\text { Products } \\
\text { given but } \\
\text { unsuitable }\end{array}$ & $\begin{array}{l}\text { Currently } \\
\text { under } \\
\text { assessment }\end{array}$ & $\begin{array}{l}\text { Problem not } \\
\text { severe } \\
\text { enough/never } \\
\text { occurred to } \\
\text { me } \\
37.8(14)\end{array}$ & $\begin{array}{l}\text { Thought NHS } \\
\text { products } \\
\text { were not nice }\end{array}$ & $\begin{array}{l}\text { Too } \\
\text { embarrassed }\end{array}$ \\
\hline
\end{tabular}


trial had made them more aware of the range of products on offer. Five had sought to change the brand of product they used and 13 stated that they had started to use WPs provided by the trial in at least some situations. Two participants had sought NHS assessments to see if they could get their products funded.

\section{Women in receipt of NHS supplies}

Women receiving NHS supplies $(N=31)$ were asked about choices offered to them and satisfaction with the products they receive. Responses are summarised in Table 26.

Restricted choice is shown, with two-thirds of women given no choice of products and some dissatisfaction with both the quality and quantity of products received. Five women reported that they continued to use the WPs provided during the study in conjunction with the NHS products they received, because they had liked the fit and comfort of the pants.

\section{NHS versus self-pay participants}

The NHS and self-paying participants were compared and no significant differences were found between them on a range of background variables including incontinence (ICIQ and Kings), income, age and employment status. However, self-payers had significantly better SF-12 physical functioning $(p=0.048)$, were more likely to walk independently $(p=0.044)$, and tended to be less dependent, according to the Barthel score $(p=0.067)$.

\section{Previous product use}

Thirteen of the participants were using MPs before the study, one used WP and the remainder were using DIs $(N=71)$. The effect of previous product use on the overall acceptability scores was examined, but this was not found to be significant.

\section{Discussion}

This clinical trial has shown that there are substantial differences between the different designs of absorbent products available to women with light incontinence. For the primary outcome variables of overall acceptability, and for mean VAS, preference and leakage performance, DI pads are better than MPs, which are better than WPs, which are better than WIs.

The superior leakage performance of DIs is evident at both low and high urine masses and it is notable that the washable designs performed relatively poorly in this respect. The leakage graph shows that even at very low urine masses, washable designs are likely to leak, indicating that the ability of the washable materials to allow fast penetration or 'strike through' of urine is poor leakage probably occurs because some urine simply runs off the interface material rather than because absorption capacity has been exceeded. A similar problem with increased risk of leakage at very low urine masses is evident with the disposable MPs, although this effect is less pronounced; it is probably because MPs are not designed to receive urine at high flow rates and the construction and materials differ from those of DI pads.

The median mass of urine was significantly different between the four designs, with the DI design measuring more than the MP design, which measured more than the WP design, which measured more than the WI design. The DI design median was around twice as much as the WI design. There are four possible explanations for this finding. First, the urine masses may have been less for the non-DI designs because more urine leaked from them; second, the women using the more leaky designs may have taken action to

TABLE 26 NHS receivers' purchasing behaviour: women receiving NHS products about service (N = 31 ) (includes 6 who receive NHS and top up themselves): \% (N)

Who makes decision about your incontinence supplies?

How much product choice are you offered?

How satisfied are you with the quality of the product you receive?

How satisfied are you with the quantity of the product you receive? (I missing)
Continence adviser $71.0(22)$

No choice

Between designs

$67.7(21)$

16. I (5)

Very satisfied

41.9 (13)

Very satisfied

46.7 (14)
Joint decision between self and continence adviser $29.0(9)$

Between different products within a design

12.9 (4)

Quite satisfied

48.4 (15)

Quite satisfied 26.7 (8)
Design and product

3.2 (I)

Not satisfied 9.7 (3)

Not satisfied 26.7 (8) 
limit their incontinence, such as increasing toileting; third, women may have avoided using these products in challenging situations (such as going out; see Figure 16, p. 30) where toilet accessibility may have been unpredictable and incontinence more likely; or fourthly, the women changed their pads more frequently. The last explanation was not borne out by consumption data, which showed that there were no significant differences between products, except for the WI design, which was used significantly less.

This indicates that the use of less effective products is not associated with greater consumption of products, but rather that it may result in activities to mitigate incontinence and avoidance of certain situations. The consumption of products used during the study was less than was reported by participants at the beginning (by around one product per day). We do not know why this is, but it is possible that participants believed that the study would in some way be connected to future provision of their products (although they were assured of the study's independence) and therefore gave generous estimations of their product consumption. Cost estimates used for the economic analysis were related to baseline consumption reports and therefore overestimated actual mean costs.

Overall, the DI had very high levels of acceptability in all situations, with very few women $(N=4)$ finding it an unacceptable option for going out, the most demanding of the activities. Discreetness and price are the main drawbacks of DIs, although discreetness was only significantly worse than for the MP. The main improvement that women suggested for DIs was a reduction in bulk. DIs are rated $36 \%$ more effective than MPs (mean VAS 79.3 versus 58.3), but are almost twice as expensive. The most common type of DI provided by the NHS was used. Smaller, more discreet, less absorbent and cheaper DIs are available. If their performance were still better than that of the other three designs, then this would reduce costs; however, their comparative performance is unknown.

The MP performed significantly worse than the DI pad for overall acceptability, preference, leakage, smell and comfort when wet. The MP was substantially cheaper than the DI and had a high level of acceptability (69\%), although few women chose it as their first choice ( $N=8$ before price). Thirty-nine women stated that they would not find the MP acceptable for 'going out', indicating that for most women full-time use of MPs is likely to be detrimental to QoL. The MP was praised for its discreetness, but higher absorbency was considered a necessary improvement, without additional bulk. MPs are rated $37 \%$ more effective that WPs (mean VAS 58.3 versus 42.7) and are $56 \%$ more expensive before laundry costs are taken into account. Although costs of provision may be borne by the NHS, laundry costs are the responsibility of the user.

The WP performed significantly worse than the MP for overall acceptability, preference, leakage, smell, comfort when wet and effect on everyday activities, but the differences were smaller than between the DI pad and the MP. The WPs were cheaper to use than MPs even when laundry costs are taken into account. More women chose the WPs as their first-choice design $(N=13)$ (despite their poorer leakage performance) than MPs, but the majority of women did not support the use of washable designs in general and reported high levels of practical problems associated with their use. However, a substantial minority of 23 women (27\%) favoured washables and would be likely to choose washable products if their leakage performance were improved.

WIs performed worse than WPs for overall opinion, preference, leakage, comfort when dry and staying in place. Most women experienced difficulty with keeping the WI in place even though they were worn with close-fitting pants (as recommended by manufacturers). Special pants are available with a pouch for a WI and use of these may improve performance, although this would increase cost.

Overall, the washable products performed much less well than the disposable products, particularly for leakage, but also for smell and comfort when wet, both of which were significantly worse for the washables than the disposables, but not significantly different between the two washables. The constituents of disposable pads, particularly superabsorbent gel and hydrophobic covering materials, are likely to be better at retaining odour (preventing smell) and reducing wet-back (i.e. retaining urine in the absorbent core) and there is much scope for improvements in the materials and construction of washable products.

There have been indications from previous studies of larger products for heavy incontinence that washables may be worse for skin health than disposables. ${ }^{27}$ This was not demonstrated unequivocally in this trial, but it must be acknowledged that the participants had light 
incontinence. Although the DI design was significantly better than the two washable designs for skin health, the MP design was only significantly better than the WI design (not the WP design). It is plausible that it is not the washable materials per se that affect skin health, but their poor leakage performance and inability to retain urine in the absorbent core (poor wetback), which may lead to wetter skin and impairment of skin health. Wet skin is more easily abraded than dry skin and is more susceptible to irritation. ${ }^{50}$

Most of the women in this trial paid for their own absorbent products and some were unaware that they may be provided by the NHS or had been denied provision. The incontinence levels of selfpaying women were similar to those obtaining free NHS products and the provision of these products by the NHS is inequitable. Where NHS products are provided, most women reported that they had little or no choice.

At the time of the trial, the NHS was offering only DIs and (to a lesser extent) WPs. Yet provision of DI pads (the design mainly provided by the NHS) is likely to be neither the most cost-effective nor the optimum strategy from the women's perspective. The cost-effectiveness analysis showed no dominant design. DIs are the most expensive and perform the best but at almost twice the cost of the MPs, which are the second most effective. A significant minority of women prefer washable products or MPs, both of which are cheaper.

Savings could be made if the NHS offered the full range of designs, gave women greater choice and allowed them to 'mix and match' the products they used according to their daily activities or circumstances. One possibility might be to provide women with direct payments or vouchers for absorbent product purchases. Women would use their vouchers on products that suit their preferences, for example to purchase WPs or MPs for use around the home and DIs for going out. A fixed-value voucher would provide an incentive for women to choose the combination of products that was most cost-effective for them.

The NHS does not currently offer MPs, yet this trial shows that women with light incontinence find them acceptable in certain situations. The retail prices of MPs are lower than those of DIs, and the NHS could use its considerable influence in the market to negotiate favourable contracts with product manufacturers and achieve further savings. Self-paying women might be offered the opportunity to purchase their incontinence supplies through the NHS. As NHS prices are typically half those of retail or mail order outlets, they would be able to reap significant personal financial benefits.

\section{Limitations}

Product development means that the characteristics and availability of individual products change over time and the products used in this study are likely to be superseded. However, the main designs are much more stable and the results should therefore outlive those of the individual products.

The sample of women living in the community with light incontinence was intended to represent the 'heavier' end of light incontinence, because women with very infrequent incontinence would be less likely to represent those who received products from the NHS and would be less able to evaluate leakage performance, which was an important outcome. However, it was also intended to include those who paid for products themselves and those who received them from the NHS. Compared with a similar study which evaluated only DI brands ${ }^{9}$ and which included only older women (mean age 71 years) who received their products from the NHS, our sample was somewhat younger (mean age 60 years) and slightly less incontinent (median urine mass $17 \mathrm{~g}$ compared with $22 \mathrm{~g}$ ). It is therefore possible that our results would have shown even greater favouring of the DI pads (which performed substantially better for leakage at higher volumes than the other designs) for an 'NHS supplied' population.

Further limitations applying to the study more generally are discussed in Chapter 7 .

\section{Conclusions}

This trial demonstrated that DI pads were better than the other designs for most aspects of performance (including leakage), and were the most acceptable and preferred design, but were the most expensive. The washable designs had relatively poor leakage performance and low acceptability compared with disposable designs (particularly WIs). Not all women chose the DI as their first choice and the alternative, cheaper, washable and disposable designs were preferred by nearly one-quarter of women and more would find them acceptable in certain situations. Costeffective management may be achieved by offering 
the range of designs and allowing women to select combinations (within a limited budget) to suit their own circumstances.

\section{Implications for healthcare}

There is evidence that:

- For women with light incontinence, DIs are better than all other designs and for most circumstances.

- The WPs with integral pad and the MP are the preferred choice for a substantial minority of women and allowing choice from the full range of designs is likely to be economical for the NHS.

- The two washable designs (WPs and WIs) had poor leakage performance compared with the disposable designs and the use of washables incurred more practical problems than the use of disposables. Restricting the range of available products to washable designs alone is therefore not recommended.

- The cheaper washable designs and MP designs are likely to be more acceptable under some circumstances than others (e.g. staying at home); allowing women to choose combinations of designs (e.g. WPs within the home, DIs for going out) within a limited budget is likely to be economical for the NHS.

- The NHS provision of absorbent products to women with light incontinence is inequitable and guidelines are needed to determine the rationale and criteria for provision.

- An NHS 'shop' (virtual or otherwise) whereby NHS vouchers (or individuals' money) could be used to purchase combinations of product designs, at cheaper prices (using the buying power of the NHS), would be welcomed by users.

\section{Research recommendations}

- Translational research to pilot the feasibility of provision of a range of designs and enabling women to chose combinations of designs within a limited budget.

- Development of washable designs (in particular WPs with integral pad) to improve leakage performance. 



\section{Chapter 4}

\section{Randomised crossover trial of disposable and washable absorbent products for women and men with moderate/heavy urinary or urinary and faecal incontinence living in community settings (Trial 2a)}

\section{Background summary}

There are four designs of disposable and washable body-worn absorbent products suitable for people with moderate/heavy incontinence (inserts, diapers, T-shaped diapers and pull-ups) (Table 27). Products are not gender-specific. Although increasing numbers of washable products are becoming available, disposable designs dominate the market and washable designs are not commonly used; none are bought by PASA.

Insert pads are the simplest, cheapest (on a per product basis) and most commonly used of the disposable designs in the UK, although the use of diaper designs, particularly for more heavily incontinent individuals, is increasing. Both of these designs have been available for many years; however, in the last few years, two new designs have become available (T-shaped diapers and pullups), which are intended to be easier for the carer or individual to apply, but their effectiveness is not known.

Selection of designs for individuals in the UK is based on little evidence. There have been no direct comparisons made of the different disposable body-worn designs and most clinical trials that have focused on comparisons of disposable and washable designs are more than 10 years old and were carried out in hospital or

TABLE 27 Pad design categories

Designs for moderate/heavy urinary and/or faecal incontinence

\begin{tabular}{|ll|}
\hline Disposable & Washable \\
\hline Inserts & Inserts \\
Diapers & Diapers \\
T-shaped diapers & T-shaped diapers \\
Pull-ups & Pull-ups \\
\hline
\end{tabular}

nursing home settings rather than in primary care settings.

There are indications from trials of products from a single design ${ }^{15,16}$ that insert pads may be less effective than diapers, but this has not been tested in a clinical trial. There are also indications that designs vary in how long they take to apply and remove; however, this has not been demonstrated clinically. ${ }^{51}$

In a small pilot study $(N=14)$ comparing a range of washable designs for heavy incontinence, ${ }^{18}$ there were indications that diaper-style washable designs perform better than other washable designs (particularly inserts) and may perform favourably when compared with disposable designs, but this has not been tested in a clinical trial.

\section{Aims}

The aim of the study was to compare the performance and cost-effectiveness of disposable and washable absorbent product designs for women and men with moderate/heavy urinary or urinary and faecal incontinence living in community settings.

\section{Design and methods}

The trial was a randomised crossover clinical trial comparing four disposable absorbent product designs (insert, diaper, T-shaped diaper, pull-up) and one washable product design (Figures 24 and 25).

\section{Recruitment of participants}

The inclusion and exclusion criteria for participants are shown in Box 2. The aim was to recruit participants who were already using an 
(a)

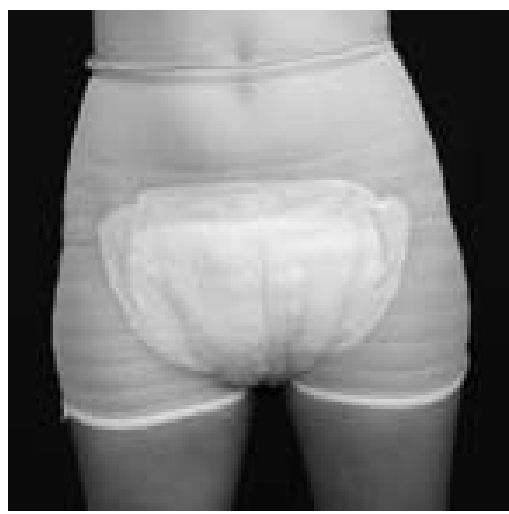

(c)

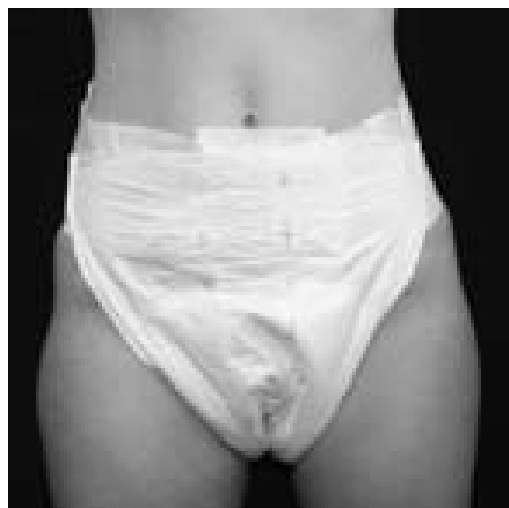

(b)

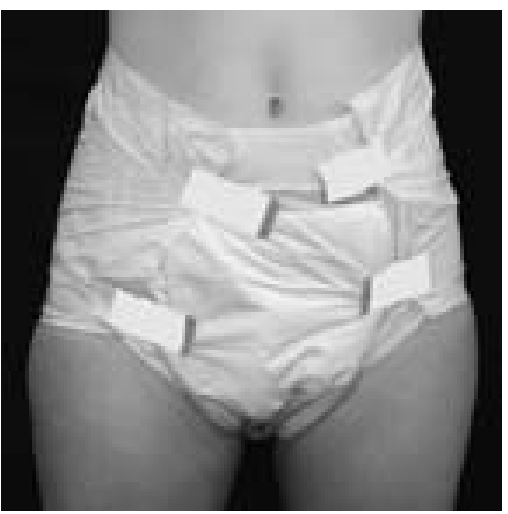

(d)

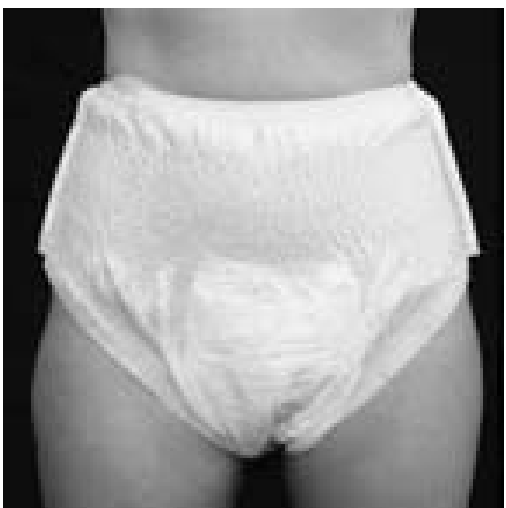

FIGURE 24 (a) Insert; (b) diaper; (c) T-shaped diaper and (d) pull-up

(a)

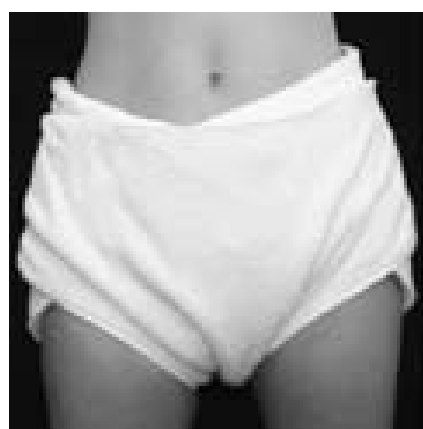

(b)

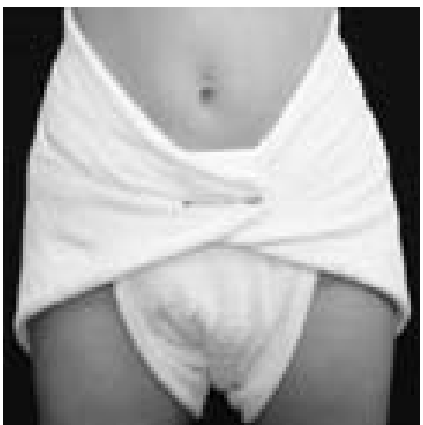

(c)

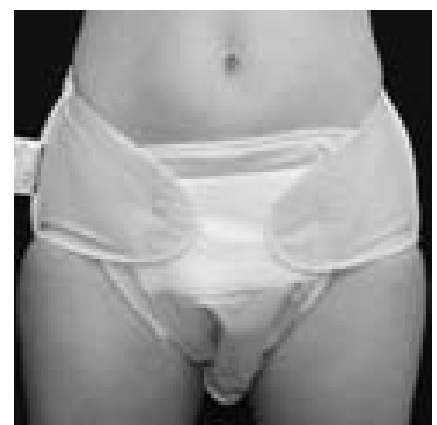

FIGURE 25 Washable diapers (these products are less homogeneous in design than the disposable product designs so pictures of all three variants are shown: (a) terry-towelling sewn into a diaper shape and (b) a simple square of terry-towelling folded into a diaper are shown without plastic pants; (c) contains integral plastic backing.

absorbent product suitable for moderate to heavy incontinence and who had consistent and stable incontinence. This was to ensure that the participants' incontinence was not likely to change during the period of the trial. Designs for moderate to heavy incontinence are not genderspecific (unlike designs for light incontinence) and both men and women were therefore recruited.
Participants were recruited to the study in the following ways:

1. A press release was prepared to announce the study and this was distributed to local and national newspapers and magazines.

2. An invitation letter was sent to purchasers of absorbent products through Promocon (the 
BOX 2 Inclusion and exclusion criteria

\section{Inclusion criteria:}

Adult women and men

Resident in the community

Incontinence status consistent and stable

Currently using absorbent products for moderate/heavy urinary and/or faecal incontinence

Willing to test washable and disposable absorbent products

Able to complete self-report questionnaires

\section{Exclusion criteria:}

Acute illness

Terminal phase of illness

national information centre for continence products) and to receivers of absorbent products through local NHS Trust delivery services in London and Southampton.

3. Advertisements were placed in the Incontact's quarterly magazine and Internet message board asking people who were interested in testing products to contact us for further information.

4. People who had taken part in previous studies were sent letters containing study information and were asked to respond if they were interested in taking part.

\section{Study process}

During the study, participants tested the five designs (four disposable, one washable), comprising 14 products (three for each design, except two for the T-shaped diaper) each tested for 1 week (overall test period 14 weeks). During testing they weighed used pads and kept a pad change/leakage diary and completed a product performance questionnaire at the end of each week of testing. At the end of the testing period, a final interview was completed to determine preferences and opinions. The study process is shown in Figure 26.

\section{Outcome measures}

The outcome measures (see Chapter 2 for more details) are listed below. All participants were given two booklets (case record forms) for day and night products. These contained the product performance questionnaires and pad change/leakage diaries that would be needed for the study.

Participants were each provided with a set of digital scales in order to weigh each used pad, record whether the product had leaked urine (none, a little, a lot) and whether leakage had resulted in incontinence laundry items. They also recorded the number of each product used day and night.

In summary, a pad change/leakage diary was used to record:

- weight of pad (g)

- leakage from product (none, a little, a lot)

- laundry resulting from incontinence (small and large items)

- number of products used per day and night.

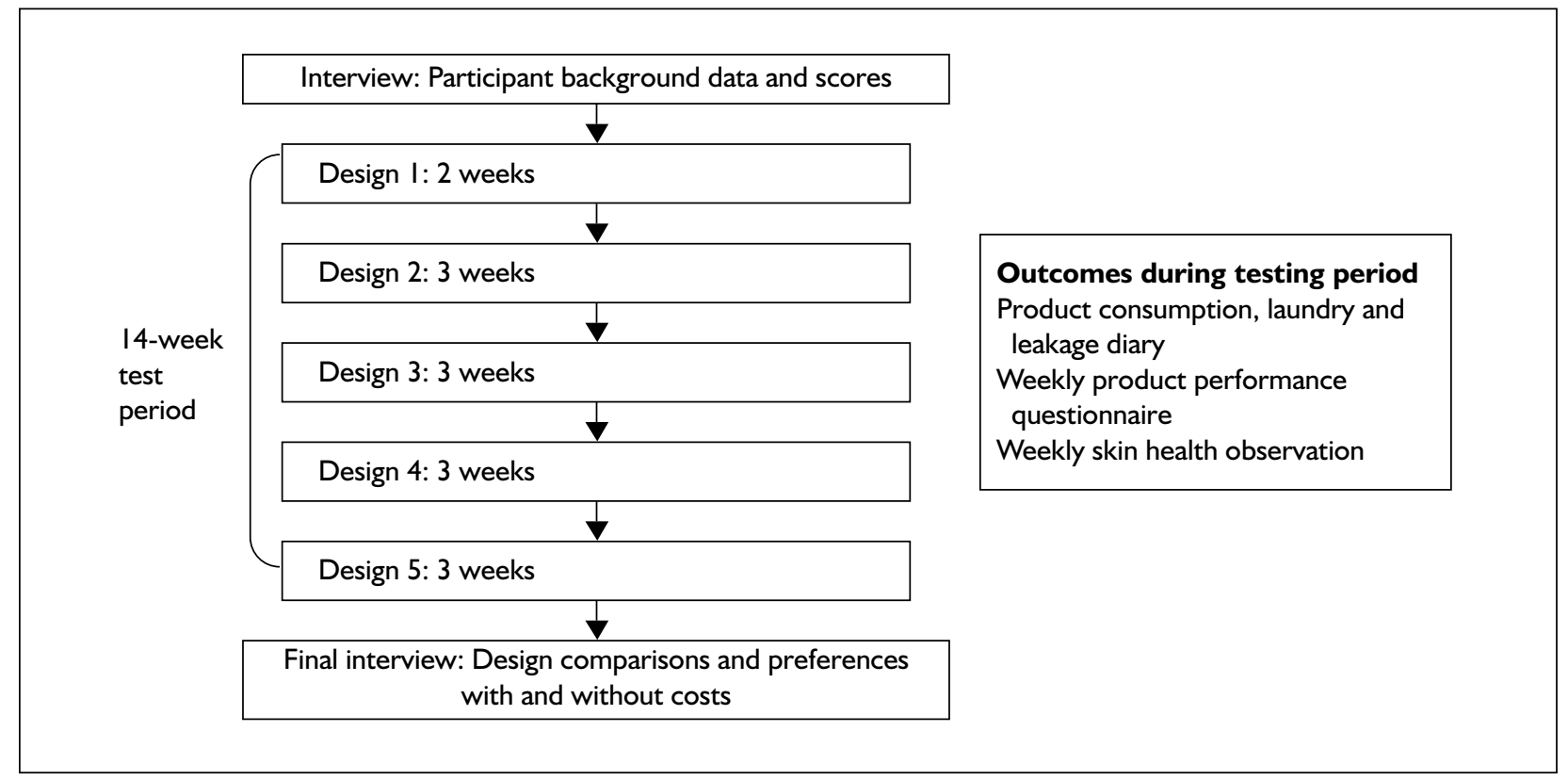


At the end of each period of product testing (1 week), a product performance questionnaire was completed to record:

- product performance variables (e.g. discreetness) rated as very good, good, okay, poor, very poor

- changes in skin health problems in pad area (none, a little or mild, a lot or moderate/severe).

At the end of the trial, a detailed final interview was completed to record:

- design preferences and rankings (with and without costs)

- overall acceptability of design (highly acceptable, acceptable, unacceptable, totally unacceptable)

- VAS (worst possible design-best possible design)

- willingness to buy (after prices disclosed)

- comments about good and poor aspects of designs

- views about washable versus disposable designs.

\section{Selection of absorbent products to represent design groups}

It is known that individual products within absorbent product design groups vary widely ${ }^{48}$ and selection of a single product to represent a given design is unsafe. Three disposable products were therefore selected to represent each disposable design group (the exception was for the T-shaped diaper because only two products were available at the time). The aim was to include products with the most commonly used absorbent capacities (according to data provided by PASA) and from a wide range of manufacturers. Candidate products for the insert, diaper and pull-up designs were tested in a pilot study (see Appendix 4) and results were used to inform selection of the three products for the clinical trial. Products had an approximate maximum absorbency (Rothwell score $^{7}$ ) of $1900 \mathrm{ml} \pm 20 \%$ for daytime use and $2400 \mathrm{ml} \pm 20 \%$ for night-time use. The aim was to compare designs with similar absorbent capacities in order to minimise the confounding effect of absorbent capacity, which may override the effect of design. For the inserts, the most commonly purchased stretch pants were provided for all three products. The three washable products chosen for the study were all diaper style and were the best performing products from a previous study. ${ }^{18}$ Two of the products were made out of traditional terry towelling (Figure $25 a$ and $b$ ), of which one (a) was sewn into a diaper shape, but also required pins to hold the pad in place and the other (b) was a simple square which required folding and pinning in place (as with a conventional baby's nappy). Both of these products were provided with separate plastic pants of the type used in a previous study. ${ }^{18}$ The third washable diaper (Figure 25c) was different from the others. It was made from a needle-felt with a woven interface and had an integral waterproof backing with Velcro patches to hold the pad in place. The two terry-towelling products performed better in the published pilot study but the third product was included because it was more typical of washable products that are most commonly considered by purchasers. All of the washable products had optional booster pads, which participants could use to increase the absorbency. Because of the differences between this product and the terry-towelling products, it was decided $a$ priori not to combine the results for this product with those for the other two in the analysis, but to present these results separately.

\section{Study preparation and procedures}

Waist and hip measurements were used to order appropriately sized products for each participant. Blinding was not practical because each design had a different appearance. Products were therefore provided in their original packaging complete with any instructions but, because washing instructions varied slightly between manufacturers, for simplicity participants were provided with one generic set of instructions (used in a previous $\operatorname{trial}^{8}$ ) that covered all the manufacturers' guidelines. The washable products were washed twice to remove any dressing and repackaged. Product packages were marked with study labels indicating that they were day or night products. The labels were colour coded to correspond with the labels on the front of the booklets, and the product performance questionnaire and pad change/leakage diaries were also colour coded. This was designed to simplify the testing procedure.

The order of testing for all products was randomised using Latin squares ${ }^{38}$ for the order of both between-design groups and within-design groups (i.e. the order of the three products of the same design). Each product was tested for 1 week and the testing of a complete design therefore took 3 weeks. However, because this method would require large numbers of each washable product to be supplied (to ensure adequate 
laundry turn-round for the week of testing), participants were asked to test the washable products in daily rotation, according to the order of testing allocated (e.g. 1, 2, 3 or 2, 3, 1). Products were randomised for both day and night use, therefore participants tested different designs during the day and night. This was done to help the participants to consider the different designs separately for day and night.

\section{Participant preparation and interviews Eligibility interview}

Potential participants who contacted us by telephone, reply-paid slip, letter or email were interviewed on the telephone. The study was described according to the participant information sheet and eligibility to join the study was established. If the person was eligible and expressed willingness to join the study, the participant information sheet and consent form were posted with a reply-paid envelope.

\section{Participant information interview}

Potential participants who returned the signed consent form were contacted and an interview was arranged either at the research centre or in their own home, or exceptionally, when neither was practical, on the telephone. During this interview, the participant background information questionnaires and scores were completed (Table 28). Participants were also asked about the effects that incontinence pad usage had on their QoL and were asked to name and rank product performance characteristics that they considered to be of greatest importance (see Chapter 6).

At this interview, the self-report study documentation and instruction booklet were explained to the participant and the digital scales for product weighing were demonstrated to ensure competence.

\section{Product testing period}

Together with their box of test products, participants were provided with the instruction booklet, which had been piloted on volunteer participants for clarity and comprehension. Electronic digital scales and plastic bags were provided for pad weighing. Participants were asked to telephone the research centre when they received the box to notify us when they were starting testing and to enable any queries to be answered.

Participants tested their 14 products (five designs) for 1 week each and completed the pad change/leakage diary and product performance questionnaire during this 14-week period. A 1-week testing period for each product has been shown to be sufficient for community participants to form an opinion about the products and for sufficient products to be collected to record pad leakage data. ${ }^{34}$ Participants could withdraw from testing a product at any time, but were asked to complete the product performance questionnaire and early stopping form to record the reasons for stopping using the product. The participant would then move on to the next product. Participants were free to withdraw from the study at any time and without giving any reason.

\section{Participant monitoring}

Participants were given contact numbers of their designated research nurse and invited to telephone the research centre if they had any queries. In addition, the participants were telephoned at the start of the study and fortnightly during the data collection period to check that they understood the procedure and to address any problems, and they were encouraged to call the research staff if they had any queries.

TABLE 28 Background descriptive data

\begin{tabular}{|ll|}
\hline Questionnaire/score & Purpose: to provide \\
\hline $\begin{array}{l}\text { Background demographic and socio-economic } \\
\text { information }\end{array}$ & $\begin{array}{c}\text { Descriptive data on age, gender, product use, socio-economic } \\
\text { data }\end{array}$ \\
Barthel score & A measure of independence in activities of daily living score \\
SF-12 & A measure of general QoL \\
Kings QoL score & A measure of incontinence-specific QoL \\
ICIQ-UI (short form) & A brief measure of incontinence-specific QoL \\
HADS & An assessment of anxiety and depressive symptoms \\
\hline
\end{tabular}




\section{Final interview}

On completion of testing, a final interview was arranged either at the research centre or in the participant's home (or exceptionally by telephone) to complete the design comparison and preferences questionnaire and to return all questionnaires and diaries.

At the final interview, participants were asked to rank the individual products tested within each design group and then rank the different designs (with and without costs). The different designs were scored on a VAS and participants rated the designs using the overall acceptability score. Participants were also asked whether they would recommend the designs to others. To assess views on value for money of different designs, participants were shown the monthly cost of using the product they had previously identified as the best value for money in each design. Monthly costs were based on the assumption that people used four products per 24 hours (the most common rate of consumption reported by participants at recruitment). For the washables, it was assumed that a stock of 12 products would be needed and each product could be washed 120 times before it needed to be replaced (manufacturers' data and researchers' experience). Laundry costs of washable items were not included, although respondents were reminded of this when making their choice among designs.

Participants were then asked questions about the different situations in which they would consider using the designs and the practicalities of using disposable and washable designs. Participants were also asked to comment on the relative strengths and limitations of the designs.

\section{Ethics}

The study was reviewed by the London multicentre research ethics committee and complied fully with ethical, governance and data protection requirements and approval was obtained through appropriate NHS research ethics committees.

\section{Analysis}

Data were entered into Microsoft Excel Version 2003 , cleaned and $10 \%$ of the data set and $100 \%$ of the primary outcome variable data were checked for accurate entry. The data were transferred to SPSS Version 14, for further analysis.

Ordinal outcome variables were analysed using cumulative logit modelling, and quantitative outcome variables were analysed by linear modelling, allowing for repeated observations by each subject. Bonferroni adjustments were made in significance tests and to CIs for multiple comparisons between designs. R software was used (www.r-project.org).

\section{Results}

\section{Participant characteristics}

A total of 286 potential participants contacted the research centre, of whom 184 met the inclusion criteria, and 134 consented to take part in the trial. A total of 117 participants began testing products and 85 completed the study and gave a final interview. Progress of participants through the trial is shown in Figure 27.

Participant characteristics are shown in Table 29. The mean age of participants was 53 years and 49 were men (57.6\%). Most participants were living in their own homes with good mobility and independence in activities of daily living. Thirtysix $(42.3 \%)$ were in full- or part-time employment or seeking work. Forty-two were married or had a partner. More than three-quarters usually used insert or diaper designs and most received their products entirely or mainly by the NHS. All but one used products during both the night and the day. Reasons for incontinence were varied, with nearly $30 \%$ of participants reporting that they did not know why they were incontinent. Nine carried out intermittent catheterisation and 23 said they had faecal incontinence in addition to urinary incontinence.

\section{Data completion}

This study proved rather demanding for participants and, although full completion of the questionnaires was encouraged during the testing period by keeping regular contact, some participants were unable to provide full data. The final interview was also rather lengthy and it was therefore agreed to carry out a shortened version with some participants which focused on the primary outcome variables. This means that for some final interview questions the number of responses does not equal 85 . The number of responses is indicated in each final interview table.

\section{Product results within design groups}

The product performance questionnaires were analysed and comparisons made between the three (or two) different products comprising each design group. This showed that two of the disposable night products (one pull-up and one insert) were 


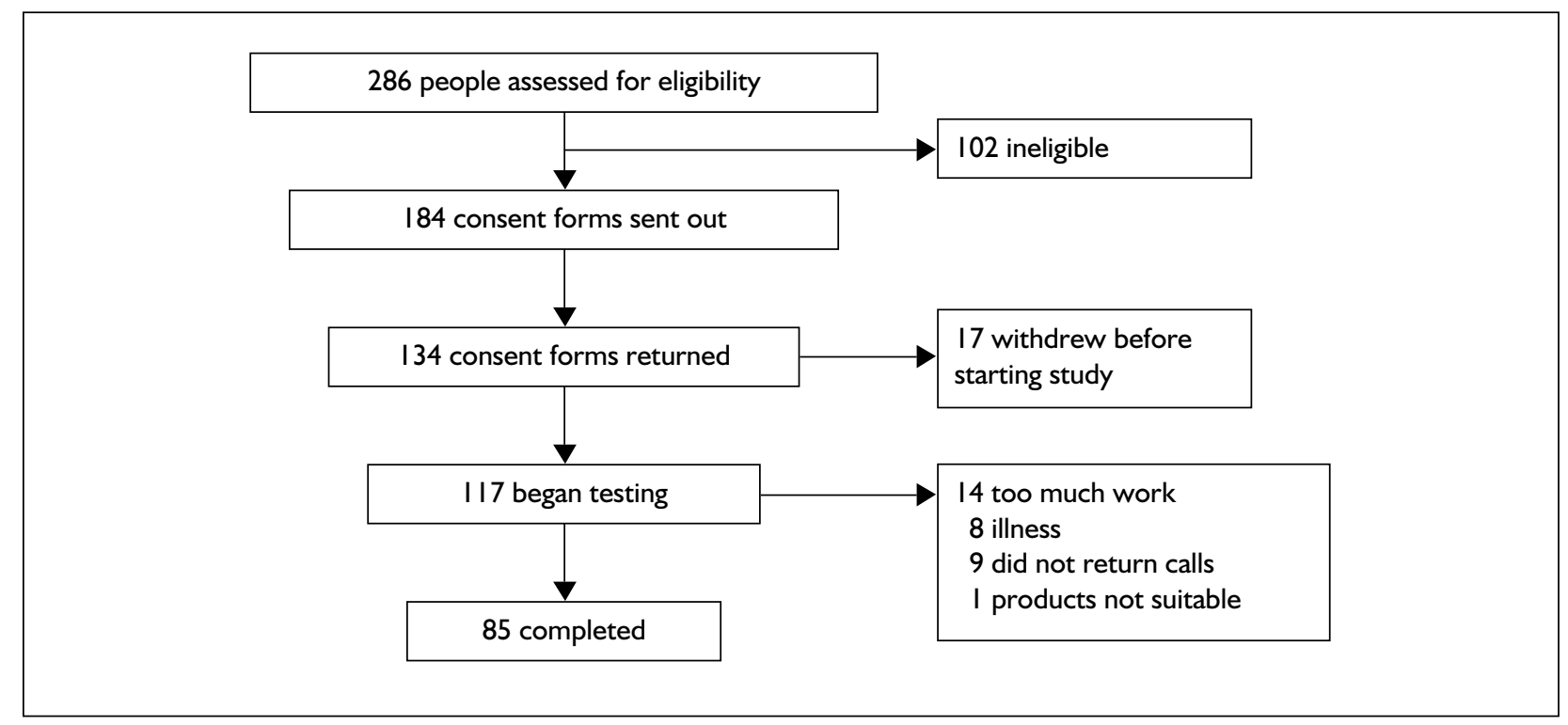

FIGURE 27 Progress of participants through the trial

TABLE 29 Participant characteristics ( $N=85$, except where missing data stated)

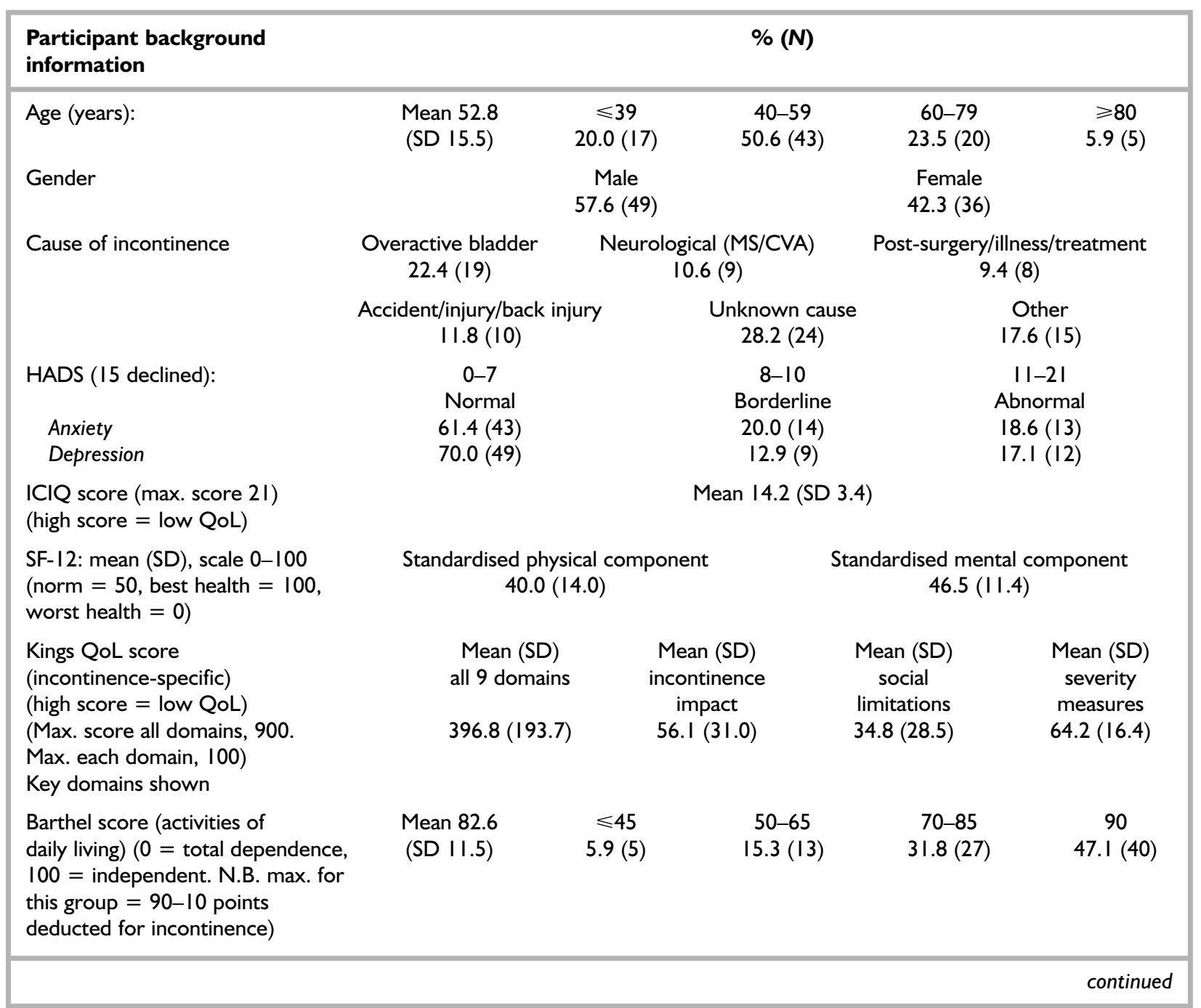


TABLE 29 Participant characteristics ( $N=85$, except where missing data stated) (cont'd)

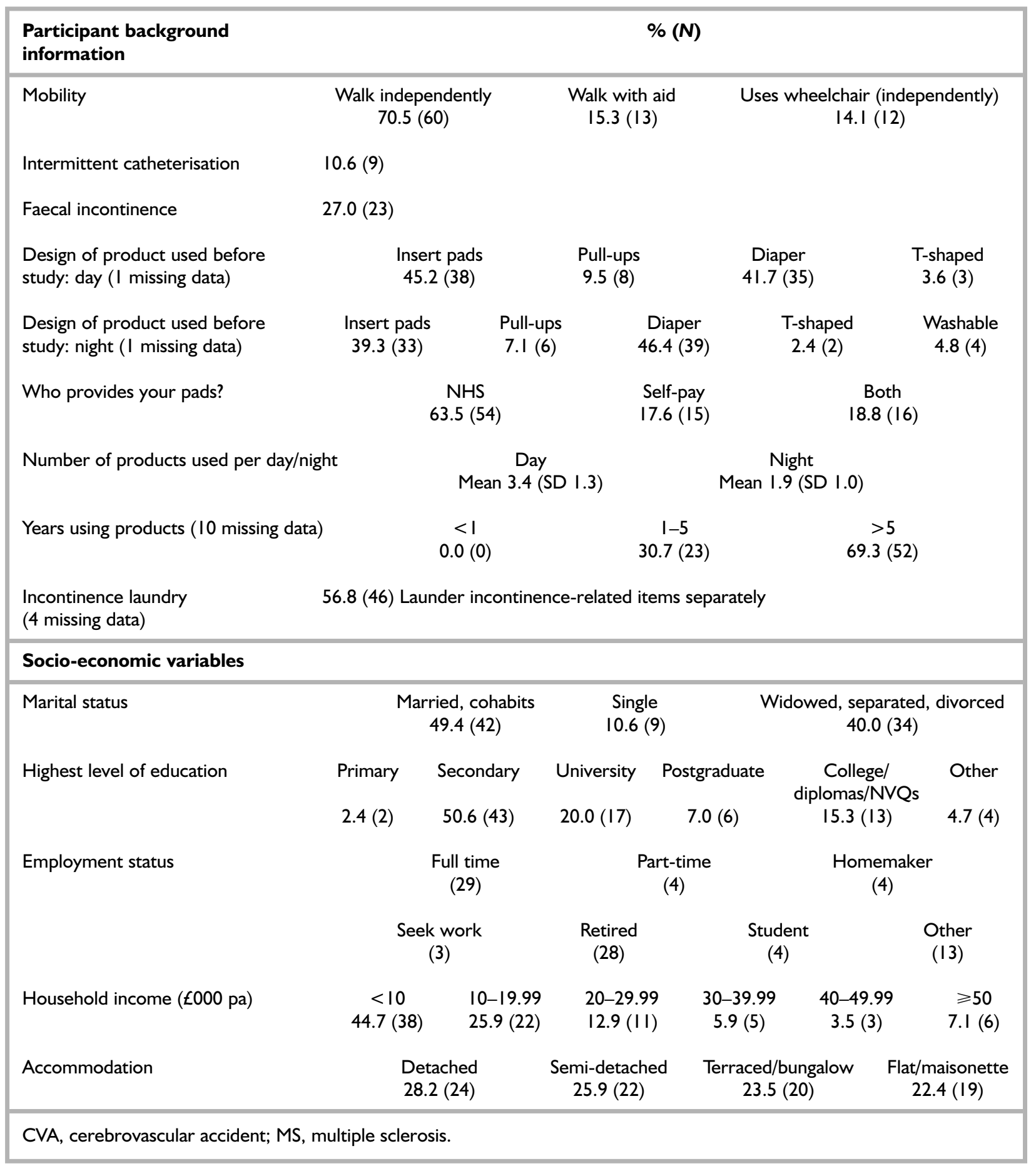

each significantly worse than the other two products in their group for leakage. Each product that came in different sizes (and therefore different absorbencies) was tested for differences in leakage performance (using pad leakage diary data), but no significant differences were found. The data from the product performance questionnaires and pad change/leakage diaries were therefore combined for the products within each design group. In order not to bias the results unfavourably for night pull-up and insert designs, the two significantly different products were excluded when combining the data from variables that may be related to leakage, namely leakage, laundry and consumption variables and variables that may be related to leakage in the product performance questionnaire (i.e. variables related to leakage: leakage, wet comfort, smell). 
To simplify analysis and to reduce the number of multiple comparisons, the four disposable designs were compared with each other (six comparisons) and the washable design (which comprised diaperstyle products) was compared only with the disposable diaper design.

As both men and women were recruited to the study, outcome measures were tested for dependence on gender. Unexpectedly, this was significant for most variables and we therefore made comparisons between designs using combined data and with data separated for men and women.

\section{Frequency and severity of leakage}

Pad leakage diary data were used to estimate the probability of the different designs leaking for different urine masses. Table 30 shows the median urine masses in the different designs.

The urine weights varied between designs with inserts containing the least urine and washables containing the most urine for day and night (gender was a significant variable and results are shown by gender in Appendix 5). Leakage performance was therefore modelled for each design, based on the binarised leakage data (none) versus (a little + a lot) and urine weights.

Figures 28 and 29 show the probability of there being no leakage for day and night at different urine masses by design (with $95 \%$ CIs).

\section{Explanation of leakage curves}

Pads do not have a simple capacity below which they are guaranteed not to leak and above which

TABLE 30 Median urine mass in each design (weighed from collected pads)

\begin{tabular}{|c|c|c|c|c|c|}
\hline & Insert & Diaper & Pull-up & T-shaped & Washable diaper \\
\hline Daytime & 234.0 & 294.5 & 257.0 & 298.0 & $4 \mid 4.0$ \\
\hline $\begin{array}{l}\text { Median urine mass }(\mathrm{g}) \\
\text { (IQ range) }\end{array}$ & $(128.5-366.5)$ & $(189.0-446.3)$ & $(147.3-388.0)$ & $(171.3-462.8)$ & $(268.5-632.0)$ \\
\hline No. of products & 1943 & 2196 & 2066 & 1426 & 819 \\
\hline Night-time & 271.5 & 363.0 & 319.0 & 345.0 & 511.5 \\
\hline $\begin{array}{l}\text { Median urine mass }(\mathrm{g}) \\
\text { (IQ range) }\end{array}$ & $(|49.0-4| 2.0)$ & $(208.0-562.0)$ & (191.0-503.5) & $(202.8-537.0)$ & $(291.3-763.5)$ \\
\hline No. of products & 1032 & 1545 & 1012 & 956 & 666 \\
\hline
\end{tabular}

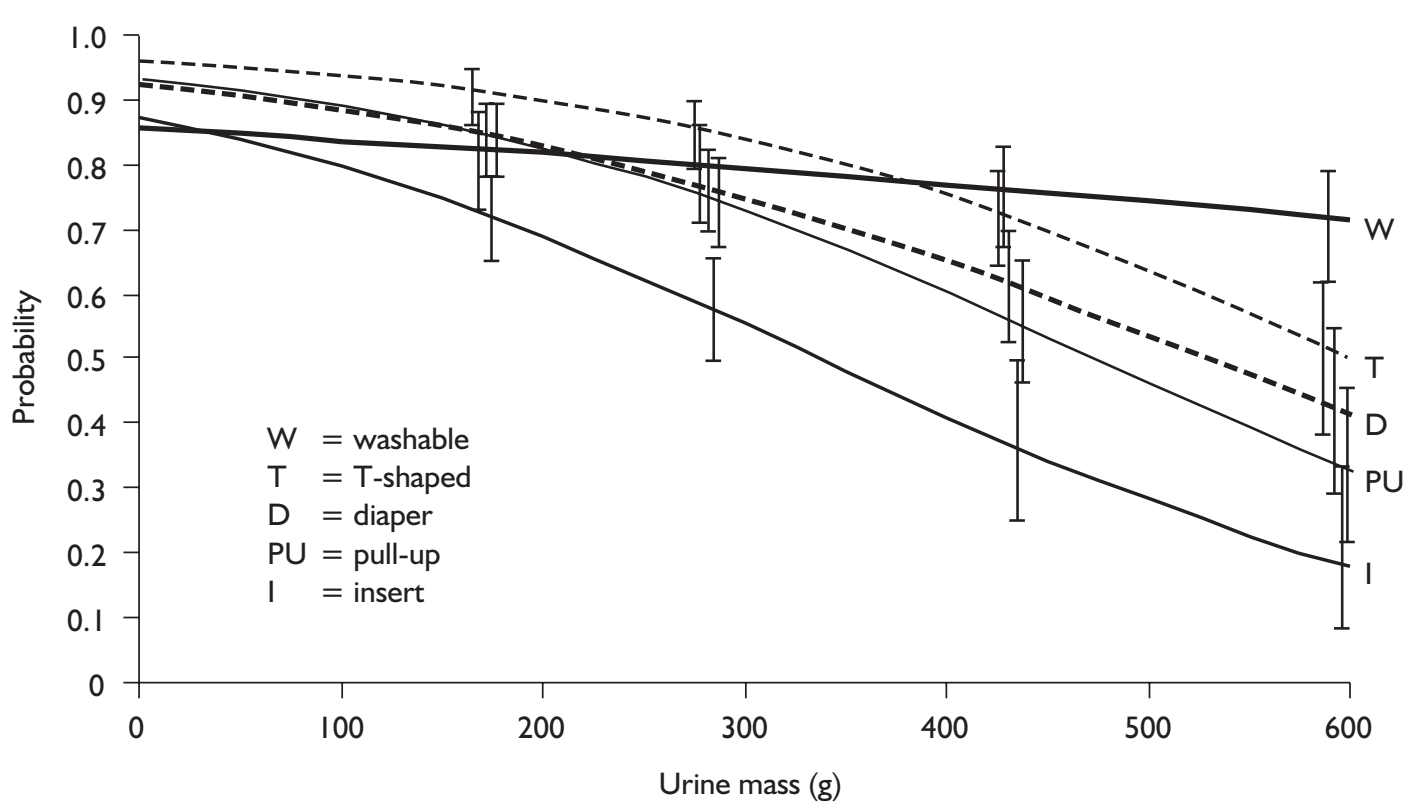

FIGURE 28 Estimated probabilities of no leakage at different urine masses with $95 \%$ Cls (day) 


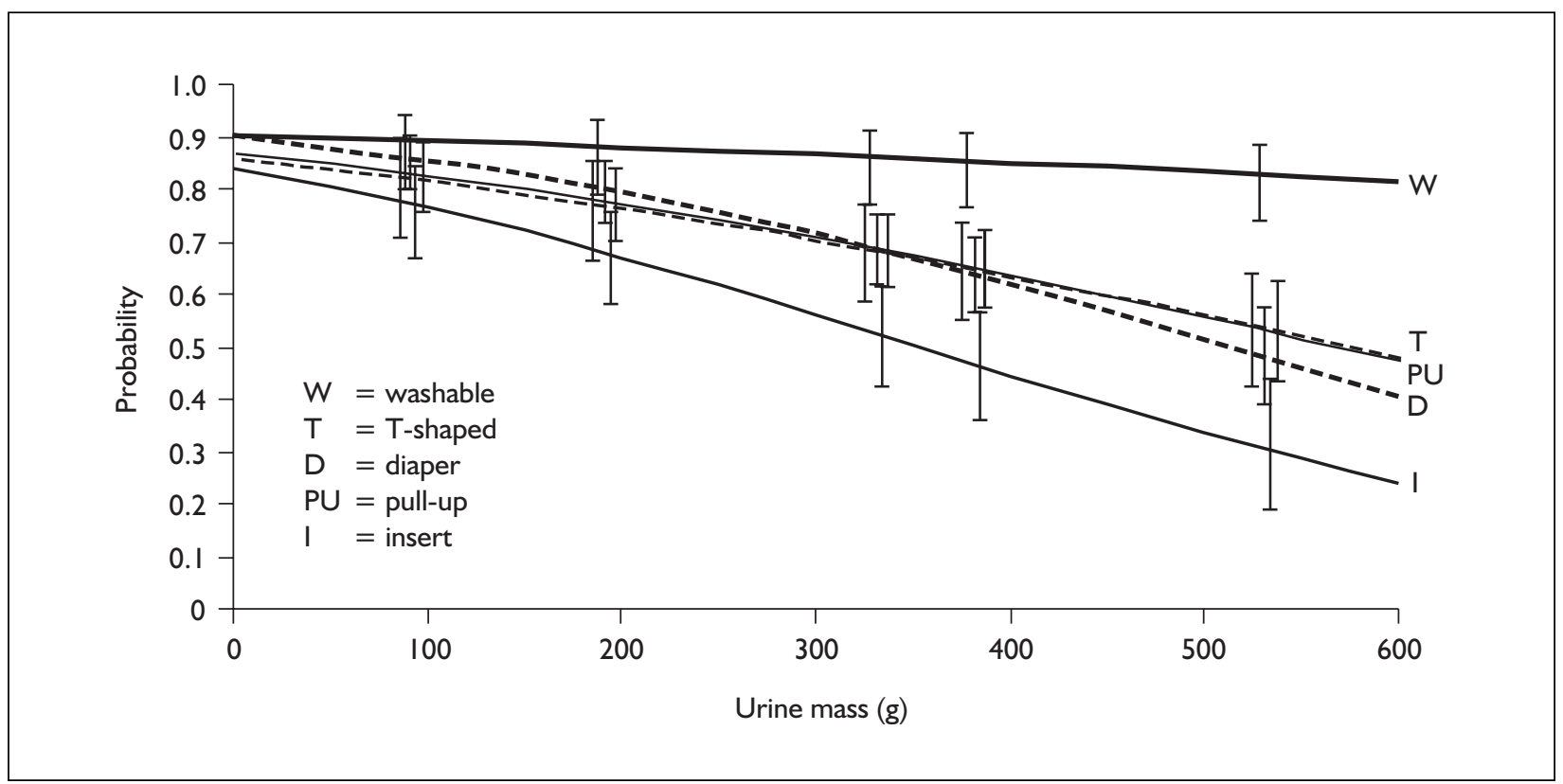

FIGURE 29 Estimated probabilities of no leakage at different urine masses with 95\% Cls (night)

they will definitely leak. Rather, as the volume (i.e. mass) of urine increases, the probability of the pad leaking increases. The leakage performance curves were constructed for each design (by combining data from the various products of the same design) and show how the probability of the design not leaking changed with increasing urine mass. In general, the more successful a design, the higher was the performance curve on the graph: a perfect design would have a probability of not leaking at all of 1 ( = certainty) for all urine masses.

Intuitively, these probability curves should have a value of 1.0 for zero urine mass - how can a pad leak if there is no urine in it? Weighing used pads provides an estimate only of the mass of urine in the pad and excludes any leakage from the pad: accordingly, the urine masses used in constructing the curves will often have been (slight)

underestimates of the actual masses voided by the wearer. For example, a pad may leak (and the urine mass in the pad be recorded as zero) if the absorbent area is out of position. One of the effects of this is that the leakage performance curves of products will meet the $y$-axis at values $<1.0$, the value which would be expected naturally. In the extreme, a pad capable of holding no urine at all would be certain to leak whatever quantity of urine its user voided and yet all used pads would contain zero urine mass.

In addition, dry masses vary (coefficient of variation of the order of $10 \%$ ) and so there will be small errors in estimated urine masses. These errors will be negligible for high urine masses but more substantial for (nearly) dry pads.

Tables 31 and 32 show the proportions of the saved and weighed pads that leaked. Gender was found to be significant for comparisons of the designs and the data for men and women are shown

TABLE 3 I Leakage performance of daytime designs (total number of products saved $=8450$ )

\begin{tabular}{lccccc} 
Leakage & \multicolumn{4}{c}{$\%(\mathbf{N}=$ number of products $)$} \\
\cline { 2 - 6 } & Insert & Diaper & Pull-up & T-shaped $^{a}$ & Washable $^{a}$ \\
\hline None & $59.9(1163)$ & $70.7(1553)$ & $72.6(1500)$ & $76.6(1092)$ & $80.1(656)$ \\
A little & $25.3(492)$ & $20.1(460)$ & $18.7(387)$ & $17.5(250)$ & $15.7(129)$ \\
A lot & $14.8(288)$ & $8.3(183)$ & $8.6(179)$ & $5.9(84)$ & $4.2(34)$
\end{tabular}

${ }^{a}$ Data combined for two products only; see the section 'Selection of absorbent products to represent design groups' (p. 48). 
TABLE 32 Leakage performance of night-time designs (total number of products saved $=52 \mathrm{II}$ )

\begin{tabular}{|c|c|c|c|c|c|}
\hline \multirow[t]{2}{*}{ Leakage } & \multicolumn{5}{|c|}{$\%(N=$ number of products $)$} \\
\hline & Insert $^{a}$ & Diaper & Pull-up ${ }^{a}$ & T-shaped $^{b}$ & Washable $^{b}$ \\
\hline None & $55.5(573)$ & $60.7(938)$ & $65.3(66 I)$ & $64.4(616)$ & $85.4(569)$ \\
\hline A little & $27.9(288)$ & $27.6(426)$ & $21.8(22 \mathrm{I})$ & $23.4(224)$ & II.4 (76) \\
\hline A lot & $16.6(17 \mid)$ & $11.7(181)$ & $12.9(130)$ & $12.1(116)$ & $3.1(2 I)$ \\
\hline
\end{tabular}

separately in Appendix 6. Leakage performance (at specified urine weights) was compared using the binarised data: (no leak) versus (a little + a lot).

The leakage results in the forest plots (Figures 31-44 with ORs and 95\% CIs) show comparisons of leakage performance between designs for the median urine weight (280 $\mathrm{g}$ for daytime and $330 \mathrm{~g}$ for night-time) for (no leak) versus (a little + a lot). Results showed that during the daytime, the inserts were worse for leakage than the other three disposable designs $(p<0.01)$ and the diaper was worse than the T-shaped diaper $(p=0.009)$. The washable/diaper comparison showed no significant difference in leakage.

At night, the insert was significantly worse than the diaper and the pull-up design $(p<0.005)$. The diaper, T-shaped and pull-up were not significantly different from each other. The washable/diaper comparison showed that the washable was better than the diaper for leakage $(p=0.0003)$.

The urine weights and leakage performance were also examined by gender. Mean urine weights showed that the men's pads contained substantially more urine than the women's pads: mean daytime urine mass $375.4 \mathrm{~g}$ for men and $215.3 \mathrm{~g}$ for women (difference $148.7 \mathrm{~g}, 95 \% \mathrm{CI}$ 79.8 to 217.7 ) mean night-time urine mass $453.4 \mathrm{~g}$ for men and $290.9 \mathrm{~g}$ for women (difference 148.5 g, 95\% CI 63.2 to 233.9). Leakage performance scores by gender (Appendix 7) showed that during the daytime men's pads leaked around $10 \%$ more than women's pads for inserts and diapers and around $20 \%$ more for pull-ups. During the night-time the difference was greater and was more than $20 \%$ for inserts, diapers and pull-ups. Differences were less for the T-shaped and much less for the washables. The leakage probability curves (Appendix 6) show that at median urine weights the leakage performance for the pull-up design was relatively better for women than for men. The insert was worst for leakage for both men and women but was particularly poor for men at night.

It should be noted that the differences in the numbers of pads saved and weighed results from the availability of only two (rather than three) T-shaped diapers, the exclusion of one of the washable products (for day and night), and the exclusion of one of the inserts and one of the pullups for night. Overall fewer pads were saved and weighed for the washable design because more participants (nearly half during the day and onethird at night) stopped testing the products prematurely (Table 33).

\section{Consumption of products}

Pad change/leakage diary data were used to calculate the mean number of products used per day and night. Table 34 shows the results for the different designs. Weighted means are used because participants recorded numbers of products used per day over variable periods (up to 7 days).

Significantly more inserts were used during both the daytime and night-time (except compared with diapers in the daytime) compared with the other

TABLE 33 Early stopping data ( $\mathrm{N}=85$ participants)

\begin{tabular}{|lccccc|}
\hline & Insert & Diaper & Pull-up & T-shaped & Washable diaper \\
\hline Mean number of participants: day & 29 & 27 & 25 & 31 & 47 \\
Mean number of participants: night & 24 & 28 & 26 & 27 & 39
\end{tabular}


TABLE 34 Consumption of day and night products ( $\mathrm{N}=85$ participants)

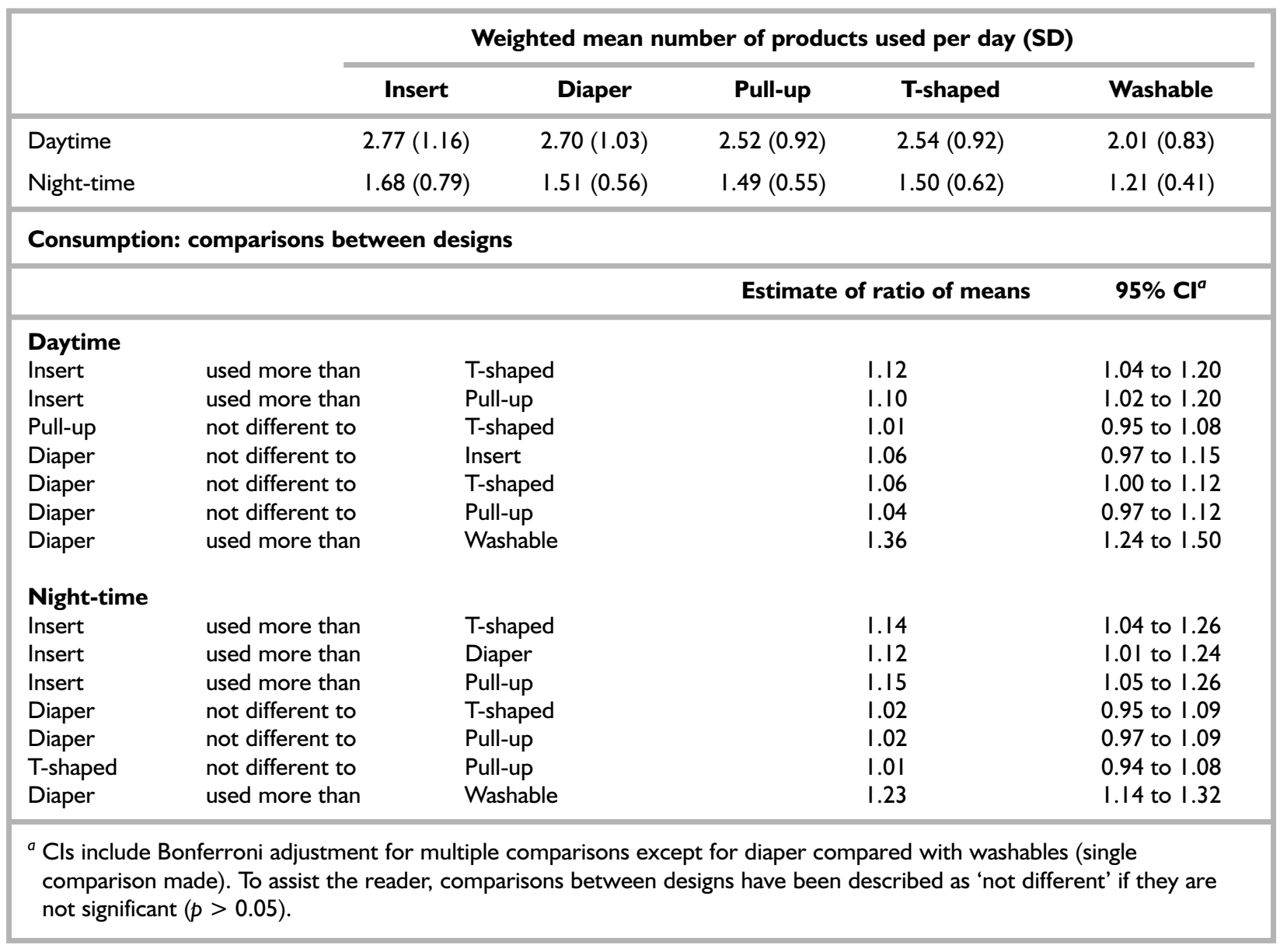

disposable designs and washables were used significantly less than diapers, both day and night. However, the differences were small (about onequarter of a pad for disposables per day and less at night). Overall, men used more products than women for all designs during the daytime and similar numbers during the night. The substantially higher urine masses measured in the men's pads could not therefore be explained by less consumption (i.e. less changing of pads) (see Appendix 8).

\section{Laundry resulting from leakage}

Pad change/leakage diary data were used to calculate the mean number of items (small and large) sent for laundering as a result of leakage from the product [none or number of items (if any)]. Table 35 shows the proportions for each design. The washable product is included as an item of laundry.

Laundry results showed that inserts produced nearly twice as many laundry items as the other three disposable designs for both day and night. There were no significant differences between the other disposable designs. When compared with the disposable diaper (and including the washable in the number of items), the washable design produced around twice as many laundry items.

\section{Skin health}

Participants were asked to complete a skin health diary every week to record the location, severity and duration of any skin health problems. The site with the maximum severity (i.e. the worst skin problem) was used to make comparisons between designs. Tables 36 and 37 show the proportions of participants with and without skin health problems for the day and night, respectively.

When worn during the daytime there was a significant difference between the inserts and the T-shaped design, (no skin problem) versus (any skin problem), with more skin problems recorded with the T-shaped product. These tended to be related to the waist-band (see 'Skin health', p. 77).

When worn during the night-time, there were no significant differences between any of the designs. 
TABLE 35 Laundry day and night

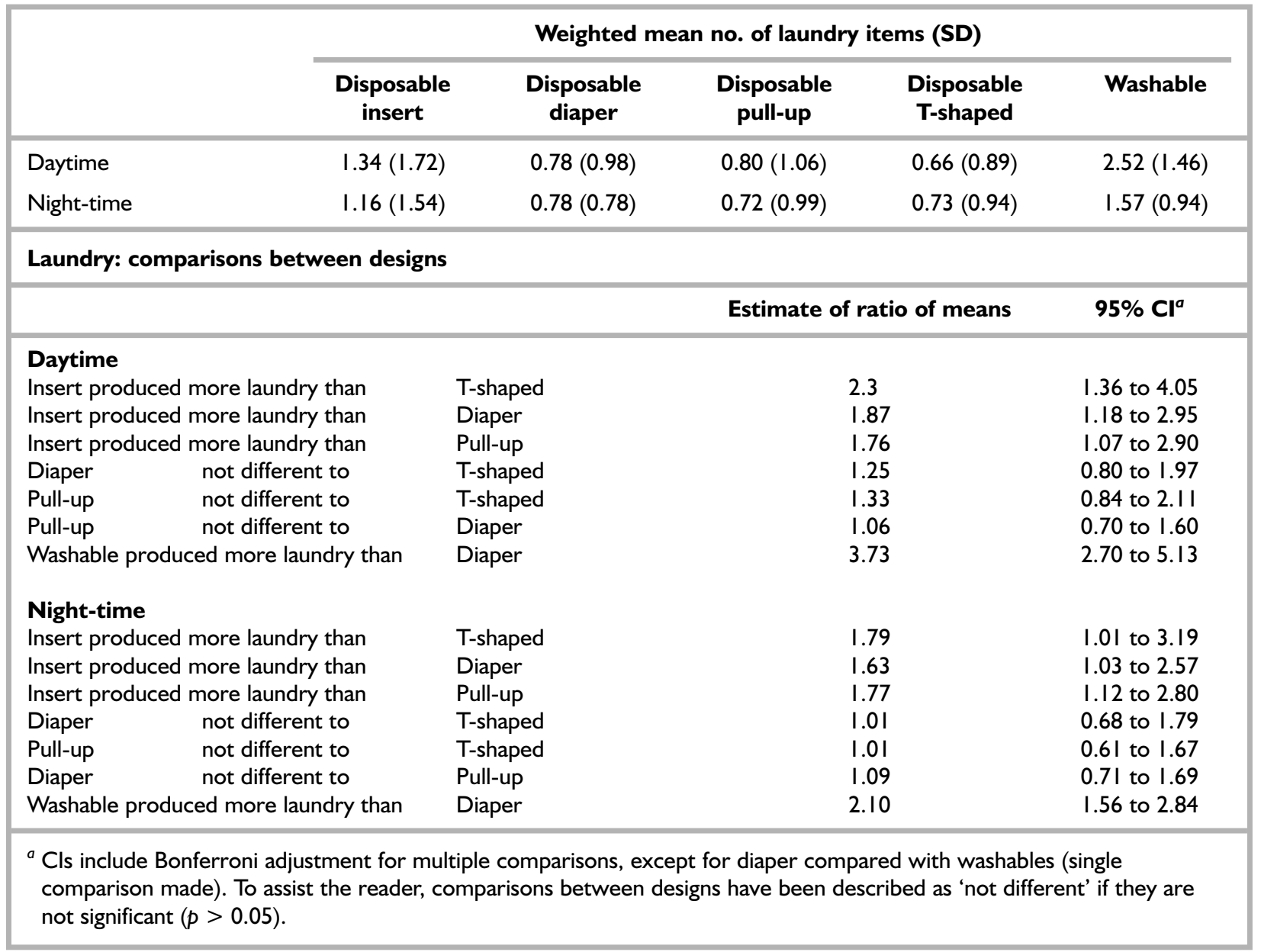

TABLE 36 Skin health problems: day ${ }^{\mathrm{a}}$

\begin{tabular}{|c|c|c|c|c|c|}
\hline \multirow[t]{2}{*}{ Skin problem } & \multicolumn{5}{|c|}{$\%(N)$} \\
\hline & $\begin{array}{l}\text { Disposable } \\
\text { insert } \\
(N=185)\end{array}$ & $\begin{array}{l}\text { Disposable } \\
\text { diaper } \\
(N=186)\end{array}$ & $\begin{array}{l}\text { Disposable } \\
\text { pull-up } \\
(N=189)\end{array}$ & $\begin{array}{l}\text { Disposable } \\
\text { T-shaped } \\
(N=124)\end{array}$ & $\begin{array}{l}\text { Washable }^{b} \\
(N=124)\end{array}$ \\
\hline None & $81.6(15 I)$ & 74.7 (139) & $75.7(143)$ & $66.9(83)$ & $71.8(89)$ \\
\hline A little (mild) & $10.8(20)$ & $14.5(27)$ & $13.2(25)$ & $13.7(17)$ & $13.7(17)$ \\
\hline A lot (moderate/severe) & $7.6(14)$ & $10.7(20)$ & II.I (2I) & $19.4(24)$ & $14.5(18)$ \\
\hline \multicolumn{6}{|c|}{$\begin{array}{l}\text { N, number of weekly observations. } \\
\text { a Comparisons between designs and } 95 \% \text { Cls are shown in forest plots in Figures } 3 I-44 \text {. } \\
\text { b Two products only; see the section 'Selection of absorbent products to represent design groups' (p. 48). }\end{array}$} \\
\hline
\end{tabular}

\section{Product performance questionnaires}

Participants completed a weekly product performance questionnaire to score the performance of each product. Scores for the highest priority variables (leakage, discreetness, smell, comfort when dry and wet, fit and staying in place; see Chapter 6) were analysed and those for individual products within designs are shown in Appendix 9. The scores for each of the three (or two) products within a design were combined to give an average response result for each variable.

Results presented in Tables 38 and 39 and in the forest plots (in Figures 31-44) are for men and women combined. Most variables analysed from the product performance questionnaire were 
TABLE 37 Skin health problems: night ${ }^{\mathrm{a}}$

\begin{tabular}{|c|c|c|c|c|c|}
\hline \multirow[t]{2}{*}{ Skin problem } & \multicolumn{5}{|c|}{$\%(N)$} \\
\hline & $\begin{array}{c}\text { Disposable } \\
\text { insert } \\
(N=188)\end{array}$ & $\begin{array}{c}\text { Disposable } \\
\text { diaper } \\
(N=186)\end{array}$ & $\begin{array}{c}\text { Disposable } \\
\text { pull-up } \\
(N=186)\end{array}$ & $\begin{array}{c}\text { Disposable }^{b} \\
\text { T-shaped } \\
(N=124)\end{array}$ & $\begin{array}{l}\text { Washable }^{b} \\
(N=123)\end{array}$ \\
\hline None & $75.5(142)$ & $71.5(133)$ & $80.0(145)$ & $74.2(92)$ & $75.6(93)$ \\
\hline A little (mild) & $11.2(21)$ & $12.4(23)$ & $11.8(22)$ & $12.9(16)$ & $18.7(23)$ \\
\hline A lot (moderate/severe) & $13.3(25)$ & I6.I (30) & $10.2(19)$ & $12.9(16)$ & $5.7(7)$ \\
\hline
\end{tabular}

significant for gender and results for men and women are presented separately in Appendix 10. Combining results for men and women has reduced the differences for some variables.

The product performance questionnaire results showed that:

- There were no significant differences between the diaper and T-shaped diaper for both day and night (including ease of putting on) [significance is defined as $p \leqslant 0.05$; forest plots (Figures 31-34) show ORs and 95\% CIs for each variable].

- The T-shaped was significantly better than the insert for leakage and smell (daytime), but otherwise was not better than other disposable designs on other variables.

- The diaper was significantly better than the insert for leakage, staying in place and smell (daytime), but for no other designs or variables.

- The insert was significantly better for discreetness compared with the T-shaped diaper and diaper, but for no other designs or variables.

- The pull-up was significantly better for staying in place than the T-shaped (day), insert (day and night); better for fit compared with the T-shaped (day and night), the diaper (day and night) and the insert (day and night); better for smell compared with the diaper and insert (night); better for discreetness compared with the T-shaped and the diaper; better for comfort when dry compared with the T-shaped (day), the diaper (night) and the insert (day); better than the insert for comfort when wet (day); and easier to put on compared with the diaper and T-shaped diaper (night).

- The diaper was significantly better than the washable for all variables during the day, except for comfort when dry (not quite significant) and significantly better only for ease of putting on and comfort when dry. The washable was significantly better for leakage.

Examination of the results by gender (Appendix 10) shows that the main differences [20\% or more for (very good, good, okay) versus (otherwise)] were in the higher ratings of leakage performance given to the pull-ups by women compared with men; the better ratings given by men for diapers for discreetness and fit; the worse ratings given by men for inserts for staying in place; the worse ratings given by women for the T-shaped for discreetness and fit; and the better ratings given by men for washables for most variables, particularly at night.

\section{Faecal incontinence}

The participant background information showed that $27 \%$ (23) of participants reported that they had both urinary and faecal incontinence before starting the study. During the final interview, participants were asked to rate the acceptability of the different designs for ability to hold faeces without leakage; between 15 and 17 participants responded to this question for the different designs (see below) and the results are shown in Table 40.

The data obtained from the final interview indicated that fewer participants were faecally incontinent than originally stated in the participant background information. This may be because the participants did not experience any faecal leakage during the period of the study, or did not experience any that they felt was serious enough to have an impact on the product or design being tested.

The small number of participants reporting on the performance of the designs for faecal incontinence means that no firm conclusions could be drawn. 
TABLE 38 Product performance questionnaire: mean results for each design (\%): day

\begin{tabular}{|c|c|c|c|c|c|c|}
\hline & & Insert & Diaper & Pull-up & $\begin{array}{l}\text { T-shaped } \\
\text { diaper }\end{array}$ & Washable \\
\hline \multirow[t]{5}{*}{ Leakage (urine) } & Very good & 9.0 & 20.5 & 23.1 & 28.2 & 25.2 \\
\hline & Good & 27.4 & 26.7 & 35.9 & 34.8 & 33.9 \\
\hline & OK & 27.9 & 30.8 & 21.5 & 23.0 & 23.5 \\
\hline & Poor & 23.7 & 15.9 & 15.4 & 11.9 & 10.4 \\
\hline & Very poor & 12.1 & 6.2 & 4.1 & 2.2 & 7.0 \\
\hline \multirow[t]{5}{*}{ Leakage (faeces) } & Very good & 3.0 & 26.2 & 24.3 & 19.4 & 34.8 \\
\hline & Good & 27.3 & 33.3 & 35.1 & 45.2 & 21.7 \\
\hline & OK & 57.6 & 28.6 & 24.3 & 22.6 & 13.0 \\
\hline & Poor & 9.1 & 4.8 & 16.2 & 9.7 & 8.7 \\
\hline & Very poor & 3.0 & 7.1 & 0.0 & 3.2 & 21.7 \\
\hline \multirow[t]{5}{*}{ Stay in place } & Very good & 7.7 & 17.0 & 44.3 & 27.9 & 12.8 \\
\hline & Good & 25.8 & 35.5 & 32.8 & 25.0 & 29.1 \\
\hline & OK & 37.6 & 35.5 & 16.4 & 27.9 & 31.6 \\
\hline & Poor & 18.6 & 10.0 & 7.0 & 15.4 & 15.4 \\
\hline & Very poor & 10.3 & 2.5 & 1.0 & 3.7 & II.I \\
\hline \multirow[t]{5}{*}{ Fit } & Very good & 8.2 & 17.5 & 31.8 & 20.7 & 9.2 \\
\hline & Good & 26.7 & 26.5 & 36.8 & 31.1 & 30.0 \\
\hline & OK & 39.5 & 31.5 & 22.4 & 23.7 & 21.7 \\
\hline & Poor & 20.5 & 20.0 & 9.0 & 18.5 & 16.7 \\
\hline & Very poor & 5.1 & 4.5 & 0.0 & 5.9 & 22.5 \\
\hline \multirow[t]{5}{*}{ Smell } & Very good & 9.3 & 10.7 & 16.2 & 16.4 & 6.1 \\
\hline & Good & 26.9 & 31.0 & 32.3 & 32.1 & 27.2 \\
\hline & OK & 42.5 & 50.8 & 39.0 & 44.8 & 37.7 \\
\hline & Poor & I7.I & 5.6 & 11.6 & 6.0 & 16.7 \\
\hline & Very poor & 4.2 & 2.0 & 1.0 & 1.0 & 12.3 \\
\hline \multirow[t]{5}{*}{ Discreet } & Very good & 13.3 & 15.0 & 33.5 & 22.2 & 1.7 \\
\hline & Good & 41.0 & 32.0 & 41.5 & 31.9 & 5.1 \\
\hline & OK & 40.0 & 33.0 & 22.0 & 28.9 & 17.8 \\
\hline & Poor & 5.1 & 16.5 & 3.0 & II.I & 32.2 \\
\hline & Very poor & 1.0 & 3.5 & 0.0 & 5.9 & 43.2 \\
\hline \multirow[t]{5}{*}{ Dry comfort } & Very good & 15.5 & 19.8 & 44.0 & 25.2 & 22.7 \\
\hline & Good & 38.1 & 40.1 & 39.0 & 37.8 & 31.1 \\
\hline & OK & 33.0 & 33.5 & 16.5 & 25.2 & 34.5 \\
\hline & Poor & 11.9 & 5.6 & 1.0 & 8.2 & 5.9 \\
\hline & Very poor & 1.6 & 1.0 & 0.0 & 3.7 & 5.9 \\
\hline \multirow[t]{5}{*}{ Wet comfort } & Very good & 8.3 & 7.1 & 14.9 & 14.9 & 7.0 \\
\hline & Good & 25.9 & 28.1 & 36.4 & 35.8 & 13.2 \\
\hline & OK & 37.3 & 45.9 & 39.0 & 35.1 & 45.6 \\
\hline & Poor & 20.2 & 14.3 & 9.2 & 12.7 & 17.5 \\
\hline & Very poor & 8.3 & 4.6 & 1.0 & 1.5 & 16.7 \\
\hline \multirow[t]{5}{*}{ Ease on (standing) } & Very good & 14.4 & 10.1 & 42.8 & 27.9 & 5.8 \\
\hline & Good & 36.4 & 33.2 & 37.8 & 25.7 & 12.4 \\
\hline & OK & 39.0 & 38.7 & 10.5 & 27.2 & 35.5 \\
\hline & Poor & 10.3 & 12.6 & 8.0 & 16.2 & 19.8 \\
\hline & Very poor & 0.0 & 5.5 & 1.0 & 2.9 & 26.5 \\
\hline
\end{tabular}


TABLE 39 Product performance questionnaire: mean results for each design (\%): night ${ }^{\mathrm{a}, \mathrm{b}}$

\begin{tabular}{|c|c|c|c|c|c|c|}
\hline & & Insert & Diaper & Pull-up & $\begin{array}{l}\text { T-shaped } \\
\text { diaper }\end{array}$ & Washable \\
\hline Leakage $^{c}$ (urine) & $\begin{array}{l}\text { Very good } \\
\text { Good } \\
\text { OK } \\
\text { Poor } \\
\text { Very poor }\end{array}$ & $\begin{array}{l}12.1 \\
29.0 \\
25.0 \\
16.9 \\
16.9\end{array}$ & $\begin{array}{r}9.8 \\
34.5 \\
33.0 \\
17.5 \\
5.2\end{array}$ & $\begin{array}{l}29.6 \\
27.4 \\
20.7 \\
11.9 \\
10.4\end{array}$ & $\begin{array}{l}19.4 \\
24.0 \\
27.1 \\
19.4 \\
10.1\end{array}$ & $\begin{array}{r}36.7 \\
30.3 \\
21.1 \\
5.5 \\
6.4\end{array}$ \\
\hline Leakage $^{c}$ (faeces) & $\begin{array}{l}\text { Very good } \\
\text { Good } \\
\text { OK } \\
\text { Poor } \\
\text { Very poor }\end{array}$ & $\begin{array}{r}9.5 \\
19.1 \\
42.9 \\
9.5 \\
19.1\end{array}$ & $\begin{array}{r}15.8 \\
52.6 \\
21.1 \\
10.5 \\
0.0\end{array}$ & $\begin{array}{r}30.8 \\
34.6 \\
23.1 \\
7.7 \\
3.9\end{array}$ & $\begin{array}{r}13.0 \\
39.1 \\
30.4 \\
8.7 \\
8.7\end{array}$ & $\begin{array}{r}22.2 \\
44.4 \\
27.8 \\
5.6 \\
0.0\end{array}$ \\
\hline Stay in place & $\begin{array}{l}\text { Very good } \\
\text { Good } \\
\text { OK } \\
\text { Poor } \\
\text { Very poor }\end{array}$ & $\begin{array}{r}8.1 \\
29.3 \\
29.3 \\
23.7 \\
9.6\end{array}$ & $\begin{array}{r}12.3 \\
43.1 \\
26.7 \\
11.8 \\
6.1\end{array}$ & $\begin{array}{r}34.0 \\
40.0 \\
17.0 \\
7.5 \\
1.5\end{array}$ & $\begin{array}{r}20.0 \\
23.9 \\
36.9 \\
16.2 \\
3.1\end{array}$ & $\begin{array}{l}16.1 \\
35.7 \\
25.9 \\
10.7 \\
11.6\end{array}$ \\
\hline Fit & $\begin{array}{l}\text { Very good } \\
\text { Good } \\
\text { OK } \\
\text { Poor } \\
\text { Very poor }\end{array}$ & $\begin{array}{r}11.1 \\
33.8 \\
30.8 \\
19.7 \\
4.6\end{array}$ & $\begin{array}{r}11.3 \\
37.6 \\
27.8 \\
17.5 \\
5.7\end{array}$ & $\begin{array}{r}27.0 \\
45.0 \\
21.5 \\
5.5 \\
1.0\end{array}$ & $\begin{array}{r}22.3 \\
19.2 \\
40.8 \\
14.6 \\
3.1\end{array}$ & $\begin{array}{l}13.3 \\
26.6 \\
29.2 \\
13.3 \\
17.7\end{array}$ \\
\hline Smell ${ }^{c}$ & $\begin{array}{l}\text { Very good } \\
\text { Good } \\
\text { OK } \\
\text { Poor } \\
\text { Very poor }\end{array}$ & $\begin{array}{r}7.9 \\
33.3 \\
42.1 \\
15.1 \\
1.6\end{array}$ & $\begin{array}{r}8.3 \\
30.1 \\
40.4 \\
17.6 \\
3.6\end{array}$ & $\begin{array}{r}19.6 \\
36.1 \\
36.8 \\
7.5 \\
0.0\end{array}$ & $\begin{array}{r}12.4 \\
25.6 \\
49.6 \\
11.6 \\
1.0\end{array}$ & $\begin{array}{r}8.3 \\
25.7 \\
36.7 \\
19.3 \\
10.1\end{array}$ \\
\hline Dry comfort & $\begin{array}{l}\text { Very good } \\
\text { Good } \\
\text { OK } \\
\text { Poor } \\
\text { Very poor }\end{array}$ & \begin{tabular}{r|}
17.7 \\
39.9 \\
36.4 \\
4.6 \\
1.5
\end{tabular} & $\begin{array}{r}14.8 \\
42.4 \\
34.7 \\
5.1 \\
3.1\end{array}$ & $\begin{array}{r}42.8 \\
39.8 \\
16.4 \\
1.0 \\
0.0\end{array}$ & $\begin{array}{r}22.3 \\
35.4 \\
35.4 \\
5.4 \\
1.5\end{array}$ & $\begin{array}{r}26.8 \\
36.6 \\
20.5 \\
6.3 \\
9.8\end{array}$ \\
\hline Wet comfort ${ }^{c}$ & $\begin{array}{l}\text { Very good } \\
\text { Good } \\
\text { OK } \\
\text { Poor } \\
\text { Very poor }\end{array}$ & $\begin{array}{r}6.4 \\
35.2 \\
42.4 \\
9.6 \\
6.4\end{array}$ & $\begin{array}{r}6.6 \\
29.6 \\
40.3 \\
16.3 \\
7.1\end{array}$ & \begin{tabular}{r|}
17.8 \\
40.7 \\
31.1 \\
8.9 \\
1.5
\end{tabular} & \begin{tabular}{r|}
10.7 \\
32.3 \\
40.0 \\
14.6 \\
2.3
\end{tabular} & $\begin{array}{l}12.7 \\
16.4 \\
41.8 \\
16.4 \\
12.7\end{array}$ \\
\hline Ease on & $\begin{array}{l}\text { Very good } \\
\text { Good } \\
\text { OK } \\
\text { Poor } \\
\text { Very poor }\end{array}$ & $\begin{array}{r}14.6 \\
39.4 \\
35.9 \\
11.6 \\
1.0\end{array}$ & $\begin{array}{r}8.7 \\
34.9 \\
39.5 \\
12.3 \\
4.6\end{array}$ & $\begin{array}{r}50.3 \\
36.3 \\
11.0 \\
2.0 \\
1.0\end{array}$ & $\begin{array}{r}26.7 \\
26.7 \\
31.3 \\
13.0 \\
2.3\end{array}$ & $\begin{array}{r}6.2 \\
19.5 \\
35.4 \\
16.8 \\
22.1\end{array}$ \\
\hline
\end{tabular}

\section{Final interview: overall opinion and preferences}

Participants were asked to rank the designs in order of their preference. Participants then marked their opinion of the design on a VAS and stated their overall acceptability of the different designs (highly acceptable, acceptable, unacceptable, totally unacceptable). Participants were also asked whether they would recommend a design for use by others. This process was repeated for nighttime products. Table 41 shows paired comparisons of preferences between designs and Table 42 shows the acceptability ratings of the designs, both for day and night use. 
TABLE 40 Acceptability of different designs for ability to hold faeces without leakage

\begin{tabular}{|c|c|}
\hline Design & $\begin{array}{c}\% \text { unacceptable } \\
\text { (N) }\end{array}$ \\
\hline \multicolumn{2}{|l|}{ Day } \\
\hline T-shaped $(N=16)$ & $25.0 \quad(4)$ \\
\hline Washable $(N=16)$ & 25.0 (4) \\
\hline $\operatorname{Diaper}(N=16)$ & $18.75(3)$ \\
\hline Insert $(N=17)$ & $35.3 \quad(6)$ \\
\hline Pull-up $(N=16)$ & $12.5 \quad(2)$ \\
\hline \multicolumn{2}{|l|}{ Night } \\
\hline T-shaped $(N=15)$ & $26.7 \quad(4)$ \\
\hline Washable $(N=15)$ & 20.0 \\
\hline $\operatorname{Diaper}(N=15)$ & $13.3 \quad(2)$ \\
\hline Insert $(N=15)$ & $26.7 \quad(4)$ \\
\hline Pull-up $(N=15)$ & 26.7 (4) \\
\hline
\end{tabular}

For the daytime, in paired comparisons of preferences the pull-up was significantly preferred to the insert only. For the diaper/washable comparison, the diaper was significantly preferred to the washable.

During the night-time, in paired comparisons of preferences the insert was significantly worse than the pull-up and the T-shaped, and the T-shaped was significantly worse than the diaper. The preferences by gender can be seen in Appendix 12 .

Scores for acceptability were binarised both as (highly acceptable) versus (other scores) and (highly acceptable/acceptable) versus (other scores). For the daytime, the pull-up was significantly better than the insert on both measures and better than the T-shaped for (highly acceptable + acceptable) versus (other). For the diaper/washable comparison, the washable was significantly worse for both measures.

TABLE 4I Preference for different designs

\begin{tabular}{|c|c|c|c|c|}
\hline \multicolumn{5}{|c|}{ Number preferring design } \\
\hline \multicolumn{3}{|c|}{ Day $(N=85)$} & \multicolumn{2}{|l|}{ Night $(N=85)$} \\
\hline \multicolumn{3}{|c|}{ Diaper 52 vs Insert 33} & \multicolumn{2}{|l|}{ Diaper 53 vs Insert 32} \\
\hline \multicolumn{3}{|c|}{ Pull-up 69 vs Insert 16} & \multicolumn{2}{|l|}{ Pull-up 66 vs Insert 19} \\
\hline \multicolumn{3}{|c|}{ Pull-up 45 vs Diaper 40} & \multicolumn{2}{|l|}{ Pull-up 40 vs Diaper 45} \\
\hline \multicolumn{3}{|c|}{ Pull-up 50 vs T-shaped 35} & \multicolumn{2}{|l|}{ Pull-up 50 vs T-shaped 35} \\
\hline \multicolumn{3}{|c|}{ T-shaped 33 vs Diaper 52} & \multicolumn{2}{|l|}{ T-shaped 27 vs Diaper 58} \\
\hline \multicolumn{3}{|c|}{ T-shaped 53 vs Insert 32} & \multicolumn{2}{|l|}{ T-shaped 56 vs Insert 29} \\
\hline \multicolumn{3}{|c|}{ Diaper 74 vs Washable I I } & \multicolumn{2}{|l|}{ Diaper 49 vs Washable $36^{a}$} \\
\hline \multicolumn{5}{|c|}{ Preferences: comparisons between designs } \\
\hline & & & Estimated odds on & $95 \% \mathrm{Cl}^{b}$ \\
\hline \multicolumn{5}{|l|}{ Daytime } \\
\hline Pull-up & preferred to & Insert & 4.31 & 2.07 to 8.97 \\
\hline T-shaped & not different to & Diaper & 0.63 & 0.35 to 1.14 \\
\hline T-shaped & not different to & Pull-up & 0.70 & 0.39 to 1.25 \\
\hline T-shaped & not different to & Insert & 1.66 & 0.92 to 1.14 \\
\hline Diaper & not different to & Insert & 1.58 & 0.88 to 2.83 \\
\hline Diaper & not different to & Pull-up & 0.89 & 0.50 to 1.58 \\
\hline Diaper & preferred to & Washable & 6.73 & 3.57 to 12.67 \\
\hline \multicolumn{5}{|c|}{ Night-time } \\
\hline Pull-up & preferred to & Insert & 3.47 & 1.75 to 6.91 \\
\hline T-shaped & preferred to & Insert & 1.93 & 1.06 to 3.53 \\
\hline Diaper & preferred to & T-shaped & 2.15 & 1.16 to 3.97 \\
\hline T-shaped & not different to & Pull-up & 0.70 & 0.39 to 1.25 \\
\hline Diaper & not different to & Inserts & 1.66 & 0.92 to 2.99 \\
\hline Diaper & not different to & Pull-up & 1.13 & 0.63 to 1.99 \\
\hline Diaper & not different to & Washable & 0.73 & 0.48 to 1.13 \\
\hline \multicolumn{5}{|c|}{$\begin{array}{l}\text { a To reduce the number of comparisons, the washable design is only compared with the diaper design of the disposables. } \\
{ }^{b} \text { Cls include Bonferroni adjustment for multiple comparisons except for diaper compared with Washables (single } \\
\text { comparison made). To assist the reader, comparisons between designs have been described as 'not different' if they are } \\
\text { not significant }(p>0.05) \text {. }\end{array}$} \\
\hline
\end{tabular}


TABLE 42 Acceptability of designs for day and night $(\mathrm{N}=85)$

\begin{tabular}{|c|c|c|c|c|c|c|c|c|c|c|}
\hline \multirow[t]{3}{*}{ Acceptability } & \multicolumn{10}{|c|}{$\%(N)$} \\
\hline & \multicolumn{2}{|c|}{ Insert } & \multicolumn{2}{|c|}{ Diaper } & \multicolumn{2}{|c|}{ Pull-up } & \multicolumn{2}{|c|}{ T-shaped } & \multicolumn{2}{|c|}{ Washable } \\
\hline & Day & Night & Day & Night & Day & Night & Day & Night & Day & Night \\
\hline Highly acceptable & $\begin{array}{l}20.0 \\
(17)\end{array}$ & $\begin{array}{l}11.8 \\
(10)\end{array}$ & $\begin{array}{l}35.3 \\
(30)\end{array}$ & $\begin{array}{l}32.9 \\
(28)\end{array}$ & $\begin{array}{l}41.2 \\
(35)\end{array}$ & $\begin{array}{l}31.8 \\
(27)\end{array}$ & $\begin{array}{l}24.7 \\
(2 I)\end{array}$ & $\begin{array}{l}15.3 \\
(13)\end{array}$ & $\begin{array}{l}4.7 \\
(4)\end{array}$ & $\begin{array}{l}42.4 \\
(36)\end{array}$ \\
\hline Acceptable & $\begin{array}{l}36.5 \\
(31)\end{array}$ & $\begin{array}{l}29.4 \\
(25)\end{array}$ & $\begin{array}{l}37.7 \\
(32)\end{array}$ & $\begin{array}{l}43.5 \\
(37)\end{array}$ & $\begin{array}{l}44.7 \\
(38)\end{array}$ & $\begin{array}{l}35.3 \\
(30)\end{array}$ & $\begin{array}{l}41.2 \\
(35)\end{array}$ & $\begin{array}{l}42.4 \\
(36)\end{array}$ & $\begin{array}{l}29.4 \\
(25)\end{array}$ & $\begin{array}{l}15.3 \\
(13)\end{array}$ \\
\hline $\begin{array}{l}\text { Unacceptable/ } \\
\text { totally unacceptable }\end{array}$ & $\begin{array}{l}43.5 \\
(37)\end{array}$ & $\begin{array}{l}58.8 \\
(50)\end{array}$ & $\begin{array}{l}27.0 \\
(23)\end{array}$ & $\begin{array}{l}23.6 \\
(20)\end{array}$ & $\begin{array}{l}14.0 \\
(12)\end{array}$ & $\begin{array}{l}32.9 \\
(28)\end{array}$ & $\begin{array}{l}34.0 \\
(29)\end{array}$ & $\begin{array}{l}42.3 \\
(36)\end{array}$ & $\begin{array}{l}65.9 \\
(56)\end{array}$ & $\begin{array}{l}42.3 \\
(36)\end{array}$ \\
\hline
\end{tabular}

For the night-time, the pull-up and the diaper were significantly better than the insert for both measures and the diaper was significantly better than the T-shaped on both measures. The washable was significantly worse than the diaper for (highly acceptable + acceptable) versus (other scores), but scores were very divided for the washable, with nearly half $(42.4 \%)$ of participants rating the washable as highly acceptable and nearly half $(42.4 \%)$ rating it as unacceptable. The acceptability scores by gender can be seen in Appendix 12. VAS scores are shown in Table 43.

VAS scores reflected the preference and acceptability scores. The VAS scores by gender can be seen in Appendix 13.

\section{Preferences and overall acceptability by gender}

Examination of preference results by gender (Appendix 11) showed that there were important

TABLE 43 Mean VAS scores (day and night) $(\mathrm{N}=85)$

\begin{tabular}{|c|c|c|c|c|c|}
\hline & \multicolumn{5}{|c|}{ Mean (SD) } \\
\hline & Insert & Diaper & Pull-up & T-shaped & Washable \\
\hline Day & $48.5(32.1)$ & $66.3(27.3)$ & $72.7(23.9)$ & $60.1(27.6)$ & $33.7(31.0)$ \\
\hline Night & $43.1(32.7)$ & $64.5(26.9)$ & $62.2(29.8)$ & $53.9(26.3)$ & $53.2(40.6)$ \\
\hline \multicolumn{6}{|c|}{ VAS scores: comparisons between designs } \\
\hline & & & \multicolumn{2}{|c|}{ Estimated difference of means } & $95 \% \mathrm{Cl}^{a}$ \\
\hline \multicolumn{6}{|l|}{ Daytime } \\
\hline Pull-up & scored higher than & Insert & \multicolumn{2}{|r|}{24.13} & 15.20 to 33.06 \\
\hline Diaper & scored higher than & Insert & \multicolumn{2}{|r|}{$|7.8|$} & 3.58 to 32.05 \\
\hline Pull-up & scored higher than & T-shaped & \multicolumn{2}{|r|}{12.52} & I.II to 23.93 \\
\hline T-shaped & not different to & Insert & \multicolumn{2}{|r|}{$|1.6|$} & -1.73 to 24.96 \\
\hline Diaper & not different to & Insert & \multicolumn{2}{|r|}{1.58} & 0.88 to 2.83 \\
\hline Diaper & not different to & Pull-up & \multicolumn{2}{|r|}{-6.32} & -18.63 to 5.10 \\
\hline Diaper & scored higher than & Washable & \multicolumn{2}{|r|}{32.66} & 26.53 to 38.78 \\
\hline \multicolumn{6}{|c|}{ Night-time } \\
\hline Pull-up & scored higher than & Insert & \multicolumn{2}{|r|}{19.11} & 9.69 to 28.53 \\
\hline Diaper & scored higher than & Insert & \multicolumn{2}{|r|}{21.40} & 6.76 to 36.04 \\
\hline Diaper & scored higher than & T-shaped & \multicolumn{2}{|r|}{10.56} & -1.36 to 19.77 \\
\hline T-shaped & not different to & Pull-up & \multicolumn{2}{|r|}{-8.27} & -19.57 to 3.03 \\
\hline T-shaped & not different to & Inserts & & 10.84 & -1.58 to 23.25 \\
\hline Diaper & not different to & Pull-up & & 2.29 & -10.59 to 15.18 \\
\hline Diaper & scored higher than & Washable & & 11.32 & 3.75 to 18.89 \\
\hline
\end{tabular}


differences between designs dependent on gender; however there were relatively small numbers in each group (49 men and 36 women) and some of the results were not significant (NS). Results showed that women preferred pull-ups to diapers (29 versus 7; $p<0.05$ both day- and night-time), and inserts to diapers (25 versus 11; NS daytime and 22 versus 14; NS night-time), whereas men preferred diapers to pull-ups (33 versus 16; NS daytime and 38 versus $11 ; p<0.05$ night-time) and diapers to inserts (41 versus $8 ; p<0.05$ daytime and 39 versus 10; $p<0.05$ night-time). Both women and men preferred the diaper to the washable during the daytime, but during the night-time, although the diaper was significantly better than the washable for women this was not significant for men and more men preferred the washable to the diaper (29 versus 20 ). Both women and men significantly preferred pull-ups to inserts both day and night.

Acceptability scores for men and women reflected their preferences (Appendix 13). Nearly two-thirds of men scored inserts as unacceptable during the day, and this rose to three-quarters at night,

compared with 17 and $33 \%$ of women, respectively. Very few women (5-8\%) found pullups unacceptable either day or night, but 20 and $51 \%$ of men found them unacceptable for day and night, respectively. Nearly half of women (44\%) found diapers unacceptable during the day and more than one-third at night compared with $14 \%$ for men both day and night. Washables were unacceptable for almost all women during the daytime (except 4/36) compared with half of men and were unacceptable for three-quarters of women at night, but for less than $20 \%$ of men.

Overall for both men and women pull-ups were better than inserts $(p<0.05)$, and for women both pull-ups and inserts (NS) were better than diapers $(p<0.05)$, whereas for men diapers were better than both pull-ups (NS) and inserts $(p<0.05)$.

\section{Acceptability of designs for different situations}

In order to consider acceptability in more detail, participants were asked in which situations they would find the different designs acceptable. The results are shown in Figure 30.

The most challenging situation for a product is going out of the home; the washables were the least acceptable product, with only $7 \%$ of participants finding them acceptable. The pull-ups were the most acceptable product, with $63 \%$ of participants finding them acceptable. When at home, all the designs were scored relatively well for acceptability (47-64\%).

\section{Explanation of forest plots}

For primary and secondary outcome variables, results are calculated as proportions, such as participants' rating of discreetness binarised as (very good + good + okay) versus (poor + very poor). For example, design A may score $60 \%$ (very good + good + okay) and $40 \%$ (poor + very poor) and design B may score $50 \%$ (very good +

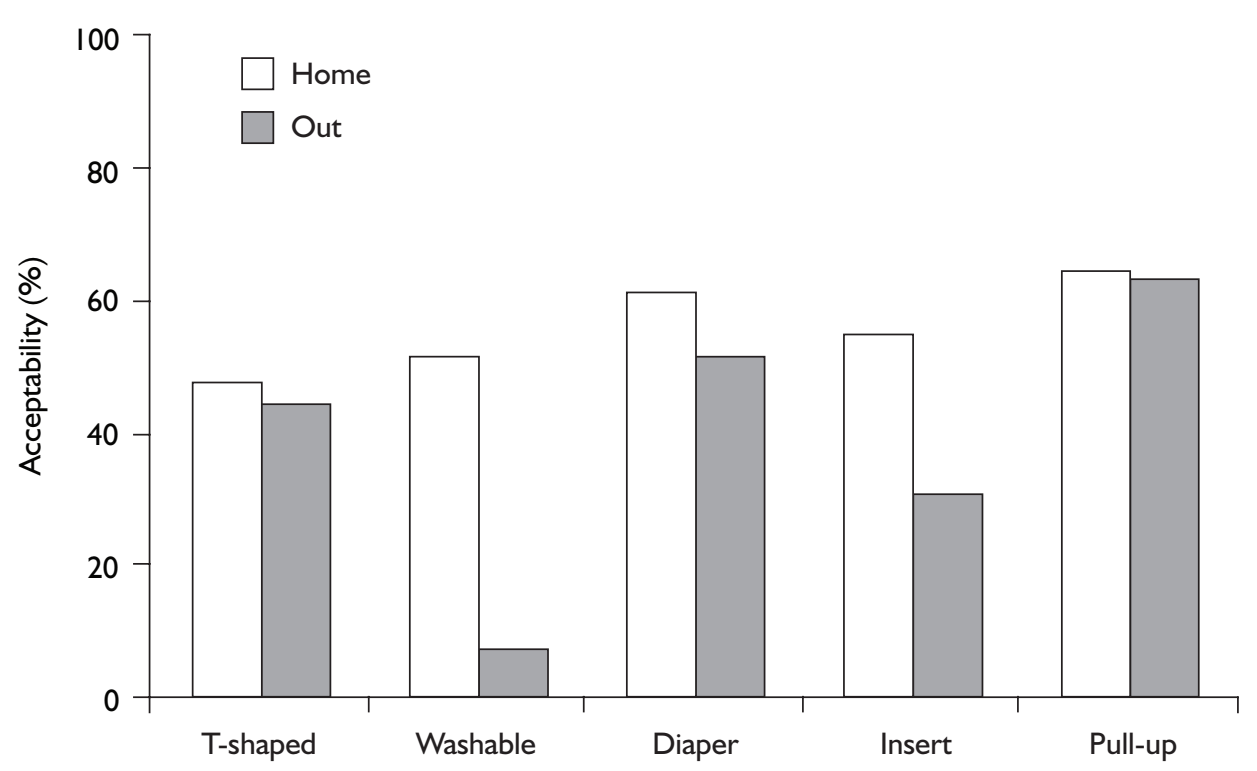

FIGURE 30 Acceptability of designs in different situations 
good + okay) and $50 \%$ (poor + very poor). In this case, it appears that design $\mathrm{A}$ is better than design $\mathrm{B}$ for discreetness. To examine whether we can be confident that this difference between the two designs is real, an OR and CI are calculated. If there is no difference between the two results, this will give an OR of 1 . Where there are differences (as in the example of discreetness above), the OR will be greater or less than one. The CI is a number that spans the OR (giving a higher and lower limit) and shows how much uncertainty there is about the OR.

The ORs and CIs have been calculated for comparisons between each pair of designs and for each variable where the results are shown as proportions. The ORs and CIs have been stacked on top of each other on a forest plot showing comparisons between each pair of designs.

The ORs and CIs are shown in relation to a vertical line which is the centre of the forest plot. This line gives the OR of 1 (i.e. no difference). Each variable is named on the far left of the forest plot and the OR and CI are written on the far right. The scale is shown on the bottom with numbers below 1 on the left and above 1 on the right.

Each OR is shown as a black box with a horizontal line (the 95\% CI) running through it. Where the line touches or crosses the vertical line (at $\mathrm{OR}=1$ ) there is no significant difference between the proportions for the two designs. Where the box and horizontal line lie completely to one or other side of the vertical line, one can be confident that the proportions for each design are significantly different.

To show readily how each pair of designs compare with each other, the ORs are plotted so that where a design scores better than the other design for any variable, the OR (i.e. the black box) is on the side of the vertical line that favours that design. Hence the ORs shown are for the second named design versus the first named design in the heading. The primary outcome variables from the final interview (overall acceptability and preference) are shown at the bottom of each forest plot and these reflect the overall performance of the different designs. The last line of the forest plot shows the odds on the second named design being preferred to the first.

There are 12 comparisons (day and night) between the four disposable designs. In addition, the washable design is only shown compared with the diaper (day and night) giving a total of 14 forest plots.

Each forest plot in Figures 31-44 shows the data obtained from:

- Leakage - diary: (from the pad change/leakage diary) binarised as (none) versus (a little + a lot).

- Leakage - rating: (the participants' rating from the final interview) binarised as (very good + good + OK) versus (poor + very poor).

- Seven key variables from the product performance questionnaire: all binarised as (very good + good + OK) versus (poor + very poor).

- Skin health problems: (data from the participants' skin health diary) binarised as (none) versus (a little + a lot).

- Overall acceptability: taken from the final interview, and binarised as (highly acceptable + acceptable) versus (unacceptable + totally unacceptable) abbreviated on the forest plots as (high/OK vs no).

- Overall acceptability: taken from the final interview, and binarised as (highly acceptable) versus $(\mathrm{OK}+$ unacceptable) abbreviated on the forest plots as (high vs OK/no).

- Preference men: this shows the odds on the second named design being preferred to the first by a man.

- Preference women: this shows the odds on the second named design being preferred to the first by a women.

\section{Comments about designs}

When ranking designs, participants were asked about the good and poor aspects of each and about why they thought their top and lowest ranked products were best and worst, respectively. An analysis of the responses given is shown in Appendix 14 by gender. Key themes were identified and the number of times each was mentioned is recorded.

Comfort, discreetness and appearance ('like normal pants') were strong points for pull-ups, although some described them as 'feminine' and this was unfavourable for men. Some people found them difficult to change, especially when out or when wearing trousers; others found them easy. Comments were made by men that there was insufficient padding or that the padding was in the wrong place for them.

Diaper comments indicated good absorbency, but bulkiness and sweatiness were negative points. Comments on T-shaped diapers also indicated 


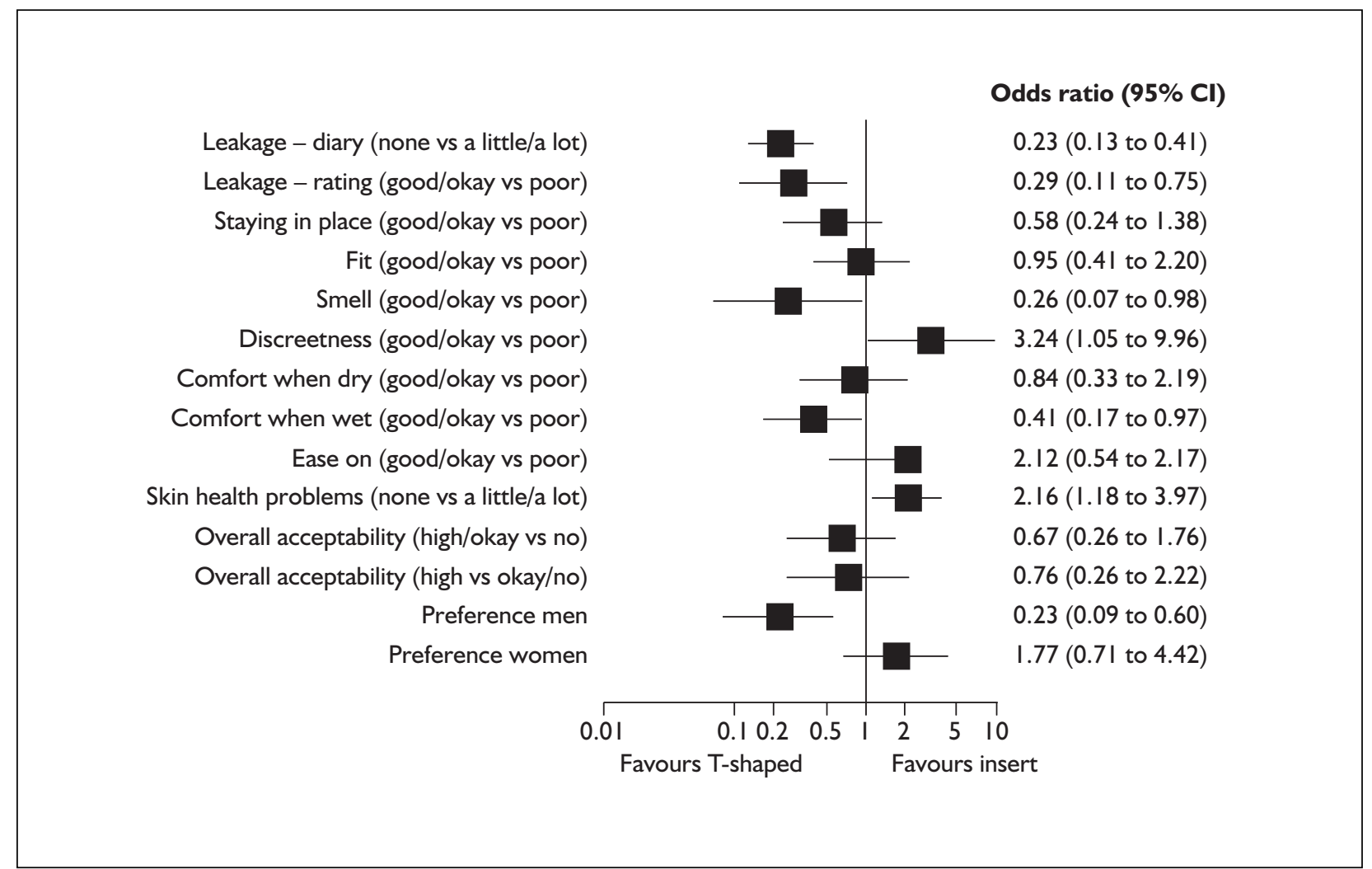

FIGURE 3 I Forest plot: T-shaped vs insert (day)

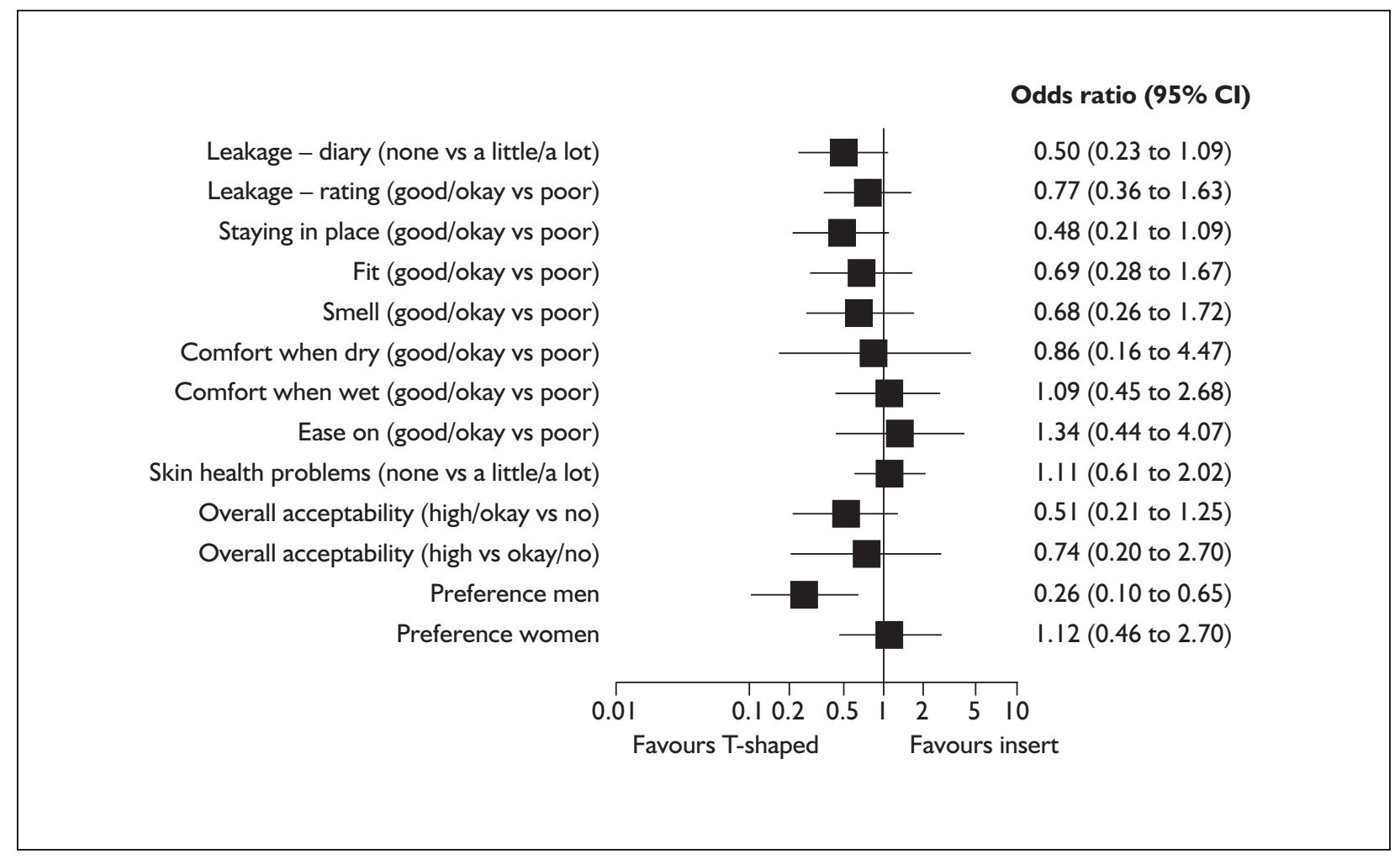

FIGURE 32 Forest plot: T-shaped vs insert (night) 


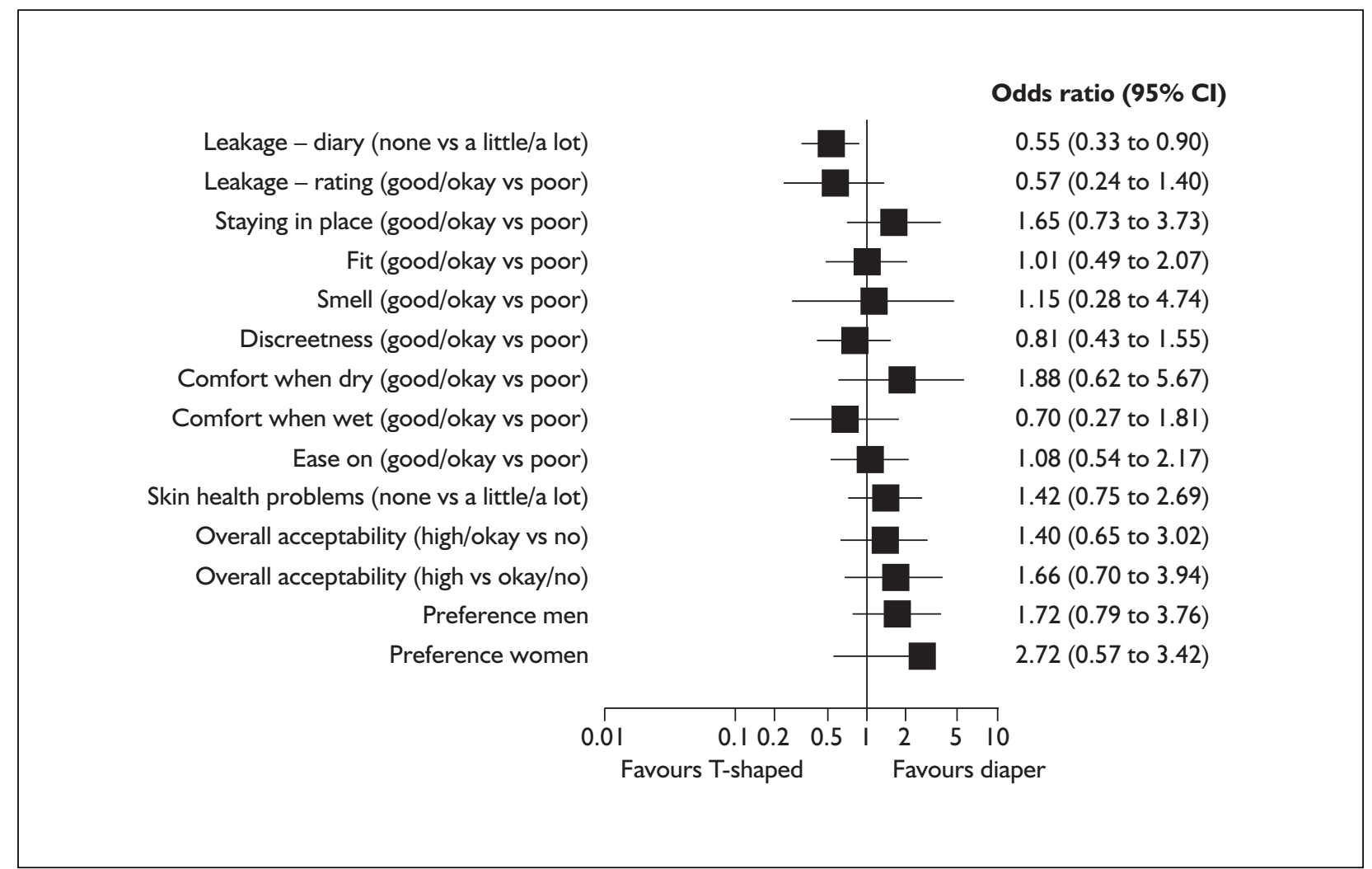

FIGURE 33 Forest plot: T-shaped vs diaper (day)

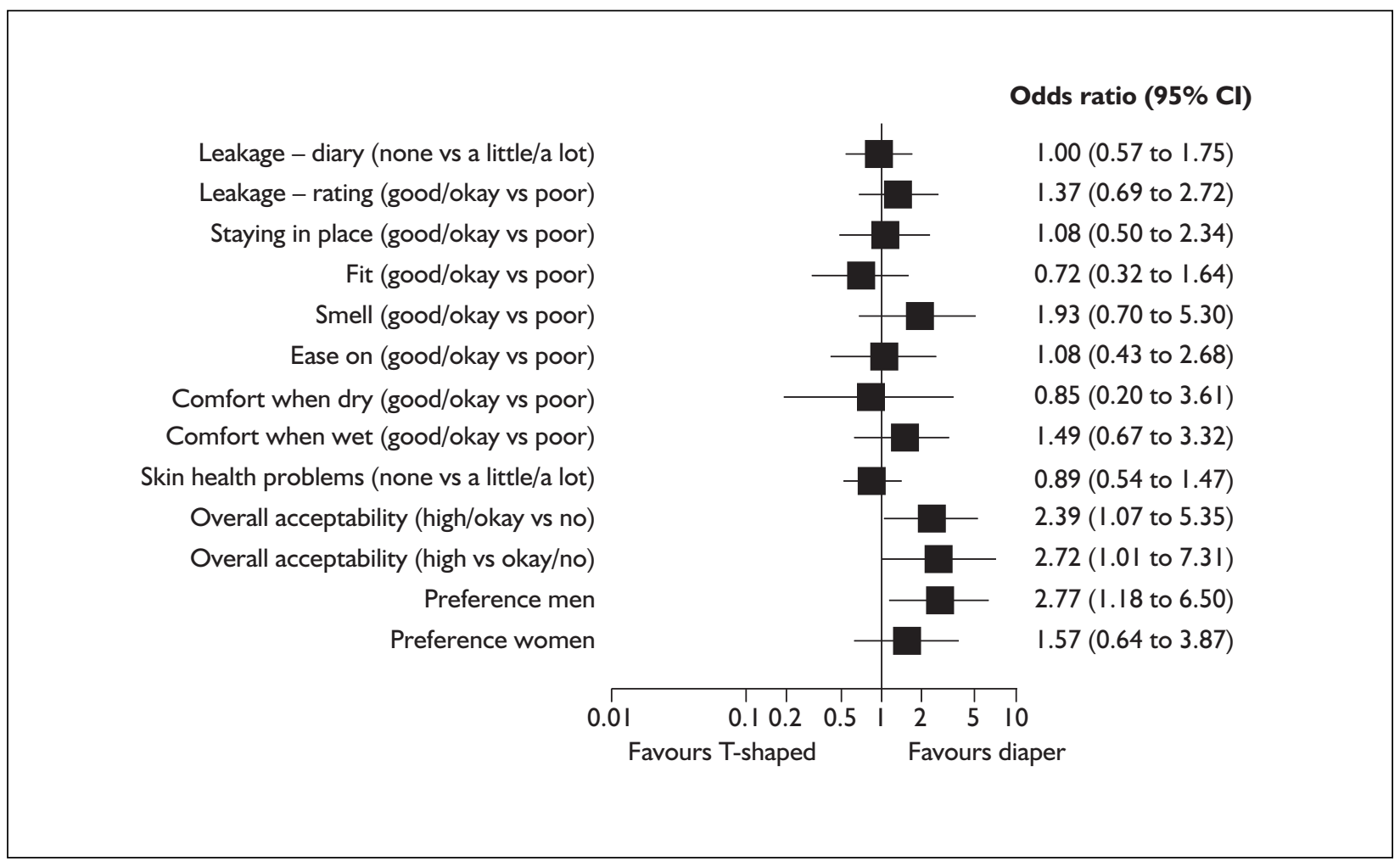

FIGURE 34 Forest plot: T-shaped vs diaper (night) 


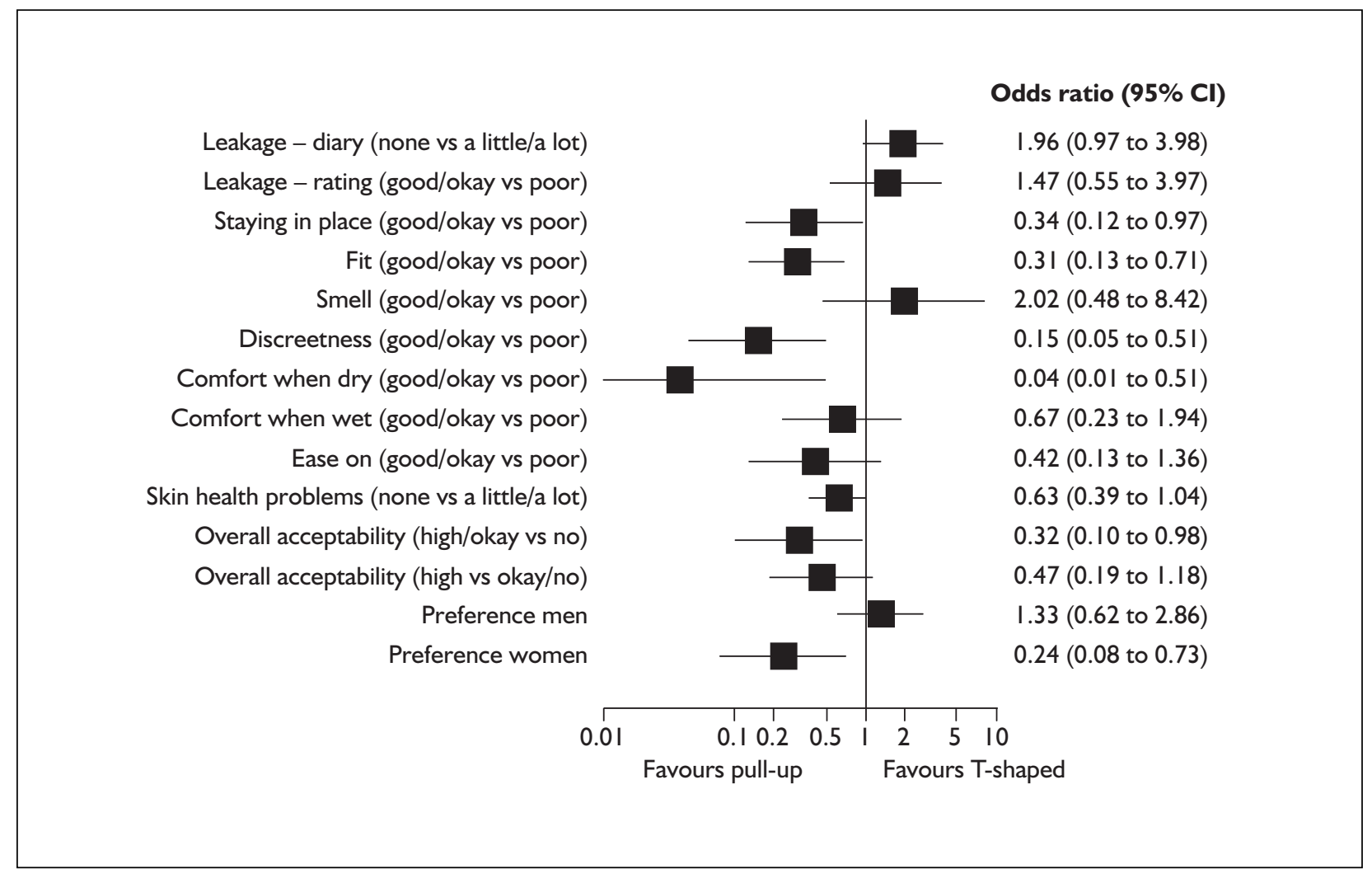

FIGURE 35 Forest plot: pull-up vs T-shaped (day)

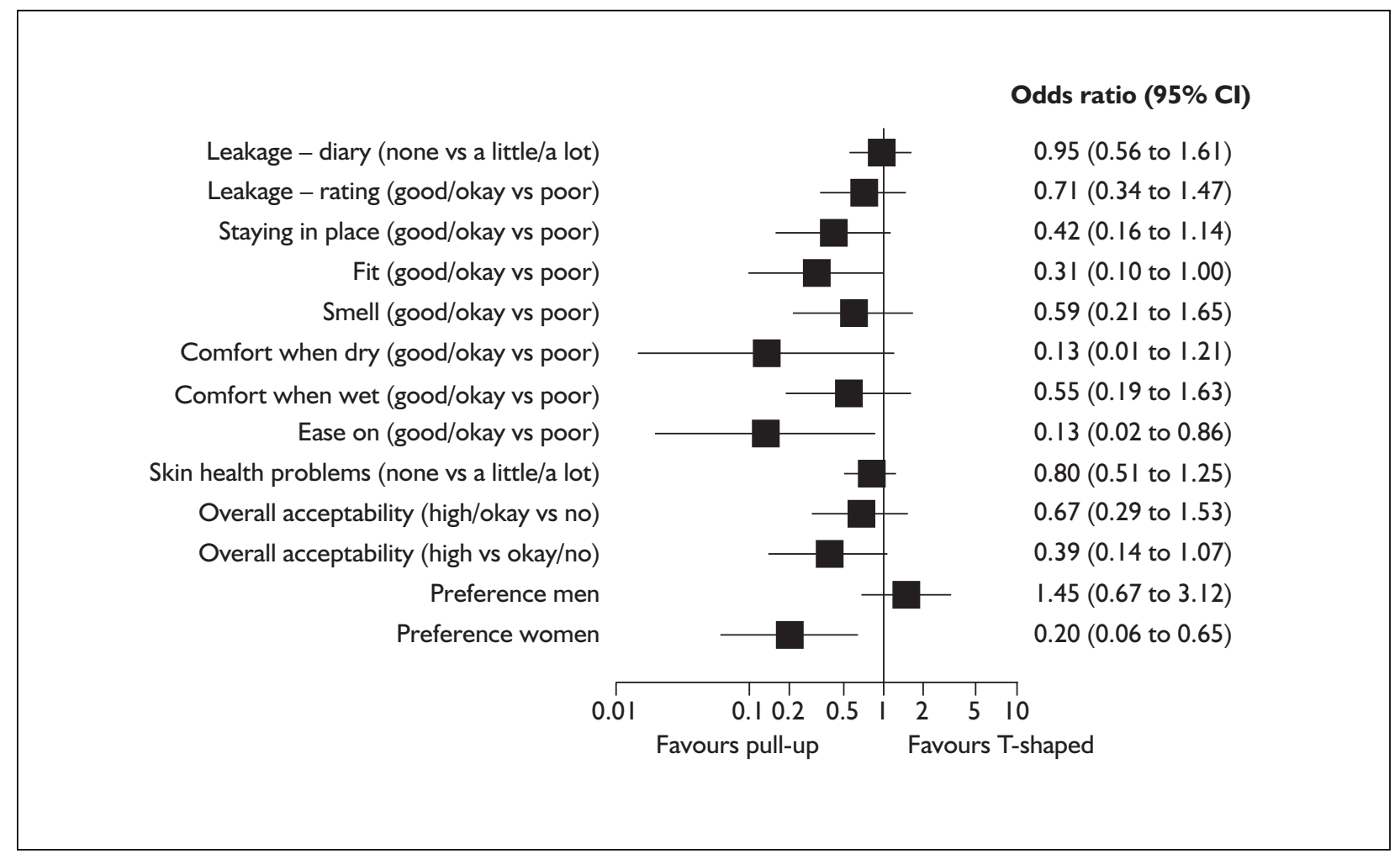

FIGURE 36 Forest plot: pull-up vs T-shaped (night) 


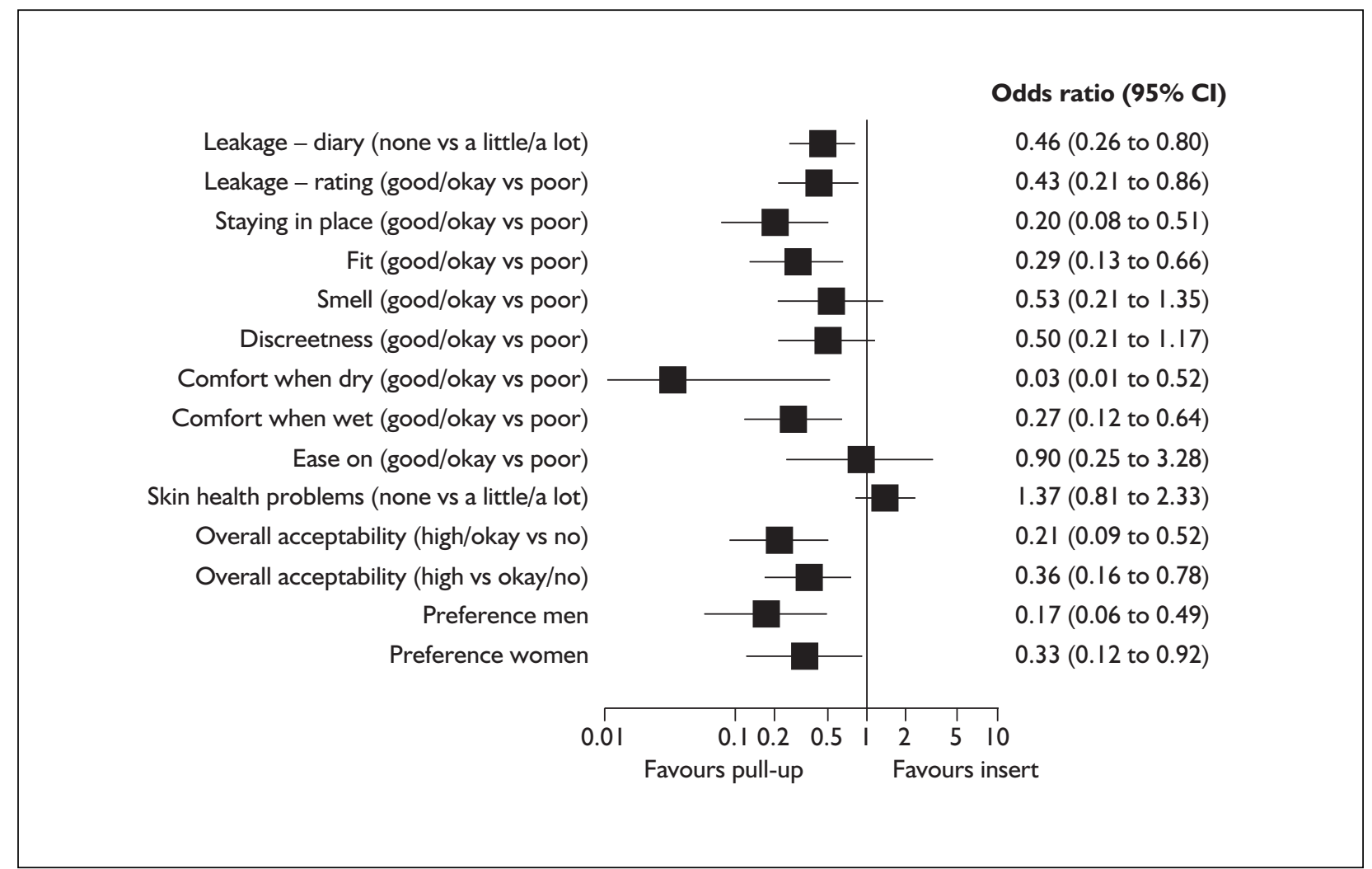

FIGURE 37 Forest plot: pull-up vs insert (day)

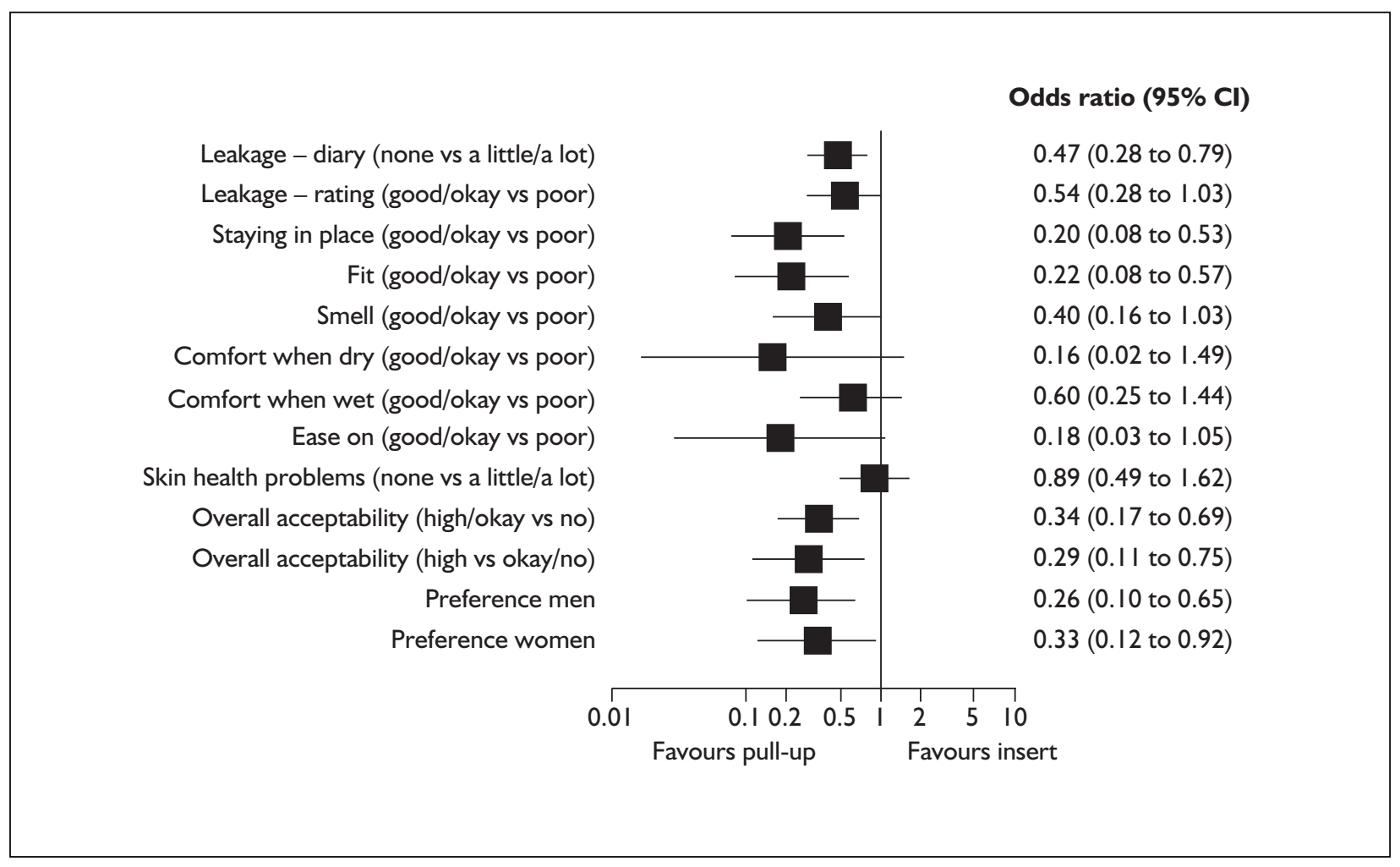

FIGURE 38 Forest plot: pull-up vs insert (night) 


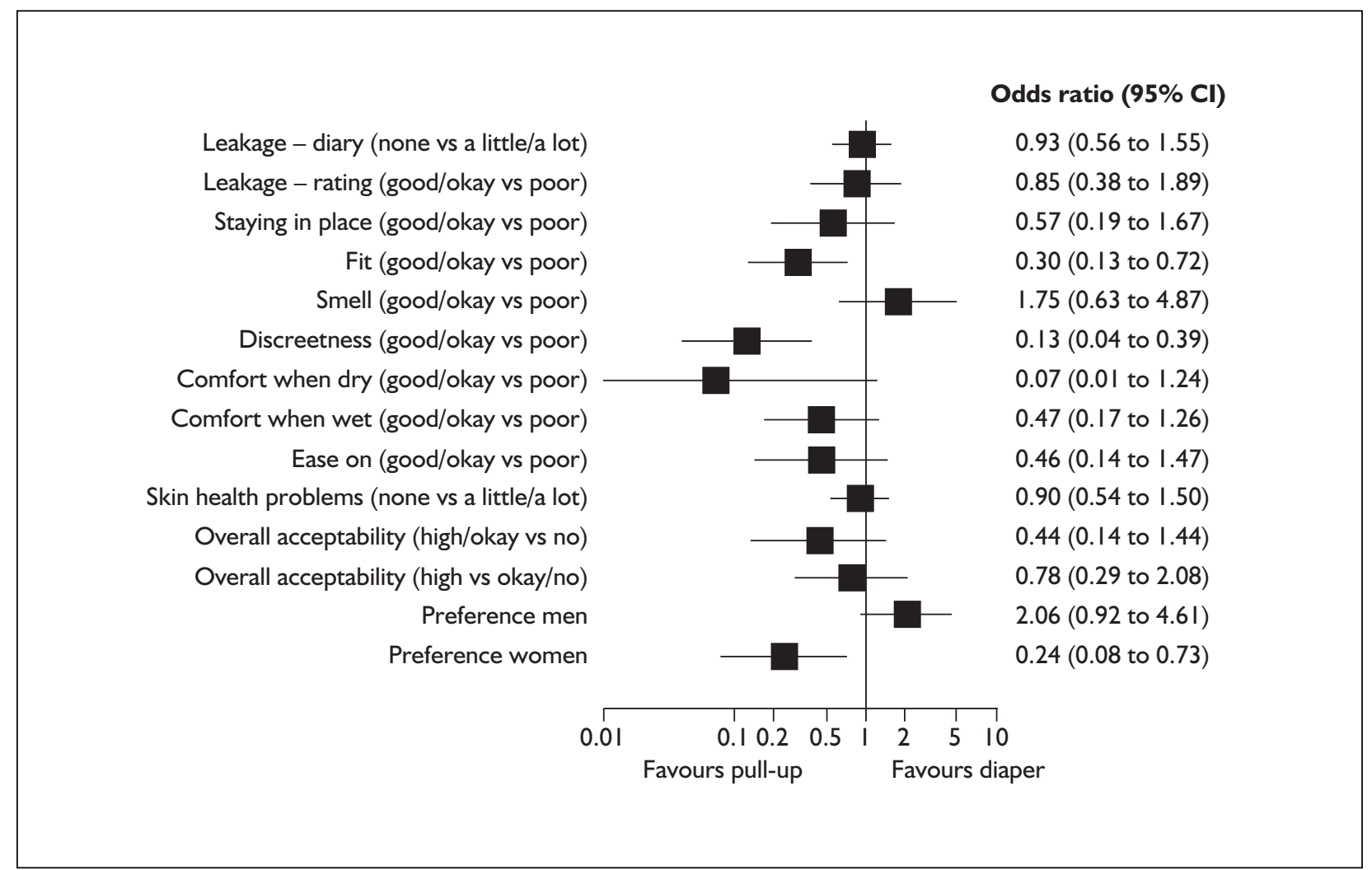

FIGURE 39 Forest plot: pull-up vs diaper (day)

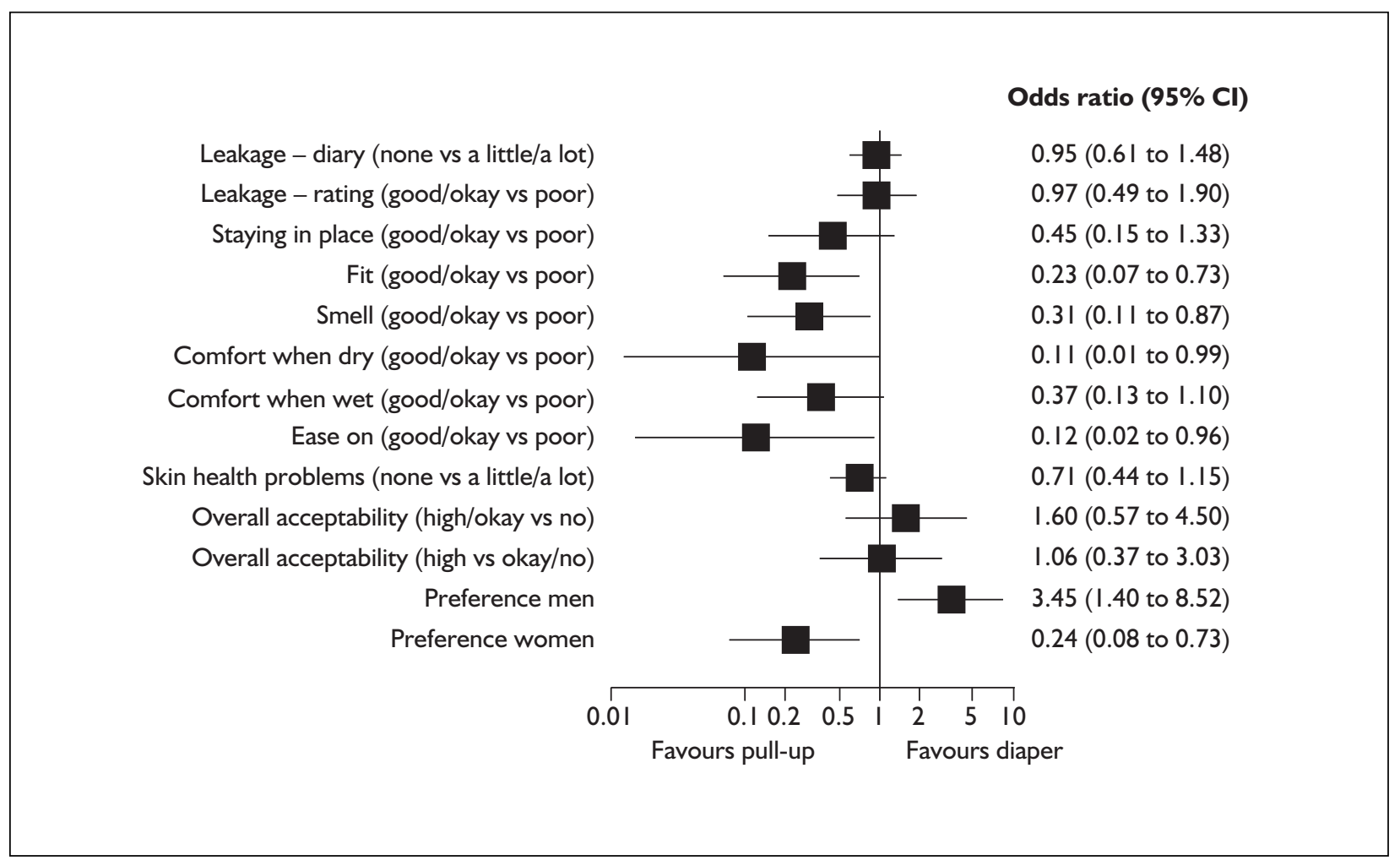

FIGURE 40 Forest plot: pull-up vs diaper (night) 


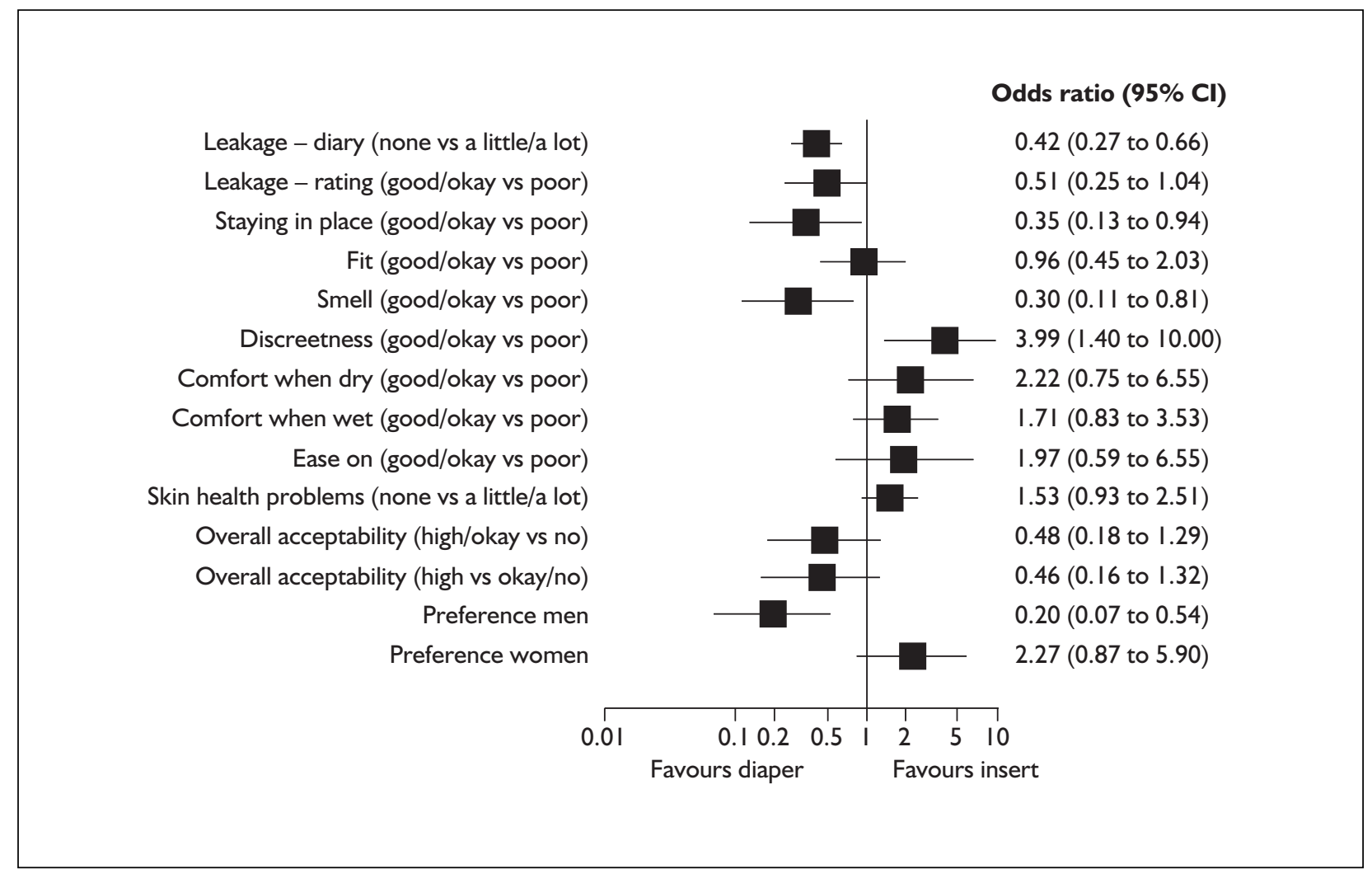

FIGURE 4 I Forest plot: diaper vs insert (day)

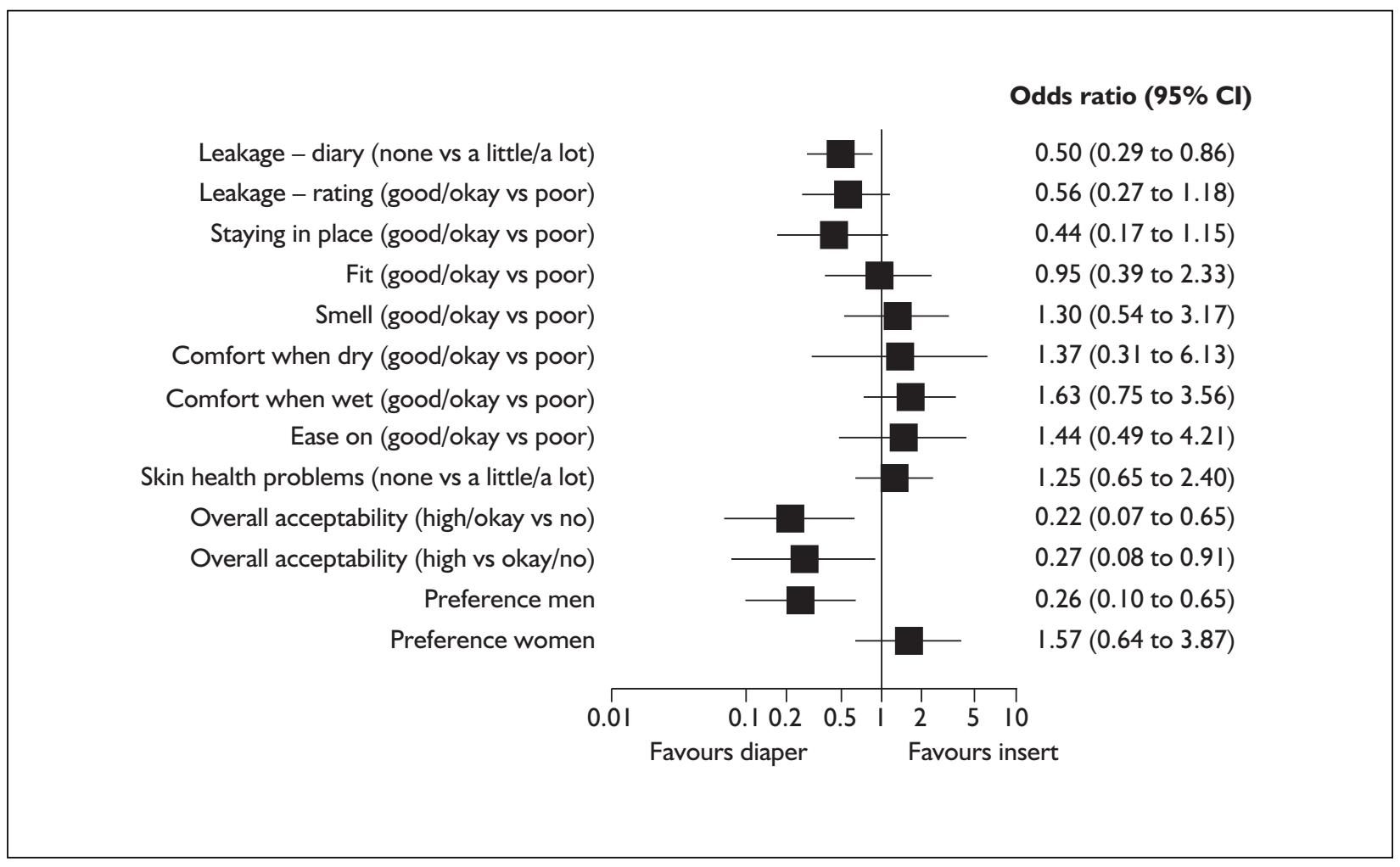

FIGURE 42 Forest plot: diaper vs insert (night) 


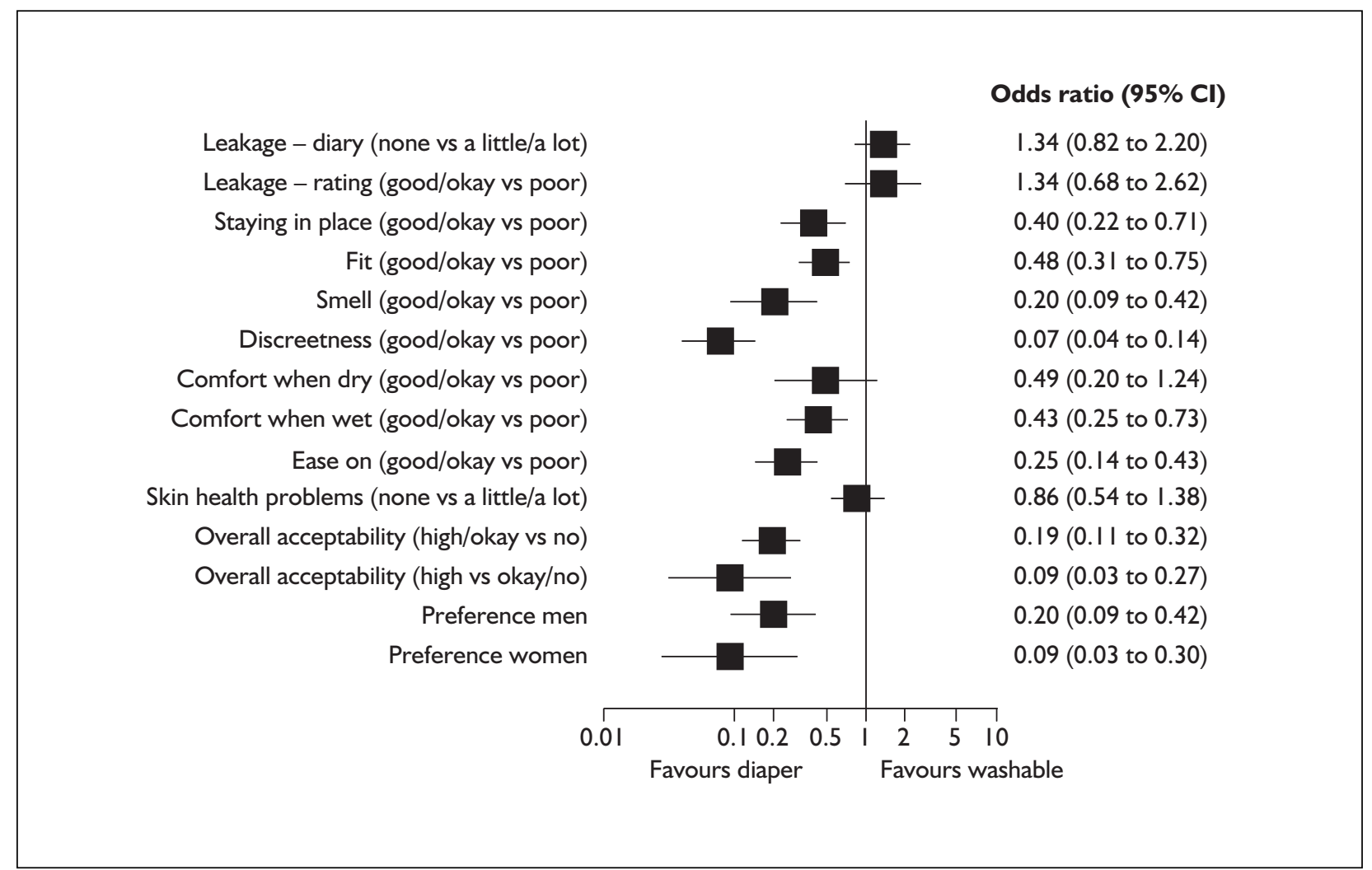

FIGURE 43 Forest plot: diaper vs washable (day)

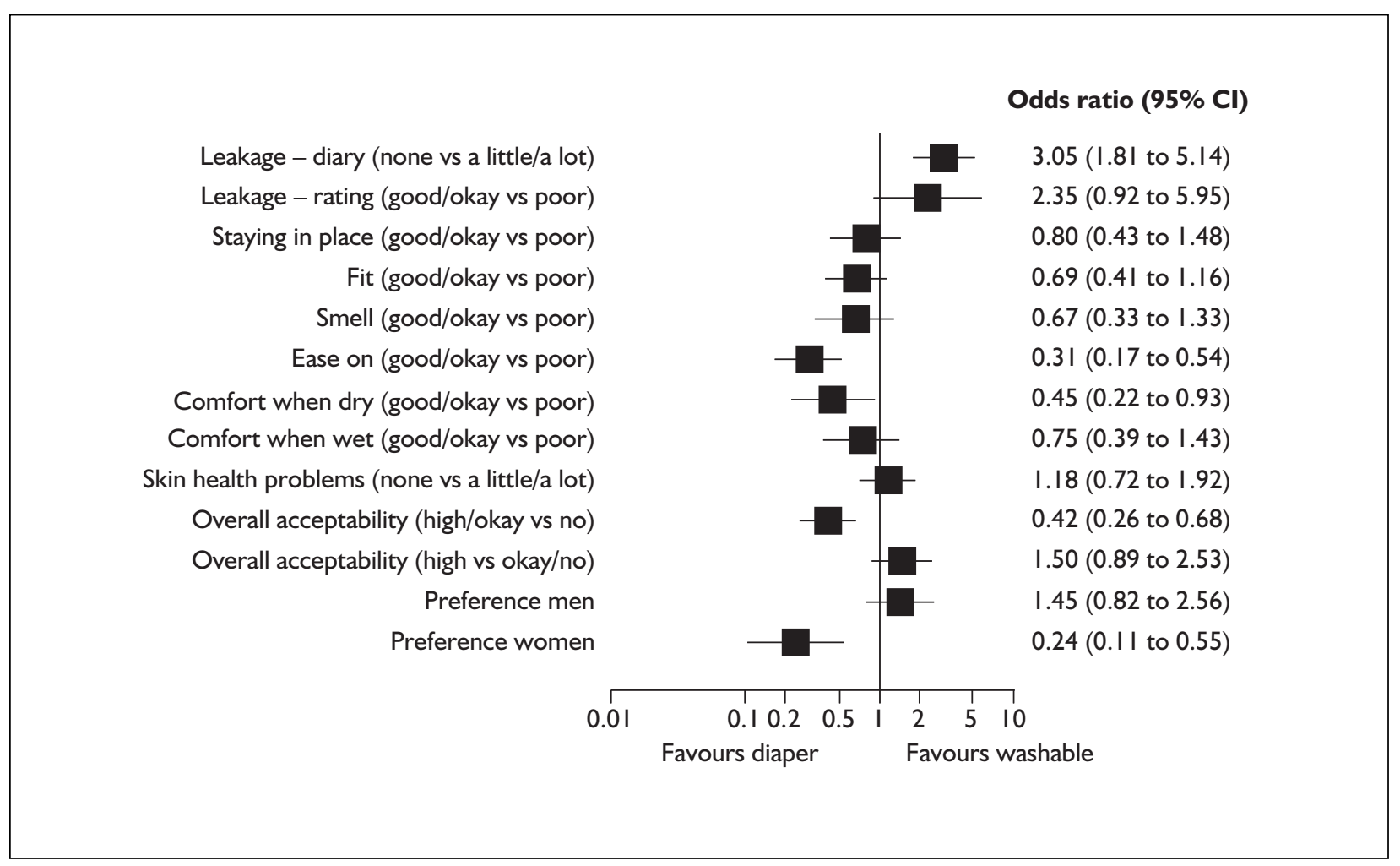

FIGURE 44 Forest plot: diaper vs washable (night) 
good absorbency, but some people experienced problems with the waistband and men in particular made comments about insufficient padding at the sides.

The main positive comments for inserts concerned ease of putting on and discreetness. Negative aspects included poor absorbency and difficulty staying in place. The washables attracted positive comments about absorbency and low leakage from men in particular, but were criticised for bulkiness and difficulties with putting them on, problems with laundry and, for women in particular, their 'babylike' appearance.

\section{Economic analysis Relative value for money}

To establish respondents' views about the relative value for money of each design, researchers asked them to consider the monthly cost of supplying the products that they had previously identified as the best value for money in each design. Retail and mail order prices prevailing at the time of the trial (April 2005) were used. Allowance was included for net pants worn with inserts and plastic pants for two of the washable products that did not have integral waterproof covering. Monthly costs were based on median reported product utilisation at baseline (three/day, one/night). For washable products, replacement rates were based on manufacturers' data about product life (270 washes for washable products, 30 washes for plastic pants), and assumptions about stocks of products that participants would hold (12 washable products and 12 pants for day use, six washable products and six pants for night use).
There was considerable variation in the prices of products within designs both day and night (Tables 44 and 45). Washables were much cheaper than disposables. Of the disposable designs, inserts and diapers were cheaper than T-shaped and pull-ups. In the day, the mean cost of the insert products that were tested was below that of the diapers, but the night diapers were cheaper than the inserts. The expense of laundering washable products (which is borne by individuals) is not included in the monthly costs, and respondents were reminded of this when asked to state their preferences.

Participants were asked if they were buying their own products, which designs they would select first, second, third, etc., and why, and which designs they would be willing to buy (Table 44). Of particular interest were participants' stated preferences between the disposable and washable designs when potential savings associated with washables became apparent.

Some switching of stated day preferences occurred into cheaper designs (washables and inserts) and away from the more expensive ones (pull-ups and T-shaped) once the relative prices were disclosed. For night products, where the washables were already more popular, and T-shaped less so, the switching was less pronounced, although there was a large swing away from pull-ups. The willingness to buy exceeded $50 \%$ only for diapers (both day and night) and for washables (night) (Table 44). This might be because most participants in this trial were not used to purchasing their supplies.

TABLE 44 Ranking with and without price (day) (no price $\mathrm{N}=85$; with price $\mathrm{N}=74$ )

\begin{tabular}{|c|c|c|c|c|c|c|c|c|c|}
\hline & \multicolumn{5}{|c|}{ Rank } & \multicolumn{3}{|c|}{$\begin{array}{l}\text { Willing to buy } \\
\text { (with price only) }\end{array}$} & \multirow[t]{2}{*}{$\begin{array}{l}\text { Cost } / \text { month } \\
\text { (range) }(t)\end{array}$} \\
\hline & Ist & 2nd & 3rd & 4th & 5th & Yes & No & $\begin{array}{c}\text { DK/ } \\
\text { missing }\end{array}$ & \\
\hline $\begin{array}{l}\text { Insert no price } \\
\text { With price }\end{array}$ & $\begin{array}{l}10.6(9) \\
14.9(11)\end{array}$ & $\begin{array}{l}21.2(18) \\
28.4(21)\end{array}$ & $\begin{array}{l}14.1(12) \\
10.8(8)\end{array}$ & $\begin{array}{l}23.5(20) \\
14.9(11)\end{array}$ & $\begin{array}{l}30.6(26) \\
31.1(23)\end{array}$ & 29 & 39 & 6 & $28.50-59.00$ \\
\hline $\begin{array}{l}\text { Diaper no price } \\
\text { With price }\end{array}$ & $\begin{array}{l}29.4(25) \\
32.4(24)\end{array}$ & $\begin{array}{l}22.4(19) \\
12.2(9)\end{array}$ & $\begin{array}{l}25.9(22) \\
27.0(20)\end{array}$ & $\begin{array}{l}20.0(17) \\
24.3(18)\end{array}$ & $\begin{array}{l}2.4(2) \\
4.1(3)\end{array}$ & 37 & 31 & 6 & $42.00-65.50$ \\
\hline $\begin{array}{l}\text { Pull-up no price } \\
\text { With price }\end{array}$ & $\begin{array}{l}37.6(32) \\
32.4(24)\end{array}$ & $\begin{array}{l}21.2(18) \\
20.3(15)\end{array}$ & $\begin{array}{l}22.4(19) \\
21.6(16)\end{array}$ & $\begin{array}{l}15.3(13) \\
18.9(14)\end{array}$ & $\begin{array}{l}3.5(3) \\
6.8(5)\end{array}$ & 32 & 36 & 6 & $74.00-88.00$ \\
\hline $\begin{array}{l}\text { T-shaped no price } \\
\text { With price }\end{array}$ & $\begin{array}{l}18.8(16) \\
12.2(9)\end{array}$ & $\begin{array}{l}27.1(23) \\
31.1(23)\end{array}$ & $\begin{array}{l}18.8(16) \\
23.0(17)\end{array}$ & $\begin{array}{l}29.4(25) \\
24.3(18)\end{array}$ & $\begin{array}{l}5.9(5) \\
9.5(7)\end{array}$ & 29 & 40 & 6 & $58.00-93.00$ \\
\hline $\begin{array}{l}\text { Washables no price } \\
\text { With price }\end{array}$ & $\begin{array}{l}3.5(3) \\
8.1(6)\end{array}$ & $\begin{array}{l}8.2(7) \\
8.1(6)\end{array}$ & $\begin{array}{l}18.8(16) \\
17.6(13)\end{array}$ & $\begin{array}{l}11.8(10) \\
17.6(13)\end{array}$ & $\begin{array}{l}57.6(49) \\
48.6(36)\end{array}$ & 28 & 42 & 4 & $7.33-10.00$ \\
\hline
\end{tabular}


TABLE 45 Ranking with and without price (night) (no price $\mathrm{N}=85$; with price $\mathrm{N}=75$ )

\begin{tabular}{|c|c|c|c|c|c|c|c|c|c|}
\hline & \multicolumn{5}{|c|}{ Rank } & \multicolumn{3}{|c|}{$\begin{array}{l}\text { Willing to buy } \\
\text { (with price only) }\end{array}$} & \multirow[t]{2}{*}{$\begin{array}{l}\text { Cost } / \text { month } \\
\text { (range) (E) }\end{array}$} \\
\hline & Ist & 2nd & 3rd & 4th & 5th & Yes & No & $\begin{array}{c}\text { DK/ } \\
\text { missing }^{a}\end{array}$ & \\
\hline $\begin{array}{l}\text { Insert no price } \\
\text { With price }\end{array}$ & $\begin{array}{l}10.6(9) \\
14.7(11)\end{array}$ & $\begin{array}{l}17.6(15) \\
16.0(12)\end{array}$ & $\begin{array}{l}11.8(10) \\
16.0(12)\end{array}$ & $\begin{array}{l}20.0(17) \\
14.7(11)\end{array}$ & $\begin{array}{l}40.0(34) \\
38.7(29)\end{array}$ & 25 & 45 & 5 & $14.30-28.40$ \\
\hline $\begin{array}{l}\text { Diaper no price } \\
\text { With price }\end{array}$ & $\begin{array}{l}17.6(15) \\
16.0(12)\end{array}$ & $\begin{array}{l}32.9(28) \\
38.7(29)\end{array}$ & $\begin{array}{l}28.2(24) \\
26.7(20)\end{array}$ & $\begin{array}{l}15.3(13) \\
16.0(12)\end{array}$ & $\begin{array}{l}5.9(5) \\
2.7(2)\end{array}$ & 39 & 32 & 4 & $12.33-16.20$ \\
\hline $\begin{array}{l}\text { Pull-up no price } \\
\text { With price }\end{array}$ & $\begin{array}{l}27.1(23) \\
21.3(16)\end{array}$ & $\begin{array}{l}16.5(14) \\
20.0(15)\end{array}$ & $\begin{array}{l}27.1(23) \\
17.3(13)\end{array}$ & $\begin{array}{l}21.2(18) \\
29.3(22)\end{array}$ & $\begin{array}{r}8.2(7) \\
12.0(9)\end{array}$ & 29 & 39 & 7 & $24.50-27.50$ \\
\hline $\begin{array}{l}\text { T-shaped no price } \\
\text { With price }\end{array}$ & $\begin{array}{r}9.4(8) \\
10.7(8)\end{array}$ & $\begin{array}{l}18.8(16) \\
10.7(8)\end{array}$ & $\begin{array}{l}28.2(24) \\
36.0(27)\end{array}$ & $\begin{array}{l}37.6(32) \\
34.7(26)\end{array}$ & $\begin{array}{l}5.9(5) \\
8.0(6)\end{array}$ & 25 & 46 & 4 & $19.30-31.00$ \\
\hline $\begin{array}{l}\text { Washables no price } \\
\text { With price }\end{array}$ & $\begin{array}{l}35.3(30) \\
37.3(28)\end{array}$ & $\begin{array}{l}14.1(12) \\
14.7(11)\end{array}$ & $\begin{array}{l}4.7(4) \\
4.0(3)\end{array}$ & $\begin{array}{l}5.9(5) \\
5.3(4)\end{array}$ & $\begin{array}{l}40.0(34) \\
38.7(29)\end{array}$ & 40 & 33 & 2 & $2.45-7.60$ \\
\hline
\end{tabular}

\section{Cost-effectiveness}

To calculate the cost-effectiveness ratios, the mean monthly cost of the products in each design and the mean of the mean product VAS scores in each design were used. Design level average ratios are shown in Table 46. Washables had the lowest cost per unit of effectiveness (VAS point) in the day (£0.27) and night (£0.11). The T-shaped had the highest ACER in the day $(£ 1.25)$ and the insert had the highest ACER at night (£0.52).

In the day analysis, there was no significant difference in the mean VAS between diapers and pull-ups $(p=0.178)$ or between diapers and T-shaped $(p=0.085)$. There were significant differences between all the other designs. With the exception of the T-shaped design, more highly priced products have higher effectiveness. The T-shaped products, however, cost more than diapers and have lower mean VAS scores.
The ICERs derived from Table 46 show that compared with diapers, the extra monthly cost of pull-ups per VAS point gained is $£ 5.00$ (without any significant increase in acceptability). It costs $£ 2.34$ for each extra VAS point gained if inserts rather than washables are purchased, and $£ 0.19$ for an extra VAS point if money is spent on diapers rather than inserts. Although inserts are significantly more acceptable than washables, diapers have significantly higher acceptability ratings than both those designs. The evidence points to diapers as the most cost-effective option for day use. However, this analysis has not taken the effect of gender into account and women preferred inserts during the day (25 versus 11 ) and their VAS scores are accordingly higher for inserts (Appendix 11). Inserts may therefore be the most cost-effective option for day use for women.

TABLE 46 Cost-effectiveness of designs

\begin{tabular}{|c|c|c|c|c|c|c|c|c|c|}
\hline \multirow{3}{*}{ Design } & \multirow{3}{*}{$\begin{array}{l}\text { Mean of } \\
\text { monthly } \\
\text { cost }(f) \text { of } \\
\text { products } \\
\text { in design } \\
(3 / \text { day } x \\
30)\end{array}$} & \multicolumn{3}{|l|}{ Day } & \multicolumn{5}{|c|}{ Night } \\
\hline & & \multirow{2}{*}{$\begin{array}{l}\text { Mean } \\
\text { VAS } \\
\text { score }\end{array}$} & \multicolumn{2}{|c|}{ ACER } & \multirow[t]{2}{*}{ Design } & \multirow{2}{*}{$\begin{array}{l}\text { Mean } \\
\text { monthly } \\
\text { cost }(f) \\
(1 / \text { night } \times \\
30)\end{array}$} & \multirow{2}{*}{$\begin{array}{l}\text { Mean } \\
\text { VAS } \\
\text { score }\end{array}$} & \multicolumn{2}{|c|}{ ACER } \\
\hline & & & $\begin{array}{l}\text { Cost } \\
\text { per } \\
\text { VAS } \\
\text { point } \\
\text { (f) }\end{array}$ & $\begin{array}{l}\text { VAS } \\
\text { points } \\
\text { per } t\end{array}$ & & & & $\begin{array}{l}\text { Cost } \\
\text { per } \\
\text { VAS } \\
\text { point } \\
\text { (t) }\end{array}$ & $\begin{array}{l}\text { VAS } \\
\text { points } \\
\text { per } t\end{array}$ \\
\hline Pull-ups & 78.70 & 72.66 & 1.08 & 0.92 & Diapers & 14.80 & 64.47 & 0.23 & 4.36 \\
\hline Diapers & 47.10 & 66.34 & 0.71 & 1.41 & Pull-ups & 25.50 & 62.18 & 0.41 & 2.43 \\
\hline T-shaped & 75.50 & 60.14 & 1.25 & 0.80 & T-shaped & 25.15 & 53.91 & 0.47 & 2.14 \\
\hline Inserts & 43.70 & 48.53 & 0.90 & I.II & Washables & 6.00 & 53.15 & 0.11 & 8.86 \\
\hline Washables & 9.00 & 33.68 & 0.27 & 3.74 & Inserts & 22.60 & 43.07 & 0.52 & 1.91 \\
\hline
\end{tabular}


In the night analysis, washables are cheaper than the other three disposable designs but were significantly less acceptable (highly acceptable + acceptable) versus (unacceptable + totally unacceptable) than the diaper design (with which it was compared). Diapers are cheaper than the other three disposable designs. They are rated significantly better than washables, T-shaped and inserts but their mean VAS score was not significantly different from that of pull-ups.

Compared with washables, the extra monthly cost of diapers and pull-ups per VAS point gained is $£ 0.78$ and £2.16, respectively. There was no difference in the acceptability of washables and pull-ups. However, washables were ranked best for night use by more people (almost all men) than both pull-ups and diapers (30 versus 23 and 15). Over one-third of the sample therefore preferred the cheapest product. For the rest who preferred a disposable design and find washables unacceptable, diapers are the most cost-effective option. However, as in the daytime, women preferred inserts to diapers (22 versus 14) and their mean VAS scores for inserts were higher than those for diapers. Inserts may therefore be the most cost-effective option for night use for women.

\section{Sensitivity analysis and sources of uncertainty}

The cost-effectiveness ratios are based on point estimates of costs and effectiveness (as represented by VAS mean scores). There is less variation in design mean VAS scores at night than in the day. Washables and inserts have significantly lower mean VAS scores than the other three designs in the day.

There are several sources of uncertainty in the cost estimates. First, the costs reflected the prices of products selected for the trial. There was considerable variability in prices of included products within designs, and the mean price was used (Tables 44 and 45). There are many different products available (especially in the diaper and the insert categories), so a different choice of product may have resulted in different mean design costs. As products may vary in characteristics and performance, and respondents were asked to evaluate the products that they had tested, it was decided that they should be presented with the associated relative prices. Two of the night insert products that were used in the trial were at the top of the price range, resulting in the mean design cost above that of the diapers group. A different choice of products could have reversed that ordering.
Second, the product prices used were those of retail/mail order outlets. A few people purchased some or all of their own products. Although all of the disposable products were purchased through PASA, at the time of the study, the NHS did not provide four of the night products tested (two diapers, one T-shaped, one pull-up) and five of the day products (one insert, one diaper, one T-shaped, two pull-ups) as standard. The PASA bulk purchase discount on the products that it supplied relative to the retail/mail order price, was about 50\% (range 33-67\%). PASA prices vary less within the diaper and insert designs than is the case in the retail/mail order market. Use of NHS prices would have affected the values of the cost-effectiveness ratios, but not the relative values unless the bulk purchase discount secured by PASA varied between designs. The washable products were purchased directly (with discount for bulk purchase) from the suppliers and none were supplied through PASA or by the NHS at the time of the study.

Third, all monthly cost estimates are based on a consumption rate of three products per day and one per night (median consumption reported by participants at baseline). This resulted in a slight underestimate of the actual mean product consumption per 24 hours recorded during testing.

Fourth, the trial found that the utilisation of products varied significantly across designs: participants made fewer changes of washables and more changes of inserts. Adjustment for this would alter the relative costs of the designs slightly.

Fifth, calculation of the monthly costs of the washables was based on assumptions about the life (number of washes) of products and the stocks that participants would hold. Varying these assumptions affects the cost-effectiveness of washables relative to disposables. Holding more stocks and increasing the replacement rate increases the costs of washables. Even when pessimistic assumptions about stocks and product life were used, washables remained substantially cheaper than disposable products.

Similarly, varying the assumptions about the replacement rate of the stretch mesh pants used with inserts and the plastic pants for washable products would affect the costs of these designs, but only marginally, as the prices of these items are very low relative to that of the products that they support. 
Sixth, the cost-effectiveness calculations are based on the purchase price of products and exclude the costs borne by consumers, the most important of which is the cost of laundry in the case of the washables. Use of disposables involves 'shoe leather' costs of purchase (except where products are delivered by the NHS) and also issues around storage and disposal, but these are generally considered to have minimal financial impact for users.

\section{Laundry and environmental costs}

Laundry costs are of two types: those associated with washing reusable products and laundry generated by leakages. Participants were reminded when making their selections between designs that the costs they were given did not include the cost of laundering the washable products. Including the laundry costs associated with washables would reduce their cost-effectiveness relative to disposables. Inserts generated significantly more laundry items than the other designs in the day and the night, and washables created significantly less leakage-generated laundry at night (but significantly more laundry overall) than the other designs, but the monetary values of these differences were not estimated.

An important consideration in the comparison of washable and disposable designs is the relative environmental cost, particularly disposal (landfill) costs of disposable designs and energy costs associated with laundering the washables. A recent report on baby nappies concluded that there was no significant difference in environmental impact between three nappy systems (disposables, home and commercial laundered), although the types of impacts did vary. ${ }^{49}$ It is assumed that these findings are generalisable to adult incontinence products and, accordingly, no allowance was made in the cost-effectiveness calculations for environmental factors.

\section{Attitudes towards washable and disposable products}

At the final interview, participants were asked an open question as to whether they favoured washable or disposable products, and why. The results are shown in Tables 47 and 48 . Less than $10 \%$ favoured washables for the daytime, but this proportion rose to more than one-third for nighttime; both environmental and absorbency reasons were the most common given.

Participants were asked how they would feel if washables were the only products supplied by the NHS and nearly two-thirds $(60.7 \%)$ said that they would be concerned.

\section{Practical aspects of washables and disposables}

Respondents were asked for their views about the practical aspects of using each type of product and the extent to which these constituted a problem (four-point scale). The results are presented in Tables 49 and 50. Practical issues associated with the use of washables constitute bigger problems in the opinions of participants, in particular dealing with wet washable products when out.

\section{Discussion}

This study is the first community-based trial of body-worn absorbent products for men and women with moderate/heavy urinary (or urinary and faecal) incontinence.

The main findings were that for day and night use the pull-up was significantly better than the insert for most variables, including overall acceptability

TABLE 47 Views on washable and disposable products (day): $\mathrm{N}=65^{\mathrm{a}}$

\begin{tabular}{|c|c|c|c|}
\hline $\begin{array}{lr}\text { Favour disposables } & 78.5 \%(5 \mathrm{I}) \\
\text { Favour washables } & 9.2 \%(6) \\
\text { No strong feeling either way } & 12.3 \%(8)\end{array}$ & & & \\
\hline Reasons for favouring disposables ${ }^{b}$ & $\mathbf{N}$ & Reasons for favouring washables ${ }^{b}$ & $\mathbf{N}$ \\
\hline Easy to use/practical/convenient & 30 & Economical/cheaper & 3 \\
\hline Being disposable/no laundry & 16 & Environment & 3 \\
\hline Less bulk/more discreet & 9 & Wash with normal laundry & 1 \\
\hline No smell & 2 & Convenient & I \\
\hline Familiarity & I & & \\
\hline Hygiene & 2 & & \\
\hline
\end{tabular}


TABLE 48 Views on washable and disposable products (night): $N=67^{\mathrm{a}}$

\begin{tabular}{|c|c|c|c|c|}
\hline $\begin{array}{l}\text { Favour disposables } \\
\text { Favour washables } \\
\text { No strong feeling either way }\end{array}$ & $\begin{array}{c}61.2 \%(4 I) \\
35.8 \%(24) \\
3.0 \%(2)\end{array}$ & & & \\
\hline \multicolumn{2}{|c|}{ Reasons for favouring disposables ${ }^{b}$} & $\mathbf{N}$ & Reasons for favouring washables ${ }^{b}$ & $\mathbf{N}$ \\
\hline \multicolumn{2}{|l|}{ Easy to use/practical/convenient } & 27 & Economical/cheaper & 6 \\
\hline \multicolumn{2}{|c|}{ Being disposable/no laundry } & 11 & Environment & 9 \\
\hline \multicolumn{2}{|l|}{ Less bulk/more discreet } & 2 & Don't move at night & I \\
\hline \multicolumn{2}{|l|}{ Environment } & I & Reliable/confidence/good absorbency & 10 \\
\hline \multirow{2}{*}{\multicolumn{2}{|c|}{ Reliable }} & I & No changes needed at night & 3 \\
\hline & & & Less space needed & 2 \\
\hline
\end{tabular}

TABLE 49 Practical aspects (day)

\begin{tabular}{|c|c|c|c|c|c|}
\hline \multirow[t]{2}{*}{ Feature } & \multicolumn{5}{|c|}{$\%(N)$} \\
\hline & $\begin{array}{c}\text { No } \\
\text { problem }\end{array}$ & $\begin{array}{c}\text { Small } \\
\text { problem }\end{array}$ & $\begin{array}{c}\text { Big } \\
\text { problem }\end{array}$ & $\begin{array}{l}\text { Insurmountable } \\
\text { problem }\end{array}$ & Total $^{a}$ \\
\hline $\begin{array}{l}\text { Big outlay to purchase stock of } \\
\text { washable products at outset }\end{array}$ & $28.1(18)$ & $32.8(21)$ & $31.3(20)$ & $7.8(5)$ & $100.0(64)$ \\
\hline $\begin{array}{l}\text { Dealing with washable products before } \\
\text { washing (e.g. rinsing out, nappy bucket) }\end{array}$ & $25.4(16)$ & $28.6(18)$ & $31.7(20)$ & $14.3(9)$ & $100.0(63)$ \\
\hline Washing washables & $33.8(22)$ & $24.6(16)$ & $33.8(22)$ & $7.7(5)$ & $100.0(65)$ \\
\hline Drying washables & $29.2(19)$ & $30.8(20)$ & $30.8(20)$ & $9.2(6)$ & $100.0(65)$ \\
\hline $\begin{array}{l}\text { Dealing with wet washable products } \\
\text { when out }\end{array}$ & $6.3(4)$ & $27.0(17)$ & $42.9(27)$ & $23.8(15)$ & $100.0(63)$ \\
\hline Disposal of used disposable products & $64.6(42)$ & $24.6(16)$ & $10.8(7)$ & $0.0(0)$ & $100.0(65)$ \\
\hline Storage of disposable products & $55.4(38)$ & $35.4(23)$ & $9.2(6)$ & $0.0(0)$ & $100.0(64)$ \\
\hline Obtaining supplies of disposable products & $59.4(38)$ & $29.7(19)$ & $9.4(6)$ & $1.6(1)$ & $100.0(64)$ \\
\hline
\end{tabular}

TABLE 50 Practical aspects (night)

\begin{tabular}{|lccccc|}
\hline Feature & \multicolumn{4}{c}{$\%(\mathbf{N})$} \\
\cline { 2 - 6 } & $\begin{array}{c}\text { No } \\
\text { problem }\end{array}$ & $\begin{array}{c}\text { Small } \\
\text { problem }\end{array}$ & $\begin{array}{c}\text { Big } \\
\text { problem }\end{array}$ & $\begin{array}{c}\text { Insurmountable } \\
\text { problem }\end{array}$ & Total $^{a}$ \\
\hline $\begin{array}{l}\text { Dealing with wet washable products } \\
\text { at night }\end{array}$ & $30.8(20)$ & $30.8(20)$ & $30.8(20)$ & $7.7(5)$ & $100.0(65)$ \\
$\begin{array}{l}\text { Dealing with wet disposable products } \\
\text { at night }\end{array}$ & $64.1(4 I)$ & $25.0(16)$ & $9.4(6)$ & $1.6(I)$ & $100.0(64)$ \\
$\begin{array}{l}\text { Big outlay to purchase stock of washable } \\
\text { products at outset }\end{array}$ & $30.0(18)$ & $36.7(22)$ & $31.7(19)$ & $1.7(I)$ & $100.0(60)$ \\
\hline \begin{tabular}{l} 
a See the section 'Data completion', p. 50. \\
\hline
\end{tabular} & & & & & \\
\hline
\end{tabular}

and preference. The diaper was significantly better than the insert for leakage for day and night but was only significantly more acceptable at night. The washable was significantly better than the diaper for leakage for both day and night but was significantly worse for most other variables, including overall

\section{Inserts}

When compared with the other disposable designs, inserts were significantly leakier than the other disposable designs and produced around twice as much laundry during the daytime. They were particularly poor for staying in place, which may account in part for their poor leakage 
performance. The main positive point for inserts was their discreetness. Despite poor leakage performance, there were indications that women preferred inserts to diapers (see below).

\section{Pull-ups}

Pull-ups scored significantly better than other designs on many performance variables (but not leakage, or overall acceptability except compared with inserts), particularly during the day and particularly for staying in place, fit, comfort when dry and discreetness. They were easier to put on than the two diaper-style designs (but not the insert) at night, but not during the day when there would be a need to remove clothing in the toilet with the pull-up. Comments indicated that changing pull-ups when out, and particularly when wearing trousers, was a problem. However, there were gender differences (see below).

\section{Diapers and T-shaped diapers}

The diaper was the most cost-effective design for the day and for the night (for those who did not find the washable acceptable), but was more likely to be preferred by men than women (see below). The diaper had no particular strong points apart from its superiority over inserts for leakage and overall acceptability (at night). The diaper was not significantly different to the T-shaped diaper for most variables but was scored significantly better for overall opinion than the T-shaped diaper at night. The T-shaped diaper was not found to be significantly easier to put on than the diaper for day or night.

\section{Washables}

The washables had very good leakage

performance, particularly for large urine volumes, both day and night, but scored poorly for most other variables, particularly discreetness and ease of putting on. Most participants found dealing with washables more problematic than dealing with disposables, particularly when outside the home. Less than $10 \%$ considered them acceptable for going out, although rather more (nearly half) considered them acceptable for staying at home. During the night-time, opinions about the washables were much divided, with nearly half (42\%) of participants (almost all men) scoring them as highly acceptable and the same proportion scoring them as unacceptable. This may have reflected its very good leakage performance (one participant commented "bombproof for leakage"), but also its poor, baby-like appearance and bulk, which many found unacceptable. The clear plastic pants and white terry-towelling absorbent closely resemble babies' nappies, yet terry-towelling can be dyed or printed and there is considerable scope for improving the appearance of plastic pants. It is notable that the third washable product (see Appendix 9) was very much worse for leakage than the two terrytowelling products and there may be considerable variability in the performance of washables in general.

\section{Faecal incontinence}

Less than one-third of participants stated that they had faecal incontinence at the beginning of the study and fewer responded to the final interview question about the performance of the designs for faecal incontinence. No firm conclusions could therefore be drawn and further evaluation of designs for the management of faecal incontinence is needed.

\section{Skin health}

No evidence was found of greater skin problems when using washable products; however, randomisation of day and night designs meant that most subjects did not test washable products continuously. As this is also likely to be the situation in practice (e.g. washables may be worn only during the night, with disposables used in the daytime), the study findings may be generally applicable.

The finding that skin problems were more frequent with the T-shaped diaper may be explained by the waist-band, which was considered to be a source of irritation by some participants. The T-shaped diapers used in the study were the first of their kind to be available on the market and discussions with one of the manufacturers indicate that initially there were problems with the waist-band, which has since been modified.

\section{Absorbency levels}

All the designs tested in this study were available in a range of absorbencies and the most commonly used absorbency levels (according to PASA data) were selected for inclusion in this study. The main difference in leakage performance results related to the poor performance of the insert design relative to the other designs; it is therefore possible that the inserts would score better if more absorbent (and more expensive) inserts were used.

\section{Gender differences}

Important differences were found between men and women in the severity of their incontinence, in the performance of the different designs and in the preferences that men and women held for 
different designs. An attempt has been made to explore these differences, but the division of the sample into the two smaller gender groups reduces the power of the study and interpretation must therefore be cautious.

\section{Severity of urinary incontinence and leakage: gender differences}

The men in the study were more severely incontinent of urine than the women. The average urine mass in the men's pads was around two-thirds greater than that in the women's pads. Pad consumption data showed that men used similar numbers of pads (possibly more during the daytime) to women and this finding could not therefore be explained by men changing their pads less frequently. In general, the leakage performance of the pads was around $10 \%$ worse for men than women during the day and around $20 \%$ worse during the night (less differences for $\mathrm{T}$ shaped and washables). This may in part be explained by the larger urine masses in the men's pads (leakage performance declines with increased urine mass), but also by anatomical differences. Women have a fixed urethra and urine loss occurs from a predictable position. For men, the orientation of the penis may vary considerably, particularly at night when lying on the side. It is therefore more difficult for pads to be leak-free for men.

\section{Leakage performance of different designs: gender differences}

Leakage performance also differed for men and women between the different pad designs. The leakage performance tables and probability curves by gender (see Appendix 6) indicate that the pull-ups performed better for women than for men (around 20\% difference) and this was supported by similar differences in the rating of leakage performance by men and women. Comments were made by men (none by women) that the absorbent padding in the pull-ups was not in the right place for them and this may be a possible explanation and should be investigated further. Inserts performed badly for leakage for both men and women but the leakage probability curves indicated that inserts performed relatively worse for men than for women at night. For example, the probability of inserts leaking at night with $250 \mathrm{~g}$ of urine is around 0.72 for women but is only around 0.52 for men (see Appendix 6). Inserts were commonly rated as being poor for staying in place (particularly by men) and this problem, combined with anatomical issues described above, may explain this finding.

\section{Overall acceptability and preferences: gender differences}

Preferences indicated by men and women are generally supported by performance findings, but there are some notable differences. Both men and women preferred pull-ups to inserts (better leakage performance and better for most other variables) for both day- and night-time. Women significantly preferred pull-ups (best leakage performance for women, high scores for most variables) to the two diaper designs, but men preferred diapers to the pull-up and T-shaped designs. This is probably because for men, unlike for women, the pull-ups are not better for leakage (and may be worse) and have an important disadvantage, in requiring trousers to be removed for changing pads. In addition, some men felt the pull-ups to be feminine ("like frilly girls' knickers", commented one participant). It is not clear why men significantly preferred the diaper to the T-shaped diaper. The T-shaped diaper was at least as good for leakage performance as the diaper (and may be better), but the T-shaped design was not found to be easier to be put on than the conventional diaper and participants made negative comments about the waist-band and the lack of padding at the sides, which may have influenced their choices.

Perhaps more surprising is the indication that women prefer inserts over diapers, given the significantly worse leakage performance for inserts. Women's preferences favouring the insert (25 versus 11 for daytime; 22 versus 14 for nighttime) were not significant, but are in the opposite direction to men's preferences. In general, women scored the diaper lower than men for key variables such as discreetness and ease of putting on and made more negative comments about the appearance of the diaper.

The washables were disliked during the daytime by both men and women (despite their superior leakage performance), but many more men found them acceptable or highly acceptable for nighttime use (40/49) use than women (9/36). This may reflect the general acceptance by men of diaperstyle designs and the general dislike of diaperstyle products by women.

For women, inserts and pull-ups may be considered essentially quite feminine designs, inserts being simply (very) large versions of familiar menstrual pads. For men, absorbent pads are not familiar products and they are faced with a choice between rather female-orientated products (inserts and pull-ups) or rather babyish ones 
(diapers). There is no male-specific product. It is probably not surprising that they opt for the most effective designs for leakage or those which they perceive have the least number of drawbacks (washables and diapers).

\section{Cost-effective provision of products}

Where people find cheaper alternatives acceptable for some situations (if not all situations), it should be possible to allow a sufficiently flexible choice of products such that potential savings could be realised. If the NHS offers the whole range of designs (i.e. includes washables) and gives greater choice through direct payments or vouchers, then clients are given an incentive to 'mix and match' designs in a way that will make the best use of the funds they have. For example, they might economise at night by buying washables and use the savings to buy pull-ups for special occasions while making diapers (or inserts) the mainstay of their daily incontinence management.

\section{Limitations}

Product development means that the characteristics and availability of individual products change over time and the products used in this study are likely to be superseded. However, the main designs are much more stable and the results should therefore outlive those of the individual products. Market changes, however, mean that absolute and relative prices can alter. For example, a greater demand for pull-ups by NHS Trusts (in response to client preferences) could enable competitive manufacturers to exploit further economies of scale in production and offer more favourable purchasing terms for PASA.

It is difficult to know how well the sample represented men and women using absorbent pads for moderate/heavy incontinence living in the community. There are no published data on the characteristics of this population. Considerable background data were collected on the sample which should enable future comparisons to be made. The inclusion of the criterion that participants were able to complete self-report questionnaires meant that individuals with cognitive impairment were not included in the study. It would not therefore be possible to generalise these results to the population of pad users with dementia, many of whom would also be looked after by carers.

The findings of substantial differences in the degree of incontinence and the preferences for different designs between men and women were important, but the subsequent need to analyse data in gender groups reduced the sample sizes for each group, with a consequent loss of power. This meant that some differences between designs (particularly in the smaller group of women) did not reach significance, and it was more difficult to reach firm conclusions. Future studies should therefore be powered to allow for analysis by gender group.

Further limitations applying to the study more generally are discussed in Chapter 7.

\section{Conclusions}

In this study, we found significant differences between the performance, overall acceptability and cost-effectiveness of the different absorbent designs for men and women with moderate/heavy incontinence. Important and unexpected differences were found between men and women for most variables and the overall conclusions (in this paragraph) should be considered alongside those by gender (in the following paragraph). The pull-up was better than the insert (but not the diaper) for the daytime and the pull-up and diaper were better than the insert at night. However, the pull-up was expensive and the diaper was the most cost-effective design for the day. For the night, the washables were the most cost-effective design, but for those who found them unacceptable the diaper was the most costeffective choice. The inserts were worse than all the other designs for leakage performance for both day and night.

Gender differences were found for most variables (including leakage performance), but few firm conclusions could be drawn because of small numbers in each group. The men were more severely incontinent than the women and generally experienced more leakage (around 20\% at night). The men did not prefer pull-ups but significantly preferred diapers to inserts and diapers were the most cost-effective product for men for the day. For the night the washable was the most cost-effective product for men, but nearly half found them unacceptable and for them the diaper was the most cost-effective product. The pull-up was significantly preferred by women to all the other designs, both day and night, but is relatively expensive. Despite inserts having worse leakage performance than diapers, women generally preferred inserts (although this was not significant), and the insert may be the more costeffective choice. The washable was unacceptable to most women for day or night. 


\section{Implications for healthcare}

There is evidence that:

- The performance of, and preferences for, different designs are different for men and women and this implies that a range of options may be needed to ensure adequate provision.

- Incontinence severity varies widely, but men (who use absorbents for moderate/heavy incontinence) are generally more severely incontinent than women and may need more products or more absorbent ones.

- Diapers are the most cost-effective disposable design, for men. However, gender differences indicate that inserts may be cost-effective for women. For women, pull-ups are strongly preferred, have better performance (than inserts) but are more expensive. Bulk contracts would reduce the price of pull-ups and make them more affordable for the NHS.

- Provision of the terry-towelling washable diaper is likely to be economical for the NHS when used at night. However, most women (and some men) strongly dislike them. Restricting the range of available products to washable designs alone is therefore not recommended.

- Allowing men and women to choose combinations of designs (washable and disposables) for day and night and for different circumstances (e.g. for women, inserts at home and pull-ups when out) within a limited budget is likely to be economical for the NHS.

- An NHS 'shop' (virtual or otherwise) whereby NHS vouchers could be used to purchase combinations of product designs, at cheaper prices (using the buying power of the NHS), would be welcomed by users.

\section{Recommendations for research}

- Translational research to pilot the feasibility of provision of a range of designs and enabling men and women to choose combinations of designs within a limited budget.

- Development of more effective and aesthetically acceptable washable products, particularly for night-time use and for women.

- Development of more effective and acceptable disposable designs specifically for men. 


\section{Chapter 5}

\section{Randomised crossover trial of disposable absorbent products for women and men with moderate/heavy urinary or urinary and faecal incontinence living in nursing homes (Trial 2b)}

\section{Background summary}

Around two-thirds of people in nursing homes and one-quarter of those in residential homes experience urinary and/or faecal incontinence and body-worn absorbent pads are the most common method of management. ${ }^{52}$ Although there are four main designs of body-worn pads available in disposable and washable variants (inserts, diapers, T-shaped diapers and pull-ups) (Table 51), disposable products dominate and washables are more seldom used in homes. Insert pads are the simplest, cheapest (on a per product basis) and most commonly used of the disposable designs in the UK, although diaper designs are also frequently used. In the last few years, two new designs have become available (T-shaped diapers and pull-ups) which are intended to be easier for the carer or individual to apply, but their effectiveness is not known.

Selection of designs for individuals in nursing and residential homes in the $\mathrm{UK}$ is based on little evidence. There have been no direct comparisons made of the different disposable body-worn designs and most clinical trials have focused on comparisons of disposable and washable designs, but they are more than 10 years old. There are indications from trials of products of a single $\operatorname{design}^{15,16}$ that insert pads may be less effective than diapers, but this has not been tested directly in a clinical trial. There are also indications that designs vary in how long they take to apply and

TABLE 5 I Classification of products for moderate/heavy incontinence

\begin{tabular}{|ll|}
\hline Disposable & Washable \\
\hline Inserts & Inserts \\
Diapers & Diapers \\
T-shaped diapers & T-shaped diapers \\
Pull-ups & Pull-ups \\
\hline
\end{tabular}

remove; however, this has not been demonstrated clinically. ${ }^{51}$

Several studies have shown that incontinence is a costly aspect of care in nursing homes, ${ }^{52}$ including laundry, disposal and staff changing costs in addition to the purchase price of the products. The choice of containment method is likely to affect significantly the overall expenditure, ${ }^{53}$ but it is not known which designs of product are most cost-effective.

\section{Aims}

The aim of the study was to compare the performance and cost-effectiveness of disposable absorbent product designs for women and men with moderate/heavy urinary/faecal incontinence.

A washable design was not included in this trial. The costs and preparation needed to introduce washable products into nursing homes are very substantial and there is a lack of clinical data on washable designs to inform selection from the many designs available. Preliminary enquires with nursing home staff also indicated that testing of washable products would pose laundry difficulties and staff would be reluctant to test them.

\section{Design and methods}

The trial was a randomised crossover clinical trial comparing four disposable absorbent product designs (insert, diaper, T-shaped diaper, pull-up) when used in nursing homes (Figure 45, p. 82).

\section{Recruitment of participants}

Nursing homes in the north London and Southampton areas were contacted to inform them 
(a)

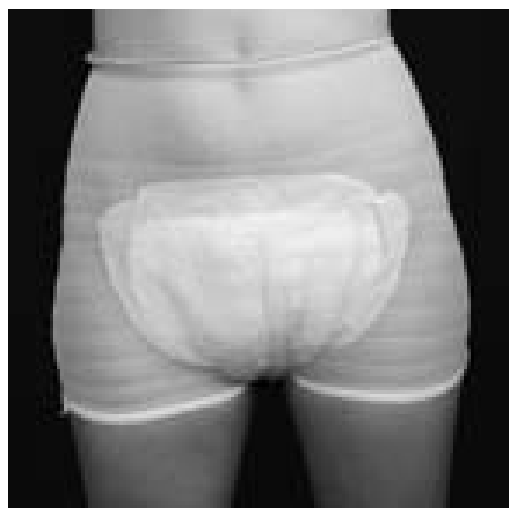

(c)

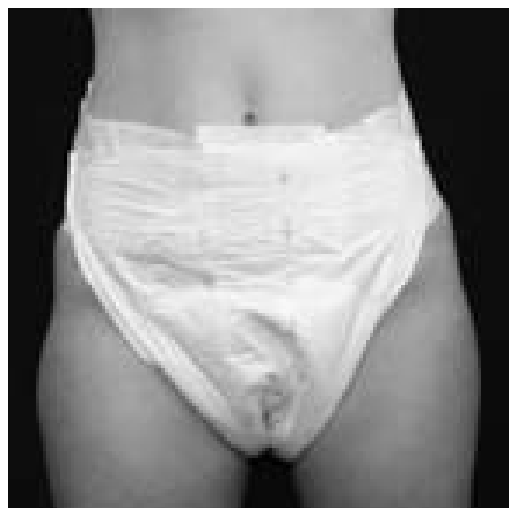

(b)

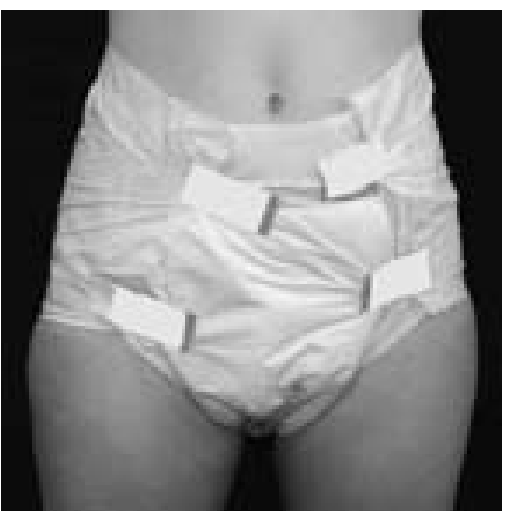

(d)

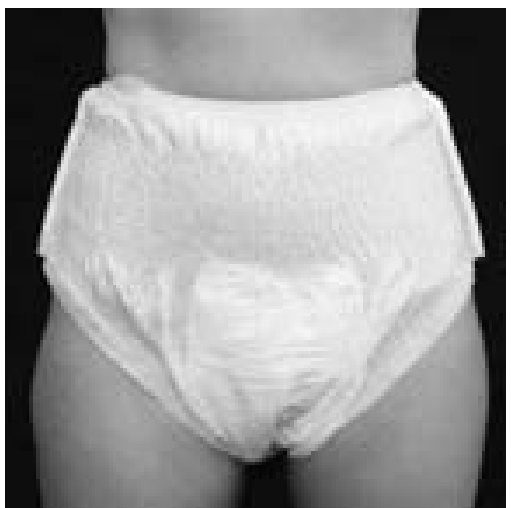

FIGURE 45 (a) Insert; (b) diaper; (c) T-shaped and (d) pull-up

about the study and to invite them to take part. In total 31 nursing homes were approached: 7 in north London and 24 in Southampton and the surrounding area. The aim was to recruit a total of 80 resident participants from a minimum of 10 homes to minimise potential bias from the group effects of single homes. The inclusion and exclusion criteria for participants are shown in Box 3.

\section{Consenting procedure}

Eligible residents were introduced to the researcher by the nursing home staff; the

\section{BOX 3 Inclusion and exclusion criteria}

\section{Inclusion criteria:}

Adult women and men

Resident in nursing homes

Currently using absorbent products for moderate/heavy urinary or urinary and faecal incontinence

\section{Exclusion criteria:}

Acute illness

Terminal phase of illness

Urethral or supra-pubic catheter researchers explained the purpose of the research to the resident and, when necessary, read the participant information sheet to the resident and discussed it with them. If the researcher felt that the resident understood the research and would be able to make an informed decision, they were given 24 hours to consider whether they wished to take part. During this time they were encouraged to discuss their decision with relatives and nursing home staff if they wished. The researcher revisited the resident the next day, checked that they still understood the study and answered any questions. If the resident was willing to proceed, they signed a consent form.

If, following the meeting, the researcher felt that the resident was unable to give their own consent due to mental impairment, relatives were contacted by post or in person and provided with study information and asked to consider if the resident would have wanted to take part in the study had she or he been able to decide for themselves. Residents were included in the trial if the relatives believed that the resident would have wanted to take part and were excluded if objections were raised by either the relatives or the 
care staff. The consenting procedure was reviewed by the ethics committee and is shown in Appendix 15.

During the study period, staff were able to discontinue the use of any product if it was deemed unsatisfactory for the participant in any way or the participant showed, in words or actions, that they did not wish to participate.

\section{Outcome measures}

The outcome measures (see Chapter 2 for more details) are listed below. Carers and (where possible) participants completed a product performance questionnaire at the end of each product testing period and a final interview at the end of the study. A primary carer was allocated for each resident together with a backup carer to cover staff holidays and sickness. We recognised from the consenting data (see above) that few residents would be able to provide complete responses to the product performance questionnaires or final interviews themselves and therefore aimed to obtain primary data from the nominated care staff, who were asked to take residents' opinions and preferences into account where available. Due to staff absence, some carers completed product performance questionnaires/final interviews for more than one subject; however, they were always encouraged to give resident-specific responses. For the final interview, the researchers prompted each carer to focus on the named participant to ensure that responses reflected the performance of the designs for the specific resident. Residents who were able to give their own opinions completed a separate shortened final interview.

\section{Pad leakage and laundry}

During the period of product testing, care staff were asked to save as many used pads as possible in individual plastic bags and complete a label (stuck to each bag) which recorded the participant's initials, the date, where the pad was worn (in bed or out of bed), whether the product had leaked urine (none, a little, a lot) and whether leakage had resulted in incontinence laundry items. Used products were then weighed daily by a researcher (or trained staff member) using digital scales, the urine mass was recorded on the label and the label was removed from the bag and stuck into a data entry book. If there were faeces in the pad, staff were instructed to dispose of the pad, but still to complete the label giving details of urine leakage and additionally to complete a card to report details of any faecal leakage.
Product pad change labels were used to record:

- laundry resulting from incontinence (small and large items)

- leakage from pad (none, a little, a lot)

- weight of used pad (g).

A baseline data questionnaire (completed by researchers) was completed through interviews with carers and residents.

At the end of each period of product testing (2 weeks), a product performance questionnaire was completed to record:

- product performance variables (e.g. discreetness) on a five-point scale (very good, good, okay, poor, very poor).

- numbers of staff usually required to carry out product change (none, one, two).

During the second week of each product testing, skin health was observed in the buttock, groin and sacral areas and the maximum severity of any skin problem was recorded:

- skin health (none, mild or a little, moderate/severe or a lot).

At the end of the trial, a final interview was completed to record:

- Design preferences and rankings.

- Acceptability of design (highly acceptable, acceptable, unacceptable, totally unacceptable), with and without costs; and whether the carer would recommend to other care staff.

- Score on a VAS (worst possible design-best possible design). A simplified 10-point measure was used in this module because piloting showed that this was easier for staff to use than the VAS used in trial 2a.

- Comments about good and poor aspects of designs.

\section{Selection of absorbent products to represent design groups}

A single product was selected to represent each of the four design groups (insert, pull-up, diaper, T-shaped diaper) for day and another for night use (a total of eight products). The products were selected from interim data available from the similar clinical trial of absorbent products which was being undertaken with community-dwelling individuals (see Chapter 4). This community trial 
included three products to represent each design group, which had been preselected from a pilot study. They had similar absorbencies to those most commonly purchased by the NHS (see Chapter 2) and, in order to avoid the confounding effects of different absorbencies, had similar absorbencies to each other $(1900 \mathrm{ml} \pm 20 \%$ for daytime use and $2400 \mathrm{ml} \pm 20 \%$ for night-time use ${ }^{7}$ ). A single product was selected to represent each design because preliminary discussions with nursing homes indicated that the additional time and complexity of testing three products to represent one design was excessive for nursing home staff.

\section{Study preparation and procedures Product preparation, randomisation and blinding}

Waist and hip measurements were used to order appropriately sized products for each participant. Blinding was not practical because each design had a different appearance. Products were therefore provided in their original packaging complete with any manufacturers' instructions. Packs of products were marked with study labels indicating whether they were day or night products. At the beginning of each 2-week testing period, the new, labelled test products were placed in the residents' bathrooms, together with the labelled plastic bags for product saving, and the previous products were removed.

Products were cluster randomised to each nursing home using Latin squares. ${ }^{38}$ Randomisation of the order of products for each individual was thought likely to cause confusion and error and participants within each home therefore used the same design of products at the same time.

\section{Staff meetings}

Care staff meetings were held at each nursing home to discuss the study with the carers and to seek their cooperation. The product designs were shown and demonstrated to staff to ensure that all carers were familiar with them. The completion of the pad labels at each pad change was also demonstrated. At these meetings, we also asked carers to prioritise the pad performance variables they considered to be of greatest importance (using a list; see Chapter 6) and these variables were selected for analysis from the product performance questionnaire.

\section{Baseline data}

Research staff collected baseline information
Chapter 2) from participants and care staff using questionnaires.

\section{Product testing period}

Each design was tested for a 2-week period; the total test period was therefore 8 weeks. Although a 1 -week testing period was used for each product in the community trials (with three products representing each design), a longer period was considered necessary for the homes to ensure that, given different shift patterns, leave and days off, staff had sufficient time to experience pad performance with included residents. The homes were visited daily for pad weighing and to discuss trial progress with staff. Product consumption was measured by counting the numbers of products used during the test period. During the second week of testing, skin health was observed and recorded by the researcher. At the end of each 2-week period, the care staff (both day and night) and participants (where possible) were asked to complete product performance questionnaires.

\section{Final interview}

On completion of the 8-week testing period, a final interview was arranged with the carers (and participants), who were asked to indicate their preferences by ranking the designs. The different designs were scored on a 10-point VAS and were rated using the overall acceptability score. An overview of the study process is shown in Figure 46.

\section{Pad change timing exercise}

The two newer designs (pull-up and T-shaped) were both engineered to be easier to put on than the conventional designs (insert and diaper) and they might therefore be expected to save on time taken for pad changes. In addition to the clinical trial, we therefore carried out a small pad-change timing study which aimed to compare the length of time designs took for pad changing. Our hypothesis was that the pull-up design would be faster than the insert design and that the T-shaped diaper design would be faster than the diaper design.

\section{Design and methods}

Crossover design: for each participant the four pad changes (with the four different designs) were carried out consecutively, in random order by the same pair of carers (or individual carer) according to Latin squares.

\section{Sample}

Residents who had taken part in the clinical trial (from three homes)and were able to give their own 


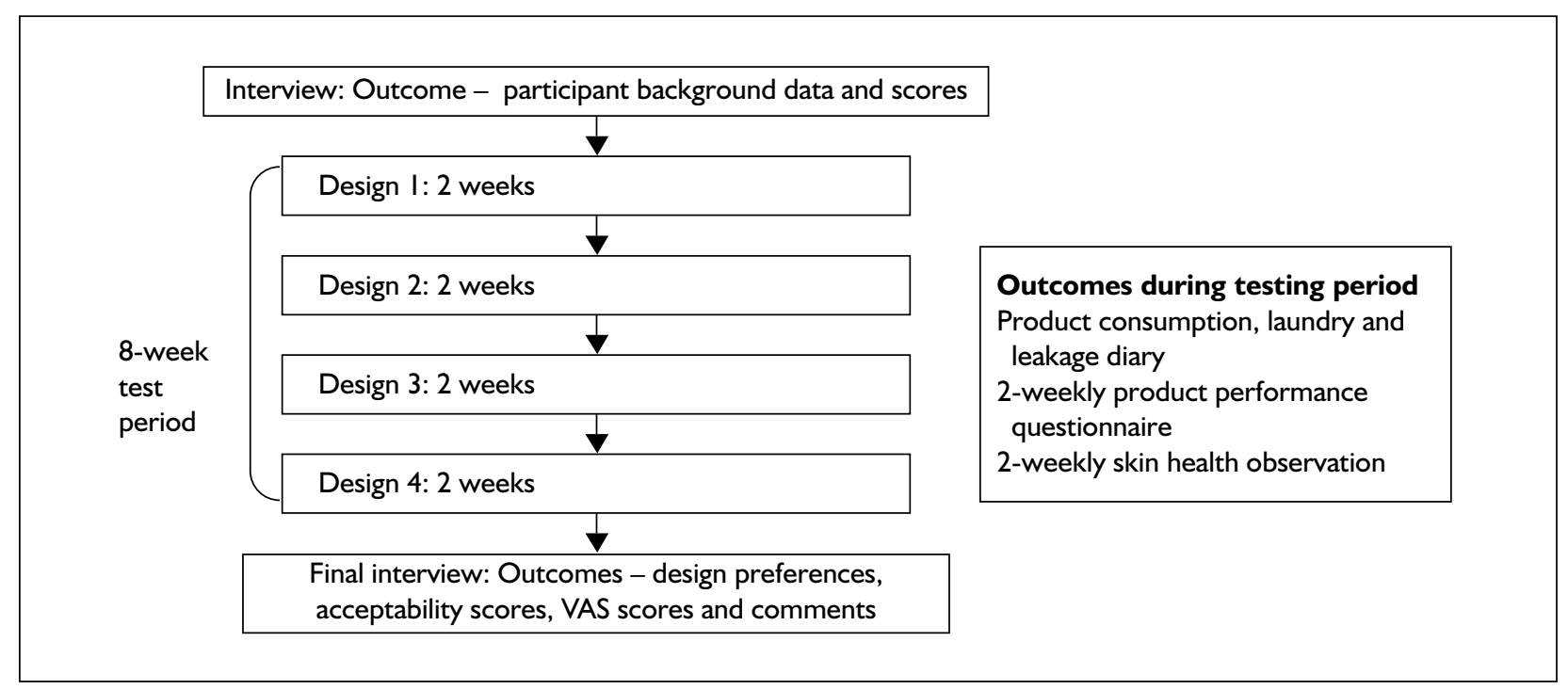

FIGURE 46 Overview of study process and outcomes

consent were asked if they wished to take part in the exercise. Staff member volunteers who had taken part in the clinical trial, regularly cared for the resident and were willing to take part in the exercise were recruited with the resident. The number of staff used to undertake the pad change was the usual number required by the resident (either one or two).

Before commencing the timing exercise, the volunteer staff member(s) carried out a practice run-through using the researcher as a model. This was to ensure that the staff members were familiar with the designs, particularly those not in regular use (pull-ups and T-shaped).

\section{Procedure}

The pad change was timed in four stages.

- Stage 1 - the time taken to remove the resident's underclothes and the absorbent product currently worn. This was measured once, at the beginning of the exercise.

- Stage 2 - the time taken to apply the pad. This was measured once for each design (i.e. four times). The timing started with the resident in the same position (sitting in a chair) and the pad was placed in the same location next to the resident. The finishing time was measured when the resident had been re-seated.

- Stage 3 - the time taken to remove the tested design and re-seat the resident. This was measured once for each design (i.e. four times).

- Stage 4 - the time taken to replace the residents clothing and re-seat them. This was measured once, at the end of the exercise.

Stages 1 and 4 were measured only once in order to minimise the effort required for the resident and staff member. These measures were used to provide estimates of the total time taken to change the residents' pad.

\section{Outcomes}

Time in seconds measured by stopwatch by the observing researcher for stages 2 and 3 (added together) of the pad change.

\section{Ethics}

The study was reviewed by the London multicentre research ethics committee and complied fully with ethical, governance and data protection requirements and approval was obtained through appropriate NHS research ethics committees.

\section{Analysis}

Data were entered into Microsoft Excel (Version 2003), cleaned and $10 \%$ of the data set and $100 \%$ of the primary outcome variable data were checked for accurate entry. Ordinal outcome variables were analysed using cumulative logit modelling, and quantitative outcome variables were analysed by linear modelling, allowing for repeated observations by each subject. Bonferroni adjustments were made in significance tests and to CIs for multiple comparisons between designs. $\mathrm{R}$ software was used (www.r-project.org). 


\section{Results}

\section{Participant characteristics}

A total of 149 potential participants were eligible from the 10 nursing homes. Consent (or agreement from a relative or third party) was obtained from 120 participants; 113 began testing products and 100 completed testing of all designs. Progress of participants through the trial is shown in Figure 47 and participant characteristics are shown in Table 52. Most of the 100 participants were female $(73 \%)$ and the mean age was 81.9 years (range $42-105$ years). Most required a high level of care; $70 \%$ were wheelchair, chair or bed bound, $89 \%$ were totally dependent on care staff for their continence needs and $90 \%$ had medium or high dependency according to the Barthel index. Half of the participants scored zero on the Hodkinson mental test score. Most (75\%) participants were using disposable inserts before the study and the rest used diapers. None were using T-shaped products and one resident was using a pull-up at night.

\section{Staff characteristics}

Ninety-six care staff (68 day staff and 28 night staff) completed the fortnightly product performance questionnaires and the final interviews. The staff characteristics are shown in Table 53. Most staff were female $(81 \%)$ and the mean age was 39 years (range 19-66 years). Most staff were care assistants and were in full-time employment. More than $95 \%$ had been in post for more than 6 months and $50 \%$ had been in post for $\geqslant 3$ years. Over $40 \%$ of staff were in their first caring job and $57 \%$ had a formal qualification, such as NVQ, which was relevant to care of older people. Two-thirds had been on a short course about care of older people.

\section{Nursing home characteristics}

Ten nursing homes were recruited, three in the London area and seven in the Southampton area. The homes varied in size: the three London homes had beds for between 52 and 62 residents, whereas the Southampton homes were generally smaller and varied from 24 to 55 beds. The home manager was asked to describe the category of resident that the home was registered to care for; the results are shown in Table 54. All the homes provided nursing care but may additionally provide care for terminally ill or physically disabled people. Some homes had a dedicated unit to care for individuals who are elderly mentally ill (including Alzheimer's disease and dementia); these homes have registration for elderly mentally infirm (EMI). The characteristics of the homes are shown in Table 55.

\section{Comparisons of different designs Leakage performance}

The leakage performance of the different designs was calculated using data from the pad change labels, which were completed at each pad change. Leakage was recorded as none, a little, a lot. Tables 56 and 57 show the proportions of saved and weighed pads that leaked.

The median urine masses were calculated for each design and are shown in Table 58.
6 died before testing started I moved home

3 relatives withdrew agreement during test period, ( 2 changed mind, I concerned about rash)

2 withdrew during study

8 died during study 
TABLE 52 Participant characteristics: ( $\mathrm{N}=100$, except where missing data stated)

\begin{tabular}{|c|c|c|c|c|c|c|c|c|c|}
\hline \multirow{2}{*}{$\begin{array}{l}\text { Participant background } \\
\text { information }\end{array}$} & \multicolumn{9}{|c|}{$\%(N)$} \\
\hline & $\begin{array}{l}\text { Mean } 81.9 \\
(S D \text { I3.3) }\end{array}$ & $\begin{array}{c}<70 \\
13.0(13)\end{array}$ & $\begin{array}{c}70-79 \\
20.0(20)\end{array}$ & $\begin{array}{c}80-84 \\
15.0(15)\end{array}$ & $\begin{array}{c}85-89 \\
20.0(20.0\end{array}$ & $\begin{array}{c}90-94 \\
0) \quad 18.0(18)\end{array}$ & $\begin{array}{r}95 \\
12(1\end{array}$ & $\begin{array}{l}-99 \\
2.0)\end{array}$ & $\begin{array}{l}\geqslant 100 \\
2.0(2)\end{array}$ \\
\hline Gender: & \multicolumn{4}{|c|}{$\begin{array}{c}\text { Male } \\
27.0(27)\end{array}$} & \multicolumn{5}{|c|}{$\begin{array}{c}\text { Female } \\
73.0(73)\end{array}$} \\
\hline $\begin{array}{l}\text { Diagnosis related to } \\
\text { incontinence: }\end{array}$ & \multicolumn{3}{|c|}{$\begin{array}{l}\text { CVA (stroke) } \\
2 \mathrm{I} .0(2 \mathrm{I})\end{array}$} & \multicolumn{2}{|c|}{$\begin{array}{c}\text { Alzheimer's/dementia } \\
29.0(29)\end{array}$} & \multicolumn{4}{|c|}{$\begin{array}{c}\text { Parkinson's disease } \\
7.0(7)\end{array}$} \\
\hline $\begin{array}{c}\text { CVA and dementia } \\
8.0(8)\end{array}$ & \multicolumn{2}{|c|}{$\begin{array}{l}\text { CVA and Parkinson's } \\
\text { I.0 (I) }\end{array}$} & \multicolumn{3}{|c|}{$\begin{array}{l}\text { Parkinson's and dementia } \\
2.0(2)\end{array}$} & \multicolumn{4}{|c|}{$\begin{array}{l}\text { Other (and unknown) } \\
\qquad 32.0(32)\end{array}$} \\
\hline Body build & \multicolumn{3}{|c|}{$\begin{array}{l}\text { Underweight } \\
20.0(20)\end{array}$} & \multicolumn{2}{|c|}{$\begin{array}{l}\text { Normal } \\
66.0(66)\end{array}$} & \multicolumn{4}{|c|}{$\begin{array}{l}\text { Overweight } \\
14.0(14)\end{array}$} \\
\hline Mobility & \multicolumn{2}{|c|}{$\begin{array}{l}\text { Independent } \\
7.0(7)\end{array}$} & $\begin{array}{l}\text { Uses aid } \\
19.0(19)\end{array}$ & \multicolumn{3}{|c|}{$\begin{array}{l}\text { Wheelchair/chairbound } \\
57.0(57)\end{array}$} & \multicolumn{3}{|c|}{$\begin{array}{l}\text { Bedbound } \\
17.0(17)\end{array}$} \\
\hline $\begin{array}{l}\text { Norton score } \\
\text { (pressure ulcer risk) }\end{array}$ & \multicolumn{3}{|c|}{$\begin{array}{c}\text { I4 or below (at greatest risk) } \\
94.0(94)\end{array}$} & \multicolumn{3}{|c|}{$\begin{array}{c}\text { 15-17 (not at risk but observe) } \\
6.0(6)\end{array}$} & \multicolumn{3}{|c|}{$\begin{array}{c}\text { I8-20 (minimal risk }) \\
0.0(())\end{array}$} \\
\hline $\begin{array}{l}\text { Braden score - pressure } \\
\text { Ulcer risk assessment } \\
\text { (level of risk) }\end{array}$ & \multicolumn{2}{|c|}{$\begin{array}{l}\text { Mean } 14.6 \\
(\text { SD 3.5) }\end{array}$} & $\begin{array}{l}-10 \text { (very high } \\
14.0(14)\end{array}$ & \multicolumn{2}{|c|}{$\begin{array}{l}\text { II-I5 (high) } \\
44.0(44)\end{array}$} & \multicolumn{2}{|c|}{$\begin{array}{l}\text { 16-19 (medium) } \\
33.0(33)\end{array}$} & \multicolumn{2}{|c|}{$\begin{array}{l}20-23 \text { (low) } \\
9.0(9)\end{array}$} \\
\hline $\begin{array}{l}\text { Barthel score (activities of } \\
\text { daily living) ( } 3 \text { missing) } \\
(0=\text { total dependence, } \\
100=\text { independent, } \\
\text { N.B. maximum for this } \\
\text { group }=90-10 \text { points } \\
\text { deducted for incontinence) }\end{array}$ & \multicolumn{2}{|c|}{$\begin{array}{l}\text { Mean } 19.8 \\
(S D \text { 18.3) }\end{array}$} & \multicolumn{3}{|c|}{$\begin{array}{c}0-20 \\
61.9(60)\end{array}$} & \multicolumn{2}{|l|}{$\begin{array}{c}25-40 \\
21.6(2 I)\end{array}$} & \multicolumn{2}{|c|}{$\begin{array}{l}45-60 \\
16.5(16)\end{array}$} \\
\hline $\begin{array}{l}\text { Hodkinson mental test } \\
(7-10=\text { not impaired, } \\
0-6 \text { abnormal, } \\
(5 \text { missing data) })\end{array}$ & \multicolumn{2}{|c|}{$\begin{array}{l}\text { Unable to answer } \\
\qquad 4.4(4)\end{array}$} & \multicolumn{3}{|c|}{$\begin{array}{c}0 \\
56.0(5 \mathrm{I})\end{array}$} & $\begin{array}{c}1-6 \\
31.9(29)\end{array}$ & & \multicolumn{2}{|c|}{$\begin{array}{c}7-10 \\
12.1(11)\end{array}$} \\
\hline Faecal incontinence & \multicolumn{3}{|c|}{$\begin{array}{c}\text { No } \\
22.0(22)\end{array}$} & \multicolumn{2}{|c|}{$\begin{array}{c}\text { Yes - small amounts } \\
12.0(12)\end{array}$} & \multicolumn{4}{|c|}{$\begin{array}{l}\text { Yes - larger amounts } \\
66.0(66)\end{array}$} \\
\hline $\begin{array}{l}\text { Design of product used before } \\
\text { study day (I missing data) }\end{array}$ & \multicolumn{3}{|c|}{$\begin{array}{l}\text { Insert } \\
76.7(76)\end{array}$} & \multicolumn{2}{|c|}{$\begin{array}{c}\text { Diaper } \\
23.2(23)\end{array}$} & & $\begin{array}{l}\text { Pull } \\
0.0\end{array}$ & & \\
\hline $\begin{array}{l}\text { Design of product used before } \\
\text { study night ( } 2 \text { missing data) }\end{array}$ & & $\begin{array}{l}\text { Insert } \\
69.4(68)\end{array}$ & & $\begin{array}{l}\text { Diap } \\
29.6\end{array}$ & $\begin{array}{l}\text { per } \\
(29)\end{array}$ & & $\begin{array}{l}\text { Pull } \\
1.0\end{array}$ & & \\
\hline $\begin{array}{l}\text { Number of products used } \\
\text { per day/night }\end{array}$ & & Mean & $\begin{array}{l}\text { Day } \\
3.26 \text { (SD } 0.9\end{array}$ & 909) & & $\begin{array}{r}\mathrm{Ni} \\
\text { Mean } 2.37\end{array}$ & ight & $.993)$ & \\
\hline
\end{tabular}

The daytime insert design contained less urine than the other three designs and night-time designs overall contained more urine than daytime designs. The urine weights varied between designs and leakage performance was therefore compared at specified urine weights using the binarised data: (no leak) versus (a little + a lot).

The urine weights were also examined by gender. Mean urine weights showed that the men's pads contained significantly more urine than the women's pads: mean daytime urine mass $214.4 \mathrm{~g}$ for men and $162.4 \mathrm{~g}$ for women (difference $53.6 \mathrm{~g}$, 95\% CI 30.0 to 77.3); the difference was not significant for night-time: $256.0 \mathrm{~g}$ for men and $176.9 \mathrm{~g}$ for women (difference $35.6,95 \% \mathrm{CI}-15.9$ to 87.2 ).

The leakage results in the forest plots (Figures 50-61) show comparisons of leakage performance between designs for the median 
TABLE 53 Characteristics of care staff [ $\mathrm{N}=96: 68$ (70.8\%) day; 28 (29.2) night]

\begin{tabular}{|c|c|c|c|}
\hline & & $\mathbf{N}$ & $\%$ \\
\hline Gender & $\begin{array}{l}\text { Male } \\
\text { Female }\end{array}$ & $\begin{array}{l}15 \\
81\end{array}$ & $\begin{array}{l}15.6 \\
84.4\end{array}$ \\
\hline Position (I missing) & $\begin{array}{l}\text { Registered nurse } \\
\text { Care assistant } \\
\text { Adaptation nurse }\end{array}$ & $\begin{array}{r}6 \\
84 \\
5\end{array}$ & $\begin{array}{r}6.3 \\
87.5 \\
5.2\end{array}$ \\
\hline First job as a carer & Yes & 42 & 43.8 \\
\hline Length of time in current position ( 4 missing) & $\begin{array}{l}<6 \text { months } \\
6 \text { months }-2 \text { years } \\
3-5 \text { years } \\
6-10 \text { years } \\
>10 \text { years }\end{array}$ & $\begin{array}{r}3 \\
41 \\
26 \\
16 \\
6\end{array}$ & $\begin{array}{r}3.1 \\
42.7 \\
27.1 \\
16.7 \\
6.3\end{array}$ \\
\hline Formal training in older people care & $\begin{array}{l}\text { NVQ or equivalent } \\
\text { Short course }\end{array}$ & $\begin{array}{l}55 \\
64\end{array}$ & $\begin{array}{l}57.3 \\
66.7\end{array}$ \\
\hline Age (years) (7 declined to answer) & $\begin{array}{l}\text { Mean } 39.24 \text { (SD 10.93) } \\
\text { Median } 37 \text { (range 19-66) }\end{array}$ & & \\
\hline
\end{tabular}

TABLE 54 Home registration categories

\begin{tabular}{|lc|}
\hline Type of home & $\begin{array}{c}\text { No. of } \\
\text { homes }\end{array}$ \\
\hline Elderly, disabled, terminally ill & 3 \\
Elderly and terminally ill & $\mathrm{I}$ \\
Elderly mentally infirm (EMI) & 3 \\
Physical disability and elderly & $\mathrm{I}$ \\
Continuing care, palliative care, dementia, & \\
frail elderly & $\mathrm{I}$ \\
\hline Nursing care & \\
\hline
\end{tabular}

urine weight (150 $\mathrm{g}$ for daytime and $180 \mathrm{~g}$ for night-time). The results showed that during the daytime, at the median urine mass $(150 \mathrm{~g})$ the insert design was significantly worse than the T-shaped design. During the night-time, the insert and the pull-up designs were significantly worse than the diaper design and the pull-up design was also significantly worse than the T-shaped design at the median urine mass (180 g). However, where differences between designs were found they were not large (typically around 10\%).

TABLE 55 Nursing home characteristics

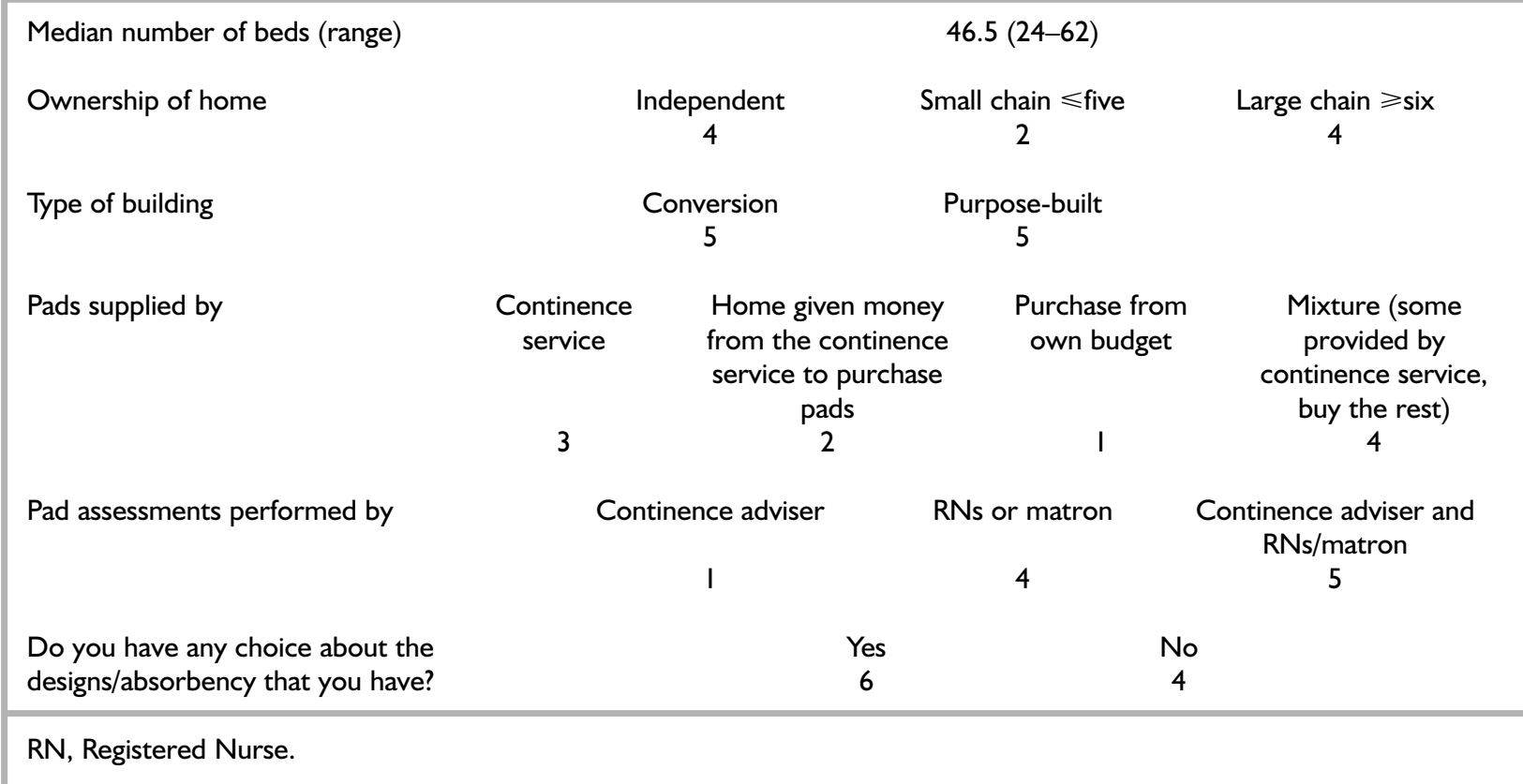


TABLE 56 Leakage performance of daytime designs (number of participants $=100$, total number of products saved $=5798$ )

\begin{tabular}{|lcccc|}
\hline & \multicolumn{3}{c}{$\%(\mathbf{N})$} \\
\cline { 2 - 5 } & Insert & Diaper & Pull-up & T-shaped \\
\hline No leakage & $69.7(992)$ & $68.8(1082)$ & $72.2(958)$ & $74.9(1105)$ \\
A little & $16.2(231)$ & $18.3(288)$ & $14.5(192)$ & $11.9(175)$ \\
A lot & $14.1(201)$ & $12.9(202)$ & $13.3(177)$ & $13.2(195)$ \\
\hline
\end{tabular}

TABLE 57 Leakage performance of night-time designs (number of participants $=100$, total number of products saved $=4646$ )

\begin{tabular}{|lcccc|}
\hline & \multicolumn{3}{c|}{$\%(\mathbf{N})$} \\
\cline { 2 - 5 } & Insert & Diaper & Pull-up & T-shaped \\
\hline No leakage & $66.1(771)$ & $70.9(904)$ & $63.3(655)$ & $68.6(802)$ \\
A little & $18.6(217)$ & $14.6(186)$ & $18.6(192)$ & $16.4(192)$ \\
A lot & $15.3(178)$ & $14.6(186)$ & $18.2(188)$ & $15.0(175)$ \\
\hline
\end{tabular}

TABLE 58 Median urine mass in each design

\begin{tabular}{|lcccc|}
\hline & Insert & Diaper & Pull-up & T-shaped \\
\hline $\begin{array}{l}\text { Daytime } \\
\text { Median urine mass (g) (IQ range) }\end{array}$ & 133.0 & 153.0 & 147.0 & 147.0 \\
No. of products & $(73.0-220.0)$ & $(81.0-261.0)$ & $(84.0-244.0)$ & $(86.0-240.5)$ \\
Night-time & 1424 & 1572 & 1327 & 1475 \\
Median urine mass (g) (IQ range) & 174.0 & 183.0 & 168.0 & 205.0 \\
& $(95.25-310.5)$ & $(100.0-314.25)$ & $(91.0-281.0)$ & $(112.0-327.0)$ \\
No. of products & 1166 & 1276 & 1035 & 1169
\end{tabular}

Based on the binarised leakage data, (none) versus (a little + a lot), and urine weights, the leakage performance was modelled for each design and Figures 48 and 49 , show the probability of there being no leakage for day and night at the different urine weights for each of the four designs.

\section{Explanation of leakage curves}

Pads do not have a simple capacity below which they are guaranteed not to leak and above which they will definitely leak. Rather, as the volume (i.e. mass) of urine increases, the probability of the pad leaking increases. The leakage performance curves were constructed for each design (by combining data from the various products of the same design) and show how the probability of the design not leaking changed with increasing urine mass. In general, the more successful a design, the higher was the performance curve on the graph: a perfect design would have a probability of not leaking at all of 1 (= certainty) for all urine masses.
Intuitively, these probability curves should have a value of 1.0 for zero urine mass - how can a pad leak if there is no urine in it? Weighing used pads provides an estimate only of the mass of urine in the pad and excludes any leakage from the pad: accordingly, the urine masses used in constructing the curves will often have been (slight) underestimates of the actual masses voided by the wearer. For example, a pad may leak (and the urine mass in the pad be recorded as zero) if the absorbent area is out of position. One of the effects of this is that the leakage performance curves of products will meet the $y$-axis at values less 1.0, the value which would be expected naturally. In the extreme, a pad capable of holding no urine at all would be certain to leak whatever quantity of urine its user voided and yet all used pads would contain zero urine mass.

In addition, dry masses vary (coefficient of variation of the order of $10 \%$ ) and so there will be 


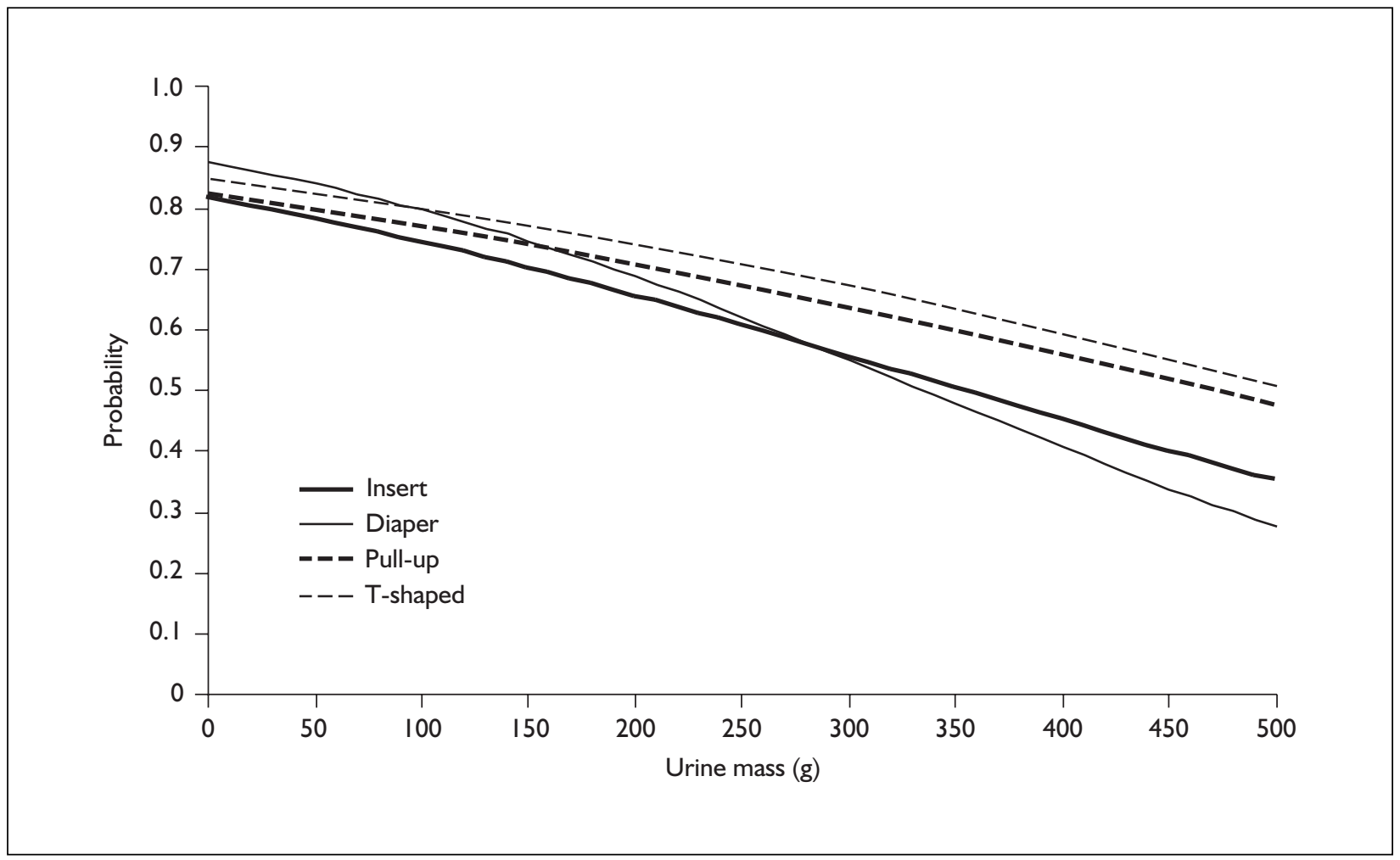

FIGURE 48 Estimated probabilities of no leakage for different urine masses by design (day)

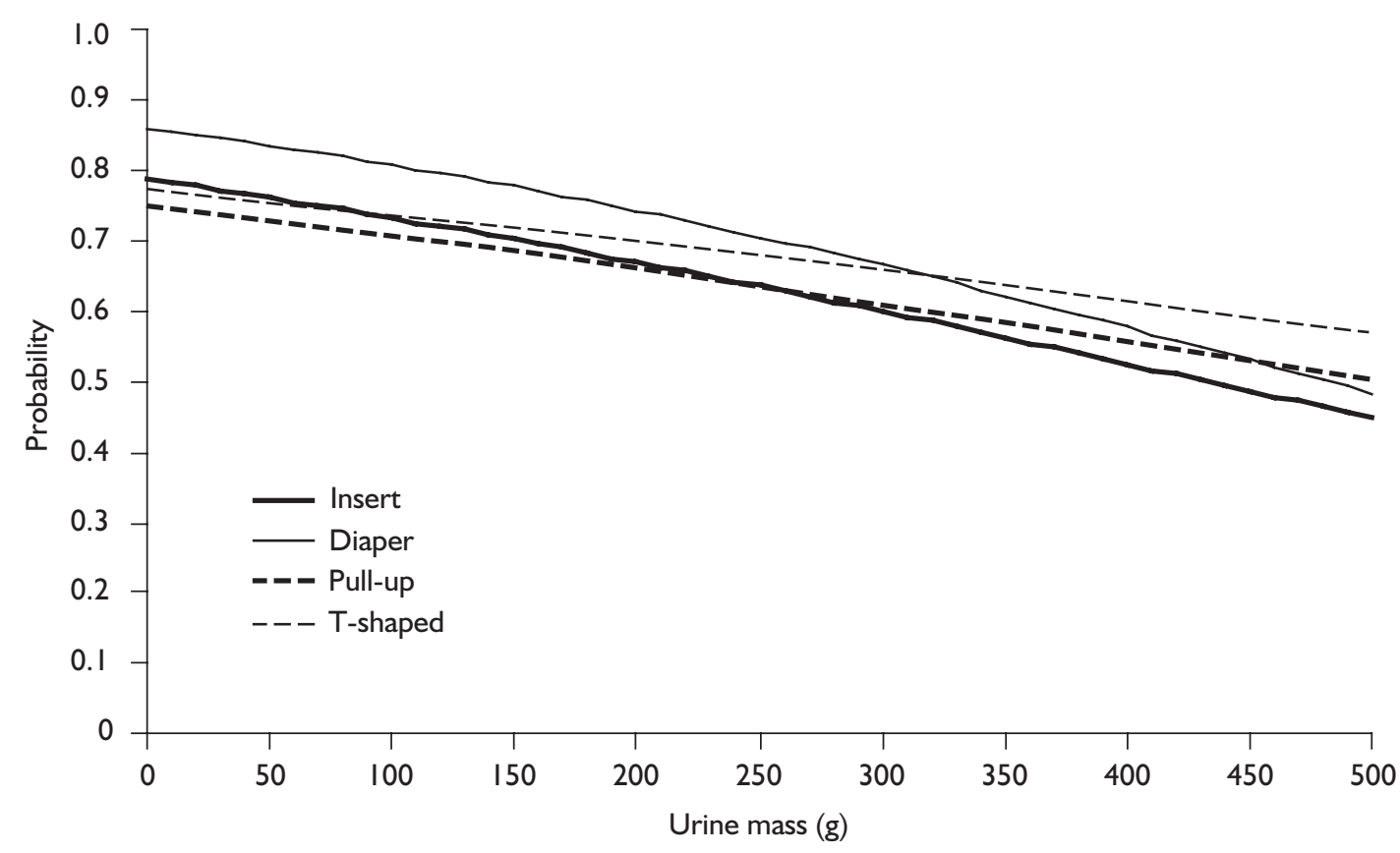

FIGURE 49 Estimated probabilities of no leakage for different urine masses by design (night) 
small errors in estimated urine masses. These errors will be negligible for high urine masses but more substantial for (nearly) dry pads.

\section{Consumption of products}

Estimates were made of the mean numbers of products used per day and per night and results for each design are shown in Tables 59 and 60.

During the daytime, significantly more pull-up designs were used than the other designs. During the night-time, significantly less pull-up designs were used than the other designs and the insert design was used significantly more than other designs. Overall during the daytime a mean of 2.59 products were used, which is less than was reported by staff at the beginning of the study (mean = 3.26), and results for the daytime were similar to the night-time. Night-time products are often applied during the afternoon and evening, in preparation for the night, and this may explain why differences in day- and night-time use were not greater. The overall night-time mean was 2.35 , which was very similar to that reported by staff $(2.37)$.

\section{Laundry resulting from leakage}

Staff were asked to record (on the pad change label) whether there was any laundry generated at a pad change (yes/no). If there was, they were asked to record the type of laundry, namely how many small and how many large items. However, staff did not usually manage to record this level of detail and so the type of laundry was not analysed. Tables 61 and 62 show the proportions of recorded

TABLE 59 Consumption: mean number of daytime designs used ( $\mathrm{N}=100$ participants)

\begin{tabular}{|c|c|c|c|c|c|}
\hline & & Insert & Diaper & Pull-up & T-shaped \\
\hline \multicolumn{2}{|c|}{$\begin{array}{l}\text { Weighted mean number of products } \\
\text { used per day (SD) }\end{array}$} & $2.5(0.69)$ & $2.5(0.76)$ & $3.0(0.92)$ & $2.4(0.78)$ \\
\hline \multicolumn{6}{|c|}{ Consumption: comparisons between designs } \\
\hline & & & \multicolumn{2}{|c|}{ Estimated difference } & $95 \% \mathrm{Cl}^{a}$ \\
\hline Insert & not significantly different to & Diaper & & 0.03 & -0.19 to 0.25 \\
\hline Insert & used significantly less than & Pull-up & & -0.40 & -0.62 to -0.18 \\
\hline Insert & not significantly different to & T-shaped & & 0.18 & -0.09 to 0.45 \\
\hline Diaper & used significantly less than & Pull-up & & -0.43 & -0.72 to -0.14 \\
\hline Diaper & not significantly different to & T-shaped & & 0.15 & -0.13 to 0.43 \\
\hline Pull-up & used significantly more than & T-shaped & & 0.58 & 0.31 to 0.86 \\
\hline
\end{tabular}

TABLE 60 Consumption: mean number of night-time products used ( $\mathrm{N}=100$ participants)

\begin{tabular}{|c|c|c|c|c|c|}
\hline & & Insert & Diaper & Pull-up & T-shaped \\
\hline $\begin{array}{l}\text { Weighte } \\
\text { used pe }\end{array}$ & $\begin{array}{l}\text { an number of products } \\
\text { (SD) }\end{array}$ & $2.8(1.13)$ & $2.4(1.14)$ & $2.1(0.79)$ & $2.5(1.15)$ \\
\hline \multicolumn{6}{|c|}{ Consumption: comparisons between designs } \\
\hline & & \multicolumn{3}{|c|}{ Estimated difference } & $95 \% \mathrm{Cl}^{a}$ \\
\hline Insert & not different to & Diaper & & 0.16 & -0.01 to 0.33 \\
\hline Insert & used more than & Pull-up & & 0.58 & 0.35 to 0.82 \\
\hline Insert & used more than & T-shaped & & 0.19 & 0.04 to 0.34 \\
\hline Diaper & used more than & Pull-up & & 0.42 & 0.17 to 0.67 \\
\hline Diaper & not different to & T-shaped & & 0.02 & -0.14 to 0.19 \\
\hline Pull-up & used less than & T-shaped & & -0.40 & -0.65 to -0.14 \\
\hline
\end{tabular}


pad changes which resulted in incontinence laundry. There were no significant differences between designs.

Laundry results showed no differences between the designs in the amount of laundry produced during the day. During the night, the diaper produced significantly less laundry than the pullup, and the diaper and T-shaped diaper produced less laundry than the insert [but these difference was small $(<5 \%)]$.

\section{Skin health}

Skin health observations on five sites within the pad area were made weekly (right and left groins and buttocks and sacrum). The site with the maximum severity (i.e. the worst skin problem) was used to make comparisons between designs.

TABLE 6 I Laundry (day): number of pad changing episodes (N) resulting in clothing/bedding being sent to laundry as a result of incontinence

\begin{tabular}{|c|c|c|c|c|c|}
\hline & & \multicolumn{4}{|c|}{$\%(N)$} \\
\hline & & Insert & Diaper & Pull-up & T-shaped \\
\hline \multirow{2}{*}{\multicolumn{2}{|c|}{$\begin{array}{l}\text { No incontinence laundry } \\
\text { Incontinence laundry }\end{array}$}} & $80.2(1230)$ & $80.0(1356)$ & $79.6(1166)$ & $82.3(134 \mid)$ \\
\hline & & $19.8(304)$ & $20.0(339)$ & $20.4(298)$ & $17.7(289)$ \\
\hline \multicolumn{6}{|c|}{ Laundry: comparisons between designs } \\
\hline & & \multicolumn{3}{|c|}{ Estimated $\mathbf{O R}^{a}$} & $95 \% \mathrm{Cl}^{b}$ \\
\hline Insert & not different to & T-shaped & \multicolumn{2}{|r|}{0.83} & 0.65 to 1.07 \\
\hline Insert & not different to & Diaper & \multicolumn{2}{|r|}{0.91} & 0.70 to 1.19 \\
\hline Insert & not different to & Pull-up & \multicolumn{2}{|r|}{1.05} & 0.82 to 1.35 \\
\hline Diaper & not different to & T-shaped & \multicolumn{2}{|r|}{0.91} & 0.68 to 1.22 \\
\hline Pull-up & not different to & T-shaped & \multicolumn{2}{|r|}{0.79} & 0.60 to 1.05 \\
\hline Diaper & not different to & Pull-up & \multicolumn{2}{|r|}{1.15} & 0.89 to 1.49 \\
\hline
\end{tabular}

TABLE 62 Laundry (night): number of pad changing episodes (N) resulting in clothing/bedding being sent to laundry as a result of incontinence

\begin{tabular}{|c|c|c|c|c|c|}
\hline & & \multicolumn{4}{|c|}{$\%(N)$} \\
\hline & & Insert & Diaper & Pull-up & T-shaped \\
\hline \multirow{2}{*}{\multicolumn{2}{|c|}{$\begin{array}{l}\text { No incontinence laundry } \\
\text { Incontinence laundry }\end{array}$}} & $74.7(930)$ & $80.4(I I 80)$ & $74.5(847)$ & $78.9(1013)$ \\
\hline & & $25.3(3 \mid 5)$ & $19.6(287)$ & $25.5(290)$ & $2 I . I(27 \mathrm{I})$ \\
\hline \multicolumn{6}{|c|}{ Laundry: comparisons between designs } \\
\hline & & \multicolumn{3}{|c|}{ Estimated $\mathbf{O R}^{a}$} & $95 \% \mathrm{Cl}^{b}$ \\
\hline Insert & more laundry than & T-shaped & \multicolumn{2}{|c|}{0.75} & 0.58 to 0.98 \\
\hline Insert & more laundry than & Diaper & \multicolumn{2}{|c|}{0.69} & 0.53 to 0.91 \\
\hline Insert & not different to & Pull-up & \multicolumn{2}{|c|}{1.02} & 0.74 to 1.42 \\
\hline Diaper & not different to & T-shaped & \multicolumn{2}{|c|}{0.91} & 0.68 to 1.22 \\
\hline Pull-up & not different to & T-shaped & \multicolumn{2}{|c|}{0.79} & 0.60 to 1.05 \\
\hline Pull-up & more laundry than & Diaper & \multicolumn{2}{|c|}{1.47} & 1.10 to 1.97 \\
\hline \multicolumn{6}{|c|}{$\begin{array}{l}{ }^{a} \text { ORs are for no laundry. } \\
{ }^{b} \text { Cls include Bonferroni adjustment for multiple comparisons, except for diaper compared with washables (single } \\
\text { comparison made). To assist the reader, comparisons between designs have been described as 'not different' if they are } \\
\text { not significant }(p>0.05) \text {. }\end{array}$} \\
\hline
\end{tabular}


Table 63 shows the proportions of participants with and without skin health problems.

There were no significant differences between designs when the data were binarised, (no skin problem) versus (otherwise). The T-shaped design had the most moderate to severe skin problems. Examination of the researchers' records of the nature of the skin problems showed that irritation in the area of the waist-belt was a common source of this problem.

\section{Product performance questionnaires}

Product performance questionnaires were completed at the end of testing each design (after 2 weeks). Results were analysed for high-priority variables and the scores are displayed in Tables 64 and 65. Comparisons between each pair of designs are shown, with these data binarised, (very good, good, okay) versus (poor, very poor), in the forest plots in Figures 50-61.

\section{Faecal incontinence}

Data from the participant background information showed that $66.0 \%$ (66) of participants experienced large amounts of faecal incontinence; this is consistent with the pad leakage diary data shown in Table 66. Data were collected via cards, which were completed by staff when a pad containing faeces was disposed of. A total of 644 cards were collected (around 10 per subject). This relatively small number of pads per design (around 160) means that it is hard to draw any firm conclusions regarding leakage performance.

The main differences between designs concerned the following variables: leakage, discreetness and ease of putting on.

- The diaper design performed significantly better than the insert for leakage (significance is defined as $p \leqslant 0.05$; forest plots (Figures 50-61) show ORs and 95\% CIs for each variable).
- The insert design was better than the diaper for discreetness and ease of putting on (standing).

The pull-up design was significantly better than the insert on most variables during the daytime but not discreetness or ease of putting on (standing).

- The pull-up was significantly more difficult to put on in the lying position than the insert during the night.

- There were no significant differences between the T-shaped diaper and the diaper, except that the diaper was easier to put on in a standing position in the day.

\section{Final interview: overall opinion and preferences}

\section{Preferences}

Carers and participants (where possible) were asked to rank the designs in order of their preference and were asked why they chose the designs as best or worst and to identify the good and poor aspects of each design. Final interview data were not available for one resident for the day and two for the night.

Table 67 shows the paired comparisons of carer preferences and Table 68 shows the rankings of the designs. Appendix 16 shows the first-choice preferences for those participants $(N=14)$ who could express an opinion. More participants chose the pull-up design than other designs (6/14), but the data were too few to analyse statistically. Appendix 17 shows the paired comparisons for the different designs by gender.

In the daytime, paired comparisons show that the pull-up was significantly better than the Tshaped diaper $(p<0.0005)$, insert $(p<0.0005)$ and diaper $(p<0.006)$. There were no significant differences between the T-shaped, insert and diaper designs.

TABLE 63 Skin health: proportions of participants with observed skin health problems $(\mathrm{N}=100)^{\mathrm{a}}$

\begin{tabular}{|lcccc|}
\hline & \multicolumn{3}{c}{$\%(\mathbf{N})$} \\
\cline { 2 - 5 } & Insert & Diaper & Pull-up & T-shaped \\
\hline No skin problem & $27.3(27)$ & $33.0(33)$ & $30.6(30)$ & $25.7(26)$ \\
A little (mild) & $39.4(39)$ & $29.0(29)$ & $40.8(40)$ & $34.0(34)$ \\
A lot (moderate/severe) & $33.3(33)$ & $38.0(38)$ & $28.6(28)$ & $40.0(40)$ \\
& $($ I missing) & & $(2$ missing) & \\
\hline${ }^{a}$ Comparisons between designs and 95\% Cls are shown in Figures 50-6I. & & \\
\hline
\end{tabular}


TABLE 64 Product performance questionnaire: design responses (\%): day ${ }^{\mathrm{a}}$

\begin{tabular}{|c|c|c|c|c|c|}
\hline & & Insert & Diaper & Pull-up & T-shaped \\
\hline Leakage (urine) & $\begin{array}{l}\text { Very good } \\
\text { Good } \\
\text { OK } \\
\text { Poor } \\
\text { Very poor }\end{array}$ & $\begin{array}{l}18.4 \\
18.4 \\
24.1 \\
24.1 \\
14.9\end{array}$ & $\begin{array}{r}17.4 \\
39.8 \\
23.5 \\
7.1 \\
12.2\end{array}$ & $\begin{array}{r}24.2 \\
44.4 \\
14.1 \\
10.1 \\
7.0\end{array}$ & $\begin{array}{r}16.5 \\
36.1 \\
27.8 \\
14.4 \\
5.2\end{array}$ \\
\hline Leakage (faeces) & $\begin{array}{l}\text { Very good } \\
\text { Good } \\
\text { OK } \\
\text { Poor } \\
\text { Very poor }\end{array}$ & $\begin{array}{l}10.6 \\
22.4 \\
32.9 \\
23.5 \\
10.6\end{array}$ & $\begin{array}{r}16.5 \\
35.1 \\
30.9 \\
13.4 \\
4.1\end{array}$ & $\begin{array}{r}17.0 \\
43.6 \\
22.3 \\
13.8 \\
3.2\end{array}$ & $\begin{array}{r}14.3 \\
33.0 \\
34.1 \\
14.3 \\
4.4\end{array}$ \\
\hline Staying in place & $\begin{array}{l}\text { Very good } \\
\text { Good } \\
\text { OK } \\
\text { Poor } \\
\text { Very poor }\end{array}$ & $\begin{array}{r}14.8 \\
20.5 \\
43.2 \\
15.9 \\
5.7\end{array}$ & $\begin{array}{r}25.0 \\
34.0 \\
30.0 \\
11.0 \\
0.0\end{array}$ & $\begin{array}{r}30.3 \\
44.4 \\
17.2 \\
4.0 \\
4.0\end{array}$ & $\begin{array}{r}10.1 \\
32.3 \\
38.4 \\
18.2 \\
1.0\end{array}$ \\
\hline Fit & $\begin{array}{l}\text { Very good } \\
\text { Good } \\
\text { OK } \\
\text { Poor } \\
\text { Very poor }\end{array}$ & \begin{tabular}{r|}
16.3 \\
19.8 \\
38.4 \\
17.4 \\
8.1
\end{tabular} & $\begin{array}{r}17.4 \\
29.6 \\
28.6 \\
23.5 \\
1.0\end{array}$ & $\begin{array}{r}21.0 \\
46.0 \\
23.0 \\
9.0 \\
1.0\end{array}$ & $\begin{array}{r}10.1 \\
30.3 \\
29.3 \\
24.2 \\
6.1\end{array}$ \\
\hline Smell & $\begin{array}{l}\text { Very good } \\
\text { Good } \\
\text { OK } \\
\text { Poor } \\
\text { Very poor }\end{array}$ & $\begin{array}{r}10.3 \\
21.8 \\
40.2 \\
23.0 \\
4.6\end{array}$ & $\begin{array}{r}11.0 \\
38.0 \\
38.0 \\
12.0 \\
1.0\end{array}$ & $\begin{array}{r}20.2 \\
46.5 \\
27.3 \\
6.1 \\
0.0\end{array}$ & $\begin{array}{r}6.2 \\
45.4 \\
36.1 \\
10.3 \\
2.1\end{array}$ \\
\hline Discreetness & $\begin{array}{l}\text { Very good } \\
\text { Good } \\
\text { OK } \\
\text { Poor } \\
\text { Very poor }\end{array}$ & $\begin{array}{r}16.3 \\
25.6 \\
53.5 \\
2.3 \\
2.3\end{array}$ & $\begin{array}{r}5.1 \\
27.3 \\
43.4 \\
21.2 \\
3.0\end{array}$ & $\begin{array}{r}22.2 \\
46.5 \\
27.3 \\
4.0 \\
0.0\end{array}$ & $\begin{array}{r}8.2 \\
32.7 \\
45.9 \\
12.2 \\
1.0\end{array}$ \\
\hline Ease on (standing) & $\begin{array}{l}\text { Very good } \\
\text { Good } \\
\text { OK } \\
\text { Poor } \\
\text { Very poor }\end{array}$ & $\begin{array}{r}29.3 \\
29.3 \\
33.3 \\
5.3 \\
2.7\end{array}$ & $\begin{array}{r}10.6 \\
27.1 \\
34.1 \\
22.4 \\
5.9\end{array}$ & $\begin{array}{r}18.8 \\
42.5 \\
25.0 \\
11.3 \\
2.5\end{array}$ & $\begin{array}{l}10.1 \\
16.5 \\
26.6 \\
32.9 \\
13.9\end{array}$ \\
\hline
\end{tabular}

In the night-time, paired comparisons show that the insert was significantly worse than the diaper $(p<0.0005)$, pull-up $(p<0.0005)$ and T-shaped designs $(p<0.0005)$. There were no significant differences between the diaper, pull-up and T-shaped designs.

During the daytime, the best design (most frequently rated first) was the pull-up, followed by the diaper and then the insert. The T-shaped diaper was the design that was most frequently rated worst.

During the night-time the diaper was most frequently rated first and the insert was most frequently rated worst. Although the pull-up was in second place with more top rankings than the T-shaped diaper, on mean ranks it was in third place.

Each design was also rated by carers on a VAS scale of 0 (worst possible design) to 10 (best possible design). VAS scores are shown in Tables 69 and 70. These results reflect preferences, with pull-ups being significantly better than T-shaped diapers, inserts and diapers $(p<0.001)$. There were no significant differences between the Tshaped, diaper and insert designs. For the nighttime, inserts were significantly worse than the other three designs $(p<0.0005)$. There were no significant differences between the T-shaped, diaper and pull-up designs. 
TABLE 65 Product performance questionnaire: design responses (\%): night ${ }^{\mathrm{a}}$

\begin{tabular}{|c|c|c|c|c|c|}
\hline & & Insert & Diaper & Pull-up & T-shaped \\
\hline Leakage (urine) & $\begin{array}{l}\text { Very good } \\
\text { Good } \\
\text { OK } \\
\text { Poor } \\
\text { Very poor }\end{array}$ & $\begin{array}{l}14.0 \\
28.0 \\
20.0 \\
24.0 \\
14.0\end{array}$ & $\begin{array}{l}20.8 \\
34.9 \\
21.9 \\
10.4 \\
12.5\end{array}$ & $\begin{array}{r}23.2 \\
29.3 \\
16.2 \\
26.3 \\
5.1\end{array}$ & $\begin{array}{r}22.6 \\
38.7 \\
21.5 \\
12.9 \\
4.3\end{array}$ \\
\hline Leakage (faeces) & $\begin{array}{l}\text { Very good } \\
\text { Good } \\
\text { OK } \\
\text { Poor } \\
\text { Very poor }\end{array}$ & $\begin{array}{r}14.9 \\
26.6 \\
36.2 \\
13.8 \\
8.5\end{array}$ & $\begin{array}{r}23.1 \\
42.9 \\
20.9 \\
6.6 \\
6.6\end{array}$ & $\begin{array}{r}16.0 \\
36.2 \\
31.9 \\
13.8 \\
2.1\end{array}$ & $\begin{array}{r}20.5 \\
35.2 \\
28.4 \\
15.9 \\
0.0\end{array}$ \\
\hline Staying in place & $\begin{array}{l}\text { Very good } \\
\text { Good } \\
\text { OK } \\
\text { Poor } \\
\text { Very poor }\end{array}$ & $\begin{array}{r}7.2 \\
42.3 \\
40.2 \\
9.3 \\
1.0\end{array}$ & $\begin{array}{r}23.2 \\
33.3 \\
31.3 \\
9.1 \\
3.0\end{array}$ & $\begin{array}{r}35.7 \\
29.6 \\
24.5 \\
7.1 \\
3.1\end{array}$ & $\begin{array}{r}22.6 \\
36.6 \\
28.0 \\
8.6 \\
4.3\end{array}$ \\
\hline Fit & $\begin{array}{l}\text { Very good } \\
\text { Good } \\
\text { OK } \\
\text { Poor } \\
\text { Very poor }\end{array}$ & \begin{tabular}{r|}
11.1 \\
29.3 \\
41.4 \\
15.2 \\
3.0
\end{tabular} & $\begin{array}{r}19.2 \\
38.4 \\
19.2 \\
15.2 \\
8.1\end{array}$ & \begin{tabular}{r|}
28.3 \\
35.4 \\
24.2 \\
10.1 \\
2.0
\end{tabular} & $\begin{array}{r}12.0 \\
47.8 \\
26.1 \\
10.9 \\
3.3\end{array}$ \\
\hline Smell & $\begin{array}{l}\text { Very good } \\
\text { Good } \\
\text { OK } \\
\text { Poor } \\
\text { Very poor }\end{array}$ & $\begin{array}{r}2.0 \\
40.4 \\
36.4 \\
12.1 \\
9.1\end{array}$ & $\begin{array}{r}7.1 \\
35.4 \\
42.4 \\
8.1 \\
7.1\end{array}$ & \begin{tabular}{r|}
16.3 \\
32.7 \\
40.8 \\
8.2 \\
2.0
\end{tabular} & $\begin{array}{r}15.1 \\
36.6 \\
37.6 \\
9.7 \\
1.1\end{array}$ \\
\hline Ease on (lying) & $\begin{array}{l}\text { Very good } \\
\text { Good } \\
\text { OK } \\
\text { Poor } \\
\text { Very poor }\end{array}$ & $\begin{array}{r}25.3 \\
33.3 \\
26.3 \\
10.1 \\
5.1\end{array}$ & \begin{tabular}{r|}
17.7 \\
43.8 \\
29.2 \\
8.3 \\
1.0
\end{tabular} & $\begin{array}{r}5.2 \\
27.1 \\
34.4 \\
27.1 \\
6.3\end{array}$ & $\begin{array}{r}15.6 \\
36.7 \\
31.1 \\
15.6 \\
1.1\end{array}$ \\
\hline
\end{tabular}

TABLE 66 Leakage of faeces from pads, day and night combined ( $\mathrm{N}=66$ participants $/ 644$ pads)

\begin{tabular}{|lc|}
\hline Design & $\begin{array}{c}\text { \% of pads not leaking } \\
\text { at all }\end{array}$ \\
\hline Insert & 56.9 \\
Diaper & 64.8 \\
Pull-up & 50.0 \\
T-shaped & 71.3 \\
\hline
\end{tabular}

\section{Acceptability}

Finally, care staff were asked to consider how acceptable each design was for the resident (Table 71).

The results for overall acceptability were binarised both as (highly acceptable) versus (otherwise) and (highly acceptable + acceptable) versus (otherwise). Both levels of comparisons are shown in the forest plots in Figures 50-61.
TABLE 67 Paired comparisons of preferences between the different designs ${ }^{\mathrm{a}}$

\begin{tabular}{|c|c|}
\hline \multicolumn{2}{|l|}{ Number preferring design } \\
\hline $\begin{array}{l}\text { Day }(\mathrm{N}=99) \\
\text { Pull-up } 65 \text { vs Insert } 34 \\
\text { Pull-up } 66 \text { vs Diaper } 33 \\
\text { Pull-up } 66 \text { vs T-shaped } 33 \\
\text { T-shaped } 49 \text { vs Insert } 50 \\
\text { T-shaped } 48 \text { vs Diaper } 5 \text { I } \\
\text { Diaper } 52 \text { vs Insert } 47\end{array}$ & $\begin{array}{l}\text { Night }(\mathrm{N}=98) \\
\text { Pull-up } 72 \text { vs Insert } 26 \\
\text { Pull-up } 40 \text { vs Diaper } 58 \\
\text { Pull-up } 47 \text { vs T-shaped } 51 \\
\text { T-shaped } 68 \text { vs Insert } 30 \\
\text { T-shaped } 41 \text { vs Diaper } 57 \\
\text { Diaper } 73 \text { vs Insert } 25\end{array}$ \\
\hline \multicolumn{2}{|c|}{$\begin{array}{l}\text { a Comparisons between designs showing the odds on } \\
\text { preferring a design with } 95 \% \text { Cls are shown in } \\
\text { Figures 50-6I (I missing data). }\end{array}$} \\
\hline
\end{tabular}

For the daytime, the pull-up was significantly better than the insert and the T-shaped diaper on both levels of comparisons and the diaper for (highly acceptable) versus (otherwise), but not quite for (highly acceptable + acceptable) versus (otherwise). 
TABLE 68 Design rankings

\begin{tabular}{|c|c|c|c|c|c|c|c|c|}
\hline \multirow[t]{3}{*}{ Design } & \multicolumn{8}{|c|}{$\%(N)$} \\
\hline & \multicolumn{4}{|c|}{$\operatorname{DAY}(N=99)^{a}$} & \multicolumn{4}{|c|}{ NIGHT $(N=98)^{b}$} \\
\hline & I st & 2nd & 3rd & 4th & Ist & 2nd & 3rd & 4th \\
\hline T-shaped & $15.2(15)$ & $28.3(28)$ & $24.2(24)$ & $32.3(32)$ & $20.4(20)$ & $37.8(37)$ & $29.6(29)$ & $12.2(12)$ \\
\hline Diaper & $22.2(22)$ & $19.2(19)$ & $36.4(36)$ & $22.2(22)$ & $39.8(39)$ & $29.6(29)$ & II.2(II) & $19.4(19)$ \\
\hline Insert & $18.2(18)$ & $27.3(27)$ & $25.3(25)$ & $29.3(29)$ & $6.1(6)$ & $19.4(19)$ & $25.2(25)$ & $49.0(48)$ \\
\hline Pull-up & $44.4(44)$ & $25.3(25)$ & $14.1(14)$ & $16.2(16)$ & 33.7 (33) & $13.3(13)$ & 33.7 (33) & $19.4(19)$ \\
\hline
\end{tabular}

TABLE 69 Mean VAS with SD (day) $(\mathrm{N}=99$, I missing data)

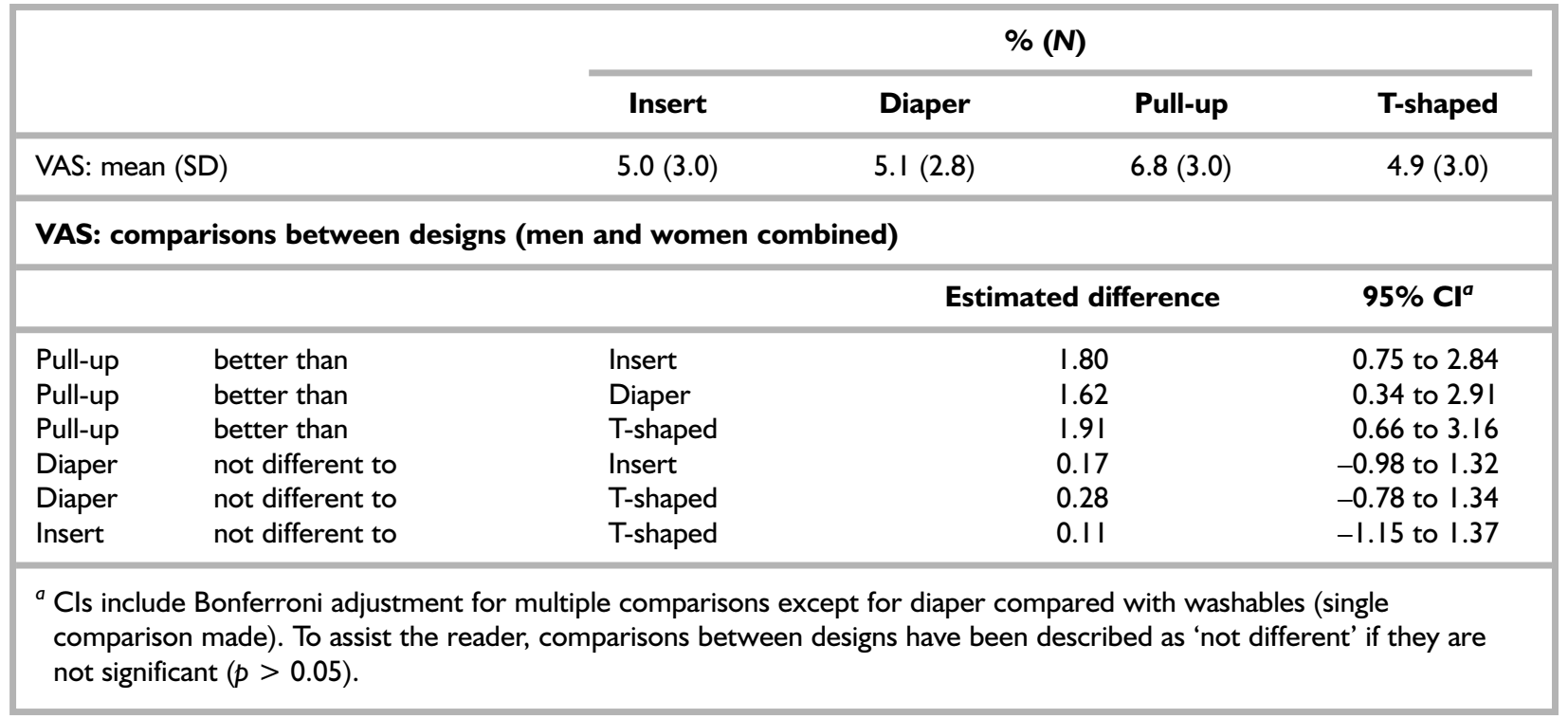

TABLE 70 Mean VAS with SD (night) ( $\mathrm{N}=98,2$ missing data)

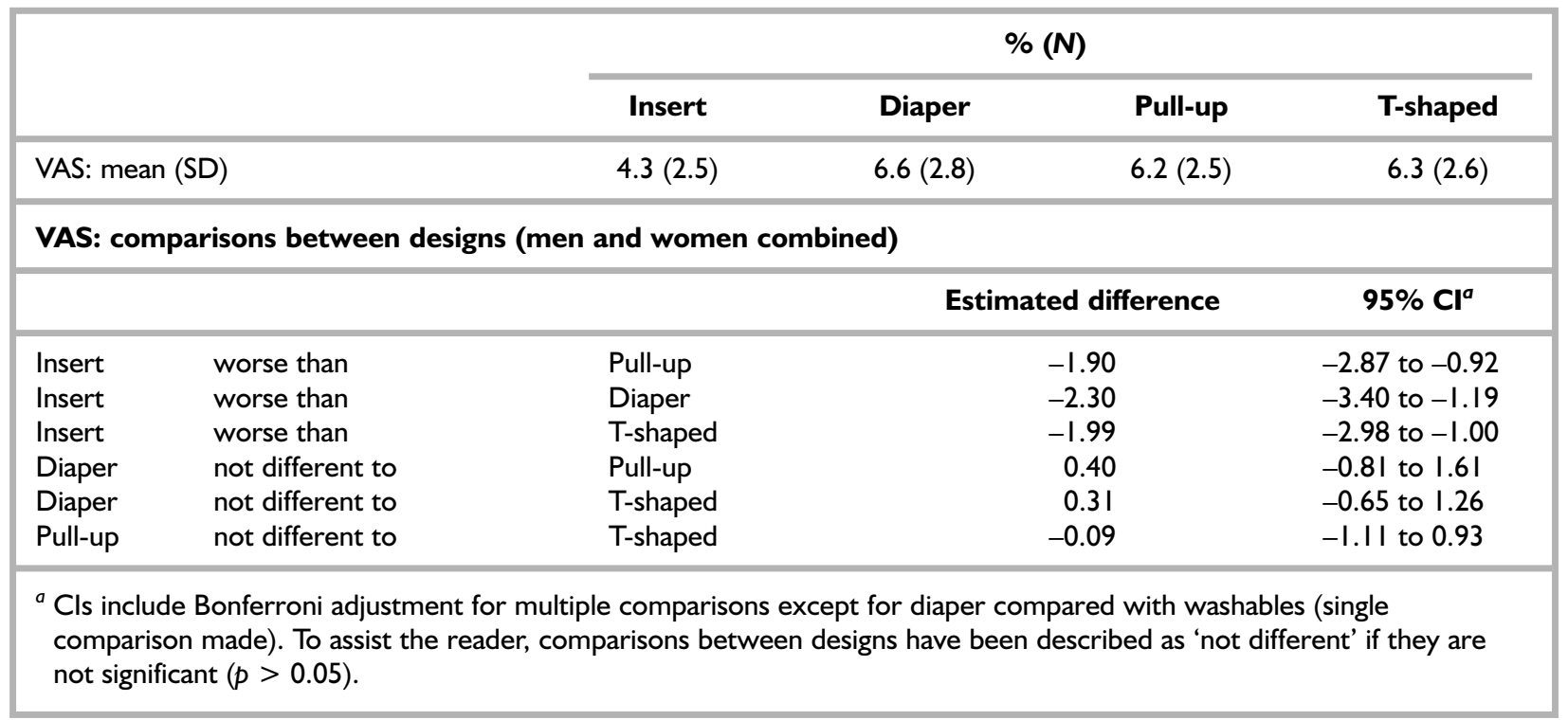


TABLE 7 I Acceptability of designs for day and night (Day: $\mathrm{N}=99$, I missing data; Night: $\mathrm{N}=98,2$ missing data) ${ }^{\mathrm{a}}$

\begin{tabular}{|c|c|c|c|c|c|c|c|c|}
\hline & \multicolumn{8}{|c|}{$\%(N)$} \\
\hline & \multicolumn{2}{|c|}{ Insert } & \multicolumn{2}{|c|}{ Diaper } & \multicolumn{2}{|c|}{ Pull-up } & \multicolumn{2}{|c|}{ T-shaped } \\
\hline & $\begin{array}{c}\text { Day } \\
(N=98)\end{array}$ & $\begin{array}{c}\text { Night } \\
(N=98)\end{array}$ & $\begin{array}{c}\text { Day } \\
(N=99)\end{array}$ & $\begin{array}{c}\text { Night } \\
(N=98)\end{array}$ & $\begin{array}{c}\text { Day } \\
(N=99)\end{array}$ & $\begin{array}{c}\text { Night } \\
(N=97)\end{array}$ & $\begin{array}{c}\text { Day } \\
(N=99)\end{array}$ & $\begin{array}{c}\text { Night } \\
(N=98)\end{array}$ \\
\hline Highly acceptable & $15.3(15)$ & $6.1(6)$ & $16.2(16)$ & $44.9(44)$ & $45.5(45)$ & $27.8(27)$ & II.I (I2) & $28.6(28)$ \\
\hline Acceptable & $44.9(44)$ & $50.0(49)$ & $47.5(47)$ & $30.6(30)$ & $35.4(35)$ & $52.6(5 \mathrm{I})$ & $50.5(50)$ & $51.0(50)$ \\
\hline $\begin{array}{l}\text { Unacceptable/totally } \\
\text { unacceptable }\end{array}$ & $39.8(39)$ & $43.8(43)$ & $36.4(36)$ & $24.5(24)$ & $19.2(19)$ & $19.6(19)$ & $37.4(37)$ & $20.4(20)$ \\
\hline
\end{tabular}

During the night-time, the inserts were significantly worse than diapers, pull-ups and T-shaped diapers at both levels of binarisation.

The results of these overall opinion and preference measures provide consistent evidence that pull-ups were significantly better than the other designs in the day and there were no significant differences between the other designs. During the night, inserts were significantly worse than the other designs and there were no significant differences between the other designs.

\section{Gender differences in final interview scores}

As gender differences were significant in the results of the community trial of the same disposable products, we analysed the final interview preference, VAS and overall acceptability data by gender. Results are shown in Appendix 17. These results show that although there was a strong and significant preference for pull-ups over the other three designs during the daytime for women, this was not the case for men, and there are indications that diapers may be better. However, the small number of men in this sample (27) means that no firm conclusions can be drawn. For men during the daytime, diapers were preferred over pull-ups (16 versus 11 ), over T-shaped diapers (18 versus 9) and over inserts (19 versus 8 ), but none of these findings reached significance. At night, the evidence favouring diapers for men was stronger. Men significantly preferred diapers over pull-ups (21 versus $6 ; p=0.04$ ) and over inserts (23 versus $4 ; p=0.007)$. Diapers were also preferred over T-shaped diapers (20 versus 7), but not significantly so.

Overall acceptability for daytime (highly acceptable) versus (otherwise) shows that outcome was significantly dependent on gender. Diapers were recorded as being highly acceptable for $41.7 \%$ $(11 / 27)$ of men compared to $6.9 \%(5 / 72)$ of women. During the night-time, the diapers were recorded as being highly acceptable for $70.4 \%$ $(19 / 27)$ of men compared with $35.6 \%(25 / 71)$ of women. The VAS results indicate similarly different results for men and women. However, we did not statistically analyse these scores between men and women because of the small number of men.

The forest plots (Figures 50-61) show the paired comparisons of ORs for key product performance and overall opinion variables.

\section{Explanation of forest plots}

For primary and secondary outcome variables, results are calculated as proportions, such as participants' rating of discreetness binarised as (very good + good + okay) versus (poor + very poor). For example, design A may score $60 \%$ (very good + good + okay) and $40 \%$ (poor + very poor) and design B may score $50 \%$ (very good + good + okay) and $50 \%$ (poor + very poor). In this case, it appears that design $\mathrm{A}$ is better than design $\mathrm{B}$ for discreetness. To examine whether we can be confident that this difference between the two designs is real an OR and CI are calculated. If there is no difference between the two results, this will give an OR of 1 . Where there are differences (as in the example of discreetness above), the OR will be greater or less than one. The CI is a number that spans the OR (giving a higher and lower limit) and shows how much uncertainty there is about the OR.

The ORs and CIs have been calculated for comparisons between each pair of designs and for each variable where the results are shown as proportions. The ORs and CIs have been stacked on top of each other on a forest plot showing comparisons between each pair of designs. 
The ORs and CIs are shown in relation to a vertical line which is the centre of the forest plot. This line gives the OR of 1 (i.e. no difference). Each variable is named on the far left of the forest plot and the OR and CI are written on the far right. The scale is shown on the bottom with numbers below 1 on the left and above 1 on the right.

Each OR is shown as a black box with a horizontal line (the $95 \% \mathrm{CI}$ ) running through it. Where the line touches or crosses the vertical line (at $\mathrm{OR}=1$ ) there is no significant difference between the proportions for the two designs. Where the box and horizontal line lie completely to one or other side of the vertical line, one can be confident that the proportions for each design are significantly different.

To show readily how each pair of designs compare with each other, the ORs are plotted so that where a design scores better than the other design for any variable the OR (i.e. the black box) is on the side of the vertical line that favours that design. Hence the ORs shown are for the second named design versus the first named design in the heading. The primary outcome variables from the final interview (overall acceptability and preference) are shown at the bottom of each forest plot and these reflect the overall performance of the different designs. The last line of the forest plot shows the odds on the second named design being preferred to the first.

For example, in the forest plot comparing the pull-up with the insert for the daytime, the plot shows that the pull-up is better than the insert on almost all variables (including overall acceptability and preference).

There are 12 comparisons (day and night) between the four disposable designs. giving a total of 12 forest plots.

Each forest plot in Figures 50-61 shows the data obtained from:

- Leakage - diary: (from the pad change/leakage diary) binarised as (none) versus (a little $+\mathrm{a}$ lot).

- Leakage - rating: (the participants' rating from the final interview) binarised as (very good + good + OK) versus (poor + very poor).

- Seven key variables from the product performance questionnaire: all binarised as (very good + good + OK) versus (poor + very poor).
- Skin health problems: (data from the participants' skin health diary) binarised as (none) versus (a little + a lot).

- Overall acceptability: taken from the final interview, and binarised as (highly acceptable + acceptable) versus (unacceptable + totally unacceptable). Abbreviated on the forest plots as (high/OK vs no).

- Overall acceptability: taken from the final interview, and binarised as (highly acceptable) versus (Okay + unacceptable). Abbreviated on the forest plots as (high vs $\mathrm{OK} / \mathrm{no}$ ).

- Preference men: this shows the odds on the second named design being preferred to the first by a man.

- Preference women: this shows the odds on the second named design being preferred to the first by a women.

\section{Comments}

At the final interview, an open request was made for carers to comment on good and poor, best and worst features of the design. These comments are summarised in Appendix 19 and in particular highlight some of the strengths of pull-ups for women, such as their dignified/pant-like/good appearance. For men it is notable that there are comparatively few negative comments about diapers either for day or for night.

\section{Views on washables}

Although washable designs had not been tested in the care homes, staff were asked how they would feel if washable products were provided for the residents to use. Responses are shown in Table 72.

\section{Reports on number of staff needed to change residents}

Care staff were also asked about the number of staff they thought would be required to change the resident usually and for each of the designs in the day (standing up and lying down) and at night (lying only). Responses are given in Appendix 20 and show no differences between designs.

TABLE 72 Staff views about using washable products

\begin{tabular}{|c|c|c|}
\hline \multirow[t]{2}{*}{ Response } & \multicolumn{2}{|c|}{$\%(n)$} \\
\hline & $\begin{array}{c}\text { Day } \\
(N=89)\end{array}$ & $\begin{array}{c}\text { Night } \\
(N=69)\end{array}$ \\
\hline It wouldn't worry me & $19.1(17)$ & $24.6(17)$ \\
\hline I would be pleased & I.I (I) & $4.3(3)$ \\
\hline I would be concerned ${ }^{a}$ & $68.5(6 I)$ & $62.3(43)$ \\
\hline I don't know & $11.2(10)$ & $8.7(6)$ \\
\hline
\end{tabular}




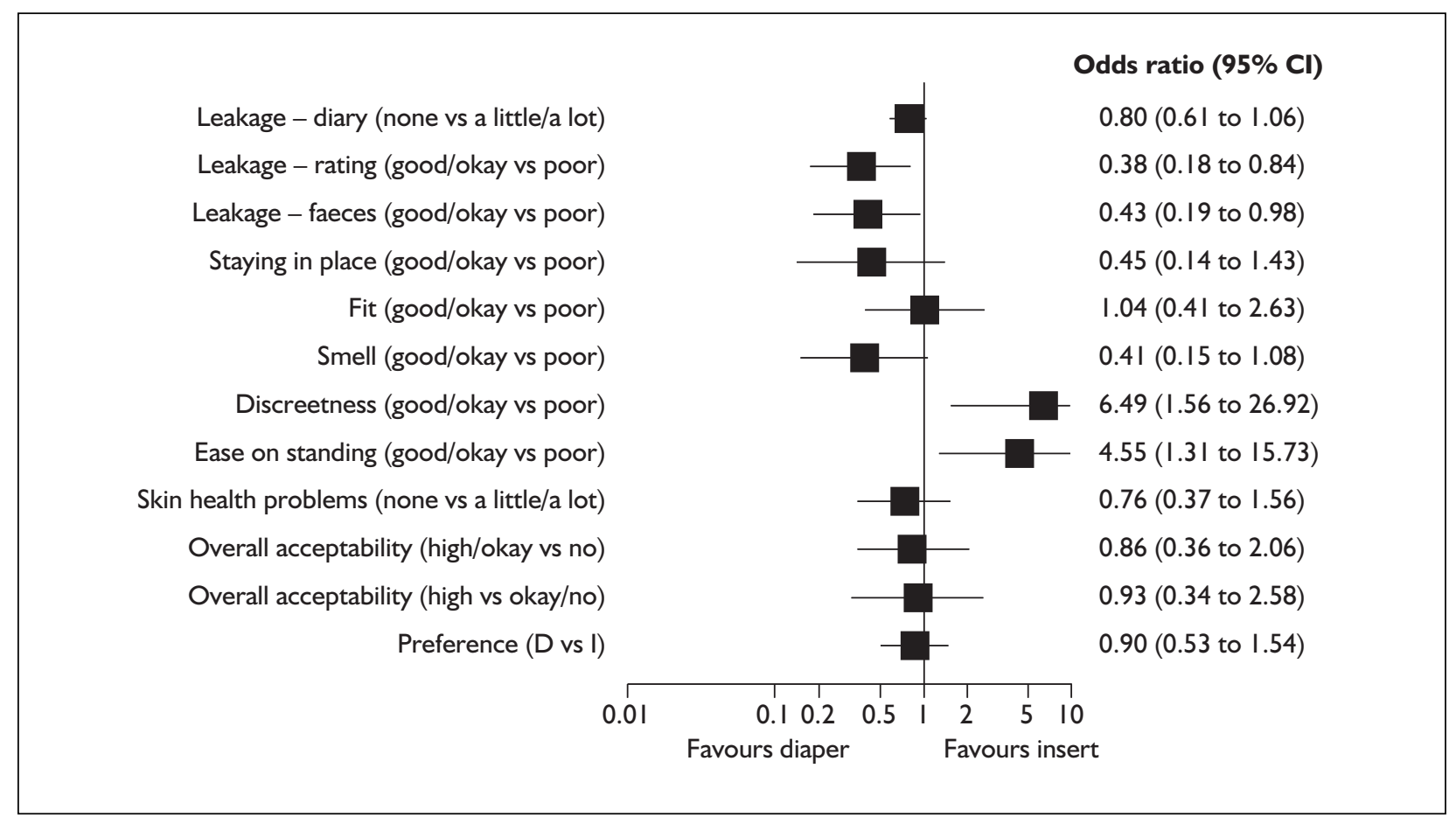

FIGURE 50 Forest plot: diaper vs insert (day)

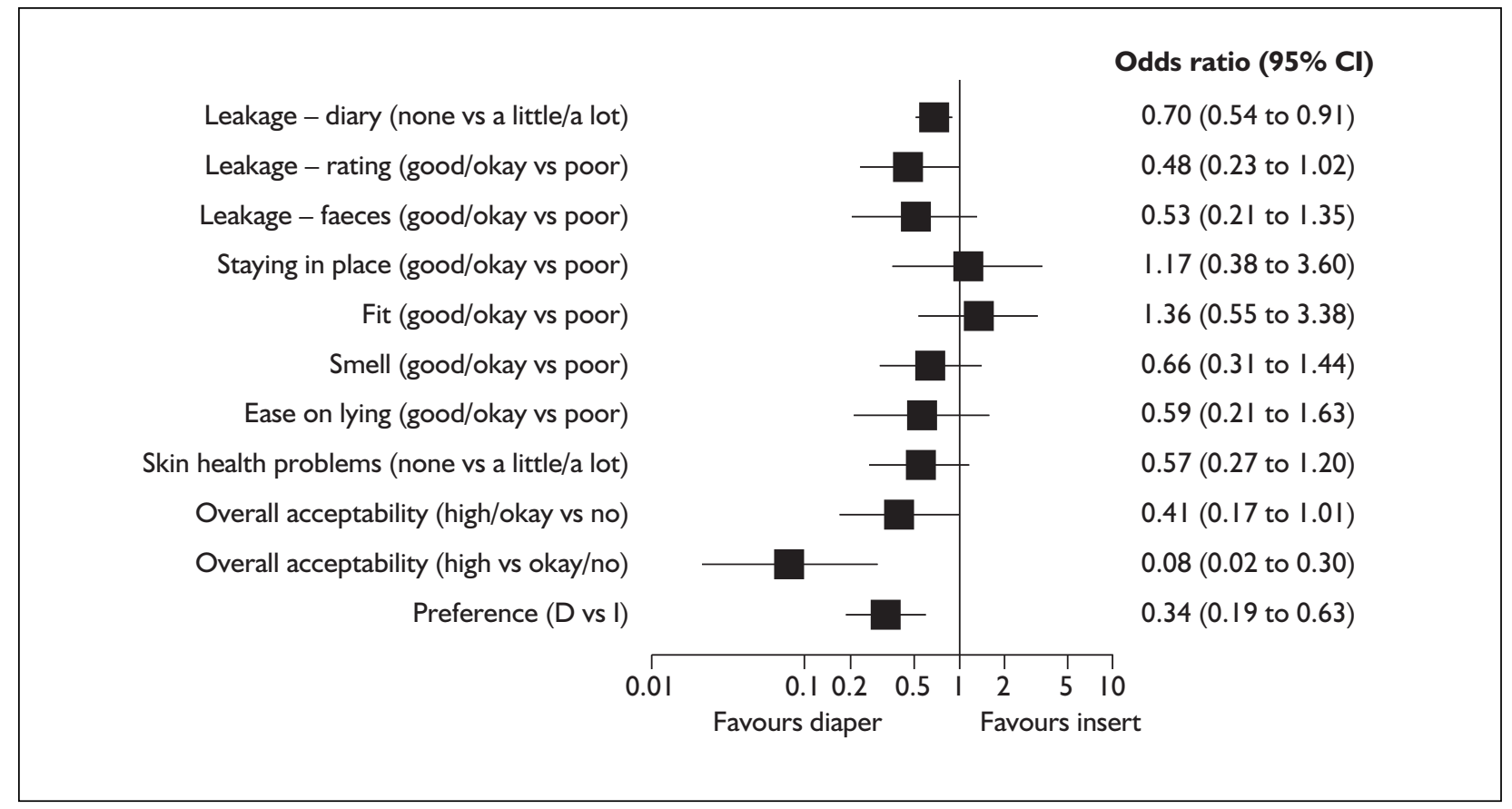

FIGURE 5I Forest plot: diaper vs insert (night)

In most homes, staff commented that for safety reasons policy required them to have two carers assisting in pad changing for all residents who needed assistance to stand or used a standing hoist. Therefore, even if it were possible to change some pad designs with fewer staff than others, it would make little difference to the number of staff required in practice.

\section{Pad change timing exercise Results}

Twelve women residents from three different homes volunteered for the pad-changing exercise. Two were unable to stand and therefore always had their pads changed in a lying position, whereas the other 10 residents were able to stand. To reduce variation, we excluded the two residents 


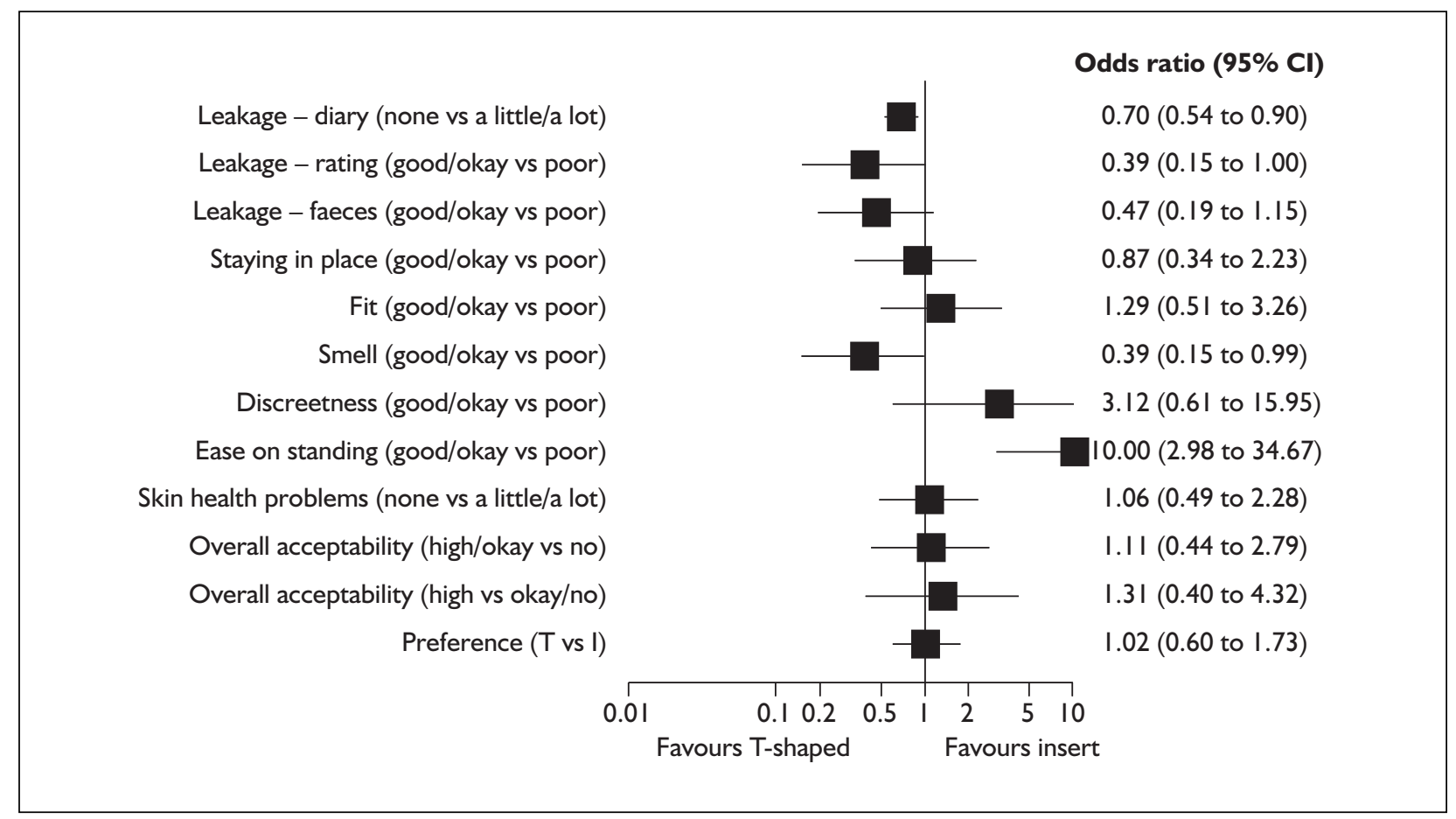

FIGURE 52 Forest plot: T-shaped vs insert (day)

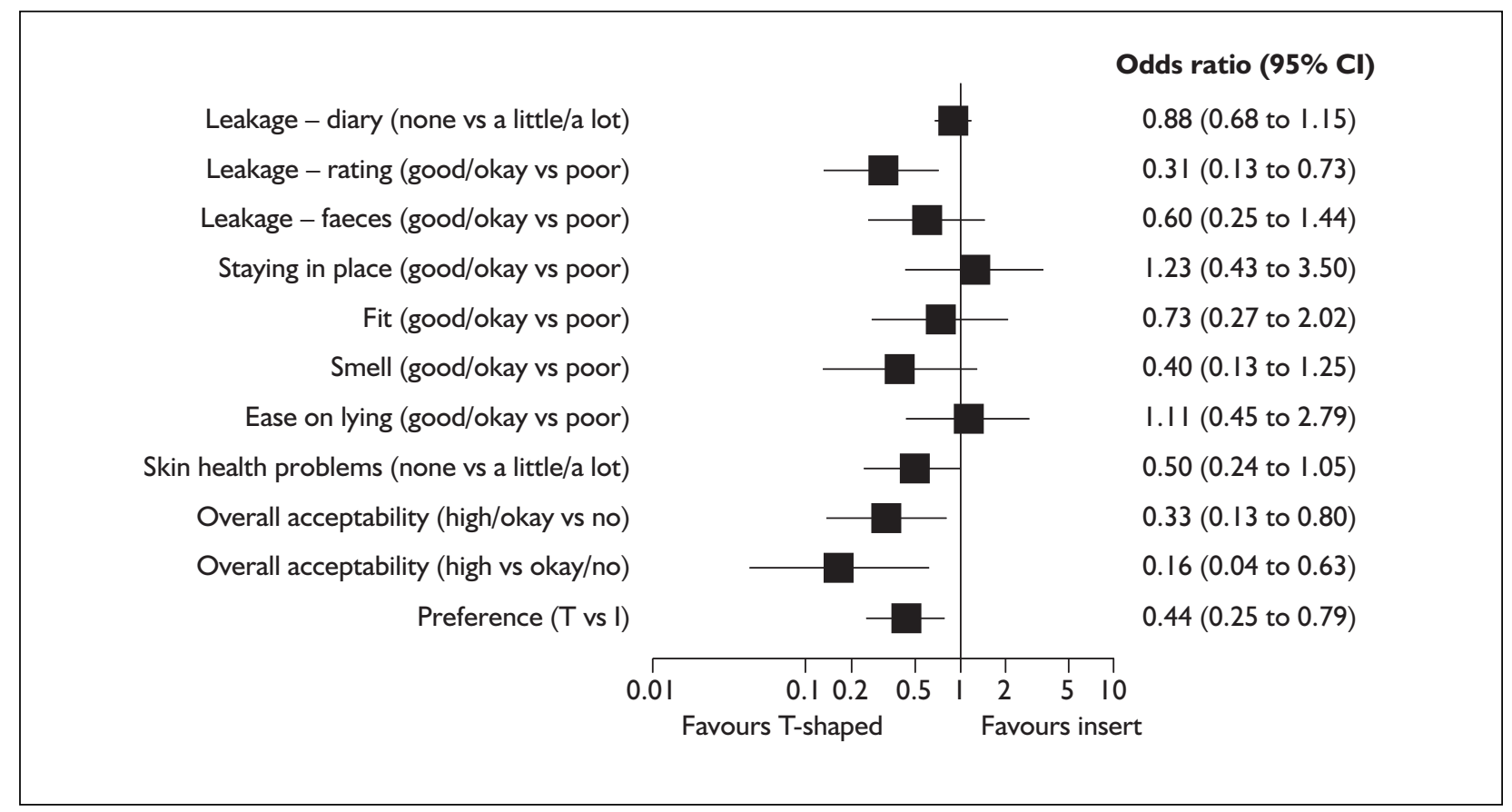

FIGURE 53 Forest plot: T-shaped vs insert (night)

who were unable to stand and 10 residents completed the exercise. Eight of these 10 residents required two members of staff to change their pads and two of these also required a standing hoist; two of the residents could be changed by one carer. Ten staff members were recruited to take part in the exercise. Staff worked in pairs or individually (depending on residents' needs), with the same staff changing all four designs for a given resident. The results of the pad timing exercise are shown in Table 73 and Figure 62. 


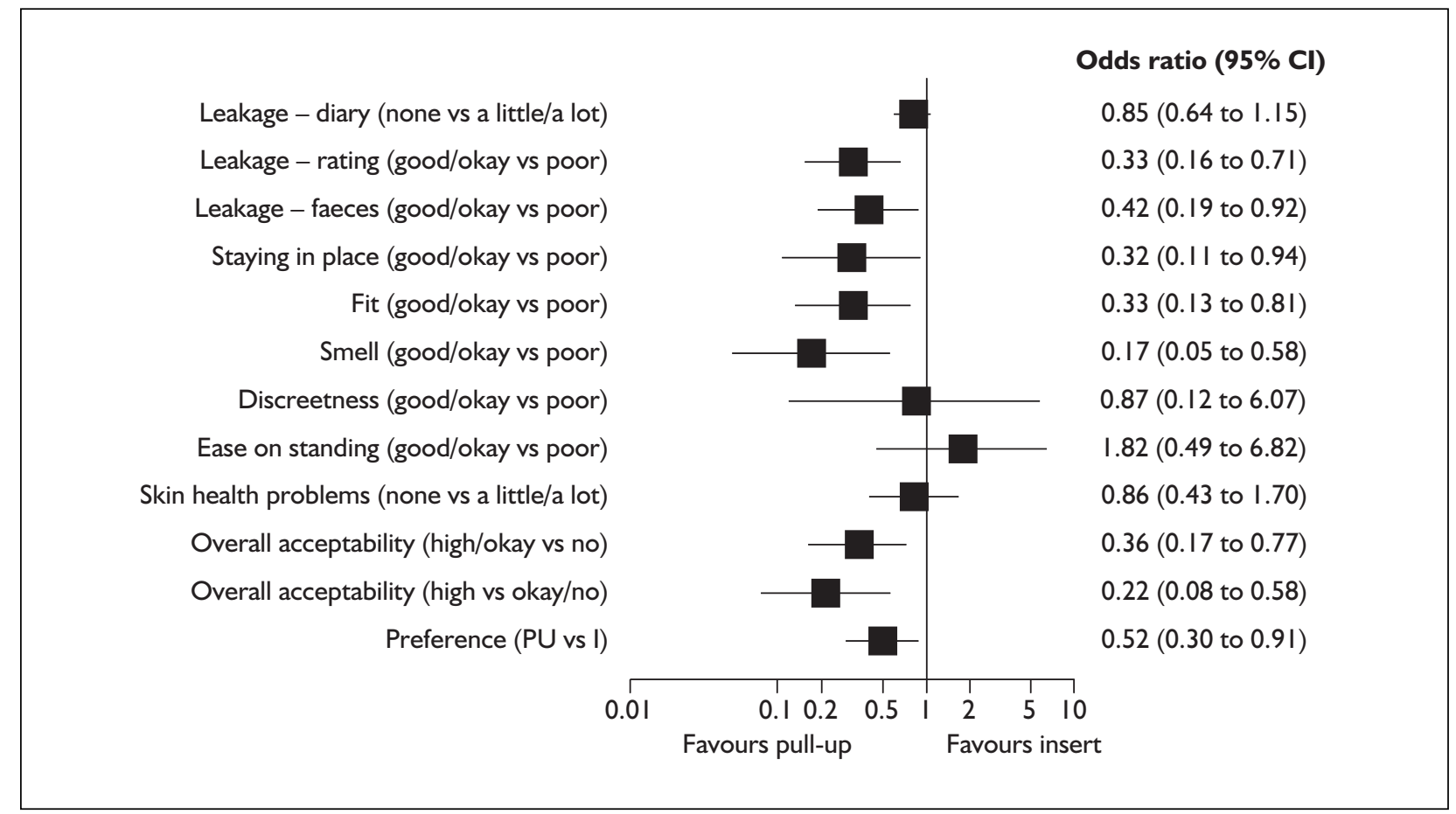

FIGURE 54 Forest plot: pull-up vs insert (day)

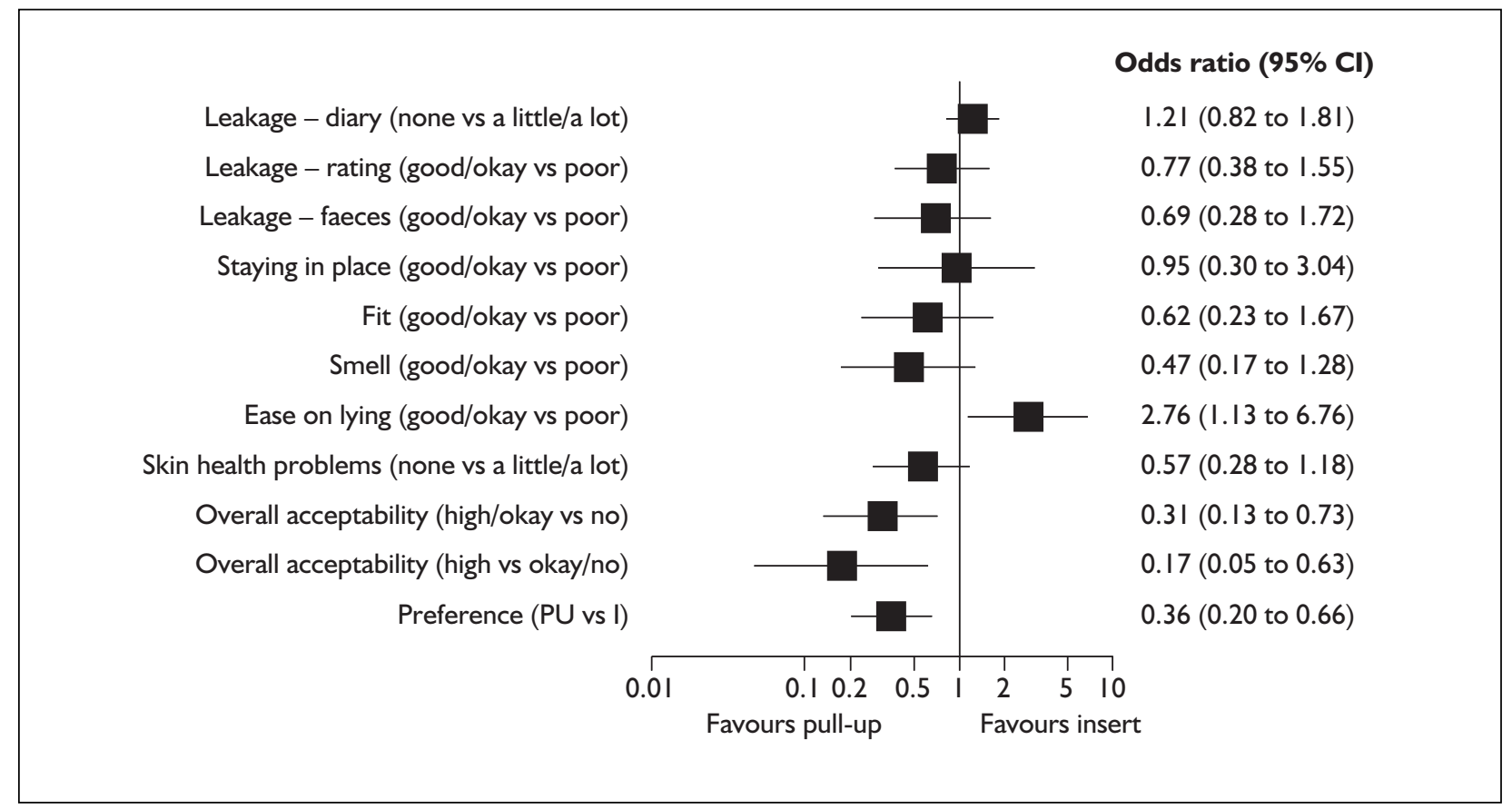

FIGURE 55 Forest plot: pull-up vs insert (night)

Pad change times varied considerably between residents according to their different disabilities, but the timings of the repeated pad changes using the different designs in a randomised order showed that there were significant differences between designs. Contrary to expectations, the T-shaped design took significantly longer to change than the diaper design. Both the diaper and T-shaped designs took significantly longer than the pull-up and insert designs (around 15-25 seconds more). However, there were no significant differences between the pull-up and insert designs. These data 


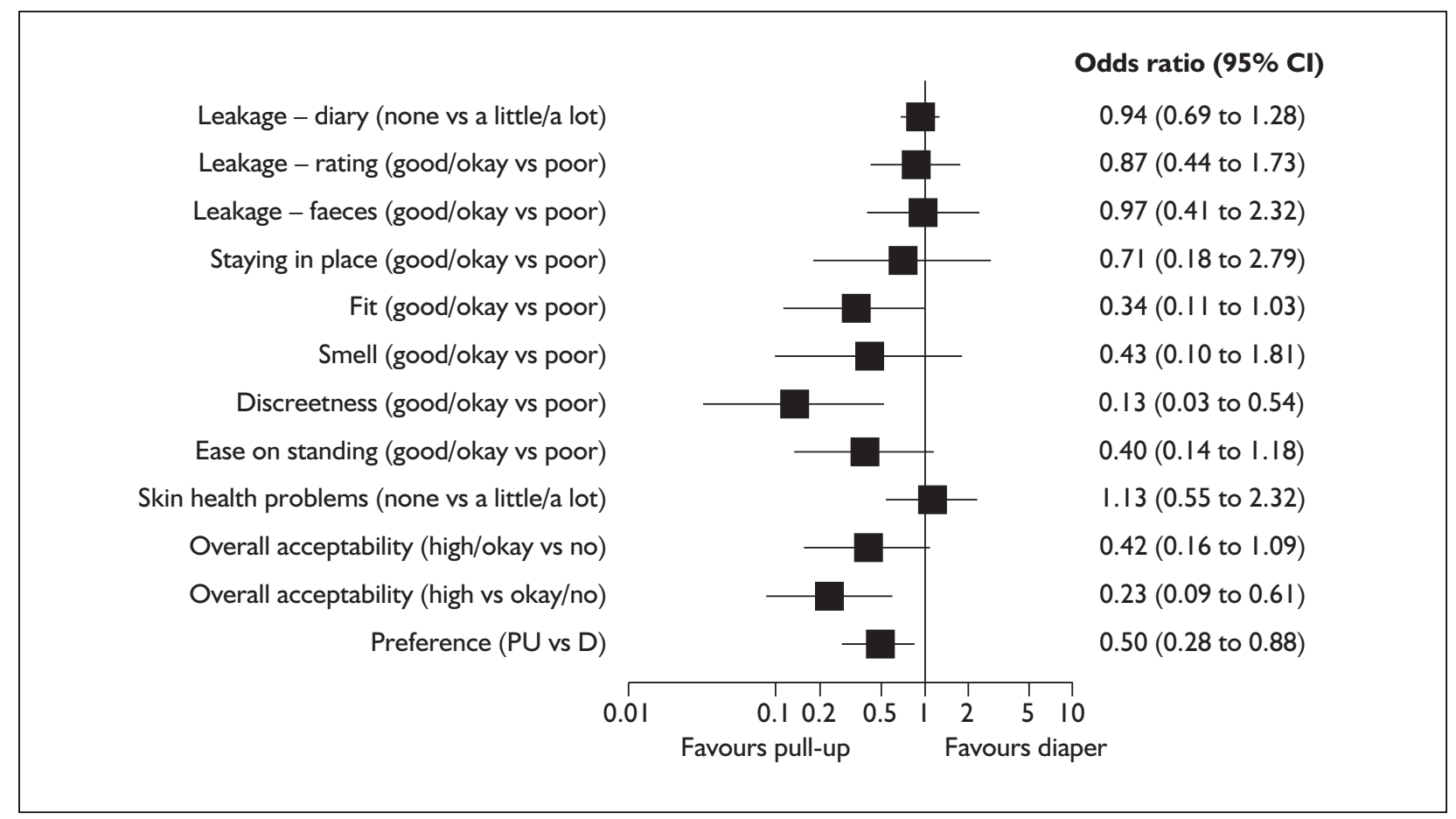

FIGURE 56 Forest plot: pull-up vs diaper (day)

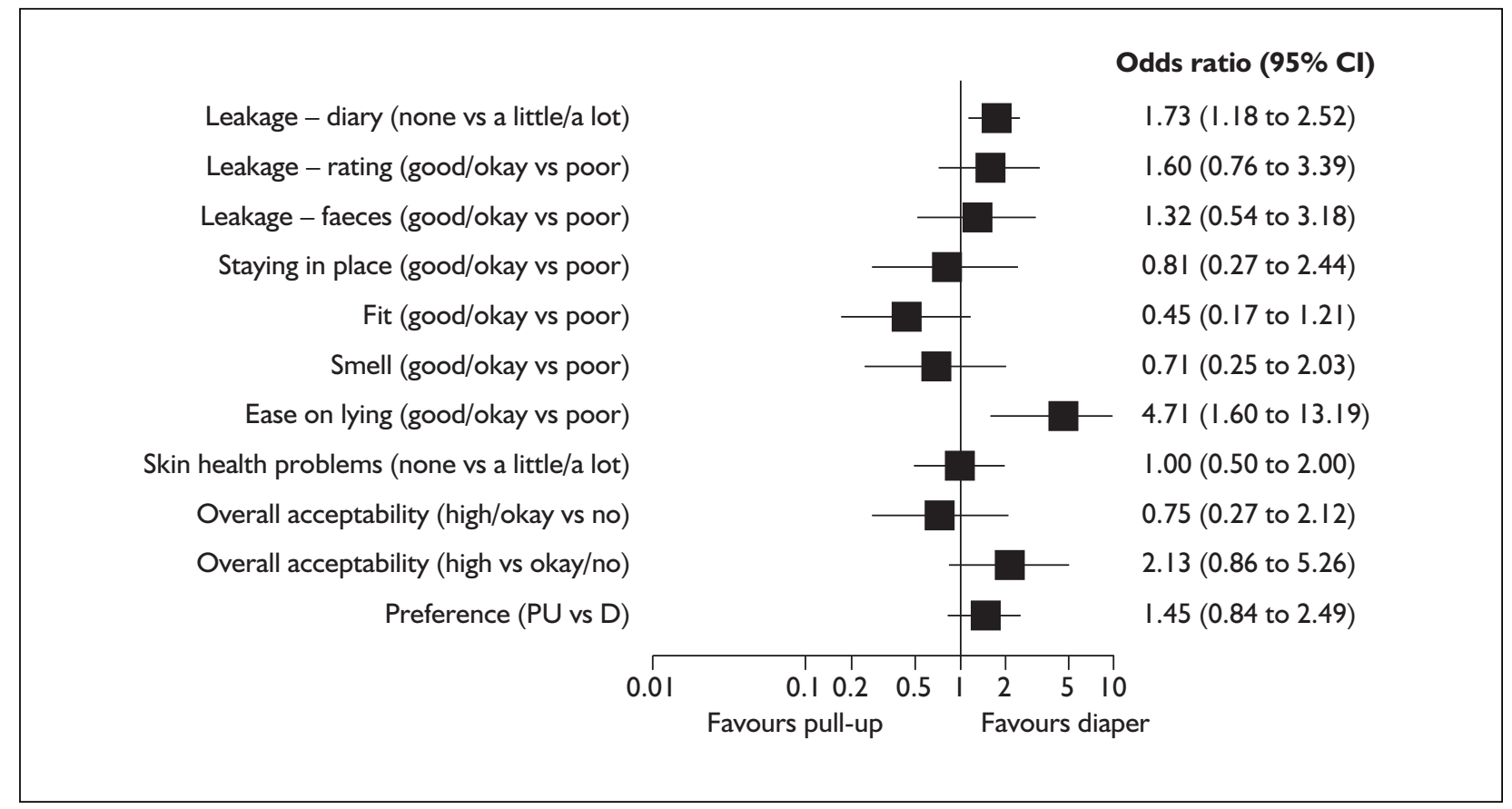

FIGURE 57 Forest plot: pull-up vs diaper (night)

support the findings from the product performance questionnaires, which also showed that the pull-up and insert designs were significantly easier to change in the standing position than the diaper and T-shaped diaper designs. Although pull-ups were found to be as quick and easy to put on as inserts, they may be more time consuming to change in practice. When a pull-up is changed, clothing (e.g. trousers, tights) must be removed completely and reapplied, whereas with the other designs clothing need only be pulled down. The data showed that pull-ups were the most successful design for women, and although there were more comments regarding difficulties with changing or 


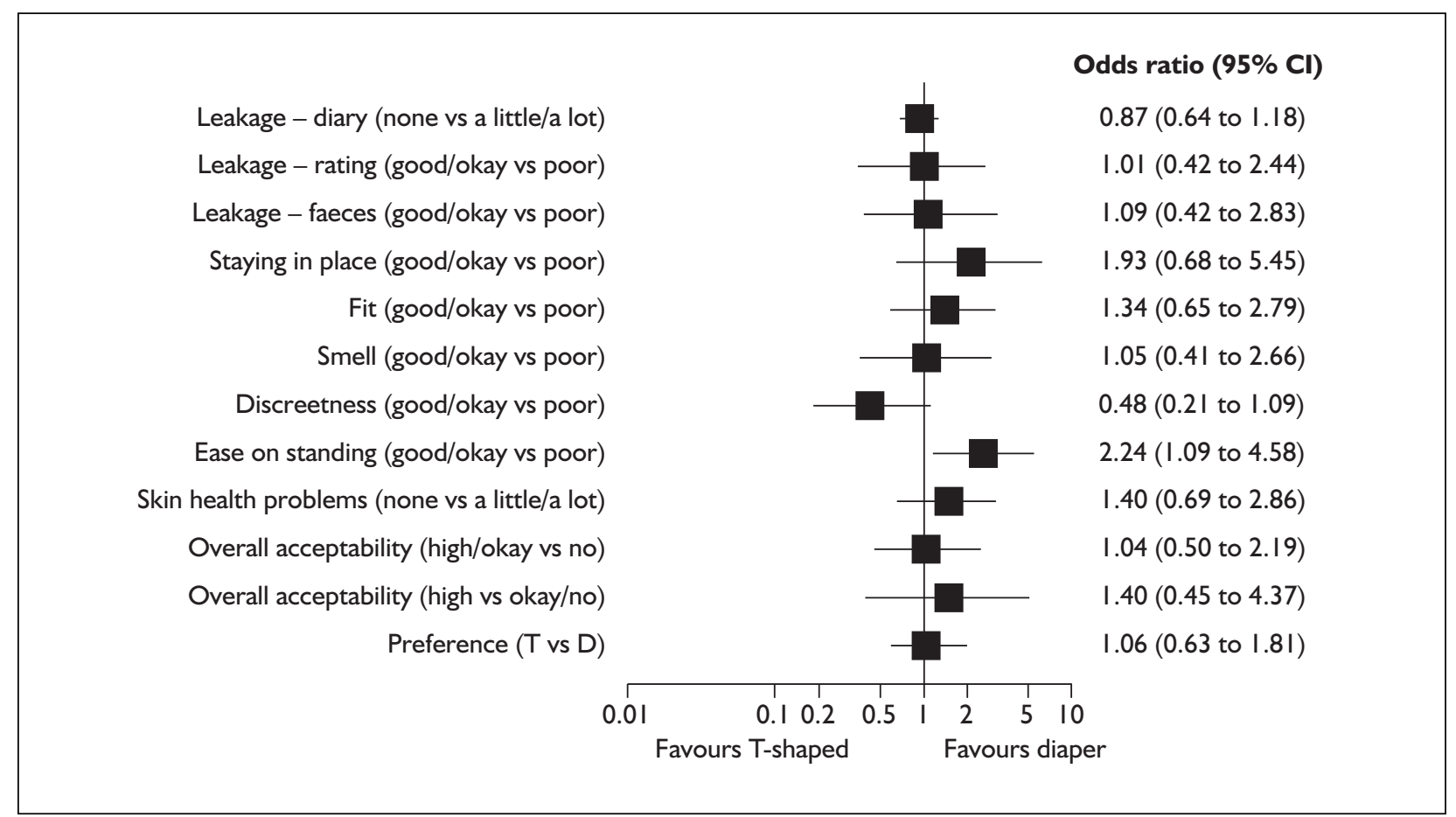

FIGURE 58 Forest plot: T-shaped vs diaper (day)

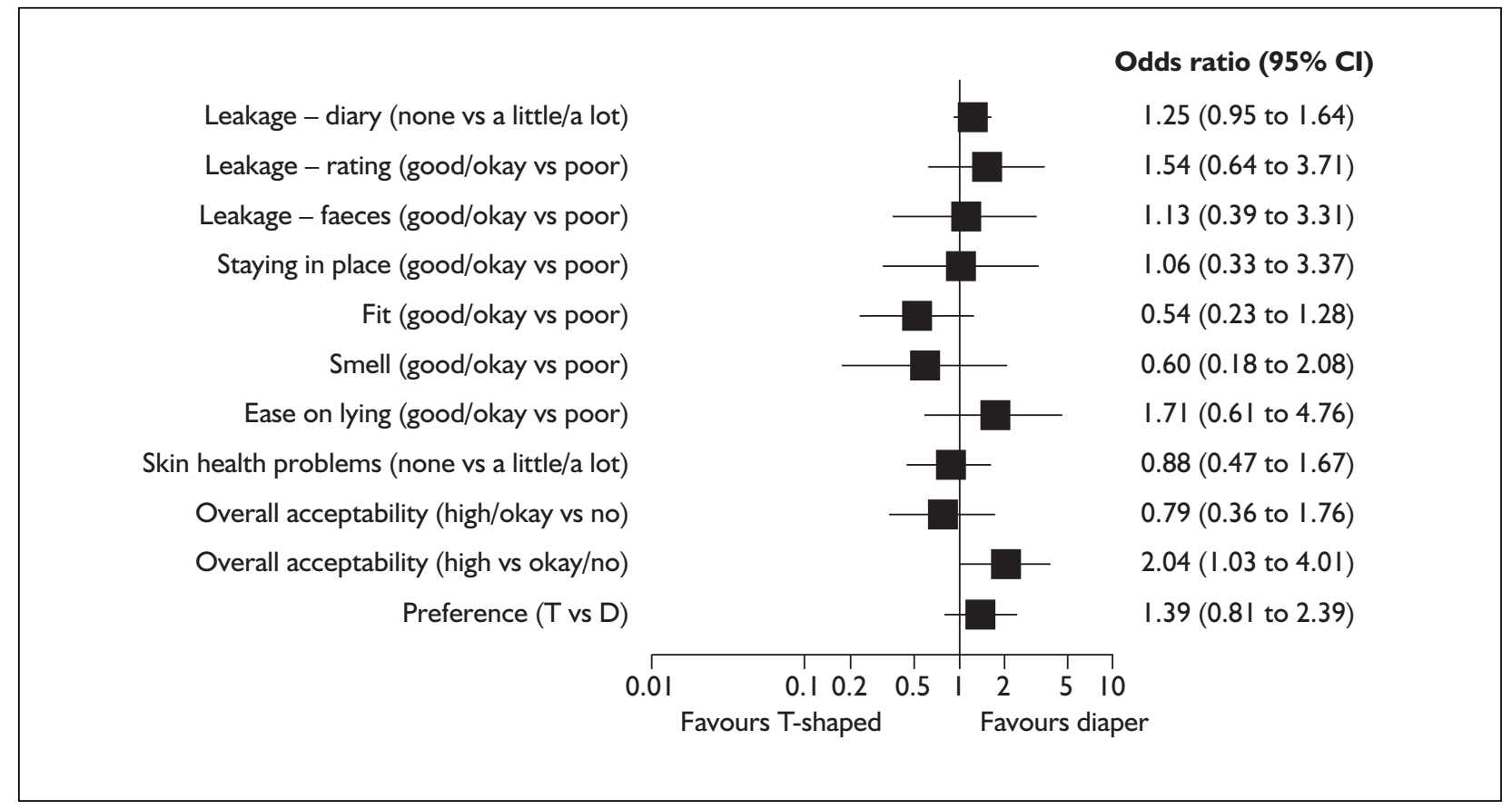

FIGURE 59 Forest plot: T-shaped vs diaper (night)

application compared with inserts, this did not affect their overall popularity.

It was speculated that because the pull-up and insert designs were both significantly easier and significantly quicker to change in the standing position than the two diaper designs, the pull-up and insert designs may be preferred by staff for daytime use. The residents were therefore categorised as being 'able to stand' or 'unable to stand' and examined their first-choice daytime design when binarised as (pull-ups + inserts) and (diaper + T-shaped). The results are shown in Table 74. 


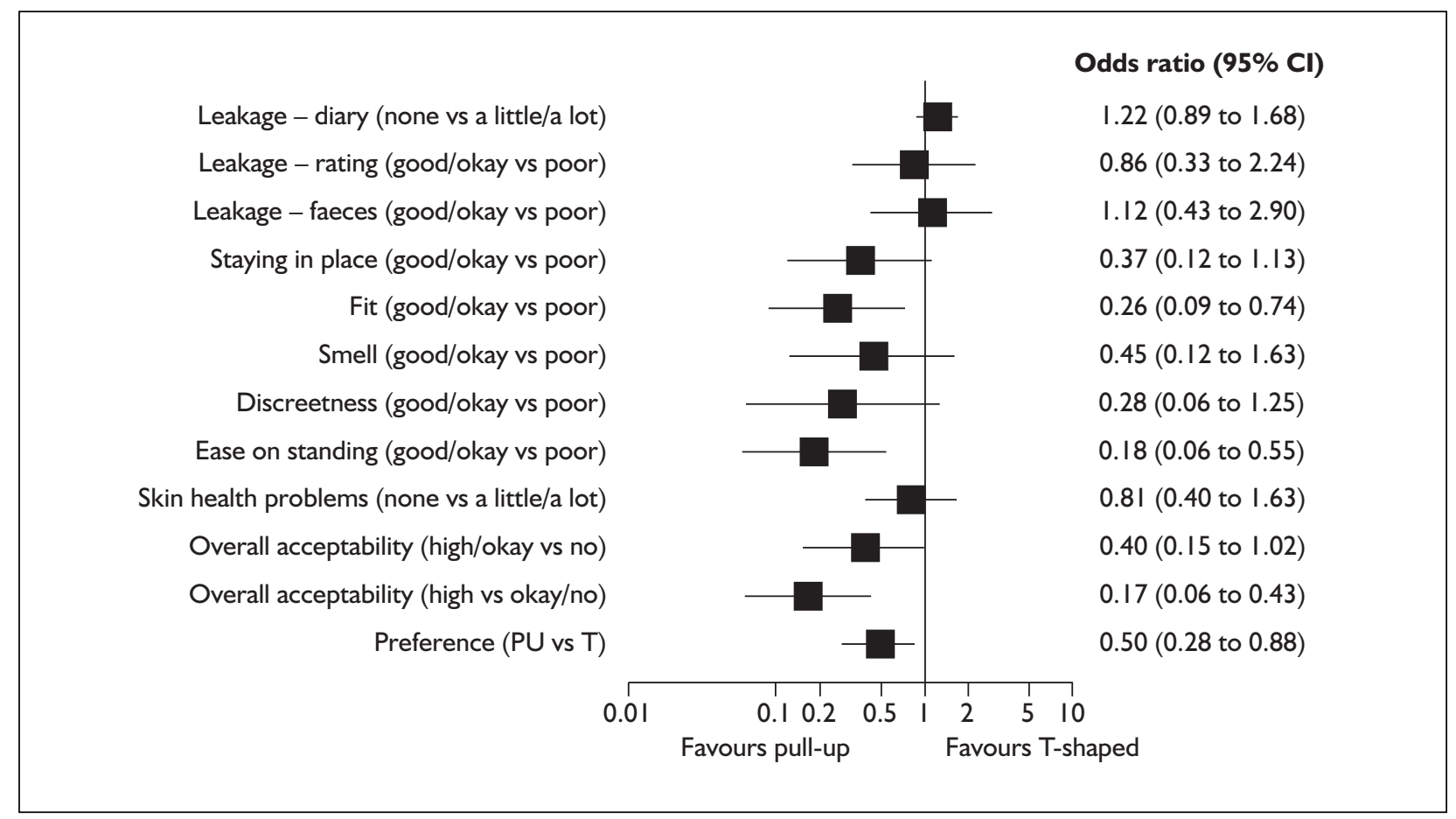

FIGURE 60 Forest plot: pull-up vs T-shaped (day)

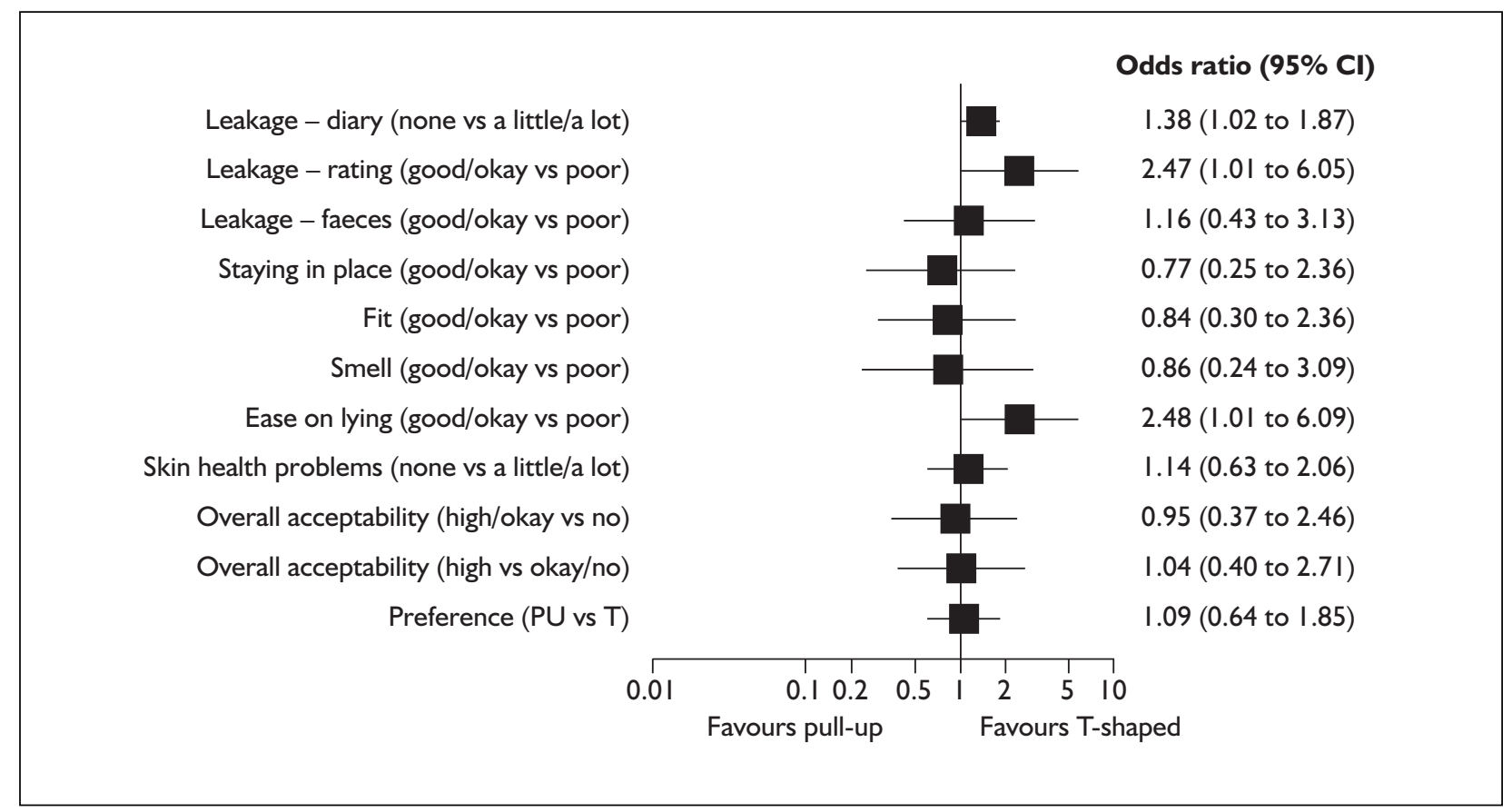

FIGURE 6I Forest plot: pull-up vs T-shaped (night)

The odds on preferring pull-up/insert for those able to stand is estimated to be 2.9 times higher than that for those unable to stand. The 95\% CI for this OR is 1.2 to 7.0 , which indicates that the pull-up/insert designs are likely to be preferable

\section{Economic analysis \\ Cost data}

The prices and costs used in both the value-formoney questions and the cost-effectiveness analysis were those derived for Trial $2 \mathrm{a}$, since the same products were used in both trials. The base 
TABLE 73 Mean pad change times for different designs $(\mathrm{N}=10)$

\begin{tabular}{|c|c|c|c|c|c|}
\hline & & Insert & Diaper & Pull-up & T-shaped \\
\hline $\begin{array}{l}\text { Time (s) } \\
\text { (SD) }\end{array}$ & & $\begin{array}{l}35.2 \\
(6.9)\end{array}$ & $\begin{array}{c}53.2 \\
(15.1)\end{array}$ & $\begin{array}{c}37.9 \\
(12.1)\end{array}$ & $\begin{array}{c}62.0 \\
(15.5)\end{array}$ \\
\hline \multicolumn{6}{|c|}{ Pad change time: comparisons between designs } \\
\hline & & & & Estimated difference & $95 \% \mathrm{Cl}^{a}$ \\
\hline Insert & not different to & & Pull-up & -2.71 & -13.58 to 8.16 \\
\hline Insert & faster than & & Diaper & $-18.0 \mid$ & -28.18 to -7.84 \\
\hline Insert & faster than & & T-shaped & -26.81 & -37.70 to -15.92 \\
\hline Pull-up & faster than & & Diaper & -15.30 & -24.63 to -5.97 \\
\hline Pull-up & faster than & & T-shaped & -24.10 & -36.99 to -11.21 \\
\hline Diaper & faster than & & T-shaped & -8.80 & -16.91 to -0.69 \\
\hline \multicolumn{6}{|c|}{$\begin{array}{l}\text { a Cls include Bonferroni adjustment for multiple comparisons, except for diaper compared with washables (single } \\
\text { comparison made). To assist the reader, comparisons between designs have been described as 'not different' if they are } \\
\text { not significant }(p>0.05) \text {. }\end{array}$} \\
\hline
\end{tabular}

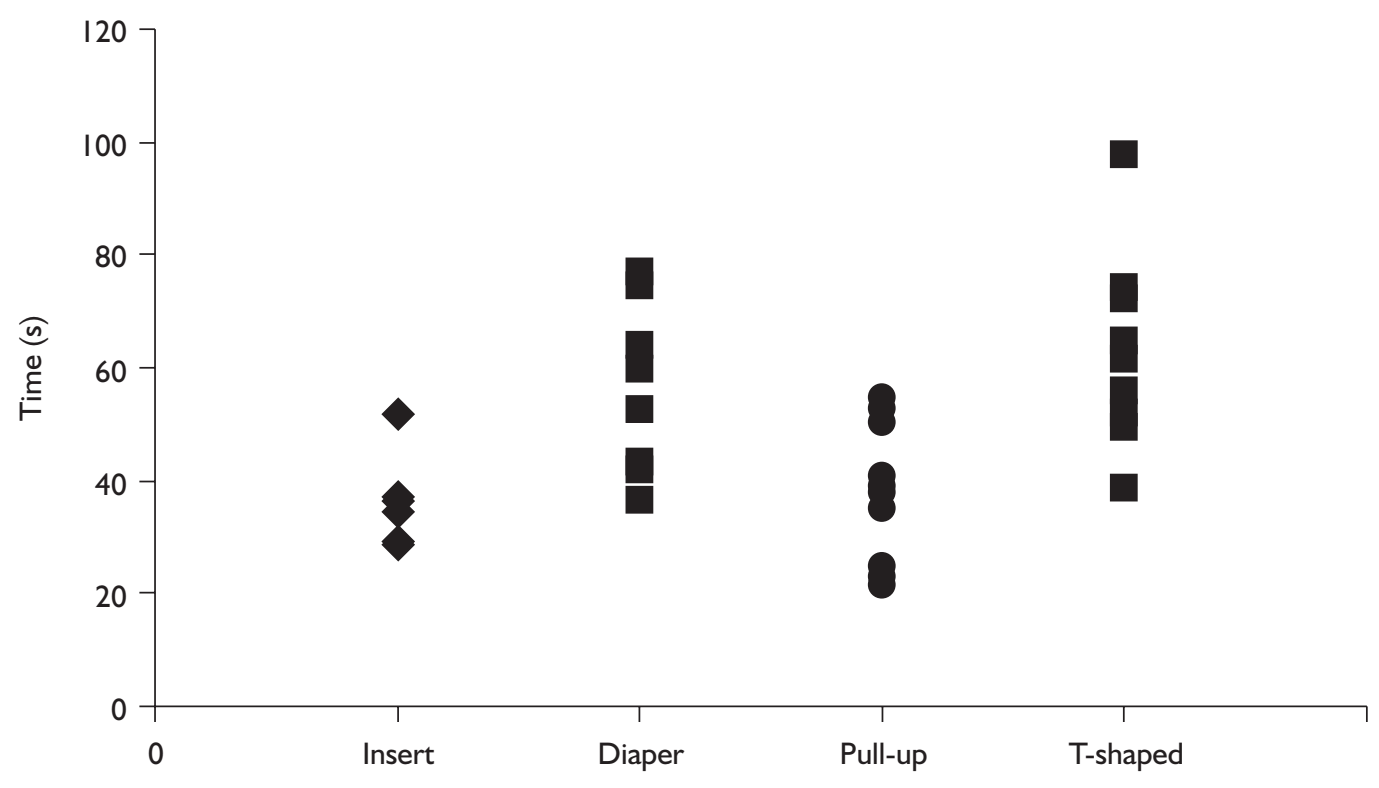

FIGURE 62 Pad change times for 10 residents ( $\mathrm{N}=10$ for each design)

TABLE 74 First-choice design and ability to stand $(\mathrm{N}=99)$

\begin{tabular}{|lcc|}
\hline & \multicolumn{2}{c|}{ First-choice daytime design } \\
\cline { 2 - 3 } & Pull-up/insert & Diaper/T-shaped \\
\hline Able to stand: \% $(N)$ & $70.5(48)$ & $29.5(20)$ \\
Unable to stand: $\%(N)$ & $45.2(14)$ & $54.8(17)$
\end{tabular}


cost metric was taken to be the monthly cost (day and night) of supplying one resident assuming a utilisation rate of three products per day and one product per night. This utilisation rate was derived from previous studies by the research team but was subsequently found to understate the median use among the sample which was $3+2$ (day and night). Prices charged by NHS Logistics at the start of the module trial (April 2005), including VAT, were used since this was the most usual source of supply for care homes at that time. Estimates for two of the products which were not supplied by the NHS at the time were based on the differential between the NHS price and the open market price for other products. Where prices differed for different sizes of any product, the mean price of all sizes was used.

\section{Relative value for money}

In piloting the final interview, care staff were given the monthly costs per resident for each design and asked to rank them on value for money. This was intended to investigate whether they would revise their preferences when the relative cost of designs was disclosed. However, care staff found this line of questioning difficult and it was dropped. Staff were instead asked to consider the differences in the costs between designs. The differences used reflected the approximate cost relativities between designs $(£ 15, £ 10, £ 5$ for the day and $£ 6, £ 4$, €2 for the night).

To probe strengths of preferences for designs, care staff were given cost differences between designs and asked if they still thought their preferred design was best if it cost the NHS the extra amounts. This exercise was conducted for day and night products. Care staff were asked to consider only designs that they had deemed to be acceptable and then to compare (as appropriate) their first and second choices, second and third choices and third and fourth choices. The results are shown in Appendix 21. Staff found these questions difficult to answer (not surprisingly) for third and fourth choices and only their views about the first and second preferences are reported.

These results show that preferences for pull-ups in the day appear to be strong and almost all care staff who had ranked pull-ups best and who answered the question felt that they were worth an extra $£ 15$ per month of cost to the NHS compared with their second-choice design. Preferences for other first-choice products were less strong. At night, strengths of preference were higher for pull-ups and T-shaped than for diapers, even though they were the overall favourite design. In general, strengths of preference reflected overall design rankings for both day and night.

\section{Cost-effectiveness}

Mean VAS scores were used to calculate ACERs, which show the cost per unit of effectiveness for any design (lower values mean benefit is produced at lower cost).

In the day, there was no significant difference in the mean VAS between T-shaped, diapers and inserts, but the mean VAS for pull-ups was significantly higher than for the other three designs.

At night, there was no significant difference in the mean VAS between T-shaped, diapers and pullups, but the mean VAS for inserts was significantly lower than for the other three designs. The costeffectiveness data are shown in Table 75.

Pull-ups were the most expensive day design. If pull-ups were provided rather than the other three

TABLE 75 Cost-effectiveness of designs

\begin{tabular}{|c|c|c|c|c|c|c|c|c|c|}
\hline \multicolumn{5}{|c|}{ Day } & \multicolumn{5}{|c|}{ Night } \\
\hline \multirow[t]{2}{*}{ Design } & \multirow{2}{*}{$\begin{array}{l}\text { Mean } \\
\text { monthly } \\
\text { cost }(t) \\
(3 / \text { day } \times \\
30)\end{array}$} & \multirow{2}{*}{$\begin{array}{l}\text { Mean } \\
\text { VAS } \\
\text { score }\end{array}$} & \multicolumn{2}{|c|}{ ACER } & \multirow[t]{2}{*}{ Design } & \multirow{2}{*}{$\begin{array}{l}\text { Mean } \\
\text { monthly } \\
\text { cost }(E) \\
(1 / \text { night } \times \\
30)\end{array}$} & \multirow{2}{*}{$\begin{array}{l}\text { Mean } \\
\text { VAS } \\
\text { score }\end{array}$} & \multicolumn{2}{|c|}{ ACER } \\
\hline & & & $\begin{array}{l}\text { Cost } \\
\text { per VAS } \\
\text { point }(f)\end{array}$ & $\begin{array}{l}\text { VAS } \\
\text { points } \\
\text { per } €\end{array}$ & & & & $\begin{array}{l}\text { Cost } \\
\text { per VAS } \\
\text { point }(t)\end{array}$ & $\begin{array}{l}\text { VAS } \\
\text { points } \\
\text { per } t\end{array}$ \\
\hline Pull-ups & 46.50 & 6.77 & 6.87 & 0.15 & Diapers & 9.00 & $6.62^{a}$ & 1.36 & 0.73 \\
\hline Diapers & 21.00 & $5.14^{a}$ & 4.08 & 0.24 & T-shaped & 10.00 & $6.32^{a}$ & 1.58 & 0.63 \\
\hline T-shaped & 25.00 & $4.86^{a}$ & 5.14 & 0.19 & Pull-ups & 15.50 & $6.22^{a}$ & 2.49 & 0.40 \\
\hline Inserts & 21.00 & $4.97^{a}$ & 4.23 & 0.24 & Inserts & 9.00 & 4.33 & 2.08 & 0.48 \\
\hline
\end{tabular}

${ }^{a}$ No significant difference. 
designs, the mean VAS would be about 1.8 points (18 percentage points) higher at a cost of £21-25 extra per resident per month. This is equivalent to 8 percentage points extra effectiveness per extra pound spent.

Diapers dominate the night designs. Although there were no significant differences in the mean VAS of diapers, T-shaped and pull-ups, diapers were the cheapest of the three. Compared with inserts that had a significantly lower mean VAS, there was no extra cost per VAS point if diapers were used, $£ 0.50 /$ month if T-shaped diapers were used and £3.42/month for pull-ups. Inserts had significantly worse mean VAS than the other three designs, and had the second highest cost per unit of effectiveness (after pull-ups).

\section{Sensitivity analysis and sources of uncertainty}

Only one product per design was tested and the cost-effectiveness ratios are based on point estimates of monthly costs and effectiveness (as represented by VAS means). Effectiveness was rated by care staff on behalf of residents, so the assessments reflect staff perspectives of what would be best for residents.

Pull-ups are significantly more effective than the other three designs in the day, but are more than twice as expensive as diapers and inserts (the cheapest of the designs). Inserts are significantly less effective than the other three designs at night. There are several sources of uncertainty in the cost estimates. First, the prices used were those prevailing at the time of the trial for the products tested and absolute and relative prices could have altered subsequently. Choice of different products within designs could also have affected relative prices.

Second, the monthly cost estimates are based on observation at baseline that suggested a consumption rate of three products per day and one per night. This was an underestimate of actual night consumption and will have affected the ACERs and ICERs but not the relativities or the outcome that favours diapers.

Third, no allowance is included for differences in laundry between designs. No significant differences were observed in the day, but at night the pull-ups and inserts generated significantly more laundry from leakage than the other two designs.

Fourth, the daily consumption of pull-ups was significantly higher than for the other designs.
This would add to the cost disadvantage of pullups, but has not been quantified and included. It is not clear why consumption of pull-ups was higher than the other designs in the day but not at night. This may reflect staff preference for pull-ups during the day and the finding that they are easy to put on during the day but not at night.

Fifth, there were no reported differences between the designs in the numbers of staff needed to change the designs. No allowance has therefore been included for different numbers of staff. For resident and staff safety reasons, it is likely to be increasingly common that homes have a policy of requiring two staff to be present to change residents who are not independent for pad changing and staff numbers are not therefore likely to be affected by pad design. In the pad change experiment, pull-ups and inserts took the shortest time (significantly shorter than diapers and T-shaped), but this only covered standing changes and the time saved was only around 15-30 seconds per pad change. In addition, these savings may not apply to night changes when residents would be lying in bed.

\section{Discussion}

\section{Inserts}

In this study, we aimed to compare designs of products that had similar absorbent capacities in order to minimise the confounding effect of absorption capacity, which may override the effect of design. However, previous studies had shown that for similar absorption capacities the insert design was significantly less effective at preventing leakage than the diaper design. ${ }^{7}$ The findings from the pad change/leakage diary data from this study showed that there was little difference in leakage performance between the designs; at the median urine weight the insert design was the worst during the daytime but only significantly so when compared with the T-shaped diaper. At night-time, the leakage performance of the insert was also worst (and very similar to the pull-up) but only significantly worse than the diaper.

However, carers in this study perceived the leakage performance of the inserts to be significantly worse than all three other designs during the day and both diaper-style designs during the night. It is notable that the median urine masses for the insert pads were substantially less than for the other designs, particularly the diaper styles, which may indicate increased changing/consumption of pads, and pad consumption data showed that 
significantly more insert pads were used at night than the other three designs. There are several possible explanations for increased consumption; it may indicate that staff took action to prevent leakage, either by changing the pads more often, or by using two pads at the same time at night, or by using some of the more absorbent night insert pads during the day to prevent daytime leakage, or that pads were used for other purposes such as to protect the bed while washing the resident. However, increased consumption may also indicate the popularity of a design. For example, the pullup was the most popular daytime design and pad consumption data show that it was used significantly more than the other three designs. Overall, the combined evidence indicates that the leakage performance of the insert design was worse than that of the other designs for both dayand night-time use.

Although there is evidence that the insert design is worse than the other three designs for leakage prevention, it does have important advantages in the daytime over the two diaper-style designs in being significantly easier and quicker to put on in a standing position. It is also more discreet under clothes (although not significantly so compared with the T-shaped diaper) and probably for these reasons it has better acceptability for daytime use than would be expected from its poor rating of leakage.

For night-time use, the advantages of the insert design are removed. It is not easier to put on in a lying position than the diaper designs and discreetness (a strength of inserts) is not a key variable at night. The poor leakage performance of the insert design dominates and is evident in that only six carers chose it for participants as their first-choice design; nearly half found it to be unacceptable at night and all three alternative designs were preferred to the insert by two-thirds to three-quarters of carers. The insert was the least successful product for night-time use.

\section{Pull-ups}

The pull-up design was the most successful design for daytime use, being preferred over all other designs by around two-thirds of carers and was the first choice for nearly half. The pull-up design has the advantages of the insert design, being easy and quick to put on in a standing position and discreet, but is better than the insert at daytime leakage, staying in place, fit and smell prevention.

During the night-time, the pull-up design was less successful, particularly for leakage, but also for ease of putting on in a lying position, for which it was significantly worse than all three alternative designs. The pull-up was used significantly less than the other designs during the night, possibly because it was difficult to change. However, despite its shortcomings, the pull-up was surprisingly popular, with a low proportion of carers finding it unacceptable for participants and it being significantly preferred to inserts (but not to any other design). The considerable enthusiasm shown by staff and residents for pull-ups during the daytime appears to have carried over to the night, despite the pull-up's disadvantages.

\section{Diaper and T-shaped diaper}

In the daytime, the diaper and the T-shaped diaper performed similarly to each other, the only significant difference being that the T-shaped diaper, contrary to expectations, was significantly worse than the diaper for ease of putting on in a standing position and for speed of pad changing. However, the T-shaped diaper was an unfamiliar product and this may have resulted in slower pad change times than would occur if the design was used regularly. Compared with the insert, both the diaper and the T-shaped diaper were significantly better for leakage during the daytime. However, both the diaper and the T-shaped diaper were rated as significantly worse than the insert and the pull-up for ease of putting on in a standing position and the diaper was also significantly worse for discreetness. Both the diaper and the T-shaped diaper were significantly worse for preference and overall acceptability than the pull-up.

During the night-time, the T-shaped diaper and the diaper performed similarly, although the diaper was significantly more acceptable at the level of (highly acceptable) versus (acceptable + unacceptable). The diaper was the most popular first-choice design for night-time use (41/98) whereas the T-shaped diaper was first choice for 19.

\section{Faecal incontinence}

Around two-thirds of the participants had faecal incontinence. Product performance questionnaire responses indicated that inserts may be least effective for containing faecal leakage (during the day). This was not strongly supported by the pad change/leakage diary data, but there were insufficient data to draw firm conclusions. Further investigation comparing the performance of designs for the management of faecal incontinence is needed. 


\section{Gender and standing ability}

The significant effects of ability to stand and gender on preferences demonstrate that different designs are likely to be more or less suitable for residents with different characteristics.

Carers had a strong preference for pull-ups for women participants, particularly during the day, and if they were able to stand for pad changes. Pull-ups have the advantage of being easy to put on in a standing position, performed more effectively for leakage than inserts and are liked for their dignified pant-like appearance. Although the inserts are as easy to put on, it seems that pull-ups are a substantial improvement and this was first choice for more than half of women (39/73), whereas only 14/73 chose inserts. Diaper style designs are much less popular choices than the pull-ups for women (7/73 chose diaper, 12/73 chose T-shaped diaper).

For women who are unable to stand for pad changing, and for all women during the nighttime, the pull-up was still a popular choice (30/73 carers chose it as first choice for night), although it may be difficult to put on for some women and is less effective for leakage during the night than during the day. In these circumstances, a diaper-style product is likely to be better. Inserts were least preferred for women during the night $(6 / 71)$ and for women who are unable to stand $(2 / 22)$.

For men who are unable to stand and for men at night, diapers and T-shaped diapers (but in particular diapers) were overwhelmingly the most popular choice, with inserts not selected for any men at night and pull-ups the first choice for only two men. Diapers were also preferred during the day for men who could stand, but less strongly so (9/18). Comments from men and their carers indicated that although easy to put on, pull-ups require trousers to be removed (whereas inserts and diapers do not), and this is a disadvantage for men.

\section{Inserts versus diapers}

Inserts and diapers are currently the most commonly used designs in the UK and both are cheaper than the newer T-shaped diaper and pull-up designs. For women, inserts are a better choice than diapers during the day; although they are significantly worse for leakage, they are easier to put on than diapers and, for most women where a pull-up was preferred, the insert was the second choice. However, for women who cannot stand for pad changing, or for use during the night-time, a diaper is likely to be preferable and is better for leakage performance.

For men, diapers are the preferred choice for most circumstances. No carer chose an insert for a man as a first choice for use during the night and only $4 / 27$ chose an insert as first choice during the day.

\section{How effective are the new pull-up and T-shaped designs?}

This study shows that the pull-up design is an important advance in continence management and is the first-choice design for most women in nursing homes. Pull-ups are significantly better than insert pads on most key variables during the daytime and are appreciated for their dignified and pant-like appearance. However, at night they are more difficult to put on than other designs for both men and women and are generally less popular for men because of the need to remove trousers when changing.

The T-shaped diaper was not found to offer significant advantages over the traditional diaper on any key variables for day or night. Although it was designed to be easier and quicker to apply, particularly in the standing position, this was not found to be the case. On the contrary, the T-shaped design was found to be significantly more difficult to apply than all other designs and took significantly longer to change. The T-shaped diaper would have been an unfamiliar design to nursing home staff and this may have contributed to the poorer ratings. However, staff training was given to all nursing homes and the staff tested the designs for a 2-week period, which should have enabled them to gain sufficient experience of using the designs. The traditional diaper was generally preferred for men $(15 / 27$ chose it as their first choice) compared with the T-shaped diaper $(3 / 27)$ but there are indications that for women the T-shaped design may be preferable (12/72 chose it as their first choice compared with $7 / 72$ for the traditional diaper); this may be because it had higher scores for discreetness (although this was not a significant finding).

\section{Limitations}

Carrying out research in nursing homes is challenging. We used several strategies to minimise carer burden and the burden on the home (e.g. all visits at times suited to staff) and to maximise data reliability (pad weighing and skin inspections carried out by researchers, supervision of product performance questionnaire completion). However, staff changes/absences and availability meant that it was difficult to ensure 
that the same staff member completed the questionnaires for an individual resident and it was frequently necessary for staff to act for each other and completion of more than one questionnaire by a staff member was common. To minimise replication of responses, questionnaire completion was supervised by researchers and staff were always encouraged to consider the individual resident when providing their responses.

In this study, only one product was used (rather than two or three) to represent each design group. This decision was made for practical reasons following consultation with nursing homes. Nursing home staff felt that it was important to limit the time of the study to a manageable period and 12 weeks was considered too long. There were also concerns that staff may be confused by multiple products and this would threaten the reliability of the data recorded. Selection of only one product does, however, threaten the validity of the study because the selected products may not adequately represent each of their design groups. The products were selected from interim data available from the similar clinical trial of absorbent products which was being undertaken with community-dwelling individuals (see Chapter 4). This community trial included three products (or two) to represent each design group, which had been preselected from a pilot study. They had similar absorbencies to those most commonly purchased by the NHS (see Chapter 2) and, in order to avoid the confounding effects of different absorbencies, had similar absorbencies to each other $(1900 \mathrm{ml} \pm 20 \%$ for daytime use and $2400 \mathrm{ml} \pm 20 \%$ for night-time use ${ }^{7}$ ). In the community study, results for each of the three products (or two) within each design group were compared and if any products were significantly worse than the other products within their design group for leakage performance variables or for overall opinion then these results were excluded from the analysis. Two night-time products were excluded (see the section 'Design results', p. 50) for these reasons, but neither of these were products that were tested in this nursing home trial. We can therefore be reasonably confident that the products used in this trial represented their design groups within their absorbency range.

Participants were recruited from 10 nursing homes in the London and Southampton areas. These homes varied in size, category of registration and ownership, but how well do they represent nursing home residents (who wear absorbent pads for incontinence) more generally? Comparisons with (the limited) participant data from the two most recent studies of nursing home residents, which tested (1) disposable insert pads ${ }^{15}$ and (2) disposable diapers, ${ }^{16}$ showed that the average age of participants in our study (around 82 years) is similar; Norton scores were slightly lower in our study $(6 \%$ were scored as being at low risk in our study compared with $10 \%{ }^{16}$ and $15 \%^{15}$ ) and Hodkinson mental test scores were very similar (around 50\% scored zero). However, although in our study the median urine weights for day and night were very similar to those in the study testing disposable insert pads ( $150 \mathrm{~g}$ day and $180 \mathrm{~g}$ night), they were lower than those in the study testing disposable diapers (which reported medians of $210 \mathrm{~g}$ for day and $280 \mathrm{~g}$ for night). A possible explanation for this discrepancy may be that the trial of disposable diapers included all diapers on the market, including many with very high absorbencies (and therefore high Rothwell scores), whereas in our trial we used diapers with similar absorbencies to the other designs included in the study, and representing the level of absorbency typically purchased by the NHS (with more moderate Rothwell scores). Use of products with very high absorbencies may have resulted in staff changing the products less frequently, with consequently higher urine masses. It seems unlikely that the participants in our study (or in the study of disposable inserts ${ }^{15}$ ) were less incontinent than those in the study of disposable diapers. ${ }^{16}$

Product development means that the characteristics and availability of individual products change over time and the products used in this study are likely to be superseded. However, the main designs are much more stable and the results should therefore outlive those of the individual products. Market changes, however, mean that absolute and relative prices can alter. For example, a greater demand for pull-ups by NHS Trusts (in response to client preferences) could enable competitive manufacturers to exploit further economies of scale in production and offer more favourable purchasing terms for PASA.

Further limitations applying to the study more generally are discussed in Chapter 7 .

\section{Conclusions}

This study showed that the main differences between the different designs of absorbent products concerned the ease with which they were applied, leakage performance and preferences for different designs, which were dependent on 
gender and ability to stand for pad changing. Pull-ups and inserts were easier and quicker to apply in the standing position than the diaper style designs. Considerable enthusiasm was shown by staff and residents for pull-ups, which represented the best design for women during the daytime, particularly those who could stand, but are the most expensive. The insert would be a cheaper alternative and is still easy to apply, but a more absorbent product may be needed. At night the diaper was the most cost-effective option for both men and women and was the most costeffective product for men during the day. The T-shaped diaper was not better than the traditional diaper overall, nor for ease of application.

\section{Implications for healthcare}

There is evidence that:

- A range of designs is required to meet the needs of carers and residents in nursing homes.

- Characteristics of residents, particularly ability to stand and gender, are likely to aid selection of the most appropriate design.

- The pull-up and insert designs are easiest and quickest to apply in the standing position.
- Pull-ups are the best design for women during the daytime but are relatively expensive. Bulk contract to reduce pull-up price and enable provision would increase satisfaction.

- For women, the insert would be a cheaper alternative than pull-ups and is still easy to apply, but a more absorbent product may be needed.

- The diaper is the most cost-effective design for men both day and night, and for women at night.

- Individual preferences vary and, where possible, residents should be consulted about product choice.

- Most care staff would be concerned about introducing washable designs and there is evidence (see Chapter 4) that if able to choose for themselves most women (and some men) would not find them acceptable. Restricting the range of available products to washable designs alone is therefore not recommended.

\section{Recommendation for research}

- Clinical trial of absorbent product designs for community-dwelling carer-dependent men and women with moderate/heavy incontinence. 



\section{Chapter 6}

\section{Absorbent products for incontinence: first stage in the development of a quality of life instrument}

\section{Introduction}

Very little is known about users' perceptions and satisfaction with pads or the impact on their lives and the Third International Conference on Incontinence in 2004 recommended the development of a QoL instrument for users of continence products. ${ }^{32}$ The results of an investigation into the effects of pad wearing on QoL are presented.

\section{Background summary}

Living with urinary incontinence has multiple implications for individuals, including a wellrecognised, negative impact on QoL. ${ }^{54-56}$ People with urinary incontinence have higher levels of depression and anxiety, feel more stigmatised and have poorer life satisfaction compared with people who are continent. ${ }^{57,58}$ Most treatments for urinary incontinence are directed towards improving symptoms and correspondingly most existing health-related QoL measures, including both generic and incontinence condition-specific instruments, are designed for use in trials where some change in patient symptoms is expected. ${ }^{59}$ However, the principal aim of using absorbent pads is to contain incontinence and, therefore, changes in the design or other characteristics of the pad are not expected to influence incontinence symptoms directly. Consequently, existing QoL tools are unlikely to be sufficiently sensitive for use with pad users. However, users' perspectives on pad-related factors are critically important to aid product selection by individuals and healthcare providers and to enhance product evaluation methodology and inform new product development. There is a need to be able to determine the balance between beneficial effects of pad use and less desirable side-effects, for both individuals and different population groups (e.g. light or heavy incontinence; physical disabilities; workplace or home settings).

The aim was to gain a better insight into how pad users' everyday lives may be affected by the management of incontinence with absorbent products and to look beyond measures of pad performance alone, towards impact on overall QoL. QoL is a complex concept which encompasses "those attributes valued by patients, including their resultant comfort or sense of wellbeing; the extent to which they are able to maintain reasonable physical, emotional and intellectual function; the degree to which they retain their ability to participate in valued activities within the family, in the workplace and in the community" ${ }^{60}$ An acknowledgement of this multi-dimensional nature of QoL helps to emphasise the importance of considering individuals' needs and experiences of pad use in relation to their own circumstances.

\section{Aims}

The aims were:

- to examine how absorbent pad use impacts on the lives of women and men with urinary incontinence

- to determine key domains for inclusion in the development of QoL measure for people using absorbent products

- to identify the pad characteristics which impact most strongly on users and should influence new product design and evaluations.

\section{Design}

The study design comprised two stages and data were collected as part of the two community-based clinical trials: for women with light incontinence (Chapter 3) and for men and women with moderate/heavy incontinence (Chapter 4). Data were also collected from nursing home care staff as part of the third clinical trial; findings are not described here and are described in Chapter 5.

\section{Stage I: determining important pad characteristics}

An initial 'bank' of pad characteristics, considered most important by users, was derived from a critical review of published literature and subsequently refined through focus group discussion with pad users. Electronic databases were systematically searched for published papers examining the use of absorbent products, using the keywords 
continence, incontinence, absorbent products, pads, evaluation and QoL. The only restriction was that papers were published in English.

Focus groups offer the advantage of group dynamics to stimulate discussion, ${ }^{61}$ but travel to a central location for group activity can be difficult for many in this population, which includes a high proportion of people with physical disability arising from disease, injury or advanced age. However, as the continence user group (Incontact) were holding their annual conference, it was possible to incorporate the focus group and invite (pad-using) volunteers who were attending the conference. The participants were asked to describe 'the ways in which wearing an absorbent pad affected their lifestyle and QoL'. The discussion was recorded and supplemented by written notes made concurrently by one of the two researchers facilitating the focus group. The researchers independently reviewed the recording transcript and written notes to identify relevant issues and then agreed on emerging categories. Categories were compared with issues identified from the literature review and formulated into a series of pad-related characteristics, which provided the basis for the subsequent ranking exercise in Stage 2.

\section{Stage 2: Face-to-face interviews and ranking exercise}

Face-to-face interviews were conducted with a large sample of women and men using pads for urinary incontinence, to examine the impact of pad use on their daily lives. Interview subjects were women with light incontinence and women and men with moderate/heavy incontinence recruited to the main clinical trials of product designs.

Interviews took place at the participant's home or the research centre. All interviews were conducted by one of two researchers who had both received prior training in the process. Interviewees were asked about the impact of absorbent product use on their daily lives and what would make life better. All participants were encouraged to give examples of how pad use and specific pad characteristics affected their lives, in order to help them think about their pad-related QoL and not simply incontinence-related QoL or satisfaction (or not) with pad performance. Lastly, they were asked to use a five-point Likert scale (where 1 represented very important and 5 not important) to rank (1) the importance of individual pad characteristics to them and (2) the five most important pad characteristics for day use and for night use.

\section{Analysis of interview data}

Interviewers aimed to promote rigour and minimise potential misperceptions by checking the accuracy of their understanding through supplementary questioning as the interview proceeded. ${ }^{62}$ Interviews were recorded and verbatim transcripts imported into HyperResearch software (ResearchWare, USA, Version 2.6) and subjected to rigorous content analysis. ${ }^{63}$ Codes were assigned to lines, sentences or paragraphs and passages of text with similar codes were grouped into categories. Some sections of transcripts were given more than one code. Categories were gradually refined through repetitive comparison of data and examination of additional written notes. Categories were grouped into emergent themes independently by two researchers and outcomes, then reviewed and agreed together.

\section{Results}

\section{Stage I}

The range of identified literature on absorbent pad use and/or product evaluation was identified (see Chapter 1). The main function of absorbent pads is to absorb urine without leakage and, unsurprisingly, 'absorbency' was the most frequently cited pad performance item in the literature. Most questionnaires used a large number of secondary outcome variables which included practical issues related to application, comfort and ease of use. These variables formed the initial bank of pad performance characteristics, which were subsequently further refined through focus group activity. Fifteen volunteers took part in the focus group and discussions contributed to the final formulation of the set of pad characteristics used later in the ranking exercise.

\section{Stage 2 - interviews}

The two community-based clinical trials (Chapters 3 and 4) were held consecutively, beginning with designs for women with light incontinence, followed by the clinical trial of designs for men and women with moderate/heavy incontinence. Participant characteristics for both trials are shown in Tables 7 (p. 24) and 29 (p. 51). Interviews were held at the beginning of the two trials and, for health or personal reasons, some participants did not go on to take part in the product-testing phase. All women from the clinical trial of products for light incontinence participated $(N=85)$, including 14 women who withdrew from the study (for health or personal 
reasons) before product testing began. All participants from the clinical trial of products for moderate/heavy incontinence took part in the ranking exercise $(N=85)$ with 29 (19 men and 10 women) taking part in the QoL interviews. Despite their apparent diversity, these 29 participants did not reveal any important differences or add any new themes to the data and data are therefore presented together.

\section{Analysis of interviews}

Content analysis of interview transcripts resulted in the identification of a single superordinate theme described as 'Containing the problem' (Figure 63). This theme encompassed critical practical issues impacting on the confidence, felt by interviewees, relating to the effective containment of their incontinence. Although the reliability of the pad to 'hold urine' was their predominant concern, they were also extremely anxious about 'hiding the problem' from others and about 'ease of use', particularly in changing and disposing of used pads. Two associated subordinate themes were 'physical impact' and 'psychological impact and social functioning'. These themes were closely inter-related (Figure 63) and issues to do with containment of urine, discreetness and physical comfort exerted a strong influence on psychological impact and social functioning.

\section{Containing the problem}

Women and men acknowledged that wearing a pad would not prevent or improve their

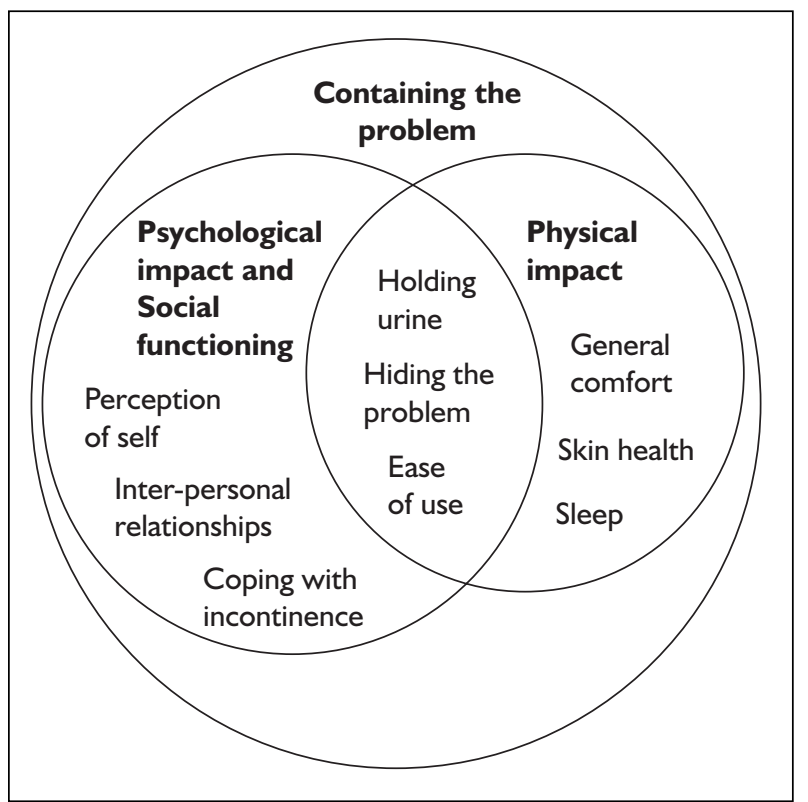

FIGURE 63 Themes from interview data, illustrating interrelationships continence symptoms, but they needed to be confident that the pad would hold urine effectively and would not be visible to others. Yet this confidence was often fragile and could easily be damaged. Many were constantly anxious about leakage and visibility of the pad. Several described feelings of panic if the pad slipped out of position. Three-quarters of interviewees (94/124) expressed a general sense of anxiety, with 52/124 raising specific concerns about pad visibility:

"It's vital to be able to carry on with everyday life. Knowing that the pad will hold urine gives you security so allows you to do things. If the pad leaks then you stop doing things. It's easy to lose confidence in yourself and stop doing everyday activities." [076]

\section{Pad discreetness and containment of smell} (odour) were identified by all women and men as crucial aspects of 'hiding the problem'. Pad size was recognised as part of a dynamic relationship between effective absorbency whilst maintaining discreetness:

\footnotetext{
"Discreetness of a pad means a huge amount. You don't want people to see it; you'd be really embarrassed if people knew you had a bladder problem. I prefer to use thin pads and change regularly, which is a bit inconvenient but better than wearing a pad that was bulky and could be seen ...." [379]

"You cover up and wear baggy clothes so no one can see the pad. You don't want them to hear it either. You would get embarrassed if someone saw the pad. It's my age, I'm young and don't want it seen. It makes life worse because I'm young." [581]
}

'Ease of use' was influenced by pad size and the convenience with which pads could be hidden discreetly in a handbag, or a rucksack (often used by men). The length of time required to change the pad was an important issue for some women and men managing busy lives:

\footnotetext{
"Being young and wanting to get on means that your time is really precious. You have constraints and you are expected to be speedy. You have a role to fulfil as a mum or a young person so speed of putting on a pad is relevant." [147]

"For longer trips out with work it's essential to change easily if out in the afternoon, say. I would at least need one change to be sure of no leaks.” [172]
}

For some people with limited dexterity, some packs of pads could be difficult to open and some pads were awkward to put on. If pads were easy to change this aided coping with incontinence 
and helped to promote a greater degree of independence.

\section{Physical impact}

The key domains within this sub-theme related to issues of 'general comfort', 'skin health' and 'sleep'. Interviewees commented that some pads were more comfortable than others but most were uncomfortable when wet. Dry comfort was closely related to pad size and fit, with poorly fitting pads known to cause discomfort and chafing at the top of legs:

\footnotetext{
"A comfortable pad gives you more confidence to go out, it makes you feel like you are wearing normal underwear, gives you more security." [34]
}

Pads also needed to stay securely in place while the wearer was moving about or they could lead to itching and soreness. Wet pads were uncomfortable because they could become more bulky and heavy and made the individual more conscious of having to wear a pad. They made the skin feel wet, causing worries about developing skin rashes and they could change shape or become lumpy and rub against the skin. Consequently, wearers tried to change them as soon as possible, but this meant having to have spares with them at all times. Wearing a pad at night presented particular difficulties for some and often resulted in poor sleep and tiredness during the day. Wet pads were often worn for longer at night and were not only uncomfortable but added to increased risks of skin irritation:

\footnotetext{
"I have a routine of using creams and wash much more regularly. Soreness makes you very uncomfortable and makes you aware the pad is there, making you feel even more unhappy or low." [222]

"Halfway through the night the last thing you need is to have problems removing a pad. Some pads can break up, which is frustrating and makes you annoyed. You end up being shattered in the day." [210]
}

\section{Psychological impact and social functioning}

These issues were initially considered as two distinct sub-themes but were later placed together because the major psychological impact was around concerns that other people would become aware of their incontinence problem. This influenced their personal perception of themselves ('self-perception'), their 'personal relationships' and their personal 'coping strategies' in familiar and unfamiliar situations. All the women and men interviewed spoke extensively of the psychological impact of their continence problems and reliance on absorbent pads on their everyday lives. The effectiveness and discreetness of the pad were critical issues which affected how they felt about themselves and how they might be seen (and judged) by others. They talked about their desire for normality, and this was often eroded by the need for pads, which eroded their feelings of femininity or masculinity and the efforts required in hiding their problems. They spoke of feeling self-conscious and being forced to select clothing which would hide the pad and any possible damp patches. This often limited their choice of 'nice clothes' and of tight-fitting fashions:

"I don't wear tight clothes in case the outline of the pad can be seen. It would be embarrassing. I have different clothes for different occasions but all tend to be baggy and they are chosen for the incontinence problem." [243]

Effective containment of smell from a wet pad, when being worn or carried prior to disposal, was a constant source of concern. When they talked about the risk of urine smells, interviewees used language which demonstrated high levels of real and potential emotional distress. They used words such as 'devastated', 'mortified', 'horrendous', 'embarrassed' and 'ashamed' to describe their feelings and fears. They worried about their proximity to other people, whether family or close friends would tell them if there was a urine smell and about giving offence to others:

"I'm terrified the pad will smell. If I was out with friends I would have to leave. I couldn't be next to them in case they could smell me and I would be utterly mortified." [324]

Some (less than 20\%) talked about open relationships with partners and/or families, and sometimes with close friends, where they felt comfortable that their continence problems were known. However, this could still cause difficulties and embarrassment, and these issues could become more acute when with friends who didn't know. Pads were considered 'unsexy' and could interfere with sexual relationships, even with supportive partners:

\footnotetext{
"Sometimes it affects being with friends because you just don't trust the pad and don't want to leave a wet patch on their seat, so you tend to leave early so it spoils the time with them and they often don't understand why you are leaving earlier than you should." [324]
}

"Nappies and plastic pants perform the best at night but I look and feel totally ridiculous in them and my 
wife thinks so too. They are virtually unacceptable." [479]

"My partner hates waking up in a wet bed; she complains about me if I smell in the morning." [172]

The possibility of the pad leaking prevented some women and men from applying for jobs and of the $25 \%$ who did go out to work most expressed concerns about the need for confidence in their pads:

"If the pad didn't hold urine then I wouldn't be able to go to work ... as it is I feel constantly anxious wondering if the pad can last long enough to get through a morning's work ...." [158]

Many women and men appeared to exist in a state of ongoing tension, with their need for social activities compromised by their concerns over pad performance and sense of security. Over two-thirds (86/124) of interviewees identified anxieties over social interactions, ranging from theatre trips, visiting friends to simply going shopping. Problems were less demanding at home or in a known environment but became increasingly dominant as the environment became less familiar and less 'safe'.

For all men and women in this study, it was important for them to be able to control their situation and to minimise pad-related anxieties. They did this by planning ahead for high-risk situations where potential leakage might occur, through their choice of clothing, knowing how long a pad could last before changing, carrying spare supplies of pads, pants, wipes and carrier bags or nappy sacks with them, avoidance of cheaper pads which could give off smells and often through simply avoiding certain situations or going to unfamiliar places:

"You prepare yourself before going to see friends, wash before going and carry wipes in bag. You tend to go over the top with padding when you are going out but then you worry about discreetness ...." [204]

Travelling and particularly staying away overnight presented major concerns about coping in an 'unsafe environment'. If interviewees did not know when or where the next accessible toilet might be found, they often felt very anxious, fearing leaks and lack of opportunity to change. Staying in hotels raised concerns over leakages in bed and poor facilities for pad disposal:

"You can't stay away from home because you are always too fearful that it will leak in someone else's bed or at a hotel so I tend to avoid these circumstances." [216]

Ability to cope with their situations varied considerably, for both those with light and those with moderate/heavy incontinence. Although for most their urinary incontinence was contained through their use of absorbent pads, it was clear that pad use brought with it other effects which severely affected their overall QoL.

\section{Pad characteristic ranking exercise}

Tables 76 and 77 summarise the pad characteristics ranked in the top five for day- or night-time use

TABLE 76 Summary of pad characteristics ranked in top five (women with light incontinence)

\begin{tabular}{|lclc|}
\hline Top $\mathbf{5}$ characteristics $($ day) & \% women $(\boldsymbol{n}=\mathbf{9 9})$ & Top $\mathbf{5}$ characteristics $(\mathbf{n i g h t})$ & \% women $(\boldsymbol{n}=\mathbf{8}$ ) \\
\hline To hold urine & 83.8 & To hold urine & 93.8 \\
To contain smell & 75.8 & To stay in place & 77.8 \\
To stay in place & 54.5 & To contain smell & 54.3 \\
Discreetness & 41.4 & Comfortable when wet & 54.3 \\
Comfort when wet & 40.4 & To keep skin dry & 48.1
\end{tabular}

TABLE 77 Summary of pad characteristics ranked in top five (moderate/heavy incontinence)

\begin{tabular}{|lclc|}
\hline Top $\mathbf{5}$ characteristics (day) & $\begin{array}{c}\text { \% of men and women } \\
(\mathbf{n}=\mathbf{6 7})\end{array}$ & Top $\mathbf{5}$ characteristics (night) & $\begin{array}{c}\text { \% men and women } \\
(\mathbf{n}=\mathbf{6 7})\end{array}$ \\
\hline To hold urine & 92.5 & To hold urine & 95.5 \\
To contain smell & 56.7 & To stay in place & 68.7 \\
To stay in place & 50.1 & Comfortable when wet & 53.7 \\
Discreetness & 46.3 & Fit & 43.3 \\
Fit & 43.3 & To keep skin dry & 37.3 \\
Comfort when wet & 35.8 & To contain smell & 34.3 \\
\hline
\end{tabular}


for the women with light incontinence and the men and women with moderate/heavy incontinence.

Although some characteristics were more closely associated than others (e.g. 'comfort' or 'ability to stay in place'), there was clear consensus on the top five ranking characteristics, with minor differences between day- and night-time use. There was also strong consistency between the two participant groups, with the main difference being the inclusion of 'fit of pad' in the moderate/heavy incontinence group. This is likely to be because products in this group are much larger and enclose the body, whereas 'fit' is likely to be less of an issue for most absorbents for light incontinence. The ability to hold urine without leaking was the most important feature for day and night. Ability to stay in place was particularly important at night and slightly less so during the day in both groups. Notably, the ability to contain smell was ranked second only to holding urine for daytime use but was also identified as important at night. Comfort when wet was important at all times but was ranked third for night-time use in both participant groups. Interviewees explained that they were likely to be in a wet pad for longer periods at night than during the day, when they would aim to change the pad as soon as it became wet. Discreetness of the pad was a particular issue for day use, with interviewees expressing considerable anxiety over whether others could see they were wearing a pad. Although there was strong agreement on the five major pad characteristics, it is important to recognise that for some individuals other characteristics featured highly. For example, ease of opening the pack and putting on the pad were ranked top by some women with dexterity and mobility difficulties.

\section{Discussion}

The ranking exercise on pad characteristics demonstrated a clear consensus on the most critical features of pad performance for women with light incontinence and men and women with moderate/heavy incontinence, but although these priorities provide some insights which may help guide product choice and new product designs, they focus almost exclusively on practical aspects of pad use. The focus group discussion and individual interviews showed that measures of pad performance alone are too insensitive to explain the impact of pad use on daily life or to be used to assess influence on QoL. This was demonstrated by the close inter-relationship between domains within the superordinate theme "containing the problem', and the two sub-themes ('physical impact' and 'psychological impact and social functioning'). Even when urine leakage was successfully contained, concerns over issues such as comfort, skin health and the need to hide the problem of urinary incontinence from others generated anxieties for users and demanded complex personal coping strategies. Although fears about urine leakage and exposure of continence problems to others are common to most people with incontinence symptoms, ${ }^{64-66}$ there were clearly a range of issues which were specifically related to pad use. These included precautions needed to contain urine effectively whilst hiding pad bulkiness, containing urine smell, disposing of used pads and planning ahead to facilitate pad changes when engaging in personal and social interactions. For most interviewees, this meant restrictions in the choices of clothing, often with an accompanying detrimental impact on self-image and confidence. It also resulted in extensive and time-consuming washing regimes, frequent use of wipes and complex planning to ensure containment of possible smells from wet pads prior to their disposal. The constant requirement for thinking ahead and being prepared to deal with wet pads were continual reminders of incontinence and women often felt they were unable to maintain the levels of normality and femininity that they wished for. Pad performance was an important factor in the level of self-confidence which could be maintained, but factors influencing overall QoL went beyond pad performance alone, impacting on psychological and social functioning across the spectrum of personal relationships, working lives and wider social interfaces.

This study makes an important new addition to a previously, poorly, researched aspect of living with incontinence. The consistencies of findings suggest that the findings could be potentially generalisable to a wider population of women and men using these products. The study has identified key domains which should be included in the development of a QoL instrument for pad users. By encompassing both positive and negative aspects of pad use, this should enable the final QoL measure to establish the 'net gain' to be achieved by different absorbent products. This model has not been applied to incontinencespecific QoL tools to date, which have focused on the effects of urinary symptoms alone.

\section{Limitations and next steps}

The current study was limited to women using products for light incontinence and women and 
men using products for moderate/heavy incontinence. It is acknowledged that there may be different issues and priorities for lightly incontinent men. The next step will be to compare data from different population groups to develop a QoL questionnaire, based on the identified domains. This draft QoL measure will be subjected to a cycle of field testing, refinement and psychometric analysis to determine its value in clinical practice and as a research and development tool.

\section{Conclusions}

The study provides important new insights into critical issues affecting women's and men's experiences of containing incontinence with absorbent pads. The findings support the need for the development of a QoL outcome measure for pad users and key domains for inclusion have been identified. A more sensitive, patient-oriented QoL instrument would contribute to improved continence care and user satisfaction, through more informed choices on appropriate products for particular users and their circumstances. Such a measure would also provide a broader perspective on product use to inform new product development and effective product evaluation methodologies.

The next stage will involve the development of questionnaire items such as 'How much does wearing this pad affect your clothing choices?' and 'How much does this pad seem like your normal underwear?' Further stages will involve processes of validation and reliability testing to produce a quality of life tool suitable for research and clinical purposes.

\section{Implications for clinical practice}

Users, purchasers and carers need comprehensive, evidence-based guidance to help inform their choice of products from the wide and constantly changing range available on the market. This study has shown that the impact of living with absorbent pads goes beyond pad performance characteristics alone and users could benefit from advice, not only on the range of pads available, but also on strategies to reduce associated anxieties and practical aspects of coping. Continence assessments should include recognition of lifestyle issues that may influence advice on most suitable products for individuals. For those users who buy their own pads and are unknown to continence services (two-thirds in this study), there is a need to find other ways of offering/disseminating appropriate advice. This may include stronger working relationships with manufacturers and suppliers. In summary, the practical outcomes of this work include identifying and understanding issues for people managing incontinence with absorbent pads, the initial stages of development of a QoL tool that can be applied to a treatment (or treatments) where no change in symptoms is expected and identification of QoL issues that should be used to inform new/improved continence product development and evaluation. 



\section{Chapter 7}

\section{Discussion, conclusions, implications for healthcare and recommendations for future research}

$\mathrm{T}$ his study comprised three clinical trials of washable and disposable designs of body-worn absorbent pads and the first stage of the development of QoL tool for people with incontinence who use absorbent pad management. Each chapter has its own discussion, study limitations and conclusions section, but issues that apply more generally or cut across the trials are discussed here.

\section{Study limitations}

\section{Participant drop-out during trials and analysis}

In all three trials, participants dropped out of the study during the course of the study and progress and attrition of subjects are shown within each module. Ill-health was a common reason, as was 'too much bother/effort', particularly for participants in the community with moderate/heavy incontinence who tested products for the longest period (14 weeks). Future trials should aim for a shorter testing period (if possible) to avoid this problem.

For data analysis, the usual practice in a parallel group randomised controlled trial would be to carry out an intention-to-treat analysis to include data from all participants who started the study. This would usually require imputing data obtained at baseline (or at the last recorded time before drop-out) to the final outcomes. The main reason for this is because participant drop-out may well relate to the intervention (such as lack of efficacy or side-effects) and participants who drop out may therefore be expected to have worse outcomes than those who do not; it would therefore be important to include them in the analysis to avoid bias.

In our trials data from participants who did not complete testing of all designs were not included in the analysis. We encouraged participants to test all designs and gave them the opportunity to cease testing any particular design (however short the test period) and move on to the next design.
Probably as a result of these efforts, very few participants dropped out for product/designrelated reasons and it is not obvious how removal of these participants from the analysis could bias the results. Inclusion of these participants presents problems for the analysis in two ways. First, it is not possible to impute data from designs that a participant has tested to designs that they have not tested. Crossover design analysis requires data from each participant from all test periods (i.e. from all designs) and participants who only provide partial data weaken the power of the study. New recruits are therefore needed until the target number for each trial is reached, with each participant providing data from all test periods (designs). Second, most participants who dropped out did not provide any data on the designs because they did not return their data collection booklets, or those that they did return were unusable. It was anticipated that it would not be possible to use data from participants who did not complete the study and so there was overrecruitment to ensure that there were sufficient participants to meet the target numbers with data in all testing periods.

\section{Final interview and recall bias}

The length of product testing (12 weeks or more for participants in the community) meant that by the time participants had their final interview (usually within 4 weeks after testing), many weeks would have passed since the participant tested products at the beginning of the study. There was therefore potential for recall bias. To minimise dependence on recall, the data collection booklets containing the participants' product performance scores (including 'overall opinion') and written comments about the products were reviewed with the participants at their final interviews. The products were displayed to aid memory and participants were asked to consider their scores and comments before comparing the designs and giving their final 'overall opinion' scores and preferences. In practice, we did not find that participants had many problems with recall and most had formed firm opinions about the designs and their preferences. 


\section{Outcome measures}

There is no single tool for evaluating the performance of absorbent products. Tools were constructed based on outcomes and validated questionnaires used in previous studies ${ }^{8,11}$ of absorbent products and, to add to the validity of these items, the data obtained from the preliminary participant interviews were used to determine and prioritise questionnaire items. However, it is recognised that assessment of product performance would be enhanced with a tool to measure the impact that product performance has on QoL and part of this study was designed to begin the process of producing such a tool. The interviews with participants to establish their priorities and to identify the impact that absorbent pads have on their QoL showed strong consistency between participants in the community-based trials, with similar issues being raised and similar priorities being rated highly for women with light incontinence and men and women with moderate/heavy incontinence. It may therefore be possible to develop a single tool that can be used for participants with different levels of incontinence and this will improve measurement of product performance in future clinical trials.

Leakage performance data for all trials were obtained by saving and weighing used pads and recording leakage severity. In the nursing homes, research staff (and sometimes trained volunteer staff) carried out the weighing to improve reliability and reduce the burden on care staff. However, these data are demanding for community participants because the process needs to be done frequently, is not very pleasant to carry out and can be impossible to achieve in certain circumstances (e.g. when out of the house). Because collecting pads is difficult for most people to achieve continuously, we did not require participants to collect all pads, but asked them to collect as many as possible. Where patients tested products for shorter periods (because they stopped testing products early), fewer data were collected and therefore there were fewer data for less popular products such as washables. The leakage performance data were used to construct leakage performance curves, and accuracy increases with number of products. It is therefore likely that these curves are less reliable where fewer products were used, but it should be noted that the smallest number of products collected from a single design exceeded 600 and a minimum of 300 products were required for the modelling. Bias may have occurred if participants saved and weighed more pads that did (or did not) leak from one particular design than another, when they had a particularly small or large urine mass, but this would have required systematic effort on behalf of participants and is not a likely scenario. The volume of urine in the pad will generally have been somewhat underestimated because some urine will have been lost through leakage or (less so) through evaporation, and this is likely to have affected the poorer performing designs (for leakage) more than the better designs.

\section{Discussion}

\section{Provision of absorbent products in the UK}

In the UK, current absorbent product practice focuses on the provision of disposable body-worn products, with the insert design predominating (for both light and moderate/heavy incontinence), but with a growing provision of diapers (mainly for heavier incontinence). There is no clear evidence to inform assessment for individual needs. Washables represent a very small share of the market and, where these are provided, they are usually for light incontinence. However, a small minority of nursing homes have changed their absorbent pad management mostly or entirely to washables. Interest in the provision of washables is generally increasing for cost reasons and also because they are perceived as more environmentally friendly, although this may not be the case. ${ }^{49}$

\section{Disposable designs for moderate/heavy incontinence: comparisons between community and nursing home results} Two of the trials (Chapters 4 and 5) included disposable designs for moderate/heavy incontinence and showed similar findings. The nursing home trial included more women than men (71 versus 29) and participants had limited or no mobility and had physical and mental disabilities; analysed results were the responses of carers (who were predominantly women). The community trial included more men than women (49 versus 36 ) and participants were mainly mobile and independent, and gave their own responses. Results from both trials showed that the leakage performance of the inserts was worse than that of the other designs for both day and night (although this was shown more in carer responses in the nursing home trial than in pad leakage data) and pull-ups were significantly better than inserts for the daytime. Gender was significant for most variables in the community trial and in the final interview data for the nursing home trial. Further analysis by gender showed similar findings in both trials. The pull-ups were found to be 
strong on most variables and significantly better than the other designs for preference and acceptability for women for the daytime. There were indications from both trials that for men diapers were preferred to other disposable designs during the daytime and that they were significantly preferred to other disposable designs at night. The surprising indication from the community trial that women preferred inserts over diapers for day (but less strongly for night) is not apparent in the nursing home results, but inserts did better for preference during the daytime than might be expected from their poor leakage results (33 diapers versus 39 inserts). This may be a reflection of the advantage of inserts being found to be easier to put on in the standing position (during the day) than the diaper. During the night (when this advantage was lost), diapers were significantly preferred to inserts.

These combined findings show that pull-ups are the design of first choice for women in the community and in nursing homes, during the daytime, but they are relatively expensive. The cheaper alternative for women would be the insert or diaper. There are indications that the insert would be a better second choice than the diaper (discreet, easier to change by carer and preferred by community women generally), but they leak more, and more products may be needed (in the community), or inserts with higher absorbency may be required to improve leakage performance, which would increase cost. For the night-time, pull-ups are still the first choice for women in the community, with indications that the insert is still preferable to the diaper as a second choice, although the same issues with increased leakage and cost will apply. The diaper design is the most costeffective for women for night-time use in nursing homes, but it should be borne in mind that some women may prefer inserts (and dislike diapers) and where possible residents should be consulted regarding their choices.

For men in the community and in nursing homes, the most cost-effective design is the diaper for both day- and night-time. There are indications that carers and men prefer the diaper to the pullup, particularly at night. The insert is significantly and substantially worse than the diaper for men for day and night (and may perform worse for men than women). Men had substantially higher urine losses than women and may need products with higher absorbency (or better products; see below) to reduce leakage.

\section{Improvements still needed for disposables}

Although the pull-up appears to be a considerable advance for disposable designs, its performance and appeal are better for women. For men there is no such comparable product. Although the diaper was the preferred design for men, it has limitations (e.g. sweatiness) and a baby-like appearance; a more masculine product, designed with the male anatomy in mind, is needed.

\section{Improvements still needed for washables}

The findings from this study indicate that washables have more potential than is reflected by current practice, but that there is a need for more product development to improve their function (particularly for women with light incontinence) and aesthetics (particularly for moderate/heavy incontinence, and particularly for women). Increase in washable product use is likely to be limited until improvements are made.

\section{Washables in nursing homes}

Washables were not tested in nursing homes, but findings from the community-based trials are useful to consider in the context of nursing homes. These showed that very few women found the washable products (in their current form) to be acceptable and opinions were strongly divided among men. It is therefore difficult to justify ethically the general introduction of washables for moderate/heavy incontinence to nursing homes until products have improved and until there is evidence that more people (particularly women) find them acceptable.

\section{Washable-disposable combinations}

Even with better performance and aesthetics, washables are more problematic to deal with than disposables, particularly outside the home, where managing wet products is a difficult problem. Combinations of disposables and washables are likely to be a better option, with washables playing a greater part while at home, and at night (particularly for heavy incontinence) when discreetness is less of an issue and bulkier products can be used. This approach would also reduce the laundry burden of washables, which would be considerable and probably intolerable for many (particularly with heavy incontinence), if washables were used all the time.

\section{Offering variety and choices}

NHS rhetoric is that it wants to be a consumerdriven service, so in the context of continence supplies people with the capacity to choose for 
themselves could be given a direct payment or a voucher and allowed to select the combination of products that is most efficient for them. This would enable users to choose combinations of designs (both cheaper and more expensive, disposable and washable) for their different circumstances (home and when out, holidays and 'best'). The provision of an NHS 'shop' to buy supplementary products at cheaper prices (due to the buying power of the NHS) would also reduce costs to users. The incontinence product market is large and competitive and manufacturers will have the incentive to develop products to meet consumers' tastes and preferences at realistic prices.

\section{NHS provision}

The NHS Supply Chain expects to purchase for an increasing proportion of the total adult incontinence market in the next few years. There is a tension between reducing product choice in order to maximise bulk purchasing discounts and the need to increase the product range to meet the diverse preferences of NHS consumers. Analysis of the product portfolio offered by NHS Logistics in the last 2 years shows that it has reduced the number of manufacturers with which it contracts. The range of inserts on offer has been reduced, but the number of T-shaped products (a relatively new line) has increased. The number of diaper products has not altered. Prices have risen across the board due to increases in the cost of basic inputs, but technological advances mean that there is excess capacity in the industry. As a result, the potential to sell to the large NHS market is likely to keep manufacturers keen to compete for a hefty share of it by a combination of price and non-price means.

\section{Quality of life}

Interviews with participants for the first stage in the development of a QoL tool for assessing the performance of absorbent products show that absorbent pad management is fraught with anxieties and practical problems, but the provision of effective products can do much to alleviate this burden. Further development of this tool is needed to permit better evaluation of products in the future.

\section{Conclusions}

This study showed that there were significant and substantial differences between the designs of absorbent products and for moderate/heavy incontinence some designs are better for men/women than others. There was considerable individual variability in preferences, and costeffective management may best be achieved by allowing users to choose combinations of designs for different circumstances within a budget.

\section{Implications for healthcare}

There is evidence that:

1. A range of disposable and washable designs need to be provided to meet cost-effectively the needs of men and women with incontinence.

2. Men may require more, or more absorbent, products than women.

3. Although some users prefer washables, current products have important limitations and restricting the range of available products to washable designs alone is not recommended.

4. Allowing men and women to choose combinations of designs for day and night and for different circumstances, within a limited budget, is likely to be economical for the NHS.

\section{Recommendations for research}

1. Translational research: to pilot the feasibility of providing choice and combinations of designs to users.

2. Development of more effective washables for women with light incontinence and more effective and appealing (particularly to women) washables for moderate/heavy incontinence.

3. Development of specifically male disposable products for moderate/heavy incontinence.

4. Further development of a tool to measure QoL for users of absorbent products.

5. Clinical trial of designs for community-dwelling carer-dependent men and women with moderate/heavy incontinence. 


\section{Acknowledgements}

This report was commissioned by the NIHR

HTA Programme. The views expressed in this report are those of the authors and not necessarily those of the NIHR HTA Programme. Any errors are the responsibility of the authors.

We would like to thank all participants who took part in this study and we would also like to thank the staff at the following nursing homes: Cheverton Lodge, Ash Court, Belmore Lodge, Court Lodge, Woodland Ridge, Oaklands, Cedar Lawn, Gorseland, the Highgate and St. George's Hospital nursing home.

\section{Steering group}

Christine Norton, Debra Evans, Hilda Matthews, Ian Parker, Frank Ursell and Ann Bowling.

\section{Contribution of authors}

Mandy Fader (Reader), Alan Cottenden (Senior Lecturer), Kathryn Getliffe (Professor of Nursing), Heather Gage (Senior Lecturer), Sinead ClarkeO’Neill (Senior Lecturer) and Rodney Brooks (Senior Lecturer [retired]) worked on the conception, design, analysis, interpretation, drafting and final approval. Katherine Jamieson (Research Nurse) and Nicholas Green (Research Nurse) assisted in the conception, design, revision and final approval. Peter Williams (Research Fellow) worked on the conception, design, revision and final approval. James Malone-Lee (Professor of Medicine) also worked on the conception, design, interpretation, revision and final approval. 



\section{References}

1. Fonda D, Abrams P. Cure sometimes, help always a "continence paradigm" for all ages and conditions. Neurourol Urodyn 2006;25:290-2.

2. Mitteness LS, Barker JC. Stigmatizing a "normal" condition: urinary incontinence in late life. Med Anthropol Q 1995;9:188-210.

3. Paterson J. Stigma associated with postprostatectomy urinary incontinence. J Wound Ostomy Continence Nurs 2000;27:168-73.

4. Continence Foundation. Making the case for investment in an integrated continence service. London: Continence Foundation; 2000.

5. Norton C, Kamm MA. Anal plug for faecal incontinence. Colorectal Dis 2001;3:323-7.

6. Evans D. Faecal incontinence products and quality of life. Nurs Times 2006;102:44-5, 47.

7. Cottenden AM, Fader MJ, Pettersson L, Brooks RJ. How well does ISO 11948-1 (the Rothwell method) for measuring the absorption capacity of incontinence pads in the laboratory correlate with clinical pad performance. Med Eng Phys 2003; 25:603-13.

8. Clarke-O’Neill S, Pettersson L, Fader M, Dean G, Brooks R, Cottenden A. A multicentre comparative evaluation: washable pants with an integral pad for light incontinence.J Clin Nurs 2002;11:79-89.

9. Clarke-O'Neill S, Pettersson L, Fader M, Cottenden A, Brooks R. A multicenter comparative evaluation: disposable pads for women with light incontinence.J Wound Ostomy Continence Nurs 2004; 31:32-42.

10. Macaulay M, Pettersson L, Fader M, Cottenden A, Brooks R. Disposable pull-ups versus disposable nappies for children with a disability. Nurs Times 2004;100:64-5.

11. Fader M, Macaulay M, Pettersson L, Brooks R, Cottenden A. A multi-centre evaluation of absorbent products for men with light urinary incontinence. Neurourol Urodyn 2006;25:689-95.

12. Baker J, Norton P. Evaluation of absorbent products for women with mild to moderate urinary incontinence. Appl Nurs Res 1996;9:29-33.

13. Brink CA. Absorbent pads, garments, and management strategies. J Am Geriatr Soc 1990; 38:368-73.

14. Clancy B, Malone-Lee J. Reducing the leakage of body-worn incontinence pads. J Adv Nurs 1991; 16:187-93.
15. Cottenden AM, Fader MJ, Pettersson L, Clinton L, Dean GE, Malone-Lee J, et al. Disposable, shaped bodyworn pads with pants for heavy incontinence. Report No. IN1. London: Medical Devices Agency; 1998.

16. Fader MJ, Pettersson L, Clinton L, Dean GE, Malone-Lee J, Feneley R, et al. All-in-one disposable bodyworn pads for heavy incontinence. Report No. IN4. London: Medical Devices Agency; 1999.

17. Cottenden AM, Ledger DJ. Predicting the leakage performance of bodyworn disposable incontinence pads using laboratory tests. J Biomed Eng 1993; 15:212-20.

18. Macaulay M, Clarke-O'Neill S, Fader M, Pettersson L, Cottenden A. A pilot study to evaluate reusable absorbent body-worn products for adults with moderate/heavy urinary incontinence. J Wound, Ostomy Continence Nursing 2004;31:357-66.

19. Beber CR. Freedom for the incontinent. Am J Nurs 1980;80:482-4.

20. Grant R. Washable pads or disposable diapers? Geriatr Nurs 1982;3:248-51.

21. Haeker S. What's best - reusable or disposable incontinence products? Text Rent 1986;69:86-91.

22. Dolman M. Continence. The cost of incontinence. Nurs Times 1988;84(31):67-9.

23. Hu TW, Kaltreider DL, Igou J. The costeffectiveness of disposable versus reusable diapers. A controlled experiment in a nursing home. J Gerontol Nurs 1990;16(2):19-24.

24. Harper DW, O'Hara PA, Lareau J, Cass J, Black EK, Stewart S, et al. Reusable versus disposable incontinent briefs: a multiperspective crossover clinical trial. J Appl Gerontol 1995;14:391-407.

25. Brown DS. Diapers and underpads, Part 1: skin integrity outcomes. Ostomy Wound Manage 1994; 40(9):20-6, 28.

26. Brown DS. Diapers and underpads, Part 2: cost outcomes. Ostomy Wound Manage 1994;40(9):34-6, 38,40 .

27. $\mathrm{Hu} \mathrm{TW}$, Kaltreider DL, Igou J. Incontinence products: which is best? Geriatr Nurs 1989;10:184-6.

28. Hu TW, Kaltreider DL, Igou JF. Disposable versus reusable incontinent products: a controlled costeffectiveness experiment. Ostomy Wound Manage 1988;21:46-53.

29. Merret S, Adams A, Jordan J. Incontinence research provides some answers. Aust Nurs J 1988; 18(2): 17-18. 
30. Cottenden AM. Aids and appliances for incontinence. The promotion and management of continence. Englewood Cliffs, NJ: Prentice Hall; 1992.

31. Brazzelli M, Shirran E, Vale L. Absorbent products for containing urinary and/or fecal incontinence in adults. J Wound Ostomy Continence Nurs 2002; 29:45-54.

32. Cottenden A, Bliss D, Fader, M, Getliffe K, Herrera $\mathrm{H}$, Patterson J, et al. Management with continence products. In Abrams P, Cardozo L, Khoury S, Wein A, editors. Incontinence. Vol. 1. Paris: Health Publication; 2005. pp. 151-223.

33. Shirran E, Brazzelli M. Absorbent products for the containment of urinary and/or faecal incontinence in adults. Cochrane Database Syst Rev 2000;(2): CD001406.

34. Fader M, Cottenden A, Brooks R. The CPE network: creating an evidence base for continence product selection. J Wound Ostomy Continence Nurs 2001;28:106-12.

35. Shumaker SA, Wyman JF, Uebersax JS, McClish D, Fantl JA. Health-related quality of life measures for women with urinary incontinence: the Incontinence Impact Questionnaire and the Urogenital Distress Inventory. Continence Program in Women (CPW) Research Group. Qual Life Res 1994;3:291-306.

36. Clarke-O'Neill S, Fader M, Cottenden A. Reusable review - a guide to washable absorbent incontinence products. IN8 (September 2001). London: Medical Devices Agency; 2001.

37. Gotzsche PC. Patients' preference in indomethacin trials: an overview. Lancet 1989;i:88-91.

38. Armitage P, Berry G. Statistical methods in medical research. 3rd ed. Blackwell: Oxford; 1994.

39. Wade DT, Collin C. The Barthel ADL index: a standard measure of physical disability? Int Disabil Stud 1988;10:64-7.

40. Avery K, Donovan J, Peter T, Shaw C, Gotoh M, Abrams P. A brief and robust measure for evaluating the symptoms and impact or urinary incontinence. Neurourol Urodyn 2004;23:322-30.

41. Kelleher CJ, Cardozo LD, Khullar V, Salvatore S. A new questionnaire to assess the quality of life of urinary incontinent women. Br J Obstet Gynaecol 1997;104:1374-9.

42. Ware JF, Kosinski M, Turner-Bowker DM, Gandek B. How to score version 2 of the SF-12 health survey (with a supplement documenting version 1). Lincoln, RI: Quality Metric; 2002.

43. Lagro-janssen T, Smits A, Van Weel C. Urinary incontinence in women and the effects on their lives. Scand J Prim Health Care 1992;10:211-16.

44. Zigmond AS, Snaith RP. The Hospital Anxiety and Depression Scale. Acta Psychiatr Scand 1983; 67:361-70.
45. Bergstrom N, Braden BJ, Laguzza A, Holman V. The Braden scale for predicting pressure sore risk. Nurs Res 1987;36:205-10.

46. Norton D, Maclaren R, Exton-Smith AN. An investigation of geriatric nursing problems in hospitals. London: National Corporation for the Care of Old People; 1962.

47. Hodkinson HM. Evaluation of a mental test score for assessment of mental impairment in the elderly. Age Ageing 1972;1:233-8.

48. Clarke-O’Neill S, Fader MJ, Pettersson L, Clinton L, Dean G, Malone-Lee J, et al. Disposable pads for light incontinence. Report No. IN9. London: Medical Devices Agency; 2002.

49. Aumônier S, Collins M. Life cycle assessment of disposable and reusable nappies in the UK. London: Environment Agency; 2005.

50. Zimmerer RE, Lawson KD, Calvert CJ. The effects of wearing diapers on skin. Pediatr Dermatol 1986; 3:95-101.

51. Cederqvist T, Magnusson B, Axelsson J. Ergonomics in hygiene products. Linköping: Linköping University; 2002.

52. Peet SM, Castleden CM, McGrother CW, Duffin HM. The management of urinary incontinence in residential and nursing homes for older people. Age Ageing 1996;25:139-43.

53. Ouslander J, Kane R. Industry case study: improving technologies aid in urinary incontinence management. Med Prod Sales 1985;10:30-6.

54. Hunskaar S, Vinsnes A. The quality of life in women with urinary incontinence as measured by the sickness impact profile. J Am Geriatr Soc 1991; 39:378-82.

55. Grimby A, Milsom I, Molander U, Wiklund I, Ekelund $\mathrm{P}$. The influence of urinary incontinence on the quality of life of elderly women. Age Ageing 1993;22:82-9.

56. Coyne KS, Zhou Z, Thompson C, Versi E. The impact on health-related quality of life of stress, urge and mixed urinary incontinence. BJU Int 2003;92:731-5.

57. Ashworth PD, Hagan MT. The meaning of incontinence: a qualitative study of non-geriatric urinary incontinence sufferers. J Adv Nurs 1993; 18:1415-23.

58. Shaw C. A review of the psychosocial predictors of help-seeking behaviour and impact on quality of life in people with urinary incontinence.J Clin Nurs 2001;10:15-24.

59. Donovan J, Bosch R, Gotoh, M, Jackson S, Naughton M, Radley S, et al. Symptom and quality of life assessment. In Abrams P, Cardozo L, Khoury S, Wein A, editors. Incontinence. Vol. 1. Paris: Health Publications; 2005. pp. 521-84. 
60. Naughton MJ, Shumaker SA. Assessment of healthrelated quality of life. In Furberg CD, editor. Fundamentals of clinical trials. St Louis, MO: Mosby Press; 1996. p. 185.

61. Kitzinger J. Introducing focus groups. In Mays N, Pope C, editors. Qualitative research in healthcare. London: BMJ Publishing Group; 1996. pp. 36-45.

62. Seale C. The quality of qualitative research. London: Sage Publications.

63. Ryan G, Bernard R. Data management and analysis methods. In Denzin N, Lincoln Y, editors. Handbook of qualitative research, 2nd ed. London: Sage Publications; 2000. pp. 769-802.
64. Irwin DE, Milsom I, Kopp Z, Abrams P, Cardozo L. Impact of overactive bladder symptoms on employment, social interactions and emotional wellbeing in six European countries. BJU Int 2006; 97:96-100.

65. Papanicolaou S, Hunskaar S, Lose G, Sykes D. Assessment of bothersomeness and impact on quality of life of urinary incontinence in women in France, Germany, Spain and the UK. BJU Int 2005; 96:831-8.

66. Margalith I, Gillon G, Godon D. Urinary incontinence in women under 65; quality of life, stress related to incontinence and patterns of seeking healthcare. Qual Life Res 2004;13:1381-90. 



\section{Appendix I}

\section{Trial I: method of product selection}

$\mathrm{T}$ he aim was to select three products that were similar to each other within each design group.

The four designs are: menstrual pads (MPs), disposable inserts (DIs), washable pants with integral pants (WPs) and washable inserts (WIs).

Previous data from the Continence Product Evaluation (CPE) network studies on the DIs and WPs were available to help make a selection of three products to represent the design in module product selections.

\section{Selection of disposable inserts}

The data from a previous CPE network study ${ }^{11}$ provided evidence on which to base our product selection. The most successful pads in this study (based on overall opinion scores) were:

- Indas Indasec Grande

- Ontex Euron Micro Extra Plus

- SCA Tena Comfort Mini Extra

- Contisure Premium Micro Plus

- Prevail Extra Plus

- Anamini Extra

- Tender Light Extra.

The following products were rejected:

Contisure Premium Micro Plus, sold by Shiloh but made by Ontex, is identical to the Microflex Super; Prevail Extra Plus had variable scores, was either loved or hated, and it was much smaller than others; Anamini Extra - ID Medica were taken over by Ontex and it is the same product as the Microflex Super sold under another name; Tender Light Extra (Tanner Brothers), which were much larger and more rectangular than the others.

\section{Selected products}

- Indas Indasec Grande

- Ontex Euron Micro Extra Plus

- SCA Tena Lady Extra (now called Tena Comfort Mini Extra).

\section{Selection of menstrual pads}

There were no recent evaluations on which to base the selection of these products. We therefore searched the market for any suitable products. MPs can be categorised into two main types, thick and thin.

It was decided that the newer thin pads may be less acceptable than thicker products. The thicker products are shown in the table below; we selected night-time products of a similar size and these are shaded in the table.

\section{Selected products}

- Always Maxi Night

- Kotex Maxi Night Time

- Boots Body-Shaped Night-time Pads.

\section{Selection of washable pants with integral pad}

There are data from a recent study carried out by the CPE Network. ${ }^{8}$ In this study, the full range of WPs available on the UK market were tested. This

\begin{tabular}{|c|c|c|c|c|c|c|}
\hline Name & Wings & Manufacturer & Place bought & Price (t) & $\begin{array}{l}\text { Quantity } \\
\text { in pack }\end{array}$ & Night-time \\
\hline Pennywise & No & SCA & Co-Op & 0.99 & 10 & Yes \\
\hline \multirow[t]{2}{*}{ Always Maxi } & No & P\&G & $\mathrm{Co}-\mathrm{Op}$ & 1.89 & $10 / 12$ & Yes \\
\hline & & & Safeway & 1.41 & & \\
\hline Always Maxi Long Plus & No & P\&G & Boots & 1.89 & 14 & No \\
\hline Bodyform Classic & Yes & SCA & Co-Op Pharmacy & 1.78 & 14 & No \\
\hline Kotex Maxi & No & Kimberly Clark & Safeway & 1.49 & 10 & Yes \\
\hline Boots & No & $?$ & Boots & 0.99 & 12 & Yes \\
\hline Always Maxi Long & No & P\&G & Boots & 1.59 & 14 & No \\
\hline
\end{tabular}


study provides the most up-to-date evidence-based product performance data available. The best performing pants with integral pad were identified from this study:

- Ganmill Duofem Elite

- Robinsons Activ Pants

- Kylie Super Pants

- Kylie Extra Pants

- Kylie Standard Pants.

We established that the size of the garment did not make a difference to the size of the absorbent pad, that is, the pad was the same size regardless of whether the pant was small, medium, large or extra large.

However, for one brand (Kylie), the style of the pant (e.g. high leg or full pant) does make a difference to the size of the pad; therefore, it was decided that unlike in the CPE network study, only one style would be offered to participants. This was thought to be acceptable to participants, as $75 \%$ had chosen the full pant in the previous study.

There has also been a change to the design of the Kylie range since the previous study. When all three types of Kylie pants were examined (Extra, Super and Standard) it was noted that all of the absorbent pads were thinner (and therefore presumably had less absorbent capacity) than the ones tested previously. In order to choose 'best' pants, it was judged that the Kylie Extra pant (the most absorbent) should be selected.

\section{Selected products}

- Kylie Extra Pants

- Robinsons Activ Pants

- Ganmill Duofem Elite.

\section{Selection of washable insert}

There are no previous evaluations on which to base the selection of WI products. We therefore searched the market for any suitable products and asked Promocon to advise us on the washable inserts (for light incontinence) of which they were aware. The search found the following products that were suitable for light incontinence:

- PHP Multi Use Mini Pads

- Milton Stay Dry Contenta Repeat Liners

- Martex (EMS Medical) Micro Liner.

As only three products were suitable, all three were used in the pilot study; the products were of similar size and design. 


\section{Appendix 2}

\section{Trial I: product performance questionnaires (results for each product in a design)}

In all tables below, an $\mathrm{X}$ indicates that a product was significantly worse (very good + good $+\mathrm{OK})$ vs (poor + very poor) than another product(s) (initial(s) shown in brackets).

\begin{tabular}{|c|c|c|c|c|}
\hline & & \multicolumn{3}{|c|}{ Menstrual pads } \\
\hline & & Boots & Kotex & Always \\
\hline \multirow{5}{*}{$\begin{array}{l}\text { Leakage } \\
\text { (day) }\end{array}$} & Very good & 18 & 13 & 16 \\
\hline & Good & 28 & 21 & 25 \\
\hline & OK & 23 & 34 & 34 \\
\hline & Poor & 24 & 20 & 16 \\
\hline & Very poor & 6 & 12 & 10 \\
\hline \multirow{5}{*}{$\begin{array}{l}\text { Leakage } \\
\text { (night) }\end{array}$} & Very good & 19 & 14 & 15 \\
\hline & Good & 22 & 21 & 25 \\
\hline & OK & 31 & 32 & 34 \\
\hline & Poor & 19 & 23 & 19 \\
\hline & Very poor & 9 & 9 & 7 \\
\hline \multirow{5}{*}{$\begin{array}{l}\text { Stay in } \\
\text { place (day) }\end{array}$} & Very good & 24 & 11 & 19 \\
\hline & Good & 32 & 40 & 39 \\
\hline & OK & 33 & 39 & 36 \\
\hline & Poor & 10 & II & 5 \\
\hline & Very poor & I & 0 & I \\
\hline \multirow[t]{5}{*}{ Smell } & Very good & 8 & 4 & 8 \\
\hline & Good & 25 & 25 & 22 \\
\hline & OK & 49 & 44 & 46 \\
\hline & Poor & 15 & 20 & 16 \\
\hline & Very poor & 2 & 7 & 7 \\
\hline \multirow[t]{5}{*}{ Discreet } & Very good & 14 & 12 & 19 \\
\hline & Good & 29 & 34 & 34 \\
\hline & OK & 40 & 35 & 35 \\
\hline & Poor & 14 & 16 & 9 \\
\hline & Very poor & 2 & 2 & 2 \\
\hline
\end{tabular}

\begin{tabular}{|c|c|c|c|c|}
\hline & & \multicolumn{3}{|c|}{ Menstrual pads } \\
\hline & & Boots & Kotex & Always \\
\hline \multirow{5}{*}{$\begin{array}{l}\text { Dry } \\
\text { comfort }\end{array}$} & Very good & 23 & 14 & 22 \\
\hline & Good & 31 & 42 & 40 \\
\hline & OK & 56 & 34 & 29 \\
\hline & Poor & 10 & 8 & 6 \\
\hline & Very poor & 1 & 1 & 2 \\
\hline \multirow{5}{*}{$\begin{array}{l}\text { Wet } \\
\text { comfort }\end{array}$} & Very good & 5 & 5 & 7 \\
\hline & Good & 29 & 21 & 25 \\
\hline & OK & 31 & 39 & 35 \\
\hline & Poor & 25 & 24 & 25 \\
\hline & Very poor & $\mathrm{II}$ & 10 & 8 \\
\hline \multirow{5}{*}{$\begin{array}{l}\text { Keep skin } \\
\text { dry }\end{array}$} & Very good & 11 & 6 & 6 \\
\hline & Good & 29 & 24 & 27 \\
\hline & OK & 36 & 42 & 45 \\
\hline & Poor & 20 & 23 & 15 \\
\hline & Very poor & 4 & 6 & 7 \\
\hline \multirow{5}{*}{$\begin{array}{l}\text { Overall } \\
\text { opinion } \\
\text { (day) }\end{array}$} & Very good & 19 & 18 & 16 \\
\hline & Good & 27 & 19 & 27 \\
\hline & OK & 20 & 32 & 34 \\
\hline & Poor & 22 & 19 & 13 \\
\hline & Very poor & 12 & 12 & 9 \\
\hline \multirow{5}{*}{$\begin{array}{l}\text { Overall } \\
\text { opinion } \\
\text { (night) }\end{array}$} & Very good & 13 & 20 & 22 \\
\hline & Good & 41 & 25 & 26 \\
\hline & OK & 14 & 27 & 40 \\
\hline & Poor & $19 \times(A)$ & 17 & 7 \\
\hline & Very poor & 13 & 12 & 5 \\
\hline
\end{tabular}




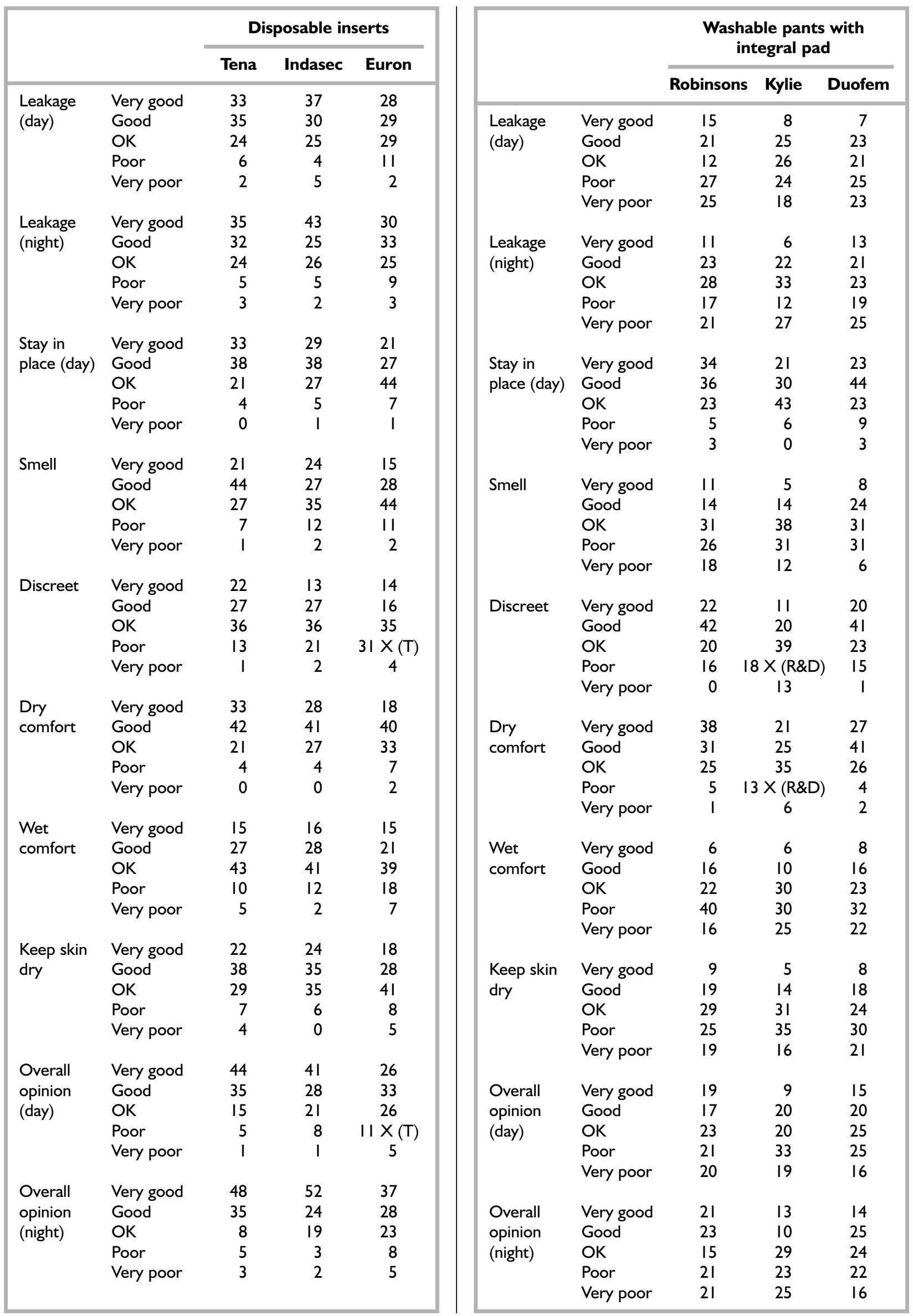




\begin{tabular}{|c|c|c|c|c|}
\hline & & \multicolumn{3}{|c|}{ Washable inserts } \\
\hline & & Martex & Contenta & PHP \\
\hline \multirow{5}{*}{$\begin{array}{l}\text { Leakage } \\
\text { (day) }\end{array}$} & Very good & I & 0 & 6 \\
\hline & Good & 11 & 12 & 8 \\
\hline & OK & 16 & 23 & 20 \\
\hline & Poor & 30 & 23 & 28 \\
\hline & Very poor & 41 & 42 & 37 \\
\hline \multirow{5}{*}{$\begin{array}{l}\text { Leakage } \\
\text { (night) }\end{array}$} & Very good & 0 & 0 & 8 \\
\hline & Good & 13 & 11 & 12 \\
\hline & OK & 23 & 32 & 19 \\
\hline & Poor & 32 & 24 & 35 \\
\hline & Very poor & 32 & 34 & 27 \\
\hline \multirow{5}{*}{$\begin{array}{l}\text { Stay in } \\
\text { place (day) }\end{array}$} & Very good & I & 3 & 8 \\
\hline & Good & 10 & 9 & 19 \\
\hline & OK & 20 & 20 & 27 \\
\hline & Poor & $\begin{array}{c}38 \times \\
(\mathrm{PHP})\end{array}$ & $\begin{array}{c}31 \times \\
(\mathrm{PHP})\end{array}$ & 31 \\
\hline & Very poor & 31 & 36 & 14 \\
\hline \multirow[t]{5}{*}{ Smell } & Very good & 2 & 2 & I \\
\hline & Good & 8 & 13 & II \\
\hline & OK & 43 & 43 & 42 \\
\hline & Poor & 28 & 33 & 26 \\
\hline & Very poor & 18 & 10 & 20 \\
\hline \multirow[t]{5}{*}{ Discreet } & Very good & 10 & 10 & 7 \\
\hline & Good & 25 & 15 & 33 \\
\hline & OK & 52 & 48 & 43 \\
\hline & Poor & 10 & $23 \times(M)$ & 12 \\
\hline & Very poor & 4 & 5 & 5 \\
\hline \multirow{5}{*}{$\begin{array}{l}\text { Dry } \\
\text { comfort }\end{array}$} & Very good & 8 & 8 & 10 \\
\hline & Good & 23 & 20 & 29 \\
\hline & OK & 44 & 49 & 48 \\
\hline & Poor & 17 & 20 & 12 \\
\hline & Very poor & 8 & 3 & 2 \\
\hline \multirow{5}{*}{$\begin{array}{l}\text { Wet } \\
\text { comfort }\end{array}$} & Very good & 0 & 0 & I \\
\hline & Good & 12 & 7 & 7 \\
\hline & OK & 24 & 36 & 27 \\
\hline & Poor & 25 & 34 & 32 \\
\hline & Very poor & 39 & 23 & 32 \\
\hline \multirow{5}{*}{$\begin{array}{l}\text { Keep skin } \\
\text { dry }\end{array}$} & Very good & 2 & 2 & 4 \\
\hline & Good & 8 & 7 & 5 \\
\hline & OK & 23 & 36 & 33 \\
\hline & Poor & 36 & 34 & 33 \\
\hline & Very poor & 30 & 21 & 27 \\
\hline \multirow{5}{*}{$\begin{array}{l}\text { Overall } \\
\text { opinion } \\
\text { (day) }\end{array}$} & Very good & 2 & 0 & 6 \\
\hline & Good & 8 & II & 12 \\
\hline & OK & 23 & 18 & 13 \\
\hline & Poor & 29 & 34 & 35 \\
\hline & Very poor & 37 & 36 & 35 \\
\hline \multirow{5}{*}{$\begin{array}{l}\text { Overall } \\
\text { opinion } \\
\text { (night) }\end{array}$} & Very good & 6 & 2 & 10 \\
\hline & Good & 8 & 10 & 10 \\
\hline & OK & 30 & 24 & 23 \\
\hline & Poor & 30 & 37 & 31 \\
\hline & Very poor & 26 & 27 & 27 \\
\hline
\end{tabular}

(c) Queen's Printer and Controller of HMSO 2008. All rights reserved. 



\section{Appendix 3}

\section{Trial I: calculation of the extra laundry costs associated with reusable products}

$\mathrm{R}$ eusable products incur two additional costs on the users: first, costs arise from laundering the washable products themselves; and second, users report higher leakage from reusable products, requiring the laundering of additional pieces of clothing.

The modal usage rate reported at baseline (four products per 24 hours) suggests that 28 WPs or WIs would be laundered per week. The mean dry weight of WIs is $20 \mathrm{~g}$. WPs are made in a variety of sizes with mean dry weights ranging from 40 to $80 \mathrm{~g}$. For the purpose of this costing exercise, a dry weight of $60 \mathrm{~g}$ is used for WPs. The dry weight of laundry generated per week is therefore $560 \mathrm{~g}$ for WIs and $1680 \mathrm{~g}$ for WPs.

Excess laundry generated by washable products compared with disposables is equivalent to 5.6 small items for WPs and 14 small items for WIs (larger items reported by participants were weighted $\times 2$ ). Assuming that small items weigh $50 \mathrm{~g}$, the weekly laundry caused by leaks for WPs and WIs is $280 \mathrm{~g}$ and $700 \mathrm{~g}$, respectively.

The total extra weekly laundry associated with WPs and WIs is therefore 1960 and $1260 \mathrm{~g}$, respectively. The load of absorbent materials recommended for domestic washing machines is $7 \mathrm{lb}(3100 \mathrm{~g})$. This means that at the end of 1 week, use of WIs and WPs rather than disposable products would create 40 and $54 \%$ of a full washing machine load, respectively.

The cost of running a washing machine varies with the make and age of the machine, the temperature, detergents used and wash programme chosen. It has been estimated that the cost of detergent and electricity for a middlerange machine and programme is $£ 0.30$.
Depreciation and maintenance would be a further $£ 0.10$ per week (assuming incontinence products were $10 \%$ of all washing and a 10-year machine life). The cost of one machine load per week is therefore about $£ 0.40$ or $£ 1.60$ per month. (www.wen.org.uk/nappies/cost_comparison, accessed 6 October 2006).

The costs of tumble drying are not included as most women $(80 \%)$ reported that they did not use this method and because tumble drying is not advised for products with plastic backings.

These calculations are a maximum estimate. If incontinence-related laundry was washed separately from other laundry, the washing machine would not be full and a cheaper economy programme could be used. If incontinence items were washed with others, the cost of the full load would be shared. It is possible that women would not want to wash all incontinence items together just once a week as this would entail storing used products (which could cause odour) and also holding stocks of at least 32 products. In fact, most women reported that they washed incontinence-related items with other pieces of laundry, which could be done at small additional cost (unless every load is full), or by hand. In addition, the estimates are based on use of four products per 24 hours, whereas the actual use was three.

\section{Conclusion}

There are many elements of uncertainty in the estimation of the extra laundry costs associated with using reusable products. For the purposes of the cost-effectiveness analysis, we used a relatively high estimate of $£ 0.25$ per week or $£ 1$ per month. 



\section{Appendix 4}

\section{Trial 2a: pilot study and product selection}

$\mathrm{T}_{\mathrm{i}}^{\mathrm{i}}$ he five main designs of absorbent products included in the study are as follows:

- disposable inserts

- disposable diapers

- disposable pull-ups

- disposable T-shaped diapers

- washable body-worn (various designs).

\section{Selection of disposable products}

Information from PASA (data supplied June 2006) shows that inserts are the most commonly purchased design, followed by diapers. There is much less purchasing of pull-ups and T-shaped products, which are more recent designs. PASA data show that the most commonly purchased inserts are in bands I10 and I11 (14 million and 10 million p.a.). The most commonly purchased diaper is in band D15 (7 million p.a.).

The aim of selecting products for inclusion in the study was to match closely the absorbent capacity, as measured by Rothwell score, ${ }^{17}$ of products from each of the design groups. This would therefore test the effect of design on product performance (rather than absorbency). The aim was also to reflect clinical practice by including products with Rothwell scores most commonly purchased.

We were unable to match products across the disposable design groups with Rothwell scores within I10 (1250-1499 g) or I1 1 (1500-1799), which are the most commonly purchased insert pads, because there were very few products in the other design groups with similar scores. We were better able to match products with Rothwell scores within D15 (1700-2099 g), which represents the most commonly purchased diaper, with three of the four different disposable design groups having some products within this band, although overall there were too few products available in all design groups for selection for the study. By expanding this band to encompass the range 1520-2280 g and aiming for a mean Rothwell score of $1900 \mathrm{~g}$, we were able to identify sufficient products in three of the four design groups (the T-shaped designs are only available with higher Rothwell scores).
It is common for products of a higher absorbent capacity to be applied for night-time use. Insert products within band I13 (2100-2499 g) are frequently purchased (7.5 million p.a.) and this level of absorbency is commonly found in diapers, both the new T-shaped products and the pull-ups. By aiming for a mean Rothwell score of $2400 \mathrm{~g}$ ( $\pm 20 \%$, i.e. $1920-2880 \mathrm{~g}$ ) for night-time use, we were able to match products from all four disposable designs.

Some products have different absorbencies for different sizes. In this case, we attempted to match the medium-sized product because we anticipated that the majority (around two-thirds) of recruited subjects would be medium sized.

To select products for inclusion in the study, a pilot study was carried out of the shortlist of products identified as above.

\section{Pilot study}

Six products were selected from each insert and diaper design based on matching the Rothwell capacity of the products: daytime products $1900 \mathrm{ml}$; night-time products $2400 \mathrm{ml} \pm 20 \%$. There is a much more limited range of products for pull-ups $(n=6)$ and all products were therefore piloted. T-shaped products were not piloted because there were only two available.

\section{Pilot methods}

- demographic information

- product performance questionnaire (weekly product test questionnaires)

- pad leakage diary.

\section{Sample}

Ten subjects tested six products from each design group (30 subjects total).

\section{Analysis}

Analysis of the results to select products for inclusion in the study was made and the following selection criteria were then applied (in order of priority):

- Rothwell score within specified range.

- One-third or more of pilot subjects found the product poor or very poor (product rejected). 
- Of the remaining products in the group, those with the highest overall opinion scores were selected.

- In the event of products scoring similarly, products were selected to ensure a range of prices and inclusion of as many companies as possible.

\section{Products selected for main study}

\section{Inserts}

- daytime products: target Rothwell score 1900 ( $\pm 20 \%$ ), range $1520-2280 \mathrm{~g}$

- night-time products: target Rothwell score 2400 ( $\pm 20 \%)$, range $1920-2880 \mathrm{~g}$.

\section{Daytime}

\begin{tabular}{|ll|}
\hline Manufacturer & Product name \\
\hline Paperpak & Attends contour Super \\
Abena & Abri-san Super \\
Hartmann & Moliform Plus \\
\hline
\end{tabular}

\section{Night-time}

\begin{tabular}{|ll|}
\hline Manufacturer & Product name \\
\hline Paperpak & Attends contour Super Plus \\
SCA & Tena Comfort Super \\
Shiloh & Contisure Super \\
\hline
\end{tabular}

\section{Diapers}

Daytime

\begin{tabular}{|ll|}
\hline Manufacturer & Product name \\
\hline Ontex & Euron form Ultra \\
Tyco & Lille Supreme fit Regular Plus \\
Paperpak & Attends Slip Extra \\
\hline
\end{tabular}

\section{Night-time}

\begin{tabular}{|ll|}
\hline Manufacturer & Product name \\
\hline Shiloh & Contifit \\
Abena & Abri-form plus \\
Vernagroup & Karocare Brief \\
\hline
\end{tabular}

Pull-ups

Daytime

\begin{tabular}{|c|c|}
\hline Manufacturer & Product name \\
\hline $\begin{array}{l}\text { Paperpak } \\
\text { Hartmann } \\
\text { Abena }\end{array}$ & 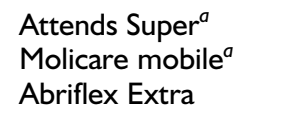 \\
\hline \multicolumn{2}{|c|}{$\begin{array}{l}{ }^{a} \text { Two products were tested during both day- and } \\
\text { night-time. }\end{array}$} \\
\hline
\end{tabular}

\section{Night-time}

\begin{tabular}{|c|c|}
\hline Manufacturer & Product name \\
\hline $\begin{array}{l}\text { Paperpak } \\
\text { Hartmann } \\
\text { SCA }\end{array}$ & $\begin{array}{l}\text { Attends Super }{ }^{a} \\
\text { Molicare mobile }^{a} \\
\text { Tena Pants Super }\end{array}$ \\
\hline \multicolumn{2}{|c|}{$\begin{array}{l}{ }^{a} \text { Two products were tested during both day- and } \\
\text { night-time. }\end{array}$} \\
\hline
\end{tabular}

T-shaped diapers

Day- and night-time

\begin{tabular}{|ll|}
\hline Manufacturer & Product name \\
\hline Abena & Abriwing \\
SCA & Tena Flex Super \\
& (Extra for daytime in nursing \\
& homes) \\
\hline
\end{tabular}

\section{Selection of washable products}

Washable body-worn designs for moderate/heavy incontinence are rarely purchased by the NHS and there are few research data to guide product selection for the study. The ISO standard (Rothwell score) has not been validated on reusable products. A pilot study of all 20 available body-worn products in the UK was published in $2004^{18}$ and this indicated relatively poor performance (particularly in the daytime) compared with disposable products. No design appeared to be superior to others; however, designs made from terry-towelling material were the most successful. The three best performing products (based on overall opinion) that were still on the market and represented different designs of products were selected for inclusion in the study. These products comprised two terrytowelling products and one other. It was thought that the terry-towelling products may perform similarly and it was decided that study findings for the non-terry-towelling product (the Martex) would be analysed separately.

The washable products selected were:

- Paddy-T (terry-towelling)

- Bullen nappy (terry-towelling)

- Martex Unisex Brief 1000.

Both the terry-towelling products can be made to different sizes to order. Two sizes of the Paddy-T and the Bullen nappy were commissioned to match the medium and large sizes available in disposable products (70-100 and 105-120 cm). The Martex product has four sizes which encompass the same size range. 


\section{Appendix 5}

\section{Trial 2a: median urine mass in each design, combined and by gender}

\begin{tabular}{|c|c|c|c|c|c|}
\hline & Insert & Diaper & Pull-up & T-shaped & $\begin{array}{l}\text { Washable } \\
\text { diaper }\end{array}$ \\
\hline $\begin{array}{l}\text { Daytime: men and women combined } \\
\text { Median urine mass }(\mathrm{g}) \\
\text { (IQ range) }\end{array}$ & $\begin{array}{c}234.0 \\
(128.5-366.5)\end{array}$ & $\begin{array}{c}294.5 \\
(189.0-46.3)\end{array}$ & $\begin{array}{c}257.0 \\
(147.3-388.0)\end{array}$ & $\begin{array}{c}298.0 \\
(171.3-462.8)\end{array}$ & $\begin{array}{c}414.0 \\
(268.5-632.0)\end{array}$ \\
\hline $\begin{array}{l}\text { Men } \\
\text { Median urine mass }(\mathrm{g}) \\
\text { (IQ range) }\end{array}$ & $\begin{array}{c}284.0 \\
(190.0-4 \mid 5.0) \\
N=1245\end{array}$ & $\begin{array}{c}347.0 \\
(238.0-491.0) \\
N=1525\end{array}$ & $\begin{array}{c}303.0 \\
(199.0-445.0) \\
N=1286\end{array}$ & $\begin{array}{c}355.0 \\
(226.0-543.0) \\
N=969\end{array}$ & $\begin{array}{c}431.0 \\
(282.0-662.0) \\
N=659\end{array}$ \\
\hline $\begin{array}{l}\text { Women } \\
\text { Median urine mass }(\mathrm{g}) \\
\text { (IQ range) }\end{array}$ & $\begin{array}{c}147.0 \\
(87.3-253.8) \\
N=698\end{array}$ & $\begin{array}{c}203.0 \\
(I 12.0-290.0) \\
N=67 \mid\end{array}$ & $\begin{array}{c}176.0 \\
(98.0-284.3) \\
N=780\end{array}$ & $\begin{array}{c}186.0 \\
(90.0-296.0) \\
N=457\end{array}$ & $\begin{array}{c}31 \mid .0 \\
(18 \mid .0-525.0) \\
N=160\end{array}$ \\
\hline Number of products & 1943 & 2196 & 2066 & 1426 & 819 \\
\hline $\begin{array}{l}\text { Night-time: men and women combined } \\
\text { Median urine mass }(\mathrm{g}) \\
\text { (IQ range) }\end{array}$ & $\begin{array}{c}27 \mid .5 \\
(|49.0-4| 2.0)\end{array}$ & $\begin{array}{c}363.0 \\
(208.0-562.0)\end{array}$ & $\begin{array}{c}319.0 \\
(191.0-503.5)\end{array}$ & $\begin{array}{c}345.0 \\
(202.8-537.0)\end{array}$ & $\begin{array}{c}511.5 \\
(291.3-763.5)\end{array}$ \\
\hline $\begin{array}{l}\text { Men } \\
\text { Median urine mass }(g) \\
\text { (IQ range) }\end{array}$ & $\begin{array}{c}320.0 \\
(189.5-473.0) \\
N=587\end{array}$ & $\begin{array}{c}442.5 \\
(286.3-623.0) \\
N=966\end{array}$ & $\begin{array}{c}385.0 \\
(234.8-58 I .3) \\
N=580\end{array}$ & $\begin{array}{c}396.5 \\
(264.5-590.3) \\
N=576\end{array}$ & $\begin{array}{c}545.0 \\
(326.8-818.3) \\
N=518\end{array}$ \\
\hline $\begin{array}{l}\text { Women } \\
\text { Median urine mass (g) } \\
\text { (IQ range) }\end{array}$ & $\begin{array}{c}209.0 \\
(I 10.0-347.0) \\
N=445\end{array}$ & $\begin{array}{c}253.0 \\
(|05.0-39| .0) \\
N=579\end{array}$ & $\begin{array}{c}250.5 \\
(122.8-402.3) \\
N=432\end{array}$ & $\begin{array}{c}269.5 \\
(163.8-395.8) \\
N=380\end{array}$ & $\begin{array}{c}443.0 \\
(194.0-590.3) \\
N=148\end{array}$ \\
\hline Number of products & 1032 & 1545 & 1012 & 956 & 666 \\
\hline
\end{tabular}





\section{Appendix 6}

\section{Trial 2a: estimated probabilities of no leakage at different urine masses, by gender}

\section{Day: women}

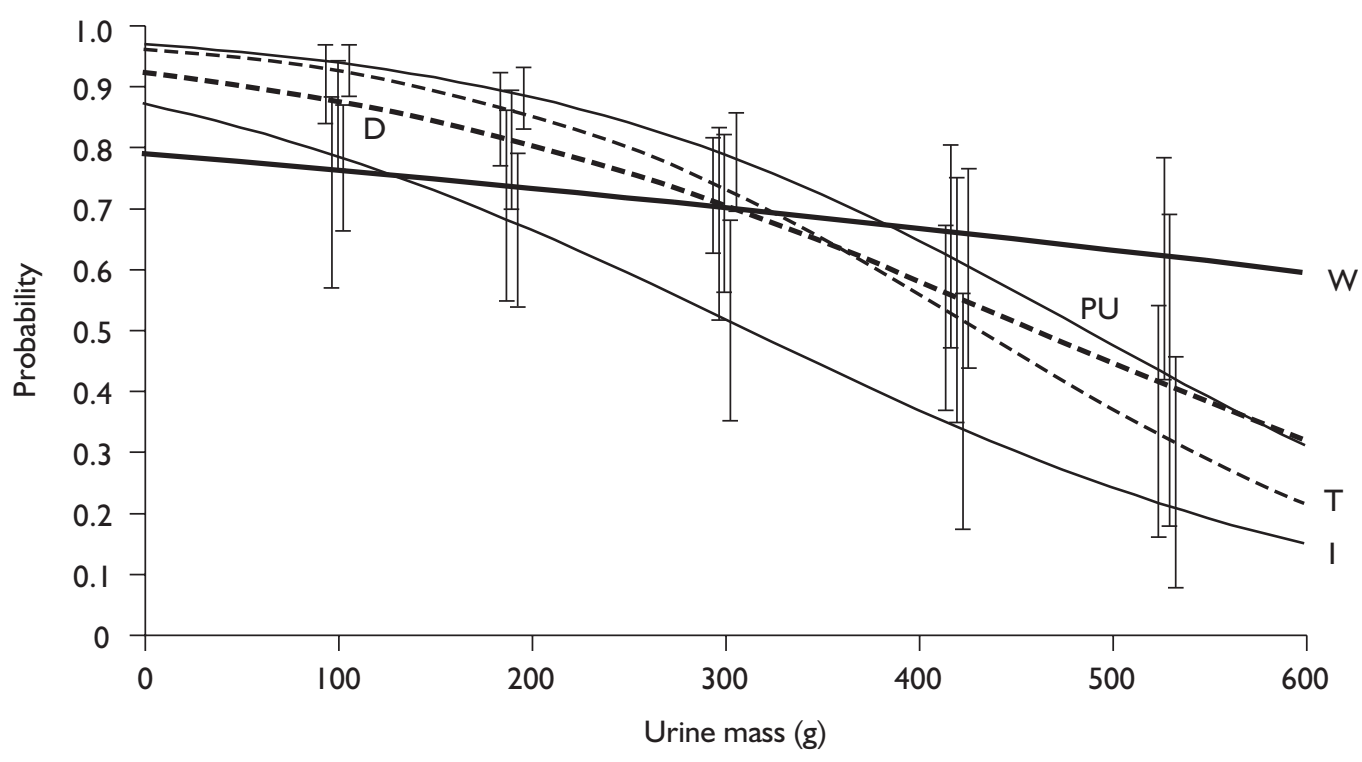

Day: men

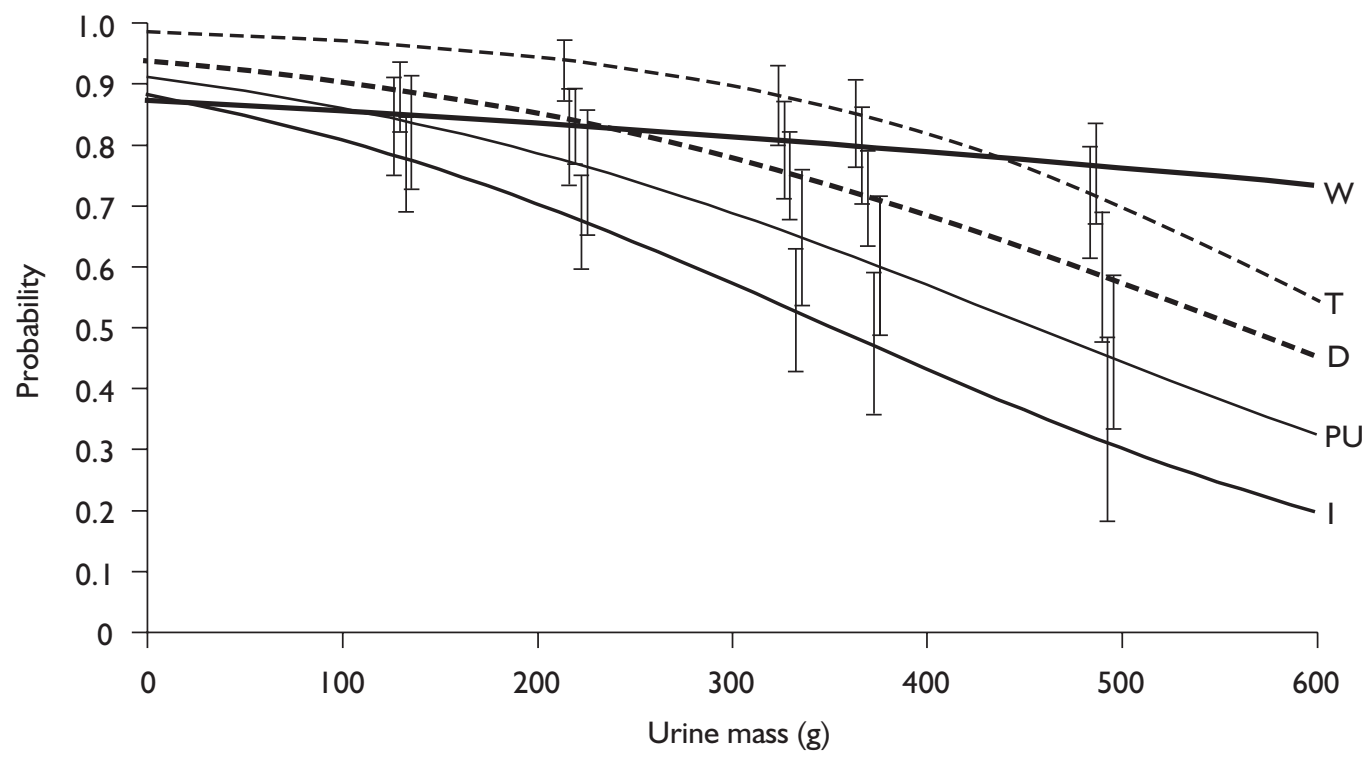


Night: women

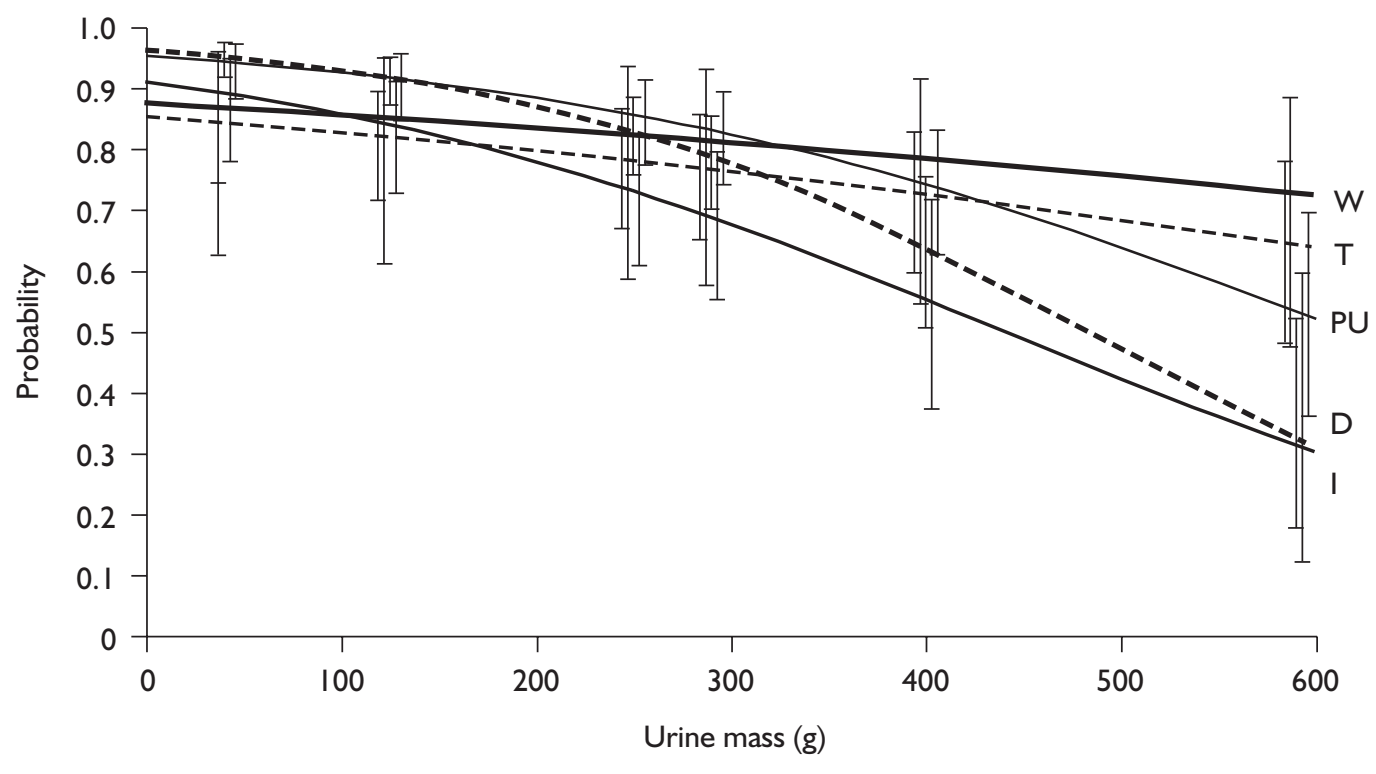

Night: men

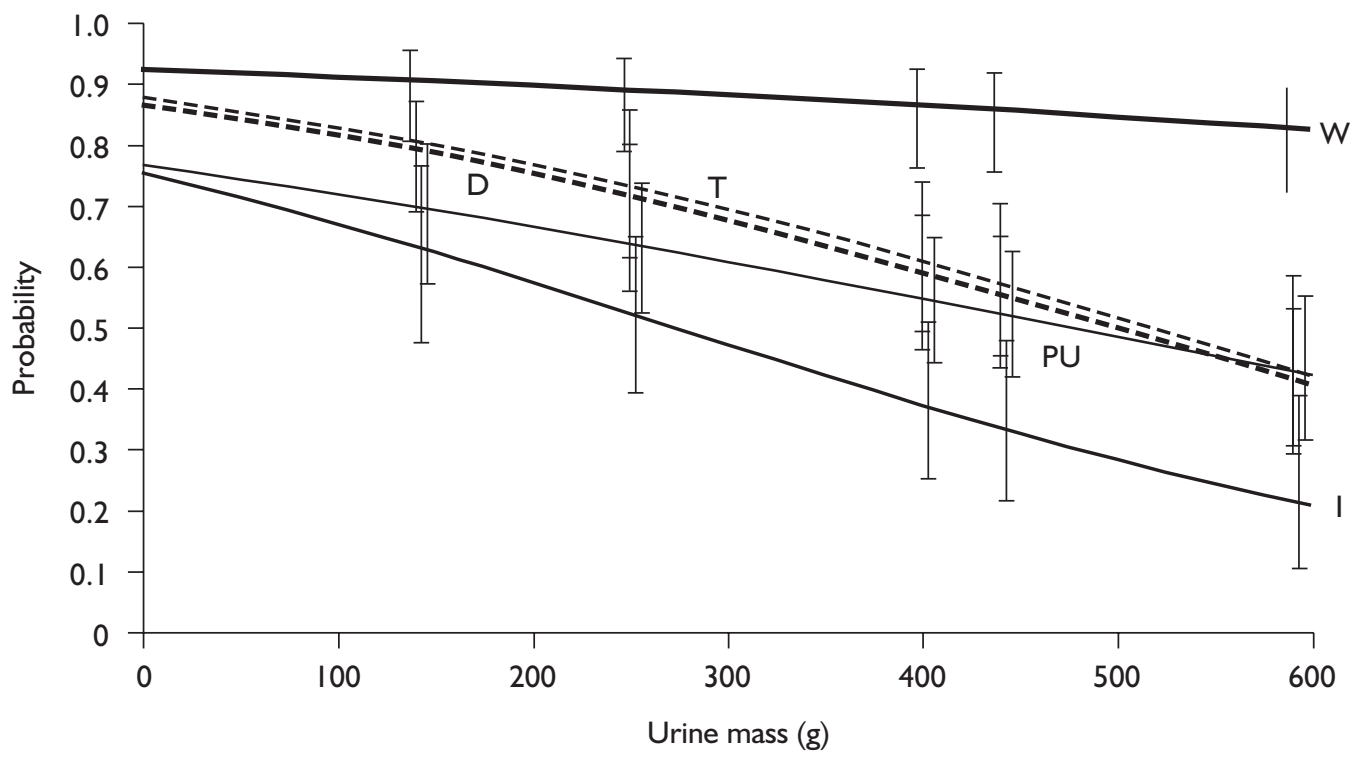




\section{Appendix 7}

\section{Trial 2a: leakage performance of designs, by gender}

\begin{tabular}{|c|c|c|c|c|c|}
\hline \multirow[t]{2}{*}{ Number of products saved $\%(N)$} & \multicolumn{5}{|c|}{ Daytime (number of subjects $N=85$ ) } \\
\hline & Insert & Diaper & Pull-up & T-shaped & $\begin{array}{c}\text { Washable } \\
\text { diaper }\end{array}$ \\
\hline No leakage & 59.9 (I | 63) & 70.7 (1553) & $72.6(1500)$ & 76.6 (1092) & $80.1(656)$ \\
\hline Men & $56.2(700)$ & $68.1(1038)$ & $64.9(834)$ & 75.1 (728) & $79.4(523)$ \\
\hline Women & $66.3(463)$ & $76.8(5 \mid 5)$ & $85.4(666)$ & 79.7 (364) & $83.1(133)$ \\
\hline A little & $25.3(492)$ & $20.1(460)$ & I8.7 (387) & I7.5 (250) & I5.7 (129) \\
\hline Men & $26.7(332)$ & $22.2(339)$ & $23.1(297)$ & $18.3(177)$ & $17.2(113)$ \\
\hline Women & $22.9(160)$ & $18.0(121)$ & $11.5(90)$ & $16.0(73)$ & $10.0(16)$ \\
\hline A lot & I4.8 (288) & $8.3(183)$ & $8.6(179)$ & $5.9(84)$ & $4.2(34)$ \\
\hline Men & $17.1(213)$ & 9.7 (I48) & $12.1(155)$ & $6.6(64)$ & $3.5(23)$ \\
\hline Women & $10.7(75)$ & $5.2(35)$ & $3.1(24)$ & $4.4(20)$ & $6.9(11)$ \\
\hline \multirow[t]{2}{*}{ Number of products saved \% $(N)$} & \multicolumn{5}{|c|}{ Night-time (number of subjects $N=85$ ) } \\
\hline & Insert & Diaper & Pull-up & T-shaped & $\begin{array}{c}\text { Washable } \\
\text { diaper }\end{array}$ \\
\hline No leakage & $55.5(573)$ & $60.7(938)$ & $65.3(66 I)$ & $64.4(616)$ & 85.4 (569) \\
\hline Men & $45.7(268)$ & $53.1(5 \mid 3)$ & $55.3(321)$ & $58.9(339)$ & $84.2(436)$ \\
\hline Women & $68.5(305)$ & $73.4(425)$ & $78.7(340)$ & $72.9(277)$ & $89.9(133)$ \\
\hline A little & $27.9(288)$ & $27.6(426)$ & $21.8(221)$ & $23.4(224)$ & I I.4 (76) \\
\hline Men & $30.5(179)$ & $32.3(3 \mid 2)$ & 25.7 (I49) & $26.2(15 \mathrm{I})$ & $12.6(65)$ \\
\hline Women & 24.5 (109) & $19.7(114)$ & $16.7(72)$ & $19.2(73)$ & $7.4(1 \mathrm{I})$ \\
\hline A lot & $16.6(171)$ & 11.7 (18I) & $12.9(130)$ & $12.1(116)$ & $3.1(2 I)$ \\
\hline Men & $23.9(140)$ & $14.6(141)$ & $19.0(110)$ & $14.9(86)$ & $3.3(17)$ \\
\hline Women & $7.0(31)$ & $6.9(40)$ & $4.6(20)$ & $7.9(30)$ & $2.7(4)$ \\
\hline
\end{tabular}





\section{Appendix 8}

\section{Trial 2a: consumption by gender - weighted mean number of products used per day/night (SD)}

\begin{tabular}{|c|c|c|c|c|c|}
\hline & \multicolumn{5}{|c|}{ Daytime ( $N=85$ participants) } \\
\hline & Insert & Diaper & Pull-up & T-shaped & $\begin{array}{c}\text { Washable } \\
\text { diaper }\end{array}$ \\
\hline All participants & $2.77(1.16)$ & $2.70(1.03)$ & $2.52(0.92)$ & $2.54(0.92)$ & $2.01(0.83)$ \\
\hline Men & $3.05(1.21)$ & $2.94(1.06)$ & $2.75(0.99)$ & $2.69(0.97)$ & $2.03(0.85)$ \\
\hline \multirow[t]{3}{*}{ Women } & $2.36(0.95)$ & $2.25(0.77)$ & $2.19(0.7 I)$ & $2.26(0.75)$ & $1.95(0.75)$ \\
\hline & \multicolumn{5}{|c|}{ Night-time ( $N=85$ participants) } \\
\hline & Insert & Diaper & Pull-up & T-shaped & $\begin{array}{c}\text { Washable } \\
\text { diaper }\end{array}$ \\
\hline All participants & $\mathrm{I} .66(0.77)$ & $1.51(0.56)$ & $1.50(0.55)$ & $1.50(0.62)$ & I.2I (0.4I) \\
\hline Men & $1.58(0.66)$ & $1.50(0.49)$ & $1.50(0.49)$ & $1.49(0.51$ & $\mathrm{I} .15(0.34)$ \\
\hline Women & $1.78(0.90)$ & $1.53(0.66)$ & $1.49(0.63)$ & $1.53(0.78)$ & I.36 (0.53) \\
\hline
\end{tabular}





\section{Appendix 9}

\section{Trial 2a: product performance questionnaires (results for each product in a design)}

In all tables below, an $\mathrm{X}$ indicates that a product was significantly worse (very good + good $+\mathrm{OK})$ vs (poor + very poor) than the numbered product(s).

\begin{tabular}{|c|c|c|c|c|c|c|c|}
\hline \multicolumn{2}{|c|}{ T-shaped (day) } & $\begin{array}{c}\begin{array}{c}\text { Tena Flex } \\
\text { Super (10) }\end{array} \\
33.9\end{array}$ & $\begin{array}{c}\text { Abri Wing } \\
\text { (I I) } \\
24.2\end{array}$ & \multicolumn{2}{|c|}{ T-shaped (night) } & $\begin{array}{c}\text { Abri Wing } \\
\text { (24) } \\
16.4\end{array}$ & $\begin{array}{c}\text { Tena Flex } \\
\text { Super (25) } \\
23.4\end{array}$ \\
\hline Leakage & $\begin{array}{l}\text { Very good } \\
\text { Good } \\
\text { OK } \\
\text { Poor } \\
\text { Very poor }\end{array}$ & $\begin{array}{r}33.9 \\
33.9 \\
20.0 \\
10.8 \\
1.5\end{array}$ & $\begin{array}{r}24.2 \\
37.9 \\
22.7 \\
12.1 \\
3.0\end{array}$ & Leakage & $\begin{array}{l}\text { Very good } \\
\text { Good } \\
\text { OK } \\
\text { Poor } \\
\text { Very poor }\end{array}$ & $\begin{array}{r}16.4 \\
23.0 \\
32.8 \\
19.7 \\
8.2\end{array}$ & $\begin{array}{r}23.4 \\
26.6 \\
23.4 \\
17.2 \\
9.4\end{array}$ \\
\hline $\begin{array}{l}\text { Stay in } \\
\text { place }\end{array}$ & $\begin{array}{l}\text { Very good } \\
\text { Good } \\
\text { OK } \\
\text { Poor } \\
\text { Very poor }\end{array}$ & $\begin{array}{r}28.8 \\
19.7 \\
30.3 \\
16.7 \\
4.6\end{array}$ & \begin{tabular}{r|}
28.8 \\
31.8 \\
22.7 \\
13.6 \\
3.0
\end{tabular} & $\begin{array}{l}\text { Stay in } \\
\text { place }\end{array}$ & $\begin{array}{l}\text { Very good } \\
\text { Good } \\
\text { OK } \\
\text { Poor } \\
\text { Very poor }\end{array}$ & $\begin{array}{r}21.0 \\
25.8 \\
40.3 \\
9.7 \\
3.2\end{array}$ & $\begin{array}{r}20.3 \\
23.4 \\
34.4 \\
18.8 \\
3.1\end{array}$ \\
\hline Smell & $\begin{array}{l}\text { Very good } \\
\text { Good } \\
\text { OK } \\
\text { Poor } \\
\text { Very poor }\end{array}$ & $\begin{array}{r}17.2 \\
39.1 \\
39.1 \\
4.7 \\
0.0\end{array}$ & $\begin{array}{r}16.7 \\
27.3 \\
47.0 \\
7.6 \\
1.5\end{array}$ & Smell & $\begin{array}{l}\text { Very good } \\
\text { Good } \\
\text { OK } \\
\text { Poor } \\
\text { Very poor }\end{array}$ & $\begin{array}{r}9.7 \\
27.4 \\
48.4 \\
12.9 \\
1.6\end{array}$ & $\begin{array}{r}15.6 \\
25.0 \\
51.6 \\
7.8 \\
0.0\end{array}$ \\
\hline Discreet & $\begin{array}{l}\text { Very good } \\
\text { Good } \\
\text { OK } \\
\text { Poor } \\
\text { Very poor }\end{array}$ & $\begin{array}{r}26.2 \\
35.4 \\
26.2 \\
6.2 \\
6.2\end{array}$ & $\begin{array}{r}19.7 \\
30.3 \\
28.8 \\
15.2 \\
6.1\end{array}$ & Discreet & $\begin{array}{l}\text { Very good } \\
\text { Good } \\
\text { OK } \\
\text { Poor } \\
\text { Very poor }\end{array}$ & $\begin{array}{r}12.9 \\
35.5 \\
35.5 \\
12.9 \\
3.2\end{array}$ & $\begin{array}{r}24.6 \\
29.2 \\
35.4 \\
9.2 \\
1.5\end{array}$ \\
\hline $\begin{array}{l}\text { Dry } \\
\text { comfort }\end{array}$ & $\begin{array}{l}\text { Very good } \\
\text { Good } \\
\text { OK } \\
\text { Poor } \\
\text { Very poor }\end{array}$ & $\begin{array}{r}26.2 \\
41.5 \\
20.0 \\
9.2 \\
3.1\end{array}$ & $\begin{array}{r}25.8 \\
36.4 \\
25.8 \\
7.6 \\
4.6\end{array}$ & $\begin{array}{l}\text { Dry } \\
\text { comfort }\end{array}$ & $\begin{array}{l}\text { Very good } \\
\text { Good } \\
\text { OK } \\
\text { Poor } \\
\text { Very poor }\end{array}$ & $\begin{array}{r}24.2 \\
33.9 \\
35.5 \\
4.8 \\
1.6\end{array}$ & $\begin{array}{r}21.9 \\
39.1 \\
34.4 \\
3.1 \\
1.6\end{array}$ \\
\hline $\begin{array}{l}\text { Wet } \\
\text { comfort }\end{array}$ & $\begin{array}{l}\text { Very good } \\
\text { Good } \\
\text { OK } \\
\text { Poor } \\
\text { Very poor }\end{array}$ & $\begin{array}{r}20.0 \\
43.1 \\
27.7 \\
7.7 \\
1.6\end{array}$ & $\begin{array}{c}10.8 \\
30.8 \\
38.5 \times(10) \\
18.5 \\
1.5\end{array}$ & $\begin{array}{l}\text { Wet } \\
\text { comfort }\end{array}$ & $\begin{array}{l}\text { Very good } \\
\text { Good } \\
\text { OK } \\
\text { Poor } \\
\text { Very poor }\end{array}$ & $\begin{array}{r}8.1 \\
30.7 \\
41.9 \\
16.1 \\
3.2\end{array}$ & $\begin{array}{r}14.0 \\
35.9 \\
35.9 \\
12.5 \\
1.6\end{array}$ \\
\hline $\begin{array}{l}\text { Keep skin } \\
\text { dry }\end{array}$ & $\begin{array}{l}\text { Very good } \\
\text { Good } \\
\text { OK } \\
\text { Poor } \\
\text { Very poor }\end{array}$ & $\begin{array}{r}20.3 \\
43.8 \\
29.7 \\
6.3 \\
0.0\end{array}$ & $\begin{array}{r}15.2 \\
30.3 \\
40.9 \\
13.6 \\
0.0\end{array}$ & $\begin{array}{l}\text { Keep skin } \\
\text { dry }\end{array}$ & $\begin{array}{l}\text { Very good } \\
\text { Good } \\
\text { OK } \\
\text { Poor } \\
\text { Very poor }\end{array}$ & $\begin{array}{r}8.1 \\
29.0 \\
43.6 \\
19.3 \\
0.0\end{array}$ & $\begin{array}{r}12.7 \\
31.8 \\
46.0 \\
7.9 \\
1.6\end{array}$ \\
\hline $\begin{array}{l}\text { Overall } \\
\text { opinion } \\
\text { (day) }\end{array}$ & $\begin{array}{l}\text { Very good } \\
\text { Good } \\
\text { OK } \\
\text { Poor } \\
\text { Very poor }\end{array}$ & $\begin{array}{r}23.3 \\
37.0 \\
21.9 \\
17.8 \\
0.0\end{array}$ & $\begin{array}{r}22.2 \\
29.2 \\
22.2 \\
23.6 \\
2.8\end{array}$ & $\begin{array}{l}\text { Overall } \\
\text { opinion } \\
\text { (night) }\end{array}$ & $\begin{array}{l}\text { Very good } \\
\text { Good } \\
\text { OK } \\
\text { Poor } \\
\text { Very poor }\end{array}$ & $\begin{array}{l}20.0 \\
21.4 \\
34.3 \\
14.3 \\
10.0\end{array}$ & $\begin{array}{r}20.6 \\
24.7 \\
30.1 \\
16.4 \\
8.2\end{array}$ \\
\hline
\end{tabular}




\begin{tabular}{|c|c|c|c|c|}
\hline Washables (day) & & $\begin{array}{l}\text { Martex Brief } 1000^{\circ} \\
\text { (12) }\end{array}$ & $\begin{array}{c}\text { Bullen Nappy } \\
\text { (terry-towelling) } \\
\text { (13) }\end{array}$ & $\begin{array}{c}\text { Paddy T } \\
\text { (terry-towelling) } \\
\text { (14) }\end{array}$ \\
\hline \multirow[t]{5}{*}{ Leakage } & Very good & 2.6 & 30.9 & 21.1 \\
\hline & Good & 15.8 & 23.6 & 43.9 \\
\hline & OK & $26.3 \times(13$ and 14$)$ & 25.4 & 19.3 \\
\hline & Poor & $26.3 \mathrm{~g}$ & 10.9 & 10.5 \\
\hline & Very poor & 29.0 & 9.1 & 5.2 \\
\hline \multirow[t]{5}{*}{ Stay in place } & Very good & 26.3 & 10.7 & 15.5 \\
\hline & Good & 29.0 & 26.8 & 32.8 \\
\hline & OK & $42 . \lg )$ & $28.6 \times(12$ and 14$)$ & 32.8 \\
\hline & Poor & 0.0 & 17.9 & 12.1 \\
\hline & Very poor & 2.6 & 16.1 & 6.9 \\
\hline \multirow[t]{5}{*}{ Smell } & Very good & 7.9 & 7.3 & 5.4 \\
\hline & Good & 18.4 & 23.6 & 32.1 \\
\hline & OK & 57.9 & 40.0 & 33.9 \\
\hline & Poor & 10.5 & 14.6 & 17.9 \\
\hline & Very poor & 5.3 & 14.6 & 10.7 \\
\hline \multirow[t]{5}{*}{ Discreet } & Very good & 0.0 & 1.8 & 1.7 \\
\hline & Good & 10.8 & 5.3 & 5.1 \\
\hline & OK & 35.1 & 15.8 & 19.0 \\
\hline & Poor & 27.0 & 28.1 & 36.2 \\
\hline & Very poor & 27.0 & 49.1 & 37.9 \\
\hline \multirow[t]{5}{*}{ Dry comfort } & Very good & 21.1 & 26.3 & 20.3 \\
\hline & Good & 18.4 & 31.6 & 32.2 \\
\hline & OK & $34.2 \times(13)$ & 28.1 & 37.3 \\
\hline & Poor & 18.4 & 8.8 & 3.4 \\
\hline & Very poor & 7.9 & 5.3 & 6.8 \\
\hline \multirow[t]{5}{*}{ Wet comfort } & Very good & 2.6 & 9.3 & 5.3 \\
\hline & Good & 10.5 & 13.0 & 14.0 \\
\hline & OK & 42.1 & 40.7 & 47.4 \\
\hline & Poor & 31.6 & 13.0 & 22.8 \\
\hline & Very poor & 13.2 & 24.1 & 10.5 \\
\hline \multirow[t]{5}{*}{ Keep skin dry } & Very good & 2.6 & 7.4 & 1.8 \\
\hline & Good & 18.4 & 13.0 & 25.0 \\
\hline & OK & 31.6 & 38.9 & 39.3 \\
\hline & Poor & 31.6 & 20.4 & 21.4 \\
\hline & Very poor & 15.8 & 20.4 & 12.5 \\
\hline \multirow[t]{5}{*}{ Overall opinion (day) } & Very good & 0.0 & 11.9 & 11.9 \\
\hline & Good & 19.1 & 16.4 & 22.4 \\
\hline & OK & $14.3 \times(14)$ & 19.4 & 23.4 \\
\hline & Poor & 26.2 & 16.4 & 16.4 \\
\hline & Very poor & 40.5 & 35.8 & 25.4 \\
\hline
\end{tabular}




\begin{tabular}{|c|c|c|c|c|}
\hline Washables (nig & & \multirow{2}{*}{$\begin{array}{c}\begin{array}{c}\text { Bullen Nappy } \\
\text { (terry-towelling) }\end{array} \\
\text { (26) } \\
34.0\end{array}$} & \multirow{2}{*}{$\begin{array}{c}\text { Paddy T } \\
\text { (terry-towelling) } \\
\text { (27) } \\
41.5\end{array}$} & \multirow{2}{*}{$\begin{array}{c}\text { Martex Brief } \\
\begin{array}{c}1000^{\circ} \\
(\mathbf{2 8})\end{array} \\
3.0\end{array}$} \\
\hline Leakage & Very good & & & \\
\hline & Good & 34.0 & 22.6 & 3.0 \\
\hline & OK & 18.9 & 24.5 & $12.1(\times 26$ and 27$)$ \\
\hline & Poor & 7.6 & 3.8 & 33.3 \\
\hline & Very poor & 5.7 & 7.6 & 48.5 \\
\hline \multirow[t]{5}{*}{ Stay in place } & Very good & 14.8 & 18.2 & 29.4 \\
\hline & Good & 37.0 & 34.6 & 26.5 \\
\hline & OK & 20.4 & 29.1 & 29.4 \\
\hline & Poor & 14.8 & 7.3 & 8.8 \\
\hline & Very poor & 13.0 & 10.9 & 5.9 \\
\hline \multirow[t]{5}{*}{ Smell } & Very good & 11.3 & 5.6 & 6.1 \\
\hline & Good & 24.5 & 27.8 & 6.1 \\
\hline & OK & 35.9 & 37.0 & 60.6 \\
\hline & Poor & 15.1 & 22.2 & 21.2 \\
\hline & Very poor & 13.2 & 7.4 & 6.1 \\
\hline \multirow[t]{5}{*}{ Discreet } & Very good & 3.9 & 0.0 & 0.0 \\
\hline & Good & 0.0 & 14.8 & 11.8 \\
\hline & OK & 23.1 & 24.1 & 38.2 \\
\hline & Poor & 34.6 & 27.8 & 29.4 \\
\hline & Very poor & 38.5 & 33.3 & 20.6 \\
\hline \multirow[t]{5}{*}{ Dry comfort } & Very good & 27.8 & 27.3 & 20.6 \\
\hline & Good & 37.0 & 36.4 & 20.6 \\
\hline & OK & 18.5 & 20.0 & $26.5 \times(26$ and 27$)$ \\
\hline & Poor & 5.6 & 7.3 & 23.5 \\
\hline & Very poor & II.I & 9.1 & 8.8 \\
\hline \multirow[t]{5}{*}{ Wet comfort } & Very good & I5.I & II.I & 6.1 \\
\hline & Good & 17.0 & 16.7 & 6.1 \\
\hline & OK & 37.7 & 42.6 & $36.4 \times(26$ and 27$)$ \\
\hline & Poor & I5.I & 18.5 & 21.2 \\
\hline & Very poor & I5.I & II.I & 30.3 \\
\hline \multirow[t]{5}{*}{ Keep skin dry } & Very good & 7.7 & 7.7 & 3.0 \\
\hline & Good & 21.2 & 21.2 & 15.2 \\
\hline & OK & 25.0 & 34.6 & $21.2 \times(27)$ \\
\hline & Poor & 32.7 & 25.0 & 33.3 \\
\hline & Very poor & 13.5 & 11.5 & 27.3 \\
\hline & Very good & 25.8 & 25.0 & 0.0 \\
\hline \multirow{4}{*}{ (night) } & Good & 25.8 & 26.7 & 8.1 \\
\hline & OK & 9.7 & 16.7 & $8.1 \times(26$ and 27$)$ \\
\hline & Poor & 9.7 & 10.0 & 32.4 \\
\hline & Very poor & 29.0 & 21.7 & 51.4 \\
\hline
\end{tabular}




\begin{tabular}{|c|c|c|c|c|}
\hline Diaper (day) & & $\begin{array}{l}\text { Lille Kendall Supreme } \\
\text { Fit Regular Plus } \\
\text { (4) }\end{array}$ & $\begin{array}{l}\text { Euron Form } \\
\text { Ultra } \\
\text { (5) }\end{array}$ & $\begin{array}{c}\text { Attends Slip } \\
\text { Extra } \\
\text { (6) }\end{array}$ \\
\hline \multirow[t]{5}{*}{ Leakage } & Very good & 13.6 & 16.4 & 32.8 \\
\hline & Good & 30.3 & 24.6 & 26.6 \\
\hline & OK & 34.9 & $27.9 \times(6)$ & 26.6 \\
\hline & Poor & 15.2 & 21.3 & 10.9 \\
\hline & Very poor & 6.1 & 9.8 & 3.1 \\
\hline \multirow[t]{5}{*}{ Stay in place } & Very good & 11.9 & 18.8 & 21.5 \\
\hline & Good & 34.3 & 42.2 & 32.3 \\
\hline & OK & 37.3 & 28.1 & 35.4 \\
\hline & Poor & 13.4 & 7.8 & 9.2 \\
\hline & Very poor & 3.0 & 3.1 & 1.5 \\
\hline \multirow[t]{5}{*}{ Smell } & Very good & 7.6 & 11.1 & 14.1 \\
\hline & Good & 33.3 & 19.1 & 42.2 \\
\hline & OK & 50.0 & 61.9 & 37.5 \\
\hline & Poor & 7.6 & 3.2 & 6.3 \\
\hline & Very poor & 1.6 & 4.8 & 0.0 \\
\hline \multirow[t]{5}{*}{ Discreet } & Very good & 11.9 & 15.6 & 18.5 \\
\hline & Good & 28.4 & 37.5 & 32.3 \\
\hline & OK & 35.8 & 28.1 & 33.9 \\
\hline & Poor & 20.9 & 12.5 & 13.9 \\
\hline & Very poor & 3.0 & 6.3 & 1.5 \\
\hline \multirow[t]{5}{*}{ Dry comfort } & Very good & 16.7 & 18.8 & 25.4 \\
\hline & Good & 37.9 & 45.3 & 39.7 \\
\hline & OK & 40.9 & 28.1 & 27.0 \\
\hline & Poor & 3.1 & 6.2 & 7.9 \\
\hline & Very poor & 1.5 & 1.6 & 0.0 \\
\hline \multirow[t]{5}{*}{ Wet comfort } & Very good & 4.6 & 9.5 & 7.9 \\
\hline & Good & 22.7 & 23.8 & 39.7 \\
\hline & OK & 56.1 & 38.1 & 39.7 \\
\hline & Poor & 13.6 & 19.1 & 11.1 \\
\hline & Very poor & 3.0 & 9.6 & 1.2 \\
\hline \multirow[t]{5}{*}{ Keep skin dry } & Very good & 3.1 & 6.4 & II.I \\
\hline & Good & 34.4 & 25.4 & 38.1 \\
\hline & OK & 37.5 & $38.1(X 6)$ & 39.7 \\
\hline & Poor & 20.3 & 23.8 & II.I \\
\hline & Very poor & 4.7 & 6.4 & 0.0 \\
\hline \multirow[t]{5}{*}{ Overall opinion (day) } & Very good & 8.2 & 14.3 & 25.4 \\
\hline & Good & 26.0 & 25.7 & 36.6 \\
\hline & OK & 38.4 & $31.4 \times(6)$ & 19.7 \\
\hline & Poor & 15.1 & 17.1 & 12.7 \\
\hline & Very poor & 12.3 & 11.4 & 5.6 \\
\hline
\end{tabular}




\begin{tabular}{|c|c|c|c|c|}
\hline Diaper (night) & & $\begin{array}{l}\text { Shiloh Contifit } \\
\text { (18) }\end{array}$ & $\begin{array}{c}\text { Karocare } \\
\text { All-in-One Brief } \\
\text { (19) }\end{array}$ & $\begin{array}{l}\text { Abri-Form Plus } \\
\text { (20) }\end{array}$ \\
\hline \multirow[t]{5}{*}{ Leakage } & Very good & 4.8 & II.I & 13.9 \\
\hline & Good & 38.7 & 25.4 & 40.0 \\
\hline & OK & 33.9 & 42.9 & 23.1 \\
\hline & Poor & 16.1 & 15.9 & 18.5 \\
\hline & Very poor & 6.5 & 4.8 & 4.6 \\
\hline \multirow[t]{5}{*}{ Stay in place } & Very good & 4.3 & 9.5 & 13.9 \\
\hline & Good & 49.2 & 46.0 & 35.4 \\
\hline & OK & 22.2 & 27.0 & 27.7 \\
\hline & Poor & 7.9 & 12.7 & 15.4 \\
\hline & Very poor & 6.4 & 4.8 & 7.7 \\
\hline \multirow[t]{5}{*}{ Smell } & Very good & 6.5 & 9.7 & 9.1 \\
\hline & Good & 32.3 & 29.0 & 30.3 \\
\hline & OK & 46.8 & 38.7 & 34.9 \\
\hline & Poor & 9.7 & 19.4 & 22.7 \\
\hline & Very poor & 4.8 & 3.2 & 3.0 \\
\hline \multirow[t]{5}{*}{ Discreet } & Very good & 7.9 & 14.3 & 15.4 \\
\hline & Good & 41.3 & 28.6 & 36.9 \\
\hline & OK & 33.3 & 42.9 & 26.2 \\
\hline & Poor & 12.7 & 11.1 & 15.4 \\
\hline & Very poor & 4.8 & 3.2 & 6.2 \\
\hline \multirow[t]{5}{*}{ Dry comfort } & Very good & 14.1 & 15.9 & 15.4 \\
\hline & Good & 45.3 & 33.3 & 49.2 \\
\hline & OK & 31.3 & 41.3 & 29.2 \\
\hline & Poor & 4.7 & 7.9 & 3.1 \\
\hline & Very poor & 4.7 & 1.6 & 3.1 \\
\hline \multirow[t]{5}{*}{ Wet comfort } & Very good & 3.2 & 7.9 & 9.1 \\
\hline & Good & 27.0 & 34.9 & 27.3 \\
\hline & OK & 49.2 & 31.8 & 37.9 \\
\hline & Poor & 11.1 & 19.1 & 19.7 \\
\hline & Very poor & 9.5 & 6.4 & 6.1 \\
\hline \multirow[t]{5}{*}{ Keep skin dry } & Very good & 3.2 & 4.8 & 10.6 \\
\hline & Good & 35.5 & 31.8 & 34.9 \\
\hline & OK & 35.5 & 34.9 & 30.3 \\
\hline & Poor & 17.7 & 22.2 & 16.7 \\
\hline & Very poor & 8.1 & 6.3 & 7.6 \\
\hline & Very good & 5.6 & 8.6 & 11.0 \\
\hline \multirow{4}{*}{ (night) } & Good & 38.0 & 28.6 & 30.1 \\
\hline & OK & 32.4 & 32.9 & 31.5 \\
\hline & Poor & 15.5 & 22.9 & 19.2 \\
\hline & Very poor & 8.5 & 7.1 & 8.2 \\
\hline
\end{tabular}




\begin{tabular}{|c|c|c|c|c|}
\hline Inserts (day) & & $\begin{array}{c}\text { Abri-San Super } \\
\text { (I) }\end{array}$ & $\begin{array}{l}\text { Moliform Plus } \\
\text { (2) }\end{array}$ & $\begin{array}{l}\text { Attends Contour } \\
\text { Super (3) }\end{array}$ \\
\hline \multirow[t]{5}{*}{ Leakage } & Very good & 9.1 & 5.0 & 13.3 \\
\hline & Good & 21.2 & 25.0 & 35.0 \\
\hline & OK & 30.3 & 33.3 & 20.0 \\
\hline & Poor & 28.8 & 23.3 & 20.0 \\
\hline & Very poor & 10.6 & 13.3 & 11.7 \\
\hline \multirow[t]{5}{*}{ Stay in place } & Very good & 6.2 & 7.9 & 9.7 \\
\hline & Good & 26.2 & 23.8 & 27.4 \\
\hline & OK & 35.4 & 42.9 & 35.5 \\
\hline & Poor & 21.5 & 15.9 & 17.7 \\
\hline & Very poor & 10.8 & 9.5 & 9.7 \\
\hline \multirow[t]{5}{*}{ Smell } & Very good & 9.1 & 4.8 & 14.8 \\
\hline & Good & 24.2 & 27.4 & 31.2 \\
\hline & OK & 42.4 & 43.5 & 39.3 \\
\hline & Poor & 22.7 & 17.7 & 9.8 \\
\hline & Very poor & 1.5 & 6.5 & 4.9 \\
\hline \multirow[t]{5}{*}{ Discreet } & Very good & 10.6 & 14.3 & 16.1 \\
\hline & Good & 42.4 & 41.3 & 38.7 \\
\hline & OK & 40.9 & 36.5 & 41.9 \\
\hline & Poor & 4.5 & 7.9 & 3.2 \\
\hline & Very poor & 1.5 & 0.0 & 0.0 \\
\hline \multirow[t]{5}{*}{ Dry comfort } & Very good & 15.2 & 14.5 & 17.7 \\
\hline & Good & 34.9 & 40.3 & 40.3 \\
\hline & OK & 31.8 & 30.7 & 33.9 \\
\hline & Poor & 16.7 & 11.3 & 8.1 \\
\hline & Very poor & 1.6 & 3.2 & 0.0 \\
\hline \multirow[t]{5}{*}{ Wet comfort } & Very good & 7.6 & 6.5 & 11.5 \\
\hline & Good & 25.8 & 24.2 & 29.5 \\
\hline & OK & 36.4 & 41.9 & 32.8 \\
\hline & Poor & 21.2 & 19.4 & 19.7 \\
\hline & Very poor & 9.1 & 8.1 & 6.6 \\
\hline \multirow[t]{5}{*}{ Keep skin dry } & Very good & 14.1 & 4.8 & 14.8 \\
\hline & Good & 21.9 & 29.0 & 34.4 \\
\hline & OK & 42.2 & 40.3 & 36.1 \\
\hline & Poor & 18.8 & 24.2 & 13.1 \\
\hline & Very poor & 3.1 & 1.6 & 1.6 \\
\hline \multirow[t]{5}{*}{ Overall opinion (day) } & Very good & 8.2 & 4.4 & 7.5 \\
\hline & Good & 21.9 & 24.6 & 28.4 \\
\hline & OK & 31.5 & 26.1 & 25.4 \\
\hline & Poor & 23.3 & 23.2 & 23.9 \\
\hline & Very poor & 15.1 & 21.7 & 14.9 \\
\hline
\end{tabular}




\begin{tabular}{|c|c|c|c|c|}
\hline Inserts (night) & & $\begin{array}{l}\text { Tena Comfort } \\
\text { Super (15) }\end{array}$ & $\begin{array}{l}\text { Attends Contour } \\
\text { Super Plus (16) }\end{array}$ & $\begin{array}{c}\text { Contisure Premium } \\
\text { Extra }^{a}(17)\end{array}$ \\
\hline Leakage & $\begin{array}{l}\text { Very good } \\
\text { Good } \\
\text { OK } \\
\text { Poor } \\
\text { Very poor }\end{array}$ & $\begin{array}{l}14.5 \\
24.2 \\
25.8 \\
16.1 \\
19.4\end{array}$ & $\begin{array}{r}9.7 \\
33.9 \\
24.2 \\
17.7 \\
14.5\end{array}$ & $\begin{array}{c}4.6 \\
24.6 \\
16.9 \times(15 \text { and } 16) \\
30.8 \\
23.1\end{array}$ \\
\hline Stay in place & $\begin{array}{l}\text { Very good } \\
\text { Good } \\
\text { OK } \\
\text { Poor } \\
\text { Very poor }\end{array}$ & $\begin{array}{r}10.8 \\
30.8 \\
24.6 \\
29.2 \\
4.6\end{array}$ & $\begin{array}{r}9.5 \\
25.4 \\
34.9 \\
17.5 \\
12.7\end{array}$ & $\begin{array}{r}4.6 \\
33.3 \\
27.3 \\
25.8 \\
9.0\end{array}$ \\
\hline Smell & $\begin{array}{l}\text { Very good } \\
\text { Good } \\
\text { OK } \\
\text { Poor } \\
\text { Very poor }\end{array}$ & $\begin{array}{r}7.8 \\
32.8 \\
40.6 \\
18.8 \\
0.0\end{array}$ & $\begin{array}{r}8.1 \\
33.9 \\
43.6 \\
11.3 \\
3.2\end{array}$ & $\begin{array}{c}6.1 \\
31.8 \\
34.9 \times(16) \\
22.7 \\
4.6\end{array}$ \\
\hline Discreet & $\begin{array}{l}\text { Very good } \\
\text { Good } \\
\text { OK } \\
\text { Poor } \\
\text { Very poor }\end{array}$ & $\begin{array}{r}10.8 \\
35.4 \\
43.1 \\
10.8 \\
0.0\end{array}$ & $\begin{array}{r}14.3 \\
38.1 \\
39.7 \\
7.9 \\
0.0\end{array}$ & $\begin{array}{r}7.6 \\
48.5 \\
37.9 \\
6.1 \\
0.0\end{array}$ \\
\hline Dry comfort & $\begin{array}{l}\text { Very good } \\
\text { Good } \\
\text { OK } \\
\text { Poor } \\
\text { Very poor }\end{array}$ & $\begin{array}{r}18.5 \\
385 \\
38.5 \\
3.1 \\
1.5\end{array}$ & $\begin{array}{r}20.6 \\
41.3 \\
30.2 \\
6.4 \\
1.6\end{array}$ & $\begin{array}{r}15.2 \\
40.9 \\
37.9 \\
4.6 \\
1.5\end{array}$ \\
\hline Wet comfort & $\begin{array}{l}\text { Very good } \\
\text { Good } \\
\text { OK } \\
\text { Poor } \\
\text { Very poor }\end{array}$ & $\begin{array}{r}6.4 \\
36.5 \\
38.1 \\
11.1 \\
7.9\end{array}$ & $\begin{array}{r}6.5 \\
33.9 \\
46.8 \\
8.1 \\
4.8\end{array}$ & $\begin{array}{c}3.0 \\
24.2 \\
40.9 \times(16) \\
21.2 \\
10.6\end{array}$ \\
\hline Keep skin dry & $\begin{array}{l}\text { Very good } \\
\text { Good } \\
\text { OK } \\
\text { Poor } \\
\text { Very poor }\end{array}$ & $\begin{array}{r}9.5 \\
28.6 \\
41.3 \\
17.5 \\
3.2\end{array}$ & $\begin{array}{r}9.7 \\
30.7 \\
43.6 \\
12.9 \\
3.2\end{array}$ & $\begin{array}{c}6.4 \\
27.0 \\
36.5 \times(16) \\
27.0 \\
3.2\end{array}$ \\
\hline $\begin{array}{l}\text { Overall opinion } \\
\text { (night) }\end{array}$ & $\begin{array}{l}\text { Very good } \\
\text { Good } \\
\text { OK } \\
\text { Poor } \\
\text { Very poor }\end{array}$ & $\begin{array}{l}12.9 \\
27.1 \\
25.7 \\
15.7 \\
18.6\end{array}$ & $\begin{array}{l}11.4 \\
31.4 \\
20.0 \\
20.0 \\
17.1\end{array}$ & $\begin{array}{c}6.9 \\
21.9 \\
17.8 \times(15 \text { and } 16) \\
31.5 \\
21.9\end{array}$ \\
\hline
\end{tabular}




\begin{tabular}{|c|c|c|c|c|}
\hline Pull-ups (day) & & $\begin{array}{c}\text { Attends } \\
\text { Pull-on Super (7) }\end{array}$ & $\begin{array}{c}\text { Molicare Mobile } \\
\text { (8) }\end{array}$ & $\begin{array}{c}\text { Abri-Flex Extra } \\
\text { (9) }\end{array}$ \\
\hline \multirow[t]{5}{*}{ Leakage } & Very good & 25.8 & 22.6 & 22.2 \\
\hline & Good & 39.4 & 30.7 & 38.1 \\
\hline & OK & 22.7 & 19.4 & 19.1 \\
\hline & Poor & 10.6 & 19.4 & 17.5 \\
\hline & Very poor & 1.5 & 8.1 & 3.2 \\
\hline \multirow[t]{5}{*}{ Stay in place } & Very good & 44.1 & 41.5 & 50.0 \\
\hline & Good & 33.8 & 30.8 & 28.1 \\
\hline & OK & 13.2 & 20.0 & 15.6 \\
\hline & Poor & 8.8 & 6.2 & 6.3 \\
\hline & Very poor & 0.0 & 1.5 & 0.0 \\
\hline \multirow[t]{5}{*}{ Smell } & Very good & 20.9 & 12.5 & 15.9 \\
\hline & Good & 28.4 & 39.1 & 31.8 \\
\hline & OK & 40.3 & 34.4 & 38.1 \\
\hline & Poor & 10.5 & 12.5 & 12.7 \\
\hline & Very poor & 0.0 & 1.6 & 1.6 \\
\hline \multirow[t]{5}{*}{ Discreet } & Very good & 29.9 & 36.9 & 35.9 \\
\hline & Good & 40.3 & 40.0 & 42.2 \\
\hline & OK & 25.4 & 21.5 & 18.8 \\
\hline & Poor & 4.5 & 1.5 & 3.1 \\
\hline & Very poor & 0.0 & 0.0 & 0.0 \\
\hline \multirow[t]{5}{*}{ Dry comfort } & Very good & 50.0 & 43.1 & 41.3 \\
\hline & Good & 35.3 & 40.0 & 42.9 \\
\hline & OK & 14.7 & 16.9 & 14.3 \\
\hline & Poor & 0.0 & 0.0 & 1.6 \\
\hline & Very poor & 0.0 & 0.0 & 0.0 \\
\hline \multirow[t]{5}{*}{ Wet comfort } & Very good & 16.2 & 14.8 & 14.5 \\
\hline & Good & 39.7 & 34.4 & 37.1 \\
\hline & OK & 33.8 & 39.3 & 40.3 \\
\hline & Poor & 8.8 & 11.5 & 8.1 \\
\hline & Very poor & 1.5 & 0.0 & 0.0 \\
\hline \multirow[t]{5}{*}{ Keep skin dry } & Very good & 22.4 & 15.6 & 15.9 \\
\hline & Good & 40.3 & 37.5 & 39.7 \\
\hline & OK & 35.8 & 39.7 & $30.2 \times(7)$ \\
\hline & Poor & 0.0 & 7.8 & 14.3 \\
\hline & Very poor & 1.5 & 0.0 & 0.0 \\
\hline Overall opinion & Very good & 34.7 & 27.9 & 29.4 \\
\hline \multirow[t]{4}{*}{ (day) } & Good & 36.1 & 33.8 & 36.8 \\
\hline & OK & 19.4 & $13.2 \times(7$ and 9$)$ & 22.1 \\
\hline & Poor & 9.7 & 20.6 & 10.3 \\
\hline & Very poor & 0.0 & 4.4 & 1.5 \\
\hline
\end{tabular}




\begin{tabular}{|c|c|c|c|c|}
\hline Pull-ups (night) & & $\begin{array}{l}\text { Attends Pull-on } \\
\text { (2I) }\end{array}$ & $\begin{array}{c}\text { Molicare Mobile }{ }^{a} \\
\text { (22) }\end{array}$ & $\begin{array}{c}\text { Tena Pants Super } \\
\text { (23) }\end{array}$ \\
\hline Leakage & $\begin{array}{l}\text { Very good } \\
\text { Good } \\
\text { OK } \\
\text { Poor } \\
\text { Very poor }\end{array}$ & $\begin{array}{r}29.4 \\
25.0 \\
25.0 \\
11.8 \\
8.8\end{array}$ & $\begin{array}{c}15.6 \\
18.8 \\
28.1 \times(2 \mid \text { and } 23) \\
25.0 \\
12.5\end{array}$ & $\begin{array}{l}31.3 \\
31.3 \\
15.6 \\
10.9 \\
10.9\end{array}$ \\
\hline Stay in place & $\begin{array}{l}\text { Very good } \\
\text { Good } \\
\text { OK } \\
\text { Poor } \\
\text { Very poor }\end{array}$ & $\begin{array}{r}38.2 \\
32.4 \\
23.5 \\
5.9 \\
0.0\end{array}$ & $\begin{array}{r}31.2 \\
41.3 \\
14.3 \\
11.1 \\
3.2\end{array}$ & $\begin{array}{r}35.4 \\
46.2 \\
10.8 \\
6.2 \\
1.5\end{array}$ \\
\hline Smell & $\begin{array}{l}\text { Very good } \\
\text { Good } \\
\text { OK } \\
\text { Poor } \\
\text { Very poor }\end{array}$ & $\begin{array}{r}22.1 \\
30.9 \\
42.7 \\
4.4 \\
0.0\end{array}$ & $\begin{array}{c}14.1 \\
28.1 \\
39.1 \times(21) \\
17.2 \\
1.6\end{array}$ & $\begin{array}{r}17.5 \\
42.9 \\
30.2 \\
9.5 \\
0.0\end{array}$ \\
\hline Discreet & $\begin{array}{l}\text { Very good } \\
\text { Good } \\
\text { OK } \\
\text { Poor } \\
\text { Very poor }\end{array}$ & $\begin{array}{r}29.4 \\
42.7 \\
26.5 \\
1.5 \\
0.0\end{array}$ & $\begin{array}{r}23.4 \\
56.3 \\
20.3 \\
0.0 \\
0.0\end{array}$ & $\begin{array}{r}30.8 \\
44.6 \\
24.6 \\
0.0 \\
0.0\end{array}$ \\
\hline Dry comfort & $\begin{array}{l}\text { Very good } \\
\text { Good } \\
\text { OK } \\
\text { Poor } \\
\text { Very poor }\end{array}$ & $\begin{array}{r}50.0 \\
33.8 \\
16.1 \\
0.0 \\
0.0\end{array}$ & $\begin{array}{r}40.6 \\
37.5 \\
20.3 \\
1.6 \\
0.0\end{array}$ & $\begin{array}{c}40.0 \\
49.2 \\
9.2 \\
1.5 \\
0.0\end{array}$ \\
\hline Wet comfort & $\begin{array}{l}\text { Very good } \\
\text { Good } \\
\text { OK } \\
\text { Poor } \\
\text { Very poor }\end{array}$ & $\begin{array}{r}22.1 \\
36.8 \\
30.9 \\
8.9 \\
1.5\end{array}$ & $\begin{array}{r}14.1 \\
21.9 \\
46.9 \\
15.6 \\
1.6\end{array}$ & $\begin{array}{r}14.1 \\
46.9 \\
29.7 \\
7.8 \\
1.6\end{array}$ \\
\hline Keep skin dry & $\begin{array}{l}\text { Very good } \\
\text { Good } \\
\text { OK } \\
\text { Poor } \\
\text { Very poor }\end{array}$ & $\begin{array}{r}27.3 \\
36.4 \\
33.3 \\
1.5 \\
1.5\end{array}$ & $\begin{array}{c}14.1 \\
28.1 \\
40.6 \times(21) \\
14.1 \\
3.1\end{array}$ & $\begin{array}{r}29.2 \\
35.4 \\
26.2 \\
9.2 \\
0.0\end{array}$ \\
\hline $\begin{array}{l}\text { Overall opinion } \\
\text { (night) }\end{array}$ & $\begin{array}{l}\text { Very good } \\
\text { Good } \\
\text { OK } \\
\text { Poor } \\
\text { Very poor }\end{array}$ & $\begin{array}{r}31.1 \\
28.4 \\
17.6 \\
16.2 \\
6.8\end{array}$ & $\begin{array}{c}22.2 \\
29.2 \\
13.9 \times(23) \\
22.2 \\
12.5\end{array}$ & $\begin{array}{r}26.1 \\
35.6 \\
15.1 \\
15.1 \\
8.2\end{array}$ \\
\hline
\end{tabular}





\section{Appendix 10}

\section{Trial 2a: design performance by gender (\%)}

\begin{tabular}{|c|c|c|c|c|c|c|}
\hline & & Very good & Good & OK & Poor & Very poor \\
\hline \multicolumn{7}{|l|}{ Women: day } \\
\hline \multirow{5}{*}{ Ease on } & T-shaped & 19.2 & 11.5 & 38.5 & 23.1 & 7.7 \\
\hline & Washable & 2.3 & 7.0 & 14.0 & 23.3 & 53.5 \\
\hline & Diaper & 10.8 & 23.0 & 29.7 & 21.6 & 14.9 \\
\hline & Insert & 25.0 & 40.8 & 28.9 & 5.3 & 0.0 \\
\hline & Pull-up & 50.0 & 32.5 & 12.5 & 5.0 & 0.0 \\
\hline \multirow[t]{5}{*}{ Fit } & T-shaped & 11.8 & 19.6 & 21.6 & 31.4 & 15.7 \\
\hline & Washable & 0.0 & 7.1 & 19.0 & 21.4 & 52.4 \\
\hline & Diaper & 13.3 & 18.7 & 29.3 & 26.7 & 12.0 \\
\hline & Insert & 13.2 & 35.5 & 38.2 & 10.5 & 2.6 \\
\hline & Pull-up & 36.3 & 35.0 & 22.5 & 6.3 & 0.0 \\
\hline \multirow[t]{5}{*}{ Comfort dry } & T-shaped & 19.6 & 27.5 & 31.4 & 13.7 & 7.8 \\
\hline & Washable & 10.0 & 10.0 & 60.0 & 7.5 & 12.5 \\
\hline & Diaper & 13.7 & 32.9 & 38.4 & 12.3 & 2.7 \\
\hline & Insert & 23.7 & 36.8 & 28.9 & 10.5 & 0.0 \\
\hline & Pull-up & 56.3 & 30.0 & 12.5 & 1.3 & 0.0 \\
\hline \multirow[t]{5}{*}{ In place } & T-shaped & 23.1 & 17.3 & 30.8 & 21.2 & 7.7 \\
\hline & Washable & 7.9 & 5.3 & 42.1 & 18.4 & 26.3 \\
\hline & Diaper & 10.7 & 33.3 & 40.0 & 9.3 & 6.7 \\
\hline & Insert & 14.7 & 33.3 & 41.3 & 5.3 & 5.3 \\
\hline & Pull-up & 60.0 & 31.3 & 7.5 & 1.3 & 0.0 \\
\hline \multirow[t]{5}{*}{ Discreet } & T-shaped & 17.6 & 23.5 & 25.5 & 17.6 & 15.7 \\
\hline & Washable & 0.0 & 4.9 & 9.8 & 14.6 & 70.7 \\
\hline & Diaper & 5.3 & 24.0 & 29.3 & 32.0 & 9.3 \\
\hline & Insert & 17.1 & 46.1 & 28.9 & 7.9 & 0.0 \\
\hline & Pull-up & 41.3 & 32.5 & 20.0 & 6.3 & 0.0 \\
\hline \multirow[t]{5}{*}{ Urine } & T-shaped & 23.5 & 31.4 & 29.4 & 11.8 & 3.9 \\
\hline & Washable & 15.8 & 21.1 & 39.5 & 10.5 & 13.2 \\
\hline & Diaper & 22.5 & 33.8 & 23.9 & 15.5 & 4.2 \\
\hline & Insert & 15.8 & 32.9 & 21.1 & 22.4 & 7.9 \\
\hline & Pull-up & 35.9 & 41.0 & 15.4 & 7.7 & 0.0 \\
\hline \multirow[t]{5}{*}{ Faeces } & T-shaped & 20.0 & 40.0 & 20.0 & 10.0 & 10.0 \\
\hline & Washable & 28.6 & 0.0 & 28.6 & 14.3 & 28.6 \\
\hline & Diaper & 30.8 & 7.7 & 30.8 & 15.4 & 15.4 \\
\hline & Insert & 8.3 & 33.3 & 50.0 & 0.0 & 8.3 \\
\hline & Pull-up & 40.0 & 20.0 & 20.0 & 20.0 & 0.0 \\
\hline \multirow[t]{5}{*}{ Comfort wet } & T-shaped & 9.8 & 31.4 & 41.2 & 13.7 & 3.9 \\
\hline & Washable & 5.3 & 5.3 & 28.9 & 36.8 & 23.7 \\
\hline & Diaper & 8.5 & 31.0 & 42.3 & 14.1 & 4.2 \\
\hline & Insert & 10.5 & 26.3 & 36.8 & 22.4 & 3.9 \\
\hline & Pull-up & 22.1 & 40.3 & 35.1 & 2.6 & 0.0 \\
\hline \multirow[t]{5}{*}{ Urine smell } & T-shaped & 17.6 & 29.4 & 39.2 & 11.8 & 2.0 \\
\hline & Washable & 7.9 & 10.5 & 28.9 & 28.9 & 23.7 \\
\hline & Diaper & 13.9 & 27.8 & 45.8 & 8.3 & 4.2 \\
\hline & Insert & 13.2 & 25.0 & 47.4 & 9.2 & 5.3 \\
\hline & Pull-up & 26.6 & 30.4 & 31.6 & 11.4 & 0.0 \\
\hline
\end{tabular}




\begin{tabular}{|c|c|c|c|c|c|c|}
\hline & & Very good & Good & OK & Poor & Very poor \\
\hline Skin dry & $\begin{array}{l}\text { T-shaped } \\
\text { Washable } \\
\text { Diaper } \\
\text { Insert } \\
\text { Pull-up }\end{array}$ & $\begin{array}{r}18.0 \\
2.7 \\
8.7 \\
14.9 \\
26.9\end{array}$ & $\begin{array}{l}32.0 \\
10.8 \\
39.1 \\
27.0 \\
39.7\end{array}$ & $\begin{array}{l}34.0 \\
24.3 \\
27.5 \\
44.6 \\
24.4\end{array}$ & $\begin{array}{r}16.0 \\
35.1 \\
18.8 \\
10.8 \\
9.0\end{array}$ & $\begin{array}{r}0.0 \\
27.0 \\
5.8 \\
2.7 \\
0.0\end{array}$ \\
\hline Ease off & $\begin{array}{l}\text { T-shaped } \\
\text { Washable } \\
\text { Diaper } \\
\text { Insert } \\
\text { Pull-up }\end{array}$ & $\begin{array}{l}20.0 \\
10.8 \\
13.0 \\
29.7 \\
47.4\end{array}$ & $\begin{array}{l}24.0 \\
13.5 \\
31.9 \\
40.5 \\
25.6\end{array}$ & $\begin{array}{l}34.0 \\
27.0 \\
26.1 \\
25.7 \\
20.5\end{array}$ & $\begin{array}{r}18.0 \\
18.9 \\
26.1 \\
4.1 \\
5.1\end{array}$ & $\begin{array}{r}4.0 \\
29.7 \\
2.9 \\
0.0 \\
1.3\end{array}$ \\
\hline $\begin{array}{l}\text { Women: nigh } \\
\text { Ease on }\end{array}$ & $\begin{array}{l}\text { T-shaped } \\
\text { Washable } \\
\text { Diaper } \\
\text { Insert } \\
\text { Pull-up }\end{array}$ & $\begin{array}{r}19.2 \\
0.0 \\
8.6 \\
19.5 \\
50.0\end{array}$ & $\begin{array}{r}23.1 \\
9.3 \\
23.5 \\
41.5 \\
32.1\end{array}$ & $\begin{array}{l}36.5 \\
16.3 \\
30.9 \\
29.3 \\
16.7\end{array}$ & $\begin{array}{r}15.4 \\
25.6 \\
25.9 \\
8.5 \\
0.0\end{array}$ & $\begin{array}{r}5.8 \\
48.8 \\
11.1 \\
1.2 \\
1.2\end{array}$ \\
\hline Fit & $\begin{array}{l}\text { T-shaped } \\
\text { Washable } \\
\text { Diaper } \\
\text { Insert } \\
\text { Pull-up }\end{array}$ & $\begin{array}{r}21.6 \\
7.0 \\
8.8 \\
11.0 \\
33.3\end{array}$ & $\begin{array}{r}19.6 \\
4.7 \\
35.0 \\
41.5 \\
47.6\end{array}$ & $\begin{array}{l}33.3 \\
25.6 \\
21.3 \\
34.1 \\
14.3\end{array}$ & $\begin{array}{r}19.6 \\
18.6 \\
22.5 \\
9.8 \\
3.6\end{array}$ & $\begin{array}{r}5.9 \\
44.2 \\
12.5 \\
3.7 \\
1.2\end{array}$ \\
\hline Comfort dry & $\begin{array}{l}\text { T-shaped } \\
\text { Washable } \\
\text { Diaper } \\
\text { Insert } \\
\text { Pull-up }\end{array}$ & $\begin{array}{l}21.6 \\
17.1 \\
13.4 \\
17.1 \\
54.8\end{array}$ & $\begin{array}{l}27.5 \\
17.1 \\
34.1 \\
43.9 \\
31.0\end{array}$ & $\begin{array}{l}37.3 \\
29.3 \\
34.1 \\
36.6 \\
13.1\end{array}$ & $\begin{array}{r}9.8 \\
12.2 \\
11.0 \\
2.4 \\
1.2\end{array}$ & $\begin{array}{r}3.9 \\
24.4 \\
7.3 \\
0.0 \\
0.0\end{array}$ \\
\hline In place & $\begin{array}{l}\text { T-shaped } \\
\text { Washable } \\
\text { Diaper } \\
\text { Insert } \\
\text { Pull-up }\end{array}$ & $\begin{array}{r}17.3 \\
2.4 \\
7.5 \\
8.5 \\
46.4\end{array}$ & $\begin{array}{l}21.2 \\
22.0 \\
37.5 \\
31.7 \\
39.3\end{array}$ & $\begin{array}{l}36.5 \\
31.7 \\
25.0 \\
37.8 \\
11.9\end{array}$ & $\begin{array}{r}23.1 \\
17.1 \\
16.3 \\
18.3 \\
2.4\end{array}$ & $\begin{array}{r}1.9 \\
26.8 \\
13.8 \\
3.7 \\
0.0\end{array}$ \\
\hline Discreet & $\begin{array}{l}\text { T-shaped } \\
\text { Washable } \\
\text { Diaper } \\
\text { Insert } \\
\text { Pull-up }\end{array}$ & $\begin{array}{r}15.4 \\
0.0 \\
8.6 \\
11.0 \\
34.5\end{array}$ & $\begin{array}{r}26.9 \\
2.5 \\
19.8 \\
36.6 \\
42.9\end{array}$ & $\begin{array}{r}32.7 \\
7.5 \\
38.3 \\
42.7 \\
21.4\end{array}$ & $\begin{array}{r}19.2 \\
25.0 \\
22.2 \\
9.8 \\
1.2\end{array}$ & $\begin{array}{r}5.8 \\
65.0 \\
11.1 \\
0.0 \\
0.0\end{array}$ \\
\hline Urine & $\begin{array}{l}\text { T-shaped } \\
\text { Washable } \\
\text { Diaper } \\
\text { Insert } \\
\text { Pull-up }\end{array}$ & $\begin{array}{l}19.6 \\
26.3 \\
11.4 \\
13.6 \\
38.1\end{array}$ & $\begin{array}{l}27.5 \\
15.8 \\
41.8 \\
39.5 \\
26.2\end{array}$ & $\begin{array}{l}25.5 \\
28.9 \\
30.4 \\
18.5 \\
22.6\end{array}$ & $\begin{array}{r}19.6 \\
13.2 \\
15.2 \\
22.2 \\
9.5\end{array}$ & $\begin{array}{r}7.8 \\
15.8 \\
1.3 \\
6.2 \\
3.6\end{array}$ \\
\hline Faeces & $\begin{array}{l}\text { T-shaped } \\
\text { Washable } \\
\text { Diaper } \\
\text { Insert } \\
\text { Pull-up }\end{array}$ & $\begin{array}{r}11.1 \\
33.3 \\
8.3 \\
0.0 \\
25.0\end{array}$ & $\begin{array}{r}33.3 \\
0.0 \\
41.7 \\
16.7 \\
25.0\end{array}$ & $\begin{array}{l}11.1 \\
50.0 \\
33.3 \\
41.7 \\
31.3\end{array}$ & $\begin{array}{l}22.2 \\
16.7 \\
16.7 \\
16.7 \\
12.5\end{array}$ & $\begin{array}{r}22.2 \\
0.0 \\
0.0 \\
25.0 \\
6.3\end{array}$ \\
\hline Comfort wet & $\begin{array}{l}\text { T-shaped } \\
\text { Washable } \\
\text { Diaper } \\
\text { Insert } \\
\text { Pull-up }\end{array}$ & $\begin{array}{r}7.8 \\
10.3 \\
7.4 \\
8.5 \\
22.9\end{array}$ & $\begin{array}{r}39.2 \\
2.6 \\
27.2 \\
31.7 \\
36.1\end{array}$ & $\begin{array}{l}31.4 \\
35.9 \\
38.3 \\
42.7 \\
36.1\end{array}$ & $\begin{array}{r}19.6 \\
25.6 \\
18.5 \\
13.4 \\
4.8\end{array}$ & $\begin{array}{r}2.0 \\
25.6 \\
8.6 \\
3.7 \\
0.0\end{array}$ \\
\hline Urine smell & $\begin{array}{l}\text { T-shaped } \\
\text { Washable } \\
\text { Diaper } \\
\text { Insert } \\
\text { Pull-up }\end{array}$ & $\begin{array}{r}13.7 \\
7.7 \\
7.5 \\
9.8 \\
25.0\end{array}$ & $\begin{array}{r}31.4 \\
7.7 \\
38.8 \\
35.4 \\
42.9\end{array}$ & $\begin{array}{l}39.2 \\
30.8 \\
30.0 \\
40.2 \\
23.8\end{array}$ & $\begin{array}{r}13.7 \\
33.3 \\
16.3 \\
13.4 \\
8.3\end{array}$ & $\begin{array}{r}2.0 \\
20.5 \\
7.5 \\
1.2 \\
0.0\end{array}$ \\
\hline
\end{tabular}




\begin{tabular}{|c|c|c|c|c|c|c|}
\hline & & Very good & Good & OK & Poor & Very poor \\
\hline Skin dry & $\begin{array}{l}\text { T-shaped } \\
\text { Washable } \\
\text { Diaper } \\
\text { Insert } \\
\text { Pull-up }\end{array}$ & $\begin{array}{r}10.0 \\
10.5 \\
8.9 \\
11.3 \\
31.7\end{array}$ & $\begin{array}{l}36.0 \\
13.2 \\
32.9 \\
32.5 \\
35.4\end{array}$ & $\begin{array}{l}38.0 \\
10.5 \\
29.1 \\
38.8 \\
25.6\end{array}$ & $\begin{array}{r}16.0 \\
44.7 \\
16.5 \\
15.0 \\
7.3\end{array}$ & $\begin{array}{r}0.0 \\
21.1 \\
12.7 \\
2.5 \\
0.0\end{array}$ \\
\hline Ease off & $\begin{array}{l}\text { T-shaped } \\
\text { Washable } \\
\text { Diaper } \\
\text { Insert } \\
\text { Pull-up }\end{array}$ & $\begin{array}{l}20.0 \\
13.5 \\
15.2 \\
29.1 \\
47.6\end{array}$ & $\begin{array}{l}40.0 \\
16.2 \\
31.6 \\
39.2 \\
25.6\end{array}$ & $\begin{array}{l}32.0 \\
13.5 \\
31.6 \\
27.8 \\
23.2\end{array}$ & $\begin{array}{r}8.0 \\
29.7 \\
16.5 \\
3.8 \\
2.4\end{array}$ & $\begin{array}{r}0.0 \\
27.0 \\
5.1 \\
0.0 \\
1.2\end{array}$ \\
\hline $\begin{array}{l}\text { Men: day } \\
\text { Ease on }\end{array}$ & $\begin{array}{l}\text { T-shaped } \\
\text { Washable } \\
\text { Diaper } \\
\text { Insert } \\
\text { Pull-up }\end{array}$ & $\begin{array}{r}33.3 \\
7.7 \\
9.6 \\
7.6 \\
38.0\end{array}$ & $\begin{array}{l}34.5 \\
15.4 \\
39.2 \\
33.6 \\
41.3\end{array}$ & $\begin{array}{r}20.2 \\
47.4 \\
44.0 \\
45.4 \\
9.1\end{array}$ & $\begin{array}{r}11.9 \\
17.9 \\
7.2 \\
13.4 \\
9.9\end{array}$ & $\begin{array}{r}0.0 \\
11.5 \\
0.0 \\
0.0 \\
1.7\end{array}$ \\
\hline Fit & $\begin{array}{l}\text { T-shaped } \\
\text { Washable } \\
\text { Diaper } \\
\text { Insert } \\
\text { Pull-up }\end{array}$ & $\begin{array}{r}26.2 \\
14.1 \\
20.0 \\
5.0 \\
28.9\end{array}$ & $\begin{array}{l}38.1 \\
42.3 \\
31.2 \\
21.0 \\
38.0\end{array}$ & $\begin{array}{l}25.0 \\
23.1 \\
32.8 \\
40.3 \\
22.3\end{array}$ & $\begin{array}{l}10.7 \\
14.1 \\
16.0 \\
26.9 \\
10.7\end{array}$ & $\begin{array}{l}0.0 \\
6.4 \\
0.0 \\
6.7 \\
0.0\end{array}$ \\
\hline Comfort dry & $\begin{array}{l}\text { T-shaped } \\
\text { Washable } \\
\text { Diaper } \\
\text { Insert } \\
\text { Pull-up }\end{array}$ & $\begin{array}{l}28.6 \\
29.1 \\
23.4 \\
10.2 \\
35.8\end{array}$ & $\begin{array}{l}44.0 \\
41.8 \\
44.4 \\
39.0 \\
45.0\end{array}$ & $\begin{array}{l}21.4 \\
21.5 \\
30.6 \\
35.6 \\
19.2\end{array}$ & $\begin{array}{r}4.8 \\
5.1 \\
1.6 \\
12.7 \\
0.0\end{array}$ & $\begin{array}{l}1.2 \\
2.5 \\
0.0 \\
2.5 \\
0.0\end{array}$ \\
\hline In place & $\begin{array}{l}\text { T-shaped } \\
\text { Washable } \\
\text { Diaper } \\
\text { Insert } \\
\text { Pull-up }\end{array}$ & $\begin{array}{r}31.0 \\
15.2 \\
20.8 \\
3.4 \\
33.9\end{array}$ & $\begin{array}{l}29.8 \\
40.5 \\
36.8 \\
21.0 \\
32.2\end{array}$ & $\begin{array}{l}26.2 \\
26.6 \\
32.0 \\
35.3 \\
22.3\end{array}$ & $\begin{array}{l}11.9 \\
13.9 \\
10.4 \\
26.9 \\
10.7\end{array}$ & $\begin{array}{r}1.2 \\
3.8 \\
0.0 \\
13.4 \\
0.8\end{array}$ \\
\hline Discreet & $\begin{array}{l}\text { T-shaped } \\
\text { Washable } \\
\text { Diaper } \\
\text { Insert } \\
\text { Pull-up }\end{array}$ & $\begin{array}{r}25.0 \\
2.6 \\
20.8 \\
10.9 \\
28.3\end{array}$ & $\begin{array}{r}36.9 \\
5.2 \\
36.8 \\
37.8 \\
47.5\end{array}$ & $\begin{array}{l}31.0 \\
22.1 \\
35.2 \\
47.1 \\
23.3\end{array}$ & $\begin{array}{r}7.1 \\
41.6 \\
7.2 \\
3.4 \\
0.8\end{array}$ & $\begin{array}{r}0.0 \\
28.6 \\
0.0 \\
0.8 \\
0.0\end{array}$ \\
\hline Urine & $\begin{array}{l}\text { T-shaped } \\
\text { Washable } \\
\text { Diaper } \\
\text { Insert } \\
\text { Pull-up }\end{array}$ & $\begin{array}{r}31.0 \\
29.9 \\
19.4 \\
4.4 \\
14.5\end{array}$ & $\begin{array}{l}36.9 \\
40.3 \\
22.6 \\
23.7 \\
32.5\end{array}$ & $\begin{array}{l}19.0 \\
15.6 \\
34.7 \\
32.5 \\
25.6\end{array}$ & $\begin{array}{l}11.9 \\
10.4 \\
16.1 \\
24.6 \\
20.5\end{array}$ & $\begin{array}{r}1.2 \\
3.9 \\
7.3 \\
14.9 \\
6.8\end{array}$ \\
\hline Faeces & $\begin{array}{l}\text { T-shaped } \\
\text { Washable } \\
\text { Diaper } \\
\text { Insert } \\
\text { Pull-up }\end{array}$ & $\begin{array}{r}19.0 \\
37.5 \\
24.1 \\
0.0 \\
13.6\end{array}$ & $\begin{array}{l}47.6 \\
31.3 \\
44.8 \\
23.8 \\
45.5\end{array}$ & $\begin{array}{r}23.8 \\
6.3 \\
27.6 \\
61.9 \\
27.3\end{array}$ & $\begin{array}{r}9.5 \\
6.3 \\
0.0 \\
14.3 \\
13.6\end{array}$ & $\begin{array}{r}0.0 \\
18.8 \\
3.4 \\
0.0 \\
0.0\end{array}$ \\
\hline Comfort wet & $\begin{array}{l}\text { T-shaped } \\
\text { Washable } \\
\text { Diaper } \\
\text { Insert } \\
\text { Pull-up }\end{array}$ & $\begin{array}{r}18.1 \\
7.9 \\
6.4 \\
6.8 \\
10.2\end{array}$ & $\begin{array}{l}38.6 \\
17.1 \\
26.4 \\
25.6 \\
33.9\end{array}$ & $\begin{array}{l}31.3 \\
53.9 \\
48.0 \\
37.6 \\
41.5\end{array}$ & $\begin{array}{r}12.0 \\
7.9 \\
14.4 \\
18.8 \\
13.6\end{array}$ & $\begin{array}{r}0.0 \\
13.2 \\
4.8 \\
11.1 \\
0.8\end{array}$ \\
\hline Urine smell & $\begin{array}{l}\text { T-shaped } \\
\text { Washable } \\
\text { Diaper } \\
\text { Insert } \\
\text { Pull-up }\end{array}$ & $\begin{array}{r}15.7 \\
5.3 \\
8.8 \\
6.8 \\
9.2\end{array}$ & $\begin{array}{l}33.7 \\
35.5 \\
32.8 \\
28.2 \\
33.6\end{array}$ & $\begin{array}{l}48.2 \\
42.1 \\
53.6 \\
39.3 \\
43.7\end{array}$ & $\begin{array}{r}2.4 \\
10.5 \\
4.0 \\
22.2 \\
11.8\end{array}$ & $\begin{array}{l}0.0 \\
6.6 \\
0.8 \\
3.4 \\
1.7\end{array}$ \\
\hline
\end{tabular}




\begin{tabular}{|c|c|c|c|c|c|c|}
\hline & & Very good & Good & OK & Poor & Very poor \\
\hline Skin dry & $\begin{array}{l}\text { T-shaped } \\
\text { Washable } \\
\text { Diaper } \\
\text { Insert } \\
\text { Pull-up }\end{array}$ & $\begin{array}{r}17.5 \\
5.5 \\
5.8 \\
8.8 \\
12.1\end{array}$ & $\begin{array}{l}40.0 \\
23.3 \\
28.9 \\
29.2 \\
38.8\end{array}$ & $\begin{array}{l}36.3 \\
46.6 \\
44.6 \\
36.3 \\
42.2\end{array}$ & $\begin{array}{r}6.3 \\
13.7 \\
18.2 \\
23.9 \\
6.0\end{array}$ & $\begin{array}{r}0.0 \\
11.0 \\
2.5 \\
1.8 \\
0.9\end{array}$ \\
\hline Ease off & $\begin{array}{l}\text { T-shaped } \\
\text { Washable } \\
\text { Diaper } \\
\text { Insert } \\
\text { Pull-up }\end{array}$ & $\begin{array}{l}43.2 \\
14.3 \\
17.2 \\
13.9 \\
41.5\end{array}$ & $\begin{array}{l}39.5 \\
40.3 \\
42.6 \\
46.1 \\
39.0\end{array}$ & $\begin{array}{l}14.8 \\
31.2 \\
37.7 \\
38.3 \\
17.8\end{array}$ & $\begin{array}{l}2.5 \\
9.1 \\
2.5 \\
1.7 \\
1.7\end{array}$ & $\begin{array}{l}0.0 \\
5.2 \\
0.0 \\
0.0 \\
0.0\end{array}$ \\
\hline $\begin{array}{l}\text { Men: night } \\
\text { Ease on }\end{array}$ & $\begin{array}{l}\text { T-shaped } \\
\text { Washable } \\
\text { Diaper } \\
\text { Insert } \\
\text { Pull-up }\end{array}$ & $\begin{array}{r}31.6 \\
10.0 \\
8.8 \\
7.8 \\
50.4\end{array}$ & $\begin{array}{l}29.1 \\
25.7 \\
43.0 \\
37.9 \\
39.3\end{array}$ & $\begin{array}{r}27.8 \\
47.1 \\
45.6 \\
40.5 \\
6.8\end{array}$ & $\begin{array}{r}11.4 \\
11.4 \\
2.6 \\
13.8 \\
3.4\end{array}$ & $\begin{array}{l}0.0 \\
5.7 \\
0.0 \\
0.0 \\
0.0\end{array}$ \\
\hline Fit & $\begin{array}{l}\text { T-shaped } \\
\text { Washable } \\
\text { Diaper } \\
\text { Insert } \\
\text { Pull-up }\end{array}$ & $\begin{array}{l}22.8 \\
17.1 \\
13.2 \\
11.2 \\
22.4\end{array}$ & $\begin{array}{l}19.0 \\
40.0 \\
39.5 \\
28.4 \\
43.1\end{array}$ & $\begin{array}{l}45.6 \\
31.4 \\
32.5 \\
28.4 \\
26.7\end{array}$ & $\begin{array}{r}11.4 \\
10.0 \\
14.0 \\
26.7 \\
6.9\end{array}$ & $\begin{array}{l}1.3 \\
1.4 \\
0.9 \\
5.2 \\
0.9\end{array}$ \\
\hline Comfort dry & $\begin{array}{l}\text { T-shaped } \\
\text { Washable } \\
\text { Diaper } \\
\text { Insert } \\
\text { Pull-up }\end{array}$ & $\begin{array}{l}22.8 \\
32.4 \\
15.8 \\
18.1 \\
34.2\end{array}$ & $\begin{array}{l}40.5 \\
47.9 \\
48.2 \\
37.1 \\
46.2\end{array}$ & $\begin{array}{l}34.2 \\
15.5 \\
35.1 \\
36.2 \\
18.8\end{array}$ & $\begin{array}{l}2.5 \\
2.8 \\
0.9 \\
6.0 \\
0.9\end{array}$ & $\begin{array}{l}0.0 \\
1.4 \\
0.0 \\
2.6 \\
0.0\end{array}$ \\
\hline In place & $\begin{array}{l}\text { T-shaped } \\
\text { Washable } \\
\text { Diaper } \\
\text { Insert } \\
\text { Pull-up }\end{array}$ & $\begin{array}{r}21.8 \\
23.9 \\
15.7 \\
7.8 \\
25.0\end{array}$ & $\begin{array}{l}25.6 \\
43.7 \\
47.0 \\
27.6 \\
40.5\end{array}$ & $\begin{array}{l}37.2 \\
22.5 \\
27.8 \\
23.3 \\
20.7\end{array}$ & $\begin{array}{r}11.5 \\
7.0 \\
8.7 \\
27.6 \\
11.2\end{array}$ & $\begin{array}{r}3.8 \\
2.8 \\
0.9 \\
13.8 \\
2.6\end{array}$ \\
\hline Discreet & $\begin{array}{l}\text { T-shaped } \\
\text { Washable } \\
\text { Diaper } \\
\text { Insert } \\
\text { Pull-up }\end{array}$ & $\begin{array}{r}20.3 \\
2.9 \\
14.9 \\
10.3 \\
22.2\end{array}$ & $\begin{array}{l}34.2 \\
10.1 \\
45.6 \\
42.2 \\
49.6\end{array}$ & $\begin{array}{l}40.5 \\
34.8 \\
33.3 \\
40.5 \\
28.2\end{array}$ & $\begin{array}{r}5.1 \\
34.8 \\
6.1 \\
6.9 \\
0.0\end{array}$ & $\begin{array}{r}0.0 \\
17.4 \\
0.0 \\
0.0 \\
0.0\end{array}$ \\
\hline Urine & $\begin{array}{l}\text { T-shaped } \\
\text { Washable } \\
\text { Diaper } \\
\text { Insert } \\
\text { Pull-up }\end{array}$ & $\begin{array}{r}19.2 \\
42.3 \\
8.7 \\
6.3 \\
15.5\end{array}$ & $\begin{array}{l}21.8 \\
38.0 \\
29.6 \\
18.8 \\
23.3\end{array}$ & $\begin{array}{l}28.2 \\
16.9 \\
34.8 \\
25.0 \\
24.1\end{array}$ & $\begin{array}{r}19.2 \\
1.4 \\
19.1 \\
20.5 \\
20.7\end{array}$ & $\begin{array}{r}11.5 \\
1.4 \\
7.8 \\
29.5 \\
16.4\end{array}$ \\
\hline Faeces & $\begin{array}{l}\text { T-shaped } \\
\text { Washable } \\
\text { Diaper } \\
\text { Insert } \\
\text { Pull-up }\end{array}$ & $\begin{array}{l}14.3 \\
16.7 \\
19.2 \\
13.0 \\
26.1\end{array}$ & $\begin{array}{l}42.9 \\
66.7 \\
57.7 \\
30.4 \\
47.8\end{array}$ & $\begin{array}{l}42.9 \\
16.7 \\
15.4 \\
30.4 \\
21.7\end{array}$ & $\begin{array}{r}0.0 \\
0.0 \\
7.7 \\
13.0 \\
4.3\end{array}$ & $\begin{array}{r}0.0 \\
0.0 \\
0.0 \\
13.0 \\
0.0\end{array}$ \\
\hline Comfort wet & $\begin{array}{l}\text { T-shaped } \\
\text { Washable } \\
\text { Diaper } \\
\text { Insert } \\
\text { Pull-up }\end{array}$ & $\begin{array}{r}12.7 \\
14.1 \\
6.1 \\
2.7 \\
12.0\end{array}$ & $\begin{array}{l}27.8 \\
23.9 \\
31.3 \\
30.1 \\
33.3\end{array}$ & $\begin{array}{l}45.6 \\
45.1 \\
41.7 \\
41.6 \\
36.8\end{array}$ & $\begin{array}{l}11.4 \\
11.3 \\
14.8 \\
14.2 \\
15.4\end{array}$ & $\begin{array}{r}2.5 \\
5.6 \\
6.1 \\
11.5 \\
2.6\end{array}$ \\
\hline Urine smell & $\begin{array}{l}\text { T-shaped } \\
\text { Washable } \\
\text { Diaper } \\
\text { Insert } \\
\text { Pull-up }\end{array}$ & $\begin{array}{r}11.5 \\
8.6 \\
8.8 \\
5.3 \\
12.3\end{array}$ & $\begin{array}{l}21.8 \\
35.7 \\
23.9 \\
30.1 \\
26.3\end{array}$ & $\begin{array}{l}56.4 \\
40.0 \\
47.8 \\
38.9 \\
47.4\end{array}$ & $\begin{array}{l}10.3 \\
11.4 \\
18.6 \\
22.1 \\
13.2\end{array}$ & $\begin{array}{l}0.0 \\
4.3 \\
0.9 \\
3.5 \\
0.9\end{array}$ \\
\hline
\end{tabular}




\begin{tabular}{|c|c|c|c|c|c|c|}
\hline & & Very good & Good & OK & Poor & Very poor \\
\hline Skin dry & $\begin{array}{l}\text { T-shaped } \\
\text { Washable } \\
\text { Diaper } \\
\text { Insert } \\
\text { Pull-up }\end{array}$ & $\begin{array}{r}10.7 \\
6.1 \\
4.5 \\
6.5 \\
17.7\end{array}$ & $\begin{array}{l}26.7 \\
25.8 \\
34.8 \\
25.9 \\
31.9\end{array}$ & $\begin{array}{l}49.3 \\
40.9 \\
36.6 \\
41.7 \\
38.9\end{array}$ & $\begin{array}{r}12.0 \\
19.7 \\
20.5 \\
22.2 \\
8.8\end{array}$ & $\begin{array}{l}1.3 \\
7.6 \\
3.6 \\
3.7 \\
2.7\end{array}$ \\
\hline Ease off & $\begin{array}{l}\text { T-shaped } \\
\text { Washable } \\
\text { Diaper } \\
\text { Insert } \\
\text { Pull-up }\end{array}$ & $\begin{array}{l}33.3 \\
19.7 \\
12.6 \\
18.8 \\
40.2\end{array}$ & $\begin{array}{l}34.7 \\
36.4 \\
40.5 \\
52.7 \\
45.5\end{array}$ & $\begin{array}{l}32.0 \\
36.4 \\
41.4 \\
27.7 \\
12.5\end{array}$ & $\begin{array}{l}0.0 \\
6.1 \\
5.4 \\
0.9 \\
1.8\end{array}$ & $\begin{array}{l}0.0 \\
1.5 \\
0.0 \\
0.0 \\
0.0\end{array}$ \\
\hline
\end{tabular}





\section{Appendix I I}

\section{Trial 2a: preference for designs, by gender}

\section{Number preferring design (daytime)}

Men $(N=49)$

Women $(N=36)$

Diaper 4 I vs Insert 8

Pull-up 42 vs Insert 7

Pull-up 16 vs Diaper 33

Pull-up 21 vs T-shaped 28

T-shaped 18 vs Diaper 31

T-shaped 40 vs Insert 9

Diaper II vs Insert 25

Pull-up 27 vs Insert 9

Pull-up 29 vs Diaper 7

Pull-up 29 vs T-shaped 7

T-shaped 15 vs Diaper 21

T-shaped I 3 vs Insert 23

Diaper 4 I vs Washable 8

Diaper 33 vs Washable 3

Number preferring design (night-time)

\begin{tabular}{|ll}
\hline Men $(\mathbf{N}=\mathbf{4 9})$ & Women $(\mathbf{N}=\mathbf{3 6})$ \\
\hline Diaper 39 vs Insert 10 & Diaper 14 vs Insert 22 \\
Pull-up 39 vs Insert 10 & Pull-up 27 vs Insert 9 \\
Pull-up II vs Diaper 38 & Pull-up 29 vs Diaper 7 \\
Pull-up 20 vs T-shaped 29 & Pull-up 30 vs T-shaped 6 \\
T-shaped I 3 vs Diaper 36 & T-shaped I4 vs Diaper 22 \\
T-shaped 39 vs Insert 10 & T-shaped I7 vs Insert 19 \\
Diaper 20 vs Washable 29 & Diaper 29 vs Washable 7
\end{tabular}





\section{Appendix 12}

\section{Trial 2a: acceptability of designs for day and night, by gender}

\begin{tabular}{|c|c|c|c|c|c|c|c|c|c|c|}
\hline \multirow{3}{*}{$\begin{array}{l}N=85 \\
\text { Men = 49 } \\
\text { Women = 36 }\end{array}$} & \multicolumn{10}{|c|}{$\%(N)$} \\
\hline & \multicolumn{2}{|c|}{ Insert } & \multicolumn{2}{|c|}{ Diaper } & \multicolumn{2}{|c|}{ Pull-up } & \multicolumn{2}{|c|}{ T-shaped } & \multicolumn{2}{|c|}{ Washable } \\
\hline & Day & Night & Day & Night & Day & Night & Day & Night & Day & Night \\
\hline $\begin{array}{l}\text { Highly } \\
\text { acceptable }\end{array}$ & $\begin{array}{l}20.0 \\
(17)\end{array}$ & $\begin{array}{l}11.8 \\
(10)\end{array}$ & $\begin{array}{l}35.3 \\
(30)\end{array}$ & $\begin{array}{l}32.9 \\
(28)\end{array}$ & $\begin{array}{l}41.2 \\
(35)\end{array}$ & $\begin{array}{l}31.8 \\
(27)\end{array}$ & $\begin{array}{l}24.7 \\
(21)\end{array}$ & $\begin{array}{l}15.3 \\
(13)\end{array}$ & $\begin{array}{l}4.7 \\
(4)\end{array}$ & $\begin{array}{l}42.4 \\
(36)\end{array}$ \\
\hline Men & $\begin{array}{l}6.0 \\
(3)\end{array}$ & $\begin{array}{l}2.0 \\
(1)\end{array}$ & $\begin{array}{l}46.9 \\
(23)\end{array}$ & $\begin{array}{l}46.9 \\
(23)\end{array}$ & $\begin{array}{l}24.5 \\
(12)\end{array}$ & $\begin{array}{l}12.2 \\
(6)\end{array}$ & $\begin{array}{l}30.6 \\
(15)\end{array}$ & $\begin{array}{l}20.4 \\
(10)\end{array}$ & $\begin{array}{l}6.1 \\
(3)\end{array}$ & $\begin{array}{l}63.3 \\
(3 I)\end{array}$ \\
\hline Women & $\begin{array}{l}38.9 \\
(14)\end{array}$ & $\begin{array}{c}25.0 \\
(9)\end{array}$ & $\begin{array}{l}19.4 \\
(7)\end{array}$ & $\begin{array}{l}13.9 \\
(5)\end{array}$ & $\begin{array}{l}63.9 \\
(23)\end{array}$ & $\begin{array}{l}58.3 \\
(2 I)\end{array}$ & $\begin{array}{l}16.7 \\
(6)\end{array}$ & $\begin{array}{l}8.3 \\
(3)\end{array}$ & $\begin{array}{l}2.8 \\
(1)\end{array}$ & $\begin{array}{l}13.9 \\
(5)\end{array}$ \\
\hline Acceptable & $\begin{array}{l}36.5 \\
(31)\end{array}$ & $\begin{array}{l}29.4 \\
(25)\end{array}$ & $\begin{array}{l}37.7 \\
(32)\end{array}$ & $\begin{array}{l}43.5 \\
(37)\end{array}$ & $\begin{array}{l}44.7 \\
(38)\end{array}$ & $\begin{array}{l}35.3 \\
(30)\end{array}$ & $\begin{array}{l}41.2 \\
(35)\end{array}$ & $\begin{array}{l}42.4 \\
(36)\end{array}$ & $\begin{array}{l}29.4 \\
(25)\end{array}$ & $\begin{array}{l}15.3 \\
(13)\end{array}$ \\
\hline Men & $\begin{array}{l}30.6 \\
(15)\end{array}$ & $\begin{array}{l}20.4 \\
(10)\end{array}$ & $\begin{array}{l}38.8 \\
(19)\end{array}$ & $\begin{array}{l}38.8 \\
(19)\end{array}$ & $\begin{array}{l}55.1 \\
(27)\end{array}$ & $\begin{array}{l}36.7 \\
(18)\end{array}$ & $\begin{array}{l}53.1 \\
(26)\end{array}$ & $\begin{array}{l}40.8 \\
(20)\end{array}$ & $\begin{array}{l}44.9 \\
(22)\end{array}$ & $\begin{array}{c}18.4 \\
(9)\end{array}$ \\
\hline Women & $\begin{array}{l}44.4 \\
(16)\end{array}$ & $\begin{array}{l}41.7 \\
(15)\end{array}$ & $\begin{array}{l}36.1 \\
(13)\end{array}$ & $\begin{array}{l}50.0 \\
(18)\end{array}$ & $\begin{array}{l}30.6 \\
(11)\end{array}$ & $\begin{array}{l}33.3 \\
(12)\end{array}$ & $\begin{array}{l}25.0 \\
(9)\end{array}$ & $\begin{array}{l}44.4 \\
(16)\end{array}$ & $\begin{array}{l}8.3 \\
(3)\end{array}$ & $\begin{array}{l}11.1 \\
(4)\end{array}$ \\
\hline $\begin{array}{l}\text { Unacceptable/ } \\
\text { totally unacceptable }\end{array}$ & $\begin{array}{l}43.5 \\
(37)\end{array}$ & $\begin{array}{l}58.8 \\
(50)\end{array}$ & $\begin{array}{l}27.0 \\
(23)\end{array}$ & $\begin{array}{l}23.6 \\
(20)\end{array}$ & $\begin{array}{l}14.0 \\
(12)\end{array}$ & $\begin{array}{l}32.9 \\
(28)\end{array}$ & $\begin{array}{l}34.0 \\
(29)\end{array}$ & $\begin{array}{l}42.3 \\
(36)\end{array}$ & $\begin{array}{l}65.9 \\
(56)\end{array}$ & $\begin{array}{l}42.3 \\
(36)\end{array}$ \\
\hline Men & $\begin{array}{l}63.3 \\
(31)\end{array}$ & $\begin{array}{l}77.6 \\
(38)\end{array}$ & $\begin{array}{l}14.3 \\
(7)\end{array}$ & $\begin{array}{l}14.3 \\
(7)\end{array}$ & $\begin{array}{l}20.4 \\
(10)\end{array}$ & $\begin{array}{l}51.0 \\
(25)\end{array}$ & $\begin{array}{l}16.3 \\
(8)\end{array}$ & $\begin{array}{c}38.8 \\
(19)\end{array}$ & $\begin{array}{l}49.0 \\
(24)\end{array}$ & $\begin{array}{c}18.3 \\
(9)\end{array}$ \\
\hline Women & $\begin{array}{c}16.7 \\
(6)\end{array}$ & $\begin{array}{l}33.4 \\
(12)\end{array}$ & $\begin{array}{l}44.5 \\
(16)\end{array}$ & $\begin{array}{l}36.1 \\
(13)\end{array}$ & $\begin{array}{l}5.6 \\
(2)\end{array}$ & $\begin{array}{l}8.4 \\
(3)\end{array}$ & $\begin{array}{l}58.3 \\
(21)\end{array}$ & $\begin{array}{l}47.2 \\
(17)\end{array}$ & $\begin{array}{l}88.8 \\
(32)\end{array}$ & $\begin{array}{c}75.0 \\
(27)\end{array}$ \\
\hline
\end{tabular}





\section{Appendix 13}

\section{Trial 2a: mean VAS scores (SD), by gender}

\begin{tabular}{|c|c|c|c|c|c|}
\hline & Insert & Diaper & Pull-up & T-shaped & Washable \\
\hline \multicolumn{6}{|l|}{ Day } \\
\hline Men and women combined & $48.5(32.1)$ & $66.3(27.3)$ & $72.7(23.9)$ & $60.1(27.6)$ & $33.7(31.0)$ \\
\hline Men & $34.6(31.5)$ & $76.4(23.5)$ & $65.9(25.3)$ & $68.1(24.7)$ & $43.0(31.6)$ \\
\hline Women & $67.5(21.7)$ & $52.6(26.4)$ & $81.8(18.5)$ & $49.3(27.9)$ & $20.9(25.6)$ \\
\hline \multicolumn{6}{|l|}{ Night } \\
\hline Men and women combined & $43.1(32.7)$ & $64.5(26.9)$ & $62.2(29.8)$ & $53.9(26.3)$ & $53.2(40.6)$ \\
\hline Men & $30.3(30.0)$ & $72.4(25.6)$ & $49.9(29.2)$ & $58.4(25.6)$ & $71.4(35.4)$ \\
\hline Women & $60.5(28.1)$ & $53.6(25.1)$ & $78.9(21.5)$ & $47.8(26.5)$ & $28.3(33.8)$ \\
\hline
\end{tabular}





\section{Appendix 14}

\section{Trial 2a: comments by gender}

\begin{tabular}{|c|c|c|c|c|c|c|c|c|}
\hline \multirow[t]{2}{*}{ Design } & \multicolumn{4}{|c|}{ Women $(N=36)$} & \multicolumn{4}{|c|}{ Men $(N=49)$} \\
\hline & Good & $\mathbf{N}$ & Poor & $\mathbf{N}$ & Good & $\mathbf{N}$ & Poor & $\mathbf{N}$ \\
\hline \multicolumn{9}{|l|}{ Day } \\
\hline \multirow[t]{6}{*}{ T-shaped } & Absorbent & 12 & Difficult to put on & 13 & Easy on/off/toilet & 15 & $\begin{array}{l}\text { Problems with } \\
\text { tabs/belt }\end{array}$ & 14 \\
\hline & Easy to use & 5 & $\begin{array}{l}\text { Problems with } \\
\text { tabs/Velcro }\end{array}$ & 10 & Comfortable & 11 & $\begin{array}{l}\text { Not enough } \\
\text { padding at sides }\end{array}$ & 6 \\
\hline & $\begin{array}{l}\text { Reliable/secure } \\
\text { confidence }\end{array}$ & 5 & Leaks & 7 & Easy to change & 11 & Leaks & 5 \\
\hline & & & Uncomfortable & 5 & Absorbent & 7 & $\begin{array}{l}\text { Sag/not secure } \\
\text { when wet }\end{array}$ & 3 \\
\hline & & & Poor fit & 3 & Secure/confidence & 3 & & \\
\hline & & & Bulky & 3 & & & & \\
\hline \multirow[t]{4}{*}{ Washable } & Absorbent/no leaks & 4 & Bulky & 18 & $\begin{array}{l}\text { Absorbency/no } \\
\text { leaks }\end{array}$ & 17 & Bulky & 32 \\
\hline & $\begin{array}{l}\text { Comfortable/ } \\
\text { kind to skin }\end{array}$ & 4 & Difficulty on/off & 14 & $\begin{array}{l}\text { Good for } \\
\text { environment }\end{array}$ & 7 & $\begin{array}{l}\text { Difficulty } \\
\text { changing/on }\end{array}$ & 16 \\
\hline & & & $\begin{array}{l}\text { Problems } \\
\quad \text { laundering }\end{array}$ & 9 & Cost savings & 5 & Laundry & 5 \\
\hline & & & $\begin{array}{l}\text { Poor appearance/ } \\
\text { disgusting/ } \\
\text { child-like }\end{array}$ & 7 & & & & \\
\hline \multirow[t]{6}{*}{ Diaper } & Absorbent/no leaks & 20 & Bulky & 18 & $\begin{array}{l}\text { Absorbency/no } \\
\text { leaks }\end{array}$ & 21 & Can be bulky & 8 \\
\hline & Secure/confident & 4 & $\begin{array}{l}\text { Difficult to put } \\
\text { on/change }\end{array}$ & 7 & $\begin{array}{l}\text { Low/reasonable } \\
\text { leakage }\end{array}$ & 7 & Difficult to put on & 8 \\
\hline & Stayed in place & 3 & $\begin{array}{l}\text { Problems with } \\
\text { tabs not sticking }\end{array}$ & 7 & Easy to change & 11 & Problems with tabs & 7 \\
\hline & & & Sweaty & 3 & & & Sweaty/hot & 5 \\
\hline & & & Leaks & 3 & & & Leaks & 4 \\
\hline & & & Uncomfortable & 3 & & & Uncomfortable & 3 \\
\hline \multirow[t]{5}{*}{ Insert } & $\begin{array}{l}\text { Easy to change/ } \\
\text { put on }\end{array}$ & 17 & Leaks & 15 & $\begin{array}{l}\text { Easy on/change/ } \\
\text { to use }\end{array}$ & 13 & $\begin{array}{l}\text { Does not stay } \\
\text { in place }\end{array}$ & 22 \\
\hline & $\begin{array}{l}\text { Absorbent/ } \\
\text { holds urine/ } \\
\text { no leaks }\end{array}$ & 8 & $\begin{array}{l}\text { Moves/does not } \\
\text { stay in place }\end{array}$ & 11 & Discreet/not bulky & 6 & Leakage & 17 \\
\hline & Discreet & 6 & $\begin{array}{l}\text { Problems with } \\
\text { pants }\end{array}$ & 3 & Absorbent & 4 & $\begin{array}{l}\text { Problems with } \\
\text { pants/having to } \\
\text { wear stretch } \\
\text { pants }\end{array}$ & 7 \\
\hline & Comfortable & 5 & Bulky & 3 & Comfortable & 3 & Not good for men & 4 \\
\hline & & & & & & & Fit/size & 4 \\
\hline
\end{tabular}




\begin{tabular}{|c|c|c|c|c|c|c|c|c|}
\hline \multirow[t]{2}{*}{ Design } & \multicolumn{4}{|c|}{ Women $(N=36)$} & \multicolumn{4}{|c|}{ Men $(N=49)$} \\
\hline & Good & $\mathbf{N}$ & Poor & $\mathbf{N}$ & Good & $\mathbf{N}$ & Poor & $\mathbf{N}$ \\
\hline \multirow[t]{5}{*}{ Pull-up } & Comfortable/soft & 19 & $\begin{array}{l}\text { Difficult to change } \\
\text { when out } \\
\text { (especially } \\
\text { removing } \\
\text { trousers) }\end{array}$ & 15 & Comfortable & 14 & $\begin{array}{l}\text { Difficult to change } \\
\text { when out }\end{array}$ & 19 \\
\hline & $\begin{array}{l}\text { Easy use/on/off/ } \\
\text { change }\end{array}$ & 14 & $\begin{array}{l}\text { Leak/low } \\
\text { absorbency }\end{array}$ & 5 & $\begin{array}{l}\text { Looks like 'normal' } \\
\text { underwear }\end{array}$ & 13 & Leaks & 14 \\
\hline & Absorbent/no leaks & II & & & $\begin{array}{l}\text { Easy to put on/off/ } \\
\text { change }\end{array}$ & 12 & $\begin{array}{l}\text { Not enough } \\
\text { padding/in wrong } \\
\text { place for men }\end{array}$ & 12 \\
\hline & Like normal pants & 13 & & & Discreet/not bulky & 8 & & \\
\hline & Discreet & 7 & & & Stays in place & 5 & & \\
\hline \multicolumn{9}{|l|}{ Night } \\
\hline \multirow[t]{4}{*}{ T-shaped } & Absorbent/no leaks & 12 & Leaks & 12 & $\begin{array}{l}\text { Easy to change/ } \\
\text { put on }\end{array}$ & 15 & $\begin{array}{l}\text { Problems with } \\
\text { tabs/waist-band }\end{array}$ & 14 \\
\hline & Easy to use & 4 & $\begin{array}{l}\text { Problems with } \\
\text { tabs/waist-band }\end{array}$ & 8 & Absorbent & 6 & Leaks & 12 \\
\hline & Secure/confidence & 4 & Difficult to put on & 6 & Comfortable & 5 & No padding at sides & 8 \\
\hline & & & No padding at sides & 4 & & & & \\
\hline \multirow[t]{3}{*}{ Washable } & Absorbent/no leaks & 9 & Difficult to put on & 12 & $\begin{array}{l}\text { Absorbency/no } \\
\text { leaks }\end{array}$ & 24 & Bulky & 12 \\
\hline & Comfortable/soft & 6 & Laundry & 10 & Comfortable & 18 & Laundry & 12 \\
\hline & & & $\begin{array}{l}\text { Baby-like/won't } \\
\text { wear nappy/ } \\
\text { disliked } \\
\text { appearance }\end{array}$ & 5 & $\begin{array}{l}\text { Slept through } \\
\text { night/good sleep }\end{array}$ & 6 & Difficult to put on & 9 \\
\hline \multirow[t]{5}{*}{ Diaper } & Absorbent/no leaks & 14 & $\begin{array}{l}\text { Difficult to put } \\
\text { on/change }\end{array}$ & 8 & Absorbent/no leaks & 15 & $\begin{array}{l}\text { Difficult to put } \\
\text { on/go to toilet }\end{array}$ & 7 \\
\hline & $\begin{array}{l}\text { Easy to use/on/off/ } \\
\text { change }\end{array}$ & 4 & Leak & 6 & Stays in place & 9 & Leak & 6 \\
\hline & & & Problems with tabs & 5 & Fit & 7 & Problems with tabs & 6 \\
\hline & & & Too big/bulky & 5 & Comfortable & 5 & Sweaty/hot/clammy & 6 \\
\hline & & & & & & & No side padding & 3 \\
\hline \multirow[t]{3}{*}{ Insert } & $\begin{array}{l}\text { Easy/quick to } \\
\text { change }\end{array}$ & 9 & Leak/not absorbent & 17 & Easy on/off/change & 10 & Leak & 23 \\
\hline & Discreet/not bulky & 5 & $\begin{array}{l}\text { Does not stay in } \\
\text { place }\end{array}$ & 10 & Discreet/not bulky & 4 & $\begin{array}{l}\text { Does not stay in } \\
\text { place }\end{array}$ & 18 \\
\hline & Comfortable & 4 & & & Comfortable & 3 & No padding at sides & 3 \\
\hline \multirow[t]{5}{*}{ Pull-up } & $\begin{array}{l}\text { Ease on/off/ } \\
\text { change/use toilet }\end{array}$ & 15 & Leak & 12 & Comfortable & 13 & $\begin{array}{l}\text { Leak/not absorbent } \\
\text { enough }\end{array}$ & 26 \\
\hline & Comfortable/soft & 14 & $\begin{array}{l}\text { Difficult on/off/ } \\
\text { change }\end{array}$ & 5 & Easy on/off/change & $\mathrm{II}$ & $\begin{array}{l}\text { Padding in wrong } \\
\text { place }\end{array}$ & 8 \\
\hline & $\begin{array}{l}\text { Looks good/like } \\
\text { underwear/ } \\
\text { feminine }\end{array}$ & 10 & & & Discreet & 5 & Difficult changing & 5 \\
\hline & Stays in place & 6 & & & $\begin{array}{l}\text { Looked good/ } \\
\text { 'normal' }\end{array}$ & 4 & & \\
\hline & Absorbent & 5 & & & Stayed in place & 4 & & \\
\hline
\end{tabular}




\section{Appendix 15}

\section{Trial 2b: consenting procedure for nursing home residents}

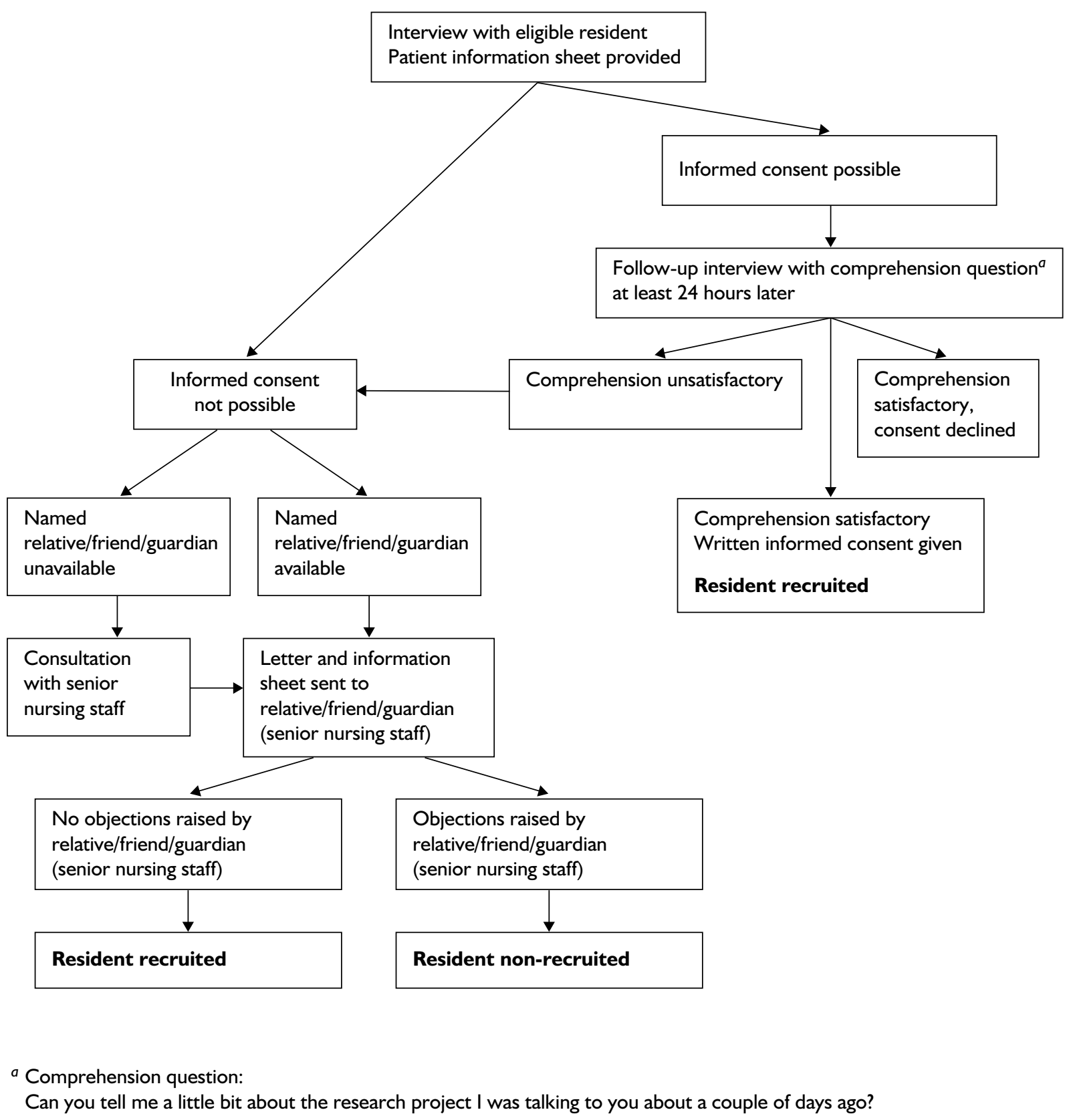


Resident initials:

\section{Resident consenting procedure}

1. Staff have identified resident as appropriate and asked permission for researcher to discuss the study with them

2. Resident does not meet inclusion/exclusion criteria

NOT RECRUITED

3. Resident interviewed, study discussed and resident information sheet given

4. (a) Resident apparently able to give informed consent and interested in taking part

(b) Resident apparently able to give informed consent but not interested in taking part

(c) Resident unable to give informed consent (go to point 7)

5. Follow-up interview carried out

6. (a) Resident recalls study and gives informed consent

RECRUITED

(b) Resident recalls study and does not consent

NOT RECRUITED

(c) Resident does not recall study and re-consents

RECRUITED

(d) Resident does not recall study and consent doubtful

7. Discuss resident with nursing home staff regarding possible participation in the study and resident's likely responses

8. Problems raised by staff

NOT RECRUITED

9. Letter sent to relative/friend/guardian OR

No relative/friend or guardian

10. (a) Relative/friend/guardian suggests inclusion

RECRUITED

(b) Relative/friend/guardian suggests exclusion

NOT RECRUITED

(c) Relative/friend/guardian requests further discussion

Further discussion with relative/friend/guardian

RECRUITED

NOT RECRUITED

If no relative/friend or guardian then staff views will be carefully considered before deciding whether resident should be included 


\section{Appendix 16}

\section{Trial 2b: resident first-choice preference}

\begin{tabular}{|c|c|c|c|c|}
\hline \multirow[t]{2}{*}{$N=14$} & \multicolumn{4}{|c|}{$\%(N)$} \\
\hline & Disposable insert & Disposable diaper & Disposable pull-up & $\begin{array}{c}\text { Disposable } \\
\text { T-shaped }\end{array}$ \\
\hline First-choice preference & 3 & 1 & 6 & 4 \\
\hline
\end{tabular}





\section{Appendix 17}

\section{Trial 2b: mean VAS scores (SD), by gender}

\begin{tabular}{|lcccc|}
\hline & Insert & Diaper & Pull-up & T-shaped \\
\hline Day & & & & \\
Men $(N=27)$ & $4.6(3.1)$ & $6.2(3.4)$ & $5.9 .(2.7)$ & $4.7(3.0)$ \\
Women $(N=72)$ & $5.1(2.9)$ & $4.8(2.4)$ & $7.1(3.0)$ & $4.9(3.0)$ \\
$(I$ missing data) & & & & \\
Night & & & & \\
Men $(N=27)$ & $3.7(2.8)$ & $7.7(2.6)$ & $5.7(2.0)$ & $6.3(3.1)$ \\
Women $(N=7 I)$ & $4.5(2.4)$ & $6.2(2.8)$ & $6.4(2.7)$ & $6.3(2.4)$ \\
$(2$ missing data) & & & & \\
\hline
\end{tabular}





\section{Appendix 18}

\section{Trial 2b: paired comparisons of preferences between the different designs, by gender}

\begin{tabular}{|ll|}
\hline & Number preferring design (daytime) \\
\hline Men $(\mathbf{N}=\mathbf{2 7})$ & Women $(\mathbf{N}=\mathbf{7 2}$, I missing data) \\
\hline Pull-up 14 vs Insert I3 & Pull-up 5I vs Insert 21 \\
Pull-up II vs Diaper 16 10 & Pull-up 55 vs Diaper I7 \\
Pull-up I7 vs T-shaped 10 & Pull-up 49 vs T-shaped 23 \\
T-shaped I6 vs Insert II & T-shaped 33 vs Insert 39 \\
T-shaped 9 vs Diaper 18 & T-shaped 39 vs Diaper 33 \\
Diaper 19 vs Insert 8 & Diaper 33 vs Insert 39 \\
\hline
\end{tabular}

\begin{tabular}{|ll|}
\hline \multicolumn{1}{|c|}{} & Number preferring design (night-time) \\
\hline Men $(\mathbf{N}=\mathbf{2 7})$ & Women $(\mathbf{N}=\mathbf{7 1}, \mathbf{2}$ missing data) \\
\hline Pull-up 20 vs Insert 7 & Pull-up 52 vs Insert 19 \\
Pull-up 6 vs Diaper 21 & Pull-up 34 vs Diaper 37 \\
Pull-up 10 vs T-shaped 17 & Pull-up 37 vs T-shaped 34 \\
T-shaped 20 vs Insert 7 & T-shaped 48 vs Insert 23 \\
T-shaped 7 vs Diaper 20 & T-shaped 34 vs Diaper 37 \\
Diaper 23 vs Insert 4 & Diaper 50 vs Insert 21 \\
\hline
\end{tabular}





\section{Appendix 19}

\section{Trial 2b: comments from carers by resident gender}

\section{Day products}

Carers could make as many comments as they wished. Comments are included if made by at least three carers.

\begin{tabular}{|c|c|c|c|c|c|c|c|c|}
\hline \multirow[t]{2}{*}{ Design } & \multicolumn{4}{|c|}{ Women $(N=72)$} & \multicolumn{4}{|c|}{ Men $(N=27)$} \\
\hline & Good & $\mathbf{N}$ & Poor & $\mathbf{N}$ & Good & $\mathbf{N}$ & Poor & $N$ \\
\hline \multirow[t]{4}{*}{ Insert } & Easy on/off/change & 33 & $\begin{array}{l}\text { Not absorbent/ } \\
\text { leaks }\end{array}$ & 29 & Easy on/off/change & 12 & $\begin{array}{l}\text { Not absorbent/ } \\
\text { leaks }\end{array}$ & 10 \\
\hline & Good fit/size & 9 & Moved around & 14 & Absorbent & 3 & Moved around & 7 \\
\hline & $\begin{array}{l}\text { Absorbent/holds } \\
\text { urine }\end{array}$ & 7 & Poor size/fit & 9 & & & Too small & 3 \\
\hline & Liked net pants & 3 & $\begin{array}{l}\text { Did not like/ } \\
\text { problems with } \\
\text { net pants }\end{array}$ & 7 & & & $\begin{array}{l}\text { Can be removed } \\
\text { by resident }\end{array}$ & 4 \\
\hline \multirow[t]{6}{*}{ Diaper } & $\begin{array}{l}\text { Absorbent/holds } \\
\text { urine }\end{array}$ & 17 & $\begin{array}{l}\text { Difficult to put on/ } \\
\text { change }\end{array}$ & 13 & $\begin{array}{l}\text { Absorbent/holds } \\
\text { urine }\end{array}$ & 7 & $\begin{array}{l}\text { Not absorbent/ } \\
\text { leaks }\end{array}$ & 8 \\
\hline & Good fit/size & 10 & Too big and bulky & 13 & Good fit & 4 & & \\
\hline & Easy on/off/change & 6 & $\begin{array}{l}\text { Too much plastic/ } \\
\text { causes sweating }\end{array}$ & 12 & Comfortable/soft & 3 & & \\
\hline & Stays in place & 5 & Poor fit/size & 10 & Easy on/off & 3 & & \\
\hline & & & $\begin{array}{l}\text { Not absorbent/ } \\
\text { leaks }\end{array}$ & 4 & Stays in place & 3 & & \\
\hline & & & Problems with tabs & 4 & Difficult to remove & 3 & & \\
\hline \multirow[t]{6}{*}{ Pull-up } & Easy on/off/change & 29 & $\begin{array}{l}\text { Difficult to put on/ } \\
\text { change }\end{array}$ & 27 & $\begin{array}{l}\text { Easy to put on/off/ } \\
\text { change }\end{array}$ & 10 & $\begin{array}{l}\text { Difficult to put on/ } \\
\text { change }\end{array}$ & 10 \\
\hline & Comfort/soft & 23 & $\begin{array}{l}\text { Not absorbent/ } \\
\text { leaks }\end{array}$ & 7 & Comfortable/soft & 7 & $\begin{array}{l}\text { Not absorbent/ } \\
\text { leaks }\end{array}$ & 4 \\
\hline & $\begin{array}{l}\text { Absorbent/holds } \\
\text { urine }\end{array}$ & 20 & Poor fit/size & 4 & $\begin{array}{l}\text { Absorbent/holds } \\
\text { urine }\end{array}$ & 6 & & \\
\hline & $\begin{array}{l}\text { Discreet/like pants/ } \\
\text { dignified }\end{array}$ & 10 & & & $\begin{array}{l}\text { Look good/like } \\
\text { pants }\end{array}$ & 3 & & \\
\hline & Stays in place & 7 & & & & & & \\
\hline & $\begin{array}{l}\text { Resident could } \\
\text { manage by self }\end{array}$ & 4 & & & & & & \\
\hline \multirow[t]{6}{*}{ T-shaped } & $\begin{array}{l}\text { Absorbent/holds } \\
\text { urine }\end{array}$ & 25 & $\begin{array}{l}\text { Difficult to put on/ } \\
\text { change }\end{array}$ & 24 & $\begin{array}{l}\text { Easy to put on/off/ } \\
\text { change }\end{array}$ & 8 & $\begin{array}{l}\text { Poor fit/not big } \\
\text { enough }\end{array}$ & 7 \\
\hline & Easy on/off/change & 16 & $\begin{array}{l}\text { Problems with } \\
\text { band/tabs }\end{array}$ & 9 & $\begin{array}{l}\text { Absorbent/holds } \\
\text { urine }\end{array}$ & 5 & Difficult on/change & 6 \\
\hline & Stays in place & 10 & $\begin{array}{l}\text { Not absorbent } \\
\text { enough/leaks }\end{array}$ & 7 & Poor fit/size & 4 & $\begin{array}{l}\text { Not absorbent } \\
\text { enough/leaks }\end{array}$ & 3 \\
\hline & Comfort/soft & 8 & Poor fit/size & 6 & Comfortable/soft & 2 & Tabs did not stick & 3 \\
\hline & Good fit & 7 & & & & & & \\
\hline & Good size/shape & 7 & & & & & & \\
\hline
\end{tabular}




\section{Night products}

Carers could make as many comments as they wished. Comments are included if made by at least three carers.

\begin{tabular}{|c|c|c|c|c|c|c|c|c|}
\hline \multirow[t]{2}{*}{ Design } & \multicolumn{4}{|c|}{ Women $(N=72)$} & \multicolumn{4}{|c|}{$\operatorname{Men}(N=27)$} \\
\hline & Good & $\mathbf{N}$ & Poor & $\mathbf{N}$ & Good & $\mathbf{N}$ & Poor & $\mathbf{N}$ \\
\hline \multirow[t]{4}{*}{ Insert } & Easy on/off/change & 27 & $\begin{array}{l}\text { Not absorbent } \\
\text { enough/leaks }\end{array}$ & 34 & $\begin{array}{l}\text { Absorbent/holds } \\
\text { urine }\end{array}$ & 6 & $\begin{array}{l}\text { Not absorbent } \\
\text { enough/leaks }\end{array}$ & 15 \\
\hline & Absorbent & 9 & Moves around & 13 & Easy to change & 5 & Moves around & 8 \\
\hline & $\begin{array}{l}\text { Can position } \\
\text { correctly }\end{array}$ & 3 & $\begin{array}{l}\text { Dislike/problems } \\
\text { with nets }\end{array}$ & 9 & Good size/fit & 3 & Poor size/fit & 7 \\
\hline & & & Poor fit/size & 6 & & & & \\
\hline \multirow[t]{6}{*}{ Diaper } & $\begin{array}{l}\text { Absorbent/holds } \\
\text { urine }\end{array}$ & 24 & $\begin{array}{l}\text { Not absorbent } \\
\text { enough/leaks }\end{array}$ & 17 & $\begin{array}{l}\text { Absorbent/holds } \\
\text { urine }\end{array}$ & 9 & $\begin{array}{l}\text { Not absorbent } \\
\text { enough/leaks }\end{array}$ & 4 \\
\hline & Easy on/off/change & 18 & $\begin{array}{l}\text { Too much plastic/ } \\
\text { sweaty }\end{array}$ & 11 & Good fit/size & 8 & & \\
\hline & Good fit/size & 12 & Too big and bulky & 6 & Comfortable/soft & 6 & & \\
\hline & Comfortable/soft & 7 & Poor fit/size & 6 & Easy on/change & 4 & & \\
\hline & Stays in place & 6 & Difficulty on/change & 3 & Stays in place & 4 & & \\
\hline & & & & & $\begin{array}{l}\text { Do not disturb } \\
\text { resident changing } \\
\text { in night }\end{array}$ & 3 & & \\
\hline \multirow[t]{6}{*}{ Pull-up } & Absorbent/no leaks & 15 & $\begin{array}{l}\text { Difficult on/off/ } \\
\text { change }\end{array}$ & 25 & Easy on/off/change & II & $\begin{array}{l}\text { Difficult on/off/ } \\
\text { change }\end{array}$ & 7 \\
\hline & Comfortable/soft & 19 & $\begin{array}{l}\text { Not absorbent } \\
\text { enough }\end{array}$ & 14 & Absorbent & 7 & $\begin{array}{l}\text { Not absorbent } \\
\text { enough/leaks }\end{array}$ & 5 \\
\hline & Good fit/size & 17 & Poor fit/size & 5 & Comfortable/soft & 7 & & \\
\hline & Easy on/off/change & II & $\begin{array}{l}\text { Difficult to remove/ } \\
\text { soiled with } \\
\text { faeces }\end{array}$ & 3 & & & & \\
\hline & Stays in place & 10 & & & & & & \\
\hline & $\begin{array}{l}\text { Good appearance/ } \\
\text { like pants }\end{array}$ & 7 & & & & & & \\
\hline \multirow[t]{6}{*}{ T-shaped } & Easy on/change & 26 & $\begin{array}{l}\text { Not absorbent } \\
\text { enough/leaks }\end{array}$ & 13 & Absorbent & 10 & Poor fit/size & 6 \\
\hline & Absorbent/no leaks & 21 & $\begin{array}{l}\text { Problem with belt/ } \\
\text { tabs }\end{array}$ & $\mathrm{II}$ & Easy on/change & 10 & $\begin{array}{l}\text { Opened/poor tabs/ } \\
\text { did not stay on }\end{array}$ & 6 \\
\hline & Good fit/size & 10 & Difficult on/change & 8 & Comfortable/soft & 4 & Difficult on & 4 \\
\hline & Comfortable/soft & 7 & & & Good fit/size & 3 & & \\
\hline & Stays in place & 6 & & & & & & \\
\hline & Keeps skin dry & 5 & & & & & & \\
\hline
\end{tabular}




\section{Appendix 20}

\section{Trial 2b: care staff views about the number of staff needed to change residents in different positions}

\begin{tabular}{|c|c|c|c|c|c|c|c|c|c|c|c|c|c|c|}
\hline \multirow[t]{2}{*}{ Position } & \multirow[t]{2}{*}{ Design } & \multicolumn{5}{|c|}{ Day } & \multicolumn{8}{|c|}{ Night } \\
\hline & & $n$ & Mean & Median & SD & Range & $n$ & $\mathbf{I}$ & 1.5 & 2 & Mean & Median & SD & Range \\
\hline \multirow[t]{5}{*}{ Standing } & Usual product & 67 & 1.67 & 2 & 0.512 & $1-3$ & & & & & & & & \\
\hline & T-shaped & 67 & 1.77 & 2 & 0.487 & $1-3$ & & & & & & & & \\
\hline & Diaper & 67 & 1.72 & 2 & 0.454 & $1-3$ & & & & & & & & \\
\hline & Insert & 67 & 1.63 & 2 & 0.553 & $1-3$ & & & & & & & & \\
\hline & Pull-up & 67 & 1.60 & 2 & 0.504 & $1-3$ & & & & & & & & \\
\hline \multirow[t]{5}{*}{ Lying } & Usual product & 85 & 1.67 & 2 & 0.459 & $1-2$ & 67 & 15 & 3 & 49 & 1.75 & 2 & 0.421 & $\mathrm{I}-2$ \\
\hline & T-shaped & 85 & 1.65 & 2 & 0.463 & $1-2$ & 70 & 17 & 8 & 45 & 1.70 & 2 & 0.429 & $1-2$ \\
\hline & Diaper & 85 & 1.65 & 2 & 0.463 & $1-2$ & 70 & 18 & 7 & 46 & 1.69 & 2 & 0.437 & $1-2$ \\
\hline & Insert & 85 & 1.61 & 2 & 0.476 & $1-2$ & 70 & 20 & 6 & 44 & 1.67 & 2 & 0.450 & $1-2$ \\
\hline & Pull-up & 85 & 1.65 & 2 & 0.463 & $1-2$ & 70 & 18 & 5 & 47 & 1.71 & 2 & 0.438 & $1-2$ \\
\hline
\end{tabular}





\section{Appendix 21}

\section{Trial 2b: care staff views about the relative value for money of different designs}

Care staff were asked only to consider designs that they considered to be acceptable. They were then asked: "Bearing in mind that incontinence products are generally purchased by the NHS using money that we all pay in taxes, would you still think your first choice design was best if it was costing the NHS $£ 15$ ( $£ 6$ per night) per month more than your second choice? If not - What if it cost $£ 10$ ( $£ 4$ per night) per month more? If not - What if it cost £5 (£2 per night) per month more?”

Results for comparisons between the second and third choices and between the third and fourth choices are not shown due to the small number of responses.

\begin{tabular}{|c|c|c|c|c|c|}
\hline Design: day & $\begin{array}{l}\text { No. ranking } \\
\text { best }\end{array}$ & $\begin{array}{l}\text { No. would } \\
\text { still choose } \\
\text { if } £ \mid 5 \\
\text { more than } \\
\text { 2nd choice }\end{array}$ & $\begin{array}{l}\text { No. would } \\
\text { still choose } \\
\text { if } £ 10 \\
\text { more than } \\
\text { 2nd choice }\end{array}$ & $\begin{array}{l}\text { No. would } \\
\text { still choose } \\
\text { if } \notin 5 \\
\text { more than } \\
\text { 2nd choice }\end{array}$ & $\begin{array}{l}\text { No. unable } \\
\text { to answer } \\
\text { question }\end{array}$ \\
\hline Pull-ups & 44 & 31 & I & I & 11 \\
\hline Diapers & 22 & 7 & 2 & 2 & 11 \\
\hline Inserts & 18 & 6 & 7 & I & 4 \\
\hline T-shaped & 15 & 3 & 3 & 2 & 7 \\
\hline
\end{tabular}

\begin{tabular}{|lccccc|}
\hline Design: night & $\begin{array}{c}\text { No. ranking } \\
\text { best }\end{array}$ & $\begin{array}{c}\text { No. would } \\
\text { still choose } \\
\text { if } \mathbf{E 6} \\
\text { more than } \\
\text { 2nd choice }\end{array}$ & $\begin{array}{c}\text { No. would } \\
\text { still choose } \\
\text { if } \mathbf{E 4} \\
\text { more than } \\
\text { 2nd choice }\end{array}$ & $\begin{array}{c}\text { No. would } \\
\text { still choose } \\
\text { if } \mathbf{E 2} \\
\text { more than } \\
\text { 2nd choice }\end{array}$ & $\begin{array}{c}\text { No. unable } \\
\text { to answer } \\
\text { question }\end{array}$ \\
\hline $\begin{array}{l}\text { Diapers } \\
\text { Pull-ups }\end{array}$ & 39 & 10 & 2 & 2 & 25 \\
T-shaped & 33 & 6 & 3 & 2 & 11 \\
Inserts & 20 & 11 & 0 & 0 & 9 \\
\hline
\end{tabular}





\section{Health Technology Assessment reports published to date}

\section{Volume I, 1997}

No. 1

Home parenteral nutrition: a systematic review.

By Richards DM, Deeks JJ, Sheldon TA, Shaffer JL.

No. 2

Diagnosis, management and screening of early localised prostate cancer.

A review by Selley S, Donovan J, Faulkner A, Coast J, Gillatt D.

No. 3

The diagnosis, management, treatment and costs of prostate cancer in England and Wales.

A review by Chamberlain J, Melia J, Moss S, Brown J.

No. 4

Screening for fragile $\mathrm{X}$ syndrome.

A review by Murray J, Cuckle $\mathrm{H}$, Taylor G, Hewison J.

No. 5

A review of near patient testing in primary care.

By Hobbs FDR, Delaney BC, Fitzmaurice DA, Wilson S, Hyde CJ, Thorpe GH, et al.

No. 6

Systematic review of outpatient services for chronic pain control.

By McQuay HJ, Moore RA, Eccleston

C, Morley S, de C Williams AC.

No. 7

Neonatal screening for inborn errors of metabolism: cost, yield and outcome.

A review by Pollitt RJ, Green A,

McCabe CJ, Booth A, Cooper NJ,

Leonard JV, et al.

No. 8

Preschool vision screening.

A review by Snowdon SK,

Stewart-Brown SL.

No. 9

Implications of socio-cultural contexts for the ethics of clinical trials.

A review by Ashcroft RE, Chadwick

DW, Clark SRL, Edwards RHT, Frith L, Hutton JL.

No. 10

A critical review of the role of neonatal hearing screening in the detection of congenital hearing impairment.

By Davis A, Bamford J, Wilson I, Ramkalawan T, Forshaw M, Wright S.
No. 11

Newborn screening for inborn errors of metabolism: a systematic review.

By Seymour CA, Thomason MJ,

Chalmers RA, Addison GM, Bain MD, Cockburn F, et al.

No. 12

Routine preoperative testing:

a systematic review of the evidence.

By Munro J, Booth A, Nicholl J.

No. 13

Systematic review of the effectiveness of laxatives in the elderly.

By Petticrew M, Watt I, Sheldon T.

No. 14

When and how to assess fast-changing technologies: a comparative study of medical applications of four generic technologies.

A review by Mowatt G, Bower DJ, Brebner JA, Cairns JA, Grant AM, McKee L.

\section{Volume 2, 1998}

No. 1

Antenatal screening for Down's syndrome.

A review by Wald NJ, Kennard A, Hackshaw A, McGuire A.

No. 2

Screening for ovarian cancer: a systematic review.

By Bell R, Petticrew M, Luengo S, Sheldon TA.

No. 3

Consensus development methods, and their use in clinical guideline development.

A review by Murphy MK, Black NA, Lamping DL, McKee CM, Sanderson $\mathrm{CFB}$, Askham J, et al.

No. 4

A cost-utility analysis of interferon beta for multiple sclerosis.

By Parkin D, McNamee P, Jacoby A, Miller P, Thomas S, Bates D.

No. 5

Effectiveness and efficiency of methods of dialysis therapy for end-stage renal disease: systematic reviews.

By MacLeod A, Grant A

Donaldson C, Khan I, Campbell M, Daly C, et al.
No. 6

Effectiveness of hip prostheses in primary total hip replacement: a critical review of evidence and an economic model.

By Faulkner A, Kennedy LG, Baxter K, Donovan J, Wilkinson M, Bevan G.

No. 7

Antimicrobial prophylaxis in colorectal surgery: a systematic review of randomised controlled trials.

By Song F, Glenny AM.

No. 8

Bone marrow and peripheral blood stem cell transplantation for malignancy.

A review by Johnson PWM, Simnett SJ Sweetenham JW, Morgan GJ, Stewart LA.

No. 9

Screening for speech and language delay: a systematic review of the literature.

By Law J, Boyle J, Harris F, Harkness A, Nye C.

No. 10

Resource allocation for chronic stable angina: a systematic review of effectiveness, costs and

cost-effectiveness of alternative interventions.

By Sculpher MJ, Petticrew M, Kelland JL, Elliott RA, Holdright DR, Buxton MJ.

No. 11

Detection, adherence and control of hypertension for the prevention of stroke: a systematic review.

By Ebrahim S.

No. 12

Postoperative analgesia and vomiting, with special reference to day-case surgery: a systematic review.

By McQuay HJ, Moore RA.

No. 13

Choosing between randomised and nonrandomised studies: a systematic review.

By Britton A, McKee M, Black N, McPherson K, Sanderson C, Bain C.

No. 14

Evaluating patient-based outcome measures for use in clinical trials.

A review by Fitzpatrick R, Davey C, Buxton MJ, Jones DR. 
No. 15

Ethical issues in the design and conduct of randomised controlled trials.

A review by Edwards SJL, Lilford RJ, Braunholtz DA, Jackson JC, Hewison J, Thornton J.

\section{No. 16}

Qualitative research methods in health technology assessment: a review of the literature.

By Murphy E, Dingwall R, Greatbatch D, Parker S, Watson P.

\section{No. 17}

The costs and benefits of paramedic skills in pre-hospital trauma care.

By Nicholl J, Hughes S, Dixon S, Turner J, Yates D.

\section{No. 18}

Systematic review of endoscopic ultrasound in gastro-oesophageal cancer.

By Harris KM, Kelly S, Berry E, Hutton J, Roderick P, Cullingworth J, et al.

No. 19

Systematic reviews of trials and other studies.

By Sutton AJ, Abrams KR, Jones DR, Sheldon TA, Song F.

\section{No. 20}

Primary total hip replacement surgery: a systematic review of outcomes and modelling of cost-effectiveness associated with different prostheses.

A review by Fitzpatrick R, Shortall E, Sculpher M, Murray D, Morris R, Lodge $\mathrm{M}$, et al.

\section{Volume 3, 1999}

No. 1

Informed decision making: an annotated bibliography and systematic review.

By Bekker H, Thornton JG,

Airey CM, Connelly JB, Hewison J, Robinson MB, et al.

No. 2

Handling uncertainty when performing economic evaluation of healthcare interventions.

A review by Briggs AH, Gray AM.

No. 3

The role of expectancies in the placebo effect and their use in the delivery of health care: a systematic review.

By Crow R, Gage H, Hampson S, Hart J, Kimber A, Thomas H.

No. 4

A randomised controlled trial of different approaches to universal antenatal HIV testing: uptake and acceptability. Annex: Antenatal HIV testing - assessment of a routine voluntary approach.

By Simpson WM, Johnstone FD, Boyd FM, Goldberg DJ, Hart GJ, Gormley $\mathrm{SM}$, et al.
No. 5

Methods for evaluating area-wide and organisation-based interventions in health and health care: a systematic review.

By Ukoumunne OC, Gulliford MC, Chinn S, Sterne JAC, Burney PGJ.

No. 6

Assessing the costs of healthcare technologies in clinical trials.

A review by Johnston $\mathrm{K}$, Buxton $\mathrm{MJ}$, Jones DR, Fitzpatrick R.

No. 7

Cooperatives and their primary care emergency centres: organisation and impact.

By Hallam L, Henthorne K.

No. 8

Screening for cystic fibrosis.

A review by Murray J, Cuckle $\mathrm{H}$, Taylor G, Littlewood J, Hewison J.

No. 9

A review of the use of health status measures in economic evaluation.

By Brazier J, Deverill M, Green C, Harper R, Booth A.

No. 10

Methods for the analysis of quality-oflife and survival data in health technology assessment.

A review by Billingham LJ, Abrams KR, Jones DR.

No. 11

Antenatal and neonatal

haemoglobinopathy screening in the

UK: review and economic analysis.

By Zeuner D, Ades AE, Karnon J,

Brown J, Dezateux C, Anionwu EN.

\section{No. 12}

Assessing the quality of reports of randomised trials: implications for the conduct of meta-analyses.

A review by Moher D, Cook DJ, Jadad AR, Tugwell P, Moher M, Jones A, et al.

No. 13

'Early warning systems' for identifying new healthcare technologies.

By Robert G, Stevens A, Gabbay J.

No. 14

A systematic review of the role of human papillomavirus testing within a cervical screening programme.

By Cuzick J, Sasieni P, Davies P, Adams J, Normand C, Frater A, et al.

\section{No. 15}

Near patient testing in diabetes clinics: appraising the costs and outcomes.

By Grieve R, Beech R, Vincent J, Mazurkiewicz J

\section{No. 16}

Positron emission tomography: establishing priorities for health technology assessment.

A review by Robert G, Milne $\mathrm{R}$.
No. 17 (Pt 1)

The debridement of chronic wounds: a systematic review.

By Bradley M, Cullum N, Sheldon T.

\section{No. 17 (Pt 2)}

Systematic reviews of wound care management: (2) Dressings and topical agents used in the healing of chronic wounds.

By Bradley M, Cullum N, Nelson EA, Petticrew M, Sheldon T, Torgerson D.

\section{No. 18}

A systematic literature review of spiral and electron beam computed

tomography: with particular reference to clinical applications in hepatic lesions, pulmonary embolus and coronary artery disease.

By Berry E, Kelly S, Hutton J, Harris KM, Roderick P, Boyce JC, et al.

\section{No. 19}

What role for statins? A review and economic model.

By Ebrahim S, Davey Smith G McCabe C, Payne N, Pickin M, Sheldon TA, et al

\section{No. 20}

Factors that limit the quality, number and progress of randomised controlled trials.

A review by Prescott RJ, Counsell CE, Gillespie WJ, Grant AM, Russell IT, Kiauka S, et al.

No. 21

Antimicrobial prophylaxis in total hip replacement: a systematic review.

By Glenny AM, Song F.

No. 22

Health promoting schools and health promotion in schools: two systematic reviews.

By Lister-Sharp D, Chapman S, Stewart-Brown S, Sowden A.

No. 23

Economic evaluation of a primary carebased education programme for patients with osteoarthritis of the knee.

A review by Lord J, Victor C, Littlejohns P, Ross FM, Axford JS.

\section{Volume 4, 2000}

No. 1

The estimation of marginal time preference in a UK-wide sample (TEMPUS) project.

A review by Cairns JA, van der Pol MM.

No. 2

Geriatric rehabilitation following fractures in older people: a systematic review.

By Cameron I, Crotty M, Currie C, Finnegan T, Gillespie L, Gillespie W, et al. 
No. 3

Screening for sickle cell disease and thalassaemia: a systematic review with supplementary research.

By Davies SC, Cronin E, Gill M, Greengross P, Hickman M, Normand C.

No. 4

Community provision of hearing aids and related audiology services.

A review by Reeves DJ, Alborz A, Hickson FS, Bamford JM.

No. 5

False-negative results in screening programmes: systematic review of impact and implications.

By Petticrew MP, Sowden AJ, Lister-Sharp D, Wright K.

No. 6

Costs and benefits of community postnatal support workers: a randomised controlled trial.

By Morrell CJ, Spiby H, Stewart P, Walters S, Morgan A.

No. 7

Implantable contraceptives (subdermal implants and hormonally impregnated intrauterine systems) versus other forms of reversible contraceptives: two systematic reviews to assess relative effectiveness, acceptability, tolerability and cost-effectiveness.

By French RS, Cowan FM, Mansour DJA, Morris S, Procter T, Hughes D, et al.

No. 8

An introduction to statistical methods for health technology assessment.

A review by White SJ, Ashby D, Brown PJ.

No. 9

Disease-modifying drugs for multiple sclerosis: a rapid and systematic review.

By Clegg A, Bryant J, Milne R.

\section{No. 10}

Publication and related biases.

A review by Song F, Eastwood AJ, Gilbody S, Duley L, Sutton AJ.

No. 11

Cost and outcome implications of the organisation of vascular services.

By Michaels J, Brazier J, Palfreyman S, Shackley P, Slack R.

No. 12

Monitoring blood glucose control in diabetes mellitus: a systematic review.

By Coster S, Gulliford MC, Seed PT, Powrie JK, Swaminathan R.

No. 13

The effectiveness of domiciliary health visiting: a systematic review of international studies

and a selective review of the British literature.

By Elkan R, Kendrick D, Hewitt M, Robinson JJA, Tolley K, Blair M, et al.

\section{No. 14}

The determinants of screening uptake and interventions for increasing uptake: a systematic review.

By Jepson R, Clegg A, Forbes C, Lewis R, Sowden A, Kleijnen J.

\section{No. 15}

The effectiveness and cost-effectiveness of prophylactic removal of wisdom teeth.

A rapid review by Song F, O'Meara S, Wilson P, Golder S, Kleijnen J.

\section{No. 16}

Ultrasound screening in pregnancy: a systematic review of the clinical effectiveness, cost-effectiveness and women's views.

By Bricker L, Garcia J, Henderson J, Mugford M, Neilson J, Roberts T, et al.

\section{No. 17}

A rapid and systematic review of the effectiveness and cost-effectiveness of the taxanes used in the treatment of advanced breast and ovarian cancer.

By Lister-Sharp D, McDonagh MS, Khan KS, Kleijnen J.

\section{No. 18}

Liquid-based cytology in cervical screening: a rapid and systematic review.

By Payne N, Chilcott J, McGoogan E.

\section{No. 19}

Randomised controlled trial of non-

directive counselling,

cognitive-behaviour therapy and usual general practitioner care in the management of depression as well as mixed anxiety and depression in primary care.

By King M, Sibbald B, Ward E, Bower P, Lloyd M, Gabbay M, et al.

\section{No. 20}

Routine referral for radiography of patients presenting with low back pain: is patients' outcome influenced by GPs' referral for plain radiography?

By Kerry S, Hilton S, Patel S, Dundas D, Rink E, Lord J.

\section{No. 21}

Systematic reviews of wound care management: (3) antimicrobial agents for chronic wounds; (4) diabetic foot ulceration.

By O'Meara S, Cullum N, Majid M, Sheldon T.

\section{No. 22}

Using routine data to complement and enhance the results of randomised controlled trials.

By Lewsey JD, Leyland AH,

Murray GD, Boddy FA.

\section{No. 23}

Coronary artery stents in the treatment of ischaemic heart disease: a rapid and systematic review.

By Meads C, Cummins C, Jolly K, Stevens A, Burls A, Hyde C.
No. 24

Outcome measures for adult critical

care: a systematic review.

By Hayes JA, Black NA,

Jenkinson C, Young JD, Rowan KM, Daly $\mathrm{K}$, et al

\section{No. 25}

A systematic review to evaluate the effectiveness of interventions to promote the initiation of breastfeeding.

By Fairbank L, O'Meara S, Renfrew MJ, Woolridge M, Sowden AJ, Lister-Sharp D.

No. 26

Implantable cardioverter defibrillators: arrhythmias. A rapid and systematic review.

By Parkes J, Bryant J, Milne R.

No. 27

Treatments for fatigue in multiple sclerosis: a rapid and systematic review.

By Brañas P, Jordan R, Fry-Smith A, Burls A, Hyde C.

No. 28

Early asthma prophylaxis, natural history, skeletal development and economy (EASE): a pilot randomised controlled trial.

By Baxter-Jones ADG, Helms PJ, Russell G, Grant A, Ross S, Cairns JA, et al.

No. 29

Screening for hypercholesterolaemia versus case finding for familial hypercholesterolaemia: a systematic review and cost-effectiveness analysis.

By Marks D, Wonderling D,

Thorogood M, Lambert H, Humphries SE, Neil HAW.

No. 30

A rapid and systematic review of the clinical effectiveness and cost-

effectiveness of glycoprotein IIb/IIIa antagonists in the medical management of unstable angina.

By McDonagh MS, Bachmann LM, Golder S, Kleijnen J, ter Riet G.

\section{No. 31}

A randomised controlled trial of prehospital intravenous fluid replacement therapy in serious trauma. By Turner J, Nicholl J, Webber L, Cox H, Dixon S, Yates D.

No. 32

Intrathecal pumps for giving opioids in chronic pain: a systematic review.

By Williams JE, Louw G, Towlerton G.

No. 33

Combination therapy (interferon alfa and ribavirin) in the treatment of chronic hepatitis C: a rapid and systematic review.

By Shepherd J, Waugh N, Hewitson P. 
No. 34

A systematic review of comparisons of effect sizes derived from randomised and non-randomised studies.

By MacLehose RR, Reeves BC, Harvey IM, Sheldon TA, Russell IT, Black AMS.

No. 35

Intravascular ultrasound-guided interventions in coronary artery disease: a systematic literature review, with decision-analytic modelling, of outcomes and cost-effectiveness.

By Berry E, Kelly S, Hutton J, Lindsay HSJ, Blaxill JM, Evans JA, et al.

No. 36

A randomised controlled trial to evaluate the effectiveness and costeffectiveness of counselling patients with chronic depression.

By Simpson S, Corney R, Fitzgerald P, Beecham J.

No. 37

Systematic review of treatments for atopic eczema.

By Hoare C, Li Wan Po A, Williams H.

No. 38

Bayesian methods in health technology assessment: a review.

By Spiegelhalter DJ, Myles JP, Jones DR, Abrams KR.

No. 39

The management of dyspepsia: a systematic review.

By Delaney B, Moayyedi P, Deeks J, Innes M, Soo S, Barton P, et al.

No. 40

A systematic review of treatments for severe psoriasis.

By Griffiths CEM, Clark CM, Chalmers RJG, Li Wan Po A, Williams HC.

\section{Volume 5, 200I}

No. 1

Clinical and cost-effectiveness of donepezil, rivastigmine and galantamine for Alzheimer's disease: a rapid and systematic review.

By Clegg A, Bryant J, Nicholson T, McIntyre L, De Broe S, Gerard K, et al.

No. 2

The clinical effectiveness and costeffectiveness of riluzole for motor neurone disease: a rapid and systematic review.

By Stewart A, Sandercock J, Bryan S, Hyde C, Barton PM, Fry-Smith A, et al.

No. 3

Equity and the economic evaluation of healthcare.

By Sassi F, Archard L, Le Grand J.

No. 4

Quality-of-life measures in chronic

diseases of childhood.

By Eiser C, Morse R.
No. 5

Eliciting public preferences for

healthcare: a systematic review of techniques.

By Ryan M, Scott DA, Reeves C, Bate A, van Teijlingen ER, Russell EM, et al.

No. 6

General health status measures for people with cognitive impairment: learning disability and acquired brain injury.

By Riemsma RP, Forbes CA, Glanville JM, Eastwood AJ, Kleijnen J.

No. 7

An assessment of screening strategies for fragile $\mathrm{X}$ syndrome in the UK.

By Pembrey ME, Barnicoat AJ, Carmichael B, Bobrow M, Turner G.

No. 8

Issues in methodological research: perspectives from researchers and commissioners.

By Lilford RJ, Richardson A, Stevens A, Fitzpatrick R, Edwards S, Rock F, et al.

No. 9

Systematic reviews of wound care management: (5) beds; (6) compression;

(7) laser therapy, therapeutic

ultrasound, electrotherapy and

electromagnetic therapy.

By Cullum N, Nelson EA, Flemming

$\mathrm{K}$, Sheldon T.

No. 10

Effects of educational and psychosocial interventions for adolescents with diabetes mellitus: a systematic review.

By Hampson SE, Skinner TC, Hart J, Storey L, Gage H, Foxcroft D, et al.

\section{No. 11}

Effectiveness of autologous chondrocyte transplantation for hyaline cartilage defects in knees: a rapid and systematic review.

By Jobanputra P, Parry D, Fry-Smith A, Burls A.

\section{No. 12}

Statistical assessment of the learning curves of health technologies.

By Ramsay CR, Grant AM, Wallace SA, Garthwaite PH, Monk AF, Russell IT.

\section{No. 13}

The effectiveness and cost-effectiveness of temozolomide for the treatment of recurrent malignant glioma: a rapid and systematic review.

By Dinnes J, Cave C, Huang S, Major K, Milne R.

\section{No. 14}

A rapid and systematic review of the clinical effectiveness and costeffectiveness of debriding agents in treating surgical wounds healing by secondary intention.

By Lewis R, Whiting P, ter Riet G, O’Meara S, Glanville J.
No. 15

Home treatment for mental health

problems: a systematic review.

By Burns T, Knapp M,

Catty J, Healey A, Henderson J, Watt $\mathrm{H}$, et al.

\section{No. 16}

How to develop cost-conscious guidelines.

By Eccles M, Mason J.

No. 17

The role of specialist nurses in multiple sclerosis: a rapid and systematic review.

By De Broe S, Christopher F, Waugh N.

No. 18

A rapid and systematic review of the clinical effectiveness and costeffectiveness of orlistat in the management of obesity.

By O'Meara S, Riemsma R, Shirran L, Mather L, ter Riet G.

\section{No. 19}

The clinical effectiveness and costeffectiveness of pioglitazone for type 2 diabetes mellitus: a rapid and systematic review.

By Chilcott J, Wight J, Lloyd Jones M, Tappenden P.

\section{No. 20}

Extended scope of nursing practice: a multicentre randomised controlled trial of appropriately trained nurses and preregistration house officers in preoperative assessment in elective general surgery.

By Kinley H, Czoski-Murray C, George S, McCabe C, Primrose J, Reilly C, et al.

No. 21

Systematic reviews of the effectiveness of day care for people with severe mental disorders: (1) Acute day hospital versus admission; (2) Vocational rehabilitation; (3) Day hospital versus outpatient care.

By Marshall M, Crowther R, AlmarazSerrano A, Creed F, Sledge W, Kluiter $\mathrm{H}$, et al.

No. 22

The measurement and monitoring of surgical adverse events.

By Bruce J, Russell EM, Mollison J, Krukowski ZH.

\section{No. 23}

Action research: a systematic review and guidance for assessment.

By Waterman H, Tillen D, Dickson R, de Koning $\mathbf{K}$.

No. 24

A rapid and systematic review of the clinical effectiveness and costeffectiveness of gemcitabine for the treatment of pancreatic cancer.

By Ward S, Morris E, Bansback N, Calvert N, Crellin A, Forman D, et al. 
No. 25

A rapid and systematic review of the evidence for the clinical effectiveness and cost-effectiveness of irinotecan, oxaliplatin and raltitrexed for the treatment of advanced colorectal cancer.

By Lloyd Jones M, Hummel S, Bansback N, Orr B, Seymour M.

\section{No. 26}

Comparison of the effectiveness of inhaler devices in asthma and chronic obstructive airways disease: a systematic review of the literature.

By Brocklebank D, Ram F, Wright J, Barry P, Cates C, Davies L, et al.

No. 27

The cost-effectiveness of magnetic resonance imaging for investigation of the knee joint.

By Bryan S, Weatherburn G, Bungay H, Hatrick C, Salas C, Parry D, et al.

\section{No. 28}

A rapid and systematic review of the clinical effectiveness and costeffectiveness of topotecan for ovarian cancer.

By Forbes C, Shirran L, Bagnall A-M, Duffy S, ter Riet G.

\section{No. 29}

Superseded by a report published in a later volume.

\section{No. 30}

The role of radiography in primary care patients with low back pain of at least 6 weeks duration: a randomised (unblinded) controlled trial.

By Kendrick D, Fielding K, Bentley E, Miller P, Kerslake R, Pringle M.

\section{No. 31}

Design and use of questionnaires: a review of best practice applicable to surveys of health service staff and patients.

By McColl E, Jacoby A, Thomas L, Soutter J, Bamford C, Steen N, et al.

\section{No. 32}

A rapid and systematic review of the clinical effectiveness and cost-

effectiveness of paclitaxel, docetaxel, gemcitabine and vinorelbine in nonsmall-cell lung cancer.

By Clegg A, Scott DA, Sidhu M, Hewitson P, Waugh N.

\section{No. 33}

Subgroup analyses in randomised controlled trials: quantifying the risks of false-positives and false-negatives.

By Brookes ST, Whitley E, Peters TJ, Mulheran PA, Egger M, Davey Smith G.

\section{No. 34}

Depot antipsychotic medication in the treatment of patients with schizophrenia: (1) Meta-review; (2) Patient and nurse attitudes.

By David AS, Adams C.

\section{No. 35}

A systematic review of controlled trials of the effectiveness and costeffectiveness of brief psychological treatments for depression.

By Churchill R, Hunot V, Corney R, Knapp M, McGuire H, Tylee A, et al.

No. 36

Cost analysis of child health surveillance.

By Sanderson D, Wright D, Acton C, Duree D.

\section{Volume 6, 2002}

\section{No. 1}

A study of the methods used to select review criteria for clinical audit.

By Hearnshaw H, Harker R, Cheater F, Baker R, Grimshaw G.

No. 2

Fludarabine as second-line therapy for B cell chronic lymphocytic leukaemia: a technology assessment.

By Hyde C, Wake B, Bryan S, Barton P, Fry-Smith A, Davenport C, et al.

No. 3

Rituximab as third-line treatment for refractory or recurrent Stage III or IV follicular non-Hodgkin's lymphoma: a systematic review and economic evaluation.

By Wake B, Hyde C, Bryan S, Barton $\mathrm{P}$, Song F, Fry-Smith A, et al.

No. 4

A systematic review of discharge arrangements for older people.

By Parker SG, Peet SM, McPherson A, Cannaby AM, Baker R, Wilson A, et al.

No. 5

The clinical effectiveness and costeffectiveness of inhaler devices used in the routine management of chronic asthma in older children: a systematic review and economic evaluation.

By Peters J, Stevenson M, Beverley C, Lim J, Smith S.

\section{No. 6}

The clinical effectiveness and costeffectiveness of sibutramine in the management of obesity: a technology assessment.

By O’Meara S, Riemsma R, Shirran L, Mather L, ter Riet G.

No. 7

The cost-effectiveness of magnetic resonance angiography for carotid artery stenosis and peripheral vascular disease: a systematic review.

By Berry E, Kelly S, Westwood ME, Davies LM, Gough MJ, Bamford JM, et al.

No. 8

Promoting physical activity in South Asian Muslim women through 'exercise on prescription'.

By Carroll B, Ali N, Azam N.
No. 9

Zanamivir for the treatment of influenza

in adults: a systematic review and economic evaluation.

By Burls A, Clark W, Stewart T, Preston C, Bryan S, Jefferson T, et al.

\section{No. 10}

A review of the natural history and epidemiology of multiple sclerosis: implications for resource allocation and health economic models.

By Richards RG, Sampson FC, Beard SM, Tappenden P.

No. 11

Screening for gestational diabetes: a systematic review and economic evaluation.

By Scott DA, Loveman E, McIntyre L, Waugh N.

No. 12

The clinical effectiveness and costeffectiveness of surgery for people with morbid obesity: a systematic review and economic evaluation.

By Clegg AJ, Colquitt J, Sidhu MK, Royle P, Loveman E, Walker A.

\section{No. 13}

The clinical effectiveness of trastuzumab for breast cancer: a systematic review.

By Lewis R, Bagnall A-M, Forbes C, Shirran E, Duffy S, Kleijnen J, et al.

\section{No. 14}

The clinical effectiveness and costeffectiveness of vinorelbine for breast cancer: a systematic review and economic evaluation.

By Lewis R, Bagnall A-M, King S, Woolacott N, Forbes C, Shirran L, et al.

\section{No. 15}

A systematic review of the effectiveness and cost-effectiveness of metal-on-metal hip resurfacing arthroplasty for treatment of hip disease.

By Vale L, Wyness L, McCormack K, McKenzie L, Brazzelli M, Stearns SC.

\section{No. 16}

The clinical effectiveness and costeffectiveness of bupropion and nicotine replacement therapy for smoking cessation: a systematic review and economic evaluation.

By Woolacott NF, Jones L, Forbes CA Mather LC, Sowden AJ, Song FJ, et al.

No. 17

A systematic review of effectiveness and economic evaluation of new drug treatments for juvenile idiopathic arthritis: etanercept.

By Cummins C, Connock M, Fry-Smith A, Burls A.

No. 18

Clinical effectiveness and costeffectiveness of growth hormone in children: a systematic review and economic evaluation.

By Bryant J, Cave C, Mihaylova B, Chase D, McIntyre L, Gerard K, et al. 
No. 19

Clinical effectiveness and cost-

effectiveness of growth hormone in adults in relation to impact on quality of life: a systematic review and economic evaluation.

By Bryant J, Loveman E, Chase D, Mihaylova B, Cave C, Gerard K, et al.

\section{No. 20}

Clinical medication review by a pharmacist of patients on repeat prescriptions in general practice: a randomised controlled trial.

By Zermansky AG, Petty DR, Raynor DK, Lowe CJ, Freementle N, Vail A.

No. 21

The effectiveness of infliximab and etanercept for the treatment of rheumatoid arthritis: a systematic review and economic evaluation.

By Jobanputra P, Barton P, Bryan S, Burls A.

No. 22

A systematic review and economic evaluation of computerised cognitive behaviour therapy for depression and anxiety.

By Kaltenthaler E, Shackley P, Stevens K, Beverley C, Parry G, Chilcott J.

No. 23

A systematic review and economic evaluation of pegylated liposomal doxorubicin hydrochloride for ovarian cancer.

By Forbes C, Wilby J, Richardson G, Sculpher M, Mather L, Reimsma R.

No. 24

A systematic review of the effectiveness of interventions based on a stages-ofchange approach to promote individual behaviour change.

By Riemsma RP, Pattenden J, Bridle C, Sowden AJ, Mather L, Watt IS, et al.

\section{No. 25}

A systematic review update of the clinical effectiveness and costeffectiveness of glycoprotein IIb/IIIa antagonists.

By Robinson M, Ginnelly L, Sculpher M, Jones L, Riemsma R, Palmer S, et al.

No. 26

A systematic review of the effectiveness, cost-effectiveness and barriers to implementation of thrombolytic and neuroprotective therapy for acute ischaemic stroke in the NHS.

By Sandercock P, Berge E, Dennis M, Forbes J, Hand P, Kwan J, et al.

\section{No. 27}

A randomised controlled crossover trial of nurse practitioner versus doctor-led outpatient care in a bronchiectasis clinic.

By Caine N, Sharples LD,

Hollingworth W, French J, Keogan M, Exley A, et al.

\section{No. 28}

Clinical effectiveness and cost consequences of selective serotonin reuptake inhibitors in the treatment of sex offenders.

By Adi Y, Ashcroft D, Browne K, Beech A, Fry-Smith A, Hyde C.

\section{No. 29}

Treatment of established osteoporosis: a systematic review and cost-utility analysis.

By Kanis JA, Brazier JE, Stevenson M, Calvert NW, Lloyd Jones M.

No. 30

Which anaesthetic agents are costeffective in day surgery? Literature review, national survey of practice and randomised controlled trial.

By Elliott RA Payne K, Moore JK,

Davies LM, Harper NJN, St Leger AS, et al.

\section{No. 31}

Screening for hepatitis $\mathrm{C}$ among injecting drug users and in genitourinary medicine clinics: systematic reviews of effectiveness, modelling study and national survey of current practice.

By Stein K, Dalziel K, Walker A, McIntyre L, Jenkins B, Horne J, et al.

No. 32

The measurement of satisfaction with healthcare: implications for practice from a systematic review of the literature.

By Crow R, Gage H, Hampson S, Hart J, Kimber A, Storey L, et al.

No. 33

The effectiveness and cost-effectiveness of imatinib in chronic myeloid leukaemia: a systematic review.

By Garside R, Round A, Dalziel K, Stein K, Royle R.

\section{No. 34}

A comparative study of hypertonic saline, daily and alternate-day rhDNase in children with cystic fibrosis.

By Suri R, Wallis C, Bush A,

Thompson S, Normand C, Flather M, et al.

No. 35

A systematic review of the costs and effectiveness of different models of paediatric home care.

By Parker G, Bhakta P, Lovett CA, Paisley S, Olsen R, Turner D, et al.

\section{Volume 7, 2003}

No. 1

How important are comprehensive literature searches and the assessment of trial quality in systematic reviews? Empirical study.

By Egger M, Jüni P, Bartlett C, Holenstein F, Sterne J.

\section{No. 2}

Systematic review of the effectiveness and cost-effectiveness, and economic evaluation, of home versus hospital or satellite unit haemodialysis for people with end-stage renal failure.

By Mowatt G, Vale L, Perez J, Wyness L, Fraser C, MacLeod A, et al.

\section{No. 3}

Systematic review and economic evaluation of the effectiveness of infliximab for the treatment of Crohn's disease.

By Clark W, Raftery J, Barton P, Song F, Fry-Smith A, Burls A.

No. 4

A review of the clinical effectiveness and cost-effectiveness of routine anti-D prophylaxis for pregnant women who are rhesus negative.

By Chilcott J, Lloyd Jones M, Wight J, Forman K, Wray J, Beverley C, et al.

No. 5

Systematic review and evaluation of the use of tumour markers in paediatric oncology: Ewing's sarcoma and neuroblastoma.

By Riley RD, Burchill SA, Abrams KR, Heney D, Lambert PC, Jones DR, et al.

No. 6

The cost-effectiveness of screening for Helicobacter pylori to reduce mortality and morbidity from gastric cancer and peptic ulcer disease: a discrete-event simulation model.

By Roderick P, Davies R, Raftery J, Crabbe D, Pearce R, Bhandari P, et al.

No. 7

The clinical effectiveness and costeffectiveness of routine dental checks: a systematic review and economic evaluation.

By Davenport C, Elley K, Salas C, Taylor-Weetman CL, Fry-Smith A, Bryan S, et al.

\section{No. 8}

A multicentre randomised controlled trial assessing the costs and benefits of using structured information and analysis of women's preferences in the management of menorrhagia.

By Kennedy ADM, Sculpher MJ, Coulter A, Dwyer N, Rees M, Horsley S, et al.

No. 9

Clinical effectiveness and cost-utility of photodynamic therapy for wet age-related macular degeneration: a systematic review and economic evaluation.

By Meads C, Salas C, Roberts T, Moore D, Fry-Smith A, Hyde C.

No. 10

Evaluation of molecular tests for prenatal diagnosis of chromosome abnormalities.

By Grimshaw GM, Szczepura A, Hultén M, MacDonald F, Nevin NC, Sutton F, et al. 
No. 11

First and second trimester antenatal screening for Down's syndrome: the results of the Serum, Urine and Ultrasound Screening Study (SURUSS).

By Wald NJ, Rodeck C, Hackshaw AK, Walters J, Chitty L, Mackinson AM.

No. 12

The effectiveness and cost-effectiveness of ultrasound locating devices for central venous access: a systematic review and economic evaluation.

By Calvert N, Hind D, McWilliams RG, Thomas SM, Beverley C, Davidson A

No. 13

A systematic review of atypical antipsychotics in schizophrenia.

By Bagnall A-M, Jones L, Lewis R, Ginnelly L, Glanville J, Torgerson D, et al.

\section{No. 14}

Prostate Testing for Cancer and Treatment (ProtecT) feasibility study.

By Donovan J, Hamdy F, Neal D, Peters T, Oliver S, Brindle L, et al.

No. 15

Early thrombolysis for the treatment of acute myocardial infarction: a systematic review and economic evaluation.

By Boland A, Dundar Y, Bagust A, Haycox A, Hill R, Mujica Mota R, et al.

\section{No. 16}

Screening for fragile $\mathrm{X}$ syndrome: a literature review and modelling.

By Song FJ, Barton P, Sleightholme V, Yao GL, Fry-Smith A

\section{No. 17}

Systematic review of endoscopic sinus surgery for nasal polyps.

By Dalziel K, Stein K, Round A, Garside R, Royle P.

\section{No. 18}

Towards efficient guidelines: how to monitor guideline use in primary care.

By Hutchinson A, McIntosh A, Cox S, Gilbert C.

\section{No. 19}

Effectiveness and cost-effectiveness of acute hospital-based spinal cord injuries services: systematic review.

By Bagnall A-M, Jones L,

Richardson G, Duffy S,

Riemsma R.

\section{No. 20}

Prioritisation of health technology assessment. The PATHS model: methods and case studies.

By Townsend J, Buxton M,
No. 21

Systematic review of the clinical effectiveness and cost-effectivenes of tension-free vaginal tape for treatment of urinary stress incontinence.

By Cody J, Wyness L, Wallace S, Glazener C, Kilonzo M, Stearns S, et al.

\section{No. 22}

The clinical and cost-effectiveness of patient education models for diabetes: a systematic review and economic evaluation.

By Loveman E, Cave C, Green C, Royle P, Dunn N, Waugh N.

\section{No. 23}

The role of modelling in prioritising and planning clinical trials.

By Chilcott J, Brennan A, Booth A, Karnon J, Tappenden P.

\section{No. 24}

Cost-benefit evaluation of routine influenza immunisation in people $65-74$ years of age.

By Allsup S, Gosney M, Haycox A, Regan M.

No. 25

The clinical and cost-effectiveness of pulsatile machine perfusion versus cold storage of kidneys for transplantation retrieved from heart-beating and nonheart-beating donors.

By Wight J, Chilcott J, Holmes M, Brewer N

\section{No. 26}

Can randomised trials rely on existing electronic data? A feasibility study to explore the value of routine data in health technology assessment.

By Williams JG, Cheung WY,

Cohen DR, Hutchings HA, Longo MF, Russell IT.

\section{No. 27}

Evaluating non-randomised intervention studies.

By Deeks JJ, Dinnes J, D’Amico R, Sowden AJ, Sakarovitch C, Song F, et al.

No. 28

A randomised controlled trial to assess the impact of a package comprising a patient-orientated, evidence-based selfhelp guidebook and patient-centred consultations on disease management and satisfaction in inflammatory bowel disease.

By Kennedy A, Nelson E, Reeves D, Richardson G, Roberts C, Robinson A, et al.

\section{No. 29}

The effectiveness of diagnostic tests for the assessment of shoulder pain due to soft tissue disorders: a systematic review.

By Dinnes J, Loveman E, McIntyre L, Waugh N.
No. 30

The value of digital imaging in diabetic retinopathy.

By Sharp PF, Olson J, Strachan F, Hipwell J, Ludbrook A, O'Donnell M, et al.

No. 31

Lowering blood pressure to prevent myocardial infarction and stroke: a new preventive strategy.

By Law M, Wald N, Morris J.

No. 32

Clinical and cost-effectiveness of capecitabine and tegafur with uracil for the treatment of metastatic colorectal cancer: systematic review and economic evaluation.

By Ward S, Kaltenthaler E, Cowan J, Brewer N.

No. 33

Clinical and cost-effectiveness of new and emerging technologies for early localised prostate cancer: a systematic review.

By Hummel S, Paisley S, Morgan A, Currie E, Brewer N.

No. 34

Literature searching for clinical and cost-effectiveness studies used in health technology assessment reports carried out for the National Institute for Clinical Excellence appraisal system.

By Royle P, Waugh N.

No. 35

Systematic review and economic decision modelling for the prevention and treatment of influenza

$\mathrm{A}$ and $\mathrm{B}$.

By Turner D, Wailoo A, Nicholson K, Cooper N, Sutton A, Abrams K.

\section{No. 36}

A randomised controlled trial to evaluate the clinical and costeffectiveness of Hickman line insertions in adult cancer patients by nurses.

By Boland A, Haycox A, Bagust A, Fitzsimmons L.

No. 37

Redesigning postnatal care: a randomised controlled trial of protocol-based midwifery-led care focused on individual women's physical and psychological health needs.

By MacArthur C, Winter HR, Bick DE, Lilford RJ, Lancashire RJ, Knowles $\mathrm{H}$, et al.

No. 38

Estimating implied rates of discount in healthcare decision-making.

By West RR, McNabb R,

Thompson AGH, Sheldon TA, Grimley Evans J. 
No. 39

Systematic review of isolation policies in the hospital management of methicillinresistant Staphylococcus aureus: a review of the literature with epidemiological and economic modelling.

By Cooper BS, Stone SP, Kibbler CC, Cookson BD, Roberts JA, Medley GF, et al.

No. 40

Treatments for spasticity and pain in multiple sclerosis: a systematic review.

By Beard S, Hunn A, Wight J.

No. 41

The inclusion of reports of randomised trials published in languages other than English in systematic reviews.

By Moher D, Pham B, Lawson ML, Klassen TP.

No. 42

The impact of screening on future health-promoting behaviours and health beliefs: a systematic review.

By Bankhead CR, Brett J, Bukach C, Webster P, Stewart-Brown S, Munafo M, et al.

\section{Volume 8, 2004}

No. 1

What is the best imaging strategy for acute stroke?

By Wardlaw JM, Keir SL, Seymour J, Lewis S, Sandercock PAG, Dennis MS, et al.

No. 2

Systematic review and modelling of the investigation of acute and chronic chest pain presenting in primary care.

By Mant J, McManus RJ, Oakes RAL, Delaney BC, Barton PM, Deeks JJ, et al.

No. 3

The effectiveness and cost-effectiveness of microwave and thermal balloon endometrial ablation for heavy menstrual bleeding: a systematic review and economic modelling.

By Garside R, Stein K, Wyatt K, Round A, Price A.

No. 4

A systematic review of the role of bisphosphonates in metastatic disease.

By Ross JR, Saunders Y, Edmonds PM, Patel S, Wonderling D, Normand C, et al.

No. 5

Systematic review of the clinical effectiveness and cost-effectiveness of capecitabine (Xeloda ${ }^{\circledR}$ ) for locally advanced and/or metastatic breast cancer.

By Jones L, Hawkins N, Westwood M, Wright K, Richardson G, Riemsma R.

No. 6

Effectiveness and efficiency of guideline dissemination and implementation strategies.

By Grimshaw JM, Thomas RE, MacLennan G, Fraser C, Ramsay CR,
No. 7

Clinical effectiveness and costs of the Sugarbaker procedure for the treatment of pseudomyxoma peritonei.

By Bryant J, Clegg AJ, Sidhu MK, Brodin H, Royle P, Davidson P.

No. 8

Psychological treatment for insomnia in the regulation of long-term hypnotic drug use.

By Morgan K, Dixon S, Mathers N, Thompson J, Tomeny M.

No. 9

Improving the evaluation of therapeutic interventions in multiple sclerosis:

development of a patient-based measure of outcome.

By Hobart JC, Riazi A, Lamping DL, Fitzpatrick R, Thompson AJ.

\section{No. 10}

A systematic review and economic evaluation of magnetic resonance cholangiopancreatography compared with diagnostic endoscopic retrograde cholangiopancreatography.

By Kaltenthaler E, Bravo Vergel Y, Chilcott J, Thomas S, Blakeborough T, Walters SJ, et al.

\section{No. 11}

The use of modelling to evaluate new drugs for patients with a chronic condition: the case of antibodies against tumour necrosis factor in rheumatoid arthritis.

By Barton P, Jobanputra P, Wilson J, Bryan S, Burls A

No. 12

Clinical effectiveness and costeffectiveness of neonatal screening for inborn errors of metabolism using tandem mass spectrometry: a systematic review.

By Pandor A, Eastham J, Beverley C, Chilcott J, Paisley S.

\section{No. 13}

Clinical effectiveness and costeffectiveness of pioglitazone and rosiglitazone in the treatment of type 2 diabetes: a systematic review and economic evaluation.

By Czoski-Murray C, Warren E, Chilcott J, Beverley C, Psyllaki MA, Cowan J.

\section{No. 14}

Routine examination of the newborn: the EMREN study. Evaluation of an extension of the midwife role including a randomised controlled trial of appropriately trained midwives and paediatric senior house officers.

By Townsend J, Wolke D, Hayes J, Davé S, Rogers C, Bloomfield L, et al.
No. 15

Involving consumers in research and development agenda setting for the NHS: developing an evidence-based approach.

By Oliver S, Clarke-Jones L, Rees R, Milne R, Buchanan P, Gabbay J, et al.

No. 16

A multi-centre randomised controlled trial of minimally invasive direct coronary bypass grafting versus percutaneous transluminal coronary angioplasty with stenting for proximal stenosis of the left anterior descending coronary artery.

By Reeves BC, Angelini GD, Bryan AJ, Taylor FC, Cripps T, Spyt TJ, et al.

No. 17

Does early magnetic resonance imaging influence management or improve outcome in patients referred to secondary care with low back pain? A pragmatic randomised controlled trial.

By Gilbert FJ, Grant AM, Gillan MGC, Vale L, Scott NW, Campbell MK, et al.

No. 18

The clinical and cost-effectiveness of anakinra for the treatment of rheumatoid arthritis in adults: a systematic review and economic analysis.

By Clark W, Jobanputra P, Barton P, Burls A.

No. 19

A rapid and systematic review and economic evaluation of the clinical and cost-effectiveness of newer drugs for treatment of mania associated with bipolar affective disorder

By Bridle C, Palmer S, Bagnall A-M, Darba J, Duffy S, Sculpher M, et al.

No. 20

Liquid-based cytology in cervical screening: an updated rapid and systematic review and economic analysis.

By Karnon J, Peters J, Platt J, Chilcott J, McGoogan E, Brewer N.

No. 21

Systematic review of the long-term effects and economic consequences of treatments for obesity and implications for health improvement.

By Avenell A, Broom J, Brown TJ, Poobalan A, Aucott L, Stearns SC, et al.

No. 22

Autoantibody testing in children with newly diagnosed type 1 diabetes mellitus.

By Dretzke J, Cummins C, Sandercock J, Fry-Smith A, Barrett T, Burls A. 
No. 23

Clinical effectiveness and cost-

effectiveness of prehospital intravenous fluids in trauma patients.

By Dretzke J, Sandercock J, Bayliss S, Burls A.

\section{No. 24}

Newer hypnotic drugs for the shortterm management of insomnia: a systematic review and economic evaluation.

By Dündar Y, Boland A, Strobl J, Dodd S, Haycox A, Bagust A, et al.

\section{No. 25}

Development and validation of methods for assessing the quality of diagnostic accuracy studies.

By Whiting P, Rutjes AWS, Dinnes J, Reitsma JB, Bossuyt PMM, Kleijnen J.

No. 26

EVALUATE hysterectomy trial: a multicentre randomised trial comparing abdominal, vaginal and laparoscopic methods of hysterectomy.

By Garry R, Fountain J, Brown J, Manca A, Mason S, Sculpher M, et al.

\section{No. 27}

Methods for expected value of information analysis in complex health economic models: developments on the health economics of interferon- $\beta$ and glatiramer acetate for multiple sclerosis.

By Tappenden P, Chilcott JB, Eggington S, Oakley J, McCabe C.

No. 28

Effectiveness and cost-effectiveness of imatinib for first-line treatment of chronic myeloid leukaemia in chronic phase: a systematic review and economic analysis.

By Dalziel K, Round A, Stein K, Garside R, Price A.

\section{No. 29}

VenUS I: a randomised controlled trial of two types of bandage for treating venous leg ulcers.

By Iglesias C, Nelson EA, Cullum NA, Torgerson DJ on behalf of the VenUS Team.

\section{No. 30}

Systematic review of the effectiveness and cost-effectiveness, and economic evaluation, of myocardial perfusion scintigraphy for the diagnosis and management of angina and myocardial infarction.

By Mowatt G, Vale L, Brazzelli M, Hernandez R, Murray A, Scott N, et al.

\section{No. 31}

A pilot study on the use of decision theory and value of information analysis as part of the NHS Health Technology Assessment programme.

By Claxton K, Ginnelly L, Sculpher M, Philips Z, Palmer S.

\section{No. 32}

The Social Support and Family Health Study: a randomised controlled trial and economic evaluation of two alternative forms of postnatal support for mothers living in disadvantaged inner-city areas.

By Wiggins M, Oakley A, Roberts I,

Turner H, Rajan L, Austerberry H, et al.

No. 33

Psychosocial aspects of genetic screening of pregnant women and newborns: a systematic review.

By Green JM, Hewison J, Bekker HL, Bryant, Cuckle HS.

\section{No. 34}

Evaluation of abnormal uterine

bleeding: comparison of three outpatient procedures within cohorts defined by age and menopausal status.

By Critchley HOD, Warner P,

Lee AJ, Brechin S, Guise J, Graham B.

\section{No. 35}

Coronary artery stents: a rapid systematic review and economic evaluation.

By Hill R, Bagust A, Bakhai A,

Dickson R, Dündar Y, Haycox A, et al.

\section{No. 36}

Review of guidelines for good practice in decision-analytic modelling in health technology assessment.

By Philips Z, Ginnelly L, Sculpher M, Claxton K, Golder S, Riemsma R, et al.

No. 37

Rituximab (MabThera ${ }^{\circledR}$ ) for aggressive non-Hodgkin's lymphoma: systematic review and economic evaluation.

By Knight C, Hind D, Brewer N, Abbott V.

No. 38

Clinical effectiveness and cost-

effectiveness of clopidogrel and modified-release dipyridamole in the secondary prevention of occlusive vascular events: a systematic review and economic evaluation.

By Jones L, Griffin S, Palmer S, Main C, Orton V, Sculpher M, et al.

\section{No. 39}

Pegylated interferon $\alpha$-2a and -2b in combination with ribavirin in the treatment of chronic hepatitis C: a systematic review and economic evaluation.

By Shepherd J, Brodin H, Cave C, Waugh N, Price A, Gabbay J.

\section{No. 40}

Clopidogrel used in combination with aspirin compared with aspirin alone in the treatment of non-ST-segmentelevation acute coronary syndromes: a systematic review and economic evaluation.

By Main C, Palmer S, Griffin S, Jones L, Orton V, Sculpher M, et al.
No. 41

Provision, uptake and cost of cardiac rehabilitation programmes: improving services to under-represented groups.

By Beswick AD, Rees K, Griebsch I, Taylor FC, Burke M, West RR, et al.

\section{No. 42}

Involving South Asian patients in clinical trials.

By Hussain-Gambles M, Leese B, Atkin K, Brown J, Mason S, Tovey P.

No. 43

Clinical and cost-effectiveness of continuous subcutaneous insulin infusion for diabetes.

By Colquitt JL, Green C, Sidhu MK, Hartwell D, Waugh N.

No. 44

Identification and assessment of ongoing trials in health technology assessment reviews.

By Song FJ, Fry-Smith A, Davenport C, Bayliss S, Adi Y, Wilson JS, et al.

No. 45

Systematic review and economic evaluation of a long-acting insulin analogue, insulin glargine

By Warren E, Weatherley-Jones E, Chilcott J, Beverley C.

\section{No. 46}

Supplementation of a home-based exercise programme with a class-based programme for people with osteoarthritis of the knees: a randomised controlled trial and health economic analysis.

By McCarthy CJ, Mills PM,

Pullen R, Richardson G, Hawkins N, Roberts CR, et al.

\section{No. 47}

Clinical and cost-effectiveness of oncedaily versus more frequent use of same potency topical corticosteroids for atopic eczema: a systematic review and economic evaluation.

By Green C, Colquitt JL, Kirby J, Davidson P, Payne E.

No. 48

Acupuncture of chronic headache disorders in primary care: randomised controlled trial and economic analysis.

By Vickers AJ, Rees RW, Zollman CE, McCarney R, Smith CM, Ellis N, et al.

No. 49

Generalisability in economic evaluation studies in healthcare: a review and case studies.

By Sculpher MJ, Pang FS, Manca A, Drummond MF, Golder S, Urdahl H, et al.

No. 50

Virtual outreach: a randomised controlled trial and economic evaluation of joint teleconferenced medical consultations.

By Wallace P, Barber J, Clayton W, Currell R, Fleming K, Garner P, et al. 


\section{Volume 9, 2005}

No. 1

Randomised controlled multiple treatment comparison to provide a cost-effectiveness rationale for the selection of antimicrobial therapy in acne.

By Ozolins M, Eady EA, Avery A, Cunliffe WJ, O'Neill C, Simpson NB, et al.

No. 2

Do the findings of case series studies vary significantly according to methodological characteristics?

By Dalziel K, Round A, Stein K, Garside R, Castelnuovo E, Payne L.

No. 3

Improving the referral process for familial breast cancer genetic counselling: findings of three randomised controlled trials of two interventions.

By Wilson BJ, Torrance N, Mollison J, Wordsworth S, Gray JR, Haites NE, et al.

No. 4

Randomised evaluation of alternative electrosurgical modalities to treat bladder outflow obstruction in men with benign prostatic hyperplasia.

By Fowler C, McAllister W, Plail R, Karim O, Yang $Q$.

No. 5

A pragmatic randomised controlled trial of the cost-effectiveness of palliative therapies for patients with inoperable oesophageal cancer.

By Shenfine J, McNamee P, Steen N, Bond J, Griffin SM.

\section{No. 6}

Impact of computer-aided detection prompts on the sensitivity and specificity of screening mammography.

By Taylor P, Champness J, GivenWilson R, Johnston K, Potts H.

No. 7

Issues in data monitoring and interim analysis of trials.

By Grant AM, Altman DG, Babiker $\mathrm{AB}$, Campbell MK, Clemens FJ, Darbyshire JH, et al.

No. 8

Lay public's understanding of equipoise and randomisation in randomised controlled trials.

By Robinson EJ, Kerr CEP, Steven AJ, Lilford RJ, Braunholtz DA, Edwards SJ, et al.

No. 9

Clinical and cost-effectiveness of electroconvulsive therapy for depressive illness, schizophrenia, catatonia and mania: systematic reviews and economic modelling studies.

By Greenhalgh J, Knight C, Hind D, Beverley C, Walters S.

\section{No. 10}

Measurement of health-related quality of life for people with dementia: development of a new instrument (DEMQOL) and an evaluation of current methodology.

By Smith SC, Lamping DL,

Banerjee S, Harwood R, Foley B, Smith $\mathrm{P}$, et al.

\section{No. 11}

Clinical effectiveness and costeffectiveness of drotrecogin alfa (activated) $\left(\right.$ Xigris $^{\circledR}$ ) for the treatment of severe sepsis in adults: a systematic review and economic evaluation.

By Green C, Dinnes J, Takeda A, Shepherd J, Hartwell D, Cave C, et al.

\section{No. 12}

A methodological review of how heterogeneity has been examined in systematic reviews of diagnostic test accuracy.

By Dinnes J, Deeks J, Kirby J, Roderick P.

\section{No. 13}

Cervical screening programmes: can automation help? Evidence from systematic reviews, an economic analysis and a simulation modelling exercise applied to the UK.

By Willis BH, Barton P, Pearmain P, Bryan S, Hyde C.

\section{No. 14}

Laparoscopic surgery for inguinal hernia repair: systematic review of effectiveness and economic evaluation.

By McCormack K, Wake B, Perez J, Fraser C, Cook J, McIntosh E, et al.

\section{No. 15}

Clinical effectiveness, tolerability and cost-effectiveness of newer drugs for epilepsy in adults: a systematic review and economic evaluation.

By Wilby J, Kainth A, Hawkins N, Epstein D, McIntosh H, McDaid C, et al.

\section{No. 16}

A randomised controlled trial to compare the cost-effectiveness of tricyclic antidepressants, selective serotonin reuptake inhibitors and lofepramine.

By Peveler R, Kendrick T, Buxton M, Longworth L, Baldwin D, Moore M, et al.

No. 17

Clinical effectiveness and costeffectiveness of immediate angioplasty for acute myocardial infarction: systematic review and economic evaluation.

By Hartwell D, Colquitt J, Loveman E, Clegg AJ, Brodin H, Waugh N, et al.
No. 18

A randomised controlled comparison of alternative strategies in stroke care.

By Kalra L, Evans A, Perez I,

Knapp M, Swift C, Donaldson N.

No. 19

The investigation and analysis of critical incidents and adverse events in healthcare.

By Woloshynowych M, Rogers S, Taylor-Adams S, Vincent C.

No. 20

Potential use of routine databases in health technology assessment.

By Raftery J, Roderick P, Stevens A.

No. 21

Clinical and cost-effectiveness of newer immunosuppressive regimens in renal transplantation: a systematic review and modelling study.

By Woodroffe R, Yao GL, Meads C, Bayliss S, Ready A, Raftery J, et al.

No. 22

A systematic review and economic evaluation of alendronate, etidronate, risedronate, raloxifene and teriparatide for the prevention and treatment of postmenopausal osteoporosis.

By Stevenson M, Lloyd Jones M, De Nigris E, Brewer N, Davis S, Oakley J.

No. 23

A systematic review to examine the impact of psycho-educational interventions on health outcomes and costs in adults and children with difficult asthma.

By Smith JR, Mugford M, Holland R, Candy B, Noble MJ, Harrison BDW, et al.

No. 24

An evaluation of the costs, effectiveness and quality of renal replacement therapy provision in renal satellite units in England and Wales.

By Roderick P, Nicholson T, Armitage A, Mehta R, Mullee M, Gerard K, et al.

No. 25

Imatinib for the treatment of patients with unresectable and/or metastatic gastrointestinal stromal tumours: systematic review and economic evaluation.

By Wilson J, Connock M, Song F, Yao G, Fry-Smith A, Raftery J, et al.

No. 26

Indirect comparisons of competing interventions.

By Glenny AM, Altman DG, Song F, Sakarovitch C, Deeks JJ, D'Amico R, et al.

No. 27

Cost-effectiveness of alternative strategies for the initial medical management of non-ST elevation acute coronary syndrome: systematic review and decision-analytical modelling.

By Robinson M, Palmer S, Sculpher M, Philips Z, Ginnelly L, Bowens A, et al. 
No. 28

Outcomes of electrically stimulated gracilis neosphincter surgery.

By Tillin T, Chambers M, Feldman R.

No. 29

The effectiveness and cost-effectiveness of pimecrolimus and tacrolimus for atopic eczema: a systematic review and economic evaluation.

By Garside R, Stein K, Castelnuovo E, Pitt M, Ashcroft D, Dimmock P, et al.

No. 30

Systematic review on urine albumin testing for early detection of diabetic complications.

By Newman DJ, Mattock MB, Dawnay ABS, Kerry S, McGuire A, Yaqoob M, et al.

No. 31

Randomised controlled trial of the costeffectiveness of water-based therapy for lower limb osteoarthritis.

By Cochrane T, Davey RC, Matthes Edwards SM.

No. 32

Longer term clinical and economic benefits of offering acupuncture care to patients with chronic low back pain.

By Thomas KJ, MacPherson H, Ratcliffe J, Thorpe L, Brazier J, Campbell M, et al.

No. 33

Cost-effectiveness and safety of epidural steroids in the management of sciatica.

By Price C, Arden N, Coglan L, Rogers P.

No. 34

The British Rheumatoid Outcome Study Group (BROSG) randomised controlled trial to compare the effectiveness and cost-effectiveness of aggressive versus symptomatic therapy in established rheumatoid arthritis.

By Symmons D, Tricker K, Roberts C, Davies L, Dawes P, Scott DL.

No. 35

Conceptual framework and systematic review of the effects of participants' and professionals' preferences in randomised controlled trials.

By King M, Nazareth I, Lampe F, Bower P, Chandler M, Morou M, et al.

No. 36

The clinical and cost-effectiveness of implantable cardioverter defibrillators: a systematic review.

By Bryant J, Brodin H, Loveman E, Payne E, Clegg A.

No. 37

A trial of problem-solving by community mental health nurses for anxiety, depression and life difficulties among general practice patients. The CPN-GP study.

By Kendrick T, Simons L,

Mynors-Wallis L, Gray A, Lathlean J,

Pickering R, et al.
No. 38

The causes and effects of sociodemographic exclusions from clinical trials.

By Bartlett C, Doyal L, Ebrahim S, Davey P, Bachmann M, Egger M, et al.

\section{No. 39}

Is hydrotherapy cost-effective? A randomised controlled trial of combined hydrotherapy programmes compared with physiotherapy land techniques in children with juvenile idiopathic arthritis.

By Epps H, Ginnelly L, Utley M, Southwood T, Gallivan S, Sculpher M, et al.

\section{No. 40}

A randomised controlled trial and costeffectiveness study of systematic screening (targeted and total population screening) versus routine practice for the detection of atrial fibrillation in people aged 65 and over. The SAFE study.

By Hobbs FDR, Fitzmaurice DA, Mant J, Murray E, Jowett S, Bryan S, et al.

\section{No. 41}

Displaced intracapsular hip fractures in fit, older people: a randomised comparison of reduction and fixation, bipolar hemiarthroplasty and total hip arthroplasty.

By Keating JF, Grant A, Masson M, Scott NW, Forbes JF.

\section{No. 42}

Long-term outcome of cognitive behaviour therapy clinical trials in central Scotland.

By Durham RC, Chambers JA, Power KG, Sharp DM, Macdonald RR, Major KA, et al.

\section{No. 43}

The effectiveness and cost-effectiveness of dual-chamber pacemakers compared with single-chamber pacemakers for bradycardia due to atrioventricular block or sick sinus syndrome: systematic review and economic evaluation.

By Castelnuovo E, Stein K, Pitt M, Garside R, Payne E.

\section{No. 44}

Newborn screening for congenital heart defects: a systematic review and cost-effectiveness analysis.

By Knowles R, Griebsch I, Dezateux C, Brown J, Bull C, Wren C.

\section{No. 45}

The clinical and cost-effectiveness of left ventricular assist devices for end-stage heart failure: a systematic review and economic evaluation.

By Clegg AJ, Scott DA, Loveman E, Colquitt J, Hutchinson J, Royle P, et al.
No. 46

The effectiveness of the Heidelberg Retina Tomograph and laser diagnostic glaucoma scanning system (GDx) in detecting and monitoring glaucoma

By Kwartz AJ, Henson DB,

Harper RA, Spencer AF, McLeod D.

\section{No. 47}

Clinical and cost-effectiveness of autologous chondrocyte implantation for cartilage defects in knee joints: systematic review and economic evaluation.

By Clar C, Cummins E, McIntyre L, Thomas S, Lamb J, Bain L, et al.

No. 48

Systematic review of effectiveness of different treatments for childhood retinoblastoma.

By McDaid C, Hartley S, Bagnall A-M, Ritchie G, Light K, Riemsma R.

No. 49

Towards evidence-based guidelines for the prevention of venous thromboembolism: systematic reviews of mechanical methods, oral anticoagulation, dextran and regional anaesthesia as thromboprophylaxis.

By Roderick P, Ferris G, Wilson K, Halls H, Jackson D, Collins R, et al.

\section{No. 50}

The effectiveness and cost-effectiveness of parent training/education programmes for the treatment of conduct disorder, including oppositional defiant disorder, in children.

By Dretzke J, Frew E, Davenport C, Barlow J, Stewart-Brown S, Sandercock J, et al.

\section{Volume 10, 2006}

No. 1

The clinical and cost-effectiveness of donepezil, rivastigmine, galantamine and memantine for Alzheimer's disease.

By Loveman E, Green C, Kirby J, Takeda A, Picot J, Payne E, et al.

No. 2

FOOD: a multicentre randomised trial evaluating feeding policies in patients admitted to hospital with a recent stroke.

By Dennis M, Lewis S, Cranswick G, Forbes J.

No. 3

The clinical effectiveness and costeffectiveness of computed tomography screening for lung cancer: systematic reviews.

By Black C, Bagust A, Boland A, Walker S, McLeod C, De Verteuil R, et al. 
No. 4

A systematic review of the effectiveness and cost-effectiveness of neuroimaging assessments used to visualise the seizure focus in people with refractory epilepsy being considered for surgery.

By Whiting P, Gupta R, Burch J, Mujica Mota RE, Wright K, Marson A, et al.

No. 5

Comparison of conference abstracts and presentations with full-text articles in the health technology assessments of rapidly evolving technologies.

By Dundar Y, Dodd S, Dickson R, Walley T, Haycox A, Williamson PR.

\section{No. 6}

Systematic review and evaluation of methods of assessing urinary incontinence.

By Martin JL, Williams KS, Abrams KR, Turner DA, Sutton AJ, Chapple C, et al.

No. 7

The clinical effectiveness and costeffectiveness of newer drugs for children with epilepsy. A systematic review.

By Connock M, Frew E, Evans B-W, Bryan S, Cummins C, Fry-Smith A, et al.

\section{No. 8}

Surveillance of Barrett's oesophagus: exploring the uncertainty through systematic review, expert workshop and economic modelling.

By Garside R, Pitt M, Somerville M, Stein K, Price A, Gilbert N.

\section{No. 9}

Topotecan, pegylated liposomal doxorubicin hydrochloride and paclitaxel for second-line or subsequent treatment of advanced ovarian cancer: a systematic review and economic evaluation.

By Main C, Bojke L, Griffin S, Norman G, Barbieri M, Mather L, et al.

No. 10

Evaluation of molecular techniques in prediction and diagnosis of cytomegalovirus disease in immunocompromised patients.

By Szczepura A, Westmoreland D, Vinogradova Y, Fox J, Clark M.

No. 11

Screening for thrombophilia in high-risk situations: systematic review and costeffectiveness analysis. The Thrombosis: Risk and Economic Assessment of Thrombophilia Screening (TREATS) study.

By Wu O, Robertson L, Twaddle S, Lowe GDO, Clark P, Greaves M, et al.

\section{No. 12}

A series of systematic reviews to inform a decision analysis for sampling and treating infected diabetic foot

ulcers.

By Nelson EA, O'Meara S, Craig D, Iglesias C, Golder S, Dalton J, et al.

\section{No. 13}

Randomised clinical trial, observational study and assessment of cost-

effectiveness of the treatment of varicose veins (REACTIV trial).

By Michaels JA, Campbell WB,

Brazier JE, MacIntyre JB, Palfreyman SJ, Ratcliffe J, et al.

\section{No. 14}

The cost-effectiveness of screening for oral cancer in primary care.

By Speight PM, Palmer S, Moles DR, Downer MC, Smith DH, Henriksson M et al.

\section{No. 15}

Measurement of the clinical and costeffectiveness of non-invasive diagnostic testing strategies for deep vein thrombosis.

By Goodacre S, Sampson F, Stevenson M, Wailoo A, Sutton A, Thomas S, et al.

\section{No. 16}

Systematic review of the effectiveness and cost-effectiveness of HealOzone ${ }^{\circledR}$ for the treatment of occlusal pit/fissure caries and root caries.

By Brazzelli M, McKenzie L, Fielding S, Fraser C, Clarkson J, Kilonzo M, et al.

\section{No. 17}

Randomised controlled trials of conventional antipsychotic versus new atypical drugs, and new atypical drugs versus clozapine, in people with schizophrenia responding poorly to, or intolerant of, current drug treatment.

By Lewis SW, Davies L, Jones PB, Barnes TRE, Murray RM, Kerwin R, et al.

\section{No. 18}

Diagnostic tests and algorithms used in the investigation of haematuria: systematic reviews and economic evaluation.

By Rodgers M, Nixon J, Hempel S, Aho T, Kelly J, Neal D, et al.

\section{No. 19}

Cognitive behavioural therapy in addition to antispasmodic therapy for irritable bowel syndrome in primary care: randomised controlled trial.

By Kennedy TM, Chalder T, McCrone P, Darnley S, Knapp M, Jones RH, et al.
No. 20

A systematic review of the clinical effectiveness and cost-effectiveness of enzyme replacement therapies for

Fabry's disease and mucopolysaccharidosis type 1 .

By Connock M, Juarez-Garcia A, Frew E, Mans A, Dretzke J, Fry-Smith A, et al.

No. 21

Health benefits of antiviral therapy for mild chronic hepatitis $\mathrm{C}$ : randomised controlled trial and economic evaluation.

By Wright M, Grieve R, Roberts J, Main J, Thomas HC on behalf of the UK Mild Hepatitis C Trial Investigators.

\section{No. 22}

Pressure relieving support surfaces: a randomised evaluation.

By Nixon J, Nelson EA, Cranny G, Iglesias CP, Hawkins K, Cullum NA, et al.

No. 23

A systematic review and economic model of the effectiveness and costeffectiveness of methylphenidate, dexamfetamine and atomoxetine for the treatment of attention deficit hyperactivity disorder in children and adolescents.

By King S, Griffin S, Hodges Z, Weatherly H, Asseburg C, Richardson G, et al.

No. 24

The clinical effectiveness and costeffectiveness of enzyme replacement therapy for Gaucher's disease: a systematic review.

By Connock M, Burls A, Frew E, Fry-Smith A, Juarez-Garcia A, McCabe C, et al.

No. 25

Effectiveness and cost-effectiveness of salicylic acid and cryotherapy for cutaneous warts. An economic decision model.

By Thomas KS, Keogh-Brown MR, Chalmers JR, Fordham RJ, Holland RC, Armstrong SJ, et al.

No. 26

A systematic literature review of the effectiveness of non-pharmacological interventions to prevent wandering in dementia and evaluation of the ethical implications and acceptability of their use.

By Robinson L, Hutchings D, Corner L, Beyer F, Dickinson H, Vanoli A, et al.

\section{No. 27}

A review of the evidence on the effects and costs of implantable cardioverter defibrillator therapy in different patient groups, and modelling of cost-

effectiveness and cost-utility for these groups in a UK context.

By Buxton M, Caine N, Chase D, Connelly D, Grace A, Jackson C, et al. 
No. 28

Adefovir dipivoxil and pegylated interferon alfa-2a for the treatment of chronic hepatitis B: a systematic review and economic evaluation.

By Shepherd J, Jones J, Takeda A, Davidson P, Price A.

No. 29

An evaluation of the clinical and costeffectiveness of pulmonary artery catheters in patient management in intensive care: a systematic review and a randomised controlled trial.

By Harvey S, Stevens K, Harrison D, Young D, Brampton W, McCabe C, et al.

\section{No. 30}

Accurate, practical and cost-effective assessment of carotid stenosis in the UK.

By Wardlaw JM, Chappell FM, Stevenson M, De Nigris E, Thomas S, Gillard J, et al.

\section{No. 31}

Etanercept and infliximab for the treatment of psoriatic arthritis: a systematic review and economic evaluation.

By Woolacott N, Bravo Vergel Y, Hawkins N, Kainth A, Khadjesari Z, Misso K, et al.

No. 32

The cost-effectiveness of testing for hepatitis $\mathrm{C}$ in former injecting drug users.

By Castelnuovo E, Thompson-Coon J, Pitt M, Cramp M, Siebert U, Price A, et al.

No. 33

Computerised cognitive behaviour therapy for depression and anxiety update: a systematic review and economic evaluation.

By Kaltenthaler E, Brazier J, De Nigris E, Tumur I, Ferriter M, Beverley C, et al.

No. 34

Cost-effectiveness of using prognostic information to select women with breast cancer for adjuvant systemic therapy.

By Williams C, Brunskill S, Altman D, Briggs A, Campbell H, Clarke M, et al.

No. 35

Psychological therapies including dialectical behaviour therapy for borderline personality disorder: a systematic review and preliminary economic evaluation.

By Brazier J, Tumur I, Holmes M, Ferriter M, Parry G, Dent-Brown K, et al.

No. 36

Clinical effectiveness and cost-

effectiveness of tests for the diagnosis and investigation of urinary tract infection in children: a systematic review and economic model.

By Whiting P, Westwood M, Bojke L, Palmer S, Richardson G, Cooper J, et al.
No. 37

Cognitive behavioural therapy in chronic fatigue syndrome: a randomised controlled trial of an outpatient group programme.

By O'Dowd H, Gladwell P, Rogers CA, Hollinghurst S, Gregory A

No. 38

A comparison of the cost-effectiveness of five strategies for the prevention of nonsteroidal anti-inflammatory drug-induced gastrointestinal toxicity: a systematic review with economic modelling.

By Brown TJ, Hooper L, Elliott RA, Payne K, Webb R, Roberts C, et al.

\section{No. 39}

The effectiveness and cost-effectiveness of computed tomography screening for coronary artery disease: systematic review.

By Waugh N, Black C, Walker S, McIntyre L, Cummins E, Hillis G.

No. 40

What are the clinical outcome and costeffectiveness of endoscopy undertaken by nurses when compared with doctors? A Multi-Institution Nurse Endoscopy Trial (MINuET).

By Williams J, Russell I, Durai D, Cheung W-Y, Farrin A, Bloor K, et al.

\section{No. 41}

The clinical and cost-effectiveness of oxaliplatin and capecitabine for the adjuvant treatment of colon cancer: systematic review and economic evaluation.

By Pandor A, Eggington S, Paisley S, Tappenden P, Sutcliffe P.

\section{No. 42}

A systematic review of the effectiveness of adalimumab, etanercept and infliximab for the treatment of rheumatoid arthritis in adults and an economic evaluation of their costeffectiveness.

By Chen Y-F, Jobanputra P, Barton P, Jowett S, Bryan S, Clark W, et al.

No. 43

Telemedicine in dermatology: a randomised controlled trial.

By Bowns IR, Collins K, Walters SJ, McDonagh AJG.

\section{No. 44}

Cost-effectiveness of cell salvage and alternative methods of minimising perioperative allogeneic blood transfusion: a systematic review and economic model.

By Davies L, Brown TJ, Haynes S, Payne K, Elliott RA, McCollum C.

\section{No. 45}

Clinical effectiveness and cost-

effectiveness of laparoscopic surgery for colorectal cancer: systematic reviews and economic evaluation.

By Murray A, Lourenco T,

de Verteuil R, Hernandez R, Fraser C, McKinley A, et al.
No. 46

Etanercept and efalizumab for the treatment of psoriasis: a systematic review.

By Woolacott N, Hawkins N, Mason A, Kainth A, Khadjesari Z, Bravo Vergel Y, et al.

No. 47

Systematic reviews of clinical decision tools for acute abdominal pain.

By Liu JLY, Wyatt JC, Deeks JJ, Clamp S, Keen J, Verde P, et al.

No. 48

Evaluation of the ventricular assist device programme in the UK.

By Sharples L, Buxton M, Caine N, Cafferty F, Demiris N, Dyer M, et al.

\section{No. 49}

A systematic review and economic model of the clinical and costeffectiveness of immunosuppressive therapy for renal transplantation in children.

By Yao G, Albon E, Adi Y, Milford D, Bayliss S, Ready A, et al.

No. 50

Amniocentesis results: investigation of anxiety. The ARIA trial.

By Hewison J, Nixon J, Fountain J, Cocks K, Jones C, Mason G, et al.

\section{Volume II, 2007}

No. 1

Pemetrexed disodium for the treatment of malignant pleural mesothelioma: a systematic review and economic evaluation.

By Dundar Y, Bagust A, Dickson R, Dodd S, Green J, Haycox A, et al.

\section{No. 2}

A systematic review and economic model of the clinical effectiveness and cost-effectiveness of docetaxel in combination with prednisone or prednisolone for the treatment of hormone-refractory metastatic prostate cancer.

By Collins R, Fenwick E, Trowman R, Perard R, Norman G, Light K, et al.

No. 3

A systematic review of rapid diagnostic tests for the detection of tuberculosis infection.

By Dinnes J, Deeks J, Kunst H, Gibson A, Cummins E, Waugh N, et al.

No. 4

The clinical effectiveness and costeffectiveness of strontium ranelate for the prevention of osteoporotic fragility fractures in postmenopausal women.

By Stevenson M, Davis S, Lloyd-Jones M, Beverley C. 
No. 5

A systematic review of quantitative and qualitative research on the role and effectiveness of written information available to patients about individual medicines.

By Raynor DK, Blenkinsopp A, Knapp P, Grime J, Nicolson DJ, Pollock K, et al.

No. 6

Oral naltrexone as a treatment for relapse prevention in formerly opioid-dependent drug users: a systematic review and economic evaluation.

By Adi Y, Juarez-Garcia A, Wang D, Jowett $\mathrm{S}$, Frew E, Day E, et al.

No. 7

Glucocorticoid-induced osteoporosis: a systematic review and cost-utility analysis.

By Kanis JA, Stevenson M, McCloskey EV, Davis S, Lloyd-Jones M.

\section{No. 8}

Epidemiological, social, diagnostic and economic evaluation of population screening for genital chlamydial infection.

By Low N, McCarthy A, Macleod J, Salisbury C, Campbell R, Roberts TE, et al.

\section{No. 9}

Methadone and buprenorphine for the management of opioid dependence: a systematic review and economic evaluation.

By Connock M, Juarez-Garcia A, Jowett S, Frew E, Liu Z, Taylor RJ, et al.

\section{No. 10}

Exercise Evaluation Randomised Trial (EXERT): a randomised trial comparing GP referral for leisure centre-based exercise, community-based walking and advice only.

By Isaacs AJ, Critchley JA, See Tai S, Buckingham K, Westley D, Harridge SDR, et al.

\section{No. 11}

Interferon alfa (pegylated and non-pegylated) and ribavirin for the treatment of mild chronic hepatitis C: a systematic review and economic evaluation.

By Shepherd J, Jones J, Hartwell D, Davidson P, Price A, Waugh N.

\section{No. 12}

Systematic review and economic evaluation of bevacizumab and cetuximab for the treatment of metastatic colorectal cancer

By Tappenden P, Jones R, Paisley S, Carroll C.

\section{No. 13}

A systematic review and economic evaluation of epoetin alfa, epoetin beta and darbepoetin alfa in anaemia associated with cancer, especially that attributable to cancer treatment.

By Wilson J, Yao GL, Raftery J,

Bohlius J, Brunskill S, Sandercock J, et al.

\section{No. 14}

A systematic review and economic evaluation of statins for the prevention of coronary events.

By Ward S, Lloyd Jones M, Pandor A, Holmes M, Ara R, Ryan A, et al.

\section{No. 15}

A systematic review of the effectiveness and cost-effectiveness of different models of community-based respite care for frail older people and their carers.

By Mason A, Weatherly H, Spilsbury K, Arksey H, Golder S, Adamson J, et al.

\section{No. 16}

Additional therapy for young children with spastic cerebral palsy:

a randomised controlled trial.

By Weindling AM, Cunningham CC, Glenn SM, Edwards RT, Reeves DJ.

\section{No. 17}

Screening for type 2 diabetes: literature review and economic modelling.

By Waugh N, Scotland G,

McNamee P, Gillett M, Brennan A, Goyder E, et al.

\section{No. 18}

The effectiveness and cost-effectiveness of cinacalcet for secondary hyperparathyroidism in end-stage renal disease patients on dialysis: a systematic review and economic evaluation.

By Garside R, Pitt M, Anderson R, Mealing S, Roome C, Snaith A, et al.

\section{No. 19}

The clinical effectiveness and cost-effectiveness of gemcitabine for metastatic breast cancer: a systematic review and economic evaluation.

By Takeda AL, Jones J, Loveman E, Tan SC, Clegg AJ.

\section{No. 20}

A systematic review of duplex ultrasound, magnetic resonance angiography and computed tomography angiography for the diagnosis and assessment of symptomatic, lower limb peripheral arterial disease.

By Collins R, Cranny G, Burch J, Aguiar-Ibáñez R, Craig D, Wright K, et al.
No. 21

The clinical effectiveness and costeffectiveness of treatments for children with idiopathic steroid-resistant nephrotic syndrome: a systematic review.

By Colquitt JL, Kirby J, Green C, Cooper K, Trompeter RS

No. 22

A systematic review of the routine monitoring of growth in children of primary school age to identify growth-related conditions.

By Fayter D, Nixon J, Hartley S, Rithalia A, Butler G, Rudolf M, et al.

No. 23

Systematic review of the effectiveness of preventing and treating Staphylococcus aureus carriage in reducing peritoneal catheter-related infections.

By McCormack K, Rabindranath K, Kilonzo M, Vale L, Fraser C, McIntyre L, et al.

\section{No. 24}

The clinical effectiveness and cost of repetitive transcranial magnetic stimulation versus electroconvulsive therapy in severe depression: a multicentre pragmatic randomised controlled trial and economic analysis.

By McLoughlin DM, Mogg A, Eranti S, Pluck G, Purvis R, Edwards D, et al.

\section{No. 25}

A randomised controlled trial and economic evaluation of direct versus indirect and individual versus group modes of speech and language therapy for children with primary language impairment.

By Boyle J, McCartney E, Forbes J, O'Hare A.

No. 26

Hormonal therapies for early breast cancer: systematic review and economic evaluation.

By Hind D, Ward S, De Nigris E, Simpson E, Carroll C, Wyld L.

No. 27

Cardioprotection against the toxic effects of anthracyclines given to children with cancer: a systematic review.

By Bryant J, Picot J, Levitt G, Sullivan I, Baxter L, Clegg A.

\section{No. 28}

Adalimumab, etanercept and infliximab for the treatment of ankylosing spondylitis: a systematic review and economic evaluation.

By McLeod C, Bagust A, Boland A, Dagenais P, Dickson R, Dundar Y, et al. 
No. 29

Prenatal screening and treatment strategies to prevent group B streptococcal and other bacterial infections in early infancy: costeffectiveness and expected value of information analyses.

By Colbourn T, Asseburg C, Bojke L, Philips Z, Claxton K, Ades AE, et al.

No. 30

Clinical effectiveness and costeffectiveness of bone morphogenetic proteins in the non-healing of fractures and spinal fusion: a systematic review.

By Garrison KR, Donell S, Ryder J, Shemilt I, Mugford M, Harvey I, et al.

\section{No. 31}

A randomised controlled trial of postoperative radiotherapy following breast-conserving surgery in a minimum-risk older population. The PRIME trial.

By Prescott RJ, Kunkler IH, Williams LJ, King CC, Jack W, van der Pol M, et al.

\section{No. 32}

Current practice, accuracy, effectiveness and cost-effectiveness of the school entry hearing screen.

By Bamford J, Fortnum H, Bristow K, Smith J, Vamvakas G, Davies L, et al.

\section{No. 33}

The clinical effectiveness and cost-effectiveness of inhaled insulin in diabetes mellitus: a systematic review and economic evaluation.

By Black C, Cummins E, Royle P, Philip S, Waugh N.

\section{No. 34}

Surveillance of cirrhosis for hepatocellular carcinoma: systematic review and economic analysis.

By Thompson Coon J, Rogers G, Hewson P, Wright D, Anderson R, Cramp M, et al.

\section{No. 35}

The Birmingham Rehabilitation Uptake Maximisation Study (BRUM). Homebased compared with hospital-based cardiac rehabilitation in a multi-ethnic population: cost-effectiveness and patient adherence.

By Jolly K, Taylor R, Lip GYH, Greenfield S, Raftery J, Mant J, et al.

No. 36

A systematic review of the clinical, public health and cost-effectiveness of rapid diagnostic tests for the detection and identification of bacterial intestinal pathogens in faeces and food.

By Abubakar I, Irvine L, Aldus CF, Wyatt GM, Fordham R, Schelenz S, et al.

\section{No. 37}

A randomised controlled trial

examining the longer-term outcomes of standard versus new antiepileptic drugs. The SANAD trial.

By Marson AG, Appleton R, Baker GA, Chadwick DW, Doughty J, Eaton B, et al.

\section{No. 38}

Clinical effectiveness and cost-

effectiveness of different models

of managing long-term oral

anticoagulation therapy: a systematic

review and economic modelling.

By Connock M, Stevens C, Fry-Smith A, Jowett S, Fitzmaurice D, Moore D, et al.

\section{No. 39}

A systematic review and economic model of the clinical effectiveness and cost-effectiveness of interventions for preventing relapse in people with bipolar disorder.

By Soares-Weiser K, Bravo Vergel Y, Beynon S, Dunn G, Barbieri M, Duffy S, et al.

\section{No. 40}

Taxanes for the adjuvant treatment of early breast cancer: systematic review and economic evaluation.

By Ward S, Simpson E, Davis S, Hind D, Rees A, Wilkinson A.

\section{No. 41}

The clinical effectiveness and costeffectiveness of screening for open angle glaucoma: a systematic review and economic evaluation.

By Burr JM, Mowatt G, Hernández R, Siddiqui MAR, Cook J, Lourenco T, et al.

\section{No. 42}

Acceptability, benefit and costs of early screening for hearing disability: a study of potential screening tests and models.

By Davis A, Smith P, Ferguson M, Stephens D, Gianopoulos I.

\section{No. 43}

Contamination in trials of educational interventions.

By Keogh-Brown MR, Bachmann MO, Shepstone L, Hewitt C, Howe A, Ramsay CR, et al.

\section{No. 44}

Overview of the clinical effectiveness of positron emission tomography imaging in selected cancers.

By Facey K, Bradbury I, Laking G, Payne E.

\section{No. 45}

The effectiveness and cost-effectiveness of carmustine implants and temozolomide for the treatment of newly diagnosed high-grade glioma: a systematic review and economic evaluation.

By Garside R, Pitt M, Anderson R, Rogers G, Dyer M, Mealing S, et al.
No. 46

Drug-eluting stents: a systematic review and economic evaluation.

By Hill RA, Boland A, Dickson R, Dündar Y, Haycox A, McLeod C, et al.

No. 47

The clinical effectiveness and costeffectiveness of cardiac resynchronisation (biventricular pacing) for heart failure: systematic review and economic model.

By Fox M, Mealing S, Anderson R, Dean J, Stein K, Price A, et al.

No. 48

Recruitment to randomised trials: strategies for trial enrolment and participation study. The STEPS study.

By Campbell MK, Snowdon C, Francis D, Elbourne D, McDonald AM, Knight R, et al.

No. 49

Cost-effectiveness of functional cardiac testing in the diagnosis and management of coronary artery disease: a randomised controlled trial.

The CECaT trial.

By Sharples L, Hughes V, Crean A, Dyer M, Buxton M, Goldsmith K, et al.

No. 50

Evaluation of diagnostic tests when there is no gold standard. A review of methods.

By Rutjes AWS, Reitsma JB,

Coomarasamy A, Khan KS,

Bossuyt PMM.

No. 51

Systematic reviews of the clinical effectiveness and cost-effectiveness of proton pump inhibitors in acute upper gastrointestinal bleeding.

By Leontiadis GI, Sreedharan A, Dorward S, Barton P, Delaney B, Howden CW, et al.

No. 52

A review and critique of modelling in prioritising and designing screening programmes.

By Karnon J, Goyder E, Tappenden P, McPhie S, Towers I, Brazier J, et al.

No. 53

An assessment of the impact of the NHS Health Technology Assessment Programme.

By Hanney S, Buxton M, Green C, Coulson D, Raftery J.

\section{Volume 12, 2008}

No. 1

A systematic review and economic model of switching from nonglycopeptide to glycopeptide antibiotic prophylaxis for surgery.

By Cranny G, Elliott R, Weatherly H, Chambers D, Hawkins N, Myers L, et al. 
No. 2

'Cut down to quit' with nicotine replacement therapies in smoking cessation: a systematic review of effectiveness and economic analysis.

By Wang D, Connock M, Barton P, Fry-Smith A, Aveyard P, Moore D.

No. 3

A systematic review of the effectiveness of strategies for reducing fracture risk in children with juvenile idiopathic arthritis with additional data on longterm risk of fracture and cost of disease management.

By Thornton J, Ashcroft D,

O'Neill T, Elliott R, Adams J, Roberts C, et al.

No. 4

Does befriending by trained lay workers improve psychological well-being and quality of life for carers of people with dementia, and at what cost? A randomised controlled trial.

By Charlesworth G, Shepstone L, Wilson E, Thalanany M, Mugford M, Poland F.

No. 5

A multi-centre retrospective cohort study comparing the efficacy, safety and costeffectiveness of hysterectomy and uterine artery embolisation for the treatment of symptomatic uterine fibroids. The HOPEFUL study.

By Hirst A, Dutton S, Wu O,

Briggs A, Edwards C, Waldenmaier L, et al.

\section{No. 6}

Methods of prediction and prevention of pre-eclampsia: systematic reviews of accuracy and effectiveness literature with economic modelling.

By Meads CA, Cnossen JS, Meher S, Juarez-Garcia A, ter Riet G, Duley L, et al.

No. 7

The use of economic evaluations in NHS decision-making: a review and empirical investigation.

By Williams I, McIver S, Moore D, Bryan S.

No. 8

Stapled haemorrhoidectomy (haemorrhoidopexy) for the treatment of haemorrhoids: a systematic review and economic evaluation.

By Burch J, Epstein D, Baba-Akbari A, Weatherly H, Fox D, Golder S, et al.

No. 9

The clinical effectiveness of diabetes education models for Type 2 diabetes: a systematic review.

By Loveman E, Frampton GK, Clegg AJ
No. 10

Payment to healthcare professionals for patient recruitment to trials: systematic review and qualitative study.

By Raftery J, Bryant J, Powell J, Kerr C, Hawker S.

\section{No. 11}

Cyclooxygenase-2 selective non-steroidal anti-inflammatory drugs (etodolac, meloxicam, celecoxib, rofecoxib, etoricoxib, valdecoxib and lumiracoxib) for osteoarthritis and rheumatoid arthritis: a systematic review and economic evaluation.

By Chen Y-F, Jobanputra P, Barton P, Bryan S, Fry-Smith A, Harris G, et al.

No. 12

The clinical effectiveness and costeffectiveness of central venous catheters treated with anti-infective agents in preventing bloodstream infections: a systematic review and economic evaluation.

By Hockenhull JC, Dwan K, Boland A, Smith G, Bagust A, Dündar Y, et al.

No. 13

Stepped treatment of older adults on laxatives. The STOOL trial.

By Mihaylov S, Stark C, McColl E, Steen N, Vanoli A, Rubin G, et al.

\section{No. 14}

A randomised controlled trial of cognitive behaviour therapy in adolescents with major depression treated by selective serotonin reuptake inhibitors. The ADAPT trial.

By Goodyer IM, Dubicka B,

Wilkinson P, Kelvin R, Roberts C, Byford S, et al.

No. 15

The use of irinotecan, oxaliplatin and raltitrexed for the treatment of advanced colorectal cancer: systematic review and economic evaluation.

By Hind D, Tappenden P, Tumur I, Eggington E, Sutcliffe P, Ryan A.

\section{No. 16}

Ranibizumab and pegaptanib for the treatment of age-related macular degeneration: a systematic review and economic evaluation.

By Colquitt JL, Jones J, Tan SC, Takeda A, Clegg AJ, Price A

\section{No. 17}

Systematic review of the clinical effectiveness and cost-effectiveness of 64-slice or higher computed tomography angiography as an alternative to invasive coronary angiography in the investigation of coronary artery disease.

By Mowatt G, Cummins E, Waugh N, Walker S, Cook J, Jia X, et al.
No. 18

Structural neuroimaging in psychosis: a systematic review and economic evaluation.

By Albon E, Tsourapas A, Frew E, Davenport C, Oyebode F, Bayliss S, et al.

\section{No. 19}

Systematic review and economic analysis of the comparative effectiveness of different inhaled corticosteroids and their usage with long-acting beta ${ }_{2}$ agonists for the treatment of chronic asthma in adults and children aged 12 years and over.

By Shepherd J, Rogers G, Anderson R, Main C, Thompson-Coon J, Hartwell D, et al.

No. 20

Systematic review and economic analysis of the comparative effectiveness of different inhaled corticosteroids and their usage with long-acting beta agonists for the treatment of chronic asthma in children under the age of 12 years.

By Main C, Shepherd J, Anderson R, Rogers G, Thompson-Coon J, Liu Z, et al.

\section{No. 21}

Ezetimibe for the treatment of hypercholesterolaemia: a systematic review and economic evaluation.

By Ara R, Tumur I, Pandor A, Duenas A, Williams R, Wilkinson A, et al.

No. 22

Topical or oral ibuprofen for chronic knee pain in older people. The TOIB study.

By Underwood M, Ashby D, Carnes D, Castelnuovo E, Cross P, Harding G, et al.

No. 23

A prospective randomised comparison of minor surgery in primary and secondary care. The MiSTIC trial.

By George S, Pockney P, Primrose J, Smith H, Little P, Kinley $\mathrm{H}$, et al.

No. 24

A review and critical appraisal of measures of therapist-patient interactions in mental health settings.

By Cahill J, Barkham M, Hardy G, Gilbody S, Richards D, Bower P, et al.

No. 25

The clinical effectiveness and costeffectiveness of screening programmes for amblyopia and strabismus in children up to the age of $4-5$ years: a systematic review and economic evaluation.

By Carlton J, Karnon J, Czoski-Murray C, Smith KJ, Marr J. 
No. 26

A systematic review of the clinical effectiveness and cost-effectiveness and economic modelling of minimal incision total hip replacement approaches in the management of arthritic disease of the hip.

By de Verteuil R, Imamura M, Zhu S, Glazener C, Fraser C, Munro N, et al.

\section{No. 27}

A preliminary model-based assessment of the cost-utility of a screening programme for early age-related macular degeneration.

By Karnon J, Czoski-Murray C, Smith K, Brand C, Chakravarthy U, Davis $\mathrm{S}$, et al.

\section{No. 28}

Intravenous magnesium sulphate and sotalol for prevention of atrial fibrillation after coronary artery bypass surgery: a systematic review and economic evaluation.

By Shepherd J, Jones J,

Frampton GK, Tanajewski L,

Turner D, Price A.
No. 29

Absorbent products for urinary/faecal incontinence: a comparative evaluation of key product designs.

By Fader M, Cottenden A, Getliffe K, Gage H, Clarke-O'Neill S, Jamieson K, et al. 



\section{Health Technology Assessment Programme}

\begin{tabular}{|c|c|c|c|}
\hline \multirow[b]{2}{*}{ Members } & $\begin{array}{l}\text { Director, } \\
\text { Professor Tom Walley, } \\
\text { Director, NHS HTA Programme, } \\
\text { Department of Pharmacology \& } \\
\text { Therapeutics, } \\
\text { University of Liverpool }\end{array}$ & $\begin{array}{l}\text { Deputy Director, } \\
\text { Professor Jon Nicholl, } \\
\text { Director, Medical Care Research } \\
\text { Unit, University of Sheffield, } \\
\text { School of Health and Related } \\
\text { Research }\end{array}$ & \\
\hline & & & \\
\hline $\begin{array}{l}\text { Chair, } \\
\text { Professor Tom Walley, } \\
\text { Director, NHS HTA Programme, } \\
\text { Department of Pharmacology \& } \\
\text { Therapeutics, } \\
\text { University of Liverpool }\end{array}$ & $\begin{array}{l}\text { Professor Bruce Campbell, } \\
\text { Consultant Vascular \& General } \\
\text { Surgeon, Royal Devon \& Exeter } \\
\text { Hospital } \\
\text { Professor Robin E Ferner, } \\
\text { Consultant Physician and } \\
\text { Director, West Midlands Centre } \\
\text { for Adverse Drug Reactions, } \\
\text { City Hospital NHS Trust, } \\
\text { Birmingham }\end{array}$ & $\begin{array}{l}\text { Dr Edmund Jessop, Medical } \\
\text { Adviser, National Specialist, } \\
\text { Commissioning Advisory Group } \\
\text { (NSCAG), Department of } \\
\text { Health, London } \\
\text { Professor Jon Nicholl, Director, } \\
\text { Medical Care Research Unit, } \\
\text { University of Sheffield, } \\
\text { School of Health and } \\
\text { Related Research }\end{array}$ & $\begin{array}{l}\text { Dr Ron Zimmern, Director, } \\
\text { Public Health Genetics Unit, } \\
\text { Strangeways Research } \\
\text { Laboratories, Cambridge }\end{array}$ \\
\hline
\end{tabular}

\section{HTA Commissioning Board}

Members

\section{Programme Director,}

Professor Tom Walley,

Director, NHS HTA Programme,

Department of Pharmacology \&

Therapeutics,

University of Liverpool

Chair,

Professor Jon Nicholl,

Director, Medical Care Research

Unit, University of Sheffield,

School of Health and Related

Research

\section{Deputy Chair,}

Dr Andrew Farmer,

University Lecturer in General

Practice, Department of

Primary Health Care,

University of Oxford

Dr Jeffrey Aronson,

Reader in Clinical

Pharmacology, Department of

Clinical Pharmacology,

Radcliffe Infirmary, Oxford
Professor Deborah Ashby,

Professor of Medical Statistics,

Department of Environmental

and Preventative Medicine,

Queen Mary University of

London

Professor Ann Bowling,

Professor of Health Services

Research, Primary Care and

Population Studies,

University College London

Professor John Cairns,

Professor of Health Economics,

Public Health Policy,

London School of Hygiene

and Tropical Medicine,

London

Professor Nicky Cullum,

Director of Centre for Evidence

Based Nursing, Department of

Health Sciences, University of

York

Professor Jon Deeks,

Professor of Health Statistics,

University of Birmingham
Professor Jenny Donovan,

Professor of Social Medicine,

Department of Social Medicine,

University of Bristol

Professor Freddie Hamdy,

Professor of Urology,

University of Sheffield

Professor Allan House,

Professor of Liaison Psychiatry,

University of Leeds

Professor Sallie Lamb, Director,

Warwick Clinical Trials Unit,

University of Warwick

Professor Stuart Logan,

Director of Health \& Social

Care Research, The Peninsula

Medical School, Universities of

Exeter \& Plymouth

Professor Miranda Mugford,

Professor of Health Economics,

University of East Anglia

Dr Linda Patterson,

Consultant Physician,

Department of Medicine,

Burnley General Hospital
Professor Ian Roberts,

Professor of Epidemiology \&

Public Health, Intervention

Research Unit, London School

of Hygiene and Tropical

Medicine

Professor Mark Sculpher,

Professor of Health Economics,

Centre for Health Economics,

Institute for Research in the

Social Services,

University of York

Professor Kate Thomas,

Professor of Complementary

and Alternative Medicine,

University of Leeds

Professor David John Torgerson, Director of York Trial Unit,

Department of Health Sciences,

University of York

Professor Hywel Williams,

Professor of

Dermato-Epidemiology,

University of Nottingham 


\section{Diagnostic Technologies \& Screening Panel}

Members

\section{Chair,}

Dr Ron Zimmern, Director of the Public Health Genetics Unit, Strangeways Research Laboratories, Cambridge

Ms Norma Armston, Freelance Consumer Advocate, Bolton

Professor Max Bachmann, Professor of Health Care Interfaces, Department of Health Policy and Practice, University of East Anglia

Professor Rudy Bilous Professor of Clinical Medicine \& Consultant Physician,

The Academic Centre,

South Tees Hospitals NHS Trust

Ms Dea Birkett, Service User Representative, London
Dr Paul Cockcroft, Consultant Medical Microbiologist and Clinical Director of Pathology, Department of Clinical Microbiology, St Mary's Hospital, Portsmouth

Professor Adrian K Dixon, Professor of Radiology, University Department of Radiology, University of Cambridge Clinical School

Dr David Elliman, Consultant in Community Child Health, Islington PCT \& Great Ormond Street Hospital, London

Professor Glyn Elwyn, Research Chair, Centre for Health Sciences Research, Cardiff University, Department of General Practice, Cardiff

Professor Paul Glasziou, Director, Centre for Evidence-Based Practice, University of Oxford
Dr Jennifer J Kurinczuk, Consultant Clinical Epidemiologist, National Perinatal Epidemiology Unit, Oxford

Dr Susanne M Ludgate, Clinical Director, Medicines \& Healthcare Products Regulatory Agency, London

Mr Stephen Pilling, Director, Centre for Outcomes, Research \& Effectiveness, Joint Director, National Collaborating Centre for Mental Health, University College London

Mrs Una Rennard,

Service User Representative,

Oxford

Dr Phil Shackley, Senior Lecturer in Health Economics, Academic Vascular Unit, University of Sheffield
Dr Margaret Somerville, Director of Public Health Learning, Peninsula Medical School, University of Plymouth

Dr Graham Taylor, Scientific Director \& Senior Lecturer, Regional DNA Laboratory, The Leeds Teaching Hospitals

Professor Lindsay Wilson Turnbull, Scientific Director, Centre for MR Investigations \& YCR Professor of Radiology, University of Hul

Professor Martin J Whittle, Clinical Co-director, National Co-ordinating Centre for Women's and Childhealth

Dr Dennis Wright, Consultant Biochemist \& Clinical Director, The North West London Hospitals NHS Trust, Middlesex

\section{Pharmaceuticals Panel}

\section{Chair,}

Professor Robin Ferner,

Consultant Physician and Director, West Midlands Centre for Adverse Drug Reactions, City Hospital NHS Trust, Birmingham

Ms Anne Baileff, Consultant Nurse in First Contact Care, Southampton City Primary Care Trust, University of Southampton
Professor Imti Choonara, Professor in Child Health, Academic Division of Child Health, University of Nottingham

Professor John Geddes, Professor of Epidemiological Psychiatry, University of Oxford

Mrs Barbara Greggains, Non-Executive Director, Greggains Management Ltd

Dr Bill Gutteridge, Medical Adviser, National Specialist Commissioning Advisory Group (NSCAG), London

Mrs Sharon Hart, Consultant Pharmaceutical Adviser, Reading
Dr Jonathan Karnon, Senior Research Fellow, Health Economics and Decision Science, University of Sheffield

Dr Yoon Loke, Senior Lecturer in Clinical Pharmacology, University of East Anglia

Ms Barbara Meredith, Lay Member, Epsom

Dr Andrew Prentice, Senior Lecturer and Consultant Obstetrician \& Gynaecologist, Department of Obstetrics \& Gynaecology, University of Cambridge

Dr Frances Rotblat, CPMP Delegate, Medicines \& Healthcare Products Regulatory Agency, London

\section{Dr Martin Shelly, General Practitioner, Leeds}

Mrs Katrina Simister, Assistant Director New Medicines, National Prescribing Centre, Liverpool

Dr Richard Tiner, Medical Director, Medical Department, Association of the British Pharmaceutical Industry, London 


\section{Therapeutic Procedures Panel}

Members

\section{Chair,}

Professor Bruce Campbell,

Consultant Vascular and General Surgeon, Department

of Surgery, Royal Devon \&

Exeter Hospital

Dr Mahmood Adil, Deputy Regional Director of Public Health, Department of Health, Manchester

Dr Aileen Clarke,

Consultant in Public Health,

Public Health Resource Unit, Oxford
Professor Matthew Cooke,

Professor of Emergency

Medicine, Warwick Emergency

Care and Rehabilitation,

University of Warwick

Mr Mark Emberton, Senior

Lecturer in Oncological

Urology, Institute of Urology,

University College Hospital

Professor Paul Gregg,

Professor of Orthopaedic

Surgical Science, Department of

General Practice and Primary

Care, South Tees Hospital NHS

Trust, Middlesbrough

Ms Maryann L Hardy,

Lecturer, Division of

Radiography, University of

Bradford
Dr Simon de Lusignan, Senior Lecturer, Primary Care Informatics, Department of Community Health Sciences, St George's Hospital Medical School, London

Dr Peter Martin, Consultant Neurologist, Addenbrooke's Hospital, Cambridge

Professor Neil McIntosh, Edward Clark Professor of Child Life \& Health, Department of Child Life \& Health, University of Edinburgh

Professor Jim Neilson, Professor of Obstetrics and Gynaecology, Department of Obstetrics and Gynaecology, University of Liverpool
Dr John C Pounsford,

Consultant Physician,

Directorate of Medical Services, North Bristol NHS Trust

Dr Karen Roberts, Nurse Consultant, Queen Elizabeth Hospital, Gateshead

Dr Vimal Sharma, Consultant Psychiatrist/Hon. Senior Lecturer, Mental Health Resource Centre, Cheshire and Wirral Partnership NHS Trust, Wallasey

Professor Scott Weich, Professor of Psychiatry, Division of Health in the Community, University of Warwick

Members

\section{Chair, \\ Dr Edmund Jessop, Medical} Adviser, National Specialist Commissioning Advisory Group (NSCAG), London

Mrs Sheila Clark, Chief Executive, St James's Hospital, Portsmouth

Mr Richard Copeland, Lead Pharmacist: Clinical Economy/Interface, Wansbeck General Hospital, Northumberland
Dr Elizabeth Fellow-Smith, Medical Director, West London Mental Health Trust, Middlesex

Mr Ian Flack, Director PPI Forum Support, Council of Ethnic Minority Voluntary Sector Organisations, Stratford

Dr John Jackson, General Practitioner, Newcastle upon Tyne

Mrs Veronica James, Chief Officer, Horsham District Age Concern, Horsham

Professor Mike Kelly, Director, Centre for Public Health Excellence,

National Institute for Health and Clinical Excellence, London
Professor Yi Mien Koh, Director of Public Health and Medical Director, London NHS (North West London Strategic Health Authority), London

Ms Jeanett Martin, Director of Clinical Leadership \& Quality, Lewisham PCT, London

Dr Chris McCall, General Practitioner, Dorset

Dr David Pencheon, Director, Eastern Region Public Health Observatory, Cambridge

Dr Ken Stein, Senior Clinical Lecturer in Public Health, Director, Peninsula Technology

Assessment Group,

University of Exeter,

Exeter
Dr Carol Tannahill, Director, Glasgow Centre for Population Health, Glasgow

Professor Margaret Thorogood, Professor of Epidemiology, University of Warwick, Coventry

Dr Ewan Wilkinson, Consultant in Public Health, Royal Liverpool University Hospital, Liverpool 


\section{Expert Advisory Network}

\section{Members}

Professor Douglas Altman, Professor of Statistics in Medicine, Centre for Statistics in Medicine, University of Oxford

Professor John Bond, Director, Centre for Health Services Research, University of Newcastle upon Tyne, School of Population \& Health Sciences, Newcastle upon Tyne

Professor Andrew Bradbury, Professor of Vascular Surgery, Solihull Hospital, Birmingham

Mr Shaun Brogan,

Chief Executive, Ridgeway

Primary Care Group, Aylesbury

Mrs Stella Burnside OBE

Chief Executive,

Regulation and Improvement

Authority, Belfast

Ms Tracy Bury,

Project Manager, World

Confederation for Physical

Therapy, London

Professor Iain T Cameron, Professor of Obstetrics and Gynaecology and Head of the School of Medicine, University of Southampton

Dr Christine Clark, Medical Writer \& Consultant Pharmacist, Rossendale

Professor Collette Clifford, Professor of Nursing \& Head of Research, School of Health Sciences, University of Birmingham, Edgbaston, Birmingham

Professor Barry Cookson, Director, Laboratory of Healthcare Associated Infection, Health Protection Agency, London

Dr Carl Counsell, Clinical Senior Lecturer in Neurology, Department of Medicine \& Therapeutics, University of Aberdeen

Professor Howard Cuckle, Professor of Reproductive Epidemiology, Department of Paediatrics, Obstetrics \& Gynaecology, University of Leeds

Dr Katherine Darton, Information Unit, MIND The Mental Health Charity, London
Professor Carol Dezateux, Professor of Paediatric Epidemiology, London

Dr Keith Dodd, Consultant Paediatrician, Derby

Mr John Dunning, Consultant Cardiothoracic Surgeon, Cardiothoracic Surgical Unit, Papworth Hospital NHS Trust, Cambridge

Mr Jonothan Earnshaw, Consultant Vascular Surgeon, Gloucestershire Royal Hospital, Gloucester

Professor Martin Eccles, Professor of Clinical

Effectiveness, Centre for Health Services Research, University of Newcastle upon Tyne

Professor Pam Enderby, Professor of Community Rehabilitation, Institute of General Practice and Primary Care, University of Sheffield

Professor Gene Feder, Professor of Primary Care Research \& Development, Centre for Health Sciences, Barts \& The London Queen Mary's School of Medicine \& Dentistry, London

Mr Leonard R Fenwick,

Chief Executive, Newcastle upon Tyne Hospitals NHS Trust

Mrs Gillian Fletcher,

Antenatal Teacher \& Tutor and President, National Childbirth Trust, Henfield

Professor Jayne Franklyn, Professor of Medicine,

Department of Medicine, University of Birmingham, Queen Elizabeth Hospital,

Edgbaston, Birmingham

Dr Neville Goodman,

Consultant Anaesthetist, Southmead Hospital, Bristol

Professor Robert E Hawkins, CRC Professor and Director of Medical Oncology, Christie CRC Research Centre, Christie Hospital NHS Trust, Manchester

Professor Allen Hutchinson, Director of Public Health \& Deputy Dean of ScHARR, Department of Public Health, University of Sheffield

Professor Peter Jones, Professor of Psychiatry, University of Cambridge, Cambridge
Professor Stan Kave, Cancer Research UK Professor of Medical Oncology, Section of Medicine, Royal Marsden Hospital \& Institute of Cancer Research, Surrey

Dr Duncan Keeley, General Practitioner (Dr Burch \& Ptnrs), The Health Centre, Thame

Dr Donna Lamping, Research Degrees Programme Director \& Reader in Psychology, Health Services Research Unit, London School of Hygiene and Tropical Medicine, London

Mr George Levvy,

Chief Executive, Motor

Neurone Disease Association, Northampton

Professor James Lindesay, Professor of Psychiatry for the Elderly, University of Leicester, Leicester General Hospital

Professor Julian Little, Professor of Human Genome Epidemiology, Department of Epidemiology \& Community Medicine, University of Ottawa

Professor Rajan Madhok, Consultant in Public Health, South Manchester Primary Care Trust, Manchester

Professor Alexander Markham, Director, Molecular Medicine Unit, St James's University Hospital, Leeds

Professor Alistaire McGuire, Professor of Health Economics, London School of Economics

Dr Peter Moore,

Freelance Science Writer, Ashtead

Dr Andrew Mortimore, Public Health Director, Southampton City Primary Care Trust, Southampton

Dr Sue Moss, Associate Director, Cancer Screening Evaluation Unit, Institute of Cancer Research, Sutton

Mrs Julietta Patnick, Director, NHS Cancer Screening Programmes, Sheffield

Professor Robert Peveler, Professor of Liaison Psychiatry, Royal South Hants Hospital, Southampton
Professor Chris Price,

Visiting Professor in Clinica Biochemistry, University of Oxford

Professor William Rosenberg, Professor of Hepatology and Consultant Physician, University of Southampton, Southampton

Professor Peter Sandercock, Professor of Medical Neurology, Department of Clinical Neurosciences, University of Edinburgh

Dr Susan Schonfield, Consultant in Public Health, Hillingdon PCT, Middlesex

Dr Eamonn Sheridan,

Consultant in Clinical Genetics, Genetics Department, St James's University Hospital, Leeds

Professor Sarah Stewart-Brown, Professor of Public Health, University of Warwick, Division of Health in the Community Warwick Medical School, LWMS, Coventry

Professor Ala Szczepura, Professor of Health Service Research, Centre for Health Services Studies, University of Warwick

Dr Ross Taylor, Senior Lecturer, Department of General Practice and Primary Care, University of Aberdeen

Mrs Joan Webster, Consumer member, HTA Expert Advisory Network 



\section{Feedback}

The HTA Programme and the authors would like to know your views about this report.

The Correspondence Page on the HTA website (http://www.hta.ac.uk) is a convenient way to publish your comments. If you prefer, you can send your comments

to the address below, telling us whether you would like us to transfer them to the website.

We look forward to hearing from you.

The National Coordinating Centre for Health Technology Assessment,

Alpha House, Enterprise Road

Southampton Science Park

Chilworth

Southampton SO 16 7NS, UK.

Fax: +44 (0) $2380595639 \quad$ Email: hta@hta.ac.uk

http://www.hta.ac.uk 